\title{
Natural resources, innovation and export growth : the wine industry in Chile and Argentina
}

Citation for published version (APA):

Farinelli, F. (2012). Natural resources, innovation and export growth : the wine industry in Chile and Argentina. [Doctoral Thesis, Maastricht University]. Datawyse / Universitaire Pers Maastricht. https://doi.org/10.26481/dis.20121218ff

Document status and date:

Published: 01/01/2012

DOI:

10.26481/dis.20121218ff

Document Version:

Publisher's PDF, also known as Version of record

\section{Please check the document version of this publication:}

- A submitted manuscript is the version of the article upon submission and before peer-review. There can be important differences between the submitted version and the official published version of record.

People interested in the research are advised to contact the author for the final version of the publication, or visit the DOI to the publisher's website.

- The final author version and the galley proof are versions of the publication after peer review.

- The final published version features the final layout of the paper including the volume, issue and page numbers.

Link to publication

\footnotetext{
General rights rights.

- You may freely distribute the URL identifying the publication in the public portal. please follow below link for the End User Agreement:

www.umlib.nl/taverne-license

Take down policy

If you believe that this document breaches copyright please contact us at:

repository@maastrichtuniversity.nl

providing details and we will investigate your claim.
}

Copyright and moral rights for the publications made accessible in the public portal are retained by the authors and/or other copyright owners and it is a condition of accessing publications that users recognise and abide by the legal requirements associated with these

- Users may download and print one copy of any publication from the public portal for the purpose of private study or research.

- You may not further distribute the material or use it for any profit-making activity or commercial gain

If the publication is distributed under the terms of Article $25 \mathrm{fa}$ of the Dutch Copyright Act, indicated by the "Taverne" license above, 


\section{NATURAL RESOURCES, INNOVATION AND EXPORT GROWTH}

ThE Wine INDUSTRY IN CHILE AND ARGENTINA

Fulvia Farinelli 
ISBN 978946159189 o

(C) copyright Fulvia Farinelli, Maastricht 2012

Cover design and wine map: Ernst van Loon (www.ernstvanloon.com) Cover picture: The Peoples Atlas 1920, London Geographical Institute Layout and printing: Datawyse / Universitaire Pers Maastricht 


\section{NATURAL RESOURCES, INNOVATION AND EXPORT GROWTH}

\section{THE WINE INDUSTRY IN CHILE AND ARGENTINA}

\section{DISSERTATION}

to obtain the degree of Doctor at Maastricht University, on the authority of the Rector Magnificus Prof. Dr. L.L.G. Soete, in accordance with the decision of the Board of Deans, to be defended in public on Tuesday 18 December 2012, at 10:15 hours

$$
\text { by }
$$

Fulvia Farinelli

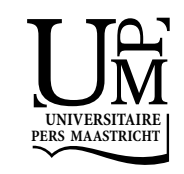




\section{Promotor}

Prof. Dr. Adam Szirmai

\section{Co-promotor}

Prof. Dr. Lynn K. Mytelka

\section{Assessment Committee}

Prof. Dr. Robin Cowan (Chairman)

Prof. Dr. Wim Naudé

Prof. Dr. Carlo Pietrobelli (University Roma Tre)

Dr. Mulu Gebreeyesus (UNU-MERIT) 
To my family and friends, who felt that this thesis' project was also theirs 

Be patient toward all that is unsolved in your heart and try to love the questions themselves. Do not now seek the answers, which cannot be given to you because you would not be able to live them. And the point is to live everything. Live the questions.

\section{Acknowledgments}

This thesis has been a life-changing experience. Some of the questions that have "lived" with me for a long time have found good answers. Others will continue to live with me in the future. The whole issue of development is a complex, intricate web of contradictory evidence and unanswered questions. This caught my attention since I was very young, and I was travelling extensively to the developing world thanks to my father's work. It seemed to me inexplicable that there were so many inequalities among countries and people, and that such obscure mechanisms were not allowing the world to become more just and equitable.

When I joined the UN, almost fifteen years ago, I started to work entirely on development issues. I found it paradoxical that developing countries could finally be in the position to use their rich natural resources endowments to their own advantage, rather than to the advantage of their colonizers, but this was only rarely happening. Hence, the present thesis addresses the relationship between natural resources and development - an issue that has been debated at length during the past decades and has been propelled back onto the front stage by the recent boom in global commodity demand.

In my work I was largely inspired by my supervisor, Prof. Lynn Mytelka, without whom this thesis would have never been started, and, for sure, would have never been completed. It was Lynn who encouraged me to apply to the UNU-MERIT PhD programme when we met at UNCTAD. I will always be grateful to her for her friendship, constant support and patience, as well as for the innumerable amount of times she had to remind me that a thesis was neither an annual report nor a position paper. She never allowed me to take easy shortcuts and always brought me back on the right track when I was lost. She also made me feel she would always be there for me, every time I could make whatever progress in my thesis' work.

It was also Lynn's suggestion to select wine among all natural resources. Wine has become a great passion and has changed my way of living. It has brought me closer to nature, to seasons, to climate, to sustainable production and to animal life-cycles. Moreover, vineyards are like a common denominator across the entire world: vineyards are always vineyards, it is the landscape around them that changes so much. So, whenever they are around, I am in a familiar setting. More importantly, wine has made 
me even more proud of my Italian identity, and even more curious and enthusiastic about tastes and habits of other cultures. So, hopefully, it has made me a better person!

Several people have fundamentally contributed to this thesis. At the beginning of my career, Alberto Castagnola taught me about some of the hidden truths of development economics, and about the increasing importance of technology and innovation for development. Stefano Kluzer familiarized me with the fascinating world of SMEs, industrial districts and clusters, and stimulated my professional interest in the Latin American continent. Later on, at UNCTAD, Lorraine Ruffing first, and Fiorina Mugione later, have been the most supportive and encouraging supervisors I could have ever wished for. It is also thanks to them, to the precious time they allowed me to take off from work, and to the understanding of my colleagues, that this thesis could be completed.

While working on it, I have also benefitted from the invaluable support of many friends. Carla helped me to overcome my worst moments, put at my disposal her contacts in Latin America to help update missing data, and transported tons of Chilean and Argentine wine magazines across the Atlantic ocean; Martina became a perfect personal shopper during a series of girly week-ends in Rome, to keep me smiling in the middle of the drafting; Blanca cooked delicious food to cheer up the innumerable times I had to rewrite entire chapters; Anna shared with me her immense wisdom, some incredibly hilarious moments, and her constant presence; Patrizia listened to all my fears and doubts until the very end, without ever getting tired of it; Justyna helped me to see how far I had gotten, when I thought that the end was still very far away; Iris taught me the importance and beauty of soul mates, and, together with her daughter Zippora, transformed Maastricht into my own refuge; Muriel took care of my plants and animals (Pinot, Merlot and Malbec!) with love and thoughtfulness, when I did not have enough time to do so; Olga called me "hija" and became my Chilean second mother; Ngoc and Quyen are the pillar of my belief in women solidarity across cultures and generations.

My male friends were certainly not less important. Ezio followed my ups and downs with the empathy that only those who have gone through the same experience can have; Abraham helped me with his talent and scientific skills, and became a friend for life since the time we spent together in Maastricht, like a real family; Paco and Saurabh contributed to transform my time in Maastricht as one of the most entertaining, stimulating, exciting year I have ever spent abroad; Ernst, beyond being a superb tango partner, helped me with his unique artistic talent and IT skills; Gary scrupulously edited an innumerable amount of wrongly placed commas, unclear sentences and imprecise verb tenses; Till contributed to improve my writing style with his intelligent feedback and smart suggestions; Andrès shared his friendship, contacts and passion for Chilean wines; on the other side of the Andes, Guillermo shared his friendship, contacts and passion for Argentine wines; José Luis was key in facilitating my field interviews in Argentina; Rodolfo made me feel that I will always have a home in Chile; Nicolas Bonnet was key in clarifying some technical aspects of complex winemaking procedures; Laurent and Markus introduced me to the hidden pleasures of Swiss wines. 
I am also particularly grateful for the continued support I received from UNU-MERIT. In particular, I would like to thank Luc, for his periodic encouragement; Robin for his tangible help, whenever I needed it; Eveline, for her assistance and support; Wilma and Marc, for making me feel welcome every time I visited the Institute. Last, but certainly not least, I'd like to thank Eddy, a Professor who makes his students feel a valuable priority of his teaching and supervisory work. I am so grateful for your precise, quick and illuminating feedback, Eddy! And thanks also for having devoted your time, together with Eveline, Iris and my colleague Thomas Van Giffen, to the finalization of the thesis' summary in Dutch.

My gratitude goes also to CEPAL, and in particular to Jorge Katz, Mario Cimoli, Wilson Perez and Giovanni Stumpo at the Division on Production, Productivity and Management, for the hospitality, intellectual feedback and support provided during the field work in Latin America. Needless to say, this thesis could have not been carried out without the time and attention generously devoted by a number of Chilean and Argentine oenologists, agronomists, university professors and wine experts, who patiently answered to all my questions.

While I was travelling across the world, from Maastricht to Santiago and Buenos Aires, my aunt Elena and my uncle Lucio, as well as my cousins Luca, Fabio, Stefania and Daniele, together with their respective spouses (Viviana, Enzo, Sandra, Cristina and Gianmarco) and descendants (Michela, Davide, Chiara, Flavio and little Matteo), made me feel that Rome is where my sense of belonging will always be the strongest.

I would also like to thank my parents, Enza and Pino, for having provided me with constant encouragement and unconditional support. Before choosing my university career, they allowed me to "test" my interests, from ancient painting and art restoration at the Academy of Arts in Florence, to international law and human rights at the International Court of Human Rights in Strasbourg, without ever questioning the sense or the logic of my choices. At the beginning of my career work, they also allowed me to accept unpaid or sporadically paid research assignments, until I could make my own living. Thanks to them, I could find what I really wanted to do in life.

Finally, thanks to Guy for his patience, and especially for sharing with me the deepest pleasure of wine-tasting. Without him, no glass of wine would have been the same.

nunc bibendum est! (now it is time to cheer!)

Geneva, 15 August 2012 



\section{Table of Contents}

Acknowledgments ................................................................................... vii

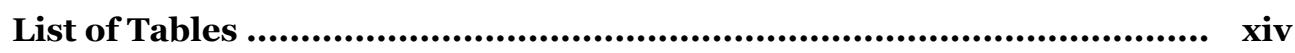

List of Figures ...................................................................................... xvii

Introduction 1. Rationale of the study ..................................................................

2. Scientific relevance ........................................................................ 6

3. Outline of the thesis ........................................................................

Chapter $1 \quad$ Theoretical Foundations ….................................................. 13

1.1 Introduction ............................................................................ 15

1.2 The historical debate on natural resources and development .... $\quad 16$

1.3 Natural resource endowments: A curse or an opportunity? ...... $\quad 21$

1.3.1 The commodity trap theory …………………………........ 21

1.3.2 The declining terms of trade theory ................................... 23

1.3.3 The Dutch disease theory ................................................... $\quad 26$

1.4 The choice between natural resources and industrialization ..... $\quad 29$

1.5 The South East Asian experience................................................. 34

1.5.1 The emergence of the South-East Asian "dragons" ........... 34

1.5.2 The South-East Asian export-led model ........................... 38

1.6 The Latin American experience ................................................... 42

1.6.1 Natural resource boom and busts in Latin America ......... $\quad 42$

1.6.2 The changing sectoral specialization of Latin America .... $\quad 48$

1.7 Conclusions ............................................................................... 53

Chapter $2 \quad$ Methodological and Analytical Framework ...................... 55

2.1 Introduction ............................................................................. 57

2.2 Key elements of the analytical framework ................................. 58

2.2.1 The knowledge intensity of resource-based industries ..... $\quad 58$

2.2.2 The Innovation System approach .................................... 63

2.2.3 The Cluster approach ...................................................... $\quad 70$

2.3 Hypotheses to be tested ........................................................... $\quad 76$

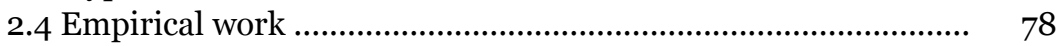

2.4.1 Selection of comparative case studies ............................... $\quad 78$

2.4.2 Macro-economic relevance ……………………….......... 82

2.5 Methods and techniques of research: Hypothesis I ................... 88

2.6 Methods and techniques of research: Hypothesis II .................. 94

2.7 Methods and techniques of research: Hypothesis III ................ 104 
Chapter 3 Structural Transformations and New Entrants in the

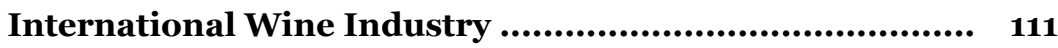

3.1 Introduction …..................................................................... 113

3.2 The wine industry in antiquity ........................................... $\quad 114$

3.3 The role of scientific discoveries in the nineteenth century ....... 118

3.4 The knowledge intensity of the modern wine industry ............. 120

3.5 The importance of international knowledge flows ................... 125

3.6 The shift in international consumption patters ...................... 132

3.7 The emergence of New World producers ............................... 136

3.8 The global restructuring of the wine industry ......................... 140

3.9 The "unexpected" entry of developing countries ....................... 143

3.10 Conclusions ...................................................................... 146

Chapter 4 Quality Improvements and International Positioning of Chilean and Argentine Wines ...................................... 149

4.1 Introduction ..................................................................... 151

4.2 Brief historical background ................................................. 151

4.3 Conditions of departure of the export boom ............................ 154

4.4 Impact of political changes and macroeconomic conditions ..... 157

4.5 Quality improvements of Chilean and Argentine wines ............ 161

4.6 International positioning of Chilean and Argentine wines ........ 171

4.7 Influence of the internal demand ......................................... 181

4.8 Conclusions ........................................................................ 184

Chapter 5 Innovation and Learning Dynamics in the Chilean and Argentine Wine Industries ....................................... $\quad 187$

5.1 Introduction ..................................................................... 189

5.2 Innovativeness of the leading Chilean and Argentine wineries . 190

5.3 Types and varieties of innovation ........................................... 195

5.4 The triggering role of FDI .................................................... 201

5.5 The role of codified and capital-embodied knowledge flows...... 207

5.6 The importance of tacit knowledge flows ................................. 212

5.7 The performance of sectoral domestic R\&D programmes and institutions ............................................................................... $\quad 224$

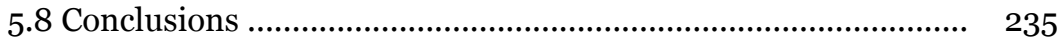

Chapter 6 Wine Clusters, Regional Innovations Systems and Export Growth in Chile and Argentina .................................... 239

6.1 Introduction .................................................................. 241

6.2 Spatial concentration, regional specialization and export

growth ............................................................................. 242

6.3 The Chilean case: Differentiating organized wine clusters

(Colchagua) vs. informal wine clusters (Curicó) ............................ 248 
6.4 The emergence of a "centralized" IS in the Chilean

Metropolitan Region

6.5 The Argentine case: Differentiating organized wine clusters

(Mendoza) vs. informal wine clusters (San Juan) .......................... 259

6.6 The emergence of Mendoza as a "learning region" ................... 264

6.7 Assessing the viability of the Chilean and Argentine "models" .. 265

6.8 Conclusions

Conclusions 1. Main findings of the thesis

2. Policy recommendations

3. Suggestions for further research

Bibliography $\mathbf{2 8 5}$

Annex I . 311

Summary $\mathbf{3 1 7}$

Nederlandse Samenvatting 321

Curriculum Vitae 325 


\section{List of Tables}

Table 1.1 Primary commodity dependence of developing countries, 2003-2005 ... 19

Table 1.2 World primary commodity prices, 2001-2007 …………………………... 20

Table 1.3 Impact of changes in terms of trade and net income payments on national disposable income in developing countries, 2004-2006 .......... $\quad 25$

Table 1.4 Share in world manufacturing value added and manufactured exports, percentage share, 1980-2000 ................................................................. 31

Table 1.5. Share of manufacturing as a percentage of GDP, 1950-2000 .................. 36

Table 1.6 Natural resource intensity and growth in Latin America .......................... 43

Table 1.7 Manufacturing value added as a share of GDP in selected Latin American countries, $1960-2000$............................................................. 50

Table 1.8 Changes in the relative weight of industrial sectors in total manufacturing output, 1970-2002 ......................................................... 51

Table 2.1 Sectoral characteristics and sources of innovation .................................. 68

Table 2.2 The Chilean and Argentine wine industries at a glance, 2008 ................. 82

Table 2.3 Robert Parker's 100-point scale ……………………………………….... 90

Table 2.4 High quality oenological grape varieties of French origin ....................... 91

Table 2.5 Wine quality segments based on price ranges ........................................... 93

Table 2.6 Selected indicators to assess quality improvements of Chilean and Argentine wines ...................................................................................... 96

Table 2.7 Argentine and Chilean wine industry structure, 2010 ............................ 98

Table 2.8 Selected variables to measure the innovativeness of Argentine and Chilean wineries .................................................................................. 100

Table 2.9 Selected indicators to assess the reliance of the Argentine and Chilean wine industries on external vs. internal sources of innovation ................ 102

Table 3.1 Main technological innovations and organizational changes in the modern wine industry ......................................................................... 124

Table 3.2 Scientific background of the pioneering group of Australian and Australian-trained "flying winemakers" and "flying wine doctors" ......... 129

Table 3.3 French wine consumption by category (litres per capita), 1970-2006 .... 134

Table 3.4 Per capita consumption of wine in EU-15 countries, 1950-2010 ............. 134

Table 3.5 Leading countries in the modern wine industry, 1986-2005 …................ 137

Table 3.6 Largest wine corporations ranked by number of host countries, 2010 ... 141

Table 3.7 Firm concentration within the international wine industry, 2006 .......... 142

Table 4.1 Strength of basic production factors in Argentina and Chile .................... 156

Table 4.2 Evolution of area planted in wine grapes in Chile, 1980-2010 ................ 158

Table 4.3 Evolution of area planted in wine grapes in Argentina, 1980-2010 ........ 160

Table 4.4 Evolution of the planted hectares with high quality oenological grape varieties in Chile, 1995-2005 ………………………….......................... 166

Table 4.5 Evolution of the planted hectares with high quality oenological grape varieties in Argentina, 1990-2005 …………………………………..... 168

Table 4.6 Evolution of Chilean wine production with Denomination of Origin ...... 170 
Table 4.7 Export volumes and prices of bottled $v$ s. bulk Chilean wines ................. 173

Table 4.8 Export volumes and prices of bottled $v$ s. bulk Argentine wines ............. 174

Table 4.9 Wine ratings by Wine Spectator, 2010 ............................................. 178

Table 4.10 Assessing quality improvements of Argentine and Chilean wine production and exports over time ..................................................... 180

Table 4.11 Wine consumption in selected countries, 2010 (litres per capita) .......... 182

Table 4.12 Domestic market (vs. export) orientation of main wine producing countries, 2009 ........................................................................ 183

Table 5.1 List of the top 25 Chilean exporters of bottled wines, 2010 .................... 191

Table 5.2 List of the top 25 Argentine exporters of bottled wines, 2010 ................. 193

Table 5.3 Degree of innovativeness of the top 25 Chilean and Argentine exporters of bottled wines, 2010 ....................................................................... 194

Table 5.4 Eco-friendly practices adopted by the top 25 Chilean exporters of bottled wines, 2010

196

Table 5.5 Eco-friendly practices adopted by the top 25 Argentine exporters of bottled wines, 2010 ........................................................................ 199

Table 5.6 Joint-ventures between foreign and Chilean wineries, 1988-2005 ......... 203

Table 5.7 Main foreign investment in the Argentine wine industry, 1992-2008 .... 206

Table 5.8 Chilean FDI in the Argentine wine industry, 1992-2008 ....................... 207

Table 5.9 Imports of presses, crushers, and other machinery for winemaking in Chile and Argentina, 1988-2008 ........................................................ 208

Table 5.10 Quality certification of the top Chilean and Argentine exporters of bottled wines, 2010

Table 5.11 Flying winemakers hired by the top 25 Chilean exporters of bottled wines

Table 5.12 Chief winemakers, oenologists, agronomists and national consultants hired by the top 25 Chilean exporters of bottled wines

Table 5.13 Main incremental innovations introduced by the top 25 Chilean exporters of bottled wines during the last five years, based on in-house $\mathrm{R} \& \mathrm{D}$

Table 5.14 Flying winemakers hired by the top 25 Argentine exporters of bottled wines

Table 5.15 Chief winemakers, oenologists, agronomists and national consultants employed by the top 25 Argentine exporters of bottled wines

Table 5.16 Main incremental innovations introduced by the top 25 Argentine exporters of bottled wines during the last five years, based on in-house $\mathrm{R} \& \mathrm{D}$

Table 5.17 Wine publication output and citation rates of the 28 most active countries, as well as specialization in wine research, 1991-2001.

Table 5.18 Funds allocated by FONDECYT and FONDEF to research projects in the Chilean wine industry, 1980-2000

Table 5.19 Funding allocated by CORFO to promote technological innovation in the Chilean wine industry, 1993-2003

Table 5.20 Wine-related research projects implemented by the Vinnova Consortium, 2010-2015

Table 5.21 Wine-related research projects coordinated by the CCDV Consortium, 
2006-2011

Table 5.22 Funding allocated by FONTAR to promote technological innovation in the Argentine wine industry, 1998-2008

Table 5.23 INTA projects for the technological upgrading of the wine industry in Argentina, Multi-year plan, 2009

Table 6.1 Chilean planted surface with vineyards, wine production and wine exports according to administrative regions, 2008

Table 6.2 Geographic concentration of the top 25 Chilean exporters of bottled wines

Table 6.3 Argentine planted surface with vineyards, wine production and wine exports according to administrative provinces, 2008

Table 6.4 Geographic concentration of the top 25 Argentine exporters of bottled wines

Table 6.5 Distribution of Chilean wine exports per region, 2004-2009 (US\$)

Table 6.6 Production of Chilean bottled premium wines with denomination of origin per Valley (in litres), 2010

Table 6.7 CORFO's TODOCHILE programme 258

Table 6.8 Supporting institutional framework of the Chilean wine industry ......... 259

Table 6.9 Distribution of Argentine wine exports per province, 2009. 261

Table 6.10 Evolution of premium wine production per Argentine province, 19802005

Table 6.11 Supporting institutional framework of the Argentine wine industry 267

Table 6.12 Origin of Chilean wine exports per region, 2004-2009 269

Table 6.13 Samples of emerging "terroir" wine production in Chile 270

Table 6.14 Origin of Argentine wine exports by province, 2002-2007 271

Table 6.15 Samples of emerging "terroir" wine production in Argentina 271 


\section{List of Figures}

Figure 1.1 Evolution of main salmon exports, 1990-2010 ....................................... 34

Figure 1.2 Evolution of main cut flowers exports, 1990-2010 ................................ 34

Figure 1.3 Per capita GDP growth in selected developing regions, 1960-2005 ….... 35

Figure 1.4 Development opportunities as a moving target ...................................... 47

Figure 2.1 Knowledge intensity of fish farming industries .................................... 60

Figure 2.2 Evolution of a technological trajectory ................................................. 64

Figure 2.3 Backward and forward linkages from the wine industry ........................ $\quad 79$

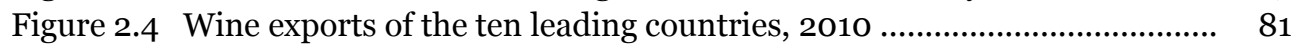

Figure 2.5 Tax revenues from unprocessed natural resources as percentage of total 83 revenues, 2008

Figure 2.6 Main Chilean export products, 2000-2010 ………………………….... 84

Figure 2.7 Growth of value added and labour productivity in the Chilean wine $\quad 85$ industry, 1996-2008

Figure 2.8 Main Argentine agroindustrial exports, 2000-2010 ............................... 86

Figure 2.9 Growth of value added and labour productivity in the Argentine wine 87 industry, 1973-2007.

Figure 2.10 Driving forces of innovation in the international wine industry ............. 89

Figure 2.11 Internal and external sources of innovation and technological change in the Argentine and Chilean wine industries ............................................ 101

Figure 2.12 Structure of organized wine clusters....................................................... 106

Figure 3.1 Knowledge intensity of modern winemaking ......................................... 121

Figure 3.2 Total exports of pressers, crushers and equipment for winemaking, 1962-2008 (in US\$) ……................................................................... 127

Figure 3.3 The importance of tacit knowledge in winemaking ................................. 128

Figure 3.4 International knowledge flows in the wine industry .............................. 131

Figure 3.5 Consumption of table and premium wines in Europe, 1982-2008 …….... 133

Figure 3.6 Rising unit values of international market sales of wine, 2004-2008 ... 135

Figure 3.7 World wine market shares, 1995-2010 .................................................... 138

Figure 3.8 Evolution of wine production in China (in quantity), 2002-2010 ........... 144

Figure 3.9 Evolution of New World wine exports (in value), 1988-2008 ............... 145

Figure 3.10 Evolution of Argentine and Chilean wine exports, in volume (thousand tons) and in value (million US\$), 1990-2010 ......................................... 146

Figure 4.1 Evolution of the area planted with high oenological quality grape varieties in Chile

Figure 4.2 Evolution of the area planted with high oenological quality grape varieties in Argentina ........................................................................... 164

Figure 4.3 Main Chilean varietal wines exported in 2009, US\$ ............................... 167

Figure 4.4 Main Argentine varietal wines exported in 2009, US\$ .......................... 169

Figure 4.5 Evolution of Chilean and Argentine wine export price per unit, 1985-

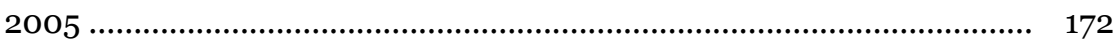

Figure 4.6 Chilean bottled wine exports by price segment, 2008 ............................ 173 
Figure 4.7 Argentine bottled wine exports by price segment, 2008 ...................... 174

Figure 4.8 Market of destination of Chilean wine exports, 1985-2008 ................... 175

Figure 4.9 Market of destination of Argentine wine exports, 1985-2008 ............... 176

Figure 4.10 Average scores of Argentine and Chilean wines by Wine Spectator,

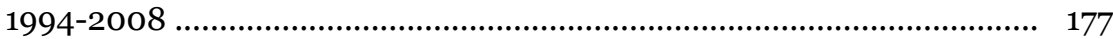

Figure 4.11 States or countries considered as most reliable sources for value wines, 179 Wine Spectator Survey, 2010

Figure 4.12 Wine consumption trends in Argentina and Chile (litres/capita), 19802010

Figure 5.1 Foreign Direct Investment inflows to the Chilean wine industry, 19742006

Figure 5.2 Relationship between the increased stock of machinery for winemaking and wine export growth in Chile, 1988-2009 209

Figure 5.3 Relationship between the increased stock of machinery for winemaking and wine export growth in Argentina, 1992-2009 209

Figure 5.4 Perceived university/industry research collaboration and quality of public research, 2002 

INTRODUCTION 


\section{Rationale of the study}

Since the early 1990s, there has been a remarkable export boom of natural resourcebased products from developing countries. Some of the most prominent cases are related to the export of processed agricultural commodities such as cut flowers from Colombia, Ethiopia and Kenya; wine from Argentina, Chile and South Africa; farmed salmon from Chile; Nile perch from Uganda; and frozen shrimps from Thailand, Viet Nam, Ecuador and Peru. Given the debate existing in the literature on the limited amount of growth opportunities offered by natural resources to developing countries, the new emphasis on natural resource-based exports represents a paradox that deserves further attention and deep investigation. ${ }^{1}$

In the 1960s, 1970s and 1980s, a number of development theories emerged that emphasized the negative impact of primary exports on development. The most prominent among these are the "resource curse", the "declining terms of trade" and the "commodity trap" theories, examined in depth in the theoretical foundations of the thesis. Such theories argue, respectively, that resource-abundant countries tend to perform more scantily in terms of economic growth than resource-poor countries, that the price of primary resources is inexorably condemned to fall compared to the price of manufactured products, and that natural resource-based industries operate as mere "enclaves", isolated from the rest of the economy. Thus, they would all consider natural resources as a poor and unadvisable alternative to industrialization.

Against this background, this thesis investigates the recent export boom of natural resource-based processed products from developing countries and reflects on whether the conditions under which it is taking place is any different from those that led to repeated failures, in the past, of a development model based on raw material exports. The surge in exports of processed agricultural commodities by some developing countries is even more surprising, considering the monopolistic role played by advanced countries in these industries, namely the presence of well-established, highly competitive producers that have dominated for decades the global market of most processed and semi-processed primary products (e.g., Italy and France in the wine industry; the Netherlands and Israel in the cut flower industry; Norway, Canada and Japan in the fishing industry).

This thesis investigates whether, contrary to common belief, the current export boom of processed natural resources from developing countries can be transformed into a viable strategy for long-term economic development. This is a particularly timely issue for those developing countries, especially in Latin America and Asia, which are caught in

\footnotetext{
1 The category of primary resources refers to both agricultural and mineral commodities. It includes mining, oil, crops, fisheries and forestry products. This thesis will focus on the category of processed agricultural commodities, including, among others, such products as sugar, cocoa, tea and coffee, as well as meat and fish (fresh, frozen, smoked or dried), and alcoholic beverages, such as wine, brandy, whiskey and beer. All these commodities belong to the manufacturing sector and are classified as "manufactured food and beverages products" in the ISIC (International Standard Industrial Classification of All Economic Activities).
} 
the "middle income trap" and can no longer compete on the basis of low wages and standardized manufacturing products. However, understanding whether an alternative use of natural resources is possible and desirable is even more important for those developing economies, mostly concentrated in Africa, that have been pushed back to dependence on raw material exports by structural adjustment programmes aimed at boosting foreign exchange earnings through the production of cash crops or other commodities for exports.

Currently, an historical transition from a consolidated natural resource "pessimism" to an embryonic natural resource "optimism" is taking place. The above-mentioned theories are at the origin of a widespread and deeply rooted negative view of the development potential of natural resource-based sectors. Such pessimism reached its peak in the early 1990s, when the Information Technology (IT) sector came to be considered the major driver of competitiveness and growth. In that period several schools of thought emerged, arguing that economic growth was strictly dependent on the creation of "high-tech", knowledge-intensive sectors, involving major new technologies. Only in the late 1990 s did scholars acknowledge that, to the contrary, advanced economies had grown on a widely distributed sectoral basis and that many of the significant industries that were traditionally considered "low-tech" were contributing to overall economic growth.

Evolutionary economists contributed to this debate by making clear that supposedly "low-tech" or traditional industries could be seen as highly innovative, if their growing $\mathrm{R} \& \mathrm{D}$ content as well as the use of scientific-based inputs in the production process were taken into account. They also observed that the knowledge intensity of production, which had permeated the manufacturing sector in the 1970s, had gradually extended to all sectors of the economy, creating a wide platform for innovation and technological accumulation in both developed and developing countries.

Only in the last few years, however, have scholars begun to acknowledge that processed primary products increasingly apply knowledge along the entire value chain, require a continuous process of innovation, and are less "staples" than specialized and diversified branded products. This has led some theorists to envisage that a process of "decommodification" of primary resources is taking place - whereby a variety of primary resources would be gradually transformed into high quality, diversified, processed goods, with rising barriers of entry, increasing value added content and higher export price per unit. ${ }^{2}$ Quite surprisingly, this holds even for the most traditional and paradigmatic primary commodities, such as coffee, tea and cocoa. Their production has increasingly integrated new concepts, such as that of "vintage plantation", "geographical indication" and "denomination of origin", giving rise to a range of extremely diversified, fashionable and thus premium-priced luxury goods, such as the Indian Darjeeling tea, the Jamaican Blue Mountain coffee, or the Arriba Nacional Ecuadorian cacao.

\footnotetext{
2 Following Kaplinsky (2006), the term "de-commodification" (of natural resource-based products) is used here to define a process leading to increasing product quality, name branding and diversification, and conferring increasing value per unit to those producers who have chosen innovation-based strategies, creating rising barriers of entry and generating high local value-added.
} 
If in the last few years the knowledge intensity of processed agricultural commodities has been gradually acknowledged, there is still a widespread scepticism about such knowledge intensity and potential for diversification of processed mineral commodities. Indeed, compared to processed agricultural commodities, processed mineral commodities do not present the same propensity towards product differentiation, and are not characterized by rising barriers to entry, based on the introduction of denomination of origin, geographical indication and certification procedures. However, the thesis provides some examples of specialized, non-agricultural natural resourcebased products, such as "boutique" steel, termite-proof wood, biodegradable composites and clean fuel, which show that even processed mineral and forestry products may be a driver of export diversification and shift towards increasingly higher value-added products, with high technological content as well as specialized and customized features.

This thesis argues, therefore, that the old pessimism about the development potential of natural resources has become obsolete and that a new way of looking at natural resource-based processing industries is needed. To support this argument, a new and different approach is developed, which looks in detail at the relationship between the organization in production and continuous innovation, and how these contribute to sustained export growth. The thesis also analyzes the factors that underlie the competitive performance of natural resource-based processing industries at the local, regional and national levels. In particular, it analyzes how, under the globalizing trends that began in the last quarter of the twentieth century, developing countries were able to transform raw primary commodities into high-quality, diversified, processed goods, with increasing value-added content and export price per unit, thus becoming a platform for development.

In this context, the issue of the long-term sustainability of export growth in natural resource-based processing industries is also addressed, by looking at their territorial and spatial dimension. Most natural resources, in fact, tend to be spatially clustered due to biological and environmental reasons. The thesis illustrates how, within clusters, geographical proximity may play a fundamental role in promoting continuous incremental innovation and technological upgrading, thanks to the creation of interfirm linkages and localized spillover effects linked to the presence of foreign investors.

However, the thesis also highlights that not all clusters are equally innovative and equally successful in sustaining export growth in the long term. Consequently, it undertakes an in-depth analysis of whether, and the extent to which, natural resourcebased clusters may experience the emergence of territorially bound specificities, "uniqueness" factors and local innovation capabilities that would make their products original, different from each other and irreplaceable in the eyes of international consumers, thus the export growth of natural resource-based products sustainable in the long term.

This process is illustrated by comparing the Chilean and Argentine wine industries. Since the 1970s, wine has represented a particularly rapidly growing natural resource-based industry. It is an emblematic case of the evolution of processed 
agricultural commodities into innovation-driven, highly diversified products. Moreover, the wine industry has the potential to generate a positive impact on the rest of the economy in terms of employment generation (both in industry and agriculture), exports with increasing local value-added and technological spillover effects. In this framework, the thesis provides solid evidence to show that wine is a processed primary product characterized by complex technological changes and a sustained increase in knowledge intensity. It also shows that, paradoxically, some developing country producers, such as Chile, Argentina and South Africa (but later on also Morocco, Lebanon, Brazil and Uruguay) have been successful in entering the industry, in sustaining their competitive positions, and in increasing their market shares.

Currently, Chile and Argentina represent the leaders within the group of new entrants from the developing world. So, it is fruitful to study such entrants, and especially to compare two cases where the performance of the wine industry has evolved differently, despite similar conditions at the outset. They also raise one of the central themes of the thesis: from the analysis of the Chilean and Argentine wine cases, can we argue that in Latin America a new, viable model of export-oriented industrialization through primary processing is gradually emerging - namely a model that can be considered an alternative to the East Asian export-oriented industrialization based on narrowly defined manufacturing?

\section{Scientific relevance}

The scientific relevance of the thesis is related to its contribution to the analysis of the ambiguous relationship between natural resource availability, commodity dependence and development. For Latin America, which has just undergone a period of stagnation, after a commonly defined "lost decade" (1980-1990), and which has recently shown signs of economic recovery, this is a timely and crucial issue. The continent is considered in the development literature as one of the leading "laboratories" for natural resource booms and busts. Its vocation to specialize in primary products has never really disappeared, as the recent upsurge of natural resource-based exports clearly shows. Over the last decade, the rise in world prices for Latin America's commodities and the related increase in their output - which fell only briefly during the financial crisis of 2008-2009 - has accounted for one-third to half of the continent's growth. Considering the volatility of commodity prices, and the fact that mineral commodities such as oil and gas are non-renewable, the importance of increasing local value-added and export diversification of agricultural commodities for the growth of the continent is undeniable.

In order to illustrate the viability of such a development strategy, the thesis relies on three bodies of literature: the literature on economic development and natural resources; the literature on regional, sectoral and national systems of innovation; and the literature on clusters. The selected bodies of literature enable to investigate three different kinds of problematic issues that are usually addressed by scholars separately: the knowledge intensity of natural resource-based industries and their capability of transmitting growth to the rest of the economy (in comparison to manufacturing 
industries, narrowly defined);3 the measurement of innovation in "low-tech" and traditional industries, and the increasing importance of incremental innovations and tacit knowledge flows in a globalized economy; the causality effect in the generation of collective efficiencies and networking dynamics at the local level, within natural resource-based clusters and regions. Thus, the scientific relevance of the thesis is mainly related to its contribution to the overall debate on the role of natural resources in development by bringing together these three different perspectives and by drawing related policy recommendations.

In particular, through the comparative analysis of the Chilean and Argentine wine industries, the thesis provides useful and timely lessons about the diversity of pathways and policies that can be adopted for the development of agricultural natural resource-based processing industries in the contemporary period. The basic argument is that the Argentine and Chilean wine industries represent examples of strategic entry opportunities being successfully exploited by developing countries. The main contribution of the thesis, therefore, through the comparative analysis of these two cases, is the identification of possible alternative ways in which resource-dependent developing countries may transform primary resources from a potential curse into a blessing. For this to happen, a number of changes need to take place that are related to the capability of diversifying the composition of exports, of creating linkages with domestic producers and input providers, of adding more value at the local level, and of increasing the knowledge content brought in by domestic actors. These changes are key in strengthening the complex and uncertain process leading to the "decommodification" of the economy. As this thesis focuses mainly on the case of processed agricultural commodities, the recommendations for further research point to the need to verify whether its findings and policy recommendations would be confirmed if applied to mineral natural resource-based processing industries.

\section{Outline of the thesis}

This thesis is divided into six chapters. Chapter 1 analyzes the different development theories that, over time, have addressed the question of whether natural resources represent an impediment or an opportunity for economic growth. It argues that the pessimism stemming from such theories, which have basically led developing countries to abandon natural resource-based sectors and industrialize, appears increasingly outdated and that "primary" resources should not be associated necessarily with "primitive" modes of production as they were in the past. Processed agricultural production, as well as agricultural production per se, have become increasingly innovative and knowledge intensive. Under these conditions, it has become difficult to compete based exclusively on price. This applies also to Latin America, even if its economic development history, illustrated in the last sections of the chapter, does not

\footnotetext{
3 In the development literature, scholars tend to refer to the manufacturing sector in a narrow sense, as synonymous with "fabrication industries", such as electronic equipment, electrical appliances, clothing, automobiles, etc. (Perez, 2010). Natural resource-based processing industries are often erroneously considered as a category apart.
} 
look propitious for it. From the observation of the steep export growth of processed agricultural commodities registered in Latin America during the past two decades, it would seem that new opportunities and implications from an economic development perspective can be detected.

Chapter 2 opens up a new way of looking at natural resource-based processing industries from a development perspective. It argues that the increasing knowledge intensity of processed agricultural commodities has inevitably raised the barriers of entry and has made them extremely challenging for newcomers. However, this does not mean that developing countries have been or will be necessarily or inevitably marginalized. To the contrary, Chapter 2 gathers the analytical and methodological tools needed to provide support to three main hypotheses and related sub-hypotheses, pointing to the opposite case:

Hypothesis I: (a) In the last quarter of the twentieth century, natural resource-based processing industries have become knowledge and innovation intensive. (b) This has opened up new windows of opportunity to developing countries.

Hypothesis II: (a) To enter natural resource-based processing industries, the capability of developing countries to access foreign knowledge and technology from abroad is crucial. (b) The creation of endogenous capabilities to innovate is key to absorbing and adapting them to the local environment.

Hypothesis III: (a) Sustained export growth in natural resource-based processing industries is linked to the transformation of natural resource-based clusters from informal into organized clusters. (b) The interaction of organized clusters with broader regional innovation systems is equally important.

More specifically, Chapter 2 presents the selection of a set of key variables related to the causal relations linking sectoral performances and export growth, and identifies a way to assess them through qualitative and quantitative indicators. It then tailors these variables (and related indicators) to the specificity of the wine industry, which is the selected agro-processing industry as a case study. This leads to the analysis in the subsequent chapters of the competitive performance of the Chilean and Argentine wine industries within the more general context of the structural transformations that are reshaping the whole industry worldwide.

Chapter 3 focuses on the wine industry. It carries out a thorough analysis of the distinctive features of the wine industry globally, and identifies the main characteristics of modern wine production habits and techniques. It illustrates the recent global market trends in the wine industry, including the explosion of international competition and the high rate of new entrants, as well as the consequent contrast between New World and Old World producers' competitive strategies and production techniques. It also provides a map of the knowledge base of the wine industry, and of the international codified and tacit knowledge flows that are at the origin of an increasing technological interdependence among winemaking economies and regions. Subsequently, Chapter 3 analyzes the relationship between this technological revolution 
and the dramatic shift in international consumption patterns from quantity to quality wines. It illustrates how international consumers have become more educated, far more demanding, and more willing to spend on high-value consumption goods, such as luxury clothing and sophisticated food products, based not only on price, but on a range of other criteria such as image, style, branding and marketing.

In light of the above, one might be sceptical about the ability of developing countries to enter the market successfully and sustain increased exports. However, trade data clearly show that some developing countries have successfully entered the wine industry, to the point that three of them, namely Chile, Argentina and South Africa, are currently ranked among the ten leading wine exporters. The specific objective of the empirical work included in the last three chapters of the thesis is to analyze the historical path, technological trajectory and the competitive dynamics of the Chilean and Argentine wine industries.

The information and data related to the Chilean wine industry were collected during a four-month stay in 2002, and two subsequent field visits, in 2005 and 2007. During the field work in Chile, the chief oenologists of 35 wineries were interviewed, with a particular focus on the 25 leading exporters of premium wines, distributed along the five main Chilean wine producing areas. Research on the Argentine wine industry was carried out during a three-month stay in 2004, and two subsequent field visits, in 2008 and 2010. During the field work in Argentina, the chief oenologists of 27 wineries were interviewed, with a particular focus on the 25 leading exporters of premium wines, concentrated in the two main Argentine winemaking provinces. In both countries, interviews were also carried out with wine experts, renowned wine academics, wine journalists and representatives of wine-related institutions and research centres, mostly located in the respective capitals. An open-ended, semi-structured questionnaire was used to give consistency to the interviews, and to leave informants free to elaborate on the aspects they felt to be more relevant (see Annex I). The findings of the field research are presented in Chapters 4, 5 and 6.

Chapter 4 looks briefly at the historical background of the Chilean and Argentine wine industries from their origins and at the impact of political changes, regulatory framework reforms and improved macroeconomic conditions in facilitating the development of the wine industry in both countries. After having acknowledged the natural assets and competitive cost structure underlying the successful export performance of the Argentine and Chilean wine industries as mere conditions of departure, Chapter 4 assesses the quality improvements introduced in the Chilean and Argentine wine industries over time and analyzes the extent to which these have been accompanied by equal improvements of their positioning in the international market. It also looks at the potential role of Chilean and Argentine local consumers in stimulating and accelerating the drive towards high-quality wines. These issues are important for understanding whether the large improvements characterizing both the Chilean and Argentine wines - as shown by their increased quality, enhanced international ranking and rising export unit value - are incidental or sustainable over time. 
Chapter 5 assesses whether the positive results achieved by the Chilean and Argentine wine industries illustrated in Chapter 4 (continued export growth and higher quality) were achieved by increasing the knowledge intensity of the local industry and by building domestic capacity, absorbing imported technology and creating domestic linkages, or by relying exclusively upon foreign direct investment (FDI) and continued imports of foreign knowledge. In order to achieve this objective, Chapter 5 measures, first of all, the innovativeness of the leading 25 Chilean and of the leading 25 Argentine exporters of bottled wines, and looks at the variety of innovations introduced, focusing not only on new methods of production, but also on the development of new products and new ways of organizing business. It then identifies the role played by external sources of innovation - such as FDI, as well as capital-embodied and codified knowledge flows - in triggering the phenomenal technological upgrading process described in the chapter. Finally, it looks at the role played by internal sources of innovation, namely at the creation of local tacit knowledge and incremental innovation, at the emergence of a wide pool of highly qualified human resources, and at the role of sectoral R\&D programmes, local universities and research centres in the creation of endogenous technological capabilities.

Chapter 6 addresses the issue of the long-term sustainability of the Chilean and Argentine export boom, by looking at the territorial dimension of the wine revolution in Chile and Argentina, and at the spatial arrangement underlying their wine export growth (see Annex II). In particular, Chapter 6 makes use of a typology that distinguishes between informal and organized wine clusters in developing countries. These are the Colchagua and Curicó wine clusters in Chile, and the Mendoza and San Juan wine clusters in Argentina. It illustrates, on the one hand, how in Chile the organized cluster of Colchagua tapped into the resources made available by a "centralized" innovation system located in the Chilean Metropolitan Region, pulling together most activities related to wine technology, business and services. This stimulated technological upgrading and innovation processes within an organized cluster, such as Colchagua, capable of absorbing the most sophisticated levels of knowledge and information. Similarly, Chapter 6 shows how in Argentina the embeddedness of the organized clusters of Mendoza in a "learning region" strengthened the learning dynamics at the local level and stimulated knowledge spillovers among foreign and local wineries, thereby "democratizing" innovation even amongst the less advanced segment of local producers. To draw lessons from the two case studies, the chapter analyzes the strengths and weaknesses, as well as the sustainability of both "models" from a comparative perspective, and emphasizes the key role of interinstitutional linkages and inter-firm networks in strengthening local competitive advantages and innovative capabilities.

The findings of the empirical work are summarized in the conclusions of the thesis and form the basis for the elaboration of an integrated, generalizable analytical framework for positioning processed primary resources along their technological and development trajectory. This thesis argues that, contrary to common belief, the availability of natural resources is not necessarily a curse and can become a spur to industrialization and a platform for creating deeper competencies and increased knowledge and innovation capacity. This depends, however, on both the accessibility to 
developing countries of tacit and codified knowledge from outside, and on their ability to absorb and adapt it to the local environment. From a development perspective, the sustainability of the export boom depends on the extent to which inter-firm and interinstitutional linkages, and networking dynamics have gradually emerged at the local level, thanks to the transformation of informal natural resource-based clusters into organized entities and to their integration into broader innovation systems. 



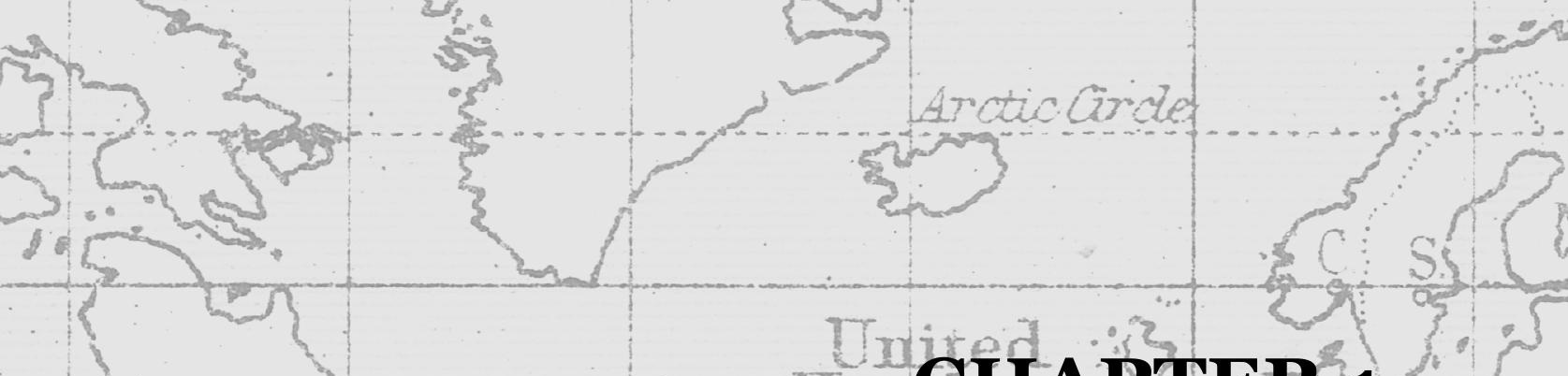


CHAPTER 1 


\subsection{Introduction}

The present chapter looks at the theoretical foundations underlying the longstanding debate on the relationship between natural resource abundance and economic performance. Such an in-depth review is essential not only by virtue of its historical relevance, but also for the timeliness of its present-day implications. Latin American countries have historically been dependent on the production and export of natural resources, both agricultural and mineral, with negative results in terms of economic development. During the last two decades, however, in addition to the sustained export growth in raw primary products, a number of Latin American countries have successfully moved into the production and export of processed primary products, and in particular of processed agricultural commodities. ${ }^{4}$ Contrary to the past, these are no longer enclave industries isolated from the rest of the economy, and their technological sophistication frequently positions them at the top of the technological complexity spectrum. This thesis argues, therefore, that the old pessimism on the relationship between natural resources and development has become obsolete, and that a new and more comprehensive way of looking at natural resources is needed.

The category of processed agricultural commodities includes, among others, products such as sugar, cocoa, tea and coffee, as well as meat and fish (fresh, frozen, smoked or dried), and alcoholic beverages such as wine, brandy, whiskey and beer. All these commodities belong to the manufacturing sector and are classified as "manufactured food and beverage products" in the ISIC (International Standard Industrial Classification of All Economic Activities). 5 They, therefore, present the same characteristics of the manufacturing sector, considering the processing phase of the final products, but are also strictly interwoven with the dynamics of the primary sector, considering the cultivation phase of raw inputs, which is often inextricably linked with their processing phase.

According to Tregenna (2011), the characteristics that are strongly associated with the manufacturing sector in general include: dynamic economies of scale; strong backward and forward linkages; high potential of learning-by-doing; and innovation and technological progress. According to Perez (2010), within the group of manufacturing industries, natural resource-based processing industries are also characterized by low-

\footnotetext{
4 The category of primary resources encompasses both agricultural and mineral products, including mining, oil, crops, fisheries and forestry. Mineral-driven economies, where the share of minerals exceeds 50 per cent of total exports, fall into two categories: oil exporting and mineral exporting countries. Exporters of agricultural commodities, where the share of crops exceeds 50 per cent of total exports, also fall into two categories: primary agricultural commodities and processed agricultural commodities exporting countries (Auty, 1998). This thesis focuses mainly on the latter, namely the category of processed agricultural commodities.

5 In the development literature, scholars tend to refer to the "manufacturing sector" in a narrow sense, as synonymous with "fabrication industries", such as electronic equipment, electrical appliances, clothing, automobiles, etc. (Perez, 2010). According to Woodward (1965), "fabricated products" can be defined as products fabricated in large quantities by workers in workshops and assembly lines.
} 
labour intensity and the need for skilled and highly skilled personnel. To the contrary, the primary sector is characterized by high-labour intensity, the need for low-skilled personnel and a widely spread income distribution capacity. Therefore, taking into account their "dual integrated nature", primary processing industries may combine a high potential for poverty reduction with the capacity to activate and strengthen the engines of growth (Perez, 2010). This thesis examines whether and how developing countries can use processed primary products, and in particular processed agricultural commodities, as a platform to spur industrialization and to acquire endogenous innovative capabilities.

In order to arrive at a deeper understanding of the contested relationship between natural resources and development, this chapter is structured as follows: Section 2 introduces the historical debate on primary commodity dependency in developing countries. Section 3 looks at the main economic theories that, during the second half of the last century, have considered natural resources a "curse" rather than an opportunity, and have pressured developing countries into abandoning natural resources and moving towards narrowly defined manufacturing. Section 4 focuses on the false choice between natural resources and industrialization, and provides counterarguments to the assumption that these are alternative rather than complementary ways of promoting development. Section 5 looks at the emergence of the South-East Asian "dragons" and at the patterns of their export-led manufacturing model, as well as at the role played by FDI in sustaining their growth in a globalized economy. Section 6 focuses more specifically on Latin America by illustrating the region's history of primary commodity "booms and busts" and describing its still embryonic reindustrialization process. Section 6 illustrates the return of Latin America to a productive specialization based on unprocessed raw materials, but also its emerging specialization based on processed primary products, after decades of deindustrialization characterized by a declining share of manufacturing value added and employment. It also examines Latin America's recent performance in terms of economic growth and technological accumulation, against the benchmark of South East Asia, through the lens and analytical tools provided by evolutionary economics. Section 7 concludes, highlighting the conditions under which natural resources may become a driver of resource-based industrialization and economic development, rather than an impediment to it.

\subsection{The historical debate on natural resources and development}

For several centuries, the colonial pattern of international trade confined developing countries to the role of primary product exporters and manufactured goods importers, thereby linking the concept of primary resource endowments with notions of poverty, underdevelopment and dependency (Szirmai, 2005). From an academic perspective, such a link has been almost unanimously interpreted as a causal relationship when the terms of trade of developing countries drastically deteriorated in the inter-war period, and resource dependent developing countries turned out to be the hardest hit by the Great Depression of the 1930s (Maddison, 1990). This led to the common perception, especially widespread in Latin America in the post World War II period (Lewis, 1954; 
Prebisch, 1950), but also in the African continent during the decade of the 1950s (Mytelka, 1989), that in order to reduce dependence on manufactured imports and international trade, developing countries would have to industrialize, to "get rid" of their pool of farmers and to turn their economies towards import-substitution.

Historical evidence shows that several developing countries - such as Argentina, Brazil and Mexico, but also China, India and South Africa - adopted import-substituting industrial strategies in the post World War II period as a reaction to the negative impact of the colonial drain, ${ }^{6}$ namely their traumatic experience with primary exports and the open economic models characterizing the colonial period (Szirmai, 2005 and 2011). Under import-substitution regimes, imports (of manufactured goods) were restricted by the imposition of high import duties, as well as quota and import licensing systems, in order to protect domestic firms at their infant stage and allow them to grow under limited pressure from international competition (Furtado, 1976).7 The expectation was that, by building their own industries, developing countries would finally break the "cage of international specialization" in traditional, non-processed primary exports, which had locked them into spirals of marginalization and economic stagnation for several decades (Bairoch and Kozul-Wright, 1996; Hobsbawm, 1994).

Half a century later, those spirals have been only partially disentangled. Currently, the gap between developing and developed countries is persisting: in 1970, the per capita GDP of developed countries was 23 times higher than that of developing countries, only narrowing to 18 times in 2007 (UNCTAD, 2008). According to Mytelka (1989), "few studies have gone beyond the condemnation of explicit colonial policies to analyze the deeper structural disincentives to industrial development that emerged in the colonial period and the mechanisms that have partially reproduced that structure even later on, as conditions changed". On the one hand, during the colonial period the massive flows of European manufactured goods towards developing countries provoked a deep deindustrialization process in many of their economies, especially in the textile and clothing industries (Bairoch and Kozul-Wright, 1996; Hobsbawm, 1994). ${ }^{8}$ On the other hand, even after independence most extractive, agro-processing and manufacturing industries in developing countries remained heavily concentrated in the hands of

\footnotetext{
6 According to Maddison (1990), the colonial drain is measured by the flow of resources from the colonies to their motherlands, based on taxation, forced delivery of crops, monopoly income for transport services, remittances of profits and transfer of currency reserves.
7 Recent development literature has put emphasis on the distortive effects of prolonged protection of the domestic market in terms of the inefficiency of local firms and their resistance to adopt innovative (rather than rent-seeking) behaviours and modern (rather than obsolete) technologies, basically due to the lack of incentives for competition (for an extensive review, see World Bank, 1987). However, import-substitution strategies have also allowed countries such as Brazil and Argentina to develop an impressive domestic manufacturing capacity until the mid-1970s, and can be considered as the point of departure of industrialization strategies of many developed and developing countries, including India (Lall, 1992), Japan (Bell and Pavitt, 1993) and some of the most dynamic East Asian economies (Rodrik, 1999).

8 From 1810-1850 developing countries were forced to eliminate all import duties and give free access, if not preferential treatment in their public procurements, to all products from the mother country. In order to raise revenues, they were allowed in some cases to impose an import duty of 5 percent (the so-called " 5 percent rule”), provided that compensatory equal taxes were imposed on domestically produced goods (Bairoch, 1993).
} 
foreign corporations, together with the import/export trade and the flow of foreign capital and technology linked to it, thus handing over to oligopolistic foreign powers the control of all economic surpluses and "entrepreneurial decisions" related to the industrial deepening of host developing countries (Gerschenkron, 1962; Farrell, 1979; Sagasti 1973; Roemer, 1996). Mytelka's study (1989) on "The unfulfilled promise of African industrialization" shows, for example, that in the late 1960 s the share of foreign ownership in large-scale manufacturing was estimated to be 68 percent in Nigeria, 78.3 percent in the Ivory Coast, 59.3 percent in Kenya and 72 percent in Gabon.

This was during the time when technology was considered a marginal factor in explaining economic growth, and there was a firm belief that technology was embodied in capital goods (i.e., machinery and equipment), largely developed in the industrialized world and then passively transferred to developing countries through FDI, patent sales or licensing agreements (Dunning, 1981; Pavitt and Bell, 1993; Bell and Albu, 1999). As a consequence, most developing countries relied on licensing rather than endogenous innovation; foreign affiliates of transnational corporations (TNCs) sourced all their technology from their parent companies; and both practices contributed to a lack of demand for local industrial research and for the establishment of linkages with a local knowledge base (Mytelka, 1978). In the best of cases, the full reliance on imported technology played a positive role in the expansion of developing countries' production capacity but persistently discouraged the creation of local technological capabilities (Pavitt and Bell, 1993). 9 It is therefore not surprising that in the late 1960s the "enclave nature" of most export-oriented productive sectors gave rise to a need to rethink the industrialization paradigm of developing countries and to turn their economies towards nationalization, ${ }^{10}$ FDI regulation and state control. This was well synthesized in the Arusha Declaration, made by Tanzanian President Julius Nyerere on 5 February 1967 (quoted in Mytelka, 1978):

The mistake we are making is to think that development begins with industries. It is a mistake because we do not have the means to establish many modern industries in our country. We do not have either the necessary finances or the technical know-how. It is not enough to say that we shall borrow the finances and the technicians from other countries to come and start the industries. The answer to do this is that we cannot get enough money and borrow enough technicians to start all the industries we need.

\footnotetext{
9 According to the definition of Pavitt and Bell (1993), the concept of "production capacity" refers to the resources used to produce industrial goods at given levels of efficiency and given input combinations: equipment (capital embodied technology), labor skills (operating and managerial know-how and experience), product and input specifications, and the organizational methods and inputs used. The concept of "technological capabilities" refers to the resources needed to generate and manage technical change, including skills, knowledge, experience, institutional structures and linkages.

10 See Farrell (1979) for a defense of a "genuine" nationalization of natural resource-based industries in developing countries, and a thorough analysis of why, after two decades of control by foreign corporations, the oil industry in Trinidad and Tobago had not acquired any critical technological capability related to oil, and why, after nationalization, the whole range of activities necessary to run the industry could not be efficiently performed in-house.
} 
In this same perspective, in December 1970 the group of Andean countries (including Bolivia, Colombia, Chile, Ecuador, Peru and Venezuela) promulgated Decision 24 on the "Common Treatment for Foreign Capital, Trademarks, Patents, Licensing Agreements and Royalties". Their objective was to encourage the limitation of transfer pricing and the renegotiation of technology contracts, so as to reduce royalty payments and eliminate restrictive clauses, thereby increasing the contribution of imported technology and of FDI to the development of the region (Mytelka, 1979). Decision 24 was also intended to strengthen the bargaining power of domestic firms at the moment of negotiating with TNCs, by establishing a mechanism for collaboration across member countries of the Andean Group (the Andean Junta) that would, on the one hand, compare the conditions that similar companies had received in other Andean countries and request equal treatment, and on the other hand, assist national firms in their choice of foreign technology suppliers, so as to maximize the potential learning benefits.

Indeed, both initiatives faced many problems in their implementation, due to a lack of administrative preparedness encountered at the national level, but they have the merit of having raised awareness of the close relationship between FDI, technology and development in both the African and Latin American continents (Mytelka, 1979 and 1989). Four decades later, in a fully liberalized international setting, such attempts to regain ownership of the gains from the exploitation of domestic resources, or to put in place mechanisms to regulate FDI, have become inconceivable, even as TNCs continue to control a large proportion of developing countries' export activities, especially in the oil and mining industries (UNCTAD, 2007). Comtrade data show that, quite surprisingly, most developing countries have remained heavily dependent on primary commodity exports, despite the remarkable shift in the composition of exports of a minority among them from primary commodities to manufactured goods (UNCTAD, 2008). Currently, 92 developing countries still depend on primary commodities for at least 50 percent of their export earnings, while 47 of these depend on non-oil commodities for over 50 percent of their annual exports (see Table 1.1).

Table 1.1 Primary commodity dependence of developing countries, 2003-2005

\begin{tabular}{lcc}
\hline & $\begin{array}{c}\text { Number of developing countries } \\
\text { that derive at least 5o percent } \\
\text { of export earnings from } \\
\text { primary commodities }\end{array}$ & $\begin{array}{c}\text { Number of developing countries } \\
\text { that derive between 20 and 49.9 } \\
\text { percent of export earnings from } \\
\text { primary commodities }\end{array}$ \\
\hline All commodities & 92 & 38 \\
Non-fuel commodities & 47 & 41 \\
Fuel & 25 & 18 \\
Ores and metals & 7 & 13 \\
Agricultural raw materials & 3 & 6 \\
Food & 29 & 39 \\
\hline
\end{tabular}

Source: UNCTAD (2008), based on Comtrade database

According to UNCTAD, in 2006 and 2007 commodity producers continued to benefit from the boom in commodity markets that started in 2002, thanks to the rising demand of emerging economies (see Table 1.2), and the price index for non-fuel commodities 
(minerals, ores and metals, agricultural raw materials) reached its highest level in current dollars since 1960 (UNCTAD, 2008). ${ }^{11}$ At the same time, the price of oil rose more than tenfold since 1999, to a record of almost 150 US\$ a barrel in 2008. In this respect, UNCTAD notes that "if the cycle of growth and industrialization in emerging economies continues, the current commodity boom may mark the beginning of a changed commodity economy in the twenty-first century, characterized by a longterm resurgence in the demand for, and value of, primary commodities in world trade" (UNCTAD, 2008).

Table 1.2 World primary commodity prices, 2001-2007

\begin{tabular}{ccc}
\hline Commodity group & $\begin{array}{c}\text { 2oo2-2006 } \\
\text { (Percentage change between } \\
\text { 2002 and 2006) }\end{array}$ & $\begin{array}{c}\text { 2007 } \\
\text { (Percentage change over } \\
\text { previous year) }\end{array}$ \\
\hline All commodities excluding crude oil & 89 & 18 \\
Food and tropical beverages & 48 & 24 \\
Vegetable oilseeds and oils & 26 & 66 \\
Agricultural raw materials & 62 & 15 \\
Minerals, ores and metals & 220 & 4 \\
Crude oil & 158 & 67 \\
\hline
\end{tabular}

Source: UNCTAD Secretariat, based on UNCTAD Commodity Price Bulletin, 2010

In this respect, several international organizations have launched alarm signals regarding the prospect that the peak reached by almost all commodity prices might again increase, rather than discourage, dependence on individual commodity exports and become a disincentive to export diversification for several developing countries (UNCTAD, 2006; World Bank, 1995; OECD, 2006). In particular, as highlighted by UNCTAD's 2006 Trade and Development Report, commodity prices typically exhibit cyclical behaviour, with alternating booms and busts depending on demand oscillations compared to supply response; therefore it would be "strategically imprudent" for commodity exporting developing countries to ignore or neglect the need for diversification of their exports and for structural change.

This is even more important if we consider that in 2007 UNCTAD predicted that commodity prices would start to decrease again in the medium term, due to a combination of factors, such as slower global economic growth, the increased supply of some commodities, the changing behaviour of investors in commodity markets and the influence of crude oil prices on the prices of many other commodities (UNCTAD, 2007). In order to interpret this phenomenon, and understand the reasons for its negative impact on development, the next section will explore the main analytical contributions in the literature on this subject.

\footnotetext{
${ }^{11}$ It should be noted that even though the price indices of all commodity groups in nominal terms have been above their declining long-term trend in real terms, most real prices of commodities are still far below their levels of the 1970 s and 1980 . Only the real price for the minerals, ores and metals group has substantially exceeded those levels, thanks to recent sustained demand originating from emerging economies, such as China and India (UNCTAD, 2007).
} 


\subsection{Natural resource endowment: A curse or an opportunity?}

The economic development literature shows that, in the past, developing countries specializing in natural resource-based exports have been systematically locked into the trap of low-wage exports or confined to a permanent extractive phase (Auty, 2001; Sachs and Warner, 1997; Sachs and Rodriguez, 1999). Oil rich countries such as Congo, Gabon, Ecuador, Mexico, Venezuela, Nigeria and Saudi Arabia are traditionally considered as some of the weakest performers among developing countries in terms of both GDP and per capita GDP growth, despite their natural resource wealth (Wright, 2001). This trend is so pronounced that several economists over the course of history have identified the existence of a "natural resource curse", according to which resourceabundant countries would be condemned to perform more poorly in terms of growth than resource-poor countries (Auty and Mikesell, 1998; Sachs and Warner, 1997). Already in 1776, Adam Smith was questioning the positive impact of a natural resource sector, such as mining, on development. He wrote:

Projects of mining, instead of replacing the capital embodied in them, together with the ordinary profits of stock, commonly absorb both capital and stock. They are projects, therefore, to which of all others a prudent law-giver who desired to increase the capital of his nation, would least chuse [sic] to give any extraordinary encouragement (Smith, 1776 p.562).

Three well-studied theories, which have emerged and kept evolving during the second half of the last century, point to the fact that there is an ambiguous and counterintuitive relationship between natural resource abundance and economic performance: the "commodity trap" theory (Hirschman, 1958; Rostow, 1960; Watkins, 1963); the "declining terms of trade" theory (Prebisch, 1950; Singer, 1950; Bairoch, 1993; Szirmai, 2005); and the "Dutch disease" theory (Corden and Neary, 1982; Sachs, 1999; Auty, 2001). All of them claim that there is an adverse relationship between economic growth and natural resource endowment. However, for all three of these, evidence is contradictory, and different schools of thought end up reaching divergent conclusions, as shown by the following sub-sections.

\subsubsection{The commodity trap theory}

From a theoretical perspective, the economic development literature warns almost unanimously of the danger of natural resource endowment for long-term economic performance and enduring competitiveness. As early as 1963, Watkins, in his "staple theory" of economic growth, argued that staple exports could generate a positive multiplier-accelerator effect by inducing new income flows, thus becoming a driver of capital formation. This would happen thanks to the creation of the strong linkage effects identified by Hirschman in $1958 . .^{12}$

\footnotetext{
12 According to Hirschman (1958), the inducement to domestic investment resulting from the increased activity of the export sector could be broken down into four broad linkage effects: backward linkage, forward linkage, fiscal linkage and demand linkage. Backward linkages refer to the supply of inputs to produce (staple) export goods; forward linkages to the processing of the staple prior to export; fiscal linkages to the taxation of
} 
Watkins, however, also specified that when staple sectors were the leading sector of the economy, economic growth would depend on the extent to which the export base would be gradually diversified. In this sense, he highlighted the risk for an economy to get caught in a "staple trap", whereby staple exports would create prosperity, but only in the short term. In the long term, they could cease to be profitable either because of diminishing returns on the supply side, or because of adverse shifts in demand due to competition from cheaper sources of supply and from synthetics, or because of the income inelasticity of foreign demand, or simply because of change of taste. This tendency could be slowed down by improving marketing techniques and introducing cost-reducing innovations, but it could be overcome only by shifting into new export lines and into production for the domestic market.

In this respect, Watkins (1963) warned about what he defined as "the most serious peril", that of staple exporters developing an inhibiting "export mentality" resulting in an over-concentration of resources in the export sector and a reluctance to promote domestic development. However, he was also convinced that the Canadian example clearly showed how growth could be positively dependent on the volume and character of staple exports, as well as on the ability to borrow, adapt and supplement foreign technology. In this sense, he classified as an "untested hypothesis" Rostow's argument (1960) that primary exports would delay industrialization, and that if a country had a comparative advantage in primary exports, it would also have a comparative disadvantage in manufacturing. He also defined as an "illusory peril" Rostow's warning about the fact that the economic growth achieved by developing countries by exploiting land and natural resources would delay their reaching the take-off stage (Rostow, 1960).

Before Rostow, Lewis (1954) had already suggested that manufacturing should be encouraged at the expense of agriculture, and that a costless shift of labour from agriculture to manufacturing could be engineered. He theorized that an unlimited supply of labour was available in countries where the population was high in relation to natural resources and that in those cases marginal productivity of labour was close to zero in large sectors of the economy. Therefore, agricultural workers could be easily diverted to manufacturing sectors without any productivity loss. However, Lewis also underlined the importance of natural resources in domestic capital formation and technical progress as key factors for promoting economic development. He argued:

The profitability of investing in a country depends upon its natural resources, upon its human material, and upon the amount of capital already invested there. The most productive investments are those which are made to open up rich, easily accessible natural resources, such as fertile soil, ores, coal or oil. [...] In the well developed parts of the world (in the resource sense) the main opportunity for productive investment lies in improving techniques [...]. It is profitable to use capital to introduce new techniques, but this is not as profitable as using capital to make available both new techniques and also new resources (Lewis, 1954, p.163).

activities related to staple production; and demand linkages to the multiplier effects generated by profits, earnings and wages spent in the local economy. 


\subsubsection{The declining terms of trade theory}

In reality, Rostow and Lewis were not alone in arguing that export growth of primary products might become "immiserizing" factors if the terms of trade turned against the country (Bhagwati, 1958). They were rather part of a consistent group of prominent economists, who, in the early days of development economics, encouraged developing countries to exit primary sectors and move into industrial production as a platform for a sound development strategy. Prebisch (1950) and Singer (1950) were the first to argue, in the early 1950s, that the terms of trade were turning in favour of manufactures and against commodities, due to three factors: the development of synthetic substitutes for primary commodities; the lower income elasticity of demand and higher price elasticity of demand of commodities; and the fact that commodities were only one of many inputs into final manufactures. Moreover, Singer (1950) pointed out that when its export earnings were high, a country was able to finance development but was lacking the incentives to do so; when its earnings were low, the incentives were there but the means were lacking. Prebisch (1950) projected a downward trend in the terms of trade for primary commodities in relation to manufactured goods, due to the fact that industrial countries were capturing most productivity increases in the form of higher workers' income and owners' rents, and thus urged developing countries to reduce their dependence on primary commodities in favour of more investment in manufactures and infrastructure.

For three decades (1950-1980), Prebisch and Singer's structuralist theories had a wide diffusion and tremendous impact, especially on Latin American economic policies. However, more recently Prebisch and Singer's views have generated a wide debate and have appeared difficult to validate in their integrity through empirical data collection. Bairoch, for example, defined the long-term deterioration in term of trade as a myth, or "a prototype of those surrounding the development of the Third World, so wide as was its acceptance among economists specializing in problems of underdevelopment" (Bairoch, 1993). He claimed that, based on the information available on productivity changes in the pre-World War II period, it is almost impossible to conclude that there has been a historical decline in the price of primary products relative to that of manufactured goods. On the contrary, since the most prominent effect of the Industrial Revolution was a rapid increase in manufacturing productivity, one can only surmise that for almost two centuries an on-going reduction in the price of manufacturing goods has taken place relative to primary products.

Consequently, Bairoch (1993) claimed that between the 1870 s and the 1920 s the terms of trade for primary products (with the exception of sugar) relative to manufactured goods improved by 10-25 percent instead of worsening. For non-oil exporters, which represent 83 percent of all developing countries, the period from 1961 to 1981 was characterized by relative price stability. It is only after $1979 / 81$ that the "barter terms of trade" of non-oil exporting developing countries really started to deteriorate (by an average of 15 percent, until 1992). This was largely due to the rapid increase in oil prices, which led to an equally rapid rise in the prices of manufactured goods. Paradoxically, the negative evolution coincides with the political independence of many developing countries, and "to a certain extent, independence could mean a freer hand 
for large purchasing companies to press for lower prices since, in such a case, local situations were no longer of direct concern for the former colonial developed country" (Bairoch, 1993).

Moreover, Bairoch (1993) argued that, from the mid-1950s onwards, the trade specialization that had characterized developing countries in the traditional phase of colonialism, whereby they were mostly exporting tropical agricultural products and importing manufactured goods, did not hold any longer. Developing countries have actually become net importers of food and almost net importers of agricultural products. Ultimately, as already highlighted by the Leontief paradox ${ }^{13}$ several decades ago, reality is more complex than the simple equation linking the terms of trade of developing countries with primary commodity exports and those of developed countries with manufactured exports, and predicting the dynamic effects of comparative advantages in primary products as ineluctably negative.

An exhaustive account of the most recent and still controversial debate on developing countries' (declining) terms of trade can be found in Szirmai's work (2005). He reminds that Kindleberger (1956) and Maizels (1963) had already expressed substantial doubts on the statistical support used by Prebisch and Singer to justify the existence of longterm declines in the terms of trade of developing countries, and had argued that no significant correlation could be found between long-term declining real export prices and economic growth of exporting countries. Some years later, authors such as Spraos (1980) and Thoburn (1977) reached the same conclusion, namely that Prebisch and Singer had largely overestimated the overall deterioration of the terms of trade of developing countries, based on the results of a renewed and comprehensive empirical data collection exercise. According to their analysis, from 1870 to 1937 the net barter terms of trade had clearly deteriorated, but from 1937 onwards they varied from country to country. Additionally, the cases of deterioration could have been negatively influenced by the decline in shipping freight prices, since imports of primary goods were valued with cost, insurance and freight included (cif), while exports of industrial products were valued free on board (fob).

More recently, authors such as Sapsford (1985) and Sarkar (1986) have argued that the declining terms of trade of developing countries were a reality both in the pre-war and in the post-war periods, and that this was especially true for the poorest among resource-dependent developing countries, whose terms of trade were worsened by increased primary exports from emerging developing economies, such as Indonesia, Malaysia and Argentina. However, later on Sarkar and Singer (1991) found that emerging manufacturing exporters, mainly from South East Asia, also experienced deterioration in their terms of trade in the post-war period, which meant a relative loss of income close to 1 percent per year, yet compensated by both productivity gains and an expansion of export volumes. Therefore, Szirmai (2005) considers the debate on the

\footnotetext{
${ }^{13}$ In 1953, Leontief found that the United States, which at the time was the most capital-abundant country in the world, exported labor-intensive commodities and imported capital-intensive commodities, in direct contradiction to Ricardo's theory of comparative advantage. "Leontief's paradox" thus refers to the paradox of the country with the world's highest capital-per worker having a lower capital-labor ratio in exports than in imports (Leontief, 1953).
} 
terms of trade still inconclusive and dependent on what products are included in the analysis (oil is often considered a special case and - he argues - erroneously excluded), the specific countries selected and the kinds of terms of trade examined.

In this respect, UNCTAD's most recent data reveal that the terms of trade of most developing countries have constantly declined in real terms (see Table 1.3), but have started to evolve favourably again since 2003, thanks to the recent primary commodity boom, especially in the case of oil exporters and exporters of minerals and mining products (UNCTAD, 2007 and 2008). For those developing countries exporting agricultural products that registered negative terms of trade, this was compensated in many cases by higher export volumes. It should be noted that changes in the terms of trade may indeed have a direct impact on the domestic income of a country, as illustrated by the table below. However, the increase in domestic income resulting from higher terms of trade may be partly rebalanced by an increase in profit remittances from countries where foreign companies control a large amount of export activities, as is the case in most developing countries exporting oil and mining products (UNCTAD, 2006 and 2007). UNCTAD data show, for example, that between 2004 and 2006 high income payments to non-resident workers drained most of the terms of trade income gains for mineral exporting countries, where TNCs account for a large amount of their export-oriented production (UNCTAD, 2008).

Table 1.3 Impact of changes in terms of trade and net income payments on national disposable income in developing countries, percentage of Gross Domestic Product, 20042006 (average)

\begin{tabular}{lccc}
\hline & $\begin{array}{c}\text { Effects from } \\
\text { changes in } \\
\text { terms of trade }\end{array}$ & $\begin{array}{c}\text { Effects from } \\
\text { changes in net } \\
\text { income payments }\end{array}$ & Net impact \\
\hline Oil exporters & $7 \cdot 3$ & -0.2 & 7.1 \\
Exporters of minerals and mining products & $5 \cdot 7$ & -4.6 & 1.1 \\
Other commodity exporters & -0.2 & -0.1 & -0.3 \\
Exporters of manufactures & -1.2 & -0.1 & -1.3 \\
\hline
\end{tabular}

Source: UNCTAD, 2008

Lastly in chronological order, Ziesemeier (2010) shows that the phenomenon of falling terms of trade still concerns several amongst the poorest developing countries. The problem is less severe in those countries that present a more diversified export structure, but only under the condition that they have specialized in goods and services with a relatively high income elasticity of demand. The author argues that this is more likely to happen the more countries are diversified, in accordance with a number of previous studies based on cross-country empirical models, claiming that export diversification is a powerful contributor to per capita income growth (Agosin, 2006; Rodrik, 2006; UNCTAD, 2008). Ziesemeier (2010) claims, therefore, that policies aimed at export diversification may be key in stopping the terms of trade from falling and from hampering economic growth - a problem that, in his view, still represents a top priority for several developing countries. 
Overall, therefore, there is a general consensus regarding the secular decline of the terms of trade of developing countries, which is reflected in the decline of the terms of trade of primary commodities versus manufactures. In this respect, however, it should be considered that, looking at the future. the literature seems to points towards a different direction. On the one hand, since the 1990 s both the manufacturing and the primary commodities sectors have become increasingly heterogeneous. The prices of some undifferentiated manufacturing products - particularly those in which China is a major exporter - have been falling, and the prices of some primary products particularly those mineral commodities suffering from supply constraints and those agricultural commodities suffering from insufficient land availability and stagnant productivity - have been constantly rising (Kaplinsky, 2006). ${ }^{14}$ Should this process be sustained in the long term, a reversal of the historical relationship between the prices of primary commodities and those of manufactures might finally happen.

On the other hand, and most importantly, as highlighted in the following section, some processed primary commodities have become increasingly differentiated and technologically sophisticated. It is, therefore, likely that in the future the attention of the debate on the terms of trade will completely shift, and will focus on the relationship between knowledge and innovation intensive products and undifferentiated, standardized products, rather than on the traditional relationship between primary commodities and manufactures. It would seem that these are now becoming obsolete analytical categories, and that commodities will be increasingly characterized by their level of knowledge and innovation intensity.

\subsubsection{The Dutch disease theory}

Quantitative economists have recently added scientific rigor to the generalized impression that economic progress entails moving away from primary resources into manufacturing. In particular, Sachs and Warner (1997; 1999; 2001) show through econometric analysis that countries with a high ratio of natural resource exports to GDP in 1970 tended to grow slowly during the following twenty years and that this negative relationship holds even after controlling for a series of variables that are supposed to have an influence on economic growth. ${ }^{15}$ World Bank studies claim that per capita GDP growth collapsed in all resource-abundant countries after the oil shocks of the 1970s, while it accelerated in most resource-poor (manufacturing-led) countries (World Bank, 1999). More generally, they also show that two of the three major commodity booms that occurred in the post World War II period - those originated by the Korean war in 1950-51, by the oil crisis in 1973-74, and by the explosive growth of China and India since 2004 - were followed by a recession of the world economy and the gradual elimination of excessive commodity inventories (IMF, 2005).

\footnotetext{
14 During the last decade, commodity price movements have been also increasingly influenced by financial speculation, namely by the participation of financial investors in commodity trade. However, this is a relatively recent phenomenon, and it is still too early to quantify its impact (UNCTAD, 2011).

15 These variables include: initial GDP, openness policy, investment rates, human capital accumulation rates, changes in the external terms of trade, government expenditure ratios, terms of trade volatility, and the efficiency of government institutions.
} 
According to Auty (2001), the danger of commodity price volatility is always present, but is more pronounced in the case of smaller resource-abundant countries, where the probability of depending on a single primary export is higher than in larger countries, and exports normally account for a larger share of GDP. This would make certain economies less self-contained, and particularly vulnerable to external shocks and growth collapses than others. In order to explain this phenomenon, several authors claim that natural resources may promote a de-industrialization process, the so-called "Dutch disease" effect, a term coined in 1977 by The Economist (The Economist, 2010) to describe the negative impact that the discovery of enormous natural gas reserves and the subsequent sharp rise in natural gas exports had on the Dutch economy in the 1970s. Despite the substantial revenue windfall, shortly after the discovery of gas, the Netherlands experienced a drastic decline in economic growth, basically due to a contraction of employment levels and industrial output (Ellman, 1981).

Dutch disease theorists explain this paradox as follows: An increase in the price of primary resources, which usually goes along with all booms in the resource sector, tends to appreciate the exchange rate and to lower the competitiveness of non-resource export sectors, thereby diverting the economy away from the manufacturing sector and originating harmful effects on the economy. In particular, Corden and Neary (1982), Neary and Wijnbergen (1986), Matsuyama (1992) and later on Sachs and Warner (1997 and 1999) used a multiple-sector model (including a primary exporting sector, a sector of tradables including both agriculture and manufacturing, and in some cases a nontradable sector) to show that a specialization in natural resources will lower the growth rate in several manners:

- by raising wages and lowering returns to capital in the manufacturing sector, thereby reducing capital accumulation (Corden and Neary, 1982);

- $\quad$ by creating a current account surplus that would lead to a currency appreciation and a consequent loss of competitiveness (Neary and Wjnbergen, 1986);

- by lowering returns to scale in education or job training, thus hampering the development of skill-intensive activities (Matsuyama, 1992); and

- by shifting inputs away from competitive manufacturing sectors in which externalities necessary for growth are generated (Sachs and Warner, 1997).

These solid arguments in support of the existence of a Dutch disease effect have been partially dismissed by a conspicuous number of scholars, convinced that if natural resources can be systematically linked to the poor performance of several natural resource abundant countries, this can hardly be explained by models and orthodox economic tools. A more comprehensive picture emerges when social and political factors are also taken into consideration, which are at the origin of a phenomenon defined by some authors as "political" Dutch disease (Auty, 1998 and 2001; Wright, 2001; Lam and Wintchekon, 2003; Rosser, 2006; Stiglitz, 2006; Mikesell, 1997). In this respect, Wright (2001) points out that 
What we may have is a set of countries whose political structures and institutions have failed to support economic development. One can well imagine that in a setting of fragile institutions and factionalized policies, windfall resource gains may be a mixed blessing. But on this reading, the underlying problems are not inherent in the resources themselves, and the successfully managed resource economies are the exception that proves this rule (Wright 2001, p.3).

Along the same lines, Auty (2001) claims:

The adverse relationship between natural resource abundance and economic development is rooted in post-war policy prescriptions and overestimated the capacity of most developing countries to pursue a coherent economic policy. To the extent that policy error caused the growth collapses and policies are options, the inverse relationship between natural resource abundance and economic development is not a deterministic one (Auty, 20o1, p.317).

According to Wright (2001) and Auty (2001), therefore, the reasons for the inverse association of resource abundance and growth are practically unknown, or more precisely they are different from country to country, and existing explanations for the Dutch disease effect have the limit of hardly taking into account the role of sociopolitical factors in shaping the economic performance of resource abundant countries. Collier (2007) has made a substantial contribution to this debate, by arguing that the explanation for the resource curse is more political than economic in nature. Based on his previous work with Goderis (Collier and Goderis, 2007), ${ }^{16}$ he claims that the Dutch disease and macroeconomic volatility account for less than half of the adverse effects of natural resource abundance on economic growth, which is rather due to the progressive deterioration of economic governance mechanisms caused by increasing resource rents. To prove his point, he shows that the negative effects of resource abundance are usually confined to non-agricultural export commodities, which are as volatile as agricultural commodities but generate much higher revenues that are directly handled by governments instead of the private sector.

More recently, Collier (2010) has further elaborated on this topic, and reached the conclusion that the interplay between politics and the availability of natural resources is bi-directional. The quality of political systems strongly affects the way in which natural resources are exploited, but natural resources do also affect the likelihood that political systems capable of best harnessing natural resources are put in place. The first relationship has already been widely explored (Gelb, 1988; Auty, 2001; Ross, 2001), and puts emphasis on the extent to which weak political systems tend to mismanage

\footnotetext{
16 In their econometric model, Collier and Goderis (2007) make a distinction between short-term and longterm effects of increasing commodity exports on country growth rates, using global data for the period 19632003. They find that commodity booms have positive effects on output during the first five years, but adverse effects in the longer run. However, they also acknowledge that, in the past, countries characterized by "good governance" - such as Australia, Canada, Norway and Botswana - have succeeded in avoiding or reducing the negative effects. Moreover, they estimate that in twenty years the growth rate of a "badly governed" African exporter of natural resources would be on average 25 percent lower than it would have been without the effect of export booms.
} 
natural assets by allowing "maldistribution", rent-seeking and inefficiency of resource extraction and by managing revenues from natural resources without considering their temporary and volatile nature. The second relationship adds a novelty to the debate, namely the clear understanding of how security and accountability - the key patterns of "good governance" - are adversely affected by the presence of resource rents. In particular, Collier (2010) identifies three different ways in which natural assets affect the political system, namely by creating an escalating need for military spending for the repression of rent-capturing rebellions and conflicts; by generating political élites that have diverging interests from voters and use techniques such as vote-buying, voter intimidation and ballot fraud to win elections; and by facilitating the erosion of checks and balances that increase the likelihood of democracy relative to dictatorship and reducing the speed of exit from disfunctional or autocratic policies.

\subsection{The choice between natural resources and industrialization}

Based on the arguments elaborated in the three above-mentioned theories, several authors in the literature express scepticism regarding the development potential of primary resources, attributing the main development role to industrialization, as they see the manufacturing sector as the primary embodiment of technological capabilities. ${ }^{17}$ They claim that "for at least two centuries the impression has been prevalent that economic progress entails moving away from natural resources into sectors based on knowledge, skills, capital and technology" (Wright, 2001), namely that "manufacturing is the only sector of the economy that appears to be able to act as a catalyst of economic development and modernization" (Lall and Pietrobelli, 2003) and that "while specializing in exports of primary goods is consistent with economic growth, maintaining a high level of income and undertaking a dynamic growth path requires a structural shift towards manufacturing industry” (Hobsbawm, 1994).

A deeper understanding of these arguments is of paramount importance, as it might help developing countries' policy makers to orient their development strategies and especially to deal adequately with the recent export boom of primary products driven by the robust and relatively sudden demand of rapidly industrializing Asian economies such as China and India. The literature on the subject argues that the development of a modern industrial sector inevitably starts by transferring surplus or unused productive resources, such as labour and savings, from the primary sector to industry (Lewis, 1954), and that substantial increases in primary sector productivity (especially in agriculture, as in the case of the green revolution, at least in its initial stages) represent

\footnotetext{
17 Economic growth has been closely associated with a deepening of the industrialization process and a shift away from agriculture and mining since the middle of the eighteenth century (Szirmai, 2005). The explanation can be found in the seminal writings of Kaldor (1957 and 1967) and Kuznets (1955 and 1966). These state that economic development involves a structural transformation in which the factors of production are transferred from the sector with the lowest productivity (agriculture and mining) to the sector where productivity is higher and the pace of technological change is more rapid (manufacturing). Therefore, a close relation between the rate of industrialization and a high rate of productivity growth can be identified. In the process of structural change the share of agriculture and mining in the total labor force declines, while the share of high-productivity industries increases.
} 
almost a pre-requisite for successful industrialization processes (Hobsbawm, 1968; Bairoch, 1993; Schafaeddin, 1998; Rodrik, 2006; Clark, 2002). It also argues that the manufacturing sector generates numerous positive inputs to sustained growth, including the introduction of "progressive methods" in the primary sector, and when this does not happen its development potential is weakened (Rosenberg, 1976).

In this respect, Mytelka (1989) usefully reminds that there are limits on the extent to which primary resources, and in particular agriculture, can provide a sufficient surplus for industry. Firstly, in the case of a mass production industrialization model, which was predominant in the 1970 s and 1980 s, the foreign capital requirements can be too high to sustain the investment needed for the existing primary export capacity, both initially and over time. Secondly, even if a surplus is produced, producers might not necessarily have the right incentives to invest in productivity improvements, rather than consumer goods or alternative forms of investment. Thirdly, if natural resources rely primarily on foreign markets for sale, declining international demand or fluctuations of commodity prices may introduce an element of vulnerability that hinders the creation of sufficient capital for industry. In this case even resource-rich developing countries may get stuck in a low-level equilibrium trap (Nurkse, 1953).

In more recent times, Sachs and Warner (1997) have applied the "big push" reasoning to show how natural resource booms can become important catalysts for development in poorer countries. According to the Big Push model, exemplified by RosensteinRodan (1943) and later on by Murphy, Schleifer and Vishny (1989), the most significant constraint to industrialization in developing countries is the limited size of their domestic market, which does not allow firms to generate enough sales to adopt increasing return technologies. Thus, the coordination of investments across all sectors, from infrastructure to capital and consumer goods, can allow one sector to enlarge the size of the market in another sector, thanks to the complementarities of the different production processes and of the demand for goods and services. In this respect, Sachs and Warner (1999) argue that natural resource booms may stimulate the kind of large demand expansion that developing economies need in order to expand the size of their market, so that entrepreneurs would find it viable to incur the fixed costs of industrialization. ${ }^{18}$ However, they also remind that natural resource booms can frustrate or even reverse the industrialization process, depending on the timing and on the sector (of tradable or non-tradable goods) in which increasing returns to scale are generated.

\footnotetext{
${ }^{18}$ In the big-push logic, anything that massively stimulates demand is desirable, from large public spending, to foreign aid, to the discovery of new minerals, or to the rise in the world price of natural resources. It is in this sense that Sachs (2005) recently advocated a "big push" to end world poverty through a doubling of foreign aid flows (to about 100 billion US\$ a year, and then doubling again in 2015), which would finance a large set of complementary investments. However, his approach has been heavily criticized for having simply re-proposed the old big push theories of the 1950s and 1960s, and in particular Rostow's argument that developing countries could achieve sustained growth thanks to aid-financed large increased investments (Rostow, 1960). In a particularly biting article, Easterly (2006) claims that all big push attempts are destined to fail due to the unsolvable information and incentive problems characterizing large scale, top-down interventions, as happened in the case of the ex-Communist planned economies but also of the structural adjustment programs so vehemently pursued by the IMF and the World Bank in the 1980s. Sachs' recommendations appear therefore to be overly simplistic and to culpably ignore the "social causes" of poverty, among which are bad institutions, bad politics, misguided interventions, corruption, as well as ineffectual aid (Easterly, 2006).
} 
Based on the above, it emerges that the traditional dichotomy between natural resources and manufacturing is based on drastic assumptions. Rather, natural resources do not inevitably represent a growth retarding factor and most of them may undergo an industrial transformation process. Moreover, sustained productivity growth cannot be achieved exclusively by the manufacturing sector narrowly defined, and there is a need for a strategic use and an appropriate balance between sectors in the course of structural transformations, even in the case of open, export-oriented economies that are now the norm among both developing and developed countries (Myint, 1980). ${ }^{19}$ In this context, Szirmai (2005) interestingly notes that "the high prestige of industrialization in the post-war period resulted in an underestimation of the positive role that primary exports have played in the past and could still play in the future". The "high prestige" attributed by the literature to industrial development has been recently reinforced by the empirical observation that the developing countries that have performed more dynamically in the past thirty years are those that show the highest share of manufacturing exports in relation to their GDP per capita (UNCTAD, 2003). The present thesis, however, claims that this is gradually changing and captures evidence signalling that we may be witnessing another historical turnaround (see Table 1.4).

Table 1.4 Share in world manufacturing value added and manufactured exports, percentage share, 1980-2000

\begin{tabular}{lcccccc}
\hline & \multicolumn{3}{c}{$\begin{array}{c}\text { Share in world } \\
\text { manufacturing value }\end{array}$} & \multicolumn{2}{c}{$\begin{array}{c}\text { Share in world } \\
\text { aded } \\
\text { manufactured exports }\end{array}$} \\
\hline & 1980 & 1990 & 2000 & 1980 & 1990 & 2000 \\
Developed countries & 64.5 & 74.1 & 74.9 & 74.1 & 77.9 & 67.3 \\
Developing countries & 16.6 & 17.0 & 22.8 & 18.9 & 18.3 & 28.9 \\
$\quad$ Latin America and the Caribbean & 7.1 & 5.6 & 5.4 & 4.3 & 2.4 & 4.7 \\
Africa & 0.9 & 0.8 & 0.8 & 5.4 & 2.6 & 2.8 \\
South and East Asia & 7.4 & 8.7 & 15.2 & 7.6 & 13.6 & 21.7 \\
China & $\mathbf{3 . 3}$ & $\mathbf{2 . 6}$ & $\mathbf{6 . 6}$ & $\mathbf{1 . 0}$ & $\mathbf{1 . 7}$ & $\mathbf{4 . 3}$ \\
\hline
\end{tabular}

Source: UNCTAD Secretariat calculations, based on UNIDO, International Yearbook of Industrial Statistics, 2006; UN Comtrade

Firstly, as argued by Kaplinsky (2007), the export price of manufactured goods is falling as a result of the rapid industrialization of emerging economies, and in particular of China. Indeed, it is likely the world economy is on the verge of a long-term shift in the manufactures-commodities terms of trade, in the opposite direction to the one (rightly or wrongly) announced by Prebisch and Singer in the early 1950s. It is foreseeable that the increasing participation of China in global product markets will determine not only a progressive decline in manufacturing prices, but also that this will have a disproportionate impact on the developing countries that face direct competition from

\footnotetext{
19 In open economies, export revenues may generate foreign income through which countries can easily acquire the inputs that are not produced domestically. Therefore, specialization will tend to occur where there are existing comparative advantages. However, this may generate serious balance of payments problems and threaten sustained economic growth. Thus, the importance of strategically deciding in which sector to invest and where to apply the most favorable incentives is no less important than in closed models, where resources are confined to the national boundaries and have to be necessarily transferred from one sector to another.
} 
Chinese producers. The world is currently in a phase of structural excess capacity, particularly for manufactured products exported by low income countries, and, in this era of global industrial capabilities, East Asian countries in general, and China in particular, are so competitive that other developing countries have little chance to win their competitive battle (Kaplinsky, 2007). Overall, future export growth of most developing countries will depend either on sustained and very rapidly rising demand from high income countries, or on their ability to out-compete other developing countries.

Secondly, during the last decade the literature has started to show that when substantial reductions in production costs have taken place as a result of increased productivity and competitiveness, economic rents produced by natural resources have not declined in line with decreases in primary commodity prices, and natural resources have become engines of growth for the rest of the economy (Yeats, 1991; Mikesell, 1997). Among the positive examples of developing countries most often quoted in the literature are Botswana, Chile, Indonesia and Malaysia but also Colombia, South Africa and Namibia (Mikesell, 1997; Stevens, 2003; Rosser, 2006). Additionally, it is now widely recognized that natural resources have been instrumental to the economic growth of several industrialized countries, such as Australia, New Zealand, Norway, the United States and Canada (Szirmai, 2005; Bairoch and Kozul-Wright, 1996; Wright, 2001; David and Wright, 1997)..$^{20}$ In these cases, primary exports have served as an engine of structural transformation by increasing per capita income and generating savings, creating a market for manufactured outputs, providing an immediate source of foreign exchange and generating raw materials necessary for processing (Timmer, 1988).

Thirdly, and most importantly for the implications that this bears on our thesis, recent data provided by UNCTAD (2009) show that commodity-dependent countries are no longer a homogeneous universe of monoculture-products exporters. They rather fall into two main categories: low-income countries dependent on the export of one or a few traditional (often tropical) products; and more dynamic, competitive middle-income countries, such as Argentina, Brazil, Chile, Colombia, Thailand, Malaysia or Viet Nam (UNCTAD, 2009). In this latter group, the exporters of new, high-quality, diversified processed primary products can be found. This has led some authors (Jaffee and Gordon, 2003; Kaplinsky and Fitter, 2004; Kaplinsky, 2005; Perez et al, 2009) to envisage a process of "de-commodification" of primary resources, whereby a variety of primary commodities would be gradually transformed from standardized "staples" into high-quality, diversified, processed goods, with raising barriers of entry, increasing value added content and higher export price per unit. Quite surprisingly, this might apply to even the most traditional and paradigmatic processed agricultural

\footnotetext{
20 After the Civil War, the United States had an export profile dominated by primary products but managed in a few decades (1890-1910) to become the world leader in manufacturing. After cotton, nearly all the leading categories of manufactured goods were closely linked to the resource economy in one way or another: petroleum products, copper, meat packing and poultry, steel works and rolling mills, coal mining, vegetable oils, grain mill products, sawmill products and so on. If the literature warns unanimously about the risk of considering the American example as a pathway for developing countries to follow, several authors seem to suggest that a closer study of such an exceptional case could "illuminate the ingredients that mark the difference between success and failure in resource-based development” (Wright, 2001).
} 
commodities, such as coffee (Kaplinsky, 2007) and, to a lesser extent, cocoa (The Economist, 2007). The production of these goods has currently integrated unusual concepts such as that of "vintage plantation" and "denomination of origin", giving rise to a range of extremely diversified, fashionable, and thus premium-priced luxury goods.

Some of the most prominent and surprising cases of dynamic and globally competitive processed primary products exported by developing countries, which underwent a "decommodification" process, are related to agro-industrial products such as wine in Chile, South Africa and Argentina; cut flowers in Colombia, Kenya and Ethiopia; frozen shrimps in Thailand, Viet Nam, Ecuador and Peru; farmed salmon in Chile and Nile perch in Uganda (UN Comtrade data). For example, in the cases of both Chile and Colombia, salmon farming and the cultivation of roses were absolutely new and were not building on traditional skills, habits and know-how. Nevertheless, both countries managed to become globally competitive and to achieve a steep export growth. Chile, for example, has become the second largest world exporter of salmon after Canada, and since 2003 is performing well above Norway and the UK (see Figure 1.1). Chilean salmon production, which is a non-traditional product, grew 17-fold between 1993 and 2004, and salmon exports grew from 291 million US\$ in 1993 to 1.4 billion US\$ in 2004 (UNCTAD, 2005). ${ }^{21}$ Similarly, in Colombia, non-indigenous varieties of cut flowers represent the top non-traditional export (Mytelka and Bortagaray, 2006). Internationally, the country ranks second behind the Netherlands and accounts for 75 percent of cut flower imports in the United States, its principal market, and it performance is still improving (see Figure 1.2).

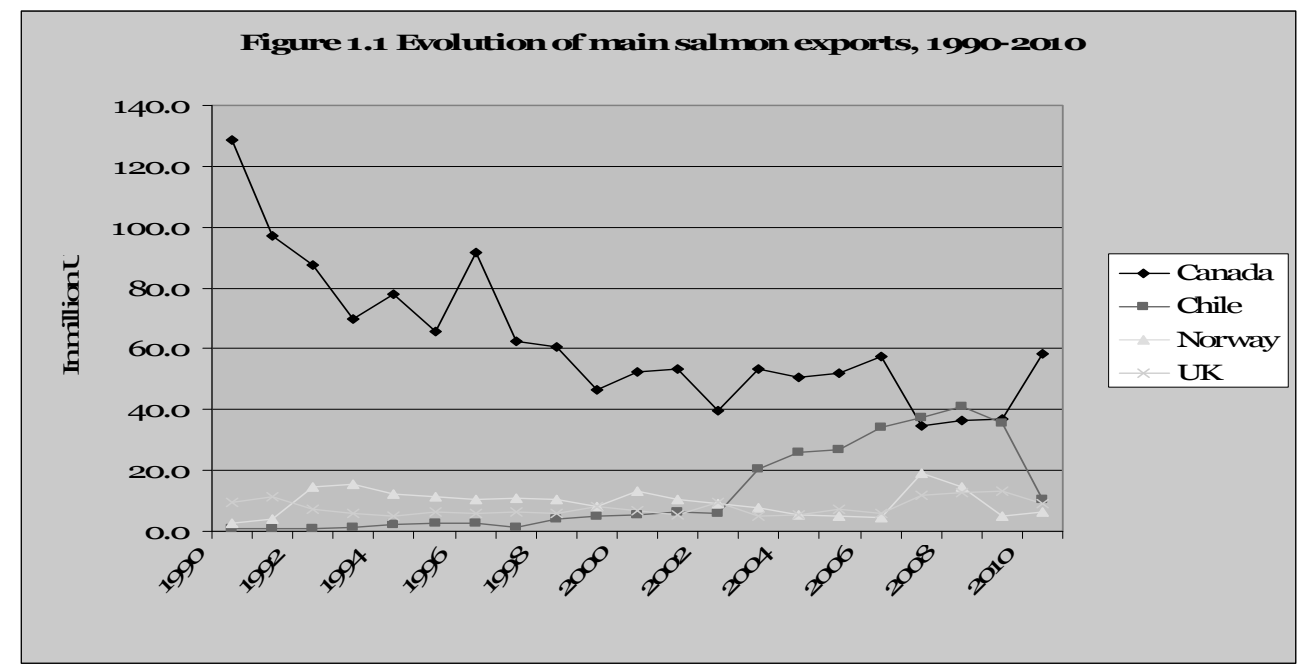

Source: UN Comtrade database (SITC Rev.3: 03711)

${ }^{21}$ It should be noted, however, that most recent Comtrade data show that the steep export growth of Chilean salmon recently experienced a sudden halt. This points to the fact that it is a challenge for an emerging country such as Chile to sustain an export boom in a natural resource-based processing sector, even when it has reached a relatively dominant position. The following chapter will explain why, after decades of continued growth, the Chilean salmon industry has undergone a deep crisis that is threatening its survival. 


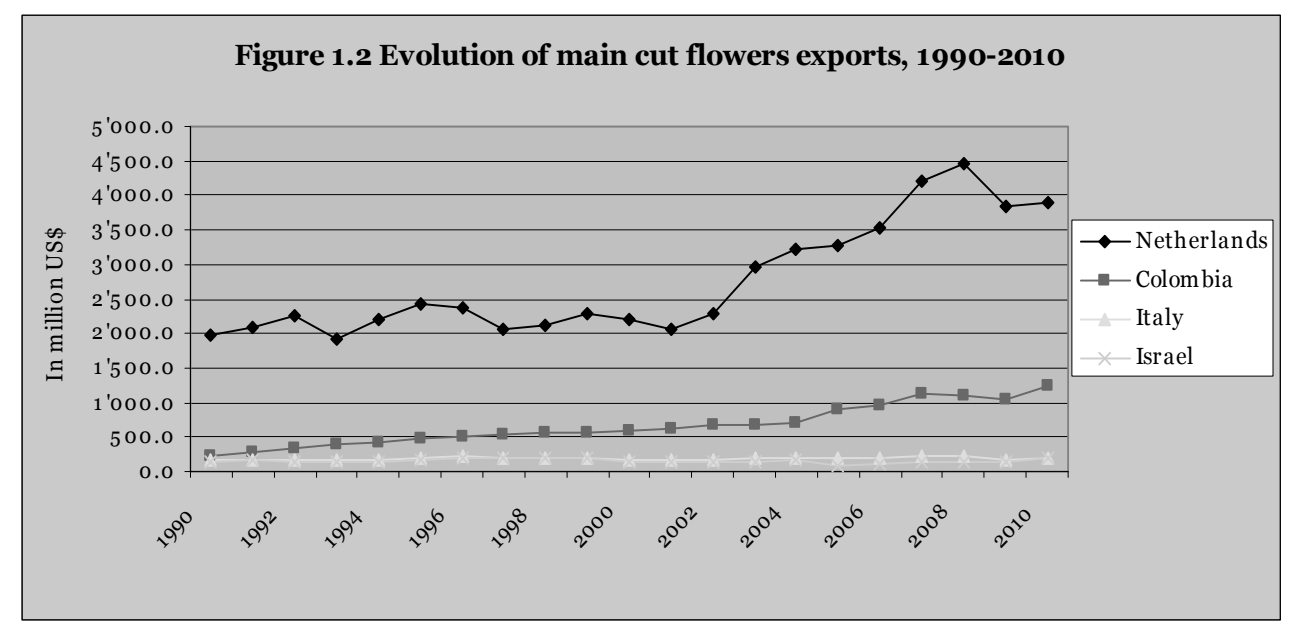

Source: UN Comtrade database (SITC Rev.3: 2927)

From the figures above, it clearly emerges not only that there are important exceptions to the slow growth bias among resource-abundant countries, and that the "resource curse" is less deterministic than some econometric models would suggest, but also that it is difficult to identify explanatory factors for the resource curse that are common to a large number of resource-abundant countries. During the last two decades, several developing countries have actually registered a steep export growth in some agroindustrial products that are less "staples" than goods attuned to their export markets (Smith, 2007; Kaplinsky, 2005). The immediate question arising from the observation of such steep export growth - to be addressed in the remaining chapters of our thesis is whether processed primary commodities should continue to be necessarily associated with "primitive" modes of production as were raw primary commodities in the past (Wright, 2001; David and Wright, 1997); and, consequently, whether or not new opportunities and implications from an economic development perspective might be detected.

\subsection{The South-East Asian experience}

\subsubsection{The emergence of the South-East Asian dragons}

Undoubtedly, the manufacturing sector has represented a powerful engine of growth for those developing countries that have successfully undertaken a rapid development process through high rates of investment, technological progress and high productivity growth (Mytelka, 1989; Bairoch and Kozul-Wright, 1996; Lall, 1992; Westphal, 2002; Hausmann, Hwang, and Rodrik 2007). Overall, though, the number of developing countries that have been able to bridge the gap with the leading industrial economies is not conspicuous and is mainly concentrated in East and South Asia (UNCTAD, 2007); hence, the expression "East Asian miracle" extracted from the title of a renowned World Bank study on the subject (World Bank, 1993). 
Data show that during the first three decades after World War II, growth actually accelerated across almost all continents (see Figure 1.3). Yet this growth momentum stalled, mainly due to the oil crisis in the early 1970 s and the debt crisis in the early 1980s, hitting particularly hard poorer developing countries in Sub-Saharan Africa, but also the bulk of developing countries in North Africa, Latin America, South and West Asia. Since then, developing countries have experienced a further widening of the income gap with advanced countries and among themselves, as well as industrial stagnation and growing poverty levels, accompanied by weak commodity prices, declining flows of official development assistance and the absence of private capital flows (UNCTAD, 2003). ${ }^{22}$

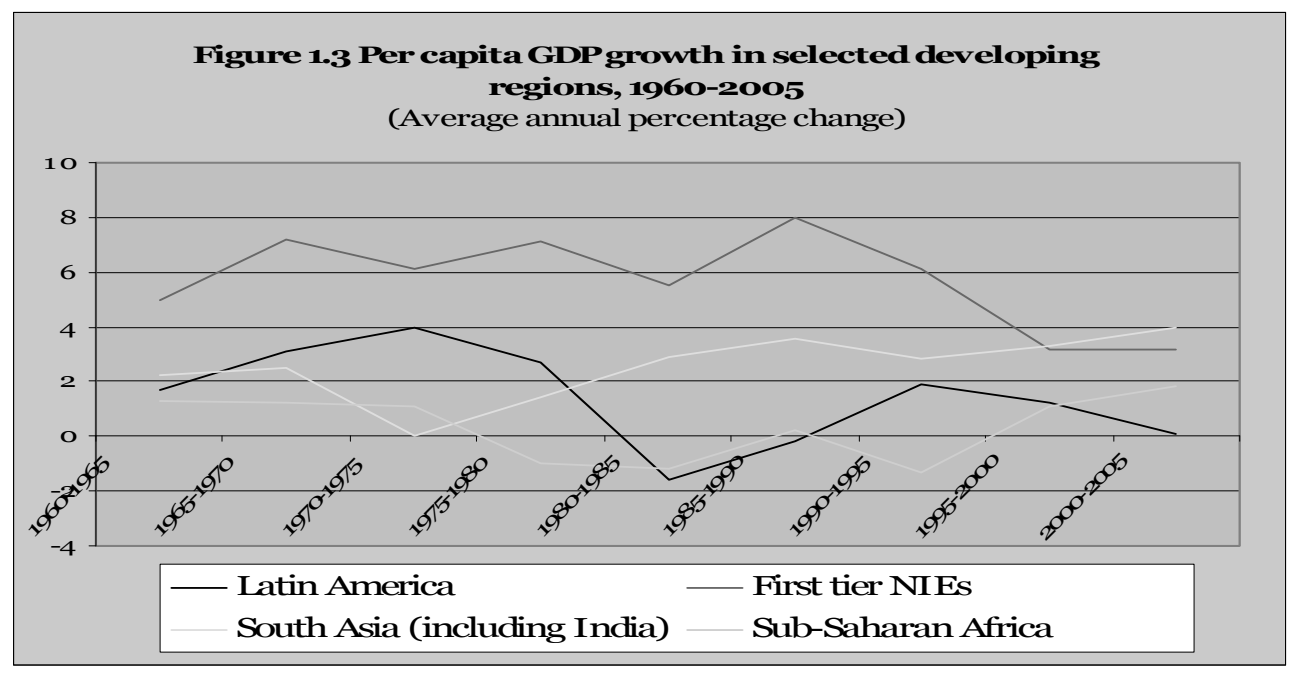

Source: World Development Indicators, World Bank, 2010

The star performers among the East Asian "tigers" or "dragons", as they are commonly known, correspond to the group of the so-called first-tier newly industrializing economies (NIEs), i.e., South Korea, Taiwan, Singapore and Hong Kong, immediately followed by the second-tier NIEs, i.e. Thailand, Malaysia, Indonesia and the Philippines. The most recent development literature also considers China and India as the newest, third-tier East Asian industrializing economies (Maddison, 2007). This section will refer mostly to the first-tier NIEs, which had all adopted an outwardlooking, market-led model in the early 1960s (as opposed to an import-substituting, closed model) and have relied, albeit to a varying degree, on the presence of FDI. ${ }^{23}$ Remarkably, they are also characterized by scarce natural resource endowments, but this ostensibly has not deterred them from a stable industrial expansion, from the early

\footnotetext{
22 Only after 2005 did the performance of developing countries in Latin America, South and West Asia and Africa start to improve again, mainly thanks to increasing demand for primary commodities and a consequent considerable progress in their terms of trade (UNCTAD, 2007).

23 In contrast to import substitution models, in open, export-oriented models incentives have a neutral impact on both domestic and export markets, or are biased in favor of the latter (Lall, 1992).
} 
1960s until now, (showing some oscillations only after the financial crisis of 1997 (see Table 1.5).

Table 1.5 Share of manufacturing as a percentage of GDP, 1950-2000

\begin{tabular}{|c|c|c|c|c|c|c|}
\hline & \multicolumn{6}{|c|}{$\begin{array}{c}\text { Manufacturing as a \% of GDP } \\
\text { (at current prices) }\end{array}$} \\
\hline & 1950 & 1960 & 1970 & 1980 & 1990 & 2000 \\
\hline China & 14.1 & 31.3 & $33 \cdot 7$ & 40.5 & 32.9 & 32.1 \\
\hline India & 10.4 & 14.1 & 14.2 & 16.7 & 16.7 & 15.6 \\
\hline Indonesia & 7.4 & 9.2 & 10.3 & 13.0 & 20.7 & 27.7 \\
\hline Malaysia & - & 8.1 & 12.4 & 21.6 & 24.2 & 32.6 \\
\hline Philippines & 8.5 & 20.3 & 24.9 & $25 \cdot 7$ & 24.8 & 22.2 \\
\hline South Korea & 8.8 & 10.4 & 17.8 & 24.2 & 27.3 & 29.4 \\
\hline Taiwan & 15.0 & 19.1 & 29.6 & 36.2 & 32.7 & 24.6 \\
\hline Thailand & 12.0 & 12.5 & 15.9 & 21.5 & 27.2 & 33.6 \\
\hline Argentina & 23.4 & 32.2 & 32.5 & 29.5 & 26.8 & 17.5 \\
\hline Brazil & 18.7 & 29.6 & 29.3 & 33.5 & 26.5 & 17.2 \\
\hline Chile & 17.1 & 24.9 & 25.9 & 21.5 & 19.6 & 19.5 \\
\hline Colombia & 12.9 & 16.5 & 21.2 & 23.9 & 20.6 & 15.8 \\
\hline Mexico & 17.2 & $15 \cdot 3$ & 23.2 & 22.3 & 20.8 & 20.3 \\
\hline Peru & 14.5 & 20.2 & 19.8 & 20.0 & 25.2 & 16.8 \\
\hline Venezuela & 10.9 & 10.7 & 16.1 & 16.0 & 14.9 & 19.8 \\
\hline Ivory Coast & - & 7.5 & 10.3 & 12.8 & 20.9 & 21.7 \\
\hline Egypt & 8.3 & 13.7 & - & 12.2 & 17.8 & 19.4 \\
\hline Ghana & - & 5.1 & 11.4 & 7.8 & 9.8 & 9.0 \\
\hline Kenya & 10.8 & 9.4 & 12.0 & 12.8 & 11.7 & 11.6 \\
\hline Morocco & 14.7 & 13.4 & 16.2 & 16.9 & 19.0 & 17.4 \\
\hline Nigeria & 1.8 & 3.8 & $3 \cdot 7$ & 8.4 & 5.5 & 3.7 \\
\hline South Africa & 16.4 & 20.1 & 22.8 & 21.6 & 23.6 & 19.0 \\
\hline Zambia & - & 4.0 & 12.1 & 19.2 & 26.5 & 11.4 \\
\hline
\end{tabular}

Source: World Bank, World Development Indicators, 2002 and Szirmai, 2008

First-tier NIEs were able to enjoy deep political and social transformations that led to high levels of GDP per capita growth and relatively low levels of income inequality (UNCTAD, 2007). To explain this phenomenon, Rodrik (2006) notes:

Economic globalization has greatly increased the premium of manufacturing, particularly of the exportable kind. In recent decades rapidly growing developing countries have been able to grow much faster than earlier antecedents (Britain during the Industrial Revolution, the United States during its catch-up with Britain in the late nineteenth century, or the European recovery in the post-war period). The reason for this is that world markets provide near-limitless demand for manufactured exports from developing countries. [...] Therefore, developing countries exporting manufactured products do not face any limit as long as they can latch on to new activities which face dynamic demand in rich countries' markets (Rodrik, 2006, p.3). 
By using the term "globalization", Rodrik refers to a series of marked trends characterizing the world economy since the early 1960s, namely a rapid pace of technological change, widespread liberalization in the trade of goods and services, a progressive removal of barriers to investment flows, and remarkable savings in communication and transportation costs. As a consequence of globalization, the volume of international trade has increased at twice the rate of growth of world output in the 1980 s and three times as fast in the 1990s, reaching double-digit record figures that make economists disagree on the extent to which trade can continue to expand faster than production (UNCTAD, 2007).

On the financial side, FDI flows reached a peak of 1,306 billion US\$ in 2006, increasing by 38 percent with respect to 2005 (and showing clear signs of recovery after the slowdown originated by the post-2007 financial and economic crisis). In 2006, around 78 ,000 TNCs and their 780,000 foreign affiliates accounted for the equivalent of 10 percent of world GDP and one third of world exports. FDI inflows to developing countries reached the highest level ever attained, namely that of 379 billion US $\$$, representing 29 percent of the total. While China continued to host the largest numbers of foreign affiliates in the world, in the last fifteen years the number of TNCs from developing countries has grown more consistently than the number of TNCs from developed countries (UNCTAD, 2007).

According to Gereffi (1994), the prominent role of FDI and of intra-industry trade, that is to say commercial exchanges between foreign affiliates of TNCs to the tune of one third of international trade, goes hand in hand with the emergence of international production networks dominated by TNCs, which locate different parts of their production all across the world. In the 1990s, the expansion of international production networks was particularly rapid, as increasing FDI inflows to developing countries were designed to relocate production to lower-cost countries for export back to the TNCs' home countries or to third markets (UNCTAD, 2002). This has twisted around the traditional notion of competitiveness, which is no longer related to the achievement of comparative advantages in the production of certain goods, but of competitive advantages in certain production activities at certain stages of the production of certain goods (Gereffi, 1994). Consequently, in most advanced countries competition between firms increasingly relies on design, research and innovation, rather than low labour costs, with production being increasingly outsourced. In this respect, Mytelka (2000) makes the interesting argument that, since the 1970s:

Manufacturing production has become increasingly knowledge-intensive as investments in intangibles such as $R \& D$, software, design, engineering, quality control, training, marketing and management came to play a greater role in the globalized production of goods and services. Much of this involved tacit rather than codified knowledge, and mastery thus required conscious effort to learn by doing, by using and by interacting. Gradually, the knowledge-intensity of production extended beyond the so-called "high technology" sectors to reshape a broad spectrum of traditional industries, thereby creating new platforms for increased technology accumulation and catching up possibilities (Mytelka, 20oo, p.393). 


\subsubsection{The South-East Asian export-led model}

While neoclassical economics explains constant equilibrium based on firms' rationality and perfect information symmetry, leading to profit maximization through price-based competition, evolutionary economics emphasizes the importance of non-price competition based on innovative activities, information asymmetries, continuous changes in technologies and routines, leading to disequilibrium and to the constant coevolution of firm and market changes (Nelson and Winter, 1982). As a consequence, evolutionary economics recommends paying more attention to the role of non-firm organizations and learning institutions, to the knowledge and learning processes of firms, to the wide range of relations among the agents and to the transformation of sectors in their boundaries, actors, products and structure. ${ }^{24}$

From an evolutionary perspective, therefore, the East Asian NIEs have been particularly clever in seizing such catching-up possibilities by running in the "new directions" opened up by globalization, by building sophisticated technological capabilities across entire value chains, and by exploiting different and successive "windows of opportunity" brought about by the old techno-economic paradigm of mass production in its mature phase and of the new techno-economic paradigm of flexible production and information technologies in its emerging phase (Perez, 1989).25 Initially focused on the manufacturing of mature products such as clothing and textiles, considered by the literature as the inevitable entry point for creating a basic industrialization platform (Perez and Soete, 1988), the East Asian NIEs subsequently switched to the "lowtechnology side of the high-technology industries", some of them even becoming leading exporters of technology in the electronics and IT fields (Hobday, 1994 and 1995).

The export success of the NIEs was originally based on labour intensive manufactures, thanks to the abundant availability of cheap labour. Later, these economies upgraded the skills of their workforce and their production capabilities, moving into more sophisticated lines of production, such as automobiles, shipbuilding or electronics. Technological accumulation and acquisition of know-how and design capabilities were crucial ingredients of such upgrading processes and key factors in avoiding the risk of being caught in a low wage, low growth development trap (Perez and Soete, 1988) or of failing to sustain their catch-up process after the (relatively easy) entry phase (Mytelka, 2004). In this sense, Perez (2002) interestingly suggests that the really useful lesson

\footnotetext{
${ }^{24} \mathrm{~A}$ more in-depth review of the perspective of evolutionary economics and of the Innovation System approach is contained in Chapter 2.

${ }^{25}$ According to Perez (1988), each great upswing of the world economy can be associated with the growth phase of a new techno-economic paradigm. This is defined as "a set of all-pervasive technologies and generic organizational principles that shape and condition the opportunities of each period". The mechanization of the textile industry, the development of the steam engine and of the railway transport system, the technological revolutions that occurred before and after World War II in heavy chemistry, physics, electric power, engineering and petro-chemistry all led to a change of paradigm and can be considered to be at the origin of major economic upswings. The "Information Age" represents the latest of such paradigm shifts.
} 
provided by the East Asian NIEs is to be found in a better understanding of the world dynamics that made their success possible, rather than in a recipe to imitate.

There is a wide and heated debate, however, on what the key ingredients are that made that recipe successful, a debate that is still highly relevant given the conspicuous number of developing countries that have tried or are trying to follow the NIEs' example. On the one hand, neoclassical approaches tend to see the East Asian miracle as the best possible evidence of the advantages of liberal trade strategies (Balassa, 1982). On the other hand, more heterodox approaches argue that the correlation between openness and economic growth tends to be weak, namely that there is no evidence that openness, in the sense of low barriers to trade and capital flows, systematically produces economic growth (Rodrik, 1999). Rather, it would seem that the benefits of openness can be fully grasped only when a set of complementary policies and institutions are put in place at the domestic level (Amsden, 1989; Wade, 1990).

According to Rodrik (2004), countries that have done well in the post-war period, such as the East Asian NIEs, are those that "have been able to formulate a domestic investment strategy to kick-start growth and those that have had the appropriate institutions to handle adverse external shocks", not those that have relied on reduced barriers to trade and capital flows. The orthodox and heterodox approaches have in common the view that macroeconomic management has been excellent in all four NIEs, and that openness can be a source of many (potential) economic benefits. However, the former is convinced that these can be ascribed to the efficiency gains and the positive spillover effects automatically generated by increased exports and specialization in comparative advantages (World Bank, 1993), while the latter claims that they originate from the possibility of importing capital and intermediate goods that may not be accessible domestically at equal or comparable costs, as well as new ideas and technologies from more advanced nations (Romer, 1993).

Overall, the East Asian experience shows that export orientation hardly means complete liberalization or the total absence of any protection or regulation, in that all NIEs adopted measures to protect selective industries, to attract, guide or limit FDI inflows and to provide access to a pool of skilled labour. It also shows that, in contrast to the univocal neoliberal interpretation of the Asian miracle, there are several kinds of "export orientation" (Lall, 2000), from the relatively laissez-faire approach adopted by the city-states of Hong Kong and Singapore to the heavy interventionist approach adopted by South Korea and Taiwan (Amsden, 1989; Wade, 1990; Kim 1997). This also corresponds to different levels of reliance on FDI, namely very high in Singapore and Hong Kong, and very low in South Korea and Taiwan.

South Korea, for example, had clear industrial priorities, maintained substantial degrees of protection and pursued active industrial and technology policies. It created large public enterprises called chaebols (e.g., the Pohang steel plant), intervened actively in technology transfer agreements (e.g., in the petrochemical sector), and took the lead in labour training and technology agreements (Lall, 1992). Taiwan set up a public sector facility to support the production of strategic industries, such as semiconductors, with the aim of coordinating the technology import, design, 
manufacturing and marketing activities of many private sector firms. It also managed to minimize the costs of trade policy reforms and latecomer industrialization by reducing and differentiating the speed of liberalization and compensating its domestic, traditionally protected, capital intensive industries for the removal of tariff and nontariff barriers, thereby alleviating the pressure from more competitive goods imported from abroad (Meng-Chun Liu, 2002).

From the above, it emerges that in explaining the success of the NIEs, the balance between incentives for production and incentives for export is far more important than export-orientation per se. In this respect, Akyuz and Gore (1996) argue that governments in East Asia managed to complement their outward orientation with a coherent domestic investment strategy that raised the private return to capital and "kindled the animal spirits of entrepreneurs" (Akyuz and Gore, 1996). They observe that openness and rising investment levels are not necessarily positively correlated and that in East Asia they do show a positive correlation, thanks mainly to the so-called "investment-profit nexus". This refers to the dynamic interaction between profit and investment, which, in the case of the NIEs, is based on three main factors: the exceptionally rapid growth of investment, supported by high rates of domestic savings, after an initial period of reliance on external sources of capital and/or technology; the importance of profits as a main source of savings and investment in industry; the role played by government in accelerating the process of capital accumulation by creating rents and pushing profits above those that could be attained by "sticking" to freemarket policies.

Further studies on the sources of East Asian growth, such as the renowned World Bank study (1993) on the "East Asian miracle", highlight the overwhelming importance of Total Factor Productivity (TFP) growth, and underline the important role of "activist" technology policies employed in order to support learning and innovation and to sustain increased levels of productivity (Chang and Cheema, 2002; World Bank, 1993; Gereffi, 1999). In particular, Gereffi (1999) notes that "the view of international trade as the fulcrum for sustained growth leaves a number of critical questions unanswered in terms of the micro-institutional foundations supporting East Asian development". He suggests that the ability of East Asian NIEs to sustain export growth and industrial upgrading over several decades is linked to their ability to move from the simple assembly of imported inputs to higher value added, domestically integrated forms of production, such as OEM (original equipment manufacturing) and OBM (original brand-name manufacturing) production. In his view, lead firms in value chains may represent a primary source of inputs, technology and know-how, and participation in both producer-driven and buyer-driven commodity chains may turn out to be a necessary step for industrial upgrading thanks to their faculty of putting firms and economies on "potentially dynamic learning curves". ${ }^{26}$

\footnotetext{
26 According to Gereffi (1994), buyer-driven value chains refer to those industries in which large retailers, branded marketers and branded manufacturers play pivotal roles in setting up decentralized production networks in a variety of exporting countries. They are very common in labor intensive consumer goods industries, such as garments, footwear, toys, consumer electronics and handicrafts. Producer-driven value chains are those in which large manufacturers, usually TNCs, play a dominating role in the entire production network, including in its backward and forward linkages. They are very common in capital- and technologyintensive industries such as automobiles, aircraft, computers, semiconductors and heavy machinery.
} 
In a broader sense, international competition from imports, entry of foreign investors and participation in international trade networks are all external factors that may stimulate technological development more thoroughly than domestic competition (Lall, 1992 and 2003). Sometimes, FDI may also represent the only means to upgrading technologies and entering high-technology activities. Lall (1996), however, also warns about the "truncated" process of technology transfer, whereby foreign affiliates usually develop some innovation capabilities but only up to a certain level. Within international production networks dominated by TNCs, in fact, it would be inefficient to develop the same sophisticated capabilities everywhere along the chain. This weakens the potential for positive externalities, technology spillover effects and value added that can be created by establishing productive linkages between foreign affiliates and local firms. The choice of the technology form, therefore, is a key factor in determining its development impact, as the experience of the NIEs well shows. South Korea, for example, has relied on imported capital goods, licensing and subcontracting as the main forms of technology transfer, accompanied by the exclusion of FDI in selected sectors and huge investment in R\&D. On the opposite end of the spectrum, Singapore has relied almost exclusively on FDI, but intervened to stimulate foreign investors to undertake technology upgrading operations and focus on high technology industries, by providing an educated and well-trained workforce through one of the world's most efficient employee training systems (Lall, 1992; Young, 1994 and 1994b).

From an evolutionary perspective, therefore, the success of the NIEs can be closely associated with the import of technology from the more advanced countries, but also with their own efforts to absorb, adjust, transform and gradually master the technical know-how involved in imported technologies (Freeman 1987 and 2008; Amsden, 1989). This has allowed them not only to rejuvenate mature technologies with modern practices (Pavitt and Bell, 1993), thus undertaking a traditional process of "incremental catching-up" from a low skill base, but also to become leaders in fast growing revolutionary industries related to the introduction of "new wave technologies" (Mytelka, 2004). One of the main insights to be retained from the analysis of the SouthEast Asian development path, therefore, is that keeping up and getting ahead requires a deliberate focus on domestic R\&D efforts and the adoption of a system-oriented approach to innovation (Mytelka, 2004). As it will be observed more in detail in the following section, a passive reliance on imported technology and an excessive dependence on TNCs that keep their main R\&D functions in home countries or show reluctance to license their technologies to close followers is an impediment for an incremental catching up process to take place. This can be successfully achieved only if deliberate policies to build local technological capabilities, education and learning are put in place (Ernst, Ganiatsos and Mytelka, 1998).

In this respect, Hobday (2012) has recently emphasized that the South-East Asian success is based on unique technological and market circumstances that cannot be easily replicated and is too often considered as an ideal model to be followed by the rest of developing countries. He has also warned that many alternative "recipes" can lead to success, and that development does not consist in an invariant, linear sequence. It is rather related to specific and distinctive historical, sectoral and geographical circumstances, which vary from country to country. The analysis of the South-East 
Asian experience can therefore provide interesting insights, but not a benchmark for the rest of developing countries.

\subsection{The Latin American experience}

\subsubsection{Natural resource booms and busts in Latin America}

A prominent study on the economic history of Latin America argues that, overall, the experience of primary export-led development has been a failure, even in those cases where major diversification efforts were put in place over time (Bulmer-Thomas, 1994). Historically, Latin American countries have been drawn into international trade as mere exporters of raw natural resources and importers of manufactured products, as happened for most developing countries in Africa and Asia shaped by the nineteenth century colonialism (Mytelka, 1999). The Latin American continent has been defined as "one of the leading laboratories for natural resource booms and busts" (Sachs and Warner, 1999). For example, in Peru, silver production doubled in the 1830 s and a guano boom occurred in the 1850s; in Mexico, gold production doubled between 1820 and 1849; in Chile, copper production rose seven times in the 1840 s and a nitrate boom occurred in the late 1890s; Cuba experienced a major boom in sugar production in the 1830s; coffee production grew uninterruptedly in Brazil, Colombia and Costa Rica during the second half of the nineteenth century (Bulmer-Thomas, 1994). In the twentieth century, oil production emerged predominantly in Venezuela, Mexico and Ecuador; Chile became the major copper producer in the world and saw its dependency on copper exports increase up to 77 percent of total exports in 1970; Uruguay and Argentina became major exporters of soybean and livestock products; Colombia experienced at least three major coffee booms in less than five decades (Sachs and Warner, 2001).

In order to gauge the importance of natural resource abundance in explaining the slower growth among eleven Latin American countries, Sachs and Warner (1999) multiplied a natural resource intensity variable for each country by the regression coefficient, estimating the association between natural resource intensity and GDP growth per capita for the period 1965-1990 (in the absence of reliable GDP data for any period before the mid-twentieth century). As a result, the authors found that not a single case emerged where GDP grew more steeply after the boom was finished than before the boom started, as big push reasoning would suggest (see Table 1.6). In particular, Venezuelan growth was 0.77 percent lower due to natural resource endowment, to the point that at the end of a 25-year period, Venezuelan per capita GDP growth would have been 14 percent higher if no resource export boom had occurred. In one case (Ecuador), a natural resource export boom may have had a positive effect on per-capita GDP initially, but was not followed by faster growth; while in two cases (Chile and Colombia), there has probably been no major effect in either direction. In four cases - namely, Bolivia, Mexico, Peru and Venezuela - per capita GDP declined substantially rather than increased after the boom period. In this respect, it is interesting to note that Chile's rapid growth occurred after 1982, when copper prices 
collapsed, and that its success is normally ascribed to a set of effective macro-economic reforms introduced in the late 1970 s to early 1980 s more than to the steep rise in its commodity exports.

Table 1.6 Natural resource intensity and growth in Latin America

\begin{tabular}{lccc}
\hline & $\begin{array}{c}\text { Natural resource } \\
\text { exports, 1970 } \\
\text { (percent of GDP) }\end{array}$ & $\begin{array}{c}\text { Growth in GDP per } \\
\text { capita, 1965-1990 }\end{array}$ & $\begin{array}{c}\text { Regression estimate of the } \\
\text { natural resource effect }\end{array}$ \\
\hline Argentina & 0.053 & -0.586 & -0.172 \\
Bolivia & 0.185 & 0.433 & -0.602 \\
Brazil & 0.055 & 2.332 & -0.179 \\
Chile & 0.149 & 0.230 & -0.485 \\
Colombia & 0.094 & 1.327 & -0.307 \\
Ecuador & 0.106 & 1.637 & -0.344 \\
Mexico & 0.024 & 0.496 & -0.079 \\
Paraguay & 0.097 & 1.212 & -0.316 \\
Peru & 0.153 & -1.666 & -0.498 \\
Uruguay & 0.091 & 0.656 & -2.97 \\
Venezuela & 0.237 & -2.200 & -0.772 \\
\hline
\end{tabular}

Source: Sachs and Warner, 1999

Sachs and Warner's findings, explored above, are not really surprising. As previously observed, the "Dutch disease" theorists, following the tradition of Hirschman (1958), claim that natural resources necessarily create weak backward and forward linkages, thus little positive impact on the other sectors of the economy. They also suggest that in booming economies the revenues from natural resource exports are consumed rather than invested, and that sudden inflows of earnings may constitute "an irresistible temptation for corruption" and an opportunity for concentrating rent-seeking activities in few private hands, or government relatives, rather than being used for development purposes (Wright, 2001). However, these explanations appear to be intrinsically limited. They can clarify why GDP in booming Latin American economies ended up at lower levels than it might have with deeper linkages or more investment, but they do not explain why growth rates declined after the booms had run their courses, or totally independently from them. Sachs and Warner (1999) themselves argue that "something more pernicious must be going on to account for slower growth", in that more complex factors need to be taken into account to understand this phenomenon in its entirety.

At the moment of independence, most Latin American countries were characterized by a structural trade deficit, with little export capacity apart from mineral products. Independence was followed by the equivalent of a "big-bang liberalization" of domestic markets and by a sudden deregulation of capital flows (UNCTAD, 2003), something surprisingly similar to the uniform and drastic trade liberalization and market deregulation that the continent was forced to introduce (once again) one and a half century later. This resulted in weaker export earnings, a growing gap between government expenditures and revenues, and a financial crisis that cut off the region from foreign investment inflows for several decades. Economic recovery started in the late nineteenth century, driven by the expansion of new, non-traditional agricultural exports, such as coffee, cocoa, sugar, beef and guano, and by the revitalization of the 
mining sector due to improving terms of trade, as the industrial revolution increased the demand for mineral products.

However, the colonial pattern of specialization, epitomized in the picture below, remained intact throughout the whole post-independence period. Mechanization of production took place exclusively in large holdings, producing for export and creating "instances of isolated modernization" that were not based on technological research and which did not generate any stimulus for the development of local technological capabilities (Herrera, 1973; Sagasti, 1973). The rest of the agricultural sector continued in a state of misery and ignorance, with urban centres dominating a sparsely populated interior of illiterate peasants. The reason for this is that large local land-owners - the main beneficiaries of the "peripheral" insertion of Latin American countries into the international trade system, together with the local oligarchies of importers and exporters - could reap sufficient benefits in terms of prestige and power with little effort and limited capital investment, thanks to the availability of land and abundant cheap labour. This is why a "dual economy" structure could persist for a long time after independence and why a resistance to incorporating modern technology, inherited from the colonial past, could become almost an intrinsic characteristic of Latin American economies (Herrera, 1973).

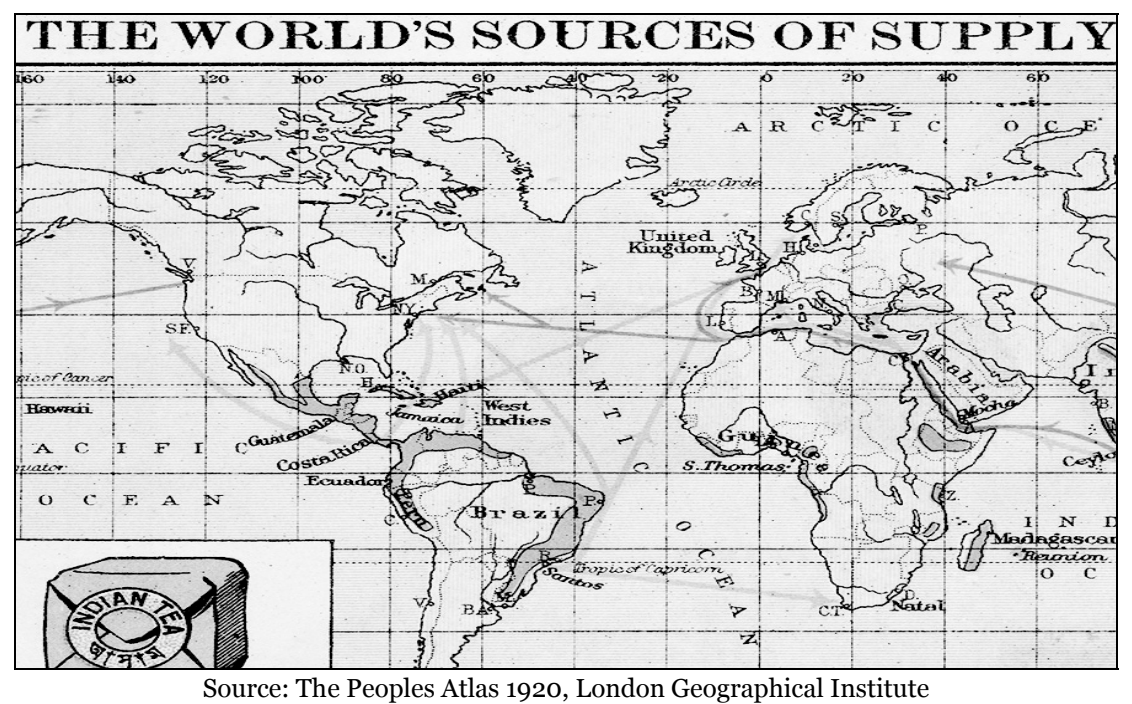

It is not surprising, therefore, that despite their success in expanding exports, the outward oriented strategies adopted by Latin American countries during the nineteenth century were unable to act as engines of industrialization and growth, either because the export sector was not sufficiently large, or because, even when it was sufficiently large, its gains could not be translated into the growth of manufactured exports (Bulmer-Thomas, 1994). This status quo was maintained until the first decades of the twentieth century, when several changes in the international context took place. The outbreak of World War I, the Great Depression, a drastic reduction in the demand for raw materials and the breakdown of the global trading system stopped the flow of manufactured goods to Latin America and provoked a continuous deterioration of the 
prices of raw materials in relation to industrial prices. Latin America had no choice but to look for opportunities of "development from within" and industrialization finally started, based on inward-oriented, import-substitution strategies. This resulted in a process of demographic expansion, rapid urbanization, a growing middle class and increasing elementary education levels, which reached its height in the period between the Great Depression until the end of World War II, when per capita income in Argentina exceeded that of France, Germany, Italy and Spain, and that of the continent as a whole was more than three times that of Japan and East Asia (UNCTAD, 2003).

In the 1960 s and 1970s, the concept of "economic dualism" came under considerable attack from dependency theorists, who argued that underdevelopment, particularly in Latin America, was the consequence of the historical process of industrialization in Europe and North America (Cardoso and Faletto, 1979; Frank, 1966; Furtado, 1962). This process had created a permanent structural gap between developing and developed countries, based on an unequal international division of labour allowing only a few, more advanced countries to produce manufactured goods and a large number of backward countries to produce raw materials. Import-substituting, state-led industrialization strategies became even more deeply rooted in such a conception under the leadership of Raul Prebisch (1978) and the Economic Commission for Latin America (ECLAC) school of thought, despite some emerging contradictions. ${ }^{27}$ Still today, the development impact of import-substitution strategies is the object of an open, contested debate.

On the one hand, contrary to received wisdom, authors such as Rodrik (1999) claim that import-substitution driven growth did not produce tremendous inefficiencies on an economic wide scale, as data clearly show that the productivity performance of many Latin American countries was, in a comparative perspective, "exemplary". They rather created a protected, and therefore profitable, home market for domestic entrepreneurs to invest in, and thus spurred growth for several decades. On the other hand, authors such as Roemer (1979) claim that import-substitution strategies increased the dependency of Latin America countries on foreign capital, which was needed to finance its domestic industrialization and sometimes its military expenditures, without generating a commensurate export capacity. Hence, the adverse impact of import substitution on savings and investment and the gigantic levels of foreign debt, made possible by the growing surpluses of the oil-exporting countries. This is at the origin of the financial instability and repeated default crises that have been pursing the continent since the early 1980 (UNCTAD, 2003).

\footnotetext{
27 Prebisch himself (quoted in Dyster, 1979) was well aware of some of these contradictions. He argued: "Primary producing developing countries on the periphery have been facing regularly deteriorating terms of trade, while industrializing countries at the center of the capitalist system have retained the rewards of their productivity within their own borders. Unfortunately Australia falsifies this hypothesis; it is a country at the periphery, exporting raw materials, whose relatively high per capita income is no more skewed in its distribution than is the case in economies at the centre". He also realized that Australia, Canada and New Zealand had all been dependent on the transfer of British resources, as much as Latin American countries had been dependent on Spanish and, more generally, foreign resources (Prebisch, 1978).
} 
In this respect, some authors argue that, after a long period of import-substitution, Latin American countries such as Mexico, Argentina and Brazil, which had experienced fifty years of rapid growth based on import-substituting industrialization, "ran out of steam" in the second half of the 1970 s and started stagnating heavily after 1980. Others argue instead that, contrary to the successful example of the East Asian countries, Latin America failed to promote competitive industries as it failed to "turn outward" on time (UNCTAD, 2003; Schaffaeddin, 1998). In particular, UNCTAD argues:

The support and protection given during the import-substituting of the 196os and 1970 allowed industry in Latin America to expand considerably faster than would have been possible under competitive conditions. Unlike in East Asia, however, which also made extensive use of industrial policies, these strategies in Latin America were not always able to promote viable industries. Consequently, with big-bang liberalization and the withdrawal of support and protection, industries in this region, confronted with stiff competition, were forced to downsize, rationalize or perish. In this sense, the Latin American deindustrialization process can be associated to a Schumpeterian process of creative destruction. However, after many years of reforms and adjustments, there is little sign of creative forces initiating a new virtuous process of accumulation, growth and structural change (UNCTAD, 2003, p.128).

From a comparative perspective, the problem seems to be rooted in the fact that Latin American industrialization started with the replacement of easily manufactured products, as the East Asian countries had done. However, in Latin America the more complex became the goods to be produced, the higher became the need to import sophisticated technologies, in the absence of a local R\&D system capable of an efficient interaction with the productive sector, which had been developed successfully in the NIEs in Asia (Herrera, 1973). According to Perez (2002), Latin American policies for industrial promotion were limited mainly to imposing customs restrictions without any accompanying effort to creating a capacity for technological innovation, and this generated a pattern of industrialization which, after an initial period, could only be maintained by heavy protection. ${ }^{28}$

In the 1960s-1970s, the import-substitution strategies adopted by many developing countries had played a complementary role to the development strategies of mature industries in advanced countries. These countries had reached market saturation and technological maturity at home, and were therefore looking for opportunities of expanding their markets and increasing their profit margins abroad, for example, by

\footnotetext{
28 To be fair, it should be acknowledged that during the import substitution period in Latin American countries, several technology agencies were created. For example, the National Council for Scientific and Technical Research (CONICET) was created in Argentina in 1958, the National Council for Scientific and Technical Development (CNP) was created in Brazil in 1951 and the National Council for Science and Technology (CONACYT) was created in Mexico in 1970. However, according to Cimoli, Ferraz and Primi (2005), in that phase a linear supply model of technology policy was prevailing, with the public sector playing a major role in identifying the priority of R\&D and having the promotion of human capital formation and basic infrastructures as ultimate objectives. The model was based on the wrong expectation that scientific progress would automatically turn into technological innovation and that innovation would spontaneously flow from public research institutions to the productive sector.
} 
exporting greater quantities of unassembled parts to the myriad TNC affiliates located around the world. In the 1980 s, the microelectronics revolution drastically changed that and opened up new development opportunities. While the NIEs managed successfully to rejuvenate imported mature technologies, to join international production networks as OEM (Original Equipment Manufacturer) suppliers, and to take a leap forward in fast growing industries, as we have seen in the previous section, Latin America failed to design a new development strategy, and to undertake intense learning and innovation efforts (see Figure 1.4). According to Amsden (1989), the emphasis on human capital and on the active absorption of technology of the NIEs "cannot be overstated", and is in sharp contrast with the much more passive transfer of technology practices common in Latin America in that period. In this respect, Perez (2003) warns:

For a developing country to believe that significant advances are possible without equivalent intensive learning efforts is an illusion. There is no shortcut to development without mastery of technology, in the simple sense of social, technical and economic know-how incorporated in people. This was blurred by the peculiar conditions of import substitution policies which for a time made it possible for many countries to achieve impressive growth performance, investing in mature plant and equipment, without intensive learning efforts (Perez, 2003, p.33).

Figure 1.4 Development opportunities as a moving target

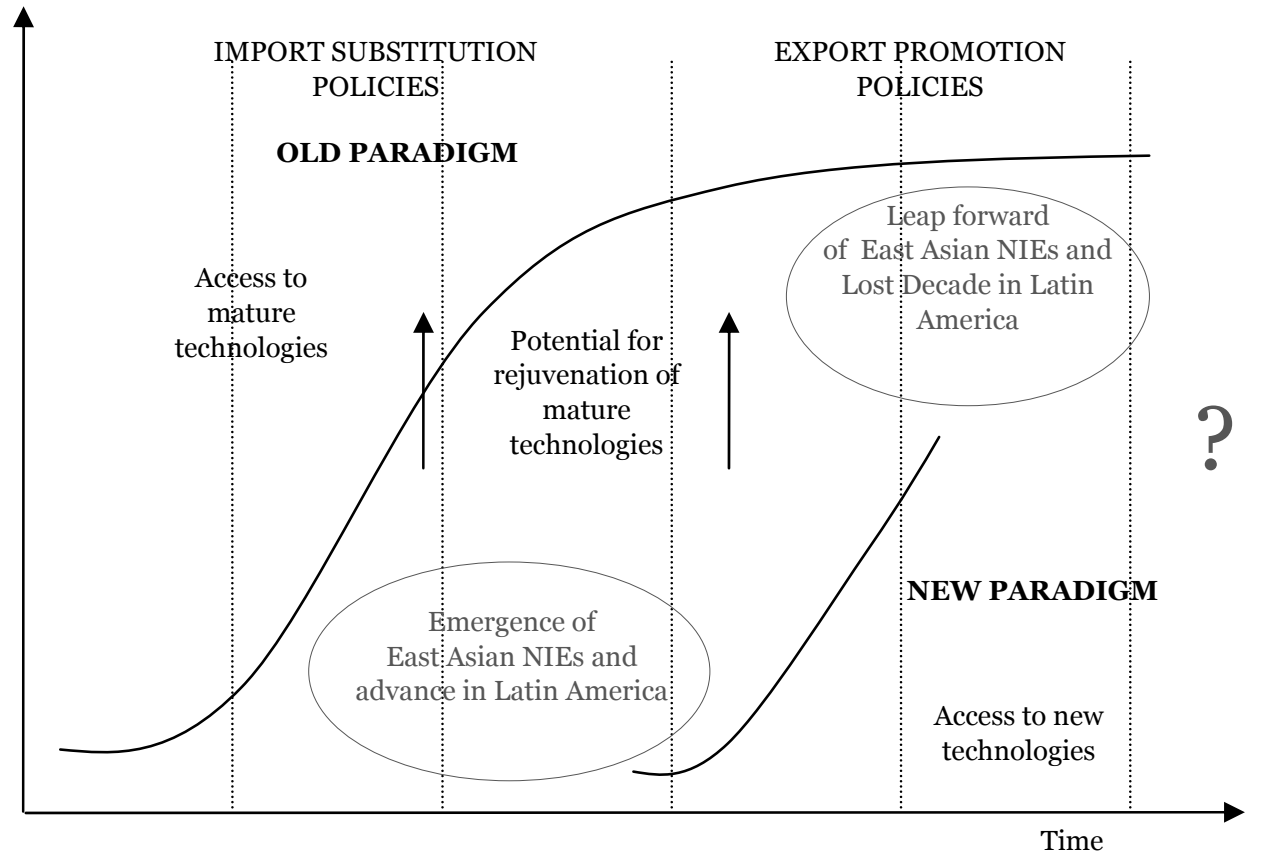

Source: Author's elaboration based on Perez, 2003

From an evolutionary perspective, two core concepts can be recalled in this context. Firstly, technological gaps between countries, sectors or regions can be possibly seen as 
the outcome of different technological and institutional capabilities (Cimoli and Della Giusta, 2000). Secondly, the specific capability of a country (sector or region) to borrow and adapt the more advanced technologies developed elsewhere lies at the very root of the industrialization process. In this sense, if we agree with Perez (1988) that development is taking advantage of changing opportunities, Latin American countries appear to have excessively relied on technology transfer from abroad, and in the 1960s1970s have failed to use imported technologies for development, thereby losing the ground gained and missing the new "windows of opportunity" created in the 1980s1990 s by the IT revolution. The question here remains, whether Latin American countries have learned to compete in a globalized economy and whether their renewed productive specialization in natural resource processing activities can be considered a desirable return to their comparative advantages (UNCTAD, 2003) or, as Cimoli and Katz (2003) put it, whether they represent an unwelcome pathway towards the further dismantling of their industrial capacities.

\subsubsection{The changing sectoral specialization of Latin America}

Surprisingly, the successful performance of the East Asian NIEs has not been matched by an equally sustained economic growth or an equally straightforward technological evolution of the rest of the developing world. Despite the well recognized "advantages of backwardness" (Gerschenkron, 1962), whereby technology gaps would provide growth opportunities to latecomers by allowing them to profit from the availability of modern technologies without facing the costs and risks associated with their development, most developing countries have been falling behind rather than catching-up (Abramovitz, 1986). Latin America is the continent that best epitomizes the stark contrast between East Asian NIEs and the rest of the developing world, in terms of growth performance and technological accumulation. Paradoxically, between 1960 and 1973, the two regions experienced the same rate of GDP growth, as well as similar levels of per capita income.

Data show that, in those years, GDP growth reached an annual average rate of 6.8 percent in the first tier NIEs, compared to 5.9 percent in Latin America. Analogously, in 1973 per capita GDP reached 3,735 US $\$$ in the NIEs, compared to 4,574 US $\$$ in Latin America (Maddison, 2001). After 1973, following the oil crisis, growth came to diverge substantially, with East Asia reaching 6.3 percent annual growth between 1974 and 2004, compared to 2.8 percent in Latin America (World Bank, 2010). Even looking at the size of the manufacturing sectors of East Asia and Latin America, it emerges that in 1970 this was surprisingly similar, totalling around 25 percent of GDP in both regions. In 1980, though, the manufacturing share of GDP had risen to almost 30 percent in East Asia and had remained at the same level of 25 percent in Latin America, while it had fallen dramatically to 17 percent of GDP in 2000 in Latin America and had remained stable in East Asia (UNCTAD, 2007). Over the period 1980-2000 all Latin American countries, with the important exception of Chile, ${ }^{29}$ experienced a period of

\footnotetext{
29 During the 1980 s and the first half of the 1990s, Chile enjoyed a steady 7 percent annual growth rate and a reduction of the unemployment rate from 22 percent in 1980 to 6 percent in 1995. Such an extraordinary economic performance, which represents a stunning exception in the region, was based on a fully export-led growth model, accompanied by an increasing specialization and an investment boom in high capital intensive
} 
sudden decline, financial instability and industrial stagnation (UNCTAD, 2003). In all Latin American countries, including Chile and oil exporters such as Venezuela and Mexico, the share of manufacturing value added in GDP collapsed, along with labour productivity levels, especially in traditional labour-intensive sectors, such as textiles and clothing. In particular, Argentina and Chile attained no more than 50 percent of the labour productivity level of the United States, while Ecuador, Paraguay and Bolivia attained only 20 percent (Katz, 2006). In the whole continent, investment in machinery and equipment stagnated or declined sharply during the 1980s, and showed only a modest recovery in the 1990 .

Furthermore, the diversion of investment to consumption, in the absence of finance on reasonable terms and of any improvement in employment and wage levels, contributed to the weakening of the "investment-profit nexus" that had been so favourable in the case of the NIEs, by linking capital formation, technological upgrading and output growth (Akyuz and Gore, 1996). Unlike in the NIEs, the increased presence of FDI in Latin America has not been conducive to faster gross fixed capital formation (GFCF). Data show, in fact, that FDI as a proportion of GDP was higher by 1.7 percent in the 1990 s compared to the 1980s, but the share of GFCF was 0.6 percent lower. By contrast, in none of the NIEs have rising FDI flows been associated with falling domestic GFCF, with the exception of the Philippines. It is not startling, therefore, that from a Latin American perspective the 1980s have been defined as a "lost development decade", and the 1990 as a "lost half decade" (Ocampo, 2002).

It should be noted that even in the case of Mexico, which saw its share of manufacturing exports increase to 62.3 percent of GDP in 2000 from 29.3 percent in 1980, such an exceptional increase has not been reflected in an analogous increase in the share of manufacturing value added in GDP, nor in an improvement of average wage levels. The case of Mexico is not the rule, but it is emblematic of an economy performing well in terms of manufactured exports but locked into the cheap end of manufacturing production. It demonstrates, therefore, that openness and export success are not necessarily positively correlated with high levels of per capita income growth, and with industrial development more in general (Rodrik, 1999). According to UNCTAD (2003), the reason for this phenomenon is that most of the increase in manufactured exports took place in those industries that have been participating in international production networks, such as clothing, electrical and non-electrical machinery, transport equipment or scientific equipment. The inclusion of these sectors in international production networks, though, was accompanied by the substitution of a significant share of domestic production by imports and by a protracted domestic concentration in labour-intensive, low-value added assembly operations. This has isolated Mexico from the world of technology generation (CEPAL, 2000) and therefore, contrary to the NIEs, the country has not been able to simultaneously upgrade its production and export structure nor to move into a wider range of medium and high technology products (see Table 1.7).

natural resource-based industries (particularly copper mining). However, during the last decade Chile has faced difficulties in diversifying into manufacturing exports and more sophisticated commodities, and growth has started to slow down. According to Moguillansky (1999), "since the second half of the 1990s Chile's prosperous growth path seems to have reached exhaustion". 
Table 1.7 Manufacturing value added as a share of GDP in selected Latin American countries, 1960-2000

\begin{tabular}{lcccc}
\hline & $\mathbf{1 9 6 0 - 1 9 6 9}$ & $\mathbf{1 9 7 0 - 1 9 7 9}$ & $\mathbf{1 9 8 0 - 1 9 8 9}$ & $\mathbf{1 9 9 0 - 2 0 0 0}$ \\
\hline Argentina & 38.6 & 35.3 & 39.3 & 20.3 \\
Brazil & 28.2 & 30.0 & 32.6 & 23.7 \\
Chile & 23.8 & 24.2 & 19.7 & 18.0 \\
Colombia & 18.9 & 23.0 & 22.0 & 17.0 \\
Mexico & 20.1 & 22.7 & 23.2 & 20.6 \\
Peru & 16.9 & 21.4 & 26.8 & 15.3 \\
Uruguay & 22.6 & 23.8 & 26.5 & 21.0 \\
Venezuela & 15.4 & 16.1 & 19.5 & 17.4 \\
\hline
\end{tabular}

Source: World Development Indicators, World Bank, 2007

In the case of Chile and Argentina, which were hit the hardest by falling shares of both manufacturing value added and investment, but also of Brazil and Mexico, a deep process of "deindustrialization" followed the introduction of drastic market-based reforms, often through the privatization of public assets, and of radical financial and trade liberalization (Cimoli and Katz, 2003; UNCTAD, 2003; Rodrik, 1999). Such reforms were introduced in Chile in the late 1970s, in Argentina in the early 1980s, in Mexico in the late 1980s, in Brazil in the early 1990s. In each of them, the impact on innovation and competitiveness was negative, in the absence of policies to facilitate their adjustment after four decades of inward-oriented, state-led growth (Mytelka, 1999). Due to rapid liberalization and market deregulation, more than 15,000 firms went bankrupt in Argentina (Chudnovsky et al., 1994; Azpiazu and Basualdo, 1995), while more than 7,000 sank or switched from production to importing in Chile (Pietrobelli, 1994; Caceres, 2000). In Mexico, the majority of domestic firms cut back on technological activities, substituting licensing for innovation in order to respond rapidly to the new competitive pressures, while in Brazil the impact of unconditional liberalization was particularly strong in labour intensive firms, such as those producing garments, footwear and textiles, as well as pulp and paper (Bercovich, 2000; Bercovich and Katz, 1997).

Overall, in Latin America the reforms resulted in hyperinflation and high levels of debt, higher industrial concentration, weaker backward and forward linkages of foreign corporations with domestic companies, and rising amounts of imported inputs. A progressive "downgrading" of the more sophisticated manufacturing sector took place, accompanied by a decline of $\mathrm{R} \& \mathrm{D}$ and engineering intensive activities, resulting in a reduction of the Latin American potential for productivity growth and innovation (Cimoli and Katz, 2003). Not surprisingly, therefore, the literature argues that the radical opening up of Latin American economies to international competition and FDI did not produce the promised result of emulating the East Asian growth story. On the contrary, it led towards slow and erratic growth and towards a new pattern of specialization characterized by considerably lower knowledge contents (Mytelka, 2007). Table 1.8 shows that in the past three decades the production structure of Argentina, Brazil, Chile and Mexico suffered a major restructuring process in favour of less productive non-tradable activities, such as housing construction; of natural resource processing industries producing standardized commodities, such as pulp and paper, iron and steel, and vegetable oil in the Southern Cone; and of low value added "maquila 
type" assembly operations, producing electronic equipment, televisions and garments for export, mostly directed towards the US, Mexico and Central America (Katz, 2006).

Table 1.8 Changes in the relative weight of industrial sectors in total manufacturing output, 1970-2002

\begin{tabular}{|c|c|c|c|c|c|c|c|c|c|c|c|c|}
\hline & \multicolumn{3}{|c|}{ ARGENTINA } & \multicolumn{3}{|c|}{ BRAZIL } & \multicolumn{3}{|c|}{ CHILE } & \multicolumn{3}{|c|}{ MEXICO } \\
\hline & '70 & 696 & '02 & '70 & 696 & '02 & '70 & 696 & '02 & '70 & '96 & '02 \\
\hline I & 13.2 & 9.9 & 6.7 & 16.2 & 25.6 & 26.5 & 11.4 & 10.4 & 10.0 & 12.0 & 14.4 & 15.6 \\
\hline II & 10.9 & 7.2 & 6.1 & 6.8 & $7 \cdot 3$ & 8.9 & $5 \cdot 5$ & 1.9 & 1.9 & 8.4 & 14.6 & 18.6 \\
\hline $\mathrm{III}+\mathrm{IV}$ & 47.8 & 62.1 & 71.7 & 37.8 & 43.4 & 41.5 & 58.3 & 59.7 & 61.9 & 43.2 & 43.4 & 40.8 \\
\hline $\mathrm{V}$ & 28.1 & 20.7 & 15.6 & 39.2 & 23.7 & 23.1 & 24.9 & 28.0 & 26.3 & 36.4 & 36.4 & 35.0 \\
\hline Total & 100 & 100 & 100 & 100 & 100 & 100 & 100 & 100 & 100 & 100 & 100 & 100 \\
\hline
\end{tabular}

Source: Katz, 2006

I Engineering intensive industries, excluding automobiles

II Automobiles

III Natural resource intensive industries, including food, beverages and tobacco

IV Natural resource processing industries

V Labour intensive industries

Data show that, since the 1970s, industrial production has remained largely dominated by resource-based industries in all Latin American countries, except Mexico. Engineering intensive activities, such as the production of machinery and equipment, dropped everywhere except Brazil, which saw a minor increase in its share of metalworking activities in manufacturing production throughout the period (Katz, 2006). However, the automobile industry, where strong engineering capabilities and a large local network of subcontractors had been built throughout the Southern Cone, lost the "fruits of import substitution" and became part of an international production system discouraging local R\&D and engineering efforts (Mytelka, 2007). This pushed the industry into what Cimoli and Katz (2003) define as a "low development trap", as they illustrate through the emblematic story of the Ford Taurus in Argentina:

The launching of the Ford Taurus on to the Argentine market in 1974 demanded 300, ooo hours of domestic engineering efforts carried out by a local team of 120 professionals employed by Ford engineering department. These professionals were responsible for generating a steady flow of incremental units of production organization and engineering knowledge required for the adaptation of the German designed blueprints to the local environment, to the available raw materials, to the idiosyncrasies of the Argentine plant, and to the technological capabilities of domestic subcontractors producing parts and components for the vehicle. [...] Domestic content for such cars was close to 90 percent of the total value of the vehicle. Nearly 400 subcontractors supplied parts and components under Ford's stringent specifications.

However, Cimoli and Katz (2003) also remind that, at present: 
The production organization model and the technological regime associated with the production of the Ford Taurus in Argentina no longer exist. Ford Argentina is now part of a world-wide integrated production system, working "on-line" with other Ford subsidiaries around the world, assembling - with less than 50 percent local content, and with no domestic engineering efforts whatsoever - a "world car" which has become something of a "commodity" [...] Production activities have become an assembly operation of imported parts and components with little, if any, effect upon development of domestic technological capabilities and mechanical engineering skills (Cimoli and Katz, 2003, pp.387-388).

According to UNCTAD (2003), the persistent and rapid deterioration of Latin America's position relative to the East Asian NIEs raises several doubts about the "appropriateness" of the macro-economic policies adopted in the region. It also leads to a certain "scepticism" concerning the ability of those policies to capitalize on the region's natural wealth in order to raise living standards for the population, let alone achieve progress towards convergence with the per capita income levels of developed countries. In this respect, Rodrik (1999) argues that only a small part of the decline in growth that many Latin American countries experienced after the late 1970s can be explained by the drop in their investment levels. Rather, "the single most important factor accounting for the diversity of post-1975 economic performance in Latin America and East Asia is the ability to maintain macroeconomics stability in the face of often turbulent external conditions. The protracted debt crisis of the 1980 in Latin America is a poignant demonstration of the consequences of the inability to handle the external shocks of the late 1970 s and 1980s" (Rodrik, 1999, pp.18).

In the economic history of Latin America, the issue of macro-economic imbalances (related to fiscal, monetary and exchange rate policies) has proven of utmost relevance, as clearly emerges from the example of Chile, which managed to avoid incurring a financial crisis in the style of Mexico and Argentina, thanks to the application of a competitive active exchange rate policy and the maintenance of a prudential supervision of the financial system (Ffrench-Davis, 2000; Rodrik, 2006). The problem, however, seems to be far from conjunctural and not only related to the achievement of macroeconomic stability per se, as the experience of the Asian NIEs well shows (Westphal, 2002; Amsden, 1989; Wade, 1990; UNCTAD, 2003).

The literature actually reflects an open debate between those who ascribe the underperformance of Latin American economies to financial instability and macro economic factors, and those who ascribe it to issues pertaining to the micro level. According to the seminal work of Cimoli and Katz (2003) on structural reforms, technological gaps and economic development in Latin America, the problem seems to be rather related to both the impact of turbulent external conditions on macro-tomicro interactions and the changing patterns of productive specialization (towards less knowledge intensive activities). This appears even more convincing considering that, during the last century, Latin America failed to replicate the successful growth and industrialization of East Asia by adopting outward-oriented strategies, but it had also failed, in earlier decades, to use natural resources as a platform of development by adopting primary-export-led development strategies (Roemer, 1979). In this sense, the 
disappointing performance of Latin America on more than one historical occasion despite the high development potential stemming from its rich natural resource endowments as well as the traditions and institutions brought from Europe (UNCTAD 2003) - brings right back to the wider debate on the natural resource curse and the opposition between primary resource exploitation and industrialization, explored in detail earlier. The return of the Latin American continent to a productive specialization based on natural resources actually opens up a series of challenging questions related to the conditions under which natural resource-based sectors may become drivers of rather than impediments to economic development. These have been only partially explored by the literature and, therefore. represent the focus of this thesis.

\subsection{Conclusions}

The present chapter argues that the former way of looking at natural resource-based sectors - as sectors characterized by an enclave nature as well as declining terms of trade - has become obsolete. A new way of looking at the primary sector, and at its potential for stimulating resource-based industrialization and economic development, has gradually emerged. On the one hand, the new demand for both agricultural and mineral commodities, mostly driven by China and India, has changed the elasticity of demand for natural resources, and, after a brief downturn during the economic crisis in 2008-2009, a long-term growth in demand for minerals and metals, as well as for agricultural products, is expected (UNCTAD, 2010). On the other hand, there are examples of countries, such as the United States, Canada and Norway, which were successful in transforming natural resource availability into a blessing, rather than a curse, and therefore represent a clear point of reference of the adaptable way in which natural resources may be used for developmental purposes (Sachs, 2005). In 2001, for example, the Conference Board of Canada described natural resource-based sectors as "world leaders in spawning high-technology services and manufacturing industries, such as geomatics, robotics, optical controls and environmental engineering, and in applying these new technologies".

The literature notes that in advanced countries, such as the United States, Australia and Canada, which represent examples of resource-rich, sparsely populated ex-colonies, the wealth related to natural resources was not exclusively derived from geological endowment, but also from the intensity of search, the sophistication of the technologies of extraction, refining and utilization, the efforts for improving market development and transportation costs, and the legal, institutional and political structures affecting all of these (Wright, 2001; Harrison, 1985).30 This led authors, such as David and Wright

\footnotetext{
${ }^{30}$ In his provocative book entitled Underdevelopment is a State of Mind, Harrison (1985) draws an interesting parallel between the economic history of Argentina and Australia. He argues that the main explanation for the economic problems of Argentina, as much as for most Latin American countries, is the lack of a political system that adequately reflects and furthers the interests of the poor. On the contrary, globalization has been a major engine of growth for other ex-colonies, such as Australia, Canada and the United States, because it has operated within effective democratic frameworks which have allowed lower-income groups to play a major role in the political process. Based on these arguments, Harrison heavily attacks the dependency theorists, and claims that the Latin American political failure is basically rooted in its "Hispanic culture" rather than its past dependency on industrialized countries.
} 
(1997), to claim that the situation of natural resource abundance was a "socially constructed state", exactly as the condition of technological leadership, and its formation was the result of a process endogenous to the economic and political system, rather than simply the result of a predetermined series of physical endowment constraints imposed by nature.

This is extremely relevant for the Latin American continent, which has experienced a deep process of deindustrialization and is paying a new attention towards natural resource-based processing industries after decades of stagnation. From an innovation perspective, Latin American integration into global trade is occurring on an increasingly asymmetric basis (Cimoli, Primi and Pugno, 2005). With a few important exceptions, such as the design and construction of commercial airplanes in Brazil (Goldstein, 2005), Latin American domestic firms are successfully participating in international production processes and international trade, but they are marginal actors in the globalization of scientific and technological activities. Their transition from "global traders to global players" is not an easy goal, regardless of the sector, and can only be achieved through a rise in the endogenous technological capabilities generated by policy support, protection and inducement, as the experience of the NIEs well shows (Katz, 2000).

Until now, these have lacked in most Latin American countries, partly as a consequence of the conditionality imposed by the World Bank and IMF through the Washington Consensus. Mainstream neoclassical approaches tend, in fact, to confine their areas of intervention to macroeconomic fundamentals and to eliminate all forms of active involvement in industrial activity. However, by doing so they have failed to explain and influence on a systematic scale the process leading to industrialization, international competitiveness and economic development (Lundvall et al, 2002; Kaplan, 2007). By contrast, heterodox economics has realized that micro policies matter. In this respect, Lall (1994) argues:

In the presence of widespread market failures, simply leaving industrial policy matters to the market can penalize the development process, in that it can hold back entry into activities with complex technologies, increased local content and the undertaking of demanding technological tasks locally, what may be broadly labelled as industrial deepening (Lall, 1994, p.34).

This is at the origin of the success and utility of the Innovation System (IS) approach, which will be illustrated in detail in Chapter 2. This thesis is based on the assumption that evolutionary economics has managed to grasp more efficiently the realities of existing development gaps among countries than neoclassical economics, and to devise more effective policies that support growth and sustainable development under the new competitive conditions. 


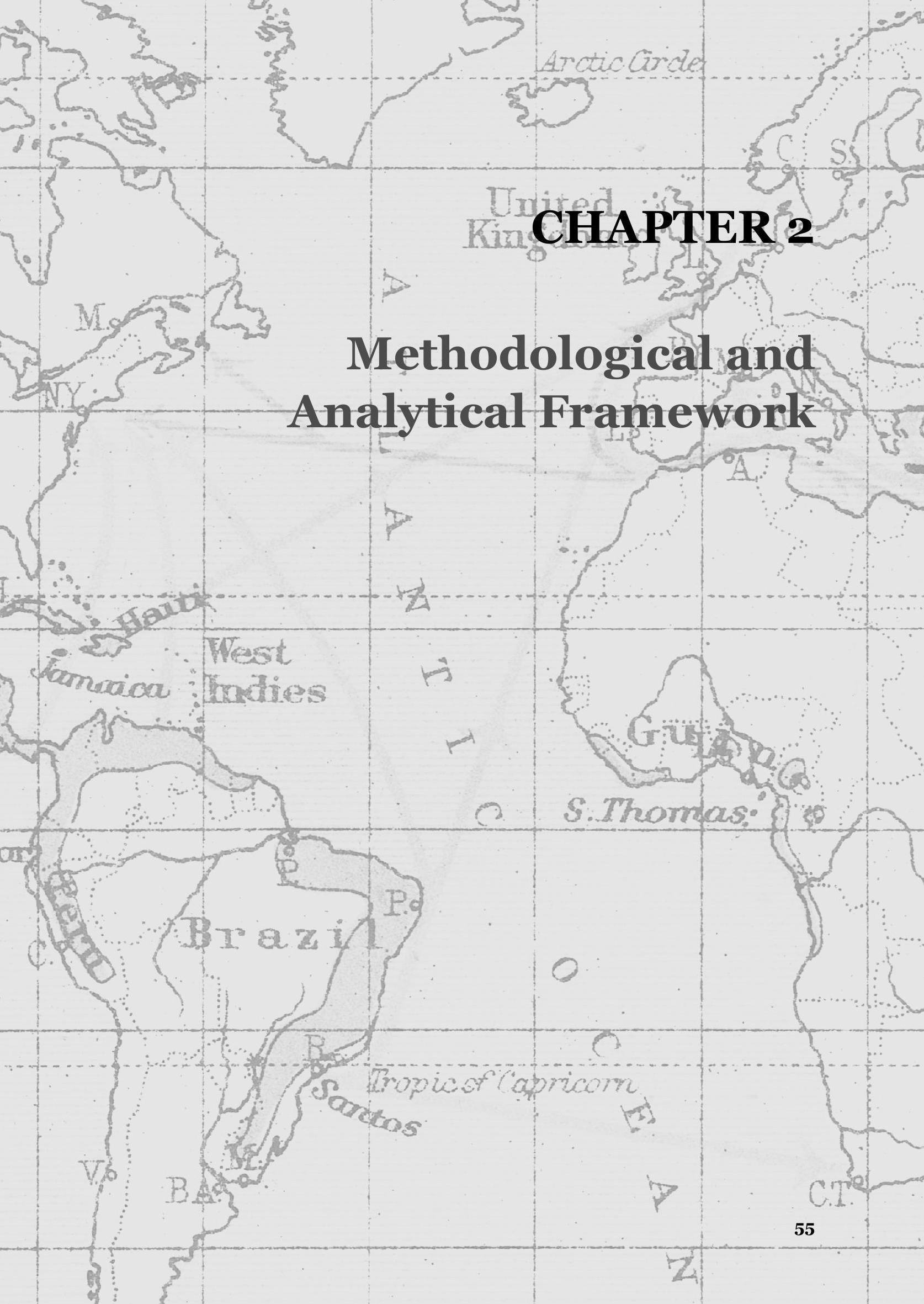


CHAPTER 2 


\subsection{Introduction}

This chapter presents the methodological and analytical framework of the thesis. It aims to explore the potential for natural resource-based processing industries to become a platform for the development of deeper competencies, increased knowledge and stronger innovation capacity. In line with the evolutionary tradition of economics, it prepares the ground for showing how, in a knowledge-based economy, innovation may become one of the key "escape routes" from the negative impacts of resource abundance described in detail in the previous chapter. This chapter also challenges the widely held yet obsolete perception that all natural resource-based industries are "enclave" industries, characterized by scarce technological dynamism, weak upstream and downstream linkages and low innovation capacity, and that economic growth largely depends on the creation of high-tech, knowledge-intensive industries, involving major new technologies.

Following the evolutionary perspective, which has gradually moved towards a more encompassing view of the innovation process, this thesis adopts a broad definition of innovation as " $a$ process by which firms master and turn into practice product design and manufacturing processes that are new to them, whether or not they are new to the universe" (Nelson and Rosenberg, 1993). This contrasts with earlier notions of the concept that had a narrow focus on science and science-based activities, and considered innovation something strictly happening only in advanced countries, large corporations, or high-tech industries (Kline and Rosenberg, 1986). Accordingly, it can be argued that firms, irrespective of the industry in which they are located, increasingly have to compete, not only on price but also on their ability to innovate (Mytelka, 2000), and that this increasingly applies to natural resource-based and traditional sectors as well (Smith, 2001).

This chapter illustrates the key elements of the analytical framework, develops three main hypotheses and related sub-hypotheses, presents the methodology chosen to explore them, and explains the rationale behind the empirical work of the thesis. It is structured as follows: Section 2 analyzes the increasing knowledge intensity of natural resource-based processing industries and illustrates how, by means of the Innovation System and Cluster approaches, developing countries can identify and take advantage of potential windows of opportunity for creating, distributing and maintaining advanced knowledge. Section 3 presents three main hypotheses and related subhypotheses, and the controversies that surround them. Section 4 explains why two case studies have been selected to carry out the empirical research from a comparative perspective, namely the wine industries of Chile and Argentina, and why they are relevant for exploring the interplay between natural resources, innovation and export growth. Sections 5, 6 and 7 provide detailed explanations of the methodology applied in the remaining chapters of the thesis in order to assess the validity of the main hypotheses and related sub-hypotheses. 


\subsection{Key elements of the analytical framework}

\subsubsection{The knowledge intensity of resource-based industries}

Contrary to received wisdom, traditionally considering mineral resources as the most intrinsically "unfriendly" raw materials from a development perspective, over the last decade scholars have begun to look at natural resource from a new perspective. In his writings on the natural resource curse, for example, Wright (2001) observes that, in today's knowledge-based economy, mineral resources necessitate extensive investments before they become valuable, and such investments include not only physical capital and transportation, but also the acquisition of knowledge about the nation's natural resource base and the development of technologies that increase the value of that base. In this respect, he argues:

The knowledge of the properties of natural resources is the basis for elaborated products within one's home country. If a country fails to move on from its extractive phase, the reason may be that it has failed to invest sufficiently in the knowledge aspects of its resource base. The key test is not so much the amount of processing that is done within a country boundary, but whether the country is participating in the learning process, and whether the learning is structured so as to internalize development goals appropriately. In order to diagnose the patient appropriately, we need to look inside the black box of the learning process. (Wright, 2001, p.25).

Along the same lines, Kaplinsky (2007) suggests:

For many decades, sustained income and rising technological capabilities seemed to be found predominantly in the manufacturing sector. There has been a tendency to underemphasize the innovation rents in some agricultural and service sectors. As in the manufacturing sector, [...] which went from post-fordism to justin-time, the capability to "individualize", differentiate and diversify products has spread to the primary sector. Coffee is now where wine was ten years ago, in a twofold sense. Firstly, consumers are learning to recognize the quality and taste nuances of different varieties of coffees and to relate these to the conditions under which the coffee is grown rather than to the image promoted by roasters and blenders. Secondly, as these taste patterns emerge, producers need to protect the reputation of their product, which is based on location specific taste characteristics, through intellectual property rights and geographical indications (Kaplinsky, 2007, p.11).

This shows that a new way of looking at the relationship between natural resources and development is gradually emerging, one which is considerably different from the old theoretical approaches discussed in detail in Chapter 1. Furthering such a perspective represents one of the original contributions of this thesis. Among all natural resourcebased processing industries, the present analysis mainly refers to food processing industries, namely to processed agricultural commodities such as wine, coffee, tea and cocoa, but also wool, potatoes, olive oil, fish and meat. In some cases, these have 
undergone the transformation from pure commodities to highly diversified, high valueadded export goods, often characterized by their own geographical indication (GI) and clear commercial branding. ${ }^{31}$ A recent study carried out by the International Trade Centre (2009) shows, for example, that there are currently more than 10,000 legally protected GIs worldwide, of which only 10 percent originate from developing countries. In the last few decades, however, a number of them, such as Darjeeling tea, Jamaica Blue Mountain coffee, Gobi Desert camel wool, Mezcal tequila, Basmati rice and Pampas beef have achieved global recognition and considerable market power (ITC, 2009).

This has led some authors, such as Kaplinsky (2007) and Perez (2010), to talk about an increasing tendency towards the "de-commodification" of natural resources, which would be reflected not only in their differentiation, brand naming and value added at the product level, but also in the higher knowledge intensity and technological dynamism of their production and processing phase, as well as of related upstream and downstream activities. ${ }^{2}$ Meyer-Stamer, Maggi and Seibel (2001) explain that, under the pressure of trade liberalization, the locus of created competitive advantages has shifted both upstream and downstream to more knowledge-based activities - as is shown by the increasing importance of, on the one hand, new materials, science and research-based inputs and, on the other hand, of quality certification and commercialization skills in distant markets. This thesis argues that such transformations are occurring in practically all natural resource-based industries, from those oriented towards the processing of agricultural products, which represent the main focus of the present analysis, to those oriented towards the extraction and processing of mineral products.

For example, Smith (2001) discusses the case of fish-farming, which represents a major industry in several developed and developing countries. He shows the extent to which ship development relies on fluid mechanics, hydrodynamics and cybernetic systems; sonar systems rely on complex knowledge of acoustic systems; fish ponds rely on wave analysis and CAD/CAM design systems; farming itself relies on research on genetic and molecular biology; monitoring relies on computer imaging and pattern recognition technologies; feeding and health systems rely on transgenic techniques. He therefore argues that fish-farming activities rest undeniably on a base of deep scientific knowledge, often developed in the university sector and sometimes subject to discontinuous change, ranging from mathematical algorithms to optimal control,

\footnotetext{
${ }^{31}$ According to the Agreement on Trade-Related Aspects of Intellectual Property Rights (TRIPS), established in 1994 and overseen by the World Trade Organization, a Geographical Indication "identifies a good as originating in a delimited territory or region where a noted quality, reputation or other characteristic of the good is essentially attributable to its geographical origin and/or the human or natural factors there" (ITC, 2009).

$3^{2}$ As observed in Chapter 1, following Kaplinsky (2007) and Perez et al. (2010), the term "de-commodification" refers to a process of major change leading to increasing product quality, name branding and diversification of natural resource-based products, conferring increasing value per unit to those producers who have chosen innovation-based strategies, creating raising barriers of entry and generating high local value-added.
} 
molecular biology, bacteriology, solid-state physics, biotechnology, informatics and robotics (see Figure 2.1).

\section{Figure 2.1 Knowledge intensity of fish farming industries}

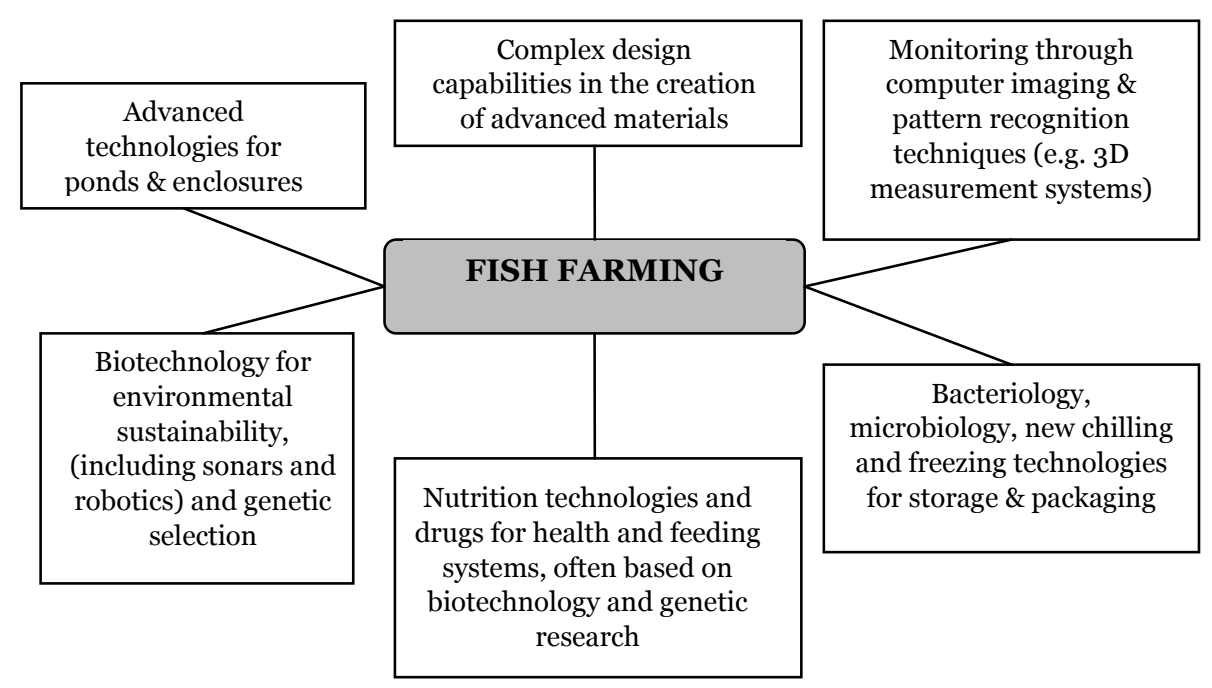

Source: Author's elaboration based on Smith (1999)

Along the same lines, Varricchio and Queiroz (2010) present the Brazilian bioethanol experience as an ideal case to illustrate how even sectors that are traditionally considered "low tech" and mature have become increasingly knowledge intensive, and how a developing country such as Brazil could become a "natural knowledge economy" by investing in $R \& D$ (the State of Sao Paulo alone has the same number of scientific publications on bioethanol as the United States) and supporting programmes aimed at improving genetic sugarcane varieties and increasing productivity. Thanks to this and to improved mastery of bioethanol processing techniques through new knowledge accumulated in areas such as alcohol-chemistry, biomass gasification and hydrolysis, mills automation and satellite monitoring - Brazil has become a worldwide reference in the production not only of bioethanol but also of even more technologically sophisticated products, such as poly-ethylene and bioplastics, and has achieved industrial diversification by developing core competencies in the production of vehicles, cars and aircrafts that are propelled solely by biofuels.

If one considers the extremely complex exploration, extraction and transport techniques needed to exploit the deep ocean oil reserves found in Brazil, combined with the deployment of a highly sophisticated international network of specialized suppliers of equipment and services, it emerges that even industries related to the extraction and processing of minerals may represent a platform to acquire complex competences, to foster downstream and upstream linkages and to generate "lateral migrations" of technology to other industrial sectors (Walker and Jourdan, 2003). They can also stimulate the development of competitive capital goods, power supplies and transport 
services that can increase the competitiveness and productivity of the rest of the economy. Another example relates to the use of microbes to extract minerals, a process defined as "bio-mining". For a long time, the bacteria commonly used in the mining industry have been collected from mining areas where they develop naturally, but more recently researchers have applied genetic engineering techniques to develop new microbes and make them more efficient, e.g., to withstand extreme heat or resist toxic chemicals such as arsenic and mercury, which are used in processing gold (Natarajan, 1992).

Indeed, compared to processed agricultural commodities, processed mineral commodities do not present the same potential for product differentiation, and are not characterized by rising barriers of entry, thanks to the introduction of denomination of origin, and geographical indication and certification procedures. However, the literature provides some examples of specialized non-agricultural natural resourcebased products, such as "boutique" steel, termite-proof wood, biodegradable composites and clean fuel - which show that even processed mineral and forestry products may be a driver of export diversification and shift towards increasingly higher value added products, with high technological content as well as specialized and customized features. In this respect, Perez (2010) interestingly highlights that acquiring capabilities in mineral, forestry and agricultural resource-based industries associated with biology and new materials may be key in positioning developing countries at the starting blocks of the next technological revolution, whereby biotechnologies, nanotechnologies, bioelectronics and new materials are expected to shape the new technological paradigm of the twenty-first century.

Additionally, in her insightful study on the importance of IT applications in natural resource industries, Moguillansky (2005) shows that the adoption of new organizational techniques - such as quality systems control and just-in-time management, the introduction of new equipment with a microelectronics base, the tendency towards "intelligent automatization" and full-scale traceability - now characterize most natural resource-related activities, from agro-processing to animal farming, from forestry to mineral extraction and processing (including oil). Perez et al. (2010) also show how the use of services incorporating ITs, from basic services of medium complexity to very highly specialized knowledge intensive business services, is transforming not only manufacturing but also natural resource based sectors. Here, market segmentation is rapidly diversifying commodities situated at the lower end with high volumes, low prices and low narrow profit margins - from differentiated products with higher profit margins and higher innovation rents. The latter originate from the value-added created by incorporating sophisticated software and R\&D activities, as well as new, high-tech research niches in specialized materials, chemicals and bio-sciences (Malerba and Breshnan, 1999).

The upside of this growing complexity is that much of the knowledge required to enter new products into a new technology system in its early phase is in the public domain and mostly available at universities and/or on the Internet. Thus, given the presence of highly qualified human resources, new windows of opportunity are continuously opened for the entry of latecomer countries (Perez, 1988). However, there is also a 
negative side. As in the case of "new wave technologies", such as biotechnology, hydrogen and nanotechnologies, the increasing knowledge intensity of most natural resource industries makes it increasingly difficult for developing countries to find an entry point based exclusively on their low labour costs, or to pursue an incrementalonly catching up process (Mytelka, 2004). This explains why, as illustrated in Chapter 1 with reference to the South East Asian experience, the new dynamics of catching-up necessarily have to go beyond the deepening of production capabilities and entail a conscious process of learning and innovation, if lagging countries wish to move from the pure extraction or production of raw materials or low value added products to more sophisticated downstream and upstream activities.

Additionally, one should not forget that the challenge for developing countries lies not only in the identification of strategic entry points, but also, and especially, in the longterm sustainability of industry growth. In their recent study on Chilean salmon farming, for example, Iizuka and Katz (2011) show how, after growing at double digit rates for more than two decades, the industry is now threatened by a serious decline, as trade data have started to show very clearly (see Figure 1.1 in the previous chapter). This is due to a combination of environmental over-exploitation and mismanagement, as well as to a lack of local capabilities to prevent and contain the outbreak of a violent, viral disease called ISA, which destroys the salmon's immunological barriers, causing its death. The authors make the point that although Chile became "world class in production" at salmon farming, it did not concomitantly develop sufficient scientific and technological capabilities to provide local solutions to emerging new issues of biosecurity, environmental sustainability and control of emerging pathogens.

Analogously, in their study on Colombian flowers, Mytelka and Bortagaray (2006) show how the country has successfully managed to diversify its dominant natural resourcebased export product - coffee - by competing in the export market for non-traditional products such as flowers. In 2006, Colombia ranked second in the international market, only behind the Netherlands, while non-native varieties of cut flowers (e.g., roses and chrysanthemums) represented the country's top non-traditional export crop. The authors show, however, how Colombian efforts have fallen short in addressing the complex problems undermining the export growth of the flower industry in the long term, such as the need for higher productivity, the need for improving flower breeding capacity and the mastery of new floriculture techniques, especially for tropical flowers, and the need for integrating more efficient production techniques that would increase the variety of flowers cultivated, at the same time lowering production costs. Given the lack of adequate response to the global challenges in the nature of production and competition characterizing the flower sector worldwide, the Colombian cut flowers export boom is now under pressure, due to the inexorable erosion of its initial comparative advantages (Mytelka and Bortagaray, 2006).

In this context, the first hypothesis can be formulated, namely that, since the last quarter of the twentieth century, natural resource-based processing industries have become increasingly knowledge and innovation intensive; in the same period, this has opened up new windows of opportunity for developing countries. As observed in Chapter 1 , however, in order to explain how this could happen a "reconceptualization" 
of development in more systemic and innovation-oriented terms is needed (Gerschenkron, 1962; Abramovitz, 1994; Mytelka, 2000; Fagerberg and Godinho, 2004; Hall, 2007).33 According to Smith (2001), in traditional and natural resourcebased sectors, which are predominant in developing countries, knowledge intensity emerges from a systemic perspective, rather than from the observation of the behaviour of individual firms, and points to the need to look at the interactive and collective nature of innovation, its systemic qualities, and the uncertainty and unpredictability of its outcomes. In this sense, a key role in the innovation process is played by inter-firm networking dynamics and inter-institutional linkages, as well as by a variety of university-industry interactions, bringing different strands of knowledge together (Mytelka, 2004).34

From an evolutionary perspective, therefore, development is not about "individual product success stories", but about the capacity to establish interrelated technology systems in evolution, which generate synergies for a self-sustained growth process (Perez, 1988). Development is also escaping the chimera of the creation of brand new "high-tech" industries, and pursuing the internal transformation of industries which already exist, through a dynamic analytical framework that enables the identification of potential windows of opportunity for creating, distributing and maintaining advanced knowledge (Smith, 2001; Lorentzen, 2008; Andersen, 2009). The Innovation System (IS) approach, explored in the following section, provides such a framework.

\subsubsection{The Innovation System (IS) approach}

A system of innovation consists of "a network of economic agents together with the institutions and policies that influence their innovative behaviour and performance" (Lundvall, 1992; Nelson, 1994). It is such a network of formal and informal links embodied in an innovation system, which stimulates the transformation of the industrial structure and the development of local technological capabilities (Cimoli and Dosi, 1995). Embedded in the IS concept lie two fundamental and unconventional ideas: firstly, institutions have an important role to play in economic change. In this context, institutions are understood as "a set of common habits, routines, established practices, rules and laws, which regulate the relations and interactions between the main actors of the innovation system" (Edquist and Johnson, 1997). Secondly, the diffusion of basic innovation is a gradual process of incremental change (see Figure 2.2) and an exhaustive process of patient modification and revision of tremendous longterm impact (Rosenberg, 1976).

\footnotetext{
33 In their recent study on the relationship between innovation and economic development, Fagerberg, Srholec and Verspagen (2009) reiterate that, if taken in its broader sense, innovation is not a "typical first world activity" and may be as relevant in developing countries as elsewhere.

34 This is even more evident in the case of new products or technologies that have become more combinatorial in nature, such as those growing out of biotechnology. These require a wide range of knowledge inputs, as well as a strong science and engineering base (Mytelka, 2004).
} 
Undoubtedly, in the Schumpeterian tradition, growth is determined by the irruption of radically new technologies into the economic system - namely, by a process of "creative destruction" that is at the heart of long wave theory (Schumpeter, 1934). However, evolutionary economic theory also realizes the importance of small, incremental improvements that make innovation technically feasible. The basic assumption is that introducing something new in a new context always requires considerable adaptations, which drastically transform inventions as they were in their original form and may be even be more important, economically, than their initial availability (Kline and Rosenberg, 1986). Consequently, according to the influential work of Freeman (1987), technological learning cannot rely exclusively on the adoption of off-the-shelf technologies. It has to be complemented by the adaptation of new technologies to local conditions, factors and needs, based on incremental changes and tacit knowledge flows (Cimoli, 2000). These, as Pavitt puts it, constitute "the most important basis for innovation-based value creation" (Pavitt, 2002).

Figure 2.2 Evolution of a technological trajectory

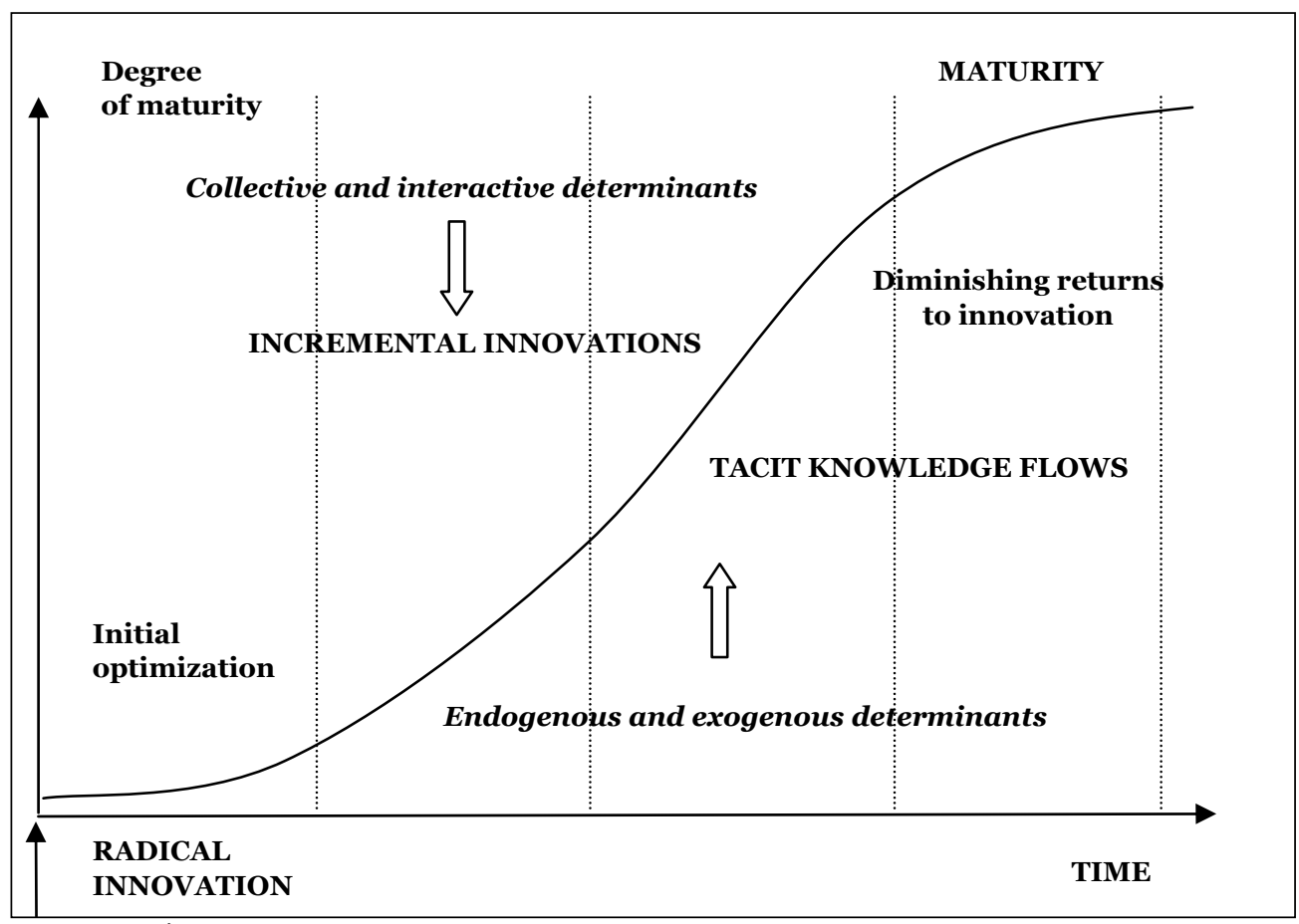

Source: Dosi, 1982

The evolutionary literature makes an important distinction between tacit and codified knowledge (Cowan and Foray, 1997). Inspired by Polanyi's (1966) work, such literature claims that knowledge goes far beyond what can be verbally expressed, and differentiates the knowledge that can be explicitly codified in blueprints, recipes, manuals, or in the form of formal training, from the tacit knowledge that remains idiosyncratic, context-specific, and "sticky" in nature (von Hippel, 1998). The latter requires considerable effort and cost to be acquired. The reason for this is that, unlike 
codified knowledge, tacit knowledge is difficult to exchange over long distances, does not travel easily and requires direct, face-to-face interactions between partners who already share some kind of basic commonalities (the same language, common cultural background, shared conventions and norms, etc.) for its effective production and transmission (Nonaka and Takeuchi, 1994).

From an evolutionary perspective, firms do not innovate in isolation. Innovation is a collective, cumulative and interactive process, involving a network of organizations, such as industry associations, universities and vocational training centres, standard setting bodies, R\&D centers, innovation and productivity centers, information gathering and analysis services, banking and other financing mechanisms. Firms are considered learning organizations embedded within a broader institutional context, which initially has been viewed as pre-eminently national (Nelson and Winter, 1982; Dosi, 1982 and 1984; Freeman, 1988; Freeman and Perez, 1988; Lundvall, 1988 and 1992). In the late 1980s, Freeman (1987) brought the concept of National Innovation Systems (NIS) into the literature, based on the seminal work of Friedrich List (1841), a sort of intellectual ancestor of the innovation system approach, who first imagined the concept of a national system of political economy and recommended that governments should play a proactive role in enhancing "national productive power".

The NIS framework is not only a holistic analytical tool, but also a particularly important policy-making tool. In a period of dynamic industrial and technological change fostered by globalization, knowledge creation and innovation are increasingly important, and countries seeking to design sustainable development strategies need a systemic policy framework to cope with the complexity and holistic nature of this challenge (Mytelka, 2000). In contrast to neoclassical economics, which sees knowledge and information flowing in a free and ubiquitous manner, evolutionary economics recognizes that learning between actors is an inherently social, dynamic process (Lundvall, 1992). This can be fostered by framework conditions that are conducive to innovation, but also by an adequate set of interrelated policies, including industrial policy, science and technology policy, education policy, labour market policy, social policy, energy policy and environmental policy (Lundvall et al., 2002). In particular, since the 1990s, innovation policies have started to be considered as a broader policy framework, addressing the interdependence of research, innovation and socioeconomic development.

Innovation policies are key to stimulating socio-economic development as they bring to the forefront the systemic coordination and correct linkages failures hampering the effective functioning of production systems (Soete, 2007). They are aimed at improving the competencies not only of innovating firms as individual, stand alone units, but also of suppliers, users, input and service providers, as well as of knowledge institutions such as universities, research institutions, technological centers and R\&D laboratories. As Lundvall and Borràs (2005) put it, in the systemic approach the institutional setup "differs across national economies and this has implications for what types of technologies and sectors thrive in the national context". This is why, in its early phase, the innovation system approach paid special attention to institutional competence building and organizational performance at the national level (Dosi and Malerba, 1996). 
Over the last decade, evolutionary scholars have continued to emphasize the systemic character of innovation but have also introduced other levels of analysis beyond the national one. In the 1990s, the literature on Regional Innovation Systems (RIS) has grown rapidly (Cooke, 1992, 1998 and 2001; Malmberg and Maskell, 1997; Howells, 1999; Asheim, 1995 and 2000).Practically at the same time the literature on Sectoral Innovation Systems (SIS) has also developed substantially (Malerba and Orsenigo, 1996; Malerba, 2001 and 2002; Marsili, 2001). A RIS is defined as "a localized network of actors in the public and private sectors whose activities and interactions generate, import, modify and diffuse new technologies" (Howells, 1999). A SIS is defined as "a set of new and established products for specific uses and the set of agents carrying out market and non-market interactions for the creation, production and sale of those products" (Malerba, 2002).

Networks and institutions, therefore, represent the main building blocks of both SIS and RIS. However, the latter stretch across several sectors in a regional rather than national economy and refer to a common knowledge base rooted in a territorial context rather than in specific product groups (Malmberg, 2003). The adoption of an increasingly fine-tuned systemic approach to innovation has led to the realization that there are different levels of analysis, all legitimate, complementary and equally important, and all linked to each other within a multilevel governance perspective (Cooke, 2004). Each one of these levels provides a decisive contribution to a better understanding of how new knowledge is generated and circulated, and how this affects the creation and diffusion of technological innovation, thereby illuminating the diverging performance of firms, regions, sectors and countries.

The RIS literature introduces a new, bottom-up approach to analyzing interorganizational learning, and acknowledges the role of embeddedness, cultural factors and social relations in the innovation process (Asheim, 1995). In particular, it emphasizes the importance of spatial proximity (that is to say, of short physical distance but also of affinity in a social or cultural sense) in the innovation process, as well as of the tacit knowledge deriving from proximity, such as localized knowledge spillovers (Cooke, 2001). The importance of proximity stems from the fact that it tends to facilitate the transfer of tacit knowledge by lowering transaction costs and encouraging cooperation among firms, thereby allowing the creation of localized knowledge spillovers, and innovation (Boschma, 2004; Malmberg and Power, 2005). This reinforces the importance of the specific social and institutional context in which tacit knowledge is produced (Gertler, 2003; Boschma, 2004; Asheim, 2005).35 According to Malmberg and Maskell (1996), trade patterns reflect the existence of localized knowledge spillovers and it is principally the learning abilities of innovation systems at the local level that explain their durability. As they explain:

When everyone has relatively easy access to codified knowledge, the creation of unique capabilities and products depends on the production and the use of tacit

\footnotetext{
35 In this respect, Nonaka and Takeuchi (1995) make the interesting argument that the process of conversion of codified knowledge to the local context encompasses four phases, namely socialization (tacit-tacit), externalization (tacit-explicit), combination (explicit-explicit) and internalization (explicit-tacit).
} 
knowledge. [...] One effect of ongoing liberalization is that many previously localized capabilities and production factors become ubiquitous. What is not ubiquified is the non-tradable/non-codifiable result of knowledge creation - the embedded tacit knowledge that at a given time can only be produced in practice. The fundamental exchange inability of this type of knowledge increases its importance as the internationalization of markets proceeds (Malmberg and Maskell, 1999, p.172).

The SIS approach recommends paying more attention to the role of non-firm organizations and learning institutions at the sectoral level, to the knowledge and learning processes of firms and the wide range of relations among them, and to the transformation of sectors in their boundaries, actors, products and structure (Malerba, 2002). Furthermore, the SIS literature emphasizes the role of demand for innovation and export specialization, and as a powerful incentive to stimulate the behaviour of economic actors (Andersen, 1994; Lundvall et al., 2002). ${ }^{36}$ According to Malerba, differences in demand conditions may play a major role in explaining differences in firms' competencies, behaviour and organization (Malerba, 1999). In particular, he claims that a certain technological demand defines the nature of the problems that firms have to address in their innovative and production activities, and the types of incentives and constraints with respect to a particular behaviour and organization. Thus, when demand conditions are combined with some basic features of knowledge and technology, the effect on firms' behaviour and organization can be significant (Breshnan, 1991).

The literature on SIS relates three key dimensions of knowledge - opportunity, appropriability and cumulativeness - to the notion of a technological and learning regime, defined as the knowledge environment in which firms operate (Nelson and Winter, 1982). The concept of "opportunity" refers to the likelihood of successful innovation; "appropriability" to the possibility of protecting innovations from imitation and of reaping profits from innovative activities; and "cumulativeness" to the degree to which the generation of new knowledge builds upon current knowledge (Malerba, 2002). If one takes the old view of natural resource-based sectors, their technology regime is characterized by low degrees of opportunity, appropriability and firm-level cumulativeness, and opportunities for innovation are typically confined to the objective of lowering production costs by introducing new raw materials, new process machinery or quality control schemes (Coenen et al., 2005). Since these become quickly available everywhere and at the same costs, the competitive advantages of the innovators are gradually and ineluctably eroded (Malmberg and Maskell, 1999).

\footnotetext{
${ }^{36}$ As early as in the 1960 , a series of empirical studies in the neoclassical literature found that the homemarket played an important role in explaining the export specialization of countries (Vernon, 1966; Linder, 1961; Posner, 1961). In the 1970s, the studies of Chenery and Syrquin (1975) identified a dominant share of domestic demand in the growth of domestic industrial output. In the 1990s, the evolutionary literature paid renewed attention to the role of demand, highlighting that domestic market size is only one of several factors that may contribute to explaining different development performances across countries (Fagerberg, 1994). Pushing further this line of reasoning, in the 1990s Porter (1998) emphasized the importance of a pool of sophisticated local customers (in contrast to remote buyers), and of specialized local demand in enhancing productivity and innovation at the firm level, especially when these are located in close geographic proximity.
} 
According to Malerba (2004), the sources of innovation and technological change are sector-specific, as much as any other sectoral competencies and characteristics. ${ }^{37}$ If the technological characteristics of the sector are combined with its dominant structure, a positioning matrix for different sectors can be obtained, based on Pavitt's (1984) original taxonomy of sectoral patterns for the acquisition of innovative knowledge (see Table 2.1). In his renowned study on the sectoral patterns of technical change, Pavitt (1984) identifies similarities and differences amongst sectors in terms of the source and nature of knowledge inputs, the size of innovating firms, and the possibilities for appropriation. The starting point of his reasoning is, in fact, the consideration that the original neo-classical formulation, according to which disembodied technological change is considered a residual factor, ignores the variety and importance of the potential sources of innovation and neglects the dynamic relationship that exists between technology and sectoral structure in a modern economy.

Table 2.1 Sectoral characteristics and sources of innovation

\begin{tabular}{|c|c|c|}
\hline $\begin{array}{c}\text { Sectoral } \\
\text { characteristic }\end{array}$ & Sectors & Main sources of innovation \\
\hline Supplier-dominated & $\begin{array}{l}\text { Traditional (textiles, } \\
\text { footwear, furniture, glass, } \\
\text { toys) and natural } \\
\text { resource-based } \\
\text { (agroindustry, wood and } \\
\text { leather, oil-refining and } \\
\text { rubber products) }\end{array}$ & $\begin{array}{l}\text { Most innovations are created by upstream suppliers } \\
\text { (chemicals, machinery, equipment, etc.) and by } \\
\text { regulation and quality standards. There is a high degree } \\
\text { of dependence on external sources for process } \\
\text { technology and a relatively small proportion of } \\
\text { innovative activity devoted to product innovations. }\end{array}$ \\
\hline $\begin{array}{l}\text { Production- } \\
\text { intensive }\end{array}$ & $\begin{array}{l}\text { Automotive, chemical, } \\
\text { metallurgy and machinery } \\
\text { industry }\end{array}$ & $\begin{array}{l}\text { Innovations are generated in areas related to the } \\
\text { planning, building and management of complex } \\
\text { systems of production or products for the value chain, } \\
\text { mainly through corporate R\&D activities, and in } \\
\text { particular through production engineering } \\
\text { departments. }\end{array}$ \\
\hline Science-based & $\begin{array}{l}\text { Electronics, } \\
\text { pharmaceuticals, } \\
\text { biotechnology, precision } \\
\text { instruments, aerospace }\end{array}$ & $\begin{array}{l}\text { Innovation is linked to firms' wide-ranging internal } \\
\text { R\&D activities and to the degree of interaction with } \\
\text { research bodies and universities, based on the rapid } \\
\text { advances of the underlying sciences. Firms produce a } \\
\text { high proportion of their process and product } \\
\text { technologies. }\end{array}$ \\
\hline
\end{tabular}

Source: Pavitt (1984)

\footnotetext{
${ }^{37}$ According to Malerba (2002), differences in the organization of innovative activities at the sectoral level may be related to a fundamental distinction between "Schumpeter Mark I" and "Schumpeter Mark II" models. Schumpeter Mark I is characterized by "creative destruction" with technological ease of entry and a major role played by entrepreneurs and new firms in innovative activities. Schumpeter Mark II is characterized by "creative accumulation", with the prevalence of large established firms and the presence of relevant barriers to entry for new innovators. The presence of major knowledge, technological and market discontinuities may signify that a Schumpeter Mark I model has recently replaced a Schumpeter Mark II model. This is the case when "a rather stable organization characterized by incumbents with monopolistic power is displaced by a more turbulent one with new firms using the new technology or focusing on the new demand" (Malerba and Orsenigo, 1996).
} 
It is interesting to note that in Pavitt's taxonomy, natural resource-based sectors have been classified as supplier-dominated sectors, where the main sources of technical knowledge were supposed to be located outside the firm. Malerba has also adopted the same view, and, referring to natural resource-based sectors, has highlighted the need to pay attention to the extent to which linkages are created between firms and upstream suppliers of machinery and equipment, as well as to regulatory and quality standards organizations both at the national and international levels. For example, in agroprocessing industries an important role has been traditionally played not only by quality certification and food safety requirements - i.e., the sanitary and phytosanitary measures (SPS) implemented by the World Trade Organization - but also by an increasing variety of environmental and social standards (Goedhuys, Janz and Mohnen, 2008). Developing countries have faced rising difficulties in meeting such standards, to the point that these have often been regarded as a form of non-tariff barriers imposed by developed countries to protect their markets (UNCTAD, 2008).

In the absence of suppliers that can produce to these quality standards, large firms tend to "verticalize", to acquire direct control of production in all its phases. They also tend to generate a high proportion of process technologies in-house, or alternatively to bring such technologies from outside (Pavitt, 1984). This leads to emphasize that an increasingly higher proportion of $\mathrm{R} \& \mathrm{D}$ around the world takes place within the broad networks of TNCs, which therefore are in a position to shape the direction and pace of technological change worldwide and to transform the global patterns of technology generation and control based on their interests and needs, which often do not necessarily correspond to the interests of host countries (Mytelka, 2000; Lall and Urata, 2003; UNCTAD, 2007b). This explains why natural resource-based sectors have been traditionally considered "enclaves" dominated by TNCs, creating a limited amount of forward and backward linkages and technological spillover effects on local firms. ${ }^{38}$ In this regard, Fu, Pietrobelli and Soete (2011) remind us that TNCs are not "an unalloyed blessing" in building technological capabilities in developing countries, while Lall (2001) warns us that technology upgrading depends on substantial and well directed domestic technological efforts and on the knowledge base of local firms. Following Pietrobelli and Rabellotti (2004), the term "technological upgrading" is used here to refer to the capacity to shift from lower to higher value-added economic activities by introducing continuous innovation in process, products and functions. Along the same lines, Bell and Pavitt (1993) argue:

The accumulation of technological capabilities necessary to reduce the gap between developed and developing countries involves more than the acquisition of

\footnotetext{
$3^{8}$ From a development perspective, it is important to highlight that TNC outsourcing strategies are no longer based merely on existing comparative advantages of host countries and focussed on pure assembly activities (Cimoli et al., 2005). Rather, TNCs are now expanding and internationalizing also their R\&D activities in order to keep up with rising demand for new technologies and to meet the demand of emerging and dynamic markets (UNCTAD, 2007b). In order to fully grasp the benefits of this new type of knowledge-based outsourcing, host (developing) countries need to put in place dynamic innovation systems that enable them to seize potential opportunities, to promote high levels of human capital formation on a continuous basis, and to own capabilities of mastering physical and cultural distances with headquarters (Cimoli et al., 2005).
} 
machinery or product design, often obtained after policies of trade liberalization. It also involves continuing, often incremental changes and the improvement of imported technologies by local actors (Bell and Pavitt, 1993, p.42).

According to Cohen and Levinthal (1989), the ability of firms to exploit external knowledge always represents a critical component of their innovative capabilities, and is actually a function of what they call "prior related knowledge". This is a prior accumulation of knowledge in the same or similar areas, conferring the capability of identifying the value of new information, assimilating it, and applying it to commercial ends. These abilities constitute a firm's or a sector's "absorptive capacity". According to Lindsay and Norman (1977), the foundation of the notion of absorptive capacity is that a certain amount of prior related knowledge is needed to assimilate and use new knowledge. Knowledge may be nominally acquired but not well utilized subsequently because individuals within the organization were not equipped with the appropriate contextual knowledge necessary to make the new information fully intelligible.

The absorptive capacity of a firm or sector, therefore, depends on a number of internal factors such as the presence of scientifically and technologically skilled human resources, the level of internal $R \& D$ allowing internal staff to interact effectively with research institutions and external knowledge sources, and the attitude of local consumers. ${ }^{39}$ In particular, according to Soete (2007), local consumers may be "very open to new designs, products, even ideas, enabling rapid diffusion of such new products created by $R \& D$ in knowledge intensive sectors, or very conservative, resistant to change and suspicious of novelty".

In line with the evolutionary tradition, therefore, the second hypothesis can be formulated, namely that in order to enter natural resource-based processing industries, the capability of developing countries to access foreign knowledge and technology from abroad is critical; however, the creation of endogenous capabilities to innovate is key to absorbing and adapting them to the local environment. It is, therefore, imperative to look at non-local connections and productive interactions with external actors, both nationally and internationally, as much as at the role of spatial proximity and geographic concentration at the regional and local (cluster) level. As Mytelka (2000) puts it:

In building the system wide capabilities required to access information and use new knowledge most effectively for innovation, managing the interface between the global and the local is critical (Mytelka, 200o, p.17).

\subsubsection{The cluster approach}

According to Asheim and Gertler (2005), "the more knowledge intensive the economic activity, the more geographically clustered it tends to be". Natural resource-based

\footnotetext{
39 Even though Cohen and Levinthal mainly restricted their considerations to firms, at a more aggregate level these may equally apply to sectors, regions or countries (Fagerberg, Srholec and Verspagen, 2009).
} 
industries are almost always geographically clustered, as they are often concentrated in the spatially defined territory in which natural factors have generated them or in areas where fertile land is available, due to cost advantage reasons (Ellison and Glaeser, 1999). Clusters have been defined as "a form of network that occurs within a geographic location, in which the proximity of firms and institutions ensures certain forms of commonality and increases the frequency and impact of interactions" (Porter, 1990), as well as "a set of economic actors concentrated along a sectoral value chain or agglomerations of specialized firms and related suppliers within a geographically delimited space” (Porter, 1998). From a geographical perspective, however, clusters are not formal administrative units; the determination of their boundaries is an issue that has been debated at length in the literature, and has to rely on the use of both statistical methods and qualitative observations (Sforzi, 2005).

The literature almost unanimously acknowledges that clusters may become important sources of externalities, which are key to promoting local competitive advantages and sustaining competitiveness in the long term (Porter, 1990; Krugman, 1991; Saxenian, 1996; Enright, 2000). ${ }^{\circ}$ However, in natural resource-based sectors these may not be automatic and, in a developing country context, may emerge later on in the industrialization process, be it in order to answer specific needs for collective action and interactive learning, or in order to respond to the threats of a crisis. In this sense, several authors in the literature see clusters as a way of promoting economic development and of catalyzing growth (Schmitz and Nadvi, 1999; Altenburg and MeyerStamer, 1999; Humphrey and Schmitz, 2002; Pietrobelli and Rabellotti, 2003; Giuliani, Pietrobelli and Rabellotti, 2005).

Reference is made here to Marshall's original work, suggesting that the accumulation of knowledge, skills and know-how takes place within spatially delimited contexts, promoting a kind of "industrial atmosphere" (a mix of competence, skills, entrepreneurial ability, trust and a sense of community) capable of enhancing economic growth (Marshall, 1920). In this context, Marshall refers to a process of cumulative local know-how, or collective learning, which positively affects innovation and knowledge creation, opening up possibilities which individual producers could not attain working alone (Schmitz, 1982; Piore and Sabel, 1984; Pyke and Sengerberger, 1992). ${ }^{41}$ The phenomenon of clustering is actually enhanced by "a shared social and cultural environment from which develop common routines, norms and standards which depend upon trust and the willingness to cooperate" (Amin and Wilkinson, 1999). This explains why Becattini - the scholar who pioneered the study of industrial districts in the early 1970s, referring to what became known later on as the "Third Italy"

\footnotetext{
40 Among others, the main externalities generated by clusters are human resource pooling; the development of specialized markets for inputs and machinery; access to information, performance benchmarks and specialized knowledge on technologies and markets; the availability of infrastructure and the friendliness of the business environment; and the complementarity of goods or services produced and of market access (Brugnoli, 2005).

${ }^{41}$ According to Marshall's own words, "when an industry has chosen a locality for itself it is likely to stay there long: so great are the advantages which people following the same skilled trade get from near neighborhood to one another. The mysteries of trade become no mysteries, but are as it were in the air, and children learn many of them, unconsciously" (p.225).
} 
(Bagnasco, 1977; Becattini, 1979; Brusco, 1982; Garofoli, 1991; Becattini and Rullani, 1993), and who revived Marshall's notion of agglomeration economies based on small firms as an alternative form of industrial organization - defines clusters as "socioterritorial entities which are characterized by the active presence of both a community and a population of firms in one naturally and historically bounded area, and where, unlike in other environments, community and firms tend to merge" (Becattini, 1990).

One of the major characteristics of clusters is the existence of strong horizontal networking dynamics, rooted in a specific territory and nurtured by proximity effects, which are indispensable for strengthening competitive advantages at the local level..$^{42}$ In particular, clusters can be considered crucial in facilitating the creation of sustained competitive advantages and export capacities over time, that tend to vary directly with the degree of agglomeration and specialization, mostly of small and medium-sized enterprises (SMEs). 43 The literature provides several case studies on the role of clusters as a driving force for sustained export growth in natural resource-based industries in the context of developing countries (Mytelka, Farinelli and Taye, 1999; Buitelaar, 2000; Perez-Aleman 2005).

Considering only the Latin American continent, for example, informative cases in this respect are the farmed salmon cluster in Chile (Montero, 2004; Perez-Aleman, 2005); the mining clusters in Peru (Torres-Zorrilla, 2000; Kuramoto, 2001), Chile (Bas et al., 2008) and Brazil (Batista, 2001); the cut flowers and sugarcane clusters in Colombia (Mytelka and Boratgaray, 2006; Millan Constain, 2002); the dairy products cluster in Argentina (Casaburi, 1999); and the wine clusters in Chile (Giuliani, 2003; Visser, 2004), Argentina (McDermott, 2005; Farinelli 2007) and Brazil (Vargas 2001; Vargas et al, 2005). In 2010, FAO, the United Nations Food and Agriculture Organization, devoted an entire report to the issue of how to enhance the competitiveness of agrobased clusters in developing countries, including several cases from Latin America (FAO, 2010).

However, one should not forget that clusters are not a magic recipe for all policymaking purposes, despite the fact that they have recently come to be seen as a sort of panacea by renowned academics, international organizations and development practitioners. Martin and Sunley (2003), for example, argue that the cluster approach has become exaggeratedly fashionable, as it is "a peculiarly elusive and hard to pin down concept".

\footnotetext{
${ }^{42}$ Clustering is pre-eminently a spatial and territorial concept, while networking is most often used to describe arms-length formal and informal cooperation among firms, taking forms such as knowledge exchange, commercial relationships, leasing and strategic alliances. The two concepts often overlap, since one of the major characteristics of clusters is the existence of strong horizontal networks of firms that result in flexible specialization and subcontracting arrangements (UNCTAD, 1998).

43 Despite the wide recognition that SMEs are numerically significant economic actors, their importance in the context of innovation systems is often overlooked. However, in developing countries most suppliers in natural resource-based industries are SMEs, whose technological capabilities and backward and forward linkages are poorly developed. According to Mytelka (2004), clusters offer unique opportunities for SMEs to engage in linkages that stimulate learning and innovation, as clearly shown by the experience of the South East Asian NIEs, where competitive SMEs, acting as subcontractors to overseas clients or to large local firms, are behind the successful export growth described in previous sections.
} 
There are also a series of negative aspects and potential disadvantages of clusters, which, they caution, should not be overlooked and stand in contrast to their claimed advantages. According to the authors, these are, among others: technological isomorphism, labour cost inflation, rising land and housing costs, widening of income disparities; over-specialization, institutional and industrial lock-in, and local congestion and environmental pressure.

The literature shows that the disadvantages of clusters, clearly identified by Martin and Sunley (2003), may predominate over potential advantages and that not all clusters are necessarily innovative or dynamic (UNCTAD, 1998).44 Some of them are caught in a spiral of stagnation and decline; some others never reach their potential and remain at the embryonic stage (Schmitz, 1995; Schmitz and Nadvi, 1999). While geographical proximity always brings along some minimal exchange of information, it does not automatically imply a process of collaboration, knowledge sharing or technological capacity building (Saxenian, 1996). Similarly, the presence of passive externalities, such as the availability of a pool of skilled labour or the stimulus of emulation, do not guarantee the presence of the critical actors needed to form a dynamic system, nor the intense formal and informal cooperation which may lead to collective efficiency and the capacity to produce endogenous and continuous innovation (McCormick, 1999; UNCTAD, 2003; Oyelaran-Oyeyinka and McCormick, 2007).

Only when clusters are effectively organized are they believed to offer unique opportunities to engage in the wide array of domestic linkages between users and producers, and between the knowledge producing sectors (universities and R\&D institutions) and the goods and services producing sectors of an economy that stimulate learning and innovation (Mytelka and Farinelli, 2000). Reference here is made to earlier work on clusters in developing countries, where a distinction was formulated between informal and organized clusters. Informal clusters generally contain micro and small firms whose technology level is low relative to the industry frontier and whose owners have weak management capabilities. Their workers are generally low skilled, and little or no continuous learning takes place for sustained skills upgrading. Although low barriers to entry may lead to growth in a number of firms located there, this does not necessarily reflect a positive dynamic as measured by the upgrading of management skills, investment in new process technology, machinery and equipment, improvement in product quality, product diversification or the development of exports.

Moreover, in informal clusters the nature of coordination and networking among firms located tends to be low and is characterized by a limited growth perspective, often cutthroat competition, little trust and little information sharing. Poor infrastructure; the absence of critical services and support structures, such as banking and financial services, productivity centers and training programmes; weak backward, horizontal and

\footnotetext{
44 In their particularly hard-hitting article entitled "Deconstructing clusters : chaotic concept or policy panacea?", Martin and Sunley (2003) argue that the cluster concept "has been so widely applied that its explanation of causality and determination has become overly stretched, thin and fractured". Thus, they foresee the future decline of its popularity, quoting Santayana (1913) who claimed that "fashionable ideas tend to share one thing in common, namely that they all eventually become unfashionable" (!).
} 
forward linkages; and a lack of information on foreign markets tend to reinforce this low growth dynamic. On the contrary, organized clusters are characterized by a process of collective activity, mainly oriented towards the provision of infrastructure and services, and the development of organizational structures designed to analyze and provide the channels to face common problems. Although most firms in these clusters are small, some have grown to medium-size and their competence level has improved through training and apprenticeship.

In terms of technological capability, firms in organized clusters have also upgraded, though few are close to the frontier. Such firms also exhibit the capacity of undertaking technology adaptations, designing new products and processes, and of bringing them quickly to market. What distinguishes organized clusters is the cooperation and networking that has emerged among member firms. These tend to accrue both formally (through agreements and contracts) and informally (through peer pressure and public good externalities) when consciously pursued forms of inter-firm and private-public sector linkages are put in place, namely deliberate joint actions, which can be of at least four distinct types (Schmitz and Nadvi, 1999):

- Joint action within vertical linkages, including backward ties and networks with suppliers and subcontractors, as well as forward ties with traders and buyers;

- Joint action within horizontal linkages between two or more local producers (including joint marketing of products, joint purchase of inputs, order sharing, common use of specialized equipment, joint product development);

- Joint action within institutional linkages among a large number of local producers and cluster-wide institutions (including business associations and business development services); and

- Public-private sector partnerships.

Although organized clusters have the potential to be innovative, the presence of organizational structures and deliberate joint actions are preliminary conditions, not guarantees, for innovation to take place, and especially for this to be sustained over time. Continuous innovation is unanimously considered by the literature to be a vital characteristic of clusters and a pre-condition for their sustainable growth (Piore and Sabel, 1984). Very interestingly, Becattini (1990) argues that an industrial district is either creative and innovative, or it is not a true industrial district. The "Marshallian anomalies", as he likes to define the complex of ideas that gravitate around the notion of an industrial district, contain an explicit reference to the social and dynamic concept wherein the process of growth of innovation and intellectual abilities is the specific engine that drives the human aspects of economic history (Becattini, 1990). In this sense, clusters do not represent a stable (nor static) organizational model of industrial production, and development and change should be looked upon as a "natural" part of their history (Asheim, 1995).

The cluster literature shows, however, that the potential benefits of agglomeration economies in promoting innovation mainly concern incremental innovations (as 
opposed to radical innovations) brought about by the presence of localized knowledge externalities, learning-by-doing, by-using and by-interacting practices, and by tacit knowledge flows (Lundvall 1998; Feldman and Francis, 2004). Following the Marshallian perspective, several authors note that clusters can more easily generate innovations by incremental steps - through a gradual improvement of the final product, of the process, and of the overall organization of production - but often face difficulties in dealing with "technological ruptures" (Bianchi, 1994; Garofoli, 1991). More specifically, it can be argued that the inability of SMEs located in clusters to break away from a technological path dependency and change technological trajectories through radical innovations is at the origin of the gradual stagnation or sudden decline of a cluster, which, in their irreversible form, can lead to a cluster's "entropic death" (Camagni, 1991; Krugman, 1991; Asheim, 1995).

From the above, it emerges that the sustained innovative capacity of a cluster does not automatically result from market automatisms. Crevoisier emphasizes the importance of understanding how clusters perform in the process of generating radical innovations, and argues that "without making this point clear, it is not possible to make any prediction about the reproduction and the duration of such systems" (Crevoisier, 1994). He also argues that "the reliance on incremental innovation would mean that these areas would very quickly exhaust the technical paradigm on which they are founded" (Crevoisier, 2004). Radical innovations, however, require substantial investments in R\&D and institutional capacity, implying a broader, systemic institutional approach to innovation. In their study aimed at identifying the key "ingredients" or - as they call them - the deep regularities of cluster formation and expansion, Breshnan, Gambardella and Saxenian (2001) take as a reference the successful and renowned case of Silicon Valley to make the observation that:

The transition from the early phase of cluster emergence to a well structured cluster yielding positive network effects implies a long and risky process of firm building and market building. In other words, the mere growth in the number of firms located in a cluster is unlikely to give rise to those agglomeration economies associated with existing successful regions, unless coupled with significant and systematic efforts and investments to build the organizational and technological capabilities required for growth, and to nurture those institutions that fuel the development of a cluster (Breshnan, Gambardella and Saxenian, 2001, p.22).

In this sense, the cluster and innovation system approaches can be considered as potentially complementary (Anderson et al., 2004). On the one hand, the cluster approach has a natural inclination to be industry and demand specific, and to study the way that micro interactions occurring on a daily basis shape local competitive relations. On the other hand, the innovation system approach focuses on the mechanisms for generating innovation, including the macro framework supporting technological development at the national level, the institutional environment generating localized learning capabilities at the regional level, and the incentive structures for innovation that are highly sectoral specific. Additionally, the innovation system approach emphasizes the need for natural resource-based industries to move from comparative to constructed advantages, preferably at the regional level, whereby competitiveness 
factors are locally constructed based on knowledge and innovation rather than natural endowments (Cooke and Leydesdorff, 2006).

Indeed, a considerable overlap exists between regional innovation systems (RIS) and clusters, given their common territorial perspective. However, RIS relate to the boundaries of an administrative region (Cooke, 2003), while clusters refer to the notion of a functional region (Malmberg, 2003). RIS can stretch across several sectors and clusters in the regional economy, provided that firms and knowledge organizations interact in a systemic manner (Asheim et al., 2005). According to Cooke (2005), " $a$ well-blessed regional innovation system will not be dependent on a mono-industrial base. As well as multiple industry sectors, a region may have some clusters; naturally not all industry is organized in clusters".

Therefore, the third hypothesis can be formulated, namely that sustained export growth in natural resource-based processing industries is linked to the transformation of clusters from informal to organized; and that the interaction of organized clusters with broader regional innovation systems is equally important. These are key to strengthening a cluster's capacity to create continuous endogenous innovation (especially of a radical nature), and to counterbalancing technological path dependency traps that are well known in the literature (Lyberaki and Pesmazoglou, 1994; Asheim, 1995).

\subsection{Hypotheses to be tested}

The literature review contained in Chapter 1 and the analytical framework outlined in the previous sections have explored three sets of analytical issues:

- The potential growth impact of natural resource-based processing sectors, their knowledge intensity from a systemic perspective, and their capability of stimulating learning and innovation;

- The importance of external and internal sources of innovation, as well as of tacit knowledge and incremental innovations, in strengthening the competitive performance of natural resource-based processing sectors; and

- The relationship between clusters, regional innovation systems and sustained export growth in natural resource-based processing sectors, and the generation of collective efficiencies and networking dynamics.

In this respect, some controversial and counter-intuitive elements have emerged from the literature review. Firstly, according to the resource curse theory, natural resourceabundant countries tend to perform more poorly in terms of growth than resource-poor countries. However, successful examples from developed countries rich in natural resources seem to contradict this theory. As anticipated in Chapter 1, the literature shows that when natural resources have been used as a platform to build networks of innovation among institutions, and to create upstream and downstream linkages 
among firms, economic rents have not declined along with decreases in primary commodity prices, and natural resources have become engines of growth for the rest of the economy (Andersen, 2009; Perez et al., 2010). The issue that is controversial relates to the replicability of such a complex transformation in developing countries, despite the low intensity of backward and forward linkages in their productive system, and the weaknesses in their technological capabilities.

Secondly, in the SIS literature natural resource-based sectors are considered supplier dominated sectors, where the main sources of innovation and technical knowledge are located outside the firm. However, many resource-based industries have become knowledge intensive and highly differentiated sectors, as the discussion on flowers in Colombia and salmon in Chile, contained in Chapter 1, clearly shows. There is, therefore, a need to adjust the basic assumptions in Pavitt's taxonomy of the sectoral patterns for the acquisition of innovative knowledge (Pavitt, 1984), according to which innovation in natural resource-based sectors (e.g., agro-food) would originate mainly, in not exclusively, from sources that are external to the firm.

Similarly, according to Malerba's sectoral classification (Malerba, 2004), in natural resource-based sectors innovation is mainly confined to productive processes and would originate from a few and highly dispersed innovative firms. To the contrary, there is evidence to show that in such sectors the sources of innovation located inside the firm play an increasingly important role, since the technological reliance on suppliers of machinery has been gradually overtaken by the need to apply sophisticated technologies to areas such as product design, smart materials and packaging, biotechnology applied to the development of new materials, which firms have to master internally to a large extent (Smith, 2001; Mytelka, 2004; von Tunzelmann and Acha, 2005).

Thirdly, the cluster literature has tended to ignore - and therefore to underplay - the role of spatial proximity in natural resource-based sectors, due to the consideration that in such sectors spatial agglomeration is forced by nature, and is not a deliberate choice of firms justified by commonly perceived advantages related to economies of scale and scope. Since the 1990s, this has gradually changed, and scholars have started to point to the positive contribution of clustering dynamics to the export performance of natural resource-based products. In particular, they have pointed to the generation of interfirm technological spillovers as an important differentiating factor concerning the development and future prospects of natural resource-based clusters (Ellison and Glaeser, 1999). However, they have paid attention almost exclusively to the patterns of collective learning and incremental innovation processes taking place within clusters, as if they were self-contained entities (Perez-Aleman, 2005). The ways in which natural resource-based clusters can avoid incurring technological isolation, leading to "lock-in" and "entropic death" phenomena (Camagni, 1991; Cohen at al., 2005), and benefit from regional constructed advantages, has been surprisingly overlooked by the cluster literature (Cooke, 2003; Giuliani, 2003).

Against this background, the empirical work of this thesis is aimed at exploring the following three hypotheses and related sub-hypotheses: 


\section{Hypothesis I}

(a) In the last quarter of the twentieth century, natural resource-based processing industries have become knowledge and innovation intensive.

(b) This has opened up new windows of opportunity to developing countries.

\section{Hypothesis II}

(a) In order to enter natural resource-based processing industries, the capability of developing countries to access foreign knowledge and technology from abroad is crucial.

(b) The creation of endogenous capabilities to innovate is key to absorbing and adapting them to the local environment.

\section{Hypothesis III}

(a) Sustained export growth in natural resource-based processing industries is linked to the transformation of natural resource-based clusters from informal into organized clusters.

(b) The interaction of organized clusters with broader regional innovation systems is equally important.

Should these be confirmed, interesting windows of opportunity might open up for developing countries with a tradition of pure extraction and exploitation of natural resources, or of manufacturing production locked in the cheap end of the market. We would also be in the presence of a phenomenon of historical relevance. As early as 1867, Karl Marx in the first volume of the Capital recognized that natural resources "may be looked at from the two points of view of quality and quantity. It is an assemblage of many properties, and may therefore be of use in various ways. [...] To discover the various uses of things is the work of history" (Marx, 1867).

\subsection{Empirical work}

\subsubsection{Selection of comparative case studies}

To carry out the empirical work of the thesis, two case studies have been selected in the wine industry, namely those of Chile and Argentina. Against the theoretical background outlined in Chapter 1, the selection of these case studies has enabled the collection of the empirical evidence needed to explore the three hypotheses stated above. Among all natural resource-based processed products, the wine industry has been selected because it is growing rapidly worldwide, and is characterized by complex technological change and a sustained increase in knowledge intensity (Smith, 2007). Wine also 
represents one of the most emblematic processed agricultural commodities, as it is at the forefront of a path of "de-commodification" that has been closely followed by others, which are now at the same stage of development as wine was ten years ago in terms of product branding, differentiation and certification. 45 Furthermore, if one takes into account its "dual integrated nature", the wine industry may generate a considerable amount of backward and forward linkages, including linkages with the primary sector, which have a wide range of applications also in other industries (see Figure 2.3). It is therefore an ideal case to show how, to use Hirschman's words (1981) "development is essentially the record of how one thing leads to another" and how the creation of linkages between related economic activities, namely between the production and processing of natural resources, may be key to this process.

Figure 2.3 Backward and forward linkages from the wine industry

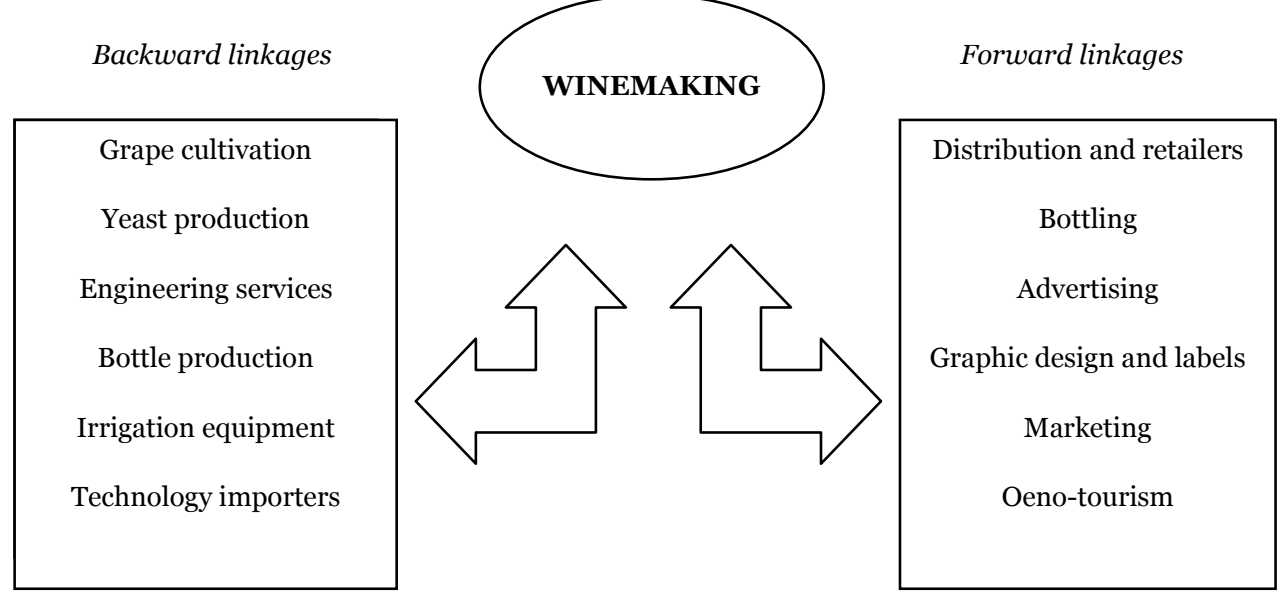

Source: Author's elaboration

From a pure commodity, wine has evolved into a highly diversified product, covering the entire quality spectrum - from cheap standardized drink for everyday consumption to luxury consumer good. In the last three decades, there have been major changes in product quality and value per unit among wine producers who have chosen innovationbased strategies. As a consequence, the wine industry has been characterized by changing shares of world output and trade and by high rates of entry, both at the firm level and at the country level, despite the rising barriers created by increasingly high quality, product differentiation and certification requirements. This is surprising, given the longstanding hegemony of a relatively small group of developed countries, such as

\footnotetext{
45 Until a decade ago, wine seemed to be quite an isolated case among processed agricultural commodities, characterized by a unique range of varieties and quality levels. It is now clear that products such as coffee, tea and cacao have the potential to become equally if not more diversified and to occupy equally high market segments. According to the CEO of Nestlé, cited in Kaplinky and Fitter (2004), "There are as many varieties of coffee, with a greater variation in taste, than there are of wines”...
} 
France, Italy and Spain (so-called “Old World" producers), which have dominated the sector for centuries.

Wine is a century-old product and may well be considered one of "the most civilized thing [s] in the world" (Hemingway, 1934). However, the wine industry has become a battleground of conflicting forces that in the future may radically change its nature. On the one hand, as many other food industries, it has become increasingly globalized and oriented toward mass production (Matthews, 2000; Nossiter, 2009) - to the point that a small number of winemaking giants, operating at the global level, are making it difficult for a myriad of small wine producers, specialized retailers and "boutique" wineries to survive and grow. Furthermore, extremely homogenous, "Coca-Cola-like" wines, conceived for large distribution in supermarkets, are outcompeting wines that differ across regions, vary from year to year, and are produced in limited and uncertain quantities. And passionate, colourful and sometimes solitary wine producers are finding it difficult to hold their own in a system where very few specialist magazines, a small number of eccentric personalities and four renowned wine critics (i.e., James Halliday in Australia, Hugh Johnson and Jancis Robinson in the UK, and Robert Parker in the United States) are able to influence the public opinion around the world (Jenster at al., 2008).

On the other hand, international consumers are also paying increasing attention to wines produced by small wineries, reflecting the local terroir, the local habits, the local history and the local vocation of the territories where they are produced (Veseth, 2011). For all of these reasons, considering its long history and importance to Western civilization and culture, the wine industry is an ideal case to understand whether, in the global economy, there exists an economically sustainable way of drawing benefits from the availability of natural resources. It is also an ideal case to assess whether, in an increasingly fast-paced, urbanized and standardized economic context, it is possible to build on the concepts of roots, memory and local identity in a way that is valued by international consumers, compatible with market forces and profitable for local producers (Trubek, 2008). Finally, considering the surge of foreign investment and takeovers in the wine industry worldwide, it is an ideal case to analyze whether in natural resource-based processing sectors, developing countries can emerge as globally competitive players and leading producers in their own right, or whether they are condemned to remain FDI-driven industrial latecomers (Anderson, 2005).

Bearing in mind the above, this thesis focuses on two case studies, namely Chile and Argentina, which represent two successful wine producers from developing countries (see Figure 2.4). Strikingly, both have managed to enter the industry, to sustain their competitive positions, and to increase their market shares, representing interesting examples of successful export growth of a natural resource-based industry, despite the presence of a well-established group of dominant players from advanced countries. As Chapter 3 will illustrate more in detail, this includes all the so-called "Old World" producers, such as France, Italy and Spain, which have traditionally dominated the wine market, but also a number of so-called "New World" producers, such as Australia, the United States and New Zealand, whose collective share of global wine exports jumped from 3 percent to 20 percent in less than two decades. 
From an academic perspective, the examples of Argentina and Chile are of particular interest because their very entrance into the global market of export wines was far from predictable. From a traditional sector totally oriented to the domestic market and in deep crisis due to political and economic instability, the Chilean wine industry has gained international recognition since the early 1980s, and has become, together with other non-traditional industries, such as salmon, completely export-oriented. In 2010, Chile ranked as the fifth largest wine exporter. It has been gradually identified by international consumers as an ideal country for producing modern varietal (fresh and fruity), good-value-for-money wines, and has won worldwide acceptance in the wine community faster than any other country in modern history (Phillips, 2000). In an industry where historical tradition and reputation are seen to count as much as quality and price, Chile was the first developing country to become an internationally recognized wine exporter - to the point that in 2001 Santiago became an official member of the "Wine Capitals of the World", alongside centers of excellence such as Bordeaux, San Francisco, Florence and Melbourne (Sharples and Knowles, 2002).

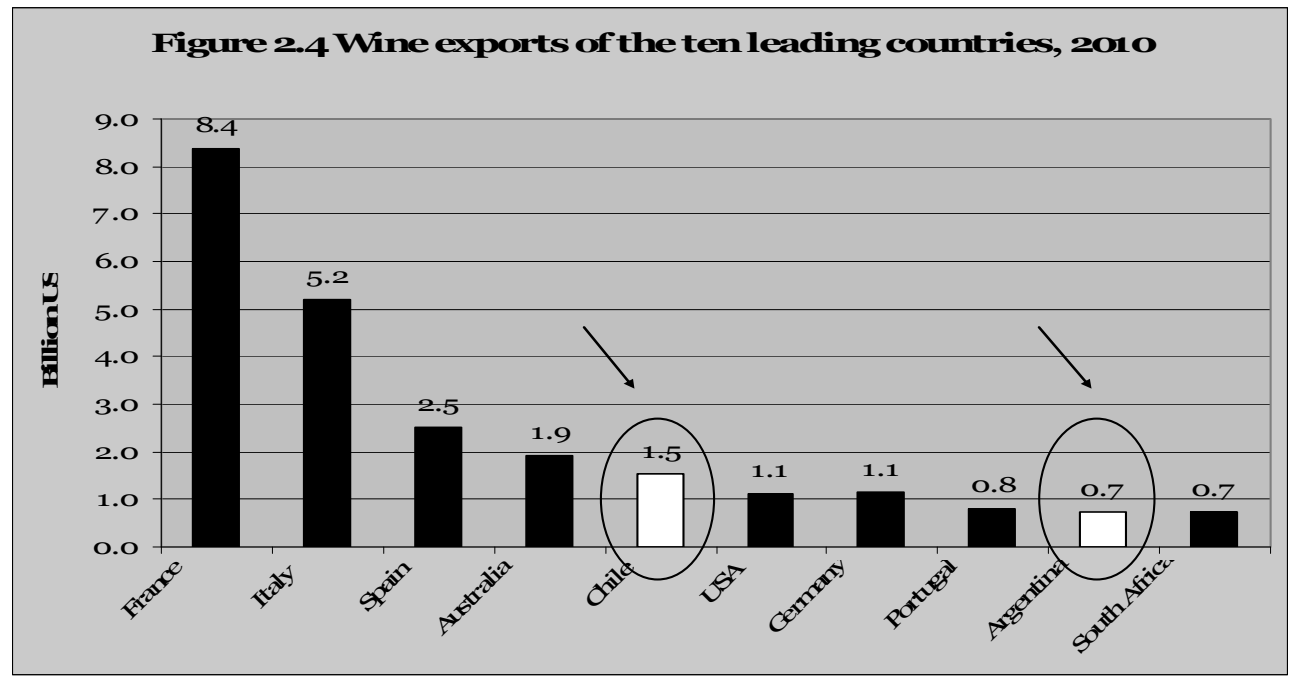

Source: Comtrade, SITC 11212 Rev.2

Paradoxically, despite very similar historical and soil conditions as a starting point for wine production, until a decade and a half ago Argentina was considered by its Chilean competitors as a "sleeping giant", where the process of technological catch-up was unfolding more slowly than in Chile, with a few years of delay, and with far less breadth and impetus in its export drive. Contrary to all predictions, though, the Argentine giant has shown clear signs of awakening. Not only does it represent the fifth largest world producer (behind France, Italy, Spain and the United States), but in 2010 it also reached the rank of ninth largest world wine exporter (behind the United States, Chile and Australia). Since the early 1990s, the Argentine wine industry has evolved rapidly, to the point that, between 2008 and 2007, Chile and Argentina experienced similar export growth rates: 31 and 29 percent respectively (see Table 2.2). In 2005, Mendoza, the most prestigious wine-growing region in Argentina, was appointed one of 
the "Wine Capitals of the World", as Santiago had been four years earlier. One should not forget, however, that the gap in the export growth of both countries remains substantial, especially in terms of total export value, considering that in 2008, for example, Chilean wine exports accounted for more than double the value of wines exported by Argentina.

Table 2.2 The Chilean and Argentine wine industries at a glance, 2008

\begin{tabular}{lcc}
\hline & Chile & Argentina \\
\hline Production (hectolitres) & $8,277,460$ & $15,045,915$ \\
Area cultivated (hectares) & 117,000 & 223,000 \\
Export volume (tons) & 586,899 & 425,228 \\
Export value (million US\$) & 1,356 & 618,3 \\
Average export price (US\$/litre) & 2.99 & 2.26 \\
Consumption (litre/per capita) & 15 & 32 \\
Average export growth (2007/2008) & $+31 \%$ & $+29 \%$ \\
\hline
\end{tabular}

Source: INV, 2010; SAG, 2010

One of the central themes of this thesis therefore emerges from the above: from the analysis of the Chilean and Argentine wine cases, can we argue that in Latin America a new, viable model of export-oriented industrialization through primary processing is gradually materializing - that is, a model which can be considered an alternative to the East Asian export-oriented industrialization based on narrowly defined manufacturing?

\subsubsection{Macro-economic relevance}

The choice of Chile and Argentina is particularly relevant because natural resources have largely contributed to the positive economic performance of these two countries and, more generally, of Latin American countries since the late 1990s. According to UNCTAD estimations, the rise in world prices for Latin America's primary commodities - and the related increase in their output, which fell only briefly during the financial crisis of 2008-2009 - has accounted for one-third to half of the continent's growth over the past decade (UNCTAD, 2010). Recent World Bank data actually show that at present Latin America is still heavily dependent on primary exports, which in 2008 represented 52 percent of the continent's exports (World Bank, 2010). In the case of Bolivia, Mexico, Peru and Venezuela, between 30 and 50 percent of tax revenues originated from exports of raw materials. In the case of Chile and Argentina, the dependency was less pronounced, ranging between 10 and 20 percent only (see Figure 2.5). 


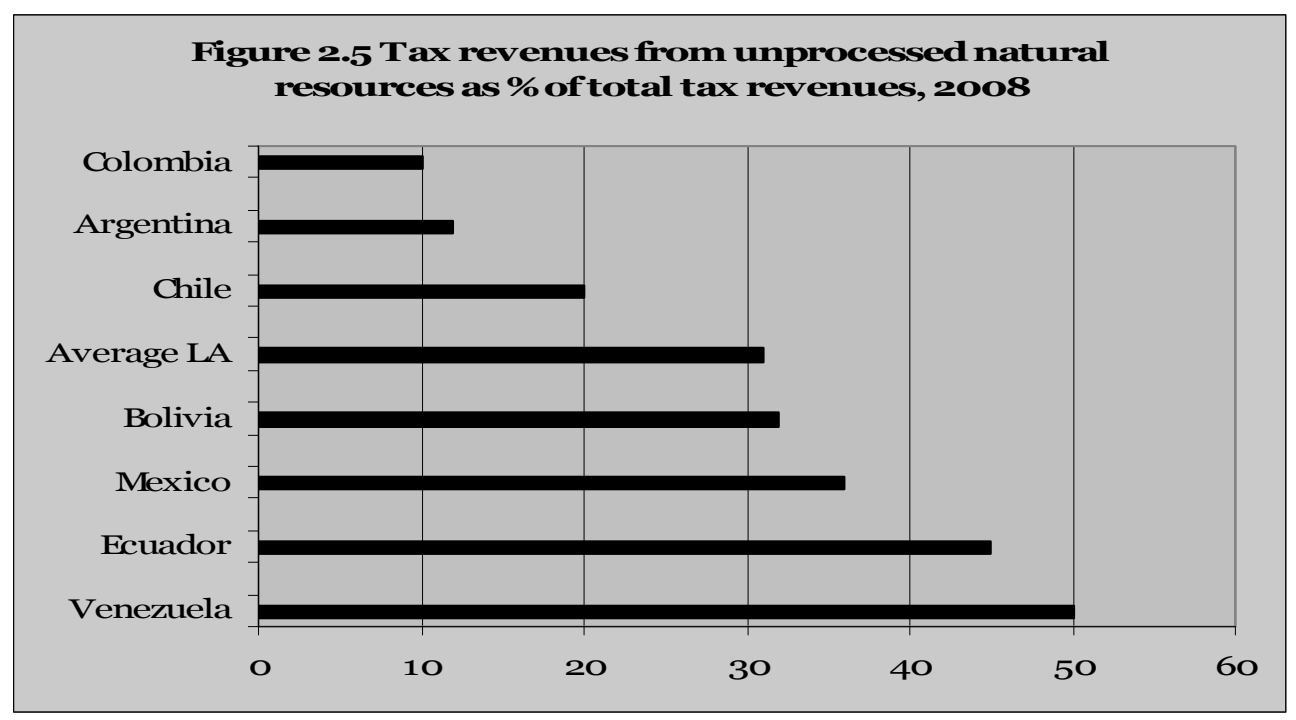

Source: World Bank, 2010

During the past two decades, both Chile and Argentina have reduced their dependency on primary commodities and taken actively part in the emerging specialization of some developing countries in natural resource-based processing sectors, discussed in detail in Chapter 1. However, they have done so in different ways. In particular, Chile has followed an orthodox, neo-liberal, export-led model and is considered to be a top performer, thanks to the outstanding export growth of natural resources in the forestry, agro-industry, fishing and mining sectors, as well as to an extraordinary investment boom in natural resource-based processing industries. ${ }^{46}$ During the 1980 s, Chile managed to diversify its export basket and substantially reduce its dependency on the export of copper, which now represents about one third of total exports 47 and has been matched by new non-mineral export products, such as wood and pulp, farmed salmon, fishmeal and other ocean products, fresh fruits, processed tomatoes, pork meat, milk products and wine, which saw their share of total exports rise from 15 percent in 1970 to above 50 percent in 2010 .

Since the 1990s, several studies have highlighted the importance of the gradual diversification of the Chilean export basket for its GDP growth - which, in 2011, reached 5.5 percent, namely the highest growth rate in Latin America. They argue that the growth of non-mining exports had a positive impact on the growth of the rest of the Chilean economy (Meller, 1994; Ffrench-Davis, 2000; Agosin and Bravo-Ortega, 2009).

\footnotetext{
46 However, Stiglitz (2002) argues that the reason why the model worked so well in Chile is that the standardized measures imposed by the Washington Consensus were not applied literally but adapted pragmatically to the country's specific needs.

47 This figure has been recently rising again to above 45 percent, due to the skyrocketing price of copper, which, however, is characterized by extremely high fluctuations. Chile produces one third of global copper output.
} 
More specifically, the creation of new non-mineral exports since the 1980 s had important externalities and allowed other sectors with potential comparative advantages to emerge, in particular those that tend to use similar public goods (Hausmann and Klinger, 2007).48 Some authors, such as Agosin and Bravo-Ortega (2009), specifically point to the importance of wine, which has opened the way to the exploration of other non-traditional exports. On the one hand, once the international demand was discovered for quality and reliable Chilean food products, other producers jumped on the bandwagon, often using the same marketing channels. On the other, the reduction in uncertainties about technology and costs generated by the success of wine exports would explain the orientation of Chilean producers towards the exports of other processed, non-mineral products (see Figure 2.6).

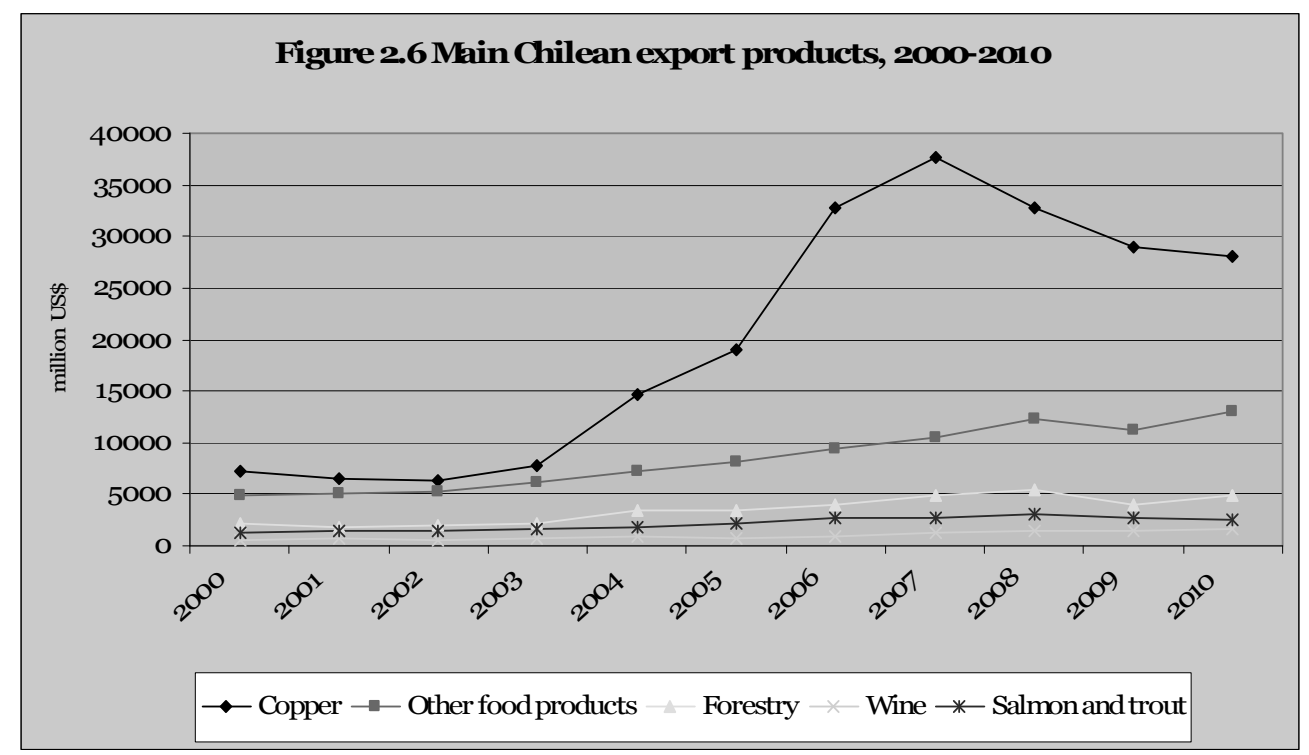

Source: Comtrade data

In 2009, Chilean processed agricultural commodity exports amounted to $\mathbf{1 1 . 2}$ billion US $\$$, reaching the fastest growth rate among the largest food exporters, namely +132 percent in the decade 2000-2009. It is expected that they will exceed 20 billion US $\$$ by 2015 and 62 billion US $\$$ by 2030 (Foreign Investment Committee, 2010). In the same year (2009), the contribution of the Chilean agro-industrial sector to total GDP was 4.7 percent, namely one third of the contribution of all manufacturing industries (12.7 percent of GDP), against 16.4 percent by the mining sector, 2.6 percent of the agricultural sector, 8 percent of the construction sector and 15.9 of the financial services sector. Currently, almost one out of four Chilean workers (23 percent) are employed in

\footnotetext{
${ }^{48}$ In this respect, Hausmann and Rodrik argue that " the probability that a country will develop the capability to be good at producing one good is related to its installed capacity in the production of other similar or nearby goods, for which the currently existing productive capabilities can be easily adapted" (in Hausmann and Klinger, 2007).
} 
the agro-industry, which also accounts for 26.3 percent of total manufacturing value added (Chilean Central Bank, 2012).49

In this context, wine represents a particularly dynamic industry. It accounts for 12 percent of Chilean agro-industrial exports and almost 2 percent of total exports. During the period 1974-2009, the wine industry attracted 50.2 percent of all FDI in the agroindustry, namely more than 1 billion US\$ out of 2.1 billion US\$ (Foreign Investment Committee, 2010).50 According to the data provided by the National Institute of Statistics, since 1996 the Chilean wine industry has experienced more than a decade of uninterrupted growth in terms of value added and labour productivity (see Figure 2.7), thereby representing a powerful contributor to growth, especially considering its pioneering role and its driving function in the proliferation and expansion of other nonmineral natural resource-based processing industries. Furthermore, in 1997 the Chilean wine industry accounted for 1.4 percent of total employment generated in the manufacturing sector, namely for 5,876 registered workers, while in 2007 it accounted for 6,571 registered workers (INE, 2012)..$^{1}$

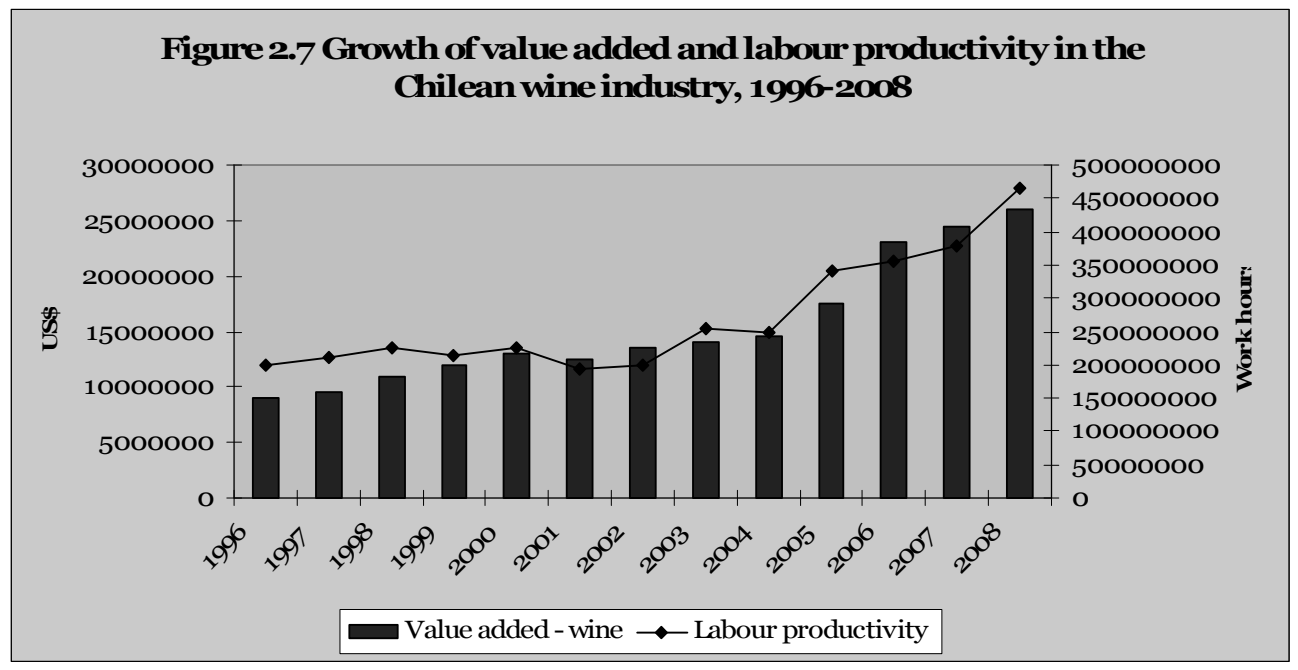

Source: Instituto Nacional de Estadisticas, 2010

The case of Argentina is different in many ways. To start with, the country is much larger than Chile, scarcely populated, and traditionally one of the world's leading exporters of agricultural products. Having attained a comparatively high level of wealth in the early twentieth century, thanks to massive exports of primary products (mainly grains and meat), since the beginning of the 1990s, Argentina has specialized in a more diversified set of industries, ranging from natural gas, mining and energy, fishing and

\footnotetext{
49 www.bcentral.cl/eng/bde/index.htm

${ }^{50}$ www.foreigninvestment.cl/images/stories/pdfs/publicaciones/agribusiness12.pdf

${ }^{51}$ www.ine.cl/canales/chile_estadistico/mercado_del_trabajo/lang=eng
} 
forestry, to soybean oil, wine and dairy products (Kosacoff, 2009; Toulan and Guillén, 1997; Agosin and Bravo-Ortega, 2006). After the turbulent decades of importsubstituting industrialization, the debt-crisis period and the market liberalization process of the 1990s, Argentina has stabilized and successfully integrated into the global economy by becoming the second largest destination of foreign investment in the Latin American continent, after Mexico, and one of the world's main exporters of soybeans, meat and milk products (see Figure 2.8), which account for more than 40 percent of total Argentine exports (ECLAC, 2011).

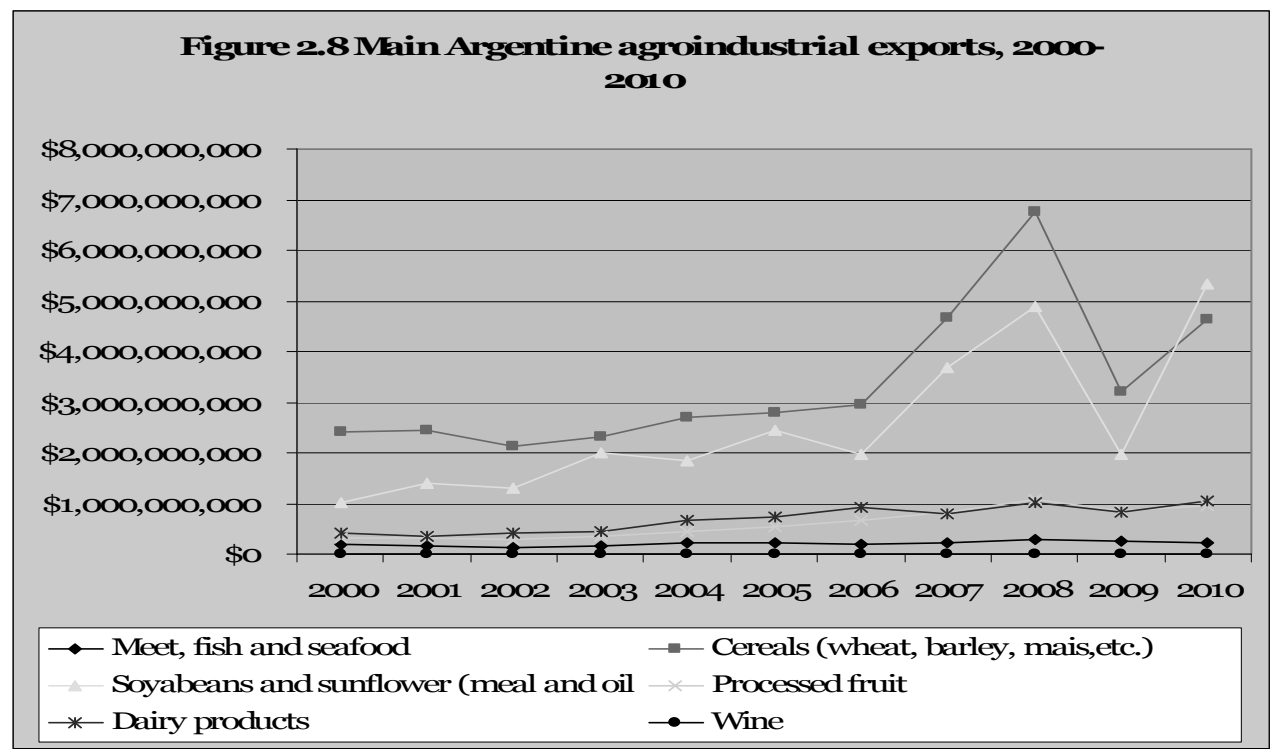

Source: Comtrade data

In 2007, the agro-industrial sector of Argentina represented 48 percent of total exports, 11 percent of employment and 15.3 percent of GDP (ECLAC, 2011). Over the period 2005-2007, the country produced 8.4 percent of world agricultural outputs, but accounted for only 2.9 percent of agricultural trade. Several products, such as beef, wine and dairy products, are actually produced mostly for the domestic market. Others, such as soybeans (meal and oil) and sunflower (meal and oil) are mostly produced for the export market, and in those cases Argentina represents, respectively, the largest and second-largest world exporter. However, they are also cases of agricultural commodities characterized by relatively lower value-added levels. Several articles in the literature point to the imperative need for Argentina to increase its share of agro-industrial exports with higher value-added levels, especially considering that the comparative advantage of Argentina's manufacturing sector has decreased over time (Lence, 2010; Bisang and Salvatierra, 2010). In this context, wine represents a notable exception. The Argentine wine industry accounts for 3 percent of agro-industrial exports and 0.78 percent of total exports. Despite its limited relative size, it has played an important pioneering role, which is serving as an example to other agro-processing industries with similar characteristics, such as olive oil, meat and beer production (Salvatierra, 2006). From an industry exclusively oriented towards the domestic market, the Argentine wine 
industry has gradually strengthened its export orientation, and has seen its value-added and labour productivity levels constantly increase since the 1980s (see Figure 2.9). It has also seen the share of the value added in its transformation phase (vs. primary and services) increase from 9 percent in 1991 to 13.8 percent 1998 to 35 percent in 2007 (ECLAC, 2011).

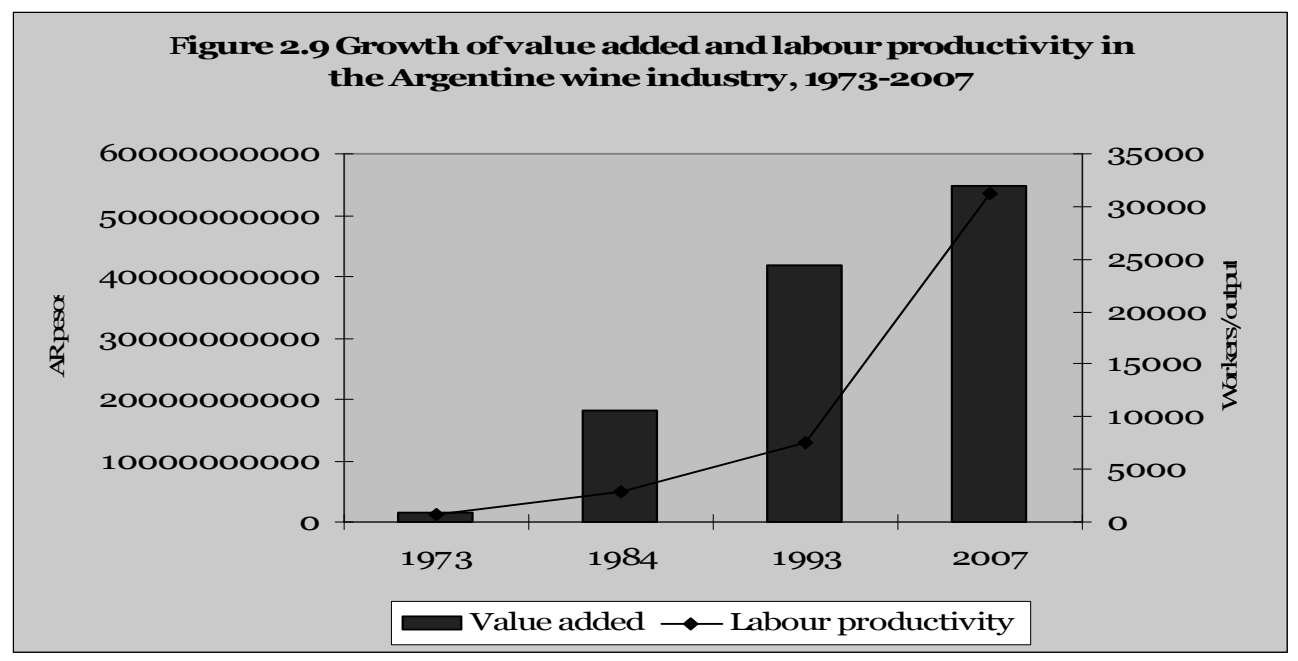

Source: CEPAL, 2010

A recent study on the socio-economic impact of the recent export boom in the nontraditional sectors of Argentina has revealed that, since liberalization, the level of employment in manufacturing has been constantly decreasing, from 1.5 million workers in 1974 to 1 million workers in 2003 (Bernat, 2012). It started to rise again only recently, reaching 1.3 million workers in 2010. Part of this increase can be ascribed to the expansion of food processing industries such as vegetable oil. With regard to the wine industry, employment levels remained substantially stable during more than one decade, oscillating from 19,000 registered workers in 1996 to 15 ,000 in 2002, and reaching again 19,000 registered workers in 2010, when the wine industry accounted for 1.8 percent of total employment in the manufacturing sector. This means that increased wine production had to be achieved thanks to higher labour productivity levels, which is consistent with the data shown by the figure above. It was also matched by a substantial increase of the average salary level of registered workers, which, in the beverage industry as a whole, rose from 1,129 Argentine pesos in 1996 to 5,799 Argentine pesos in 2010.

Given the above, this thesis is based on the assumption that the wine industry originated an important demonstration effect and can be considered as a relevant contributor to macro-economic growth in both Chile and Argentina. It is expected that the comparative micro-level analysis of the Chilean and Argentine wine industries, carried out in this thesis, will provide useful and timely lessons about the diversity of pathways and policies that can be adopted for the development of natural resource-based processing sectors in the contemporary period. 


\subsection{Methods and techniques of research: Hypothesis I}

In order to examine the first hypothesis, ${ }^{22}$ Chapter 3 will analyze the main features of the wine industry at world-wide level and the evolution of modern wine production techniques. It will also show how, despite being a very old natural resource-based product, wine has been subjected to the gradual transformation from a simple, undifferentiated commodity to a highly diversified, technologically sophisticated consumer good. This will allow (in Chapter 4) an analysis of the competitive performance of the Chilean and Argentine wine industries within the more general context of the structural transformations that are reshaping the industry at the global level, and with respect to the most recent advancements in the technological frontier and knowledge contents (Archibugi et al., 2009). It will also allow (in Chapter 5) an assessment of the extent to which the entry of Chile and Argentina in the international wine industry was merely an extension of earlier practices or required additional, sustained efforts to meet increasingly complex technological and quality standards.

After a brief overview of the history of wine since antiquity and an analysis of the technological evolution of the wine industry over the past centuries, the main driving forces of innovation in the modern wine industry will be identified, defined as "those forces that provide a clear stimulus and a specific directionality to the innovation efforts in a certain industry" (Perez at al., 2008). In line with the evolutionary tradition (Nelson, 1994; Metcalfe, 1998), attention will be paid to both the supply and the demand sides, and in particular to the dynamics of technological change and the evolution of consumer tastes (see Figure 2.10). Based on a review of the specialized literature on the subject, a number of selected interviews with key informants and an analysis of the industry data available, the crucial knowledge intensive phases in modern wine production will be identified and a map of the knowledge base of the present wine industry will be provided.

Chapter 3 will clearly distinguish international tacit, capital-embodied and codified knowledge flows, which are at the origin of an increasing technological interdependence among winemaking economies and regions. It will also identify the main technological innovations and organizational changes that have characterized the three main areas of modern wine production - viticulture, viniculture and marketing. These have all largely contributed to the transformation of wine from a commodity to a highly differentiated, knowledge intensive natural resource-based product, characterized by high value-added and quality standards. From a preliminary review of the technical literature on the subject, some of these innovations include clone selection, rootstock analysis, row spacing and orientation, vine density and irrigation through advanced instrumentation, microbiology of yeasts and bacteria, cold fermentation, use of small oak barrels, control of ageing time, use of additives and preservatives, and electronic labelling.

\footnotetext{
$5^{2}$ Hypothesis I: (a) In the last quarter of the twentieth century, natural resource-based processing industries have become knowledge and innovation intensive. (b) This has opened up new windows of opportunity to developing countries.
} 
Figure 2.10 Driving forces of innovation in the international wine industry

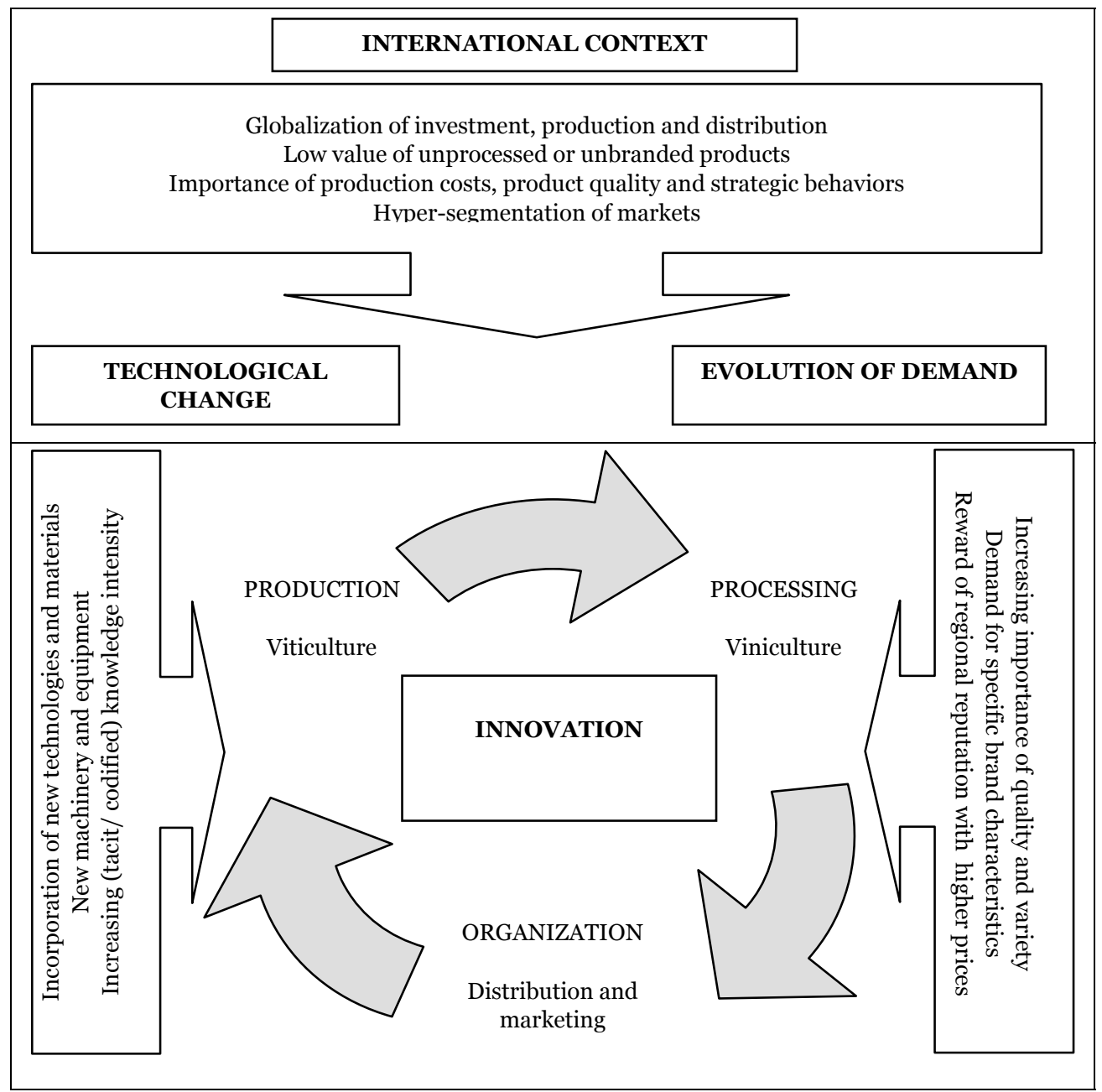

Source: Author's elaboration based on Perez et al. (2009)

In order to understand how these complex and sophisticated techniques may have contributed to the gradual "de-commodification" of wine, 53 there is a need to define, measure and systematize the concept of wine "quality". This is a challenging task, since the perception of quality is inevitably influenced by subjective, highly idiosyncratic criteria and depends on individual taste, expectations and aesthetic culture (Oczkowski, 2001). The Romans had already recognized the subjective dimension of wine quality in the famous proverb "quam ob rem de pricipatu se quisque iudicem statuet" - concerning wine, everybody should rely only on personal judgments

53 As further illustrated in Chapter 3, quality wine has been a rare and expensive luxury good, reserved for centuries to the élites. Until recently the wine that common people drink on a daily basis has consisted of a relatively standardized, undifferentiated product. 
(Pliny the Elder, Naturalis Historia, book XIV). In more recent times, the most famous quote on wine quality belongs to the reputed American oenologist Maynard Amerine, who claimed that "quality in wines is much easier to recognize than to define" (Amerine and Roessler, 1976).

During the last three decades, however, the modern wine industry has been able to clearly quantify some of the components determining wine quality: negative quality factors, such as off-doors, are scientifically detectable and objectively classifiable; positive quality factors are usually ranked according to a series of codified categories: subtlety and complexity, balance and harmony, duration, aging potential, stylistic purity, varietal expression. Moreover, one should consider that, despite their clear limitations, quality indicators, such as those just mentioned, are reflected in both ranking by experts and consumer acceptance statistics (Jackson, 2008). The best known wine rankings are published in specialized journals such as Wine Spectator, Wine Enthusiast, Decanter, and on a yearly basis in wine guides signed by renowned critics such as Hugh Johnson, Oz Clark, Jancis Robinson and Robert Parker.

In this context, the widely diffused and highly criticized 100-point scale invented more than thirty years ago by Robert Parker has been defined as "a precision assessment tool that offers consumers certainties in an uncertain world" (Brook, 2000).54 In his newsletter The Wine Advocate, Robert Parker regularly judges the wines he tastes, awarding them points out of 100, based on the scale illustrated below (see Table 2.3). The underlying assumption of Parker's scale, which has become the dominant force in the wine world, is that a professional assessment of wine quality is possible. His opinion has been widely endorsed at the global scale. The writers for one of the most influential specialized wine magazines in the United States - Wine Spectator, Wine Enthusiast and Wine \& Spirits - all currently use Parker's 100-point rating scale.

Table 2.3 Robert Parker's 1oo-point scale

\begin{tabular}{lll}
\hline Points & Definition & Quality \\
\hline $95-100$ & A great wine & Outstanding \\
$90-94$ & A wine of superior character and style & Excellent \\
$85-89$ & A wine with special qualities & Very good \\
$80-84$ & A solid, well made wine & Good \\
$75-79$ & A drinkable wine that may have minor flaws & Mediocre \\
$50-74$ & Not recommended & Bad \\
\hline
\end{tabular}

Source: Parker, 2008

Also in Europe, Parker's writings have had a tremendous influence on the winemaking community, and especially on premium wine producers. According to Beazley (2000):

\footnotetext{
54 Parker's scoring system starts with a potential of 50 points. The wine's general color and appearance can earn up to 5 points. Aroma and bouquet can earn up to 15 points, depending also on the wine's cleanliness. The flavor and finish can earn up to 20 points, depending also on the wine's depth and length on the palate. Finally, the potential for further evolution and improvement through aging can earn up to 10 points.
} 
The financial implications [of Parker's writings] are so significant that no European fine-wine producer can afford to ignore them, making him a stylistic dictator. [...] The excitement and market-making which Parker's work has generated, though, has brought publicity to the wine community as a whole; few would dispute that the overall quality of Bordeaux's greatest wines is higher at the end of the twentieth century than anytime before, and Burgundy, the Rhone Valley, Piedmont and Tuscany are also flourishing, thanks in part to the formmaking provided by his regular assessments (Beazley, 20oo, p.56).

At the same time, however, many wine critics are increasingly unsympathetic towards the "Parkerization" of the wine industry worldwide, and in particular, towards the convergence on a pronounced wine "oakiness" and high alcohol contents as a global style of winemaking, irrespective of the characteristics and the importance of local terroir (McCoy, 2006).55 This is even more significant, considering that Parker's scale has traditionally refers to higher-priced premium wines only, and has not included either ordinary table or bulk wines until 2009, when he published a guide of wines priced under 25 US\$ (Parker, 2009). It should be recalled here that wines are internationally classified based on alcohol concentration. These are still, sparkling and fortified wines. ${ }^{6}$ Still wines, which account for 88 percent of the market, are divided into basic and premium wines. In general, premium wines are made of high oenological quality varieties of French origin and are usually sold bottled, rather than in bulk as most basic wines are. High oenological quality varieties include grape varieties - such as Cabernet Sauvignon, Merlot, Pinot Noir, Cabernet Franc, Chardonnay, Sauvignon Blanc - which are particularly appreciated by international consumers and, therefore, dominate the world wine export markets (see Table 2.4).

Table 2.4 High quality oenological grape varieties of French origin

Red varieties

White varieties
Cabernet Sauvignon, Carmenère, Malbec, Merlot, Pinotage, Pinot Noir, Sangiovese, Syrah, Tempranillo, Zinfandel

Chardonnay, Chenin Blanc, Pinot Blanc, Sauvignon Blanc, Sauvignon Gris, Sémillion

\footnotetext{
55 One of the main indicators of success for wine producers is traditionally represented by the number of new oak barrels they have in their cellars. During the last twenty years, oak-aging has become increasingly fashionable among consumers, and skilled winemakers have learned to use it almost systematically to accelerate the clarification and stabilization of wine and to accentuate its complexity. However, an excessive use of oak leads to a certain standardization of wine taste, in that the toasty and vanilla-like flavor of oak tends to overlay wine acidity and fruitiness. In order to overcome this problem, winemakers in France and Italy are currently experimenting with the use of larger casks to reduce the proportion of wine that remains for a year or two in direct contact with wood, and they are often replacing the small Bordeaux and Burgundy casks (225 and 228 litres, respectively) with 500 litre casks (The FT, 6/7 November 2010).

56 The alcohol content of still and sparkling wines ranges between 9 and 16 percent by volume. The third category, that of fortified wines, ranges between 16 and 22 percent by volume. Sparkling wines (dry or sweet) include, among others, the French champagne, the Italian spumante, the Portuguese viñho verde. Fortified wines include, among others, marsala, vermouths, ports and sherries.
} 
Premium wines also follow the rules of appellation control or geographical indication, while basic wines normally do not (Johnson, 2007). In the wine industry, the concept of quality is increasingly associated not only with the presence of high oenological quality grape varieties, but also with the concept of terroir, namely the idea that quality is linked to "an origin of some kind" (Trubek, 2008). The French term terroir is presently used in the specialized literature to define the characteristics of a determined viticultural site in terms of soil, weather conditions and farming techniques, all contributing to the unique qualities of the wine. According to Hugh Johnson (1998), the reason why wines taste differently is that the composition of the soil where grapes are grown may vary drastically, much as everything above the surface does. ${ }^{57}$ Even if the production process of wine appears to be very simple, the end product presents tremendous differences in taste, aromas and quality, which have been valued by consumers of all times. These can be ascribed to the soil, climate and other natural circumstances characterizing the region where vines are grown, as much as to the way in which wine has been vinified. $5^{8}$

The attempt to codify what Trubek (2008) has defined as "the taste of place", connected to the idea of quality, dates back to the 1930s, when France introduced the AOC (appellations d'origine contrôlées) or appellation control legislation in order to protect French wines from a growing international competition, namely a legally defined and protected geographical indication system which identifies where the wine grapes are grown. As early as 1855, however, the establishment of the renowned Bordeaux wine classification system introduced the idea that a scientific approach to the local terroir, as something that could be known and studied, was not only possible but also desirable from a marketing perspective (Rohel, 2010). 59

Currently, in some wine producing countries, especially in the New World, the appellation control legislation is limited to aspects of geographic origin and varietal authenticity. In others, especially in the Old World, it regulates grape varietal use, dictates production procedures, prohibits certain vineyard practices (such as irrigation),

57 In this respect, he argues: "Properly understood, the concept of "terroir" means the whole ecology of a vineyard, every aspect of the surroundings, from bedrock to late frosts and autumn mists, not excluding the way the vineyard is tended, nor even the soul of the vigneron" (Johnson, 1998, p. 4).

58 The concept of terroir originally applied exclusively to wine, and is now being gradually associated with other natural resource-based products, in a way that is surprising and, until a few years ago, almost unthinkable. For example, an article published by Wine Spectator in November 2010 illustrates the merits of cacao originating from Chuao in Venezuela. It argues that Chuao cacao beans possess a complexity, length and a range of flavors that are very difficult to achieve elsewhere, and that producers are learning how to accentuate Chuao's unique characteristics (nut dark roast flavors and bitter finish) through different planting and processing techniques. Additionally, it seems that experimental planting of Chuao trees in other areas did not produce the same results, and that scientific investigation, following the path of research in the wine industry, is now looking at the impact of different climate, soil and plant genetics (i.e., of different terroirs) on cacao quality (Wine Spectator, Nov. 30 2010).

59 In the 1855 classification, a five-group hierarchy was established for the best wines of the Medoc region, based on price. Despite its longevity and popularity, however, several recent studies have pointed to the obsoleteness of this classification. According to Lewin (2009), for example, only one third of Medoc wines would currently belong to the same group as in 1855 , if they were reclassified based on their average prices over the past decade. 
limits maximum yields and specifies maturation conditions. As will be explained in more detail in Chapter 3, such more rigid practice is meant to assure both quality and stylistic authenticity, but there is a wide debate on whether highly constraining appellation control systems, rigorously adopted in Europe really succeed in doing so, and on whether quality can more generally be guaranteed by law (Jackson, 2008).

Despite some notable exceptions, there is no doubt that the overarching international context and the regulatory framework, negotiated internationally and defining the product, its ingredients and its geographical origin, have played a major role in shaping wine quality standards, as well as production and trade patterns, thus "shaping also the impact of particular fields of technological innovation" (Smith, 2007). The changes in product characteristics towards rising value-added content are clearly reflected by the range of increasingly differentiated prices at which wines are sold on the market. As illustrated in the second part of Chapter 3, international consumers tend not only to pay higher prices for bottled, high quality premium wines than bulk wines, but also to distinguish several categories of premium wines (see Table 2.5).

Table 2.5 Wine quality segments based on price ranges

\begin{tabular}{|c|c|c|c|c|c|}
\hline Category & $\begin{array}{c}\text { Quality } \\
\text { segments }\end{array}$ & Definition & $\begin{array}{l}\text { Price range } \\
\text { US\$/bottle }\end{array}$ & $\begin{array}{c}\text { Main } \\
\text { characteristics }\end{array}$ & $\begin{array}{l}\text { Geographical } \\
\text { indication }\end{array}$ \\
\hline \multirow[t]{3}{*}{$\begin{array}{l}\text { Premium } \\
\text { Wine }\end{array}$} & $\begin{array}{l}\text { Highest } \\
\text { quality } \\
\text { standard in } \\
\text { the premium } \\
\text { category }\end{array}$ & $\begin{array}{l}\text { Ultra- } \\
\text { premium }\end{array}$ & $50-100$ & $\begin{array}{l}\text { Consolidated image } \\
\text { over time; } \\
\text { complexity and } \\
\text { aging potential; } \\
\text { excellent reports by } \\
\text { critics }\end{array}$ & $\begin{array}{l}\text { Wines come from } \\
\text { geographically defined } \\
\text { and limited areas. In the } \\
\text { Old World, they also have } \\
\text { to follow specific rules } \\
\text { regarding the grape } \\
\text { variety, alcohol content, } \\
\text { yield, pruning, etc. }\end{array}$ \\
\hline & $\begin{array}{l}\text { Intermediate } \\
\text { quality } \\
\text { standard in } \\
\text { the premium } \\
\text { category }\end{array}$ & $\begin{array}{l}\text { Super- } \\
\text { premium }\end{array}$ & $20-50$ & $\begin{array}{l}\text { Recognizable } \\
\text { brand; complex } \\
\text { structure; good } \\
\text { reports by critics; } \\
\text { richness and } \\
\text { character. }\end{array}$ & $\begin{array}{l}\text { Wines come from } \\
\text { geographically defined } \\
\text { and limited areas. In the } \\
\text { Old World, rules are less } \\
\text { strict than those } \\
\text { governing the highest } \\
\text { segment }\end{array}$ \\
\hline & $\begin{array}{l}\text { Lowest } \\
\text { quality } \\
\text { standard in } \\
\text { the premium } \\
\text { category }\end{array}$ & $\begin{array}{l}\text { Popular- } \\
\text { premium }\end{array}$ & $5^{-8}$ & $\begin{array}{l}\text { Recognizable } \\
\text { varietal } \\
\text { characteristics; } \\
\text { fruity flavour; easy } \\
\text { to drink }\end{array}$ & $\begin{array}{l}\text { The standard of the wine } \\
\text { varies with the region, the } \\
\text { grape variety and the } \\
\text { year. Governing rules are } \\
\text { soft }\end{array}$ \\
\hline \multirow[t]{2}{*}{ Basic wine } & & $\begin{array}{l}\text { Bottled table } \\
\text { wine }\end{array}$ & $1-3$ & $\begin{array}{l}\text { Varietal; simple } \\
\text { structure; not much } \\
\text { character }\end{array}$ & $\begin{array}{l}\text { No geographical } \\
\text { indication rules }\end{array}$ \\
\hline & & Bulk wine & $<1$ & $\begin{array}{l}\text { No brand; no } \\
\text { restrictions; simple } \\
\text { structure }\end{array}$ & \\
\hline
\end{tabular}

Source: Author's elaboration based on Rabobank, 2007 
The table above reflects the reality of an extremely diversified product, which, at the cheap end of the market, can be considered a relatively ordinary, affordable beverage and, at the highest end, a luxury, positional good (Archibugi, 2007). ${ }^{60}$ Against this background, Chapter 3 will illustrate the drastic restructuring process that has characterized the international wine industry since the early 1970s, both on the supply and on the demand side. It will rely on the UN Comtrade data set on international trade, as well as on information and data from the International Organization of Vine and Wine (OIV), in order to analyze the explosion of international competition in wine exports (both in quantity and value), the high rate of new entrants (so-called New World producers), and the contrast between New World and Old World producers' competitive strategies and production techniques. Chapter 3 will also illustrate the unexpected entry of developing countries, such as Chile and Argentina, in the world wine industry. This is a surprising phenomenon since one would expect that the increasing knowledge intensity of the wine industry would make entry conditions for developing countries narrower with respect to the past. The solidity of the current position of Chile and Argentina as leading wine exporters actually opens up a series of interesting questions about the determinants of the export boom of their wine industries, their different performance over time, and the extent to which their increased exports have been characterized by increased quality, value-added and technological change, or have been confined to the low-end of the quality spectrum.

\subsection{Methods and techniques of research: Hypothesis II}

In order to examine the second hypothesis, ${ }^{61}$ Chapters 4 and 5 will analyze the patterns of the surprising export boom of Chilean and Argentine wines from a comparative perspective, and the way in which the knowledge and technology needed to consolidate it were acquired. In particular, Chapter 4 will analyze the quality improvements and related technological changes that occurred after Chile and Argentina entered the international market. It is worth remembering that, until a few years ago, the Argentine wine style was totally unattractive to international palates, and wine was produced in massive quantities for a particularly healthy but indulgent domestic market. In this respect, Stein (2004) claims:

The wines made during the 1970 for the Argentine taste were heavily coloured, alcoholic beverages of thirteen percent or more degrees and were often oxidized in

\footnotetext{
60 Plenty of evidence shows that international premium wine prices are strongly correlated to Parker's ratings, namely that changes in ratings for the same wine result in large price changes (Gibbs et al., 2009; Hadj Ali et al., 2008). Price elasticity with respect to ratings has increased considerably since 1993, in parallel to the increased globalization of the premium wine market (Gibbs et al., 2009). This is due to the increased proportion of "naïve" (vs "sophisticated") consumers that globalization has brought into the market, and who rely on reputational information rather than their own personal taste and quality assessment to purchase premium wines.

${ }^{61}$ Hypothesis II: (a) In order to enter natural resource-based processing industries, the capability of developing countries to access foreign knowledge and technology from abroad is crucial. (b) The creation of endogenous capabilities to innovate is key to absorbing and adapting them to the local environment.
} 
flavour as a result of exposure to varying amounts of air after fermentation. Many producers stabilized their wines with boiled must, producing a sweetish drink with similarities to poor quality Sherry. Boiled must was not the only thing added to wine: the practice of watering wines, initiated during the early years of the industry, continued to occur fairly frequently according to contemporary observers (Stein, 2004, p.11).

Analogously, until the 1970s Chilean wines were confined to the niche of decent-butnot-great wines, and were often criticized as boring and monotonous, based on the limited number of varieties cultivated and the relative homogeneity of their taste (Robinson, 2001). In this respect, Robinson (2005) argues:

Chile's golden age was the end of the nineteenth century, when the rest of the wine world had been crippled by phylloxera, and this isolated wine producer could supply almost limitless quantities of healthy, deep-coloured wines [...] For the next hundred years there were very few changes in the vineyards and cellars of Chile. Professionals visiting the country in the late 1970 s were quickly frustrated at the oxidized style of wines bottled for the local market. This tended to favour very fruity wines, lower in tannins and higher in acidity, very far from what foreign buyers would ever like (Robinson, 2005, p.134).

From the above, it becomes clear how the export success of the Chilean and Argentine wine industries was far from predictable, and how crucial it is to investigate whether their successful export performance was a natural extension of earlier practices, or rather the result of radical changes in product and process techniques that led to tangible improvements in product quality over time. In order to understand whether the recent export boom of Argentina and Chilean wines was based on a constantly increasing product quality, or whether only quantity increased and quality levels deteriorated or remained unchanged over time, the series of proxy indicators of wine quality specified below will be used (see Table 2.6).

In particular, the selected indicators will assess the progress (or lack thereof) in the achievement of product differentiation, through the replacement of low quality grapes (the País or Criolla variety) with high quality grapes of French origin required for export wines, the identification and valorization of a typical, emblematic variety and the introduction of zoning practices related to geographical indication. Subsequently, the selected indicators will track the progress (or lack of) in the positioning in the international market of Argentine and Chilean wines. Through their measurement, it will be possible to determine, for example, whether Chile and Argentina have been able to access the market niches of premium and super-premium wines, increasingly demanded by international consumers, and whether their international ranking has improved over time. The shift in their international market shares by country of destination, and the evolution of their export prices per unit, will be also illustrated. ${ }^{62}$

\footnotetext{
${ }^{62}$ In this respect, von Tunzelmann and Acha (2005) argue that in traditional sectors, producing different types of the same categories of good (product differentiation) is an important way to penetrate new markets and to overcome the income inelasticity of demand in existing markets. They also argue that the availability of advanced technologies represents a key asset in making new products that can satisfy the new "necessities" of
} 
Table 2.6 Selected indicators to assess quality improvements of Chilean and Argentine wines

\begin{tabular}{|c|c|c|}
\hline Area & Quality indicators & Relevance \\
\hline \multirow[t]{3}{*}{$\begin{array}{l}\text { Product } \\
\text { differentiation }\end{array}$} & $\begin{array}{l}\text { Replacement of low quality } \\
\text { grapes (the País or Criolla } \\
\text { variety), with high quality grapes } \\
\text { of French origin }\end{array}$ & $\begin{array}{l}\text { Due to its adaptability to all climatic } \\
\text { conditions, the País or Criolla grape has } \\
\text { been for centuries the most common vine } \\
\text { cultivated in both Chile and Argentina. } \\
\text { Given its poor oenological quality, it is only } \\
\text { suited for inexpensive, domestic wine } \\
\text { consumption }\end{array}$ \\
\hline & $\begin{array}{l}\text { Identification and valorization of } \\
\text { a typical, emblematic variety } \\
\text { (such as Zinfandel in California, } \\
\text { Tannat in Uruguay, or Pinotage } \\
\text { in South Africa) }\end{array}$ & $\begin{array}{l}\text { The identification of an indigenous variety is } \\
\text { very important for strengthening the } \\
\text { international recognition of a national } \\
\text { identity and for differentiating from foreign } \\
\text { competitors }\end{array}$ \\
\hline & $\begin{array}{l}\text { Introduction of zoning practices } \\
\text { of main winemaking areas and } \\
\text { designation of origin regulations }\end{array}$ & $\begin{array}{l}\text { A reliable appellation system is considered } \\
\text { synonymous with high quality almost } \\
\text { everywhere in the world and is a key asset } \\
\text { for strengthening international reputation. }\end{array}$ \\
\hline \multirow[t]{3}{*}{$\begin{array}{l}\text { Positioning } \\
\text { in the international } \\
\text { market }\end{array}$} & Rising export unit values & $\begin{array}{l}\text { An increase of export prices generally } \\
\text { reflects the higher quality of the products } \\
\text { being offered. Changing economic } \\
\text { conditions, however, may also have an } \\
\text { influence }\end{array}$ \\
\hline & $\begin{array}{l}\text { Increased exports to demanding } \\
\text { markets of destinations }\end{array}$ & $\begin{array}{l}\text { Until the } 1980 \text { s, both Chilean and Argentine } \\
\text { wine exports were concentrating in Latin } \\
\text { America, a market traditionally demanding } \\
\text { lower quality wines than, e.g., Europe or the } \\
\text { United States }\end{array}$ \\
\hline & $\begin{array}{l}\text { Better international ranking over } \\
\text { time }\end{array}$ & $\begin{array}{l}\text { Global competition in wines is very } \\
\text { pronounced. Serious investment in } \\
\text { marketing strategies and branding usually } \\
\text { results in increased international } \\
\text { recognition and ranking in international } \\
\text { competitions }\end{array}$ \\
\hline
\end{tabular}

Source: Author's elaboration

From a methodological perspective, measuring innovation is not an easy or straightforward task. Traditionally, innovation indicators have focused on R\&D expenditures, patents, and education of human resources, based on a linear inputoutput model in which only research could lead to technology (Kline and Rosenberg, 1986). The evolutionary literature, however, highlights the inadequacy of such traditional indicators to reflect the real magnitude and variety of innovation activities,

more demanding consumers who earn higher incomes. In addition to quality upgrading, these consumers may also turn their attention towards products that have new characteristics, allowing them to be safer and more environmentally friendly. 
which are incremental, cumulative and tacit in nature (Nelson and Winter, 1982; Freeman, 1987; Lundvall, 1992) and, thus, to the existence of unresolved measurement problems (Smith, 1999 and 2005; Fagerberg, 1999 and 2004; Marins, 2008). Moreover, there is a tendency to attach excessive importance to the impact of critical technologies, technological ruptures, and breakthroughs in the early stages of the inventive process, and to neglect the importance of the later stages and of the fact that the main source of productivity improvement are also other than those emanating from major innovations (Kline and Rosenberg, 1986).

In this respect, Smith (2000) argues:

The point is that direct $R \& D$ is but one indicator of knowledge content, and that technological intensity in not mapped solely by $R \& D$. [...] With respect to the identification of the knowledge economy with high technology industries, two objections can be made. First, $R \& D$ is by no means the only measure of knowledge-creating activities. Second, the knowledge that is relevant to an industry may be distributed across many sectors or agents; thus, a low-R\&D industry may well be a major user of knowledge generated elsewhere (Smith, 200o, p.4).

To emphasize innovation in this sense is not to deny the role that $\mathrm{R} \& \mathrm{D}$, undertaken by large domestic firms and TNCs, can play in generating new knowledge. ${ }^{63}$ Rather, the point is to avoid the common overemphasis on $\mathrm{R} \& \mathrm{D}$ in the innovation process, and to pay more attention to the opportunities for learning and innovation emerging in most productive sectors in the economy, including natural resources, through all internal and external actors that affect innovation and within different forms of industrial organization. Consequently, it is necessary to open the "black box" of innovation activities at the sectoral level. In order to do this, the CIS (Community Innovation Survey) methodology will be followed. This suggests that if it is not possible to estimate innovation in terms of total $\mathrm{R} \& \mathrm{D}$ expenditures or number of patents, as a proxy it is important to know if firms have been involved in certain innovation activities or not, whereby innovation activities are considered as all those steps necessary to develop and implement technologically new or improved products (Smith, 2005).

Chapter 5 , therefore, is based on a field survey, taking as a unit of analysis the leading 25 exporters of bottled wines in Chile and the leading 25 exporters of bottled wines in Argentina. The information and data related to the Chilean wine industry were collected during a four-month stay in 2002, and two subsequent field visits in 2005 and 2007. The information and data related to the Argentine wine industry, instead, were collected during a three-month stay in 2004, and two subsequent field visits in 2008 and 2010.

\footnotetext{
63 Pushing further this line of reasoning, Goedhuys, Janz and Mohnen (2008) have recently studied the knowledge-based determinants of productivity in "low-tech" industries. They found that these differ substantially across industries, namely in food processing productivity levels seems to be mostly related to the quality of management and foreign ownership linkages; in textiles, firms' productivity depends on imports of new machinery and R\&D; in garments and leather products, this depends mostly on R\&D and design activities, quality management and licensing of technologies.
} 
During the field work in Chile, the chief oenologists of 35 wineries were interviewed: the 25 leading exporters of premium wines, distributed along the five main Chilean wine producing areas; 4 wineries equipped with old machinery and selling only in the local market; and 6 recently established wineries. During the field work in Argentina, the chief oenologists of 27 wineries were interviewed: the 25 leading exporters of premium wines, concentrated in the two main Argentine winemaking provinces, as well 2 large and rather obsolete traditional cooperatives that target domestic consumers. In both countries, 60-90 minute personal conversations were held with the chief oenologists of all the wineries interviewed, accompanied in some cases by the winery owners, who often volunteered to complement the conversation with a visit to the winery installations. An open-ended, semi-structured questionnaire was adopted to provide consistency to the interviews, and to leave selected informants free to elaborate on those aspects they felt were more relevant (see Annex I). During the field work in Chile and Argentina, a consistent number of interviews was also carried out with wine experts, university professors, wine journalists and representatives of wine-related institutions, associations and research centers, mostly located in the respective capitals.

The choice of the unit of analysis is justified by the high level of consolidation of both the Chilean and the Argentine wine industries, which makes 25 a quite representative number of the most (presumably) innovative exporting wineries (see Table 2.7). Despite its wide production base (in 2010, there were 934 registered wineries by the National Institute of Vitiviniculture), in Argentina only five companies account for 80 percent of the basic segment in the domestic market. In terms of export concentration, the leading 25 exporters account for 75 percent of total exports, while the top 5 companies account for 55 percent of all wine exports. These are Zuccardi, Trivento Catena Zapata, Norton and Trapiche, namely three foreign-owned and two nationally owned wineries. In Chile, in 2010 there were 360 wineries registered by SAG, and the level of export consolidation was comparable to that of Argentina. However, the leading exporting companies are larger (albeit relatively small compared to the US and Australian giants) and remain family controlled or are owned by national industry groups. In terms of export concentration, 4 companies account for 42 percent of the total export market. These are Concha y Toro, San Pedro, Santa Rita and Undurraga (Concha y Toro alone controls more than 20 percent of the export market), while the top 25 exporting companies represent 65 percent of total exports.

Table 2.7 Chilean and Argentine wine industry structure, 2010

\begin{tabular}{lcc}
\hline & Chile & Argentina \\
\hline Number of commercial grape growers & 8,000 & 26,000 \\
Area cultivated with wine grapes & 114,000 & 217,000 \\
Hectares per grower & 14 & 8.3 \\
Number of wineries & 360 & 934 \\
Number of exporting wineries & 120 & 257 \\
Consolidation ratio ( C -3$)^{*}$ & $34 \%$ & $39 \%$ \\
\hline
\end{tabular}

Source: Rabobank, 2007

${ }^{*} \mathrm{C}-3$ ratio $=\%$ of total production by top 3 producers 
In order to assess the magnitude and variety of innovation activities of the top 25 Chilean and Argentine exporters of bottled wines, and in line with the Schumpeterian tradition, it will be necessary to look not only at new methods of production, but also at the development of new products and new ways of organizing business (Schumpeter, 1939). Reference will be made to Pavitt's taxonomy, according to which natural resource-based sectors are mostly characterized by process innovation undertaken by large high-tech firms (Pavitt, 1984). However, attention will be also paid to the counterarguments provided by several other scholars, who claim that traditional and natural resource-based industries are becoming increasingly knowledge intensive and market driven, thus more responsive to changes on the demand side. They are also increasingly applying sophisticated engineering techniques not only to production but also to areas such as sanitation, quality assurance, environmental sustainability, marketing, packaging and new materials development (Smith, 2001; von Tunzelman and Acha, 2005; Mytelka, 2004).

Therefore, one of the main goals of the survey at the firm level will be to verify the extent to which the top 25 Chilean and Argentine exporters of bottled wines are innovative and have engaged in a technological upgrading process that is considered key to modern winemaking. ${ }^{64}$ As it will be explained in Chapter 3 , this can be applied to three main areas: new winemaking processing techniques, new vine growing techniques for product development, and new marketing techniques. After having analyzed the nature and magnitude of innovation at the firm level, in Chapter 5 the sources of innovation in the Argentine and Chilean wine industries will be specifically investigated, in order to assess whether their export success was a natural extension of earlier practices or the result of radical changes in product and process techniques introduced by foreign investors. Given the sectoral characteristics of the wine industry, the traditional tendency of developing countries to rely on foreign technology in most natural resource-based sectors, and the growing complexity of the knowledge base necessary for innovation, it would not be surprising to find a certain dependency on foreign sources of innovation, such as imports of equipment and machinery, inflows of FDI and international knowledge flows (see Table 2.8).

As Fagerberg and Srholec (2007) put it, "the growing complexity of the knowledge bases necessary for innovation means that even large firms increasingly depend on external sources in their innovative activity". Given the costs and uncertainties related to the innovation process in a developing country context, this often translates into depending heavily on sources located outside the country ( $\mathrm{Fu}$, Pietrobelli and Soete, 2011). From an evolutionary perspective, therefore, it is particularly interesting to study the extent to which sophisticated technological competencies, which are at the centre of the industrialization process - such as the development of local innovation capabilities and the creation of endogenous knowledge - are related to both the accessibility of knowledge and technology from outside and the ability to absorb and adapt it to the local environment through considerable efforts of local firms and institutions (Bell and

\footnotetext{
64 As already mentioned earlier, the term "technological upgrading" refers to the capacity of shifting from lower to higher valued-added economic activities by introducing continuous innovation in processes, products and functions (Pietrobelli and Rabellotti, 2004).
} 
Pavitt, 1993; Pietrobelli, 1996; Cimoli, 2000; Lall and Urata, 2003; Fu, Pietrobelli and Soete, 2011).

Table 2.8 Selected variables to measure the innovativeness of Argentine and Chilean wineries

\begin{tabular}{|c|c|c|}
\hline Type & Main innovations & Relevance \\
\hline \multirow{5}{*}{$\begin{array}{l}\text { Product/ } \\
\text { Viticulture }\end{array}$} & $\begin{array}{l}\text { Identification of best terroirs and of best } \\
\text { clones for each variety }\end{array}$ & $\begin{array}{l}\text { Allows the selection of the best geographic } \\
\text { areas for the best clones of each variety }\end{array}$ \\
\hline & $\begin{array}{l}\text { Introduction of new varieties (in addition } \\
\text { to top four most widely diffused) }\end{array}$ & $\begin{array}{l}\text { Allows the diversification of the production } \\
\text { and the retention of wine consumers }\end{array}$ \\
\hline & $\begin{array}{l}\text { Introduction of drip or furrow irrigation } \\
\text { systems (vs. flooding irrigation) }\end{array}$ & $\begin{array}{l}\text { Allows better control of the amount of water } \\
\text { the plant receives and the timing, thus the } \\
\text { production of top quality grapes }\end{array}$ \\
\hline & $\begin{array}{l}\text { Limitation of the yields for top brands } \\
\text { (Wine Spectator }>90 \text { points) }\end{array}$ & $\begin{array}{l}\text { Allows the growth of grape quality by lowering } \\
\text { yields and concentrating sugar contents }\end{array}$ \\
\hline & $\begin{array}{l}\text { Introduction of organic and/or } \\
\text { biodynamic farming cultivation } \\
\text { techniques }\end{array}$ & $\begin{array}{l}\text { Allows more harmony among the animal, } \\
\text { vegetal and mineral elements of the vineyard }\end{array}$ \\
\hline \multirow[t]{5}{*}{$\begin{array}{l}\text { Process/ } \\
\text { Viniculture }\end{array}$} & $\begin{array}{l}\text { Replacement of big old casks for aging } \\
\text { with smaller oak barrels imported from } \\
\text { the USA and/or France }\end{array}$ & $\begin{array}{l}\text { Allows better aging and the maximum varietal } \\
\text { expression, particularly in the case of red } \\
\text { wines }\end{array}$ \\
\hline & $\begin{array}{l}\text { Use of stainless steel tanks for } \\
\text { vinification }\end{array}$ & $\begin{array}{l}\text { Allows adequate fermentation and retains the } \\
\text { grape's intensity in the must }\end{array}$ \\
\hline & $\begin{array}{l}\text { Installation of refrigeration devices for } \\
\text { both fermentation and maturation }\end{array}$ & $\begin{array}{l}\text { Allows the control of wine temperature, } \\
\text { avoiding excessive acidity levels }\end{array}$ \\
\hline & $\begin{array}{l}\text { Replacement of old vertical presses with } \\
\text { pneumatic presses }\end{array}$ & $\begin{array}{l}\text { Allows a more gently pressing of grapes, } \\
\text { extracting better juice and avoiding unwanted } \\
\text { aromas }\end{array}$ \\
\hline & Use of gravity flow mechanisms & $\begin{array}{l}\text { Allows the avoidance of hydraulic pumps, } \\
\text { preserving the grape's expression }\end{array}$ \\
\hline \multirow{5}{*}{$\begin{array}{l}\text { Organization } \\
\& \text { marketing }\end{array}$} & Creation of new terroir brands & $\begin{array}{l}\text { Allows the diversification of the offering and } \\
\text { the attraction of new customers }\end{array}$ \\
\hline & $\begin{array}{l}\text { Participation at international wine } \\
\text { competitions }\end{array}$ & $\begin{array}{l}\text { Allows the improvement of image and } \\
\text { positioning at international level }\end{array}$ \\
\hline & $\begin{array}{l}\text { Use of social networks (Facebook, } \\
\text { Youtube and/or Twitter) for marketing } \\
\text { purposes }\end{array}$ & $\begin{array}{l}\text { Allows the outreach of a different, usually } \\
\text { younger pool of consumers and the } \\
\text { rejuvenation of the image of the winery }\end{array}$ \\
\hline & $\begin{array}{l}\text { Organization of winery tours, food and } \\
\text { wine tastings, cultural events }\end{array}$ & $\begin{array}{l}\text { Allows the captivation of diversified wine } \\
\text { consumers through wine tourist attractions }\end{array}$ \\
\hline & $\begin{array}{l}\text { Adoption of a sophisticated architectural } \\
\text { design of the winery as a marketing tool }\end{array}$ & $\begin{array}{l}\text { Allows the attraction of visitors and the } \\
\text { characterization of the winery in a distinctive } \\
\text { manner }\end{array}$ \\
\hline
\end{tabular}

Source: Author's elaboration 
In the case of the Chilean and Argentine wine industries, therefore, both internal and external sources of innovation and technological change will be examined (see Figure 2.11). It is widely acknowledged that firms cannot be only passive recipients of new knowledge, and the acquisition of skills and resources from outside has to be matched by the generation of expertise internally (Powell, 1995). Also, the ability to exploit external knowledge is a function of the level of prior related knowledge, conferring the ability to recognize the value of new information, assimilate it, and apply it to commercial ends (Cohen and Levinthal, 1989).

Figure 2.11. Internal and external sources of innovation and technological change in the Argentine and Chilean wine industries

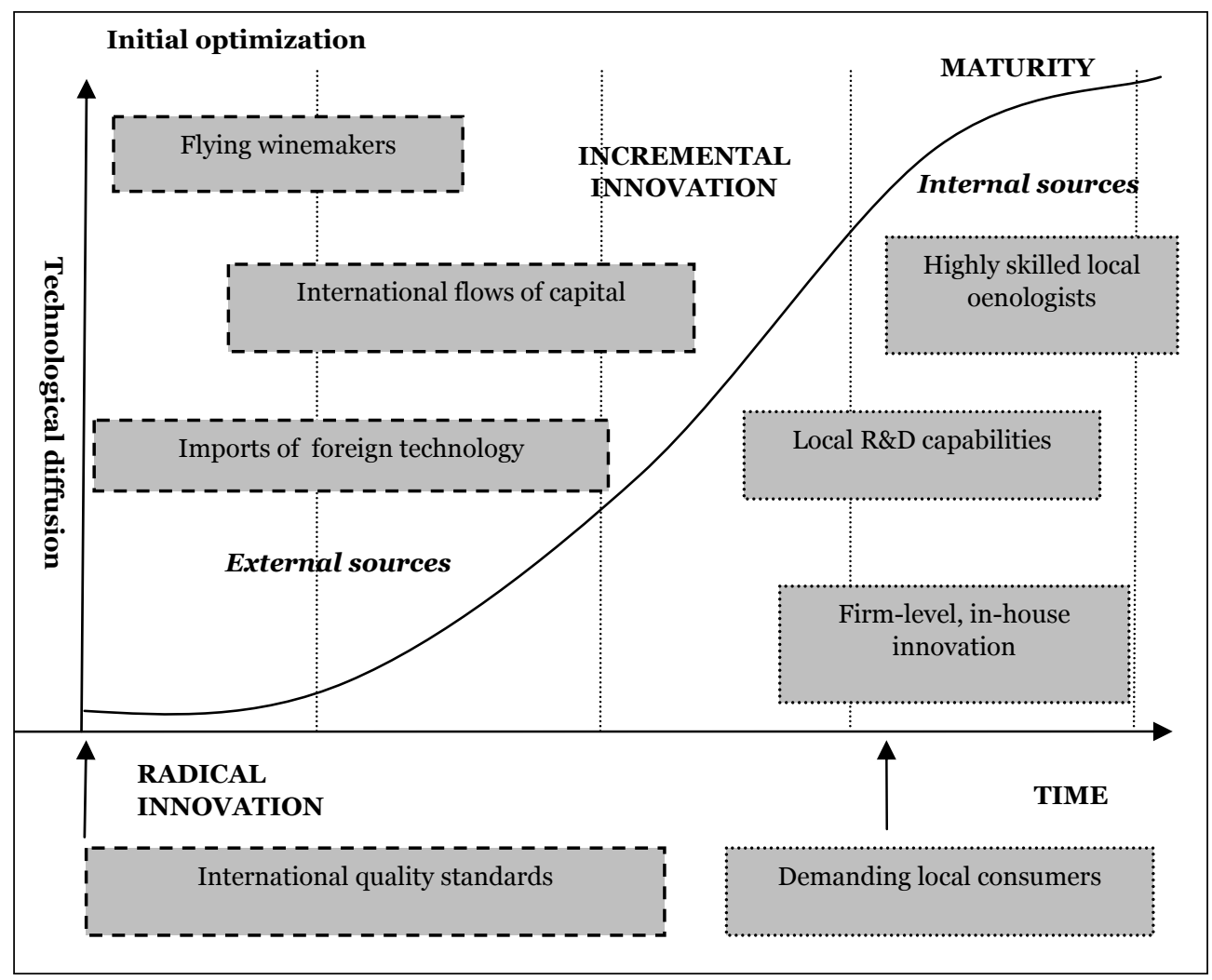

Source: Author's elaboration based on Dosi, 1982

Consequently, Chapter 5 will assess, on the one hand, the extent to which the industry has been relying on imported technology, foreign capital and tacit and codified knowledge flows, and, on the other hand, the extent to which it has been able to meet international quality standards, which involves generating substantial technical and organizational knowledge (Perez-Aleman, 2005). While it will be possible to rely on macro-economic data to assess the first two variables related to the import of winemaking technology and the inflows of FDI in the wine industry, the study will rely 
on first-hand data collected during the field work to qualify the presence and the impact of foreign investment in the Chilean and Argentine wine industries (see Table 2.9).

Table 2.9 Selected indicators to assess the reliance of the Argentine and Chilean wine industries on external vs. internal sources of innovation

\begin{tabular}{|c|c|c|c|c|c|}
\hline \multicolumn{3}{|c|}{ External sources } & \multicolumn{3}{|c|}{ Internal sources } \\
\hline Source & $\begin{array}{l}\text { Type of } \\
\text { data }\end{array}$ & Indicator & Source & $\begin{array}{l}\text { Type of } \\
\text { data }\end{array}$ & Indicator \\
\hline $\begin{array}{l}\text { Imports of foreign } \\
\text { machinery }\end{array}$ & $\begin{array}{l}\text { Macro level: } \\
\text { Comtrade } \\
\text { database }\end{array}$ & $\begin{array}{l}\text { Value of } \\
\text { Chilean and } \\
\text { Argentine } \\
\text { imports of } \\
\text { foreign wine } \\
\text { machinery }\end{array}$ & $\begin{array}{l}\text { Highly } \\
\text { qualified } \\
\text { human } \\
\text { resources }\end{array}$ & $\begin{array}{l}\text { Micro level: } \\
\text { Author's } \\
\text { survey of } \\
\text { leading } 25 \\
\text { exporting } \\
\text { wineries }\end{array}$ & $\begin{array}{l}\text { Qualification } \\
\text { of Argentine } \\
\text { and Chilean } \\
\text { oenologists }\end{array}$ \\
\hline Inflows of FDI & $\begin{array}{l}\text { Macro level: } \\
\text { Foreign } \\
\text { Investment } \\
\text { Committee } \\
\text { estimation } \\
\text { (Chile) and } \\
\text { Author's } \\
\text { estimation } \\
\text { (Argentina) }\end{array}$ & $\begin{array}{l}\text { FDI flows in } \\
\text { the Chilean } \\
\text { and } \\
\text { Argentine } \\
\text { wine } \\
\text { industry }\end{array}$ & $\begin{array}{l}\text { In-house } \\
\text { innovation } \\
\text { capacity }\end{array}$ & $\begin{array}{l}\text { Micro level: } \\
\text { Author's } \\
\text { survey of } \\
\text { leading } 25 \\
\text { exporting } \\
\text { wineries }\end{array}$ & $\begin{array}{l}\text { Number of } \\
\text { firms having } \\
\text { introduced } \\
\text { incremental } \\
\text { innovations } \\
\text { thanks to in- } \\
\text { house efforts }\end{array}$ \\
\hline \multirow[t]{2}{*}{$\begin{array}{l}\text { Flows of } \\
\text { international } \\
\text { (tacit and } \\
\text { codified) } \\
\text { knowledge }\end{array}$} & $\begin{array}{l}\text { Micro level: } \\
\text { Author's } \\
\text { survey of } \\
\text { leading } 25 \\
\text { exporting } \\
\text { wineries }\end{array}$ & $\begin{array}{l}\text { Number of } \\
\text { firms that } \\
\text { have } \\
\text { contracted } \\
\text { foreign } \\
\text { consultants }\end{array}$ & $\begin{array}{l}\text { R\&D } \\
\text { activities in } \\
\text { local } \\
\text { universities } \\
\text { and research } \\
\text { institutions }\end{array}$ & $\begin{array}{l}\text { Macro level: } \\
\text { Available } \\
\text { literature on } \\
\text { the subject } \\
\text { and } \\
\text { Author's } \\
\text { interviews }\end{array}$ & $\begin{array}{l}\text { Number of } \\
\text { wine research } \\
\text { institutions } \\
\text { and programs }\end{array}$ \\
\hline & & $\begin{array}{l}\text { Number of } \\
\text { oenologists } \\
\text { who have } \\
\text { studied in } \\
\text { foreign } \\
\text { universities }\end{array}$ & & & $\begin{array}{l}\text { Wine } \\
\text { publication } \\
\text { output and } \\
\text { citations }\end{array}$ \\
\hline $\begin{array}{l}\text { Adoption of } \\
\text { international } \\
\text { quality standards }\end{array}$ & $\begin{array}{l}\text { Micro level: } \\
\text { Author's } \\
\text { survey of } \\
\text { leading } 25 \\
\text { exporting } \\
\text { wineries }\end{array}$ & $\begin{array}{l}\text { Number of } \\
\text { firms that } \\
\text { have } \\
\text { achieved } \\
\text { quality } \\
\text { certification } \\
\text { (e.g. HCCP, } \\
\text { ISO, etc.) }\end{array}$ & $\begin{array}{l}\text { Presence of } \\
\text { demanding } \\
\text { local buyers }\end{array}$ & $\begin{array}{l}\text { Macro level: } \\
\text { Available } \\
\text { literature on } \\
\text { the subject }\end{array}$ & $\begin{array}{l}\text { Type and level } \\
\text { of domestic } \\
\text { consumption }\end{array}$ \\
\hline
\end{tabular}

Source: Author's elaboration 
Particular efforts will be undertaken to detect the presence of joint-ventures between foreign and domestic firms, as joint-ventures, among all types of FDI, may be more conducive to the transfer and generation of knowledge and technology to domestic partners, namely of positive spillovers to local firms and long-lasting effects for development (Narula and Lall, 2004; Te Velde, 2006; Te Velde and Nair, 2006; UNCTAD, 2009). Additionally, as shown in the table above, the research will rely on micro level data collected during the field survey to measure the extent to which international quality standards by local wineries and the presence of tacit and codified knowledge flows through the presence of foreign winemakers and consultants have been attained.

In this respect, Giuliani (2007) argues that in the wine industry the capacity to absorb codified knowledge through a process of decoding and the capacity to absorb tacit knowledge are equally important. Tacit knowledge is the result of a process of accumulating experience over time and is complementary to codified knowledge. Oenologists and agronomists, who both embody tacit skills, are decoders of codified knowledge and apply it to a complex, ever-changing environment. The evolutionary literature suggests that, as technology becomes more sophisticated and science advances, the ratio of codified to tacit knowledge also increases. It also suggests that, as codification is never complete, some forms of tacit knowledge always play an important role (Cowan and Foray, 1997). In the wine industry, although procedures used for winemaking have been, to a large extent, codified, the adaptation of both vinicultural and viticultural techniques to local geographical and climatic conditions, and to the type of wine being made (whether it is for immediate or deferred consumption) cannot be codified, and relies rather on the application of tacit knowledge.

Therefore, it will be important assess the extent to which technology and knowledge has been absorbed in a way that is conducive to development, namely the presence of a solid local absorptive capacity. Due to the lack of aggregated data, this assessment will be carried out by using two main indicators through the firm-level surveys (Soete, 2006): the presence of a highly qualified professional staff in the wineries and their inhouse innovation activities. Additionally, at a more macro level endogenous sources of innovation will be searched for, by looking at $\mathbf{R} \& \mathbf{D}$ efforts undertaken by Chile and Argentina at the sectoral level and at the presence of demanding buyers in the home markets, which are considered by the evolutionary literature as key to stimulating innovation and quality improvements.

Finally, the overall macroeconomic framework conditions and the impact of policy and macro-level structural changes introduced over the last decade on the productive systems of Chile and Argentina will be examined. In particular, the interaction between micro and macro policies and their effect on the incentives to innovate will be assessed. Evidence shows in fact that globalization has deeply affected the patterns of productive specialization in Latin America, and that the structure and behaviour of innovation systems have dramatically changed after the transition from import substitution regimes to an open, deregulated and almost completely liberalized environment. In this respect, Cimoli et al. (2005) argue that, after the structural reforms, most Latin American countries went through a drastic evolution of their technology policy models 
and completed the transition from totally supply-side linear schemes (reminiscent of the import substitution phase), to totally demand-side linear schemes. However, in a well-functioning innovation system, both demand-side and supply-side incentives are needed. In Chapter 5, the different ways in which the transformation of this complex balance has affected the technological capabilities in Chile and Argentina will be highlighted.

\subsection{Methods and techniques of research: Hypothesis III}

In order to examine the propositions contained in the third hypothesis, ${ }^{65}$ the causal relationship between the configuration of clusters, regional innovation systems and sustained export growth will be examined. The evolutionary literature has come to see the technological gap between countries, sectors or regions as the possible outcome of different technological and institutional policies and of a different mix of demand-pull and technology-push incentives, i.e., of a different way in which policies rely on the combination of public and private goods to generate innovative results (Lundvall et al., 2002). Chapter 6 will go beyond the "linear logic" of policy incentives and move towards the analysis of a more synchronized evolution pattern of production structures and technology policies at all levels, i.e., national, but also sectoral, regional and local. In particular, the cluster dimension will be the point of departure of the analysis, since it is known that natural resources are often geographically clustered, and that in the wine industry clusters may represent important centers of externalities for the production of endogenous learning and production capabilities.

During the last decade, the literature applying the cluster analysis to the wine industry has proliferated. Studies have looked at wine clusters in a variety of developed and developing countries, among which Argentina (Farinelli, 2007; Mc Dermott, 2005); Australia (Aylward, 2004; Smith and Marsh, 2007); Brazil (Vargas, 2002; Vargas, Cassiolato and Britto, 2006); California (Porter, 1998); Canada (Mytelka and Goertzen,

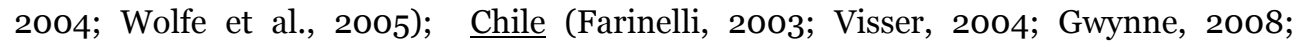
Giuliani, 2003 and 2007); Czech Republic (Tomsik, and Prokes, 2011); France (Ditter, 2005; Bélis-Bergouignan et al, 2010); Italy (Zanni, 2004; Giuliani, 2006; Rabellotti and Morrison, 2009); South Africa (Wood and Kaplan, 2005 and 2008); Portugal (Rebelo et al., 2010; Muhr and Rebelo, 2011); Spain (Larreina and Aguado, 2008); Uruguay (Penn, 2001). Less frequently, scholars have looked at the wine industry from an innovation system perspective in the search for determinants of success and competitive performance related to "extra cluster" connections at the regional, sectoral or national level (Migone and Howlett, 2010; Cusmano, Morrison and Rabellotti, 2009; Giuliani and Bell, 2007).

The present study will look at both the emergence of synergies and collective efficiencies stemming from geographical proximity advantages and social interaction at

\footnotetext{
65 Hypothesis III: (a) Sustained export growth in natural resource-based processing industries is linked to the transformation of natural resource-based clusters from informal into organized clusters. (b) The interaction of organized clusters with broader regional innovation systems is equally important
} 
the cluster level, as well as the interplay between clusters and regional innovation systems. To do so, it will rely on both quantitative and qualitative data collected through the firm surveys during the field work, interviews with key informants, and on the consultation of official statistical sources (national institutes of statistics, business associations, export promotion boards, international organizations and universities). To begin with, the top 25 exporting wineries at the cluster level will be mapped out in both Chile and Argentina, and the geographical distribution and concentration of wine exports at the regional level will be verified (see Annex II). Subsequently, under the cluster approach, the study will focus on the following aspects:

- the critical actors in the local productive system, such as: firms (buyers, producers, suppliers), service providers, research institutions, productivity centers, training programs, universities, banking and financial structures, certification bodies, etc. and their respective competences;

- the passive externalities generated by agglomerations and the advantages of geographical proximity (common infrastructure; a skilled pool of labour, with industry-specific competencies; dedicated business services; specialized suppliers and service providers; the availability of non-tradable, intermediate outputs; the easy transmission of new ideas, knowledge and informational spillovers);

- the vertical relationships between users and producers, and horizontal collaboration between producing firms yielding to "collective efficiencies" (interfirm linkages, cooperative competition, diffused know-how, reduced transaction costs, the spirit of emulation, confidential channels for information exchange, accelerated innovation through problem-solving);

- the supporting role that local political and social institutions play in the development of partnering activity and in removing obstacles and bottlenecks for business ventures (e.g. the role of business associations);

- current local development policies and measures for developing territorial competitiveness;

- the extent of trust, social cohesion and sense of identity, the embeddedness of the industry in the society.

Noting the distinction between informal and organized clusters, the existence of any correlation between the presence of organized (versus informal) clusters and successful export performance (defined as "sustained export growth for more than one decade") will be detected. In this respect, the views in the literature seem to coincide. If Aylward (2004) argues that "it is the desire to export and to expand markets that triggers systemic organization at the cluster level”, Malmberg and Power (2005) claim that "knowledge in clusters is created through various forms of inter-organizational collaborative actions", while Perez-Aleman (2005) suggests that "the emergence of dynamic clusters depends on building institutions that enable coordinate learning among firms to improve capabilities, processes and products". 
As it has emerged in the literature review, the ability of firms in a cluster to upgrade their capabilities and improve their performance depends on a complex web of actors, which includes firms (buyers, producers, specialized suppliers), but also service providers, research institutions, productivity centers, training programs, universities, banking and financial structures, certification bodies, etc. In an organized cluster, these actors are highly interconnected and include a wide array of other entities that are important to competition, some of which extend laterally to producers from complementary clusters (see Figure 2.12). This is even more apparent in the case of industries relying on technologies that are combinatorial in nature (Mytelka, 2004).

Figure 2.12 Structure of organized wine clusters

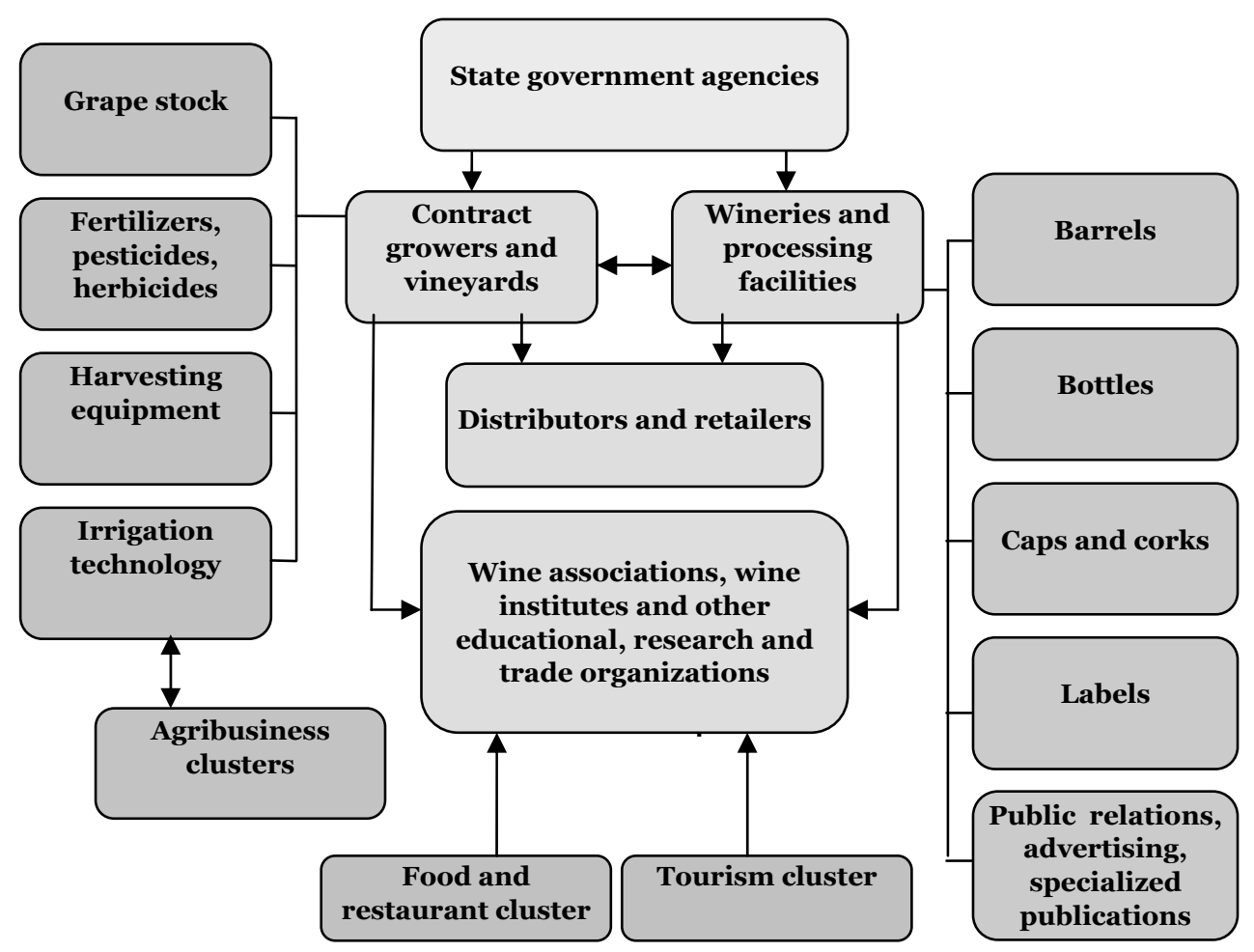

Source: Adapted from Porter, 1998

In this respect, Boschma and Iammarino (2007) argue that the more diversified the regional economy, the more knowledge spillovers will occur, thanks to the presence of “Jacobs' externalities" (Jacobs, 1969), that is, the interaction among local firms that operate in different industries. This is particularly the case in industries where there are complementary or shared competencies, so-called "related varieties", and where the colocation of R\&D centers, component fabrication, customer support, specialized suppliers, etc. can facilitate the diffusion of new ideas and innovation, and recombine pieces of knowledge in novel ways. 
In order to the detect the presence of organized (versus informal) clusters, the study will rely on the categorization proposed by Nadvi and Schmitz (1999), who distinguish four types of inter-organizational collaborative action, namely:

- joint action within vertical linkages, including backward ties and networks with suppliers and subcontractors, and forward ties with traders and buyers;

- joint action within horizontal linkages, between two or more local producers (including joint marketing of products, joint purchase of inputs, order sharing, common use of specialized equipment, joint product development);

- $\quad$ joint action within institutional linkages among a large number of local producers and cluster-wide institutions (including business associations and business development services);

- $\quad$ joint action made possible by public-private partnerships.

With respect to the issue of detecting the presence of intense collaborative interaction among similar and related firms, the provocative arguments of Malmberg and Power (2005) are particularly noted. In their interesting study on the mechanisms explaining knowledge creation at the cluster level, the authors found that, to date, the existence of cooperative behaviour among firms within clusters can be supported by very limited evidence through available literature. Their point is well taken, namely that the willingness of clustered firms to engage in organized transactions and collaborations among themselves is a relevant knowledge creation mechanism, but has often been overemphasized. More importantly, however, their point that substantial informal knowledge exchanges at the cluster level seem to rather happen among specialized individuals and skilled labour through social interaction (Saxenian, 1994) is especially noted.

In this sense, the ability to form and maintain effective socio-economic relations can be considered a key competence of clusters. Therefore, special attention will be paid to track the mobility of local professionals at the cluster and inter-cluster level, in particular of local oenologists, based on the assumption that very often the most successful clusters in terms of knowledge creation are the ones with the highest rates on inter-firm labour mobility (Power and Lundmark, 2004). As Malmberg and Power (2005) put it:

Knowledge, rather flowing freely within the boundaries of the cluster, circulates within small epistemic communities [...] The acquisition knowledge through the hiring of experts from other firms can be useful as a means for exploring technologically distant knowledge as well as for extending the hiring firm's geographical reach. Distant contexts may offer ideas and insights that can be extremely useful to innovation through knowledge recombination (Malmberg and Power, 2005, $p$ 423). 
Subsequently, the study will identify possible correlation factors among building blocks of clusters (dependent variables) and regional performances (independent variables). ${ }^{66}$ In fact, the capability of clusters of diffusing information and knowledge, as well as of importing it from elsewhere, depends on the creation of interactive networks with both internal and external agents, as well as various kinds of $\mathrm{R} \& \mathrm{D}$ cooperation, between firms as well as between firms and research laboratories, which take place mostly at the regional level. As Lundvall and Borràs put it (1999), "the region is increasingly the level at which innovation is produced through regional networks of innovators, local clusters and the cross-fertilizing effects of research institutions". Under the RIS perspective, therefore, the study will focus on the following aspects:

- the critical actors in the regional innovation system, such as: firms (buyers, producers, suppliers), service providers, research institutions, productivity centers, training programs, universities, banking and financial structures, certification bodies, regional branches of industry associations chambers of commerce, etc., and their respective competences;

- the distribution of knowledge across all the various regional agents (firms, universities, technology institutes, R\&D centers and other "bridging institutions", such as technology or innovation centers, institutions involved in education, and training, and institutions responsible for the financing of innovation);

- the nature and the extensiveness of linkages and interactions dealing with technological and innovation issues taking place among the key institutions and players at the regional level;

- the presence of related varieties within the same region, which enhance effective interactive learning, knowledge diffusion and innovation;

- the degree of openness, the capacity to absorb/attract external resources, and the role of FDI in terms of knowledge transfer and technological spillovers;

- current regional policies (industrial, technological, commercial, financial, educational, etc.) that shape the parameters within which actors at the regional level make decisions about investment, linkages and innovation.

In this context, Cooke and Leydesdorff's (2006) views are fully shared, according to which regions represent the most relevant system of reference for stimulating knowledge-based economic development, thanks to the creation of regional systemic advantages, or "constructed advantages", which are essential to promote innovation and growth. In this respect, Asheim and Gertler (2005) note that regions are characterized by a "unique institutional endowment", and that the systemic character of RSI is reinforced by the existence of a specific regional culture, resulting from

\footnotetext{
66 According to Cooke and Leydesdorff (2006), a region is an administrative division of a country. It is nested territorially beneath the level of the country, but above the local or municipal level.
} 
distinctive regional attitudes, values, norms, routines and expectations, which determine how firms interact with each other in the regional economy.

Therefore, the study will also take into consideration what Cooke (2001) defines as infra-structural and supra-structural variables. These relate, on one hand, to the availability of "proximity capital", thanks to the autonomous spending competence of regions and the presence of a regional credit-based system in which the regional administration can be involved in co-financing or in the provision of loan guarantees; and, on the other hand, they relate to an intangible factor that is equally important in mobilizing the innovation potential of a region, namely its institutional, organizational and governance embeddedness. This is defined as the extent to which a social community operates based on shared norms of cooperation, trustful interaction, inclusive rather than exclusive operational mechanisms, and consultative rather than authoritarian and hierarchical governance methods (Cooke, 2001).

Finally, it should be noted that this research takes into account the importance of the national dimension, as it is known that, contrary to RSI, NSI usually sets scientific priorities and funds basic research and university level training, thus shaping the way in which social relationships among economic actors would occur also at the local level (Cooke, 2001; Chistopherson, 2002). However, the findings of Saxenian's comparative study of California's Silicon Valley and Route 138 (Saxenian, 1994) are also taken into account, according to which the same national institutional platform may originate widely divergent regional innovation systems, as well as a variety of clusters specialized in the same product but performing very differently. In this respect, Carlsson and Stankiewicz (1991) emphasize that "high technological density and diversity are properties of regions rather than countries". The concluding chapter of the thesis will provide, therefore, an integrated, generalizable analytical framework for positioning the wine industry, and, more generally, natural resource-based processing industries along their technological and development trajectory, through policy interventions at the national, regional and cluster level. 



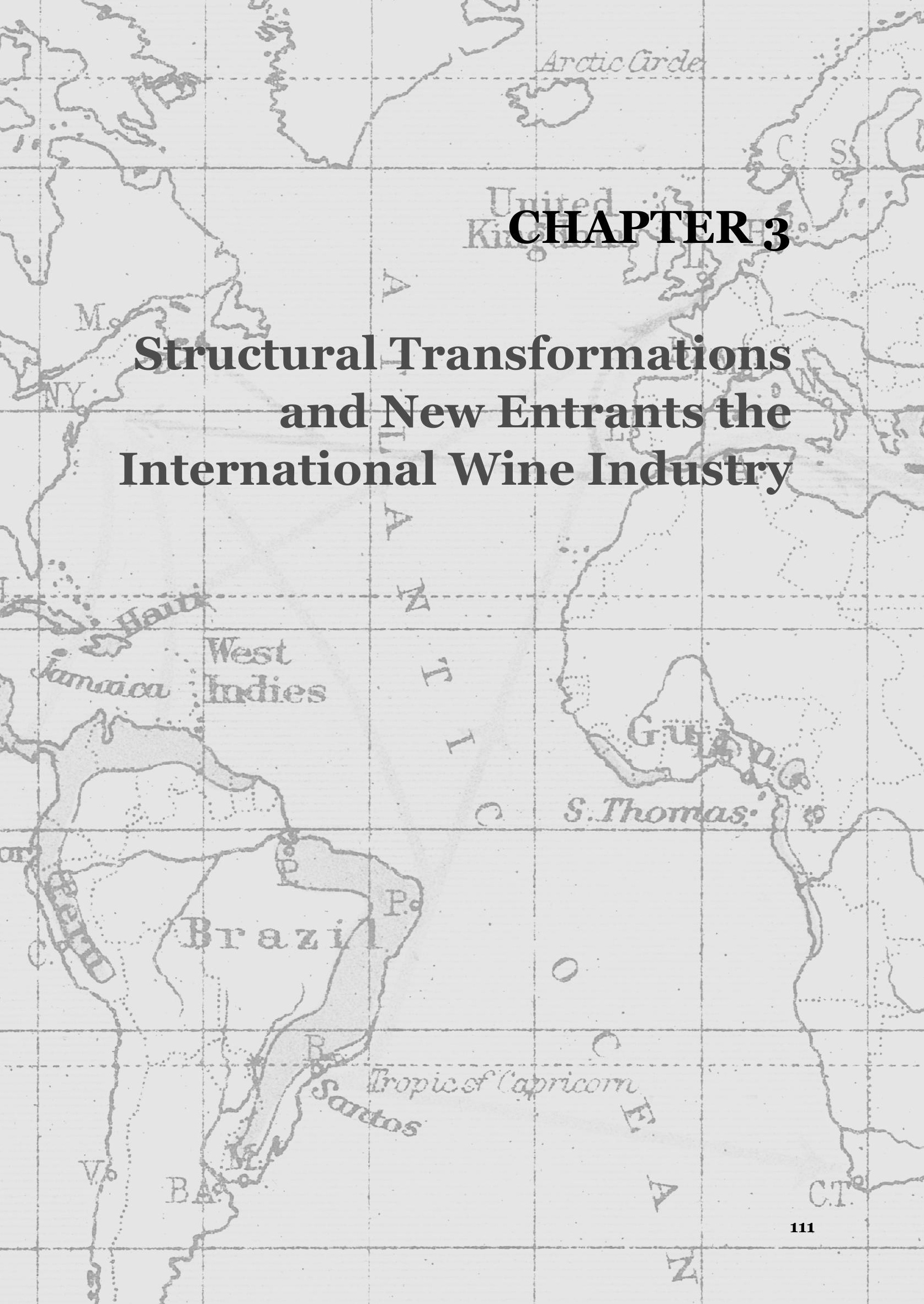


CHAPTER 3

112 


\subsection{Introduction}

Chapter 1 has highlighted that, for at least two centuries, there has been a generalized perception that economic progress entailed moving away from natural resources into more sophisticated industries based on knowledge, skills, capital and technology. By making reference to the case of the cut flowers industry in Colombia and to the case of farmed salmon in Chile, Chapter 2 has also observed that - along with manufacturing - traditional and natural resource-based sectors have also become more knowledge intensive, and that natural resources are not necessarily confined to the low end of the technology spectrum anymore. The present chapter focuses on the wine industry as an ideal case to illustrate how natural resource-based processing sectors have become increasingly knowledge and innovation intensive. The chapter provides solid evidence of the increasing importance of both codified and tacit knowledge in the emergence of the modern concept of quality winemaking. It shows how the growth of the international wine trade, which has characterized the last quarter of the twentieth century, was mainly due to a group of new entrants - so-called "New World" producers - that managed to compete in a market dominated for centuries by established "Old World" producers, based on quality upgrading, R\&D and the incorporation of sophisticated new machinery and equipment. ${ }^{67}$ This chapter also explores the opportunities and challenges for the entry of developing countries into the modern wine industry. It thus lays the ground to explore the hypothesis that entry opportunities do exist - but that for developing countries, taking advantage of them is increasingly difficult due to growing technological complexity.

This chapter is structured as follows: Section 2 provides an historical overview of winemaking since antiquity. Section 3 traces the growing knowledge intensity of the wine industry to the late nineteenth century, when science was brought in to solve problems of different nature both in the area of viticulture and in the area of viniculture. Section 4 illustrates the deepening of this process in the last quarter of the twentieth century, when innovation of all sorts permeated the wine industry in all its phases. Section 5 focuses on the key role of tacit, codified and capital-embodied knowledge in modern winemaking, as pillars of the so-called "wine revolution". Section 6 examines the relationship between this revolution and the dramatic shift in international wine consumption patterns. Section 7 shows how the capacity to innovate was key to the ability of New World producers to become leading wine exporters, and how this translated into fast-growing world wine market shares. Section 8 illustrates show FDI flows, mergers and acquisitions (M\&A), alliances and joint-ventures have radically changed the structure of the world wine industry. Section 9 portrays the

\footnotetext{
67 "New World" wine producers include industrialized countries such as the United States, New Zealand and Australia, but also developing countries, such as Chile, Argentina and South Africa. These are all former settler colonies and have entered the world wine market only recently, even though vineyards have existed in their territories since the times of colonization. "Old World" wine producers include European countries, such as France, Italy and Spain, which have represented for centuries the leading wine producers, exporters and consumers.
} 
surprising entry of developing countries under these new circumstances. The concluding section sets the stage for the three remaining chapters, incorporating the empirical work of the thesis.

\subsection{The wine industry in antiquity}

Wine represents one of the oldest consumer goods that was traded among countries and has a history of being characterized, identified and distinguished based on its geographical origin. Since Roman times, ancient consumers had already developed a quite sophisticated taste and were prepared to pay remarkable sums to enjoy wines produced in the most reputed regions (Jenster et al., 2008). In this section, the fundamentals of the history of wine in the ancient world will be provided, illustrating basic technical concepts related to wine quality, variety and production techniques. Such concepts will be elaborated and contextualized in a more modern scenario in the following sections, but it is interesting to note that they were present and more or less formally recognized since antiquity.

According to the first book of the Old Testament, the first grapevines were planted by Noah on the high, cool plains of Mount Ararat, where Noah's Ark landed after the waters of the Great Flood receded (Genesis, 9:20-1). Thus, it is not uncommon to find literary references to the biblical origin of wine. The earliest scientific evidence of wine residues, however, dates back more than 7,500 years, namely to the mid-fifth millennium BC. They were detected during archaeological excavations in Iran, in the northern Zagros Mountains, thanks to the presence of tartaric acid and calcium tartrate deposits (Phillips, 2000; McGovern, 2003).68 Older examples of fermented beverages have been also discovered in China, dating to 9,00o years ago, but these seem to have been produced from rice, honey or hawthorn (Jackson, 2008).

Historians believe that wine was first developed in the late Stone Age, probably by someone who accidentally left some grapes in a jar, where fermentation spontaneously occurred with the help of wandering yeasts (Taber, 2005). From an historical perspective, though, there is a longstanding debate on whether the definition of wine would be applicable to any fermented grape juice or should be restricted to that of a grape juice that is intentionally fermented and stored to maintain its properties (Unwin, 1991). ${ }^{69}$ As a matter of fact, the production process of wine is very simple: It

\footnotetext{
68 In September 2010, researchers from the Costen Institute of Archaeology at the University of California, Los Angeles, discovered in a cavern of Armenia what they believe to be the oldest known winery, dating to about 6,100 years ago (4,100 BC). They found a large vat set in a platform for treading grapes, along with well preserved remains of crushed grapes, seeds and vine leaves, as well as storage jars, a drinking cup and bowls. Quite interestingly, the ancient seeds belong to a domesticated grape variety, called Vitis vinifera vinifera, which is still used to make red wine today (The Wall Street Journal, 11 January 2011).

69 The first law defining wine as the result of the fermentation of fresh grapes thanks to deliberately inoculated yeasts was adopted in France in 1889 (Campbell, 2004). From a regulatory perspective, the European Union, which represents the most important actor in the world wine industry, currently defines wine as "the product obtained exclusively from the total or partial alcoholic fermentation of fresh grapes, whether or not crushed, or of grape must" (Annexure I to EU Regulation No. 822/87).
} 
basically requires grape juice (called "must" at the beginning of the fermentation process) to be pressed, collected and stored in tanks until its fermentation is completed. Although wine grapes ferment very quickly, thanks to the presence of fermentable sugars and indigenous yeasts, the latter do not necessarily belong to the grape flora but can be rather found in the bark and sap of oak trees. Not surprisingly, the traditional habit of grapevines to climb trees (as well as other supports) may explain the accidental inoculation of grapes and grape juice with oak yeasts (Jackson, 2008).

The earliest unequivocal evidence of intentional winemaking can be traced to Egypt, where archaeologists found representations of wine presses in the region of Udimu, dating to 3000 BC, as well as wine amphorae in both King Semerkhet's (2770 BC) and King Tutankhamun's tombs (1325 BC). There is also evidence that with the Egyptians wine came to be an integral part of the economy. Archaeologists found documents dating to about $2500 \mathrm{BC}$ referring to the existence of a tax on wine and of a public official, called the "Inspector of Wine", whose task was to taste and evaluate the quality of wine before it was stored or sold (Pellechia, 2006). After Egypt, wine followed the military leadership of the Greeks and the Romans. Thanks to Greek settlers, the first wine reached France, in particular Massalia (the present Marseille), in $600 \mathrm{BC}$, and the Italic peninsula between 1000 and 800 BC. Since then, Western European countries, and in particular France and Italy, have become the undisputed leaders of the international wine industry, representing by far the biggest producers, consumers and exporters of wine until the present days.

It is thanks to the Romans that the area of wine production reached from southern England in the North to northern Africa in the South, and from Portugal and Spain to the West to Western Russia in the East. Many centuries later, French and Spanish colonizers replicated the prodigious expansion of grapevine cultivation realized by the Romans by spreading it further into the most temperate climatic regions of the globe..$^{70}$ At the time of the Roman Empire, vine growing had already been transformed from a periodic, haphazard event to a codified cultivation practice, according to which, from wild and uncontrolled, vine growth had to be restricted to a convenient height by training the plants along trellises and stakes in order to facilitate fruit ripening and harvesting. Combined with advances in winemaking and storage, such as the habit of sealing wine amphorae with cork and storing them upside down to keep the cork wet, the Romans set the stage for the proliferation of the wine trade. After $1000 \mathrm{BC}$, in fact, wine became a highly traded commodity and was distributed throughout the greater Mediterranean area (Phillips, 2000). However, there is clear evidence that wine had started to be traded even earlier, by the Phoenicians and the Carthaginians. The Code of

\footnotetext{
${ }^{70}$ Wine production is traditionally restricted to areas with Mediterranean-like climates, ranging between the 10 and $20^{\circ} \mathrm{C}$ annual isotherms. This corresponds to the geographical latitudes between 30 and 40-50 degrees, both in the Northern and Southern Hemisphere, where vines receive enough sunshine to ensure consistent yields and are protected from damaging frosts. Extension into cooler or warmer climates has been made possible by the introduction of increasingly sophisticated oenological practices, compensating for the disadvantages of non ideal climatic conditions. For example, nowadays grapes are cloned to improve their resistance to cold and diseases, while canopy management practices can enhance the ripening potential of the fruit. In warmer climates, modern temperature control techniques can make sure that the fermentation process of wine is kept under control and not disrupted by excessive heat (Phillips, 2000).
} 
Hammurabi (1750 BC), for example, comprised rules governing wine trade and established severe punishments for fraudulent wine merchants found guilty of watering down wine, namely to be drowned in the Tigris or the Euphrates River. The same punishment was also prescribed for those who were found drunk and behaving unruly in the city-state of Babylon, where wine was not produced, but certainly bought and sold in abundance (Pellechia, 2006).

The distinction between quality and ordinary wine also goes back to antiquity. Throughout Egyptian, Greek and Roman times, for common citizens and workers, wine mainly represented an ordinary, mass-produced commodity, consumed as a basic daily food - Pliny the Elder used to call it vinum operarium (wine for the working class) and was produced by using already fermented grapes. It tasted so bad that it often needed to be corrected, or as the Romans would say "medicated", with herbs, spices and ingenious artifices. It is known, for example, that the Romans used to add pitch and resin to wine to mask its defects and deterioration, that lower alcoholic grade wines were often treated with highly concentrated must, and that inferior quality wines were blended with sea water and flavoured with honey, spices and medical herbs. Overall, there is a widespread perception that Roman wines - which have been ironically defined by the famous wine critic Hugh Johnson as "something between vinegar and Beaujolais" - would hardly appeal to modern palates (Jackson, 2008; Johnson, 2007). The recipe provided by Cato the Elder in his detailed essay on agriculture gives a better idea of its probable quality:

Pour into a jar 10 quadrantals of must, 2 quadrantals of sharp vinegar, 2 quadrantals of boiled must, 50 quadrantals of fresh water. Stir with a stick thrice a day for five consecutive days. Then add 64 sextarii of old sea-water, cover the jar, and seal ten days later. This wine will last you until the summer solstice; whatever is left over after the solstice will be a very sharp and excellent vinegar. If your place is far from the sea, you may use this recipe for Greek wine: pour 20 quadrantals of must into a copper or lead boiler and heat. As soon as the wine boils, remove the fire; and when the wine has cooled, pour into a jar holding 40 quadrantals. Pour 1 modius of salt and 1 quadrantal of fresh water into a separate vessel, and let a brine be made; and when the brine is made pour it into the jar. Pound rush and calamus in a mortar to make a sufficient quantity, and pour 1 sextarius into the jar to give it an odour. Thirty days later seal the jar, and rack off into amphorae in the spring. Let it stand for two years in the sun, then bring it under cover (Marcus Cato, De Agricultura).

Throughout the ancient times, higher quality wines were also produced and traded in limited quantities for the benefit of the élites. For example, it was already under Numa Pompilio, the second of the seven Kings of Rome (754 BC - 673 BC), that vine growers became aware of the importance of pruning to be able to raise the sugar content of must, and to extract more and better aromas from the crushed skin of grapes - to the point that pruning became a compulsory practice for the production of higher quality wines. Literary sources from the times of the Roman Empire reveal that not only minimum wine aging had already been met, but also that distinctions between vintages, vineyards and regions were regularly made. In his Satires, the famous 
Latin poet Horace praises a wine stored for forty-six years in a cork sealed amphora (Saturae, book IV), while in the Georgics, the Latin poet Virgil argues that the existing varieties of wine were innumerable, to the point that counting them would have been like counting the grains of sand elevated by the Southern winds or the waves of the sea during a thunderstorm (Georgicon, book II). ${ }^{71}$ In his Encyclopedia on Natural History, Pliny the Elder listed 91 varieties of wine, including 50 of higher quality wine and 38 varieties of foreign wines. He also provided some remarkably modern suggestions on how to produce sweet wines, such as adding boiled-down must or leaving the grapes to partially dry in the sun, and argued that higher quality wine should be aged naturally, and not smoked nor stored in the sun (Naturalis Historia, book XII).

Since antiquity, wine has also played a major symbolic role. It was often used for religious rituals and was key in ceremonial settings, as it was considered a powerful means for humans to get closer to the deities - a belief that has been kept alive by the Christian tradition until now. Offering wine to the gods was usual in Mesopotamia, Egypt, Greece and in Rome, while the divine characters of Bacchus or Dionysius were specifically attributed to the celebration of the vine and wine, which became powerful symbols of the mystery of birth and fertility, as well as of death and rebirth (Phillips, 2000). The symbolic role of wine was indeed reinforced by the discovery, since the early Egyptians, of the therapeutic properties of wine, which represented one of the main substances utilized for disinfecting, diuretic and digestive purposes. Thus, it was prescribed as a treatment for several human afflictions: to increase the appetite, to purge the body of worms, to treat asthma, and to disinfect wounds. Actually, the modern debate on the health-giving effects of wine, in opposition to its harmful effects in the case of excessive consumption, started in the ancient world, where moderate consumption, in good company and only until reaching modest inebriation, was considered a form to be moral and civilized. ${ }^{72}$ Additionally, wine certainly represented a safer option than most of the water available until the twentieth century. In the nineteenth century, the French scientist Luis Pasteur actually used to define wine as "the most healthful and most hygienic of beverages" (Pasteur, 1875).

\footnotetext{
71 In the second book of the Georgics, celebrating Bacchus and illustrating different plants cultivation techniques, Virgil argues: "Sed neque quam multae species nec nomina quae sin test numerus, neque enim numero compredere refert; quem qui scire velit, Libyci velit aequoris idem discere quam multae Zephyro turbentur harenae aut, ubi navigiis violentor indicit Eurus, nosse quot Ionii veniant ad litora fluctus" (Virgil, Georgicon, book II, p.32).
}

\footnotetext{
72 After centuries of cyclical obscurantism towards wine consumption, initiated in the Middle Ages and protracted until the post World War II period, the discovery of the "French paradox" in 1991 by the French scientist Serge Renaud, namely the fact that, thanks to the daily consumption of wine, the French had a low rate of heart disease despite eating a diet predisposed to high cholesterol, brought back the debate on the therapeutic properties of wine. This has been widely centered on whether red and white wines are equally effective in lowering cholesterol levels, and whether other forms of alcohol are as beneficial as wine (Estreicher, 2006). Since the early 1990s, researchers have been investigating the properties of red wines, which seem to contain extremely high quantities of "resveratrol", the polyphenol that has proven most effective in the fight against heart diseases and cancer, thanks to its antioxidant properties (Wine Spectator, June 2009). However, the development of experimental drugs based on resveratrol, led by scientists at both Harvard Medical School and Cornell University, is still proving a challenge, since until now resveratrol alone has failed to make a significant impact on patients. This seems to be due to the fact that red wine contains several kinds of unknown polyphenolic compounds, the combination of which might be responsible for improved health (Wine Spectator, January-February 2011).
} 


\subsection{The role of scientific discoveries in the nineteenth century}

As observed in the previous section, problem-solving and innovation have characterized the wine industry since antiquity. What has changed in modern times is that science has been gradually applied to the whole industrial process. During the last three centuries, science also laid the foundation for the modern conception of quality winemaking. In particular, wines began to take their modern expression thanks to three major scientific discoveries: the oenological use of sulphur for its antimicrobial and antioxidant properties, which has improved wine conservation and the aging potential; the creation of post-phylloxera vines, which repopulated vineyards devastated by disease in the 1860s; the understanding of the complex chemical structure of wine, which resulted in the development of the modern styles of Bordeaux, Burgundy, and Champagne wines. It is thanks to such major scientific advancements that it is now possible to enjoy an increasing variety of better wines, and that, as will be shown more in detail in the following sections, the consumption of more complex, diversified wines could prevail over the consumption of cheaper, ordinary wines on a worldwide scale (Paul, 1996).

The disinfecting properties of burning sulphur have been known since the ancient Romans, and were most likely discovered by the famous physician Galen (Pellechia, 2006). However, its association with wine is more recent. The very first reference to the use of sulphur dioxide to avoid wine spoilage dates back to 1487, when, to this purpose, an anonymous German agronomist from Rotenburg recommended burning "three wood splinters, covered with powdered sulphur, mixed with viola root and incense, in upturned casks and then seal them" (Jackson, 2008). The use of sulphur in barrel treatment became relatively common in Western Europe in the seventeenth century, when, thanks to this practice, the likelihood of producing better quality wines and extending their aging potential increased exponentially. Thus, the indirect, accidental incorporation of sulphur dioxide into wine through its contact with the inside of treated barrels has a long, secular history.

However, the deliberate incorporation of purified sulphur dioxide into wine, in the form of liquefied gas, began only in the twentieth century and belongs to the set of modern oenological practices aimed at preventing oxidation and controlling fermentation during grape crushing, as well as at inhibiting browning reactions, bleaching pigments and suppressing oxidized doors during post-fermentation and wine maturation. Even today, sulphur dioxide still represents the most important antimicrobial and antioxidant additive in wine, as well as the primary disinfectant of wine equipment (Jackson, 2008). Modern temperature control techniques have limited its need, which is particularly important since recent medical research findings have highlighted the detrimental consequences of an excessive amount of sulphites on human health, such as asthma, headaches and allergenic reactions. In 1974, a Joint FAO/WHO Expert Committee on Food Additives established an internationally recognized ceiling of human daily sulphite intake (equal to $0.7 \mathrm{mg} / \mathrm{kg}$ body weight), deriving from wine consumption as well as from normal food metabolism, while in early 2000's EU regulations obliged producers to specify on their labels the amount of sulphite residues contained in wine bottles (FAO, 2009). 
Looking strictly at viticulture, the rescue of the vines essential for the production of quality wines can be attributed to the achievements of viticultural science at the universities of Montpellier and Bordeaux. In the 1840's powdery mildew (oidium), a fungus native to North America, spread all over Europe, with disastrous consequences: crop losses of up to a quarter of the potential harvest and contamination of the fruit with typical off-flavours. It took the University of Bordeaux ten years to discover the right antidote, which consisted of powdered sulphur dusted on the vines. When an even more aggressive form of mildew, called downy mildew, appeared in Europe in 1878, the scientists in Bordeaux were ready to respond, and in less than four years developed the adequate cure: a blue mixture of copper sulphate and lime, which is known under the name of "Bordeaux mixture", and which is still considered a fundamental treatment for fungus diseases of most kinds (Halliday, 2007).

Despite the fact that the outbreak of different forms of mildew had spread all over Europe and put its wine production in serious danger, the worst was still to come. At the end of the nineteenth century, the famous epidemic of phylloxera was so devastating that it threatened to kill all of Europe's vines and to wipe out the wine industry of the entire continent. Phylloxera is a small yellow aphid less than a millimetre long, introduced into Europe with botanical specimens brought from the US by plant collectors. It was identified only with great difficulty since in Europe it lives almost exclusively underground, infecting the roots of the vinifera vines by feeding on their sap, and - as sap ceases to circulate and the infected roots die - leaving the vine without sustenance. In 1868, a French botanist from the University of Montpellier, Jules-Emile Planchon, discovered the invisible parasite and named it phylloxera vastatrix (the "dry leaf devastator"). Planchon discovered that the aphid had been accidentally imported from the United States and proved that the solution had to be found in the American vines themselves, which were normally not affected by the parasite. After several attempts to find substitute hybrid vines, to fight the parasite with chemical insecticides, and to halt the plague's progress by uprooting, burning or inundation, the most effective solution actually came by grafting the vinifera vines onto resistant rootstocks of American vines, carefully selected in 1874 by the Bordeaux botanist and pioneer geneticist Alexis Millardet. It took a few more years of controversial and harsh debate on the risks of adopting American rootstocks and of contaminating the French wine with the undesirable "foxy" taste of American grapes, until an international congress held in Bordeaux in 1881 formally recommended the solution of grafting European vines onto the rootstocks of American vines. A programme of grafting began, and by 1900 more than two thirds of the vines growing in France had American roots (Campbell, 2004).

Shifting from vine growing to winemaking, the chemists Louis Pasteur and Antoine Chaptal are two scientists of great importance in the history of biochemistry and laid the foundations of modern oenology. Much of wine science is actually expressed in terms of chemistry, because of the botanical nature of the raw materials used and their microbial transformation into wine. Both Pasteur and Chaptal spent their careers dealing with agricultural problems, especially diseases, and provided a fundamental contribution to the understanding of what had been for centuries the chemical and biological mysteries of wine. In particular, in 1860 Pasteur discovered the central 
importance of yeasts and bacteria in the fermentation process, and identified the basic principles of food conservation, thereby improving substantially the quality and durability of wine, thus reshaping wine production methods not only in France but everywhere.73 Fundamentally, Pasteur discovered that fermentation occurred when an organism (yeast) attacked the sugar in must, and that wine turned to vinegar when it succumbed to the bacteria present within it. He also understood the role oxygen played in the degradation of wine (he was the first to suggest that wine bottles should be kept in a horizontal rather than a vertical position), and explained that the contact between wine and oxygen had to be controlled to the maximum extent possible, since it encouraged the proliferation of bacteria that turned wine into vinegar (Phillips, 2000).

Indeed, it took many years for such new habits to be endorsed by the community of peasants and owners of small vineyards. These sceptics persisted for decades to ignore the scientific incongruence of some traditional wine-making methods, despite the efforts of Napoleon's government to disseminate the new information to wine producers, mainly through Chaptal's booklet entitled The Art of Making Wine. However, there is no doubt that both the discovery of the process of heating as a way of eliminating bacteria, and the discovery of the process of adding sugar to increase the alcohol level of wine, and thus its durability - respectively called "pasteurization" and "chaptalization" from the name of their inventors - set in motion a chain of events that is at the origin of the incredible range and quality of modern wines. In this sense, it can be argued that the scientific discoveries of the nineteenth century created the preconditions for the technological revolution and the new culture of wine that emerged in the twentieth century, as the next section will illustrate in detail. The twentieth century saw the systematic application of science and technology to all aspects of viticulture and viniculture, including traditional functions such as harvesting, pruning, bottling and wine tasting - which is perhaps unexpected in an industry often regarded as traditional and mature, dating back more than seven thousand years. As the renowned wine critic Robert Parker puts it: "Making great wine is an art, but making good wine is a science" (Johnson, 2007).

\subsection{The knowledge intensity of the modern wine industry}

Since the last quarter of the twentieth century, an intensive technological modernization process has gradually permeated the wine industry in all its phases. This process has become more pervasive since the wine industry started to operate on a global scale, and innovation, knowledge inputs and technological capacity have become

\footnotetext{
73 Pasteur himself, a real wine passionate, realized the potential for his discoveries to lay the ground for a new, modern "science" of winemaking, and the impact this would have in increasing wine quality in general, but also in reducing losses and in promoting the wine trade: "Plus on réfléchira aux causes des maladies des vins, plus on se convaincra que l'art de la vinification, et les soins que l'expérience des siècles a proclamés nécessaires, ont principalement leur raison d'être dans les conditions mêmes de la vie et de la manière d'agir des parasites du vin, de telle sorte que, si l'on pouvait arriver à supprimer par une opération pratique très simple, les causes des altérations spontanées des vins, on pourrait, sans nul doute, fonder un art nouveau de faire le vin beaucoup plus efficace pour supprimer les pertes qu'occasionnent les maladies des vins, très propre par conséquent à l'extension du commerce de cette denrée” (Pasteur, Etudes sur le vin, page 53).
} 
key to success in an increasingly globalized market. In terms of R\&D, three main pillars of wine science seem to have emerged: grape culture; wine production; and sensory analysis and marketing.

Firstly, in order to master the determinants of wine quality, it has become essential to understand the physiology and genetics of the vine, while notions of microclimatology and soil physio-chemistry are key to explaining grape quality and vineyard yields. Secondly, the role of chemicals in the winery has progressively diminished, but that of physics has increased, with a view to understanding how presses can produce a clearer juice, how gravitational flows can better preserve the integrity of the liquids and how fine filtration technologies can improve wine structure. Thirdly, the knowledge of human sensory psycho-physiology has become essential for interpreting wine quality, while the possibility of testing the organoleptic qualities of wine with electronic devices has made possible a totally new, science-based type of quality assessment (Jackson, 2008). Therefore, the knowledge and skills required to make quality wines have become increasingly complex and sophisticated, while modern winemaking, by drawing on different scientific fields, has become inter-disciplinary in nature (see Figure 3.1).

\section{Figure 3.1 Knowledge intensity of modern winemaking}

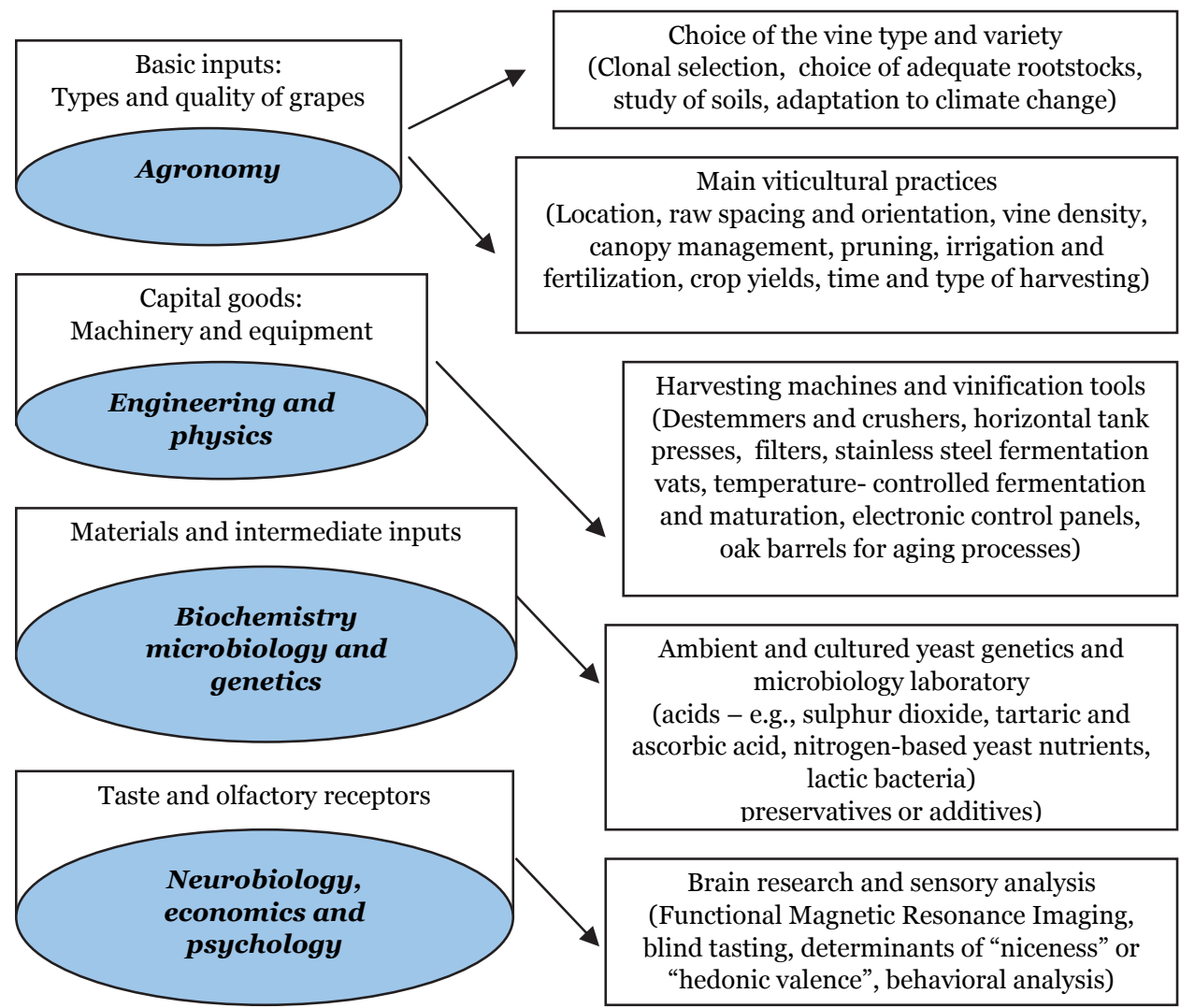

Source: Author's elaboration 
The motivations for technological development in the wine industry are related to different objectives, namely a deeper understanding of the relevant botanical and soil management issues in the vineyards, but also a deepening of the scientific knowledge needed to control the process of fermentation and wine structure. The latter is often associated with a drive for economies of scale within an industry where these are increasingly important but not automatically available, since wine producers worldwide tend to operate on a small scale and in a fragmented manner (Smith, 2007). The first process, in the area of viticulture, is probably where the highest number of innovations have been recently introduced, under the increasingly shared belief that quality begins with the plant and its culture, i.e., that "good wine is made in the vineyard", as most small passionate vine-growers and winemakers like to claim.

In particular, the art of vineyard management through "precision viticulture techniques" has now become the science of plot handling, whereby each block of vines within each vineyard is treated differently according to its individual requirements. Global positioning systems (GPS) are just one high-tech example of how this can be achieved, especially in extensive vineyards, but precision viticulture also makes use of satellite imaging, yield monitoring, multispectral digital videos and state-of-the-art software. During the harvest, for example, the position of each of the mechanical harvesters can be pinpointed via GPS and its progress mapped precisely. Infrared aerial images can indicate the different degree of vegetative growth in the vineyards, and help in planning differential harvest activities. When grapes reach the winery, it is possible to track their precise source through yield monitoring, giving the grower an unprecedented opportunity to tackle vintage variation problems, from one year to the other, in terms of quality, quantity and oenological behaviour.

Increasing efforts are also directed towards identifying the most suitable rootstocks and clones for each variety within each country, within each region, within each vineyard, and even within each individual vineyard plot. The precise choice of non-vinifera rootstocks (generically known as "American" rootstocks), which are phylloxera resistant, is proving to be of fundamental importance. For example, in several countries naturally vigorous rootstocks are now being replaced by those that have been specially bred to limit vigour, and which can better tolerate difficult climatic conditions. The technique of clonal selection is particularly useful when an individual vine has been noted for a certain quality, e.g., the ability to ripen early or the affinity to a particular type of soil. There is widely accepted evidence that using the correct type of clone in the correct site has a fundamental impact on yields and grape quality. For example, in France alone 25 certified clones of Cabernet Sauvignon and 31 clones of Chardonnay are currently in use, exhibiting different combinations of productivity versus sugar content (Galet, 2000).

Additionally, vine scientists are experimenting with genetic modification (GM) techniques in order to develop transgenic vines resistant to pests, diseases, and abiotic (non-living) stresses. In essence, genes carrying DNA which is known, for example, for its resistance to frost, to phylloxera or to powdery mildew can be isolated from one grape variety and inserted into the genetic material of a different grape variety. As in the case of other plants, there is not yet enough empirical evidence on how 
foreign genes behave in their new settings. Therefore, no GM wines have been made to date, but GM vines are being developed and tested in some wine-producing countries, such as Australia, the United States and Israel. However, major efforts are being made by researchers worldwide to ensure the conservation, the characterization and the management of the genetic resources of the vine. For example, a project sponsored in 2005 by the European Union and including 27 partners from 17 countries is aimed at establishing a European database on the genetic resources of all vines that are present in Europe. Until now, 2,500 varieties have been identified and made available to researchers, which is a remarkable achievement considering that of the 5-8,000 varieties existing in the world, only 400 are currently cultivated for commercial purposes (OIV, 2010).

In order to introduce greater predictability and faster aging into wine quality, in the area of viniculture wine scientists have developed increasingly sophisticated strategies to control fermentation. For example, micro-oxygenation is a winemaking technique aimed at stimulating a slow, controlled oxidation of barrel-aging in wines that are kept in stainless-steel tanks, by adding very low levels of oxygen to a developing wine over an extended period. Micro-oxygenation is supposed to build optimum structure, reduce herbaceous or vegetal characters, provide colour stability and increase the roundness of the wine. However, there is ample debate on the usefulness of this technique. On the one hand, it allows red wines to mature earlier (for example, thanks to microoxygenation, in Australia red wines reach the market the same year of their production). On the other hand, reputable scientists, even from the New World, claim that the chemical effects of this technique on wines are not predictable, and that the impact of artificially producing a more aged structure in young wines is not fully known yet.

The same contradictory views are related to the use of reverse osmosis, an innovative technique aimed at removing excessive alcohol from finished wines. Reverse osmosis may concentrate the must before fermentation or extract ethylphenol (a contributor to the negative flavours of brettanomyces yeasts, a common spoilage fungus infecting wine) from developing wine, through tangential or cross-flow filtration technique which disassemble and reassemble wines - a technique developed by a US company called Vinovation. To traditionalists, however, reverse osmosis is an unacceptable manipulation, a real threat to the authentic "soul" of the wine, a way to kill uniqueness and to turn wine back into a commodity by introducing a boring uniformity and an artificial homogeneity. As a matter of fact, it is an effective technique of producing large quantities of medium-priced constant quality wines for supermarkets and large retailers. This, together with long distance mechanical systems for the transport of grapes, large scale fermentation and storage facilities, electronic instruments for quality monitoring and global logistic capabilities, is what is required to make economies of scale and scope a reality. As Smith (2007) argues, "producing consistent quantity in production runs involving millions of bottles is a major technological problem, which modern wine innovation has largely solved".

In the area of marketing, an increasingly competitive scenario, a considerable amount of commercial intelligence is needed in order to reach the desired, targeted consumers 
(see Table 3.1). In the twenty-first century, in order to match existing supply with potential demand, it has become necessary to properly understand the complexity of shelf space margins, product life cycles, consumer behavioural patterns, sophisticated pricing strategies and modern distribution techniques (Jenster et al., 2008). In particular, there is no way a wine producer can achieve success and remain competitive in the marketplace without a thorough appreciation of human behaviour and product choice.

In this context, the discipline of neurobiology of behaviour has largely contributed to a deeper understanding of consumers' preferences and of the factors influencing the subjective definition of wine quality. The science of sensory analysis has also provided crucial information on the variables that contribute to the sensory perception determining flavour preferences in foods and beverages (Bisson et al., 2002).

From a simple tool for quality control, which was applied in order to detect defects and unpleasant aromas before wine reached the consumers, sensory analysis has also become an increasingly sophisticated discipline, relying on the use of human tasters as an analytical tool for understanding the relationship among chemistry, perception, preference and behaviour. Even more challenging is the scientific study of the role of non-sensory factors, such as pricing, reputation and label information, compared to the role of chemical and sensory factors in influencing consumer preferences.

Table 3.1 Main technological innovations and organizational changes in the modern wine industry

\begin{tabular}{|c|c|}
\hline Viticulture & $\begin{array}{l}\text { Application of canopy management techniques } \\
\text { Identification of the best clones for each variety and introduction of new varieties } \\
\text { Proper planning of new vineyard sites } \\
\text { Harvest of the grapes at their peak of ripeness } \\
\text { Limitation of the yields to increase grape quality } \\
\text { Use of drip irrigation systems instead of flooding irrigation } \\
\text { Increasing diffusion of soil analysis } \\
\text { Organic farming and eco-friendly cultivation practices }\end{array}$ \\
\hline Viniculture & $\begin{array}{l}\text { Replacement of old vats with new oak barrels imported from the US and/or France } \\
\text { Installation of refrigeration devices for both fermentation and maturation } \\
\text { Replacement of old oak casks with epoxy-cemented vats or stainless steel tanks } \\
\text { Use of gravity flows to avoid excessive use of hydraulic pumps } \\
\text { Use of native versus international yeasts } \\
\text { Quality testing through own lab facilities and quality certification }\end{array}$ \\
\hline $\begin{array}{l}\text { Organization \& } \\
\text { marketing }\end{array}$ & $\begin{array}{l}\text { Participation at international wine competitions } \\
\text { Increased vertical integration to achieve total control and monitoring of the grapes, } \\
\text { Essential to making quality wines } \\
\text { Signing premium contracts with grape growers producing high quality grapes } \\
\text { Brand development targeting different market segments } \\
\text { Pursuing quality certification as a marketing strategy } \\
\text { Organization of food and wine tasting events } \\
\text { Sophisticated architectural design of the winery } \\
\text { Use of social networks (Facebook, Youtube and/or Twitter) for marketing purposes }\end{array}$ \\
\hline
\end{tabular}

Source: Author's elaboration 


\subsection{The importance of international knowledge flows}

This section illustrates in detail how, since the 1970s, the wine industry has started to operate on the basis not only of increasing codified and embodied knowledge, but also of tacit knowledge flows, and how this has further stimulated the transformation of wine into a dynamic, innovative and growth-oriented industry in terms of both production and exports. To start with, the modern wine industry heavily relies on the production of codified knowledge, namely, of knowledge expressed through a formal language or code, often in a scientific context (Nelson and Winter, 1982). The mix of new disciplines and advanced sciences illustrated above represents the pillars of a deep technological revolution that could not have taken place without considerable basic and applied research efforts carried out by universities and specialized research centers around the world.

To cite but a few examples, in Italy, during 1991-2003, in the Piedmont region alone 48 different research projects were financed by the regional government in different wine-related fields, such as organic agriculture, product quality, plant and soil defences, varietal improvement, quality systems and biodiversity (Morrison and Rabellotti, 2006). These projects were carried out by 193 local actors, including technical schools, private laboratories and firms, as well as several national and regional research institutes, such as the Institute of Plant Virology (a centre specialized in viticulture belonging to the National Research Council), the Experimental Institute of Oenology and Viticulture, the Regional Advisory Phyto-pathological Service, as well as by the Faculty of Agronomy of the Universities of Torino, Piacenza, Bologna, Milano and Firenze. More generally, researchers in Italy have been paying particular attention to the effects of climate change on the vine and to the different possibilities of adaptation. Mathematical models prospecting different climate change scenarios demonstrate, for example, that, practically in all Italian regions, yields will be considerably reduced, drought being the key factor (OIV, 2010).

In the United States, the University of California at Davis and Cornell University in New York developed the very first prototypes of mechanical harvesters in the mid 1960s, and, much later, the first nematode, phylloxera and virus-resistant rootstocks (Taber, 2006). At present, research efforts at both universities seem to be particularly focused on alternative methods of reducing wineries' carbon footprints. Wine Spectator (April 2010) reports that eco-friendly cellars with carbon-neutral wine collections have become increasingly popular in New York, and that wineries pay increasing attention to their carbon emissions. Since the late 1990s, Californian wineries have been massively installing solar power plants in order to reduce electricity costs and to support their sustainable branding. Considering that new technologies are making small-scale wind generation more affordable and efficient, wind power is now being tested by a handful of wineries in Oregon, Napa Valley and New York's Finger Lakes, under a research project financed by USDA Rural Energy Program. Research on sustainable wine production through responsible agricultural and winemaking practices has also been indicated as a priority by the USDA National Organic Program. Under its umbrella, issues related to organic and biodynamic certifications, but also water conservation, 
materials handling, soil management, employee education and training, bottling and transportation, are currently addressed (USDA, 2010).74

In Australia, the Commonwealth Scientific and Industrial Research Organization (CSIRO), the largest Australian public R\&D organization, played a key role in sustaining the technological transformation of the Australian wine industry in the 1980s, and prepared the industry to respond to the change in consumer tastes in the 1990s (Smith, 2007). In 2002, the Grape and Wine Research and Development Corporation (GWRDC) was mandated to "enable a sustainable innovative and profitable future" for the Australian wine industry through strategic investment in R\&D. The GWRDC is financed by levies paid by both the Australian grape-growers and winemakers (respectively, 2 US\$ per ton of grapes delivered to the wineries and 5 US\$ per ton of grapes crushed), as well as by a substantial contribution of the Australian Government, equal to a maximum of 0.5 percent of the gross value of production. Among the main achievements of GWRDC's Five Year R\&D Plan, 2002-2007, chemical inputs in the vineyards have been reduced using pest management and environmental management systems, and water use efficiencies have resulted from research into vine water requirements and soil factors. More recently, due to the severe warming that has affected Australia in 2007, 2008 and 2009, research efforts have been focusing on the identification of new stock and vine varieties that are resistant to drought and salinity (OIV, 2010).

In France, the viticultural and oenological sciences at the Universities of Bordeaux and Montpellier are at the origin of the reconstitution of French (post-phylloxeric) vineyards in the late nineteenth Century, as illustrated in the previous section, but also of the development of the widespread top-quality wine models of Bordeaux, Burgundy and Champagne (Paul, 1996).75 Since the 1960s, both the Universities of Bordeaux and Montpellier work in strict collaboration with INRA (Institut National de la Recherche Agronomique), borrowing highly qualified scientific and technical personnel and sharing R\&D costs, with the aim of promoting research on quality wines. Since the 1990s, it has also become possible to carry out higher academic and professional degrees under the DEA programme (Diplome d'études approfondies oenologieampélologie), which admits a maximum of 30 students every year, and is carried out in collaboration with several research and teaching bodies, such as the Station Oenologique de Montpellier, the Institut de la Vigne de Villenave d'Ornon, the Institute

\footnotetext{
74 Organic vine cultivation mainly aims at reducing or completely avoiding the use of chemical pesticides and fertilizers. However, there is a multiplicity of terms and diversity of organic systems that can be differentiated (the most common are organic, reasoned and integrated). Internationally, the demand for organic wines is increasing, and consumers are ready to pay higher prices for them. Biodynamic wines, instead, refer to the use of a calendar that shows the influence of the moon on plants, and recommends different timing for the cultivation phases, such as sowing and harvesting.

75 Since World War II, the Bordeaux region has become the epicenter of wine quality and wine education thanks to a group of renowned professors of oenology, among which Emile Peynaud and Jean Ribéreau-Gayon, who, ahead of their time, advocated the importance innovative viticultural techniques to capture a fully ripened fruit, such as leaf pulling, crop thinning and late harvest, which have now become the universal parameters of quality winemaking. The justification for all these efforts was that France, seeing itself as the number one country in the world of viniculture, had to maintain the highest level of quality and to lead research in this area.
} 
Universitaire de la Vigne et du Vin de Bourgogne, the Institute National Polytechnique de Toulouse, the Institut d'Oenologie de Bordeaux (Paul, 1996). Currently, researchers in many French institutions are studying the effects of global warming, and in particular the problem of the modification of traditional harvesting dates, which has been gradually anticipated by at least ten days in most French regions. Research findings show that this corresponds to an average one degree rise in temperatures, and highlight what are the adaptation possibilities to one or maximum two degrees of warming range, from the positioning of the vineyards, to the choice of the varieties and soil management. It seems however that none of these measures can respond to a three to five degree temperature increase, as anticipated by the most pessimistic scenarios (OIV, 2010).

The rapid diffusion of the results of such huge worldwide R\&D efforts, and of the consequent wide spectrum of new knowledge and technologies produced, has been accelerated by increasing flows of foreign machinery exports, thus of capitalembodied technology, among all main wine producing countries. This process was stimulated by international consumer pressure for tasting higher quality, diversified wines, as will be shown more in detail in the following section, but also by the increasing liberalization of markets in the late 1970s, which facilitated international flows of commodities, manufacturing goods and financial assets, as well as international technology transfers. As shown in Figure 3.2, the total exports of presses, crushers and modern equipment for winemaking rose uninterruptedly from the mid1970 s until 2008, when the financial crisis hit the investment capacity of most leading wine exporters. The production of winemaking equipment was actually led by one of the leading wine exporters: Italy - a country well known for its strengths in traditional exports, but also for its ability to combine the exports of traditional goods with the exports of related machinery - followed by Germany and France.

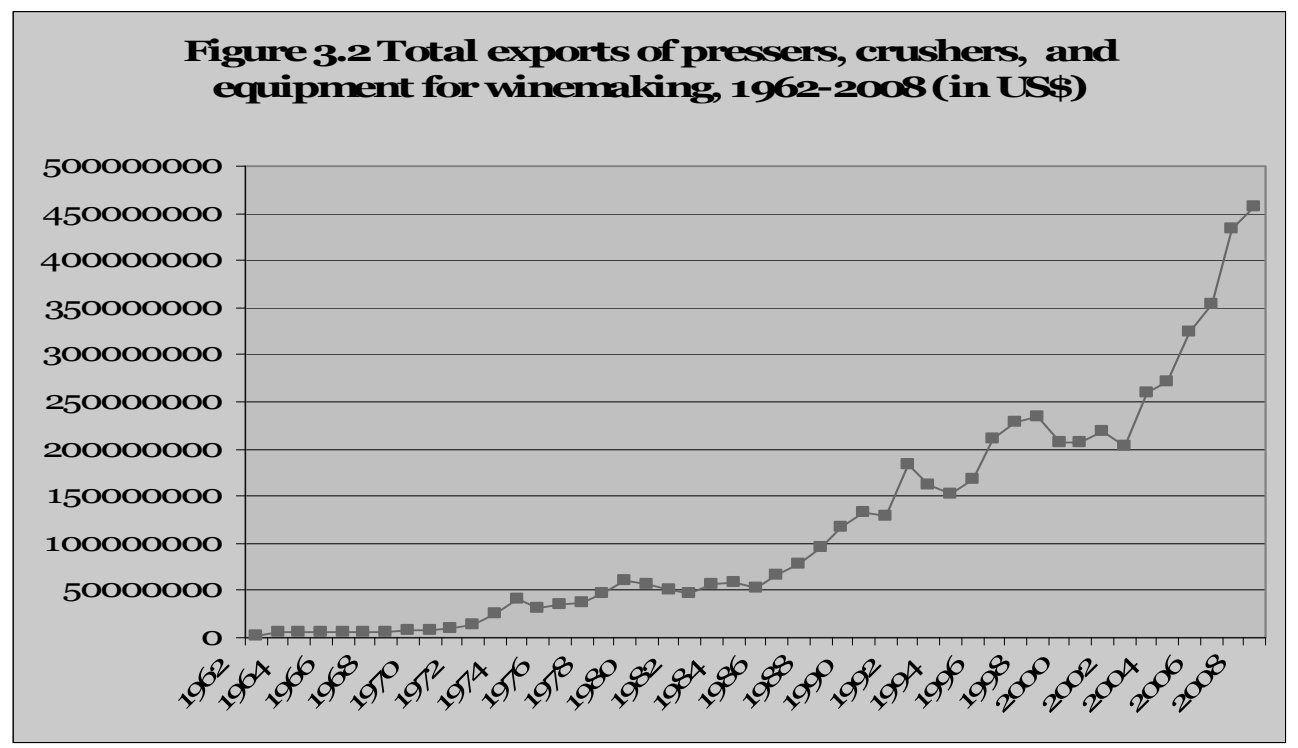

Source: Comtrade data, SITC (Rev.1) 71291 
Evolutionary economics, however, underlines that "the accumulation of technological capabilities involves more than the acquisition of machinery or product design, and the assimilation of related know-how, often obtained after policies of trade liberalization. It also involves continuing, incremental technical change" (Bell and Pavitt, 1995). In the wine industry, massive flows of codified and capital-embodied knowledge were actually accompanied by an increased number of individuals offering their services abroad, and the spread of ideas and technologies developed in their home country, therefore by regular face-to-face interaction opportunities and physical colocation of skilled, highly trained people as complementary channels of learning and continuous innovation through the transfer of tacit knowledge (Anderson, 2004).

It should be recalled here that, as mentioned in Chapter 2, the increased mechanization of the modern wine industry and the deeper understanding of the scientific principles underlying vinification do not imply that tacit knowledge, embedded in people, is less important (Giuliani, 2007). For example, most problem-solving activities do not usually rely on automated processes (see Figure 3.3). Rather, it is the perception and experience of skilled human resources (i.e., the tacit knowledge of agronomists or oenologists) that are the most effective means of solving complex problems, such as the pace and components of different phyto-sanitary treatments or the timing of harvest under difficult weather conditions. Additionally, the choice of the right clone within a given variety can be done, in theory, based on the characteristics of the soil, but in practice it also requires the accumulated knowledge, experience and intuition of vine growers concerning the needs of their specific terroir.

Figure 3.3 The importance of tacit knowledge in winemaking

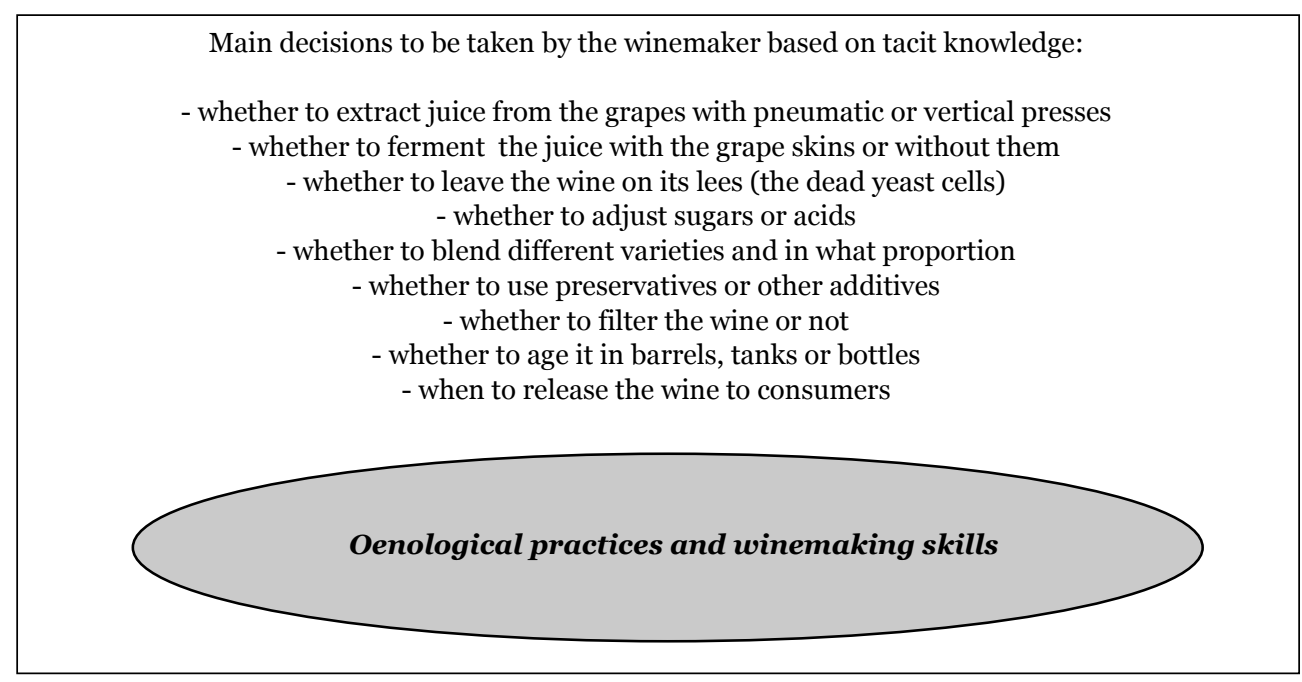

Source: Author's elaboration

During the 1980 s and 1990s, a small number of young, highly trained winemakers, mainly from California and Australia, so-called "flying winemakers", became the main 
transmission belt of the technological revolution in the wine industry. Flying winemakers largely contributed to the massive tacit knowledge flows that are at the origin of a drastic increase in technically well-made wines all over the world, and have the merit of having diffused a new, rigorous approach to winemaking, based on scientific studies and solid academic background (see Table 3.2). In particular, the new generation of consultant oenologists and viticulturalists that emerged in the early $1980 \mathrm{~s}$ became responsible for the diffusion among the international winemaking community of the basis of oenological literacy much faster than would have happened otherwise. They also contributed to the diffusion of that part of first-hand knowledge and accumulated experience over time which is not transferrable through a formal language or code, and which plays, and always will play (Cowan and Foray, 1997), an important, complementary role in quality winemaking.

Table 3.2 Scientific background of the pioneering group of Australian and Australian-trained "flying winemakers" and "flying wine doctors"

\begin{tabular}{|c|c|c|c|c|}
\hline Name & Nationality & Oenology Degree & $\begin{array}{c}\text { First assignment } \\
\text { abroad }\end{array}$ & $\begin{array}{c}\text { Current } \\
\text { winemaking } \\
\text { consultancy } \\
\text { projects }\end{array}$ \\
\hline Peter Bright & Australian & $\begin{array}{l}\text { Roseworthy } \\
\text { Agricultural College, } \\
\text { University of } \\
\text { Adelaide, } 1977\end{array}$ & $\begin{array}{l}\text { Joao Pires Winery, } \\
\text { Portugal, } 1978\end{array}$ & $\begin{array}{l}\text { Portugal, Italy, } \\
\text { Spain, Argentina, } \\
\text { Chile, Uruguay }\end{array}$ \\
\hline Gaetane Carron & French & $\begin{array}{l}\text { University of Dijon, } \\
1989\end{array}$ & $\begin{array}{l}\text { Rosemount Estate, } \\
\text { Australia, } 1990\end{array}$ & $\begin{array}{l}\text { Australia, China, } \\
\text { United States } \\
\text { (Oregon and } \\
\text { California), Chile }\end{array}$ \\
\hline Randall Grahm & US & $\begin{array}{l}\text { University of } \\
\text { California at Davis, } \\
1979\end{array}$ & $\begin{array}{l}\text { Rosemount Estate, } \\
\text { Australia, } 1983\end{array}$ & California \\
\hline Kym Milne & Australian & $\begin{array}{l}\text { Roseworthy } \\
\text { Agricultural College, } \\
\text { University of } \\
\text { Adelaide, } 1980\end{array}$ & $\begin{array}{l}\text { Villa Maria Estate, } \\
\text { New Zealand, } 1981\end{array}$ & $\begin{array}{l}\text { France, Hungary, } \\
\text { Italy (Puglia, Sicily, } \\
\text { Trentino and } \\
\text { Tuscany), South } \\
\text { Africa, Spain }\end{array}$ \\
\hline $\begin{array}{l}\text { Ignacio } \\
\text { Recabarren }\end{array}$ & Chilean & $\begin{array}{l}\text { Catholic University } \\
\text { of Chile, } 1972\end{array}$ & $\begin{array}{l}\text { Rosemount Estate, } \\
\text { Australia, } 1985\end{array}$ & $\begin{array}{l}\text { Australia and New } \\
\text { Zealand }\end{array}$ \\
\hline $\begin{array}{l}\text { Andrew Pirie } \\
\text { (flying doctor) }\end{array}$ & Australian & $\begin{array}{l}\text { B.Sc. and M.Sc. in } \\
\text { Agronomy and PhD } \\
\text { in vine physiology at } \\
\text { University of Sydney, } \\
1973\end{array}$ & $\begin{array}{l}\text { Pipers Brook, } \\
\text { Tasmania, } 1974\end{array}$ & $\begin{array}{l}\text { Current president of } \\
\text { the Australian Wine } \\
\text { Export Council and } \\
\text { of the Vineyards } \\
\text { Association of } \\
\text { Tasmania }\end{array}$ \\
\hline $\begin{array}{l}\text { Richard Smart } \\
\text { (flying doctor) }\end{array}$ & Australian & $\begin{array}{l}\text { B.Sc. and M.Sc. at } \\
\text { Sydney University, } \\
\text { PhD in Agricultural } \\
\text { Science at } \\
\text { Stellenbosch } \\
\text { University, } 1978\end{array}$ & $\begin{array}{l}\text { Government } \\
\text { Viticultural } \\
\text { Scientist, New } \\
\text { Zealand, 1980s }\end{array}$ & $\begin{array}{l}\text { Former Dean of } \\
\text { Roseworthy Agric. } \\
\text { College, University of } \\
\text { Adelaide; now over } \\
200 \text { clients in } 16 \\
\text { countries }\end{array}$ \\
\hline $\begin{array}{l}\text { John } \\
\text { Worontshak }\end{array}$ & Australian & $\begin{array}{l}\text { Charles Sturt } \\
\text { University, Wagga } \\
\text { Wagga, } 1981\end{array}$ & $\begin{array}{l}\text { Clos du Bois, } \\
\text { California, } 1983\end{array}$ & $\begin{array}{l}\text { Czech Republic, } \\
\text { Argentina, Canada, } \\
\text { Chile, Mexico, Israel, } \\
\text { South Africa }\end{array}$ \\
\hline
\end{tabular}

Source: Author's elaboration based on Arkell, 1999. 
The term "flying winemakers" was first coined by the British wine merchant Tony Laithwaite in 1987 to define a group of Australian travelling consultants or winemakers formed in Australian universities and estates. Being under-employed during the summers of the Northern hemisphere, these consultants had started to travel to remote parts of Europe on a counter-seasonal basis to turn low-grade, bulk wine into good quality, exportable wines, suiting the market needs of wholesalers and retailers. By the end of the 1990s, for example, more than ten percent of the British supermarket wine offerings were made-to-measure wines, produced by itinerant, non-resident winemakers in both the Northern and the Southern Hemisphere, with the help of Australian technology and know-how, and the assistance of Australian "flying wine doctors" with an impressive list of academic qualifications.

However, it would be a mistake to assume that most flying winemakers are of Australian origin or have been trained in Australian universities. Since the 1990s, the counter-seasonal flow of flying winemakers has become multi-directional and originated from most wine-producing areas. Currently, the presence of Australian, Californian or Chilean flying winemakers working abroad is at least equal to that of Old World winemakers flying to the New World on a counter-seasonal basis. Just to cite a few examples, the French brothers Jacques and Francois Lurton are leading suppliers of New World wines to British retail chains, while the British consultant oenologist Angela Muir has helped Eastern European wines to suit British tastes. In Bordeaux, the French consultant Bruno Prats is now making wines in Portugal, Chile and South Africa, after having spent thirty years as lead oenologist of Chateau Cos D'Estournel, while the Pomerol-based consultant Michel Rolland has become a figure of international importance and advises not only the top Bordeaux producers, but also over 90 clients in eight countries (e.g., Argentina, Chile, Hungary, India, Italy, Morocco, Spain and the United States). Also, in Italy, the group of leading international consultant oenologists includes such names as Alberto Antonini, Vittorio Fiore, Maurizio Castelli, Franco Bernabei and Roberto Cipresso. In Spain and Portugal, Pacho Campo, David Baverstock and Joao Ramos have gradually reached international stature (Beazley, 2000).

Despite their unequivocal role in the rapid modernization of the wine industry at a wide scale, and in de-codifying, interpreting and applying increasing amounts of codified knowledge, according to several wine critics flying winemakers have also had an enormous and quite controversial influence on the stylistic evolution of wine and wine consumer tastes that characterized the late twentieth century (Robinson, 2001; Clarke et al, 2006; Cipresso, 2008). As a matter of fact, the diffusion of a certain stylistic homogeneity and the gradual erosion of the sense of terroir in favour of fresh, varietal, fruity wines, illustrated in more detail in the following section, has a lot to do with the use of new winemaking techniques introduced for the first time in Australia, and largely diffused by flying makers, such as the use of oak chips to enrich the natural flavour of wine and the adjustment of alcohol and acid balances to obtain clean fruit flavours (Beazley, 2000).

Indeed, international routines and foreign winemakers have generally proven weak in extracting regional character and uniqueness factors from New World wines. However, this is not surprising and is in line with the hypothesis that in a globalized context, the 
diffusion of codified knowledge enhances rather than devalues the significance of local tacit knowledge (Enright, 2000). According to Giuliani (2007), in spite of huge techno-scientific changes, tacit knowledge persists in being important in the wine industry, but it is a tacit knowledge of a different nature with respect to the manual dexterity and sensory perceptions of traditional wine producers. The novelty is twofold. On the one hand, even for countries with a long tradition of wine production, the capacity to compete in the international market depends more and more on the capacity to apply new scientific knowledge, new technologies and new production techniques, thus on the capacity to de-codify and interpret large amounts of codified knowledge, and to understand, absorb and adapt a considerable amount of knowledge being transferred through international flows among a very diversified typology of actors and institutions (see Figure 3.4). On the other hand, international consumers are demanding increasingly diversified, geographically typified wines. Thus, the capacity to adapt imported technologies to local conditions, and improve upon them through local tacit knowledge, has become essential to extracting high-quality, unique wines from each specific terroir.

Figure 3.4 International knowledge flows in the wine industry

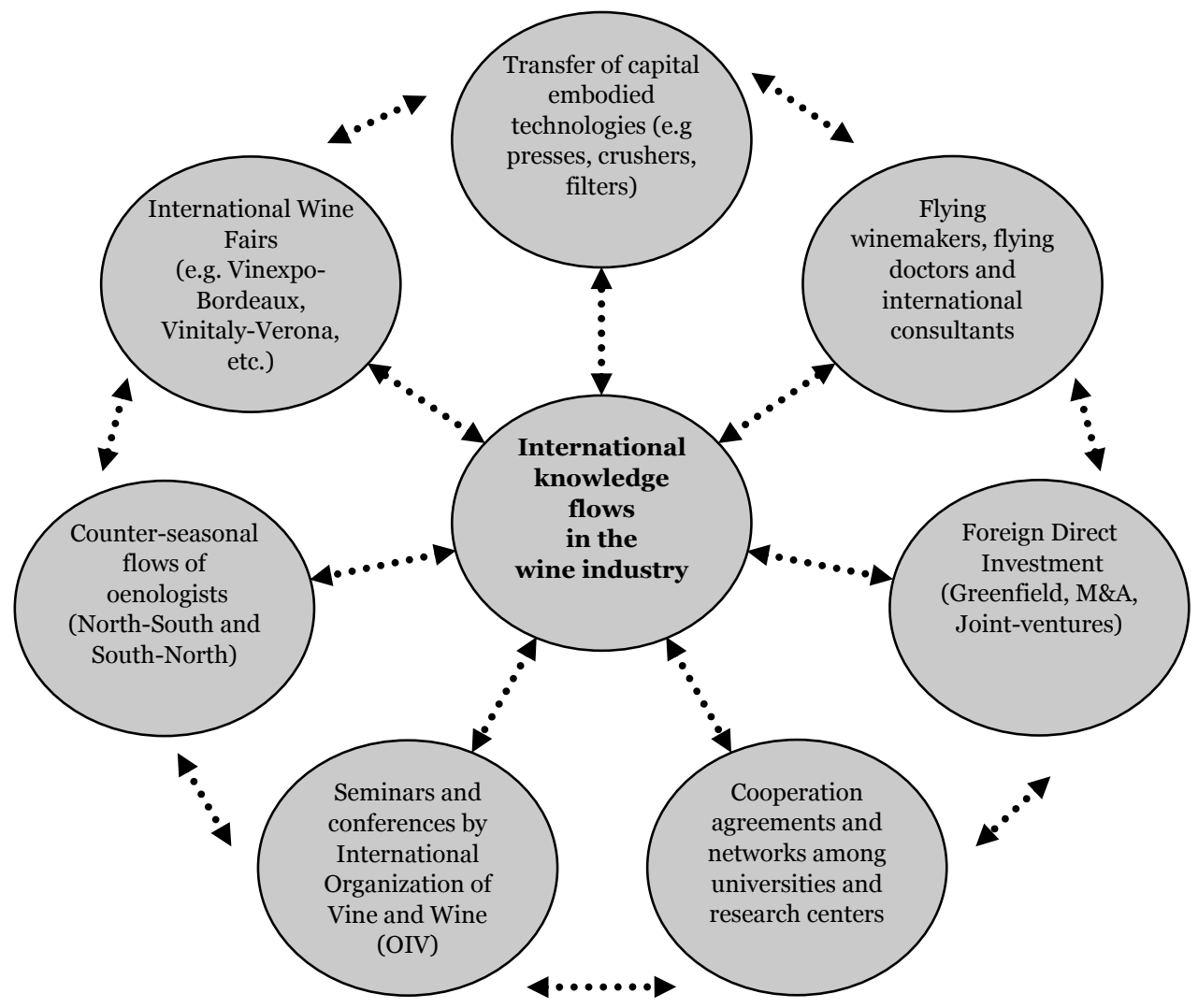

Source: Author's elaboration 


\subsection{The shift in international consumption patterns}

Even though wine has been made for so many centuries and in so many places, outstanding wine has always been rare and expensive, a sort of luxury good reserved to the upper classes. On the contrary, the table wine common people would drink on a daily basis has traditionally been a relatively standardized product. For centuries, for example, wine has represented an essential source of calories in the daily diets of workers in France, Italy and Spain. It may seem surprising, but until a few decades ago, wine was produced according to the habits and practices of many other staple products, such as maize, soy beans or wheat. Growers often planted vines regardless of their suitability to soil and prevailing climate conditions. Periodically, farmers replaced an unprofitable cash crop with vines in order to jump onto a more profitable bandwagon, or vice versa. Additionally, producers looked at quantity as the most important indicator of a successful performance, and all possible technological efforts were made in order to increase the yields per hectare, regardless of the consequences on fruit quality and ripening potential.

Until only a few decades ago, the alcoholic grade of reds was so aggressive that water was regularly added in the glass before drinking, while it was not uncommon to add chemical additives in the demijohns of whites stored in home cellars in order to soften their acidity. ${ }^{76}$ Even in France - the unchallenged leader in wine production, consumption and export - the typical wine shop's core business was inexpensive table wine, called vin ordinaire. 77 This was the wine that average French families would drink during meals, bottled out of tanks and sold by the litre in maximum four varieties, namely one or two types of reds, one rosé and one white (Taber, 2005). And this was also the wine that was blended on a regular basis with Algerian or Moroccan wines, to strengthen its alcoholic grade and/or to intensify the concentration of its colour. Such a practice was perfectly legal, since the French legislation allowed the vin ordinaire to contain a maximum of 15 percent of foreign wine. 78

However, this situation has changed radically. First of all, thanks to the immense socioeconomic changes and the prosperity characterizing the post-war period, and as a result

\footnotetext{
${ }^{76}$ During past centuries, in spite of chemical corrective substances, it was not uncommon to add a piece of raw meat in the wine barrels in order to stop its acidification process. In his late nineteenth century studies on wine, Louis Pasteur provided a scientific explanation of such a surprising habit: "Le vin qui commence a aigrir porte à sa surface une pellicule de mycoderma aceti. [...] Les substances albuminoides et extractives introduites en dissolution dans le vin par la viande facilitent la multiplication du mycoderma vini, lequel pourra étouffer le mycoderma aceti, et pourtant l'acétification s'arrêtera" (Louis Pasteur, Etudes sur le vin, 1875, p. 127).

77 Taber (2005) recalls that for centuries nobody seriously challenged the categorical statement that opened the Wines of France guide in 1951: "The greatest wines on earth come from France. While grapes have been grown in Western Europe for generations, in the world of wine there is France, and then everybody else".

78 This explains why, quite surprisingly, France has traditionally represented not only one of the largest exporters, but also one of the largest importers of wine, and in particular of bulk red wine. In the last three decades, for example, it ranked alternatively first or second among leading wine producers, first or second among leading wine exporters, and alternatively, third or fourth among leading wine importers.
} 
of an unprecedented redistribution of income (in the industrialized countries real GDP per capita more than doubled over the past fifty years), international consumers have started to become more educated, far more demanding, and more willing to spend on high-value consumption goods, such as luxury clothing, sophisticated food products, design furniture, and so on, symbolizing "desirable ways of living" (Smith and Marsh, 2007; Jenster et al., 2008). Secondly, international consumers' buying preferences came to be determined not only by price, but by a range of other criteria such as wine quality, price/quality ratio, image, style, branding and marketing (Brook, 2006).

As part of this trend, a drastic shift in consumption patterns towards higher quality, premium wines has taken place - to the point that plenty of low quality, mostly inexpensive table wines sold under widely available brands started to be rejected by the once undemanding north European or American wine markets (see Figure 3.5). As a consequence, a complete shift in the wine business's competitiveness strategies has gradually occurred, based on falling demand for cheap table wines for domestic consumption and rising demand for bottled premium wines attuned to the export market, increasingly characterized by modern brands and diversified individual styles. It should be noted, however, that, even if aggregate data may not show it already, such consumption patterns might be changing again in the future, due to the levelling off of income as a consequence of the financial crisis in 2008-2009. According to the OIV, the negative impact of the crisis started to become apparent in the second half of 2009, when the consumption of table wines with no geographical indication started to register a slight increase, after having constantly declined for more than a decade (OIV, 2010).

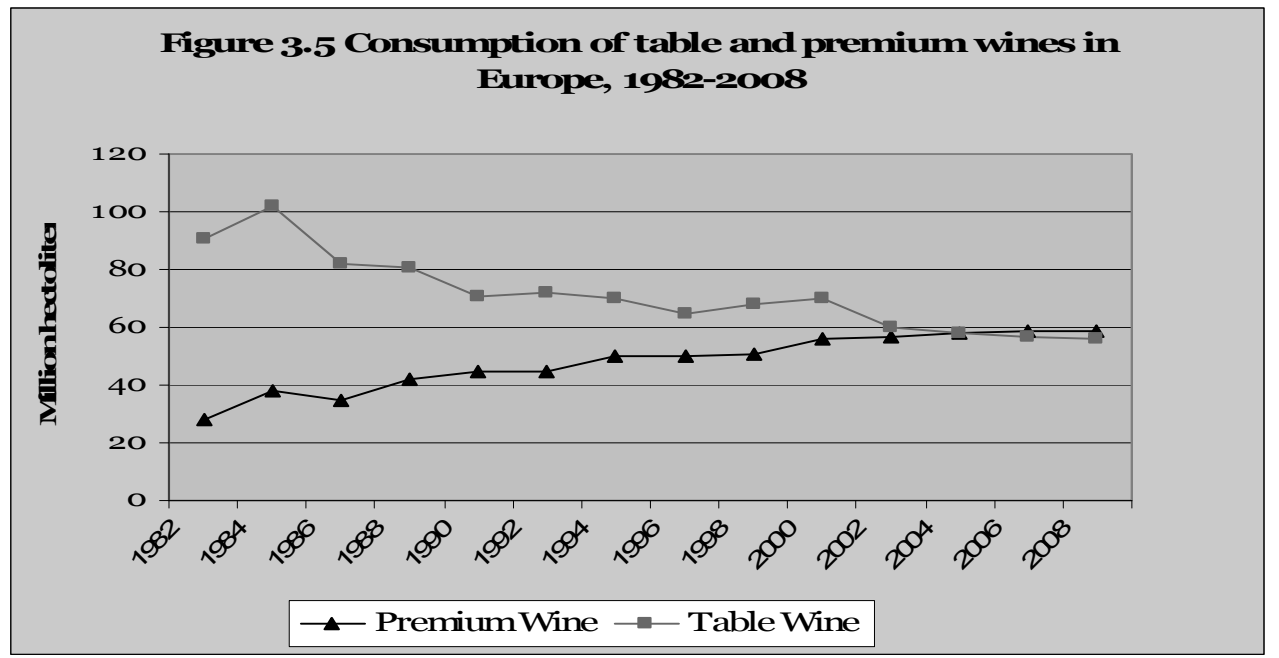

Source: Jenster et al., 2008

As shown by the figure above, European consumption levels of table and premium wines started to converge in the early 1980s, and in the early 2000 s they finally crossed and interchanged their trends. In France, for example, from an average consumption of 100 litres per capita of table wine in the 1970s, consumption sank to 53 litres per capita in the 1990s, and to 15 litres per capita in the early 2000s. On the contrary, fine 
wine consumption increased from 2 litres per capita in the 1970 to 11 litres per capita in the 1990s, and to 18 litres per capita in the early 2000s (see Table 3.3). This resulted from the fact that wine, traditionally consumed as an integral part of the diet, became more an optional, luxury consumer product and was replaced by water and other soft drinks in accompanying meals in the daily consumption habits of the French, as well as the Southern Europeans more generally. Additionally, stricter drinking-driving legislation introduced in the last few years and increasingly frequent anti-alcohol campaigns carried out by temperance movements have provoked further continuous drops in average per capita consumption.

Table 3.3 French wine consumption by category (litres per capita), 1970-2006

\begin{tabular}{lccccc}
\hline Wine category & $\mathbf{1 9 7 0 - 1 9 8 0}$ & $\mathbf{1 9 9 0 - 2 0 0 0}$ & $\mathbf{2 0 0 3 / \mathbf { 2 0 0 4 }}$ & $\mathbf{2 0 0 4 / 2 0 0 5}$ & $\mathbf{2 0 0 5 / 2 0 0 6}$ \\
\hline Fine wines & 2 & 11 & 15 & 17 & 18 \\
Table wines & 98 & 53 & 17 & 15 & 15 \\
Total & 100 & 64 & 32 & 32 & 33 \\
\hline
\end{tabular}

Source: Author's elaboration based on DGI/DGDDI (General Customs Office, Excise Taxes)

Indeed, the drastic decline in wine consumption that has characterized the leading European producing and consuming countries since the 1970s (see Table 3.4) is related to a shift towards less but better quality, more expensive, premium wines. However, such decline also has to be seen against a rise in the consumption of substitution drinks, such as bottled water, beer, soft-drinks and distilled spirits, and against the ups and downs of economic growth and macroeconomic stability (Jenster et al., 2008). The decline in wine consumption in those countries that have historically been the largest producers of wine - such as France, Italy and Spain - have already started in the 1950s, well before the upsurge of higher priced, premium wines.

Table 3.4 Per capita consumption of wine in EU-15 countries, 1950-2010

\begin{tabular}{lccccccc}
\hline \multicolumn{1}{c}{ Country } & $\mathbf{1 9 5 0}$ & $\mathbf{1 9 7 0}$ & $\mathbf{1 9 8 0}$ & $\mathbf{1 9 9 0}$ & $\mathbf{2 0 0 0}$ & $\mathbf{2 0 0 5}$ & $\mathbf{2 0 1 0}$ \\
\hline Austria & 14.2 & 34.6 & 35.8 & 35.0 & 31.8 & 30.4 & 29.3 \\
Belgium & 5.7 & 14.2 & 20.6 & 24.9 & 20.0 & 18.1 & 25.1 \\
Denmark & 3.0 & 5.9 & 14.0 & 21.3 & 30.9 & 34.5 & 35.1 \\
Finland & 0.5 & 3.3 & 4.8 & 6.5 & 19.2 & 22.6 & 10.8 \\
France & 124.5 & 109.1 & 91.0 & 72.7 & 56.0 & 52.6 & 51.0 \\
Germany & 4.7 & 16.0 & 25.5 & 26.1 & 23.6 & 24.0 & 25.0 \\
Greece & 35.0 & 40.0 & 44.9 & 32.8 & 34.0 & 34.5 & 29.3 \\
Ireland & 2.2 & 3.3 & 4.7 & 8.7 & 33.2 & 33.0 & 19.7 \\
Italy & 83.0 & 113.7 & 92.9 & 62.5 & 51.0 & 48.0 & 44.5 \\
Luxembourg & 23.2 & 37.3 & 48.2 & 58.2 & 60.8 & 60.0 & 54.2 \\
Netherlands & 0.5 & 5.2 & 12.9 & 14.5 & 18.8 & 19.0 & 17.8 \\
Portugal & 64.3 & 72.5 & 68.7 & 50.0 & 50.0 & 52.0 & 43.6 \\
Spain & 47.0 & 61.5 & 64.7 & 37.4 & 33.0 & 32.0 & 36.0 \\
Sweden & 1.1 & 6.4 & 9.5 & 12.3 & 15.3 & 16.0 & 20.6 \\
UK & 1.1 & 2.9 & 7.2 & 11.6 & 16.9 & 18.7 & 20.7 \\
\hline
\end{tabular}

Source: OIV, 2011 
In France, for example, per capita consumption of wine in the early 1950s was 125 litres. By the 1970 s it had fallen to 109 litres, by the 1990 s to 73 litres, and by the 2000 s to 56 litres. Thus, in fifty years, French per capita consumption of wine fell by 60 percent. During the same period, it fell by 45 percent in Italy and by 30 percent in Spain. While wine consumption in the traditional wine producing countries continued to decline, growth in new countries brought about a new swing in world consumption since the mid-1980s. For example, in Nordic European countries - such as Sweden, Finland and Denmark - consumption has increased remarkably, more or less at the same rate as in the Netherlands and the UK, and in Eastern European countries, including Russia. The same has happened, outside Europe, in the United States, Japan, and, more recently, in China.

If, on a global scale, data on per capita wine consumption in volume reveal a long term decline, data on wine sales in value clearly reveal a more positive trend (see Figure 3.6). In 2008, the global wine market generated total revenues of 222.6 billion US $\$$, representing an annual growth rate of 2.6 percent for the period 2004-2008. The European market grew as well, with an annual growth rate of 2.2 percent, reaching a value of 170.1 billion US\$ in 2008. The forecast of wine market specialists, before the outbreak of the crisis, was that similar growth patterns would characterize the five-year period 2008-2013, when the total amount of wine sales was expected to reach a value of 254.6 billion US\$, and those of Europe more specifically of 192.4 billion US\$, with an annual growth rate reaching respectively 2.7 percent and 2.5 percent by the end of 2013 (Datamonitor, 2008). It is still unclear to what extent the negative impact of the recent economic and financial crisis will prove these forecasts wrong (OIV, 2011).

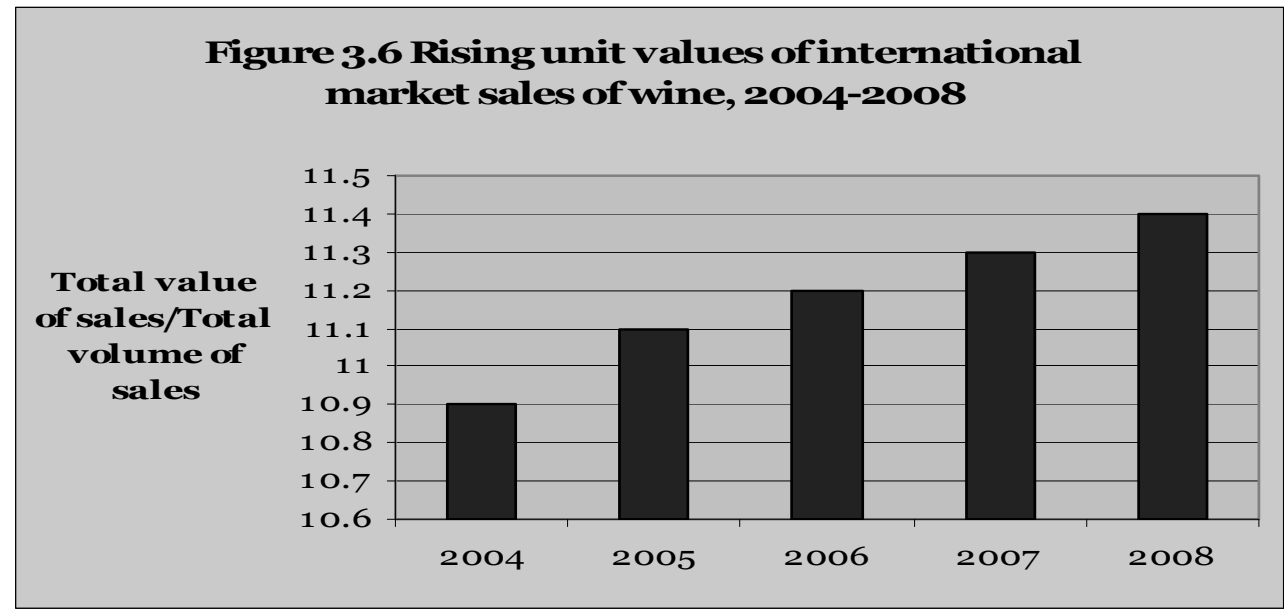

Source: Author's elaboration based on Datamonitor, 2008

As shown by the figure above, data until the crisis show that quality improvements in wine production are clearly reflected in rising unit values of wine sales. Overall, this supports the assumption that the modern wine industry is characterized by a low income elasticity of demand for wine as a general product, but also by a high income elasticity of demand for quality wines with certain characteristics or attributes (Smith, 
2007). In the previous sections we have shown how these can be ascribed to major innovative upgrading and quality improvements, which have transformed wine into a high value, diversified product, with changing consumption patterns and increasing market shares gained by premium wines to the detriment of table wines, to the point that the concept of "market premiumization" has become a common expression in the specialized literature.

\subsection{The emergence of New World producers}

In parallel to the changes on the demand side, several changes on the supply side of wine production have occurred over the past decades, outlined in this section. France, Italy and Spain have traditionally represented the most important wine producing and exporting countries but also the primary wine-consuming countries. However, since the 1970s, this situation has gradually changed. The transformation of wine from a standardized product into a highly diversified product, with increasing value-added content, was accompanied by the aggressive entrance into the international wine market of a number of so-called "New World" producers, led by Australia and the United States. Quite surprisingly, these managed to enter an industry that was traditionally dominated by the presence of a few countries with a winemaking tradition of more than twenty centuries, despite their lack of history and the fact they did not enjoy the same high-quality image of their established competitors (especially France). For example, Australia is now part of the group of the top 4 wine exporters, while the United States forms part of the group of the top 4 wine producers, importers and consumers.

To appreciate the amplitude of the unexpected explosion of New World producers, it is sufficient to highlight that, in the early 1980 s, wine guides dedicated no more than one paragraph to the New World, with great emphasis placed mainly on the United States. This is not too surprising, since Robert Mondavi had already kicked off his "Californian renaissance" in 1966, and had started to win the first gold medals in international competitions as early as the late 1970 (Arkell, 1999). At that time, however, Australia was given the same consideration as Canada, West Africa, Hungary and the UK by the wine critics, while New Zealand was only sporadically mentioned (Parker, 2008; Taber, 2007). Data provided by the OIV show that, despite the aggressive entry of New World producers, the forces of tradition are very strong, and European countries have continued to lead the world wine industry, with Italy and France producing and exporting the largest volumes of wine. However, Europe has lost ground with respect to all the most important wine market indicators, in favour of emerging producers located mostly in the Southern Hemisphere. If, until the 1980s, the New World producers combined used to produce less wine than either France or Italy, in 2010 France and Italy together represented (only) 56 percent of the world's wine production (OIV, 2011).

Paradoxically, California and Australia, and not France or Italy, kicked off the groundbreaking transition from the production of cheap basic wine for domestic consumption to the production of higher quality, branded wines for exports, described in the previous section (see Table 3.5). Some of the most remarkable technological 
developments of the late twentieth century, especially in the field of viniculture, were led by New World producers, and not by those Old World producers who had established the wine habits and practices of the New World at the time of colonization. Old World methods have actually represented for centuries a sort of glorified, unquestioned myth. However, the willingness and ability of New World producers to improve and update the most traditional viticultural practices, to pioneer new winemaking technologies, and to adapt and experiment without fear and preconceived ideas, represent some of the most significant factors in the development of modern winemaking.

Table 3.5 - Leading countries in the modern wine industry, 1986-2005

\begin{tabular}{|c|c|c|c|c|}
\hline & 1986-1990 & 1991-1995 & 1996-2000 & 2001-2005 \\
\hline \multicolumn{5}{|c|}{ Top 4 wine producers (in thousands of hectolitres) } \\
\hline France & 64,641 & 52,886 & 56,271 & 51,919 \\
\hline Italy & 65,715 & 60,768 & 54,386 & 49,409 \\
\hline Spain & 33,519 & 26,438 & 34,162 & 36,993 \\
\hline USA & 18,167 & 17,619 & 20,386 & 20,399 \\
\hline \multicolumn{5}{|c|}{ Top 4 wine exporters (in thousands of hectolitres) } \\
\hline Italy & 12,551 & 15,069 & 14,830 & 14,955 \\
\hline France & 12,776 & 11,478 & 15,271 & 14,820 \\
\hline Spain & 4,645 & 7,353 & 8,817 & 12,076 \\
\hline Australia & 249 & 1,002 & 2,088 & 5,455 \\
\hline \multicolumn{5}{|c|}{ Top 4 wine importers (in thousands of hectolitres) } \\
\hline Germany & 8,533 & 9,776 & 10,796 & 12,238 \\
\hline $\mathrm{UK}$ & 6,085 & 6,586 & 8,437 & 11,241 \\
\hline USA & 2,985 & 2,507 & 4,096 & 5,939 \\
\hline France & 4,772 & 5,679 & 5,641 & 5,106 \\
\hline \multicolumn{5}{|c|}{ Top 4 wine consumers (in thousands of hectolitres) } \\
\hline France & 41,715 & 37,310 & 35,305 & 33,913 \\
\hline Italy & 36,621 & 35,122 & 31,950 & 28,504 \\
\hline Germany & 18,389 & 18,544 & 19,279 & 19,949 \\
\hline USA & 20,791 & 18,759 & 20,814 & 23,401 \\
\hline
\end{tabular}

Source: OIV, 2011

According to Brook (2000), the reasons California and Australia, and not France or Italy, introduced such radical innovations have to be ascribed to the differences in their natural conditions. Since the climates of the New World are too hot, no good wine could be produced until means were found to cool the fermentation process through modern refrigeration techniques and stainless steel tanks. This, together with a new emphasis on hygiene, represents the pillar of the most important technological revolution of twentieth century wine-making. In other words, in order to break the hegemony of the "frontrunners", New World producers had to not only introduce radical innovations 
into the production process, but also revolutionize the traditional Old World supplydriven model of production by introducing new, more market-oriented types of wines and business models that would allow them to produce more standardized wines as a means to enter the industry and gain market shares.

In pursuing such a significant revolution, New World producers have been helped by the freedom and autonomy of their young wine industries, lacking the restrictions and inhibiting rules of the European appellation systems, or the demanding regulations governing pruning methods and maximum yields typical of the Old World, which have often limited innovativeness and kept producers bound to past habits and practices. Contrary to the Old World, where most vine populated land has been handed over from generation to generation for centuries, New World growers have been free to choose where to site their vineyards, what varieties to plant, and what styles of wine to produce. Therefore, free from any "cultural legacy", New World producers have been able to combine adequate planning (based on altitude, proximity to water, temperature, soil composition, and so on) with state-of-the-art technologies. This, together with the new attention paid to varietal labelling as a marketing tool, is at the origin of the typical fresh, clean, fruit-driven flavours of the New World wines that international consumer have praised and preferred so unequivocally (see Figure 3.7).

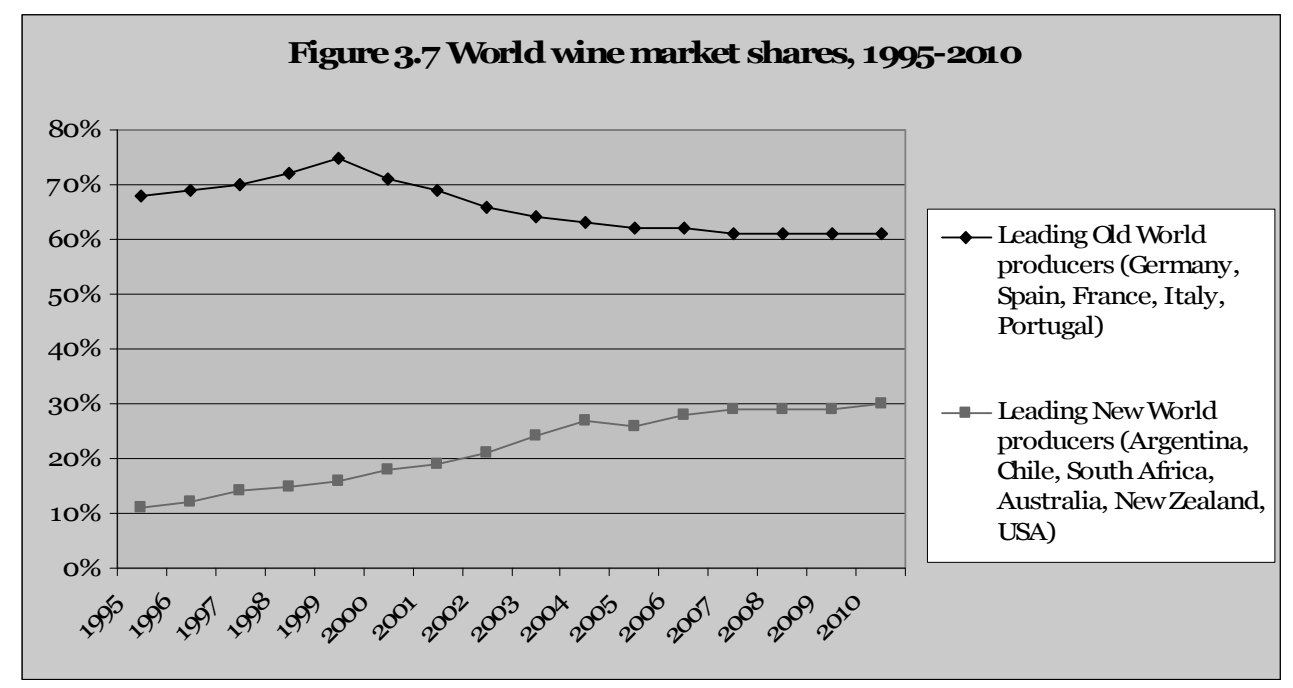

Source: Author's elaboration based on OIV, 2011

In the 1970s, when the exports of Californian and Australian wines started to take off and to gradually gain world market share, a real clash of polarized approaches between New World and Old World producers took place, basically highlighting the "nature versus technology" dichotomy. According to Old World philosophy, each vineyard should deliver a unique, indelible flavour owing to the unique interaction between a certain soil, geography and climate. The winemakers' task is, therefore, "to unleash the individual expression of the grapes and let it fill in the glass” (Peynaud, 1984). 
In this sense, the Old World has often criticized the New World for being too interventionist and for "fabricating" one-dimensional wines, often ending up "fashioning grapes into styles of wines to which the grapes would not naturally lend themselves" (Peynaud, 1984). On the contrary, according to the New World philosophy, what is needed to produce good quality wines is the ability of the winemaker, and especially sound technical tools. From the New World perspective, the French concept of terroir, especially concerning the need to register delimited wine producing areas in order to preserve the indigenous identity of the regions through restrictive appellation systems, is considered nothing more than a marketing invention that Europeans have adopted with the excuse of their "indefectible faith in nature", only to hide their protectionist purposes.

These approaches remained irreconcilable until the legendary Paris Tasting of 1976. In what was considered a "non-event" (Taber, 2005), a panel of top French wine judges and experts compared in a blind tasting some of France's most famous wines (ten red Bordeaux-style Cabernet Sauvignons and ten white Burgundy-style Chardonnays) with a new generation of practically unknown wines from California. Everybody's expectation was that clearly France would win, considering that until then California was best known for cheap jug wine (Taber, 2005; Beazley, 2000). Quite unexpectedly, though, the competition was won by two new generation, California wines, both in the red and white categories, namely by a 1973 Stag's Leap Wine Cellars Cabernet Sauvignon and by a 1973 Chateau Montelena Chardonnay. As a result, the international wine industry was completely transformed, and New World wines gained credibility and reputation. In particular, California saw its name reinforced forever, as a quality wine producing region. According to the renowned wine critic Robert Parker, the Paris Tasting was a "watershed" in the history of wine, in that "it destroyed the myth of French supremacy and marked the democratization of the wine world" (Parker, 2002).

Paradoxically, since the Paris tasting the opposition between Old and New World is being gradually reduced, and their differences in both style and production techniques have become less pronounced. On the one hand, New World producers have become less aggressive in applying science, and have recognized that good wine cannot be made without good grapes, thus agreeing on the need to go back to the roots and to nature. On the other hand, innovative producers in the Old World have adopted new technologies and are increasingly producing wines with fresh varietal styles. Additionally, the development of more temperate climatic regions within the New World is delivering finer wines, considered more European in style. And at the same time, given the incredible success of varietal labelling introduced by the New World, the Old World has finally adopted - with success - this new marketing concept.

From a technological perspective, the two worlds are still divided by polarized views on two main technical issues: one is the use of mechanical harvesting, the other is the use of artificial irrigation techniques. The Old World tends to believe, in fact, that irrigated vines and mechanically harvested grapes, which belong predominantly to the culture and habits of the New World, result in poorer wines - which is not necessarily nor always the case. However, the use of temperature controlled fermentation and of 
stainless steel tanks, which is essential to preserving aroma and fruit flavours, has become one of the most important factors for quality winemaking everywhere in the world. As a matter of fact, it would be a mistake to believe that the commercial success of more affordable, good quality premium wines, which has characterized the wine industry since the 1980 , was only due to the innovative marketing strategies introduced by the New World. Essentially, it has been made possible thanks to the higher quality achieved by wine producers worldwide, namely to a real technological revolution that, as highlighted in this section, started to permeate the wine industry in the 1970s, and diffused quickly into both the New and the Old Worlds.

The following section will show that the ability of the New World wines to enter the global wine industry was rendered even more difficult by the structural transformation that has characterized the industry since the late 1980s, leading to consolidation and firm concentration dynamics that have introduced production and distribution systems operating on a global rather than a local scale.

\subsection{The global restructuring of the wine industry}

Since the late 1980 s, in parallel to the dramatic increase in the share of wine production that is traded internationally, there has been a surge of foreign investment, mergers and acquisitions, and takeovers in the industry (Anderson, 2004). The globalization of the wine industry has opened up indeed new entry opportunities to new and emerging producers, but has also put under tremendous pressure the most traditional and consolidated producers, who were forced to move away from the production of cheap basic wine for domestic consumption towards the production of branded quality wines following the tastes of international consumers. Anderson (2004) rightly argues that for those European growers who had to drastically reduce their grapevine area in the $1980 \mathrm{~s}$ and 1990s, it must have added "insult to injury to see wines from New World upstarts suddenly invading the export markets they have used to soak up their surplus wine".79

Among the New World producers, the first country that recognized that the wine market was becoming global and that deliberately responded to the opening of such new market opportunities was Australia, which could rely on cheaper viticultural land and a weaker currency than, for example, the United States. ${ }^{80}$ It was actually Australia that led the transition towards high-knowledge intensive, "industrial" wines, often criticized for their standardized formula and one-dimensional blueprint, which was inspired by the results of R\&D and by high-tech production techniques. The knowledge flows through flying winemakers and the transfers of wine machinery, however, are just

\footnotetext{
79 Until the 1970s, only 8-10 percent of the world's wine production was traded internationally, and 80 percent of that trade took place between European countries. At that time, the participation of non-European countries in the international wine market was practically non-existent (Alvarado, 2004).

80 According to Anderson (2004), one of the main factors that drove the export boom of New World wines was a change in the British liquor licensing laws in the 1970s, allowing supermarkets and large retailers, such as Marks and Spencer, Waitrose and Tesco, to sell wine. This encouraged the middle class to experiment with products, such as wine, that had previously been reserved for the upper class.
} 
the tip of the iceberg of an industry that has completely internationalized its production and distribution systems (see Table 3.6). Both Old and New World wineries have intensified their international involvement, creating foreign affiliates as illustrated by the table below, or forming new alliances and joint-ventures with foreign companies to reap economies of scale and scope, including through vertical integration with large distributors (Anderson, 2004; Outreville and Hanni, 2011).

Table 3.6 Largest wine corporations ranked by number of host countries, 2010

\begin{tabular}{|c|c|c|c|c|}
\hline Rank & Company & Home country & $\begin{array}{c}\text { Number of } \\
\text { host } \\
\text { countries }\end{array}$ & $\begin{array}{l}\text { Number of } \\
\text { affiliates or } \\
\text { subsidiaries }\end{array}$ \\
\hline 1 & Brown-Forman Corporation & United States & 26 & 45 \\
\hline 2 & Pernod Ricard S.A. & France & 25 & 97 \\
\hline 3 & Freixenet S.A. & Spain & 20 & 34 \\
\hline 4 & Davide Campari-Milano S.p.A. & Italy & 17 & 30 \\
\hline 5 & Belvédère Group & France/Poland & 16 & 65 \\
\hline 6 & Foster's Group & Australia & 11 & 40 \\
\hline 7 & Diageo PLC & United Kingdom & 10 & 11 \\
\hline 8 & Sektkellerei Henkell \& Co AG & Germany & 9 & 15 \\
\hline 9 & Vranken-Pommery Monopole & France & 9 & 26 \\
\hline 10 & Kirin Holdings Company, Limited & Japan & 9 & 33 \\
\hline 11 & Vina Concha y Toro S.A. & Chile & 7 & 23 \\
\hline 12 & LVMH Moët Hennessy Division & France & 7 & n.a \\
\hline 13 & Constellation Brands, Inc. & United States & 6 & 42 \\
\hline 14 & Sektkellerei Schloss Wachenheim AG & Germany & 6 & 47 \\
\hline 15 & Distell Group Limited & South Africa & 6 & n.a \\
\hline 16 & AdVini (JeanJean/M.Laroche) & France & 6 & 27 \\
\hline 17 & Société des Produits Marnier-Lapostolle & France & 5 & n.a \\
\hline 18 & Central European Dist. Corp. & United States & 3 & n.a \\
\hline 19 & Australian Vintage Ltd. & Australia & 2 & 29 \\
\hline 20 & Henri Maire & France & 2 & 13 \\
\hline
\end{tabular}

Source: Outreville and Hanni, 2011

In 1979, Opus One was the first international joint-venture in the wine industry, involving Baron Philippe de Rothschild in Bordeaux and Robert Mondavi in Napa Valley, California. Many renowned French-Californian ventures have been successful since then, some of which involve champagne producers. In addition, the wine industry has been characterized by a considerable number of takeovers and direct investments by Western European companies in South America, Australia, New Zealand and, most recently, Eastern Europe and China; by Australian companies in North America and Europe; and by North American companies in South America, France and Italy. Just to cite a few examples, in 1989, Pernod Ricard bought the Australian Orlando Wyndham Wines and created the world famous Jacob's Creek brand. In 2001, Mildara Blass took over the Californian firm of Beringer, thereby creating the famous Blass-Beringer brand, and also invested in the Italian Chianti. Since the early 1990s, BRL Hardy has invested in the South of France, signed a distribution agreement with Dragon Seal in China, and merged with the US giant Constellation to form the world's largest wine company. Lafite Rothschild has substantial holdings in Chile, while the Italian Antinori is present in South Africa and Argentina. 
Overall, a reorganization of the wine industry, mainly consisting of a gradual process of firm concentration within the global wine market, has taken place (Phillips, 2000). In the New World, a few big companies - such as E\&J Gallo, Constellation Brands, the Wine Group, Bronco Wine Company and Beringer Blass Wine Estates in the United States, and Fosters Group, Orlando, Southcorp and BRL Hardy in Australia - are dominating the market by selling large volumes of standardized wines under their own brands or under those of large supermarkets and/or distribution chains. Leading wineries in the New World often look like refineries and are engaged in a worldwide battle for market share that obliges them to produce stereotypical, almost industrial, wines, which taste the same every year. In order to avoid the typical European taste variations and quality oscillations due to the climate unpredictability of springs and autumns, they utilize large-scale, low-cost, highly mechanized production methods and take over smaller promising companies, thereby vertically integrating their production as a brewery or a distiller would normally do.

In the Old World, the average size of the wineries is still much smaller than in the New World, and the level of firm concentration is not as high (see Table 3.7). The extreme fragmentation of production (the average vineyard is 1-1.5 hectares in Italy and Germany, and 6-7 hectares in France and Spain, against 61 hectares in the United States and 60 hectares in Australia), represents the main limitation to a quick conversion process, but there is clearly awareness that that those producers that have not upgraded their production of table wines to premium wines are competing for a decreasing number of low-priced consumers.

Table 3.7 Firm concentration within the international wine industry, 2006

\begin{tabular}{lrcc}
\hline & & $\begin{array}{c}\text { Top 3's share of national wine } \\
\text { production (\%) }\end{array}$ & $\begin{array}{c}\text { Number of hectares per } \\
\text { grower }\end{array}$ \\
\hline Old World & France & 13 & \\
& Italy & 6 & 7.4 \\
Spain & 12 & 5.3 \\
New World & & \\
& United States & 61 & 40.2 \\
& Australia & 60 & 20.6 \\
& New Zealand & 70 & 25.5 \\
\hline
\end{tabular}

Source: Rabobank, 2007

The consolidated trend towards corporate ownership of a large number of previously independent wine-producers, however, is not only a characteristic of the New World. One of the largest companies in Europe, for example, is Luis Vuitton Moët-Hennessy (LVMH), which is present in several luxury goods and which produces some of the best known champagne - such as Moët Chandon, Veuve Clicquot and Krug - and a series of prestigious wine companies in France, Argentina and Australia, including the famous 
Chateau d'Yquem and Chateau Lafite. ${ }^{81}$ The French Pernod Ricard, on the other hand, owns Orlando in Australia and Montana in New Zealand, the largest individual producer in the country. A major distinction remains, though, between the Old and the New World industry structures, in terms of firm concentration and average number of hectares per grower, as clearly shown by the table above (Smith, 2007).

Both in the Old and the New World, it has become increasingly difficult for smaller companies to enter into a distribution chain, which requires supplying large volumes on a continuous basis, and to reach larger markets. However, small boutique wineries producing unique hand-crafted wines continue to proliferate, showing a deep respect for the concept of terroir and protecting the nuances of local character. This is true even in the New World, where clear market leaders have emerged with strong brands, and where a new phenomenon seems to be emerging, namely the rise of micro boutique wineries that produce high-quality wines. To do well in the age of super-marketing and consolidated winemaking giants, the most successful small and medium wineries, both in the Old and the New World, are constantly improving their technical skills, as well as their marketing and distribution techniques, often by establishing niche arrangements with larger producers (Smith, 2007). This is probably the reason why, overall, the wine industry is characterized by a not-so huge firm concentration, compared to other beverages ${ }^{82}$ and why the increasing globalization of wine has not (yet) resulted in the homogenization of wine, as one might have feared some years ago (Anderson and Wood, 2006).

\subsection{The "unexpected" entry of developing countries}

From the above, it clearly emerges how, at the end of the last century, the wine industry started to operate within a global context, and how this brought about tremendous changes, both on the supply and the demand sides. Since the 1970s, a group of New World producers, composed of former colonies of European nations, gradually emerged and made itself known for the production of high quality, reasonably priced, relatively easy-to-drink wines. These were particularly appreciated by international consumers who, encouraged by the opening up of increasingly liberalized and free markets in the 1980 , could access high quality, affordable, high-value wines. Currently, the most reputed wine guides devote full chapters to New World producers, such as the United States (focusing not only on the widely known wines of California, but also on those produced in Washington and Oregon), Australia, Canada and New Zealand. More surprisingly, however, they are also paying growing attention to developing countries, such as Chile, Argentina and South Africa, and the expansion of wine production in Morocco, Lebanon, Hungary and Georgia, as well as in unusual places, such as China

\footnotetext{
${ }^{81}$ According to Storchmann (2011), a 1787 bottle of Chateau Lafite, formerly owned by Thomas Jefferson - the third President of the United States (1801-1809) - is the most expensive bottle of wine ever sold in the world. It was auctioned off at Christie's in London in 1985, at a price of approximately 322,00o US\$.

${ }^{82}$ According to Rabobank (2007), the world market share of the three largest wine firms in the late 1990s was just 6 percent, compared to 35 percent for beer, 42 percent of spirits and 78 percent of soft drinks.
} 
(see Figure 3.8), Egypt, India, Japan, Kenya, Korea, Vietnam and Zimbabwe (Wine Spectator, April 2012). ${ }^{8}$

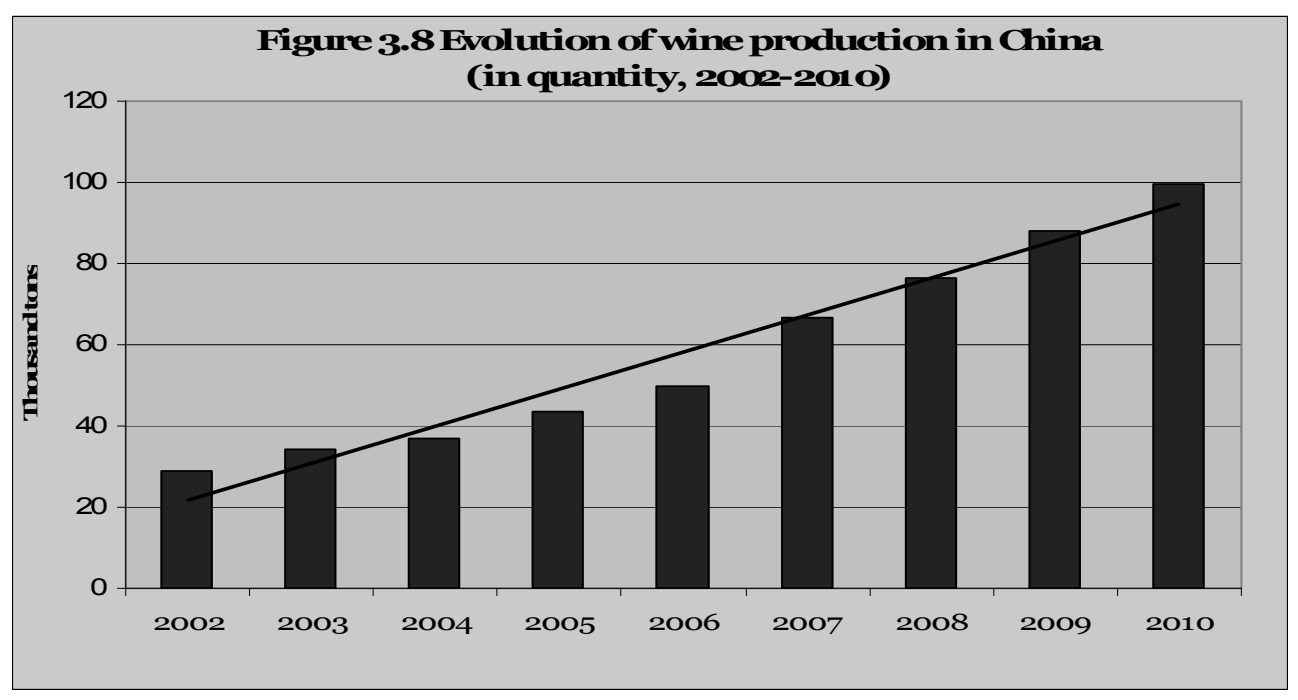

Source: OIV, 2011

As already noted in Chapter 2, the entry of developing countries into the international wine market is surprising, considering not only the dominant position of a few consolidated European producers, but also especially the fact that the growing knowledge intensity and the deep structural changes that have characterized the wine industry over the last four decades should have made entry conditions for developing countries particularly prohibitive, if not impossible. In order to be successful, new entrants, such as Australia and California, have actually managed to adapt to rapidly changing market forces of demand and supply at both the national and the international levels. They have done so by combining standard industrial methods, individual creativity and the most innovative technologies, thereby meeting the new, selective and discriminating preference for quality wines made by increasingly knowledgeable and well-informed consumers (Bisson et al., 2002).

Taking advantage of the growing interest in - and rising demand for - New World wines, Chile, Argentina and South Africa have followed suit and became successful and widely known wine exporters in their own right (see Figure 3.9). In particular, during the last few years, Australia seems to have lost its dominating role among the group of New Word producers, and its export performance has almost been matched by that of Chile. Looking more specifically at the export performance of Chile and Argentina between 1985 and 2010, we find that Chile actually came in second in terms of relative

83 Although in 2009 China become the sixth largest wine producer in the world, with 12 million hectoliters of wine produced per year (almost the same amount as Australia and Argentina), it is not yet considered a major New World player in the wine industry, since it exports less than 1 percent of its total production (OIV, 2010). Since 1997, wine production has more than tripled, while wine consumption has reached 14 million hectoliters, turning China into the fifth largest wine consumer. 
export growth (+1022 percent), while Argentina came in fourth $(+478$ percent) after Australia $(+1,723$ percent) and South Africa (+965 percent) - that is, after their main competitors from the New World, but well before the principal Old World producers.

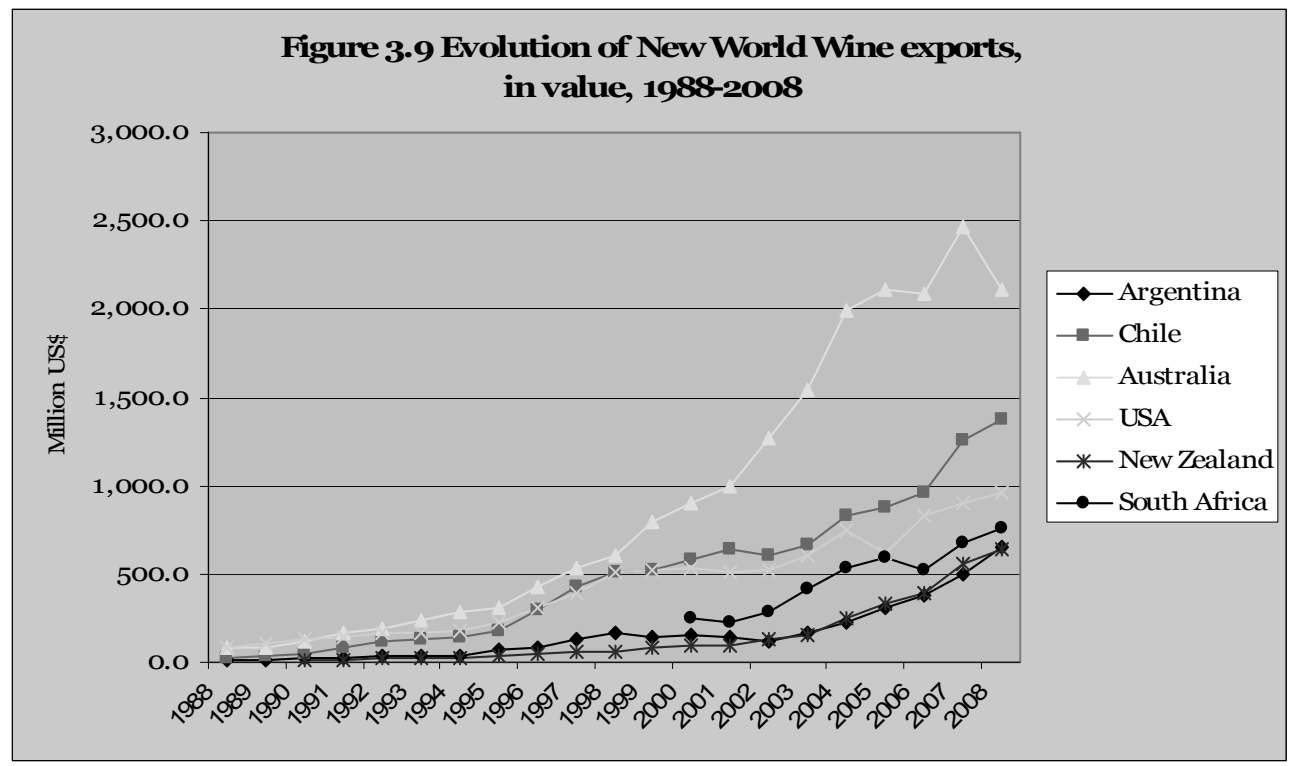

Source: Comtrade (11212), SITC Rev.2

Quite remarkably, both Chile and Argentina have seen their wine exports grow uninterruptedly for almost two decades, both in terms of volume and of value. From 1985 to 2010, the export of Chilean wines to international markets increased from 29.1 thousand tons to 586.8 thousand tons per year in terms of volume and from 23 million US\$ to 1,370 billion US\$ per year in terms of value. This is clearly reflected in the drastic growth in world market shares of Chilean wines, which have increased from 0.5 per cent to 7.5 percent in less than two decades (OIV, 2011). Even more impressively, looking at comparative figures, in 2008 Chile was the world's tenth largest producer of wine but its fifth largest exporter (ranking immediately after Australia, France, Spain, and Italy). In 2010, it exported more than two thirds (73 percent) of its total production, reaching the highest export ratio in the whole industry, while it exported only 2.5 percent in 1985 .

Argentina represents the most important wine country in Latin America in terms of cultivated vine area and in terms of per capita consumption, but the export boom of Argentine wines is more recent with respect to that of Chile. From 1985 to 2010, the export of Argentine wines to international markets increased substantially from 17 thousand tons to 430 thousand tons in terms of volume, and from 10.8 million to 641 million US\$ in terms of value. However, contrary to Chile, wine in Argentina is mainly produced for internal consumption, and wine exports represent a minor percentage of domestic production. In 2010, Argentina exported less than 15 percent of its domestic production (3.5 percent of overall world exports), compared to 73 percent in Chile and 
48 percent in Australia (respectively, 7.5 percent and 8 percent of total world exports), while in 1986 it exported only 1.5 percent (see Figure 3.10).

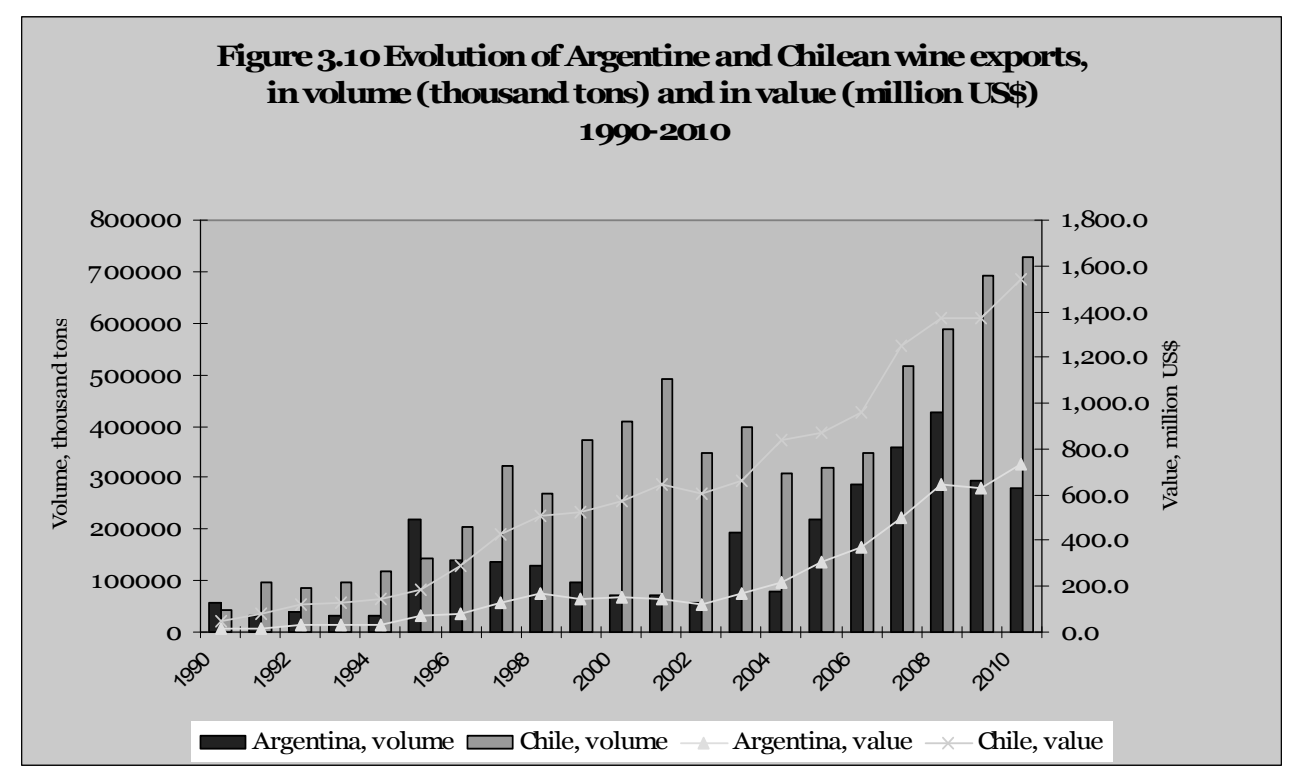

Source: Comtrade (11212), SITC Rev.2

Overall, there is clear evidence that both Chile and Argentina have acquired significant shares of the international wine market over the last two decades, thus legitimately belonging to the emerging group of New World producers. However, the different amplitude of their export performance and the time lag of their export boom deserve further investigation, especially considering not only their similar natural and historical conditions of departure, but also the geographical vicinity of the main Chilean and Argentine wine regions (Mendoza, in Argentina, is only $300 \mathrm{~km}$ from the Chilean Central Valley, from which it is separated by the Andean Cordillera). Additionally, the dynamism of their export trends opens up a series of interesting questions - to be addressed in the following chapters - related to the sustainability of the position of new developing country producers in the international market, especially considering the double challenge represented by a market demanding increasingly high-quality standards and by an industry where major technological changes have been introduced by latecomers as the only way to break the hegemony of Old World producers and gain new competitive advantages.

\subsection{Conclusions}

This chapter has highlighted that, similar to other natural resources, wine has become a high value, extremely diversified product. Since Roman times, wine has been known for its infinite varieties. Average consumers, however, have always drunk ordinary table wines, practically a commodity. Since the last quarter of the twentieth century, the 
consumption of ordinary table wine has generally declined, but this fall in demand has only affected cheap table wines, whereas demand for quality wines has continued to increase. The shift from quantity- to quality-oriented wine consumption is attributable to changes in lifestyles and rising levels of GDP per capita, and has meant that, for most international consumers, wine is no longer an ordinary everyday beverage or a caloric supplement, but a high-quality, highly priced (occasional) luxury good.

Despite being a mature and very old product, the art of winemaking relies on the interaction of different scientific fields and knowledge groups: agronomy and scientific instrumentation, chemistry and biology, mechanical engineering and physics, and neurobiology, sensory analysis and psychology. It also relies on large amounts of codified and capital-embodied knowledge, as well as on tacit knowledge supporting complex decision making and continuous technological adaptation and improvement. Thus, contrary to those who think that natural resources are low-tech industries, this chapter shows that wine has become a knowledge-intensive, sophisticated and diversified product. This corroborates Archibugi's view that "no industry should be considered mature, since almost all of them can be affected and transformed by new technologies" (Archibugi, 2007). The sub-hypothesis that natural resource-based industries can be extremely sophisticated in terms of innovation and technological content has been therefore validated.

The deep technological revolution of wine production in all its phases was led in the 1970 s by two new entrants, namely Australia and the United States. These New World producers have challenged the century-old hegemony and the consolidated habits of Old World producers, such as Italy, France and Spain. They have also reshaped the patterns of competition and the technological trajectory of the wine industry worldwide, and have out-competed Old World producers in the international market. This could have raised the barriers of entry for developing countries and made access to international markets prohibitive, if not impossible. Paradoxically, however, the present chapter shows that the group of New World producers that emerged during the last quarter of the twentieth century includes also developing countries, such as Chile and Argentina, which have been able to grasp the new windows of opportunity created in the wine industry in a strategic manner. The sub-hypothesis that the increasing knowledge intensity of natural resource-based industries has opened up new prospects to developing countries has been therefore also validated.

As noted in Chapter 1, however, this phenomenon per se it is not new. Both Chile and Argentina have traditionally been successful exporters of primary commodities in the past and have experienced a series of export "booms and busts" that did not succeed in promoting sustainable economic growth. The key questions to be addressed in the following chapters are whether the continued export growth of wines from Chile and Argentina corresponds to a parallel increase in quality, how this happened and whether evidence can be traced that these achievements (continued export growth and higher quality) are likely to be sustainable. 



\section{CHAPTER 4}

Quality Improvements and

\section{International Positioning of} Chilean and Argentine Wines 
CHAPTER 4

150 


\subsection{Introduction}

The previous chapter has demonstrated that the wine industry has become a sophisticated, knowledge-intensive, natural resource-based industry. Over time, this has translated into major quality improvements and considerable technological changes. In light of this, one might be sceptical about the ability of developing countries to enter the market successfully and sustain increased exports. However, trade data clearly show that some developing countries have successfully entered the wine industry, to the point that three of them - Chile, Argentina and South Africa - currently rank among the top ten leading wine exporters.

This chapter explores the modalities of how this happened. It specifically looks at the cases of Chile and Argentina, adopting a comparative perspective. It provides information on the historical and political backgrounds to the export boom of Chilean and Argentine wines, as well as on this boom's conditions of departure in terms of natural competitive advantages, with the aim of understanding the specific context under which it developed.

In particular, this chapter addresses a number of key questions: for example, what can explain the fact that the wine export boom unfolded only in the 1980 os in Chile and in the 1990s in Argentina and not earlier, as, for example, in California and Australia? Is there evidence to suggest that Chilean and Argentine wine exports have been characterized by an increase in quality and value-added contents over time? Are the (internal and external) conditions under which the Chilean and Argentine wine industries compete at the global scale any different from those that, in other industries, led to repeated failures in the past?

In order to answer these questions, Chapter 4 is structured as follows: Section 2 illustrates the historical background to the Chilean and Argentine wine industries from their origin. Section 3 looks at the impact of political changes, regulatory framework reforms and improved macro-economic conditions in facilitating the development of the wine industry in both countries. Section 4 discusses the natural assets and competitive cost structure that underlay the successful export performance of the Argentine and Chilean wine industries at their point of departure. Section 5 assesses the quality improvements introduced in the Chilean and Argentine wine industries over time. Section 6 explores whether such improvements have been matched by an equal improvement of their positioning in the international market. Section 7 looks at the role of local demand in stimulating and accelerating the drive towards increasingly highquality wines. The concluding section points to the need to verify (a task that will be taken up in Chapter 5) whether such quality improvements were mirrored by a technological upgrading process by leading Chilean and Argentine wineries, and the extent to which such technological upgrading was achieved by creating domestic linkages and increasing the knowledge intensity of the local industry. 


\subsection{Brief historical background}

The history of the Chilean wine industry begins in the early sixteenth century, at the time of Spanish colonization and with the entrance of early priests from Peru into Chile. The Spanish priest, Don Francisco Carabantes, is said to have brought to Chile in 1548 the first Criolla vine cuttings, originating from the Canary Islands. In 1551, the Spanish conquistador, Don Francisco de Aguirre, planted the first vineyards in the fertile and well-watered areas around Copiapo and La Serena, five hundred miles to the north of Santiago. Five years later, in a letter to the King of Spain, Charles the Fifth, the Spanish conquistador, Pedro de Valdivia, who had taken possession of Chile in the name of Spain in 1540, refers to the widespread consumption of wine in the capital Santiago. Originally produced purely for sacramental purposes, wine, being an essential element in the celebration of the Eucharist, had spread throughout the country as a beverage for daily consumption by the end of the sixteenth century (Sharples and Knowles, 2002).

Chilean wine production became so important that in 1654 the Spanish "mother country" had to impose a royal ban on vine growing in order to curtail the Chilean wine expansion and to protect its own export trade. Despite the ban, which was lifted in 1678 but issued again in 1767 , by the end of the seventeenth century Chile was competing with all the main European producers, and had already gained the reputation of an exporter of large volumes of cheap, drinkable wines - a reputation which continued throughout the eighteenth and nineteenth centuries. The most commonly exported variety was the País, a simple red grape that was also planted by Spanish priests in the rest of the Americas (where it is also known as Missión or Criolla).

Only after Chilean independence in 1850 did a new period of expansion for wine production and export begin, and the gradual shift from Spanish to the more classic, internationally appreciated French grapes was initiated. In 1830, a French scientist, Claudio Gay, assisted the Chilean government in setting up an experimental botanical nursery, called Quinta Normal, and had brought along 40,00o French and Italian (prephylloxera) vinifera vines. It was Don Silvestre Ochagavia, though, who first planted high-quality, pre-Phylloxera vinifera cuttings for commercial purposes on his estate in Talagante in the Maipo Valley, a few miles south of Santiago. In 1851, he invited a French oenologist, Joseph Bertrand, to advise him on how to improve his winemaking techniques and to increase the quality of his wines. Soon imitated by the other large landowners, Ochagavia inaugurated a steady interchange of French winemakers and an intense knowledge flow between Europe and Chile. There are records of Chilean wines being exhibited at wine fairs in Vienna in 1873, in Bordeaux in 1882, in Liverpool in 1885 and in Paris in 1889, where a Chilean wine first won the Grand Prize at the Paris Great Exhibition. According to Hernandez (2000), as production rose from 51 million litres in 1875 , to 110 million litres in 1883 , to 275 million litres in 1903 , the Chilean wine industry started to search for foreign markets and became the main exporter in South America.

As in Chile, the Criolla (or País) grape was brought to Argentina by the Spanish conquistadores in the mid-sixteenth century. It was the Jesuit missionary Juan Cidrón, credited as the father of the Argentine wine industry, who brought the first varieties 
across the Andes from La Serena to Santiago del Estero. He was sent from Chile to Argentina in 1543, and is recorded to have arrived "with a crucifix in one hand and a bundle of vine-shoots and cottonseed in the other" (Fielden, 2001). Soon after, vine cultivation spread to the provinces of Salta (in 1556), Mendoza and San Juan (1561 and 1562), Misiones (1575) and lastly Cordoba, Santa Fé and Buenos Aires (1598), parallel to the spread of Catholicism in the country. Wine production remained confined to local consumption, and close to the main centers of population, until the advent of the railway in 1885, whereupon it started to concentrate in the Western province of Mendoza. Here, the French agronomist Michel Aimé Pouget introduced French varieties of high oenological quality in 1860, while the Italian engineer Cesar Cipolletti systematized the irrigation network. In 1865, the businessman Tiburcio Benegas installed in Mendoza his Trapiche winery and, overcoming all sorts of difficulties, planted French varieties imported from Chile, thereby becoming a reference for local producers. 84

The industry began to grow in earnest at the end of the nineteenth century, with the arrival of Italian, Spanish and Portuguese immigrants, who brought with them a deep know-how of vine growing and winemaking, as well as a longstanding culture of wine drinking. A first group of Portuguese prisoners, captured during a war between Spain and Portugal, arrived in Argentina in 1777. This was followed shortly after by a group of 122 Italian, 96 French, 30 Spanish, 18 German and 11 Swiss immigrants, which already included a number of agronomists and vine growers. According to Argentina's industrial census, in 1895 there were 13,000 hectares planted with vineyards and 43 registered wine enterprises employing 3,500 people, 85 percent of which were owned by immigrants. The history of the best-known Argentine wine companies - such as Arizu, Rutini, Bianchi, Flichman, Pulenta, Bianchi, Toso, Giol, Graffigna, or Peñaflor reveals the foreign (mainly Italian and Spanish) origin of their founding families, and the close link between the expansion of the industry and the different waves of immigration that arrived in Argentina at different stages since the late eighteenth century.

In the 1920s, the competition generated by imports of European wines led several local producers to buy advanced technologies from Europe in order to improve the quality of wines produced in Argentina. Since then, Argentina has become completely independent in terms of wine production. Compared to Chile, higher levels of per capita wine consumption, together with the larger size of the economy, have oriented Argentine producers more towards the national than to the international market. Indeed, Argentina represents the only New World producer from the Southern hemisphere with per capita wine consumption levels that have been, and still are, comparable to those of the Northern hemisphere. In this respect one should highlight that - despite being considered "New World" producers - both Chile and Argentina can rely upon a centuries-old winemaking practice, dating back to the colonial period, and

\footnotetext{
84 Alvarado (2004) reports that in 1884 Benegas "travelled by mule to Chile to study the progress of transAndean vitiviniculture. His return to Argentina was complicated because snow closed the mountain pass. As a consequence, he had to endure the long sea voyage through the Strait of Magellan".
} 
that the definition of "New World" producer, despite being widely accepted, is thus inherently misleading.

Of course, the presence of Spanish colonizers per se can hardly be considered an explanation or guarantee for success. In fact, Jesuit missionaries planted Criolla vineshoots almost everywhere in Latin America, since they needed wine not only for sacramental purposes, in order to celebrate masses, but also for treating diseases, as well as for ordinary consumption. Vines were even planted in locations that were very hot and humid, or not particularly apt to vine cultivation, such as Peru, Ecuador, Paraguay, Bolivia, Dominican Republic, Brazil and Mexico. Most of these countries are still producers of low-quality wines, scarcely appreciated by international consumers.

The present chapter analyzes why the efforts of the Spanish conquerors, bringing to Latin America their advanced culture of winemaking and their habit of daily wine consumption, gave rise to a prosperous, export-oriented wine industry only in Chile and Argentina, and why this happened with such a long delay. It also assesses the extent to which the export growth of Chilean and Argentine wines was matched by a parallel increase in quality and local value added. The next chapter will further assess whether these results (continued export growth and higher quality) have been achieved by increasing the knowledge intensity of the local industry and by building domestic capacity, absorbing imported technology and creating domestic linkages, or by relying upon FDI and continued imports of knowledge embodied in foreign wine makers.

\subsection{Conditions of departure of the export boom}

When analyzing the recent export boom of Argentine and Chilean wines, compared to other Latin American countries - such as Peru, Ecuador or Bolivia - it is striking to note how unanimously the specialized literature on the subject considers the natural and climatic conditions of Chile and Argentina ideal for vine cultivation - with this also being a common topic in the local and international press. Talking about Chile, the renowned foreign consultant Michel Rolland invented a slogan that became very popular in the Chilean winemaking world: "If I were a wine, I would want to be planted in Chile!" (Rolland, 2005). A few years earlier, on the other side of the Andes, Rolland argued: "If there is anywhere a place that encompasses the perfect match of climate, soil, costs and human resources for the genuine development of a new and exceptional viticulture, that place is undoubtedly Argentina" (Rolland and Chrabolowsky, 2003).

The key and most-publicized viticultural advantage of Chile is the absence of pests and diseases, such as oidium and phylloxera, which, as stated in the previous chapter, decimated the vineyards of France in the late nineteenth century. In order to survive, the Europeans had (and still have) to graft their vines onto resistant American rootstocks, which inevitably alter the flavour of the wine. Chileans are the only producers in the world who can plant phylloxera-free vines, since the typical French varieties were imported into Chile in 1851 , thereby fully preserving their identity and original taste until the present day (to the point that international agronomists have 
proposed including them in UNESCO's World Heritage protected patrimony). This offers several practical advantages: from extending the average duration of the plant production cycle (to 100-150 years), to reducing the cost of spraying treatments down to a minimum. But perhaps more importantly, it allows international commentators to claim that the Chilean wine made from the classic French grape varieties tastes "more authentically French than its modern French counterparts" (Arkell, 1999; Duijker, 1999).

Another commonly recognized viticultural asset of Chile is related to the country's very favourable natural conditions: climate (limited precipitation, high levels of summer sunshine and great luminosity, moderate temperatures, light winds), soil composition and types (mostly poor in organic matter and well-drained) and geography (splendid natural barriers that completely isolate the country - the Andes Cordillera to the East, the ocean to the West, the Atacama desert to the North, the Antarctic to the South) make Chile the ideal place to produce quality wines. Thanks to climate conditions and limited humidity, fungi, insects and viruses that normally affect grape growers around the world are practically unknown in Chile. Finally, across the long, slim country, the wine producing regions occupy a $1,400 \mathrm{~km}$ central band out of the $2,600 \mathrm{~km}$ length, providing a number of different soil types and climate conditions which allow the cultivation of a diversified range of wine grape varieties. ${ }^{85}$

Contrary to Chile, Argentina is characterized by more delicate climatic conditions. Climate is more unpredictable than in Chile, with spring frosts and summer hails. However, from a more qualitative point of view, Argentina has a more diversified terroir and a broader range in the latitude of planted vineyards (from the cool lowlands of Patagonia in the South to the high altitudes of Calchaquies Valley in the far North) than Chile, California, Australia, or any other New World producer (Austral Spectator, 2004). ${ }^{86}$ In particular, the wide range of climatic conditions and the presence of high altitude plains with cool climates are considered a real asset for the production of quality wines (Arkell, 1999). They are at the origin, for example, of the production of more than 50 grape varieties, including the red Malbec and the white Torrontés, which represent the two typical and internationally recognized Argentine specialties, as will be seen in more detail in the following sections.

In the words of renowned international wine consultant Michel Rolland:

Argentina is still in its infancy, as far as international recognition is concerned, but will go from strength to strength as it continues to realize the potential of its natural advantages: virtually phylloxera-free vines, healthy growing conditions, a long ripening season and great soils and, above all, freedom for creativity and minimal bureaucracy (Rolland, 2003, p.3).

\footnotetext{
85 Chile is divided into 13 administrative regions (I-XII from North to South), plus the Metropolitan Region, including the capital city, Santiago, and its surroundings. Grape growing for wine production currently takes place in one third of the territory and in 7 of the 13 Chilean regions.

${ }^{86}$ Argentina is a Federal State and is administratively organized into 24 provinces and the Autonomous City of Buenos Aires, the Federal Capital District. Wine grapes are grown in 13 of the 24 provinces, and in 8 of them viticulture represents an economically meaningful activity.
} 
As a matter of fact, Chile and Argentina are both considered a sort of "viticultural Nirvana" where grapes can achieve slow maturation and a perfect equilibrium of sugars, tannins and acids (see Table 4.1). Additionally, land and production costs are comparable, and are lower with respect to their direct competitors, such as Australia, California and New Zealand (Rabobank, 2007).

Table 4.1 Strength of basic production factors in Chile and Argentina

\begin{tabular}{|c|c|c|}
\hline & Chile & Argentina \\
\hline Geography & $\begin{array}{l}\text { Isolation (no phylloxera, few diseases) } \\
\text { Wine growing regions between latitudes } \\
33^{\circ} \text { and } 27^{\circ} \text { South from Atacama desert to } \\
\text { Tierra del Fuego) }\end{array}$ & $\begin{array}{l}\text { Different regions and altitudes (from Salta to } \\
\text { Patagonia) } \\
\text { Very high average altitude of vineyards - } \\
2,700 \mathrm{ft} \text { (intense sunlight, cold nights, dry } \\
\text { mountain air) }\end{array}$ \\
\hline Climate & $\begin{array}{l}\text { Four clearly differentiated seasons } \\
\text { Little rain in spring and almost none in } \\
\text { summer and autumn } \\
\text { Cold winters but low incidence of frost in } \\
\text { spring } \\
\text { Intense light (adds flavour) } \\
\text { Abundant water from the Andes } \\
\text { No need of reservoirs for irrigation } \\
\text { Numerous microclimates } \\
\text { Wide thermal range }\end{array}$ & $\begin{array}{l}\text { Intense light (adds flavour) } \\
\text { Abundant water } \\
\text { High plains with cool climate } \\
\text { Well-defined winters, hot summers } \\
\text { Little rain (but abundant melting snow from } \\
\text { the Andes allows irrigation when required) } \\
\text { Ample sunshine } \\
\text { Few diseases } \\
\text { No much wind, except Patagonia } \\
\text { No hail, except Mendoza }\end{array}$ \\
\hline Land & $\begin{array}{l}\text { Relatively cheap land } \\
\text { (approx. 20,000 US\$ per hectare) }\end{array}$ & $\begin{array}{l}\text { Abundant and cheap land } \\
\text { (approx. 16,00o US } \$ \text { per hectare) }\end{array}$ \\
\hline Raw materials & $\begin{array}{l}\text { Little use of pesticides } \\
\text { Presence of pre-phylloxera vines, no } \\
\text { American rootstocks } \\
\text { Mainly drip irrigation } \\
\text { Totally ungrafted vines }\end{array}$ & $\begin{array}{l}\text { Little use of pesticides } \\
50 \% \text { of vines are more than } 25 \text { years old } \\
\text { Mainly flood irrigation } \\
\text { Mainly ungrafted vines }\end{array}$ \\
\hline Labour & $\begin{array}{l}\text { Low unskilled labour costs } \\
\text { Easily available manpower }\end{array}$ & $\begin{array}{l}\text { Low unskilled labour costs } \\
\text { Easily available manpower }\end{array}$ \\
\hline $\begin{array}{l}\text { Firm gate price } \\
\text { /litre }\end{array}$ & $0.30-0.40$ US\$ & $0.40-0.50$ US\$ \\
\hline
\end{tabular}

Source: Author's elaboration based on Rabobank, 2006 and 2007

As seen in the table above, both Chile and Argentina rely on very favourable natural conditions for wine production, as well as on a series of competitive basic production factors, such as low cost of inputs (e.g., limited use of pesticides and use of ungrafted vines), cheap labour and abundant land. Therefore, it is not as surprising that both countries have become successful wine exporters, nor that they are performing better than other Latin American countries. However, such favourable characteristics have always existed as a point of departure and have represented a structural comparative advantage for centuries. Besides, they can also be found in less successful wine producing developing countries, such as Uruguay and Brazil (Benavente, 2004). Thus, none of these factors alone can fully explain why Chile and Argentina have suddenly 
succeeded in competing in an increasingly knowledge-intensive and technologically sophisticated industry, where a few established producers - such as France, Italy and Spain - have dominated the international market for centuries. The following sections will explore the main features characterizing this unexpected export boom of Chilean and Argentine wines, together with how the boom unfolded and the forces that drove it.

\subsection{Impact of political changes and macro-economic conditions}

The timing of the recent entry of the Chilean and Argentine wine industries into the international market can be directly related to the process of trade liberalization and market opening that characterized the early 1980 s in Chile, and the early $1990 \mathrm{~s}$ in Argentina, as well as to those countries' transition to democracy. Their delay, with respect to other New World producers, can be ascribed to a series of conjunctural socioeconomic factors, such as a turbulent political climate, unstable macroeconomic conditions, economic recession and social unrest under the dictatorship of Pinochet in Chile (1973-1988) and the military regimes consecutively led by Videla (1976-1981), Viola (1981), Galtieri (1981-1982) and Bignone (1982-1983) in Argentina. These factors prevented both countries from attracting foreign investors, modernizing and competing in a timely manner compared to other New World producers. As mentioned in Chapter 3, these producers had started aggressively marketing and promoting their wines overseas in the 1970s, if not earlier - as in the case of California, which started in the early 1960 .

Paradoxically, as already mentioned, at the beginning of the twentieth century, the Chilean wine industry was thriving, and Chilean wines started gaining recognition at several European fairs, such as the International Exhibition in Vienna in 1873, in Bordeaux in 1882, in Liverpool in 1885 or Paris in 1889. In 1903, the Undurraga winery sent its first exports to the United States, while in 1910 the Chilean President Pedro Montt travelled abroad with 200 cases of wine as a symbol representing the best products of the country. In 1924, Manuel Rojas, an agricultural engineer sent by the Chilean government to France, Spain, Italy and Portugal to study the most advanced European winemaking practices, wrote an essay reporting on the changes underway in Chilean vineyards and wines, and argued that his country was not "inferior to France in matters of vineyard care and vinification", and that Chilean landowners had "easily assimilated advances arriving from the Old World and had become more competent through observation and by reading special essays" (Alvarado, 2004).

Between the 1930s and 1970s, conservative governments imposed heavy taxes on wine and enforced strict limits on the amount of wine that could be produced in order to combat over-production and to lower excessive alcohol consumption (more than 80 litres per capita). Since colonial times, wine production had been considered a highly lucrative activity and a considerable source of tax revenues. However, specific tax laws on alcohol were not adopted until 1902, when Law N. 1515, establishing the "Alcohol Tax Administration", was formally promulgated. An amendment to this law was approved in 1912, in order to take into consideration the geographic location of the 
vineyards. ${ }^{87}$ In 1939, a new alcohol law, prohibiting the plantation of new vineyards, was unanimously adopted by right-wing parliamentarians, including several important winemakers, who were in favour of limiting overproduction, as well as left-wing parliamentarians, including future President Salvador Allende, who thought that alcohol was devastating the working class and undermining national productivity. However, this measure had minor influence on alcohol consumption, and seriously discouraged the adoption of modern cultivation techniques that favoured quality at the expense of productivity.

Under the government of Allende (1970-1973), radical land reforms resulted in the splitting up and/or expropriation of large estates, and thousands of hectares of vineyards were abandoned. Subsequently, under the military dictatorship of Augusto Pinochet (1973-1988), wine consumption dropped dramatically (from 50 to 11 litres per capita) and exports suffered from the semi-isolation of the country from the rest of the world. In two decades, almost half of the vineyards were lost: of the 109,300 wine grape-growing hectares in 1980, there were only 65,203 left in 1990 (see Table 4.2). During the second half of the 1970s, the drastic liberalization of the wine market complicated the situation further by determining a complete saturation of the domestic market and the collapse of wine prices. ${ }^{88}$ The military regime dismissed all import substitution policies that had been in place since the 1940s, adopting an orthodox model based on trade openness, financial liberalization and privatization. By the early 1980s, however, this model had already exacerbated the vulnerability of the Chilean economy to external forces (Ffrench-Davis, 1983), and the dramatic financial crisis triggered by Mexico in 1982 pushed the country's economy into a deep recession. The combination of domestic stagnation (GDP fell by 14 percent) with an excess of foreign debt obliged the government to take over the national banking system, as well as more than half of existing private firms.

Table 4.2 Evolution of area planted in wine grapes in Chile, 1980-2010

\begin{tabular}{cc}
\hline Year & Area (hectares) \\
\hline 1980 & 109,000 \\
1985 & 67,000 \\
1990 & 65,000 \\
1995 & 54,000 \\
2000 & 103,000 \\
2005 & 114,000 \\
2010 & 117,500 \\
\hline
\end{tabular}

Source: SAG 2011

\footnotetext{
87 According to the detailed review of Alvarado (2006), the vineyards north of the Maule River paid 30 pesos per irrigated hectare and 15 pesos per non-irrigated hectare. South of the river, payment was 20 and 10 pesos, respectively.

${ }^{88}$ In 1974, the military government approved a decree (DL 261) that lifted the prohibition, introduced in 1939, on planning new vineyards. In 1978, another decree (DL 2753) removed all administrative controls that had been put in place to limit and control wine production. As a consequence, growers replanted low-quality, highyield varieties, and in 1983 wine production hit the historical peak of 650 million liters (Pszczolkowski, 1991).
} 
Not before the 1990s, with the end of the dictatorship, did foreign investors show a renewed interest in the potential of the Chilean economy and its fertile natural conditions, and were reassured by the results of the more "pragmatic", export-led model to promote economic growth (Stiglitz, 2002). Measures such as the Liberalization Decree on Foreign Investment was introduced by the military government in the second half of the 1980s, with the aim of promoting economic recovery. However, tangible positive results came about only after democratic elections were finally held, resulting in the election of President Patricio Alwyn. With the transition to democracy, the introduction of export subsidies, better control of the financial system and the stabilization of both inflation and interest rates, the wine revolution could finally take off. Thanks to the arrival of foreign investors, the trend towards a drastic uprooting of vines that had characterized the 1980s, and the progressive replacement of vineyards with pines and eucalyptus trees for the expanding wood-processing industry, could be completely reversed. In 2000, the total amount of planted land could rise again to 103,876 hectares, the same level as in the 1950s, representing an 81 percent increase in only five years. ${ }^{89}$

The same is true for Argentina, even though, with respect to Chile, the Argentine wine industry entered the world market with approximately ten years delay. This can be ascribed to a prolonged turmoil of political nature, as well as to the radical changes and instability that characterized Argentina's macroeconomic setting differently from Chile, especially considering that until 1989 a strict import substitution policy kept the Argentine internal market, including that for wine, fully protected. Between 1930 and 1950, Argentina suffered a strong depression and recovered from it only after the end of Word War II. However, in 1955 the populist president Juan Peron was forced to leave the country, and a long period of political instability began. This included the return to power of Peron in 1973, the short government of his wife Isabel (1973-1974), and a succession of military governments until 1989, which brought in their wake corruption, bureaucracy and isolation from the world community. The entire economy was heavily affected by such instability, including the wine industry which remained entangled in the production of low-quality, mass-oriented wines. This instability was epitomized by the progressive eradication of three quarters of the French noble varieties introduced by the botanist Aimé Pouget in 1880, and the massive re-planting in the 1980s of Criolla grape pergolas with very high yields for cheap and high production.

Consequently, during the decade of the 1980 s the Argentine wine industry underwent a sharp decline and emerged from its ashes only in the late 1990s, five centuries after the Jesuit missionaries planted the first Criolla vine-shoots. In order to appreciate the magnitude of the crisis, it should be noted that, according to data provided by the

\footnotetext{
${ }^{89}$ As a result of good economic returns obtained for wine production during the last decade, the total planted area of vines for wine has constantly increased (from 104,00o hectares in 2000 to 119,000 hectares in 2010). According to the estimations of the Ministry of Agriculture, Chile's total volume of exportable wine was expected to further expand in 2011. However, in 2010 wine production was affected by unusual freezing weather during spring time, which affected vineyards in most production areas, as well as by the earthquake that hit the central-southern part of Chile on February $27^{\text {th, }}$. According to Vinos de Chile, the industry association, more than half of winery installations were severely damaged, while 125 million litres of wine were lost as storage tanks were destroyed and bottles broken (The Economist, April 10 ${ }^{\text {th }}, 2010$ ).
} 
Argentine National Institute for Vitiviniculture (INV), 90 if in 1979 the production of wine in Argentina had reached 27 million hectolitres, in 1990 it was almost half of this. Analogously, annual per capita consumption of wine decreased from 76.3 litres in 1979 to just 54.1 litres in 1990, while the area of planted vineyards decreased from 316,000 hectares to 210,000 hectares over the same period. After a peak in wine production reached in the 1970 - and matched by two other significant peaks: that in per capita wine consumption (92 litres in 1978) and in the area of planted vineyards (350,000 hectares in 1977) - the early 1980 s were characterized by the inexorable burst of a bubble driven by over-production and inflated prices (see Table 4.3).

Table 4.3 Evolution of area planted in wine grapes in Argentina, 1980-2010

\begin{tabular}{cc}
\hline Year & Area (hectares) \\
\hline 1980 & 320,000 \\
1985 & 295,000 \\
1990 & 210,000 \\
1995 & 210,000 \\
2000 & 209,000 \\
2005 & 207,000 \\
2010 & 211,000 \\
\hline
\end{tabular}

Source: INV, 2011

At the origin of the crisis a combination of factors can be found. The over-regulation of the domestic market isolated and protected the local industry for too long, within the framework of a rigorous import-substitution regime. This led to the development, on the one hand, of a supply and equipment industry which, without any competition from the external market, produced expensive and outdated inputs, and, on the other hand, of a structure of production based on gigantic state-owned wineries, such as Giol and Cavic, where the goal of the modernization process was "to process the greatest quantities of grapes possible and produce the wines as quickly as possible for distribution to the market" (Stein, 2004).

Additionally, the traditional equation high yields of low oenological quality grapes equals massive consumption of commodity wine jugs - which reached its highest peak in the 1970 s and was related to the remarkable growth and redistribution of income started in the post-war period - suddenly proved wrong. If for almost three decades, demand had exceeded supply, the rapid expansion of the consumption of other beverages (such as beer, fruit juices and soft drinks) and a progressive move away from table wines to fine wines led to the accumulation of stocks without a market and the imposition of artificially high prices which kept Argentine wine exports well below 2 percent of production until the mid-1990s. Considering the lack of people educated in making fine wine without excessive pandering to local tastes, the decay of the industry was anything but surprising.

After 1991, a drastic trade liberalization and privatization process took place, led by President Carlos Menem and symbolized by the Deregulation Decree Nr. 2284, dated 31

90 Source:http://www.inv.gov.ar/PDF/Estadisticas/PanoramaViti/panorama_vitivinicola20o2.pdf. 
October 1991, and by a radical monetary reform which pegged the Argentine peso to the US dollar - a policy which put an end to a long period of financial instability and hyperinflation but culminated ten years later in a 140 billion US $\$$ external debt default and a devastating financial crisis. Paradoxically, however, the wine industry was one of the few industries that performed greatly during the decade of the 1990s, and also one of the few exceptions during the 2001-2002 financial crisis, as both local and foreign companies continued to expand and increase their operations despite four years of uninterrupted recession.

This phenomenon can be explained by the impact of two subsequent positive dynamics. First, during the 1990s the one-to-one convertibility of the peso to the US dollar allowed local winemakers to access the latest technology and top quality inputs from abroad at convenient prices. Only financial stability could finally set in motion a much-needed technological conversion and modernization process, based on realistic cost-benefit calculations and project evaluations. It is estimated that in less than ten years the industry invested 1.3 billion US $\$$ in new agronomic techniques, such as drip irrigation, pest control and the identification and certification of planted varieties through genetics, as well as in oenological techniques, such as cold storage and the use of stainless steel tanks. Everything from agriculture to bottling and packaging was renovated, often thanks to the contribution of foreign consultants, including the famous French winemaker Michel Rolland.

In 2002, Argentina was ravaged again by a deep crisis, characterized by economic and social unrest, and the resignation of four presidents over the Christmas period. The free flotation of the national currency was re-established and the dollar/peso peg abolished, initially by a controlled 30 percent devaluation, followed by a free floating rate. This meant that in dollar terms domestic production costs reduced considerably, thanks to lower labour and utility costs, and wineries started to place products on international markets at lower prices than before. Ultimately, the devaluation of the peso remarkably favoured the most export-driven firms, ending the loss-of-competitiveness damage caused by an unrealistic overvaluation of the peso. Suddenly, this allowed Argentine wines to find themselves in a strongly competitive position in the international arena, and exports were finally set to rise. Consequently, total Argentine wine exports actually fell by 22 percent in 2000, due to the sharp financial crisis that characterized the economy, but a decline in the sale of lower quality bulk wine was quickly offset by higher export revenue from fine wine (which rose to a record 140 million U\$ in 2003 from 120 million U\$ in 2001). In 2008, total export revenues had jumped by another 45 percent with respect to 2003 (OIV, 2011).

\subsection{Quality improvements of Chilean and Argentine wines}

The previous sections have highlighted that, contrary to the past, a competitive pricing structure based only on static comparative advantages - such as natural resource endowments, low labour costs or the availability of cheap land - was certainly not enough for Argentina and Chile to breach into the international wine market. Under the new circumstances - characterized by the aggressive entry of New World producers, 
such as California and Australia, and by the defensive-offensive reaction of Old World producers, who have been fighting back to regain lost market shares - upgrading the quality of the wines produced, adapting them to commercial requirements, differentiating the product and meeting international standards and consumer tastes were the necessary conditions for all latecomers in entering the international wine industry.

Surprisingly, Chile and Argentina succeeded where others have failed. The following sections, therefore, will assess to what extent the quality of Chilean and Argentine wine improved over time, and whether such improvements have corresponded to higher perceived value in the international market. It should be recalled here that quality is inherently a subjective, idiosyncratic concept, and thus very difficult to measure. However, Chapter 2 a set of indicators have been identified - relating to both the product characteristics per se, as well as its positioning in the international market aimed at measuring the evolution of Argentine and Chilean wines over time in terms of quality improvements. The indicators include:

- the replacement of low quality grapes traditionally grown in Chile and Argentina (such as País, Cereza, Missión or Criolla) with high-quality grapes of French origin, which are more highly demanded by international consumers;

- the identification and valorization of a typical, endogenous variety, which is very important for strengthening the national (wine) identity and for differentiating it from foreign competitors with a "symbolic" local specialty; and

- the introduction of zoning practices of principal winemaking areas and the designation of origin regulations, which are considered synonymous with quality almost everywhere.

Looking at the market, rather than at the product per se, it becomes clear that, in order to track the quality upgrading of Chilean and Argentine wine exports, it is equally important to measure the following variables:

- the export unit values trends, which generally reflect the higher quality of the products being offered;

- changes in the composition of destination markets, which may be traditionally oriented towards wines of different quality levels; and

- the evolution of international rankings over time, as measured in the present case by Wine Spectator, which is one the most influential and reputed international wine magazines. ${ }^{91}$

\footnotetext{
${ }^{91}$ Some studies show that the findings don't change if other international magazines, or wine guides, are taken as a reference. For example, McDermott (2005) compared the ranking of Chilean and Argentine wines by Wine Spectator and Wine Enthusiast from 1993-2003, and found that overall, the weighted scores of the two magazines differed but to the same degree for both countries, thus the ultimate message of the comparative analysis did not change.
} 


\section{Replacement of low quality grapes (the País variety), with high-quality grapes of French origin}

In the case of Chile, the global trend towards an increase in the consumption of fine wines and the concomitant steep decline in consumption of table wine, as described in the previous chapter, is reflected in the drastic replacement of the traditional, lowquality wine grape variety (País), with fine French grape varieties required for the production of export wines (see Figure 4.1), namely Cabernet Sauvignon, Merlot, Chardonnay and Sauvignon Blanc, but also, to some extent, Syrah and Pinot Noir (Wine Spectator, March 2012). Jancis Robinson, a prominent wine writer who publishes weekly columns in the Financial Times, recently argued that, contrary to the past, Chile can now produce not only well-made wines of Cabernet Sauvignon and Merlot grapes, but also a "full-throttle Syrah, a surprisingly delicate Pinot Noir, and some of the most interesting old-vine Carignan in the world, as well as a range of competent white wines". She also argued that "the most exciting thing about Chile is how rapidly its wine scene has been evolving with an ever-wider range of successful grape varieties and newer, cooler wine regions emerging all the time" (The Financial Times, 25-26 September 2010). 92

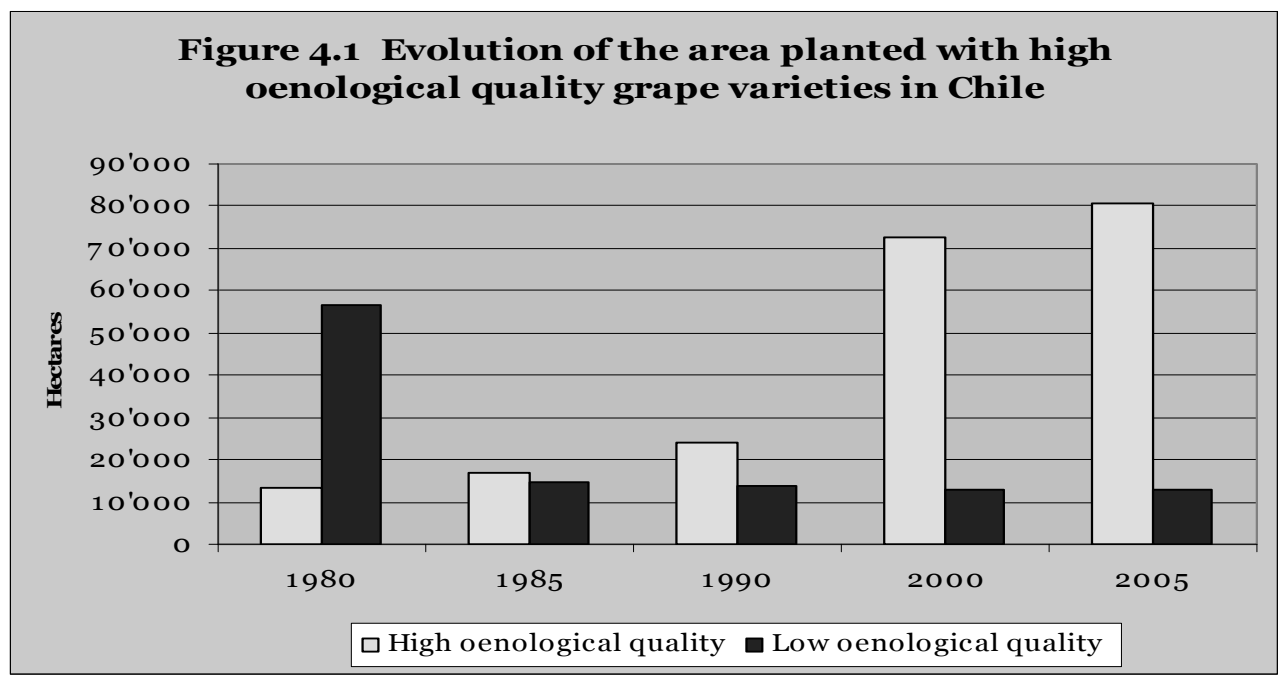

Source: Author's elaboration based on SAG, 2009

- High oenological quality grapes: Cabernet Sauvignon, Merlot, Syrah, Pinot Noir, Carmenère, Cabernet Franc (red varieties); Chardonnay, Sauvignon Blanc, Riesling, Semillon, Gewürztraminer (white varieties)

- $\quad$ Low oenological quality grapes: País, Missión, Criolla

In the late 1980s, more than 10,000 hectares of vines were replanted in Chile with what are internationally considered high-quality oenological varieties (defined in Chapter 2,

${ }^{22}$ Source: http://www.ft.com/cms/s/2/e31cb6be-c769-11df-aeb1-00144feab49a.html\#axzz22IekHUB8. 
Section 5), and since then these have largely overtaken the amount of hectares planted with the old País variety. Wine experts argue that some of the best red wines of the Southern Hemisphere come from Chile and are made principally from Cabernet Sauvignon, which is the base of the great Medoc wines (Purdy, 2001). In fact, Cabernet Sauvignon represents the most planted red variety in Chile: in 1997 it surpassed, and subsequently overtook by more than double, the local País variety. Currently, higher quality premium wines are made solely from Cabernet Sauvignon, even though many of these still lack the structure to age and develop in a bottle, which is something most sophisticated wine consumers would normally look for (Robinson, 2005). Chilean super-premium wines, made of an assemblage of red varieties (Bordeaux style) and aged in small oak barrels, have seen their profile being raised uninterruptedly.

As in the case of Chile, data on the evolution of vineyards' planted area confirm that Argentina is following the worldwide tendency, led by changing consumer tastes, to switch from the massive production of ordinary table wines to a lower quantity but higher value production of premium wines. Although the Criolla grape still represents about half of the country's vineyards, the 1980s were characterized by an intensive eradication process of all grape vines of lower oenological quality ( -35 percent) and the 1990 s by a stabilization of the vine planted area, as well as by a sustained process of conversion towards international fine varieties. At the end of the 1990s, one eighth of total planted vineyard area had been converted to the production of exportable wine varietals made of high oenological quality grapes (see Figure 4.2). However, besides betting on the traditional French varieties to appeal to international markets, as the large majority of Chilean producers have done in the past, Argentine vine growers have atypically preserved a space for old European varieties such as Bonarda, Sangiovese and Nebbiolo, allowing them to offer a much broader range of wines beyond the "big four" French varieties than any other New World producer. This puts Argentina in the group of wine-making countries with the broadest range of grape varieties in the world.

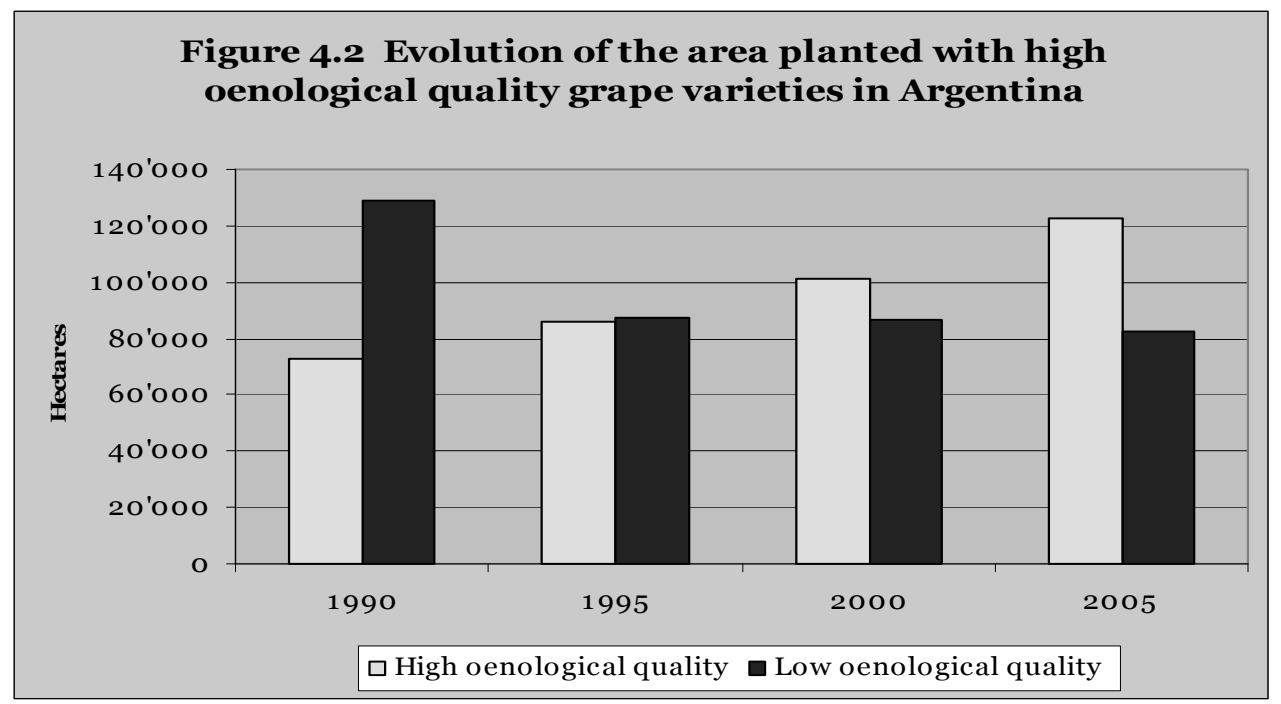

Source: Author's elaboration based on INV, 2009 
- High oenological quality grapes: Barbera, Bonarda, Cabernet Franc, Cabernet Sauvignon, Malbec, Merlot, Pinot Noir, Sangiovese, Syrah, Tannat (red varieties); Tempranillo, Chardonnay, Chenin Blanc, Pedro Gimenez, Pinot Blanc, Sauvignon Blanc, Sauvignonasse, Semillón, Torrontés Riojano, Ugni Blanc, Viognier (white varieties)

- $\quad$ Low oenological quality grapes: País, Missión, Criolla

The stirring of the export potential of Argentine wines is even more interesting, considering that their distinguishing features bring them so far from most New World wines and so close to the European culture that Argentina could be better defined as an atypical, half-way “old” New World producer (Farinelli, 2007; Goldfarb, 2007). Already in 1884, the founder of the modern Argentine wine industry, Tiburcio Benegas, recommended that wine should be made in a European style, namely that of bourgogne and bordeaux, using fine French grape varieties rather than the widely spread Criolla grape and avoiding all forms of adulteration, quite common at that time.93 This shows the familiarity of Argentine consumers with assemblage or blend wines of European style, and the fact that, contrary to many other New World producers, the bias towards pure varietal wines was recently introduced by the changing fashion of international markets.

\section{Identification and valorization of a typical variety}

In the Chilean case, special attention needs to be paid to the growth of the Carmenère variety $(+104$ percent in the last three years), which is becoming more and more the "wine of Chile". Grown in very few other countries, Carmenère was cultivated and vinified for decades in Chile as Merlot, because of its similar, "plummy" and herbaceous taste. Not until 1994 did Jean-Michel Bourisquot, a French ampelographer94 from Montpellier, suggest during one of his visits to the country that there were strange differences in some of the Chilean Merlot plantations (e.g., darker collared leaves, larger grapes, longer ripening periods). He also suggested that these were not due to the presence of different clones of Merlot but very likely to a totally different variety called Carmenère, which was once known as Grand Vidure and had disappeared from most European countries after the explosion of phylloxera.

At present, Carmenère is almost unique to Chile, with a total of 6,849 hectares planted (see Table 4.4). After the discovery, some producers tried to deny the evidence, fearing a collapse of their (blended) Merlot sales, but many others quickly understood that Carmenère could become for Chile the equivalent of Pinotage in South Africa, Tannat in

\footnotetext{
93 According to Stein (2004), from his Trapiche winery Tiburcio Benegas formulated real recipes for what he called imitation Bordeaux and Bourgogne wines. The imitation Bordeaux wines consisted of 75 percent Malbec with 25 percent Cabernet Sauvignon and another kind of Cabernet (Franc?) plus a bit of white Semillon. Imitation Burgundy wines were made of 25 percent Grey Pinot Noir, 25 percent Gamay and a touch of Pinot Blanc and Gamay Blanc.

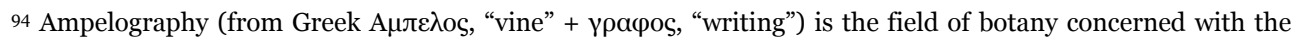
identification and classification of grapevines. Traditionally this has been done by comparing the shape and colour of the vine leaves and grape berries; more recently the study of vines has been revolutionised by DNA fingerprinting (Source: Wikipedia).
} 
Uruguay or Zinfandel in California. In the world, only 4,500 additional hectares are planted in Northern Italy, Napa Valley and Washington State, while China has started a few new plantations of this variety. Carmenère was discovered in 1994 in the oldest winery in Chile, Viña Carmen, which had imported this variety in the 1850s. In 2009, Jean-Michel Bourisquot commemorated the fifteenth anniversary of the rediscovery of Carmenère in Chile, and acknowledged the role of Viña Carmen "in having given back this variety not only to Chile but to the entire world" (Wine Spectator, March 2010).

Table 4.4 Evolution of the planted hectares with high quality oenological grape varieties in Chile, 1995-2005

\begin{tabular}{|c|c|c|c|c|c|c|}
\hline Grape Variety & 1995 & 2000 & 2005 & $\begin{array}{c}\text { Variation } \\
2005 / 2000\end{array}$ & $\begin{array}{c}\text { Variation } \\
\mathbf{2 0 0 0 / 1 9 9 5}\end{array}$ & $\begin{array}{c}\text { Variation } \\
2005 / 1995\end{array}$ \\
\hline \multicolumn{7}{|c|}{ Red varieties } \\
\hline Cabernet Sauvignon & 12,281 & 35,967 & 40,441 & $+12,44 \%$ & $+192,87 \%$ & $+229,30 \%$ \\
\hline Merlot & 2,704 & 12,824 & 13,142 & $+2,48 \%$ & $+374,26 \%$ & $+386,02 \%$ \\
\hline Pinot Noir & 215 & 1,613 & 1,361 & $-15,62 \%$ & $+650 \%$ & $+533,02 \%$ \\
\hline Carmenère & - & 4,719 & 6,849 & $+45,14 \%$ & & \\
\hline Syrah & 19 & 2,039 & 2,988 & $+46,54 \%$ & $+10631,58 \%$ & $+15626 \%$ \\
\hline Cabernet Franc & 17 & 689 & 1,099 & $+59,51 \%$ & $+3952,94 \%$ & $+6364 \%$ \\
\hline \multicolumn{7}{|c|}{ White varieties } \\
\hline Chardonnay & 4,402 & 7,672 & 8,156 & $+6,31 \%$ & $+6,31 \%$ & $+85,28 \%$ \\
\hline Sauvignon Blanc & 6,135 & 6,790 & 8,379 & $+23,40 \%$ & $+23,40 \%$ & $+3658 \%$ \\
\hline Chenin Blanc & 106 & 76 & 76 & o\% & o\% & $-28,30 \%$ \\
\hline Riesling & 296 & 286 & 293 & $+2,45 \%$ & $+2,45 \%$ & $-2,01 \%$ \\
\hline Semillón & 2,649 & 1,892 & 1,708 & $-9,73 \%$ & $-9,73 \%$ & $-35,52 \%$ \\
\hline País & 15,280 & 15,179 & 14,909 & $-1,78 \%$ & $-1,78 \%$ & $-2,43 \%$ \\
\hline
\end{tabular}

Source: SAG, 2009

According to data provided by the Chilean Agricultural and Ranching Service (SAG), Carmenère currently represents 25 percent of total Chilean wine exports, and will become the country's icon product within the next ten years. 95 At present, the best Chilean Carmenères are still blended with Cabernet Sauvignon, but many oenologists are trying their best to extract the most attractive taste from this "new" and relatively unknown wine grape. The Chilean Carmenère is now being exported as a varietal alone (see Figure 4.3) and increasingly receiving international recognition. For example, in 2009 the Carmin de Peumo Carmenère from Concha y Toro was awarded 97 points by Robert Parker, in his magazine the Wine Advocate.

As will be explained in more detail in Chapter 5, this success is also due to the remarkable progress Chileans have achieved in identifying the best terroir for each variety, namely Maipo Valley for Cabernet Sauvignon, Casablanca and Limarí Valley for Chardonnay, San Antonio Valley for Sauvignon Blanc, Colchagua and Peumo Valley for

95 Source: www.sag.cl 
Carmenère, Leyda Valley for Pinot Noir. ${ }^{6}$ In the past, Chilean vineyards used to be planted in the hottest zones of the central winemaking belt, which begins in Santiago and ends 300 kilometres away to its south. Currently, vines are being planted in cooler areas, especially in sub-regions marked by the ocean's influence, and a detailed mapping of the Chilean viticultural potential, which has been neglected for long time, is finally underway, as the recent commitment of several Chilean institutions and research centers to fill this gap (described in Chapter 5) clearly shows.

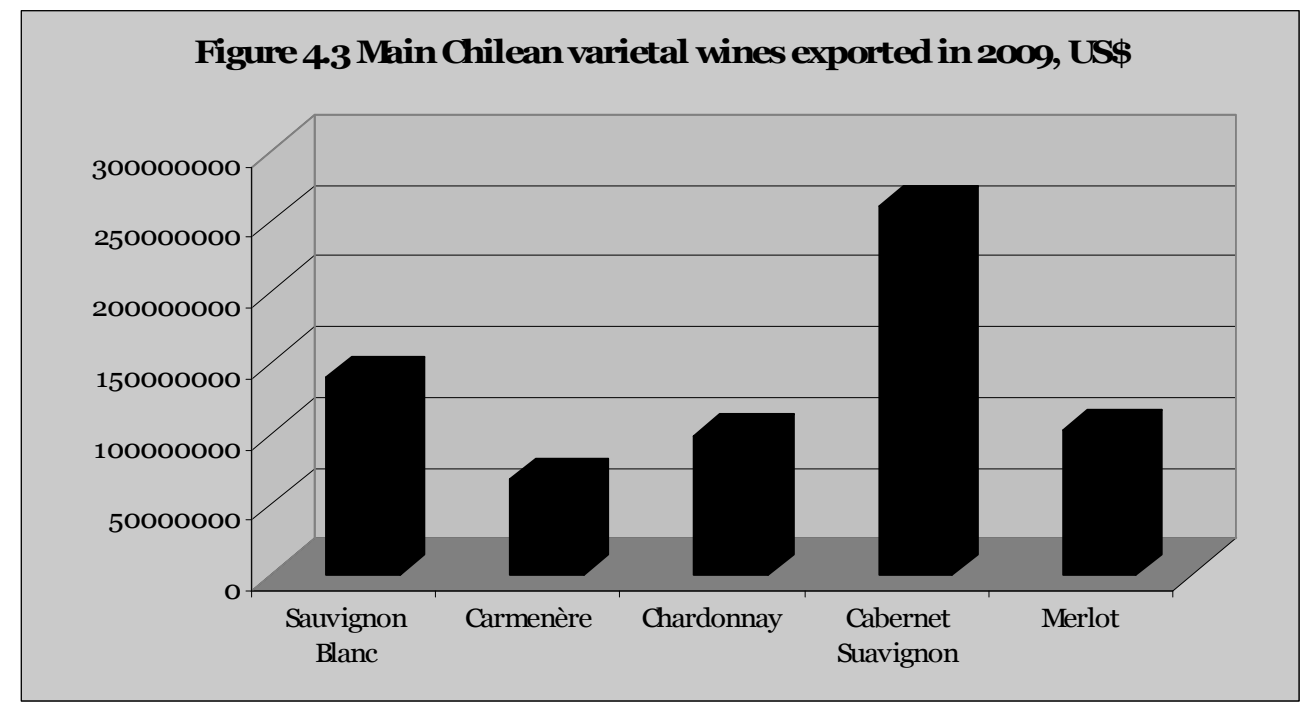

Source: ProChile, 2010

As in the case of Carmenère in Chile, over the past decade Malbec has become the flagship of Argentine wines. It is derived from French Cot, but has developed distinctive characteristics which, after 130 or 140 annual cycles, transformed it into a truly "endogenous" variety. Currently it represents nearly half of the area devoted to finer varieties, and its importance has been growing uninterruptedly (see Table 4.5). Malbec is considered by the specialized literature as Argentina's "winning horse" (Wine Spectator, December 2009). The winemaker Nicolas Catena was the first Argentine winemaker who made a premium varietal Malbec for export, in 1994. The forefather of Nicolas Catena, who emigrated from Italy to Argentina in 1898, had planted the very first Malbec vineyards in Argentina in 1902. Until 1989, however, the family winery was known mainly as a table wine producer.

In the 1980s, Nicolas Catena spent a few years in California, as a post-doctoral student in economics at the University of Berkeley. When he returned to Argentina, in the late 1980s, he brought back with him all the lessons and the new ideas about winemaking

${ }^{96}$ In Chile, there are thirteen wine sub-regions, so-called « Valleys », which stretch from about 400 kilometers north of the capital city, Santiago, down to 650 kilometers south. Within this elongated area, there are several different climate and soil conditions, depending on the proximity of the valleys to the Pacific Ocean, rather than to the Andean mountains or their central position. 
techniques, vertical integration to acquire more control over the quality of grapes produced, and varietal focus for marketing purposes, which were permeating the Napa Valley. It nevertheless took fifteen years of research at the vineyards and three years of trial-and-errors at the winery before he could bottle the first Catena Malbec. In turn, he successfully experimented with a new, unusual pricing strategy for the Argentine context, which consisted of establishing straight away a high price from the start for all his premium wines, a price that international consumers at the time were reluctant to pay for a wine from the New World (13-16 US\$ rather than the usual 4-6 US $\$$ ). His strategy was so successful that Catena Zapata is now selling its Malbec Reserva for more than 100 US\$.

Table 4.5 Evolution of the planted hectares with high quality oenological grape varieties in Argentina, 1990-2005

\begin{tabular}{|c|c|c|c|c|c|c|}
\hline Grape Variety & 1990 & 2000 & 2005 & $\begin{array}{c}\text { Variation } \\
\mathbf{2 0 0 5 / 2 0 0 0}\end{array}$ & $\begin{array}{c}\text { Variation } \\
\mathbf{2 0 0 0} / \mathbf{1 9 9 0}\end{array}$ & $\begin{array}{c}\text { Variation } \\
2005 / 1990\end{array}$ \\
\hline \multicolumn{7}{|c|}{ Red varieties } \\
\hline Malbec & 10,457 & 16,349 & 21,183 & $+29,57 \%$ & $+56,35 \%$ & $+102,47 \%$ \\
\hline Bonarda & 12,186 & 14,989 & 18,033 & $+20,31 \%$ & $+23,00 \%$ & $+47,98 \%$ \\
\hline Cabernet Sauvignon & 2,347 & 12,199 & 16,928 & $+38,77 \%$ & $+419,77 \%$ & $+621,26 \%$ \\
\hline Syrah & 687 & 7,915 & 11,678 & $+47,60 \%$ & $+1051,67 \%$ & $+1599,85 \%$ \\
\hline Merlot & 1,160 & 5,513 & 7,371 & $+33,70 \%$ & $+375,26 \%$ & $+535,43 \%$ \\
\hline Tempranillo & 5,659 & 4,335 & 6,099 & $+40,69 \%$ & $-23,40 \%$ & $+7,78 \%$ \\
\hline Pinot Noir & 232 & 1,047 & 1,253 & $+19,68 \%$ & $+351,29 \%$ & $+440,09 \%$ \\
\hline Barbera & 958 & 1,061 & 910 & $-14,23 \%$ & $+10,75 \%$ & $-5,01 \%$ \\
\hline \multicolumn{7}{|c|}{ White varieties } \\
\hline Torrontés Riojano & 8,625 & 8,181 & 8,106 & $-0,92 \%$ & $-5,15 \%$ & $-6,02 \%$ \\
\hline Chardonnay & 908 & 4,525 & 4,771 & $+5,44 \%$ & $+398,35 \%$ & $+425,44 \%$ \\
\hline Chenin & 4,031 & 3,591 & 3,027 & $-15,71 \%$ & $-10,92 \%$ & $-24,91 \%$ \\
\hline Ugni Blanc & 2,229 & 2,846 & 2,603 & $-8,54 \%$ & $+27,68 \%$ & $+16,78 \%$ \\
\hline Semillon & 1,255 & 1,028 & 988 & $-3,89 \%$ & $-18,09 \%$ & $-21,27 \%$ \\
\hline Sauvignon Blanc & 278 & 827 & 1,478 & $+78,72 \%$ & $+197,48 \%$ & $+431,65 \%$ \\
\hline Sauvignonasse & 998 & 798 & 713 & $-10,65 \%$ & $-20,04 \%$ & $-28,56 \%$ \\
\hline Riesling & 293 & 156 & 131 & $-16,03 \%$ & $-46,76 \%$ & $-55,29 \%$ \\
\hline Total & 18,617 & 22,047 & 21,373 & & & \\
\hline País (Criolla) & 129,071 & 87,347 & 82,447 & $-5,61 \%$ & $-32,33 \%$ & $-36,13 \%$ \\
\hline
\end{tabular}

Source: INV, 2009

The increased popularity of Malbec is spearheading Argentine wine exports, and over half of Argentine exported wines are either varietal bottlings of Malbec or Malbec-based blends (see Figure 4.4). Additionally, one quarter of the 600 Malbec wines reviewed by Wine Spectator in 2009 received ratings above 90 points, an outstanding result compared to other varieties, especially considering that international consumers are just starting to get familiar with different styles of Malbec, originating from different terroirs, namely from the warmer areas in northern Mendoza (e.g. Agrelo and Lujan de 
Cuyo) to the cooler areas in the southern part (e.g. Tupungato and La Consulta). This shows the immense potential of this variety, in terms of diversification and distinctive styles. In the future, Argentina is expected to further increase its export potential thanks to the growing popularity of its emblematic Malbec grape, to the point that wine experts have predicted that by 2015 Argentine red Malbecs will occupy a "place in the pantheon of noble wines" (Fielden, 2001; Stein, 2004 and 2008; Stein and Zucca, 2005). As the renowned wine critic Robert Parker explains, "Malbec, a grape long considered challenging and often disappointing in France, produces prodigious wines of great perfume, quality and longevity in Argentina. Malbec is the red wine hope of Argentina" (Parker, 2005).

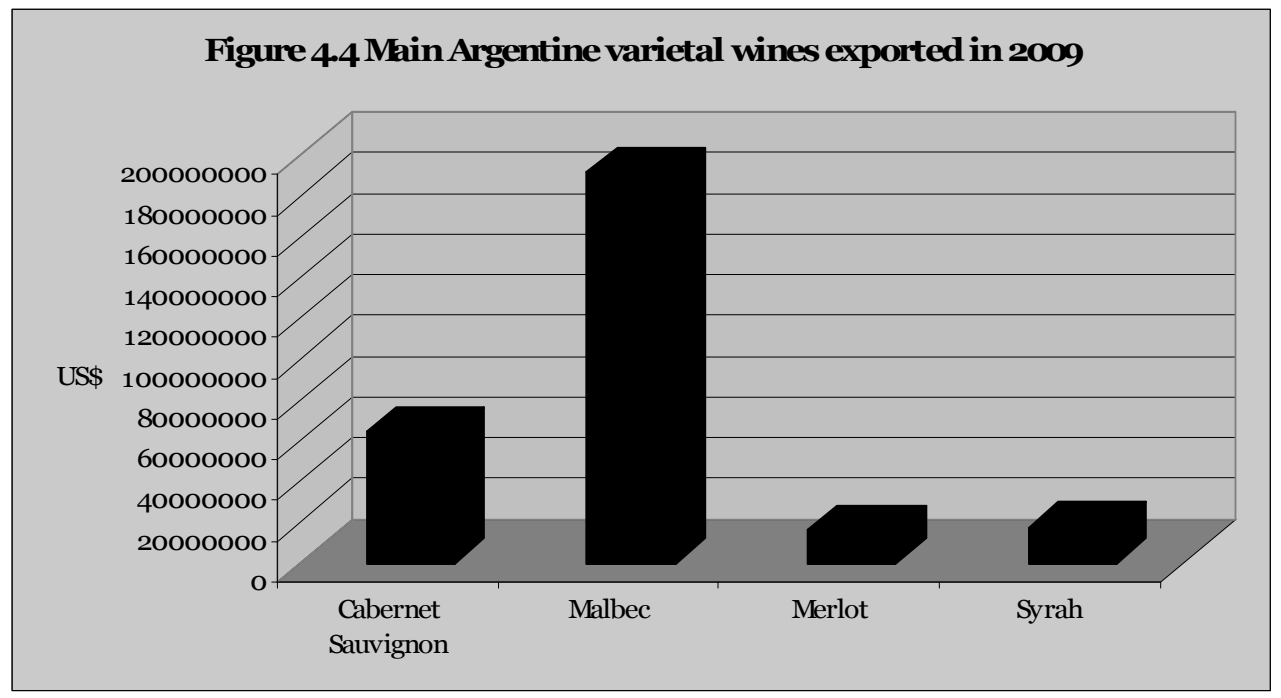

Source: Pro Mendoza, 2010

\section{Introduction of zoning practices of main winemaking areas and designation of origin regulations}

Another indicator of the commitment of the Chilean wine industry to quality upgrading and diversification is the introduction of the denomination of origin concept. According to Law 464 enacted in 1995, five large wine producing regions have been recognized in Chile, from North to South, corresponding to the same number of regional appellations (Denominaciòn de Orìgen). Within each region, thirteen sub-regions or valleys are distinguished, together with a number of zones for each sub-region. With a great variety of soils and different climates, the valleys (or sub-regions) carry the names that most often appear on Chilean wine labels. In particular, Article 3 of Law 464 establishes that the name of the valley origin can only appear on the label if at least 75 percent of the bottled wine has been produced with grapes that have been cultivated in that valley, and also that only high-quality grape varieties can be certified through the appellation system. 
Data show that in 1997 Chile produced 2.4 million hectolitres of wine with denomination of origin, corresponding to 57 percent of total wine production, while ten years later this amount had increased to 7 million hectolitres, corresponding to 85 percent of total wine production (see Table 4.6). There is clear evidence that Chile is following the international pattern of shifting from the production of table, bulk wines to the production of fine, bottled wines, and progressively increasing the quality of bottled wine produced by following the rules of denomination of origin, which are compatible with the EU regulatory system.

Table 4.6 Evolution of Chilean wine production with Denomination of Origin

\begin{tabular}{cccccc}
\hline Year & \multicolumn{2}{c}{$\begin{array}{c}\text { Premium wine with } \\
\text { Denomination of Origin }\end{array}$} & $\begin{array}{c}\text { Premium wine } \\
\text { without D.O. }\end{array}$ & Table wine & Total \\
& $\begin{array}{c}\text { Quantity } \\
\text { (in hectolitres) }\end{array}$ & \% of total & $\begin{array}{c}\text { Quantity } \\
\text { (in hectolitres) }\end{array}$ & $\begin{array}{c}\text { Quantity } \\
\text { (in hectolitres) }\end{array}$ \\
$\mathbf{1 9 9 7}$ & $2,489,287$ & $57,75 \%$ & $1,330,057$ & 490,905 & $4,310,249$ \\
$\mathbf{1 9 9 8}$ & $2,996,983$ & $56,92 \%$ & $1,443,082$ & 825,438 & $5,265,503$ \\
$\mathbf{1 9 9 9}$ & $2,395,729$ & $55,97 \%$ & $1,318,548$ & 565,874 & $4,280,151$ \\
$\mathbf{2 0 0 0}$ & $3,748,213$ & $58,39 \%$ & $1,956,098$ & 715,063 & $6,419,374$ \\
$\mathbf{2 0 0 1}$ & $4,460,397$ & $81,82 \%$ & 583,290 & $5,451,785$ \\
$\mathbf{2 0 0 2}$ & $4,430,500$ & $78,79 \%$ & 834,463 & 358,267 & $5,623,230$ \\
$\mathbf{2 0 0 3}$ & $5,460,865$ & $81,72 \%$ & 947,611 & 273,745 & $6,682,221$ \\
$\mathbf{2 0 0 4}$ & $5,474,888$ & $86,89 \%$ & 577,173 & 248,675 & $6,300,736$ \\
$\mathbf{2 0 0 5}$ & $6,303,212$ & $79,93 \%$ & $1,047,796$ & 534,503 & $7,885,511$ \\
$\mathbf{2 0 0 6}$ & $7,163,042$ & $84,78 \%$ & 861,365 & 424,370 & $8,448,777$ \\
$\mathbf{2 0 0 7}$ & $7,038,873$ & $85,04 \%$ & 879,062 & 359,525 & $8,277,460$ \\
$\mathbf{2 0 0 8}$ & $6,919,658$ & $79,64 \%$ & $1,331,964$ & 436,552 & $8,688,173$ \\
$\mathbf{2 0 0 9}$ & $8,665,659$ & $85,86 \%$ & $1,152,065$ & 275,198 & $10,092,923$ \\
$\mathbf{2 0 1 0}$ & $7,445,528$ & $81,35 \%$ & $1,271,634$ & 435,222 & $9,152,384$ \\
\hline
\end{tabular}

Source: Author's elaboration based on SAG, 2011

The Chilean system of regions, sub-regions, zones and areas set up by the law ideally tries to emulate the European conception of "denomination", which would become an integral part of the names of the wines. However, the geographic areas have been identified based on political and administrative criteria, rather than on winemaking ones. It has been argued, for example, that, from a strictly scientific point of view, it would probably have made more sense to trace vertical distinctions rather than simple horizontal ones. The climate (fresher closer to the Andes and to the sea, warmer in the central valleys) is actually one of the most important distinguishing factor of the Chilean terroirs (Robinson, 1999). Additionally, the "embryonic" Chilean denomination of origin system is inspired by principles of geographical reference, but includes no other standard regulating harvesting or winemaking practices, as is the case in the European system (Arkell, 1999).

In any case, the Agriculture and Livestock Service (SAG, Servicio Agricola y Ganadero), the government institution dealing with wine control and certification by the Ministry of Agriculture, deserves a special mention for having actively pursued the promulgation of this law and is now acting as a regulatory and control body for its enactment. Chile has been very active also in promoting international wine trade by 
recognizing the effectiveness of the regulatory systems for wine standards of New World producers. In 2001 it became part of a Mutual Acceptance Agreement on Oenological and Winemaking practices between the governments of the USA, Canada, Australia, Chile and New Zealand, which represents a breakthrough to access new export markets.

The case of Argentina is very different. The denomination of origin law was enacted only in 2004, and is presently applied to three regions only, namely Lujàn de Cuyo, San Rafael (in the Mendoza province), and Rio Negro,97 and to much more limited quantities in comparison to the total amount of DOC wine produced in Chile. Accurate data on the amount of wine vinified with DOC certification is currently missing. However, the recognition of the DOC certification is regulated by rigorous filters and control mechanisms by INV, the National Institute for Vitiviniculture. In fact, the Argentine wine industry is the most tightly controlled of the continent: through INV, the state annually sets the dates for the end of the harvest and the release of the new wines, and it establishes the minimum percentage of alcohol of that year's wines thereby neglecting some of the most envied and criticized freedoms of the New World, which Chile, instead, has transformed into one of its key competitive advantages.

\subsection{International positioning of Chilean and Argentine wines}

This section assesses whether the substantial efforts put in place to improve the quality of Chilean and Argentine wines, described above, correspond to an equally visible improvement of average prices, international ranking and market outreach over time. From an analytical perspective, these represent also key variables, since in the wine industry the definition of product quality is no longer the exclusive domain of wine producers, and a predominant role is now played by consumers, who are often inexperienced and purchase wines in supermarkets (Cusmano, Morrison and Rabellotti, 2009). As Aylward and Zanko (2006) put it, "beyond any intrinsic characteristics, the ultimate criterion of [wine] quality is the value perceived by the market". For developing countries, as the examples of the Chilean and Argentine industries show, this makes entry conditions even more difficult, as they have to face a twofold challenge: that of increasing the quality contents of their wines, but also that of consolidating their reputation to make sure that international consumers clearly perceive such improvements and are available to reward them with increasingly high prices.

\section{Rising export unit values}

Looking at the composition of wine exports, it emerges that, in 2008, more than 70 percent of the wines produced in Chile were exported. Of these, approximately two thirds were fine wines sold in bottle at 3.64 US\$, while one third were sold in bulk at

\footnotetext{
97 In Argentina, the viticultural zone can be divided into three well differentiated areas due to their natural climatic characteristics and the diversity of their soils: the Northeast area, including the provinces of Calchaqui, Catamarca and La Rioja; the Midwest area, including the Mendoza and San Juan provinces, where the majority of vineyards are concentrated; and the South area, including the Neuquén, Rio Negro and Chubut provinces.
} 
o.63 US $\$$ per litre. On average, Chilean export prices per unit increased over the last years from an average of 1.20 US $\$$ per litre in the period $1985-90$, to 1.40 US $\$$ in the period 1991-95, to 1.45 US $\$$ in the period $1996-2000$ US $\$$, to 1.80 US $\$$ in the period 2001-2005, up to 2.26 US\$ per litre in 2008 (Rabobank, 2009). Contrary to the Chilean case, in Argentina ordinary table wines now represent 30 to 40 percent of all exports and are sold at approximately 0.50 US\$ per litre, while premium wines, which are sold in bottle at 2.40 US $\$$ per litre, represent more than half of export volume and over 70 percent of export value (see Figure 4.5). This is reflected in the dramatic increase of the Argentine export price per unit, which, increased over the last years from an average of 0.45 US $\$$ per litre in the period 1985-90, to 0.75 US $\$$ in the period 1991-95, to 1.17 US\$ in the period 1996-2000 US\$, to 1.20 in the period 2001-2005, up to 2.27 US\$ per litre in 2008, which was marginally above the export price per unit of Chilean wine (Rabobank, 2009).

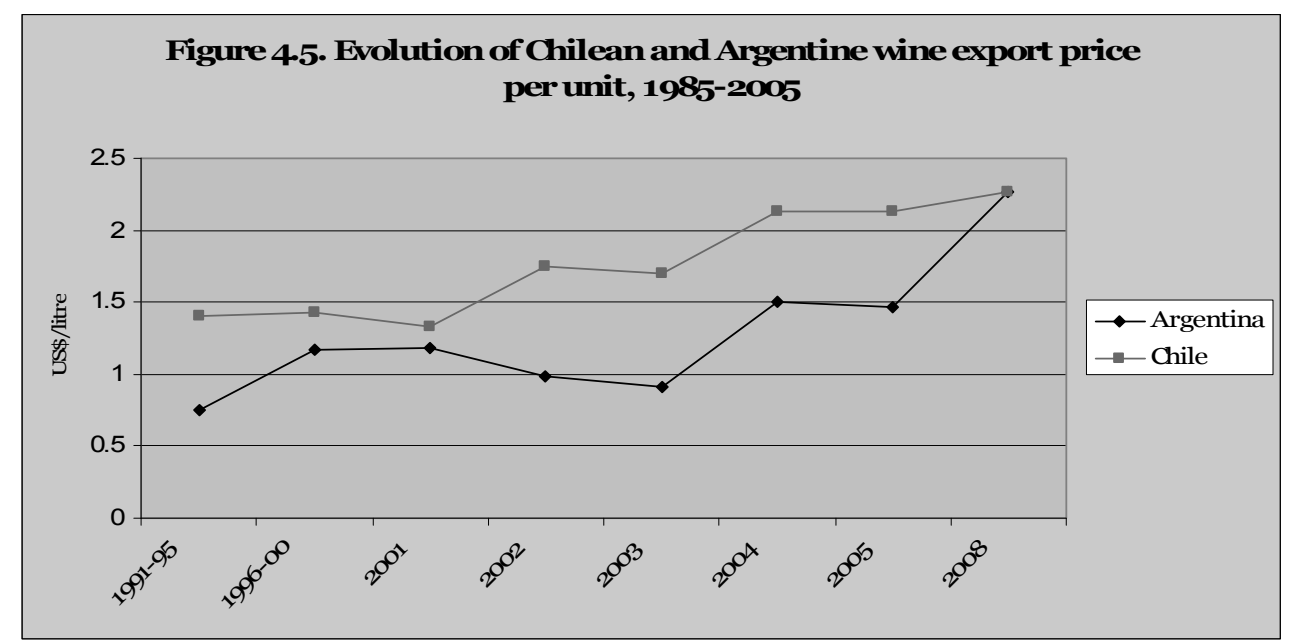

Source: Author's elaboration based on Rabobank, 2007

Indeed, demanding international consumers have been increasingly receptive towards wine originating from South America, and this allowed Chile to more than double the average price per unit of foreign sales in two decades - a clear indication of the surprising strength of its wine exports in the world market, especially considering that Australia represents its direct competitor. Chile has traditionally exported both bottled and bulk wine. The efforts of many wineries to increase their premium-bottled wine exports are reflected in the expansion of bottled versus bulk wine exports.

It should be highlighted that, in the 1980s, less than 1 percent of the total production was exported in bottles (Alvarado, 2004). The now common $750 c c$ bottles were introduced in Chile in 1964 by a local winery (Concha y Toro). Until then, most Chilean wine was distributed internationally in bulk, in demijohns of 10 litres or jugs of 5 litres. At present, the situation has changed substantially: the quantity of wine exported in bottles has equalled and then surpassed the quantity exported in bulk (it now represents 86 percent of total wine exports) and the price per hectolitre is now 3.7 times higher (see Table 4.7). 
Table 4.7 Export volumes and prices of bottled vs. bulk Chilean wines

\begin{tabular}{ccccc}
\hline \multicolumn{2}{c}{ Wine export volume (litres) } & \multicolumn{2}{c}{ Wine export price (US\$ per litre, FOB) } \\
\hline & Bottled & Bulk & Bottled & Bulk \\
2007 & $364,500,000$ & 352,000 & 2.99 & 0.54 \\
2008 & $370,500,000$ & 218,000 & 3.17 & 0.92 \\
2009 & $382,900,000$ & 279,000 & 2.89 & 0.77 \\
2010 & $426,000,000$ & 275,000 & 3.00 & 0.97 \\
\hline
\end{tabular}

Source: US Foreign Agricultural Service, 2010; Viñas de Chile, 2011

The transition illustrated by the table above was far from easy or automatic. Over time, Chile has developed the reputation of an exporter of low-priced, good quality, extremely fruity and "clean" varietal wines. Thus, for a long time a few international consumers have been ready to pay 10-15 US\$ for a bottle of Chilean wine. In 2008, almost half of the Chilean bottled wine exported was paid 15-25 US\$ per case, which corresponds to 1.25-2.08 US\$ per bottle (see Figure 4.6). Wine experts argue that Chilean wines tend to receive an inferior price than its competitors, for the same intrinsic value product. In other words, there is a gap between the intrinsic quality (physical, chemical, tasting) and the perceived quality, which leads consumers to pay an inferior price. This is a serious weakness, which involves aspects that go beyond purely quality issues, and increasingly appears to be a matter of image, commercialization, market intelligence and after sale services. Additionally, even though the "classic" French varieties are indeed the most successful at the international level, and an emblematic variety (Carmenère) has been clearly identified, Chile has not yet developed a local style which is strong enough for international consumers to distinguish Chilean wines with enough clarity and originality (Purdy, 2000).

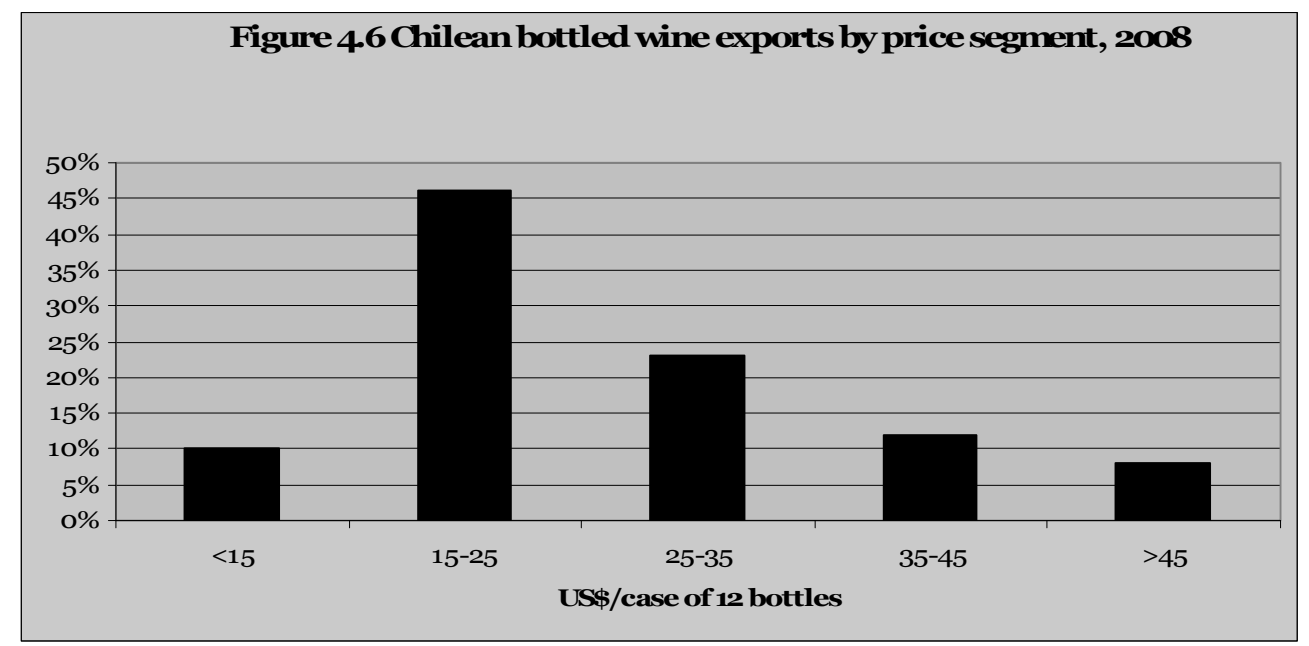

Source: ProChile, 2010

Contrary to Chile, Argentina, has avoided becoming trapped in the niche of good quality cheap wines. Its growth has been slower but it has targeted higher prices since 
the beginning. Jancis Robinson, the wine critic of the Financial Times, recently argued that, compared to Chile, Argentina could offer wines with "a stronger personality and substantially upper along the scale” (The Financial Times, 25-26 September 2010). The reluctance of Argentine winemakers to follow marked international trends, as Chile has done very effectively, explains why Argentina does not have a clear image in the export market yet, but in the medium to long term this could be a tremendous advantage, since it will allow the country to produce wines with different varieties and styles. As it can be seen from the table below, between 2007 and 2010, exports of bulk wine diminished drastically ( -35 percent), while exports of bottled wines more than tripled. The price of bottled wine increased from 2.77 US $\$$ per litre in 2007 to 3.35 US\$ per litre in 2010, while the price of bulk wine increased from 0.34 US\$ per litre to 0.84 US\$ per litre during the same period (see Table 4.8).

Table 4.8 Export volumes and prices of bottled vs. bulk Argentine wines

\begin{tabular}{lcccc}
\hline & \multicolumn{2}{c}{ Wine export volume (litres) } & \multicolumn{2}{c}{ Wine export price (US\$ per litre, FOB) } \\
\hline 2007 & Bottled & Bulk & Bottled & Bulk \\
2008 & $63,739,500$ & $68,046,000$ & 2.77 & 0.34 \\
2009 & $72,660,000$ & $99,714,000$ & 3.12 & 0.39 \\
2010 & $176,891,833$ & $69,078,601$ & 3.12 & 0.53 \\
\hline
\end{tabular}

Source: Wines of Argentina, based on data provided by DGA, 2011

On average, in 2008 half of the Argentine bottled wine exported earned 18-38 US\$ per case, which corresponds to 1.5-3.1 US $\$$ per bottle (see Figure 4.7). This shows that the international prices of Argentine wines are becoming comparable to those of the better known Chilean wines, and that Argentina is becoming known for its ability to produce high-quality wines as well.

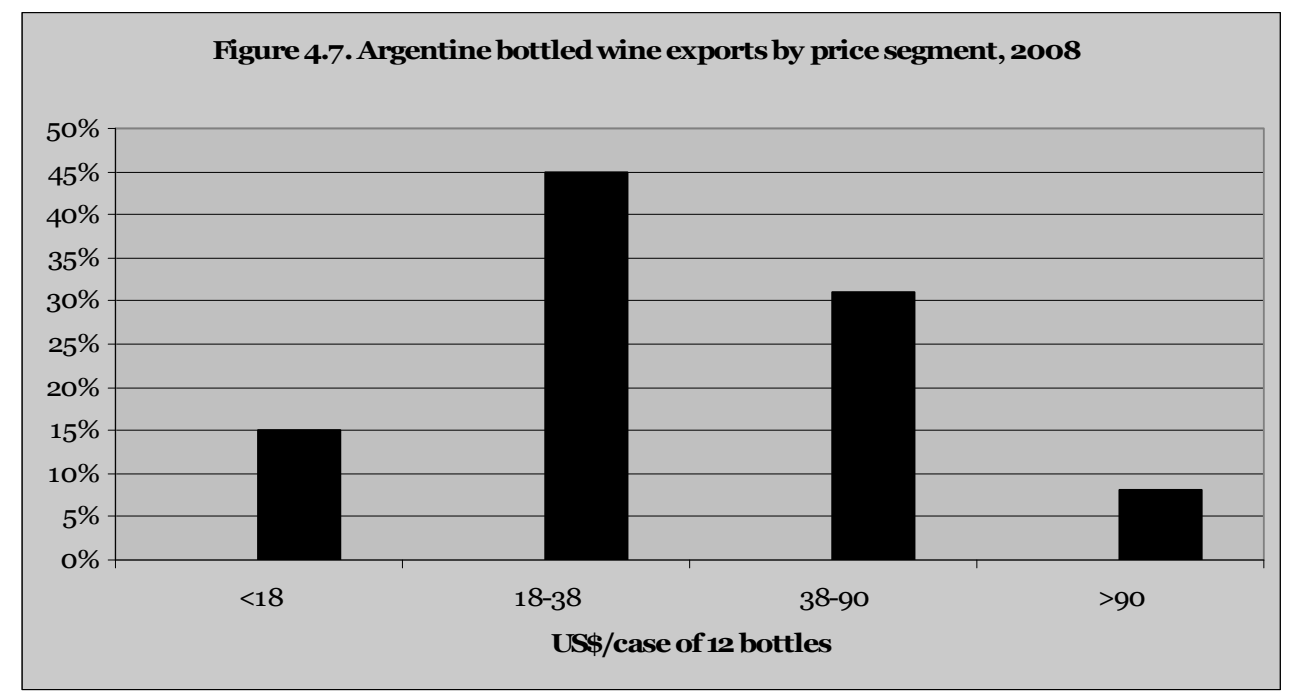

Source: Wines of Argentina, 2010 


\section{Increased exports to more demanding market destinations}

In terms of countries of destination, the United States have represented Chile's biggest export market for over a decade, but since 1999 they rank second, after the European Union (led by Great Britain). Canada is the third, but a large part is imported in bulk and bottled locally under names that sometimes do not explicitly recall the Chilean origin of the wine. Since the early 1990s, Chilean wines have received an increasingly enthusiastic reception in Western Europe (especially in Germany, the Netherlands, Switzerland and the Nordic countries), which together represent the destination of almost 50 percent of Chilean exports. This allowed a remarkable expansion and diversification of their final market destinations: from 36 countries in 1984, Chile was exporting wine to over 122 countries in 2008. Among these, China has become one of the largest markets for Chilean wines, although this only emerges clearly when looking at figures in terms of volume and not in terms of value. This is explained by the fact that China does not yet represent a sophisticated, discerning market, which would create demand pull effects on quality upgrading. More importantly, as shown by the figure below, there has been a drastic increase in the share of wine exports directed to higherquality markets (such as Europe and the United States), and a drastic decrease of the share of exports directed to low-level, cheap markets (such as those of Latin America, where Chile traditionally exported the bulk of its sweet, lower quality wines). In particular, in 198536.2 percent of Chilean wine exports in terms of value were destined to Latin American countries, while in 2008 this figure had dropped to 7.1 percent. Conversely, in 1985 the percentage of wine exports destined to Western Europe was 3.6, while in 2008 it had risen to 42.3 percent. In 2008, the UK was the main market destination, followed by the US, Canada and Mexico (see Figure 4.8).

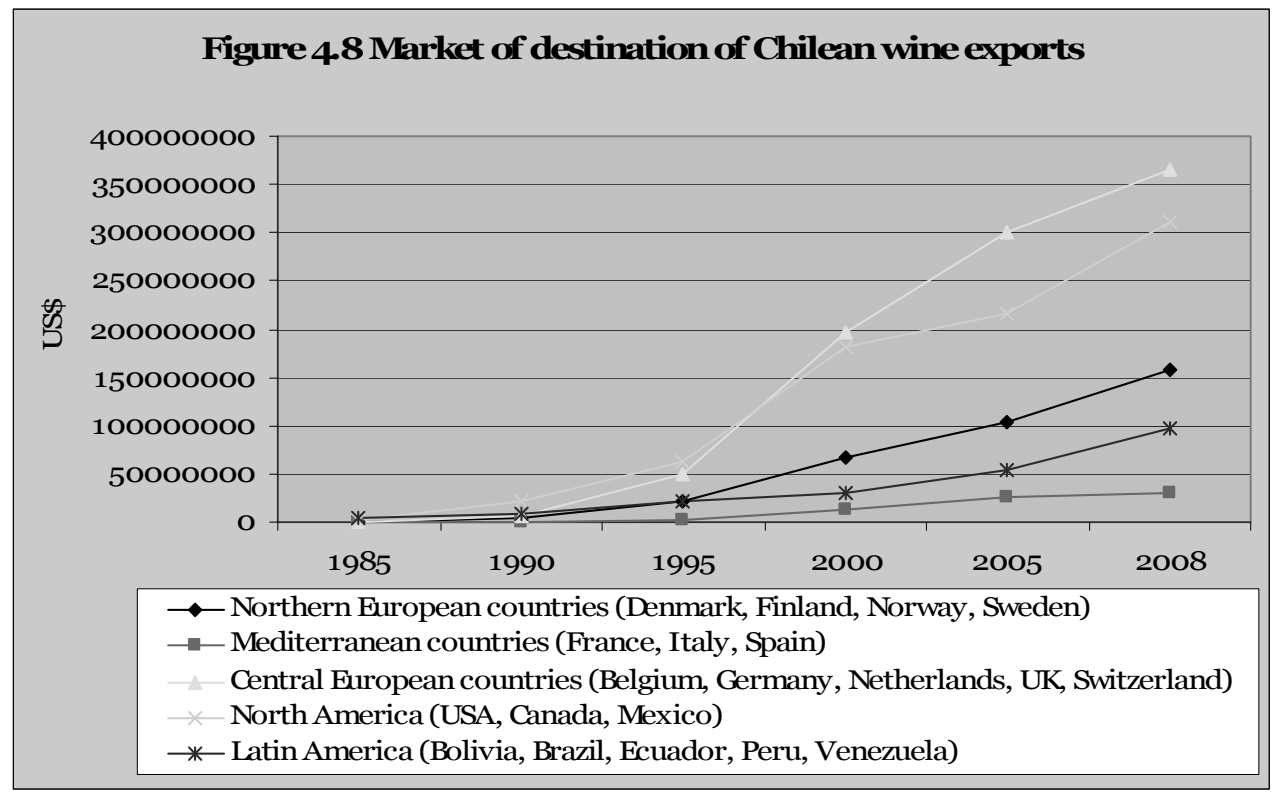

Source: Comtrade 
In the case of Argentine wines, the industry successfully managed to diversify its exports to different geographical markets. At present, the main importing countries are Great Britain and the United States, followed by Japan and Belgium. This represents an important quality indicator, since in the past, as in the case of Chile, the main importers of Argentine wines were traditionally other Latin American countries which used to orient their imports towards bulk table wine. From 22 countries in 1984, in 2008 Argentina exported its wines to more than 115 countries. Argentina's exports to the United States have grown much faster than, for example, Chile's (see Figure 4.9). In particular, in the period in which Argentine exports to the US were growing by nearly 80 percent, Chilean exports to the US hardly registered any increase. In 1985, 18 percent of Argentine wine exports were destined to the North American market. In 2008, this figure had reached the top ceiling of 37 percent. At present, the US market alone absorbs almost 30 percent of all Argentine wine exports, driven by an increasing number of US consumers seeking diversity and expressing a clear preference for wellidentifiable varietal wines (Stein, 2008). Contrary to Chile, though, the percentage of wine exports destined to the Latin American market has continued to increase over time, and has now reached a ceiling of 10.2 percent.

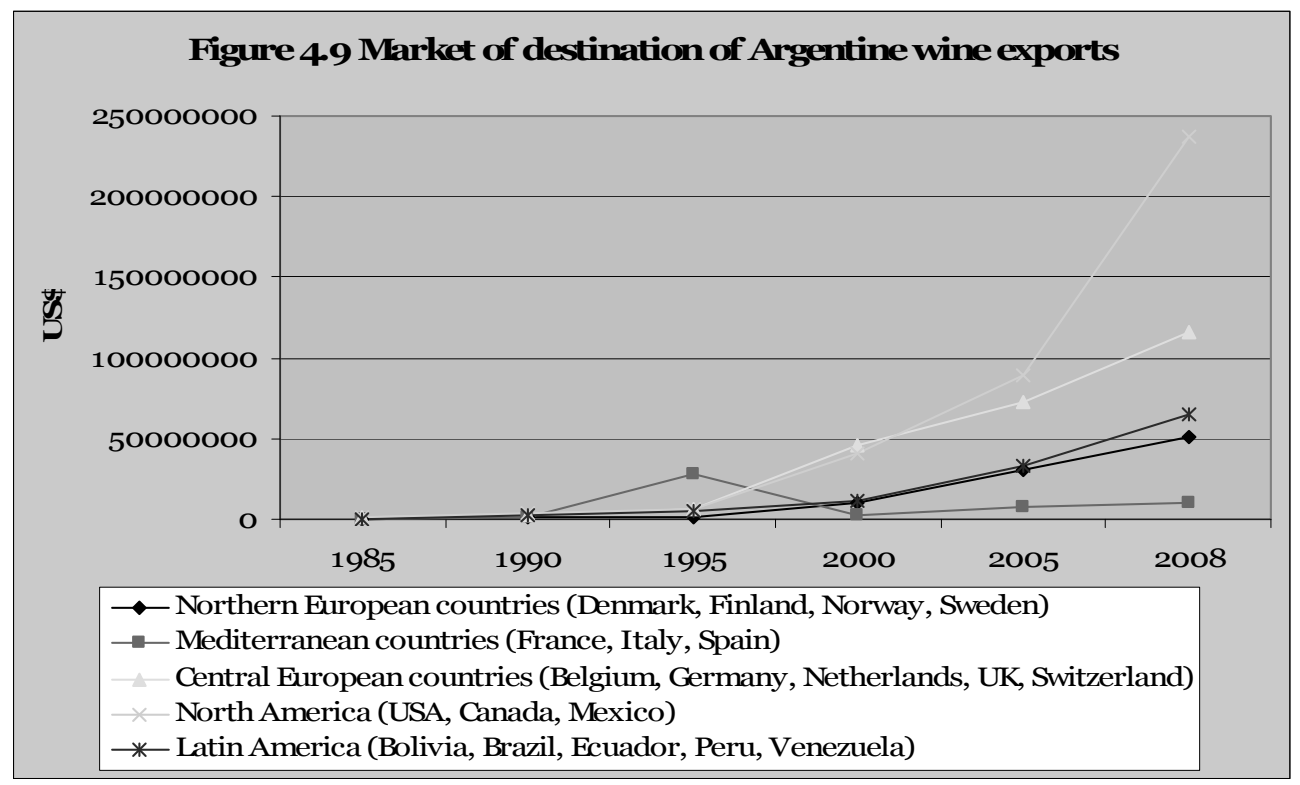

Source: Comtrade

\section{Better international ranking over time}

Data show that the capacity of Chile and Argentina to produce premium and superpremium wine is gradually being recognized at the international level. Their average scores by Wine Spectator, for example, have improved substantially over time (see Figure 4.10). In this respect, Agosin, Alvarez and Bravo-Ortega (20102) argue that the wine-country image is fundamental, and that there are important externalities affecting 
it, either positively or negatively. Chile has certainly benefitted from its reputation as a reliable, organized and stable country, as well from the popularity of other agroindustrial exports such as salmon or table fruits. Compared to Chile, though, Argentina possesses a better country image, and can count on the international popularity of tango, Patagonia and football, as well as on the charm of its capital, Buenos Aires, as symbols of beauty, entertainment and passion. These assets have certainly contributed to mark the positive image of Argentina and to increase the international recognition of its wines.

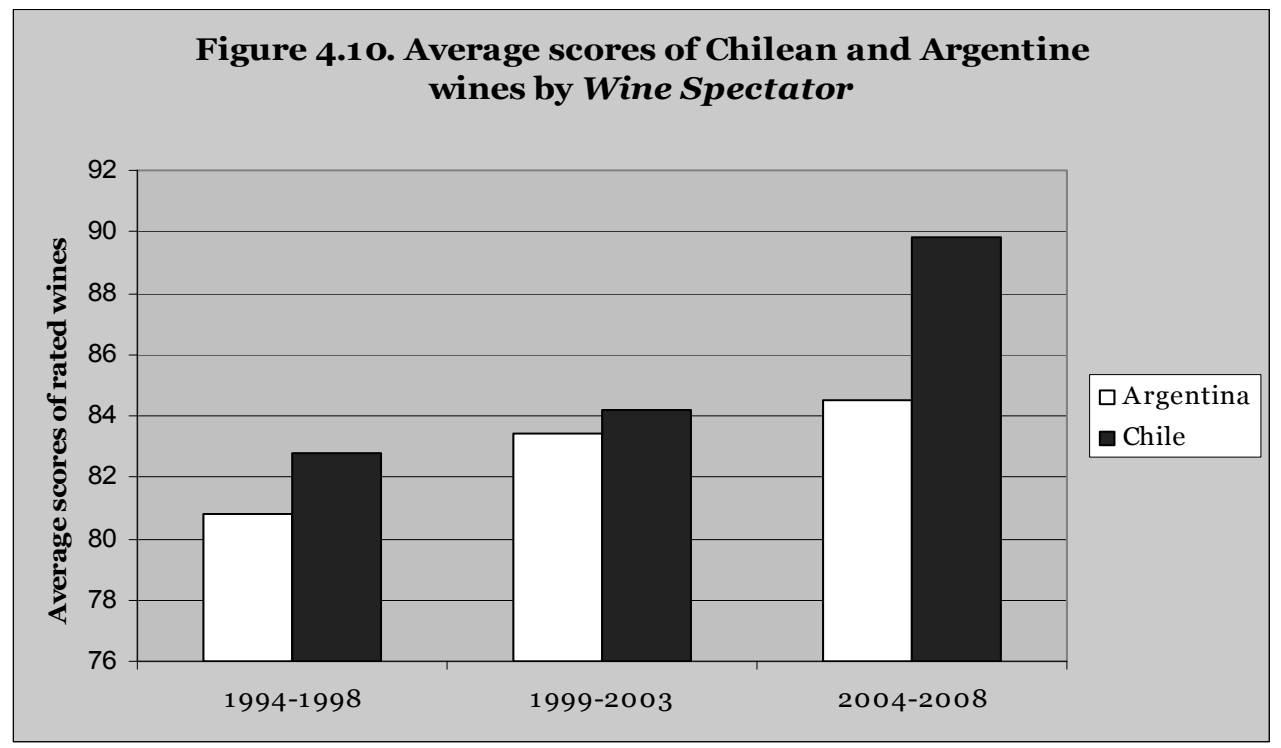

Source: Author's elaboration based on Wine Spectator database, 2009

A sign of the growing stature of Chile on the wine world stage is the increased number of not only reserve wines, but also of cabernet-based premium and ultra-premium wines for which international consumers are starting to pay prices normally associated to class Bordeaux bottles. Almaviva, Clos Apalta, Don Melchor, Don Maximiano and Montes Alpha M., are some of the wines that are reputed to justify the price (over 50 US\$), and are identifying Chile as prime-wine producing land, as was the case with California a decade or two ago. The clear sign of this breakthrough is that in 2008, for the first time in history, a Chilean wine, the Clos Apalta from Casa Lapostolle, ranked first in the list of the Top 100 wines by Wine Spectator, with 96 points (which, as explained in Chapter 3, are computed based on four criteria: quality, value, availability and passion). Clos Apalta, which represents one of the few Chilean super-premium, icon wines, was selected among 19,500 wines reviewed in blind tastings from 14 countries around the world.

Analogously, Argentina is now producing icon and super-premium wines. The top scoring Argentine wines are generally Malbecs. The Achaval-Ferrer Malbec Finca Altamira, for example, produced from old, low-yielding vines located in a cool, highelevation area of southern Mendoza, received 97 points for several consecutive years 
and is now valued in the international market at more than 112 US\$. Achaval-Ferrer was also appointed winery of the year by Wine Spectator in 2009. This is not an isolated case. Malbecs by Catena Zapata, La Consulta, Bodega Mendel and Viña Cobos, scored above 90 points and are valued on the market at more than 100 US $\$$ as well. Comparative data related to the ratings of Wine Spectator in 2010 show that the international performance of Argentina can now be fully compared to that of Chile (see Table 4.9) - but also and especially that Argentina is challenging the New World wine producer "trap" by targeting a higher segment of the international market, rather than being caught at its lowest end. The specialized literature, however, suggests that, in order to get to the next level, Argentine wines should aim to reach the same international recognition of Malbec with other varieties, such as Cabernet Sauvignon, Torrontés or Syrah (Wine Spectator, June 2010).

Table 4.9 Wine ratings by Wine Spectator, 2010

\begin{tabular}{|c|c|c|c|c|c|c|}
\hline & $\begin{array}{c}\text { Number of } \\
\text { observations/ } \\
\text { Average price }\end{array}$ & $\begin{array}{l}\text { 95-100 } \\
\text { points }\end{array}$ & $\begin{array}{c}\text { 90-94 } \\
\text { points }\end{array}$ & $\begin{array}{l}85-89 \\
\text { points }\end{array}$ & $\begin{array}{l}\text { 8o-84 } \\
\text { points }\end{array}$ & $\begin{array}{l}50-79 \\
\text { points }\end{array}$ \\
\hline Argentina & $624 / 53$ US\$ & $1 \%$ & $13 \%$ & $45 \%$ & $33 \%$ & $8 \%$ \\
\hline Chile & $576 / 42$ US\$ & o\% & $12 \%$ & $52 \%$ & $31 \%$ & $5 \%$ \\
\hline Australia & $512 / 50$ US\$ & $1 \%$ & $24 \%$ & $63 \%$ & $10 \%$ & $2 \%$ \\
\hline California & $2,758 / 74$ US\$ & $3 \%$ & $26 \%$ & $51 \%$ & $18 \%$ & $2 \%$ \\
\hline New Zealand & $223 / 29$ US\$ & $1 \%$ & $27 \%$ & $62 \%$ & $8 \%$ & $2 \%$ \\
\hline South Africa & $450 / 28$ US\$ & $1 \%$ & $28 \%$ & $46 \%$ & $20 \%$ & $5 \%$ \\
\hline France & 4,084/ 96 US\$ & $2 \%$ & $39 \%$ & $49 \%$ & $9 \%$ & $1 \%$ \\
\hline Italy & $1,737 / 55$ US\$ & $3 \%$ & $32 \%$ & $51 \%$ & $12 \%$ & $2 \%$ \\
\hline Spain & $932 / 69$ US\$ & $1 \%$ & $16 \%$ & $48 \%$ & $29 \%$ & $6 \%$ \\
\hline
\end{tabular}

Source: Wine Spectator, Jan.-Feb. 2011

The table above reveals, that a large gap still exists between the perceived "quality" of Argentine and Chilean wines as reflected in Wine Spectator ratings, compared to other New World and Old World producers, especially in the range of good wines, valued by Wine Spectator with 90-94 and 85-89 points. If this represents a weakness of the Chilean and Argentine wine industries that is certainly not easy to overcome, it should be considered that the emergence of élite super-premium Chilean and Argentine wines hardly was a less ambitious challenge, and might well function as a triggering factor to increase the number wines rated in the most valued categories after the top one.

This expectation is reinforced by the results of the periodic survey carried out by Wine Spectator in early 2010, with the aim of detecting main trends in wine preferences and buying habits of wine lovers (Wine Spectator, October 2010). Quite interestingly, when asked to identify the top three states or countries viewed as the most reliable source of value, South America came out particularly high. As top source for reliable value, 43 percent of respondents chose Chile, while 40 percent of respondents chose Argentina, closely followed by other New World producers such as California (36 percent) and 
Australia (34 percent). Remarkably, Chile has taken over from Australia the role of provider of reliable and affordable red wines and of fresh and fruity white wines. Among Old World producers, Spain is the only producer who could compete with New World producers, with 36 percent of preferences, followed very distantly by Italy and France, with 22 percent of preferences each (see Figure 4.11). This confirms the rising reputation of wines from Chile and Argentina, and in particular the appreciation of international consumers for good quality, relatively low-priced wines.

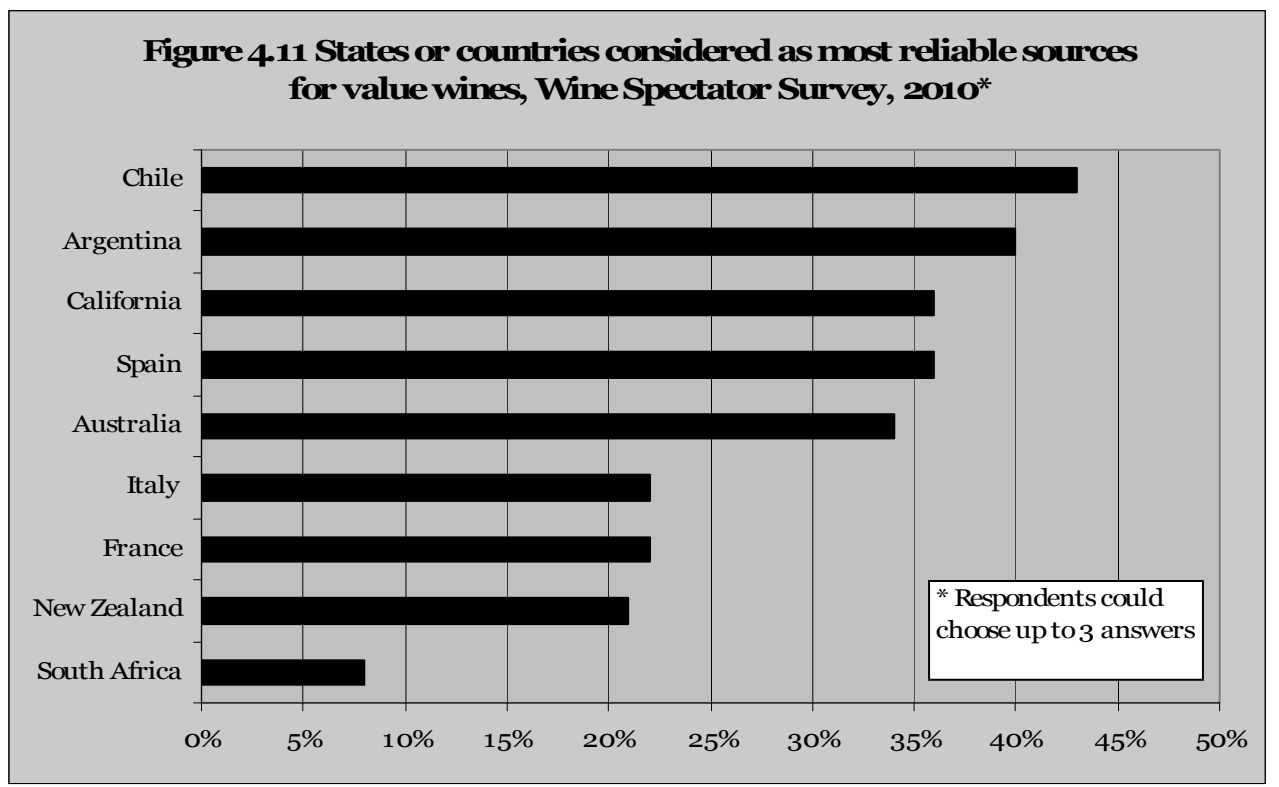

Source: Wine Spectator, October 2010

In summary, the data presented in this section show that in the last few decades both Chile and Argentina have performed well not only in terms of export growth, but also in terms of quality upgrading and of positioning in the international market. This means that Chilean and Argentine wine production has become increasingly adapted to international taste, and that several improvements occurred in all areas under examination (see Table 4.10). In the case of Chile, strong progress took place in three areas: the considerable uprooting and replacement of low oenological quality grapes with high oenological quality grapes; the rising trends of export unit values; the increasingly better international ranking achieved by Chilean wines over time. Good improvements were detected in another two areas, namely: the introduction of zoning practices and denomination of origin regulations; and the shift of Chilean wine exports towards more demanding market destinations. Moderate but valuable progress was detected in the identification of a typical variety (Carmenère).

In the case of Argentina, strong improvements were detected in two areas: the identification of Malbec as a typical variety and the shift of Argentine wine exports towards more demanding market destinations, such as the United States. Good improvements were detected in two other areas: rising export unit values and the 
increasingly better international ranking achieved by Argentine wines over time. Moderate but still valuable progress was detected the remaining two areas, namely the gradual uprooting and replacement of low oenological quality grapes with high oenological quality grapes and the introduction (still at embryonic stage) of zoning practices and denomination or origin regulations, which are very important to penetrate the European market, with the latter lying substantially behind the requirements of the international market.

Table 4.10 Assessing quality improvements of Chilean and Argentine wine production and exports over time

\begin{tabular}{llll}
\hline Area & Quality indicators & Chile & Argentina \\
\hline $\begin{array}{l}\text { Product quality and } \\
\text { differentiation: }\end{array}$ & $\begin{array}{l}\text { Replacement of low-quality grapes } \\
\text { with high-quality grapes }\end{array}$ & ++ & + \\
& $\begin{array}{l}\text { Identification and valorization of a } \\
\text { typical, emblematic variety }\end{array}$ & +- & ++ \\
& $\begin{array}{l}\text { Introduction of zoning practices and } \\
\text { designation of origin regulations }\end{array}$ & + & +- \\
& $\begin{array}{l}\text { Rising export unit values } \\
\text { Positioning in the } \\
\text { international } \\
\text { market: }\end{array}$ & $+\begin{array}{l}\text { Increased exports to more } \\
\text { demanding markets of destinations }\end{array}$ & + \\
& $\begin{array}{l}\text { Better international ranking over } \\
\text { time }\end{array}$ & ++ \\
\hline
\end{tabular}

Source: Author's elaboration

It should also be noted that in none of the six areas under consideration were found truly negative results, even though a few areas were identified where a need for further improvement clearly emerged. In particular, in the case of Chile, these relate to the insufficient valorization of Carmenère as an emblematic variety and, in the case of Argentina, to the still too embryonic adoption of zoning practices and designation of origin regulations and to the slow replacement of the País low quality variety with higher quality grapes. The presence of such persistent weaknesses further validates the hypothesis that, for developing countries, taking advantage of entry opportunities in natural resource-based industries such as wine is increasingly difficult and is mainly based on a continuous process of innovation and quality upgrading. This is even more convincing considering that, as illustrated in the following section, in developing countries the domestic demand for such products is often weak due to low purchasing power, and therefore they often depend on favourable international circumstances and consumer trends to trigger the quality upgrading process of local products. 


\subsection{Influence of the internal demand}

In the past, Chile has been considered a wine drinking country for a long time. Up until the last three decades, Chileans used to drink wine on a daily basis and consumption levels were comparable to those of France, Italy or Spain (about 60 litres per capita). In the 1960s, Chilean wineries produced almost exclusively for the domestic market (with an average consumption of 53 litres per capita), and wine production constantly increased, parallel to national demographic growth. Crowley (2001) reports that in addition to table wine, Chileans, especially in the countryside, used to drink "pipeño" (an unfiltered wine to be drunk immediately after harvest) and "chicha" (a low-alcohol wine to be drunk before complete fermentation). Until the mid-1980s, two low-quality varieties, namely País and Muscat of Alexandria, still represented more than 60 percent of planted vineyards, and even the few wines made of Cabernet Sauvignon were far from appealing to the taste of international consumers.

Since then, the level of domestic wine consumption per capita in Chile has been decreasing dramatically (see Figure 4.12). During the last decades, substitution drinks such as beer and soft drinks have become increasingly popular, thanks to the rising purchasing power of the urban population and to the effectiveness of aggressive advertising campaigns against wine. Beer consumption levels, for example, experienced an uninterrupted upward trend and nearly tripled in less than two decades (Del Pozo, 1998). Wine consumption data from OIV show that average per capita wine consumption fell from 52 litres in 1980 to only 15 litres in 1995, due to a combination of anti-alcohol campaigns and changing consumer habits (Morel-Astorga, 2001). Currently, Chilean consumption levels are the lowest among all major wine producing and exporting countries (19 litres per capita in 2010).

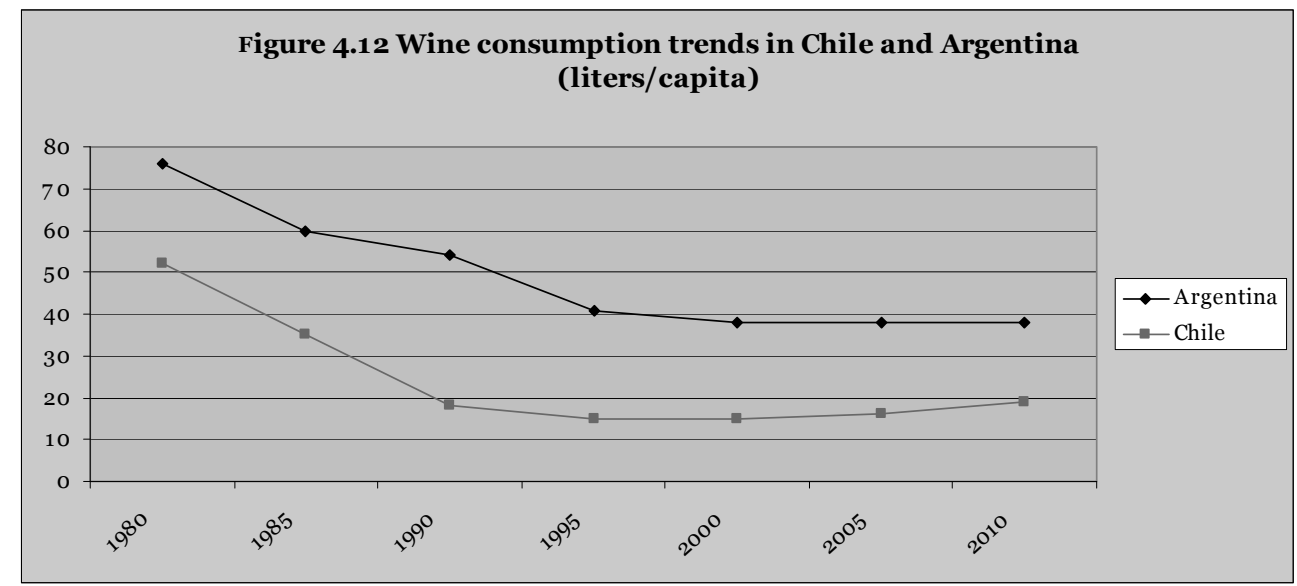

Source: OIV, 2011

In 2010, the levels of per capita internal consumption in Argentina were double those of Chile: 38 against 19 litres per person per year. Argentina has experienced the same declining trend of per capita consumption as Chile, as well as all other wine producing countries. As observed in Chapter 3, world consumption levels have actually fallen 
steadily since the 1970s, from an average of over 100 litres per capita to an average of less than 50 litres per capita. Many of the EU countries, such as the UK, now have an average consumption of 20 litres per capita, while in the US average per capita consumption is just under 10 litres (see Table 4.11). In Argentina, if in the 1970s wine consumption levels were still at 90 litres per capita, in 2000 they had decreased to 38 litres, and only subsequently stabilized. One should not forget, however, that Argentina remains the fifth largest per capita wine consumer in the world, and its consumption levels can be compared to the highest among European countries, such as Spain.

Table 4.11 Wine consumption in selected countries, 2010 (litres per capita)

\begin{tabular}{cc}
\hline Country & Litres per capita \\
\hline France & 51 \\
Italy & 44 \\
Portugal & 43 \\
Spain & 40 \\
Argentina & $\mathbf{3 8}$ \\
Croatia & 36 \\
Germany & 25 \\
United Kingdom & 20 \\
Chile & $\mathbf{1 9}$ \\
Canada & $\mathbf{1 1}$ \\
United States & 9 \\
Russian Federation & 7 \\
Japan & 2.5 \\
China & 1 \\
\hline
\end{tabular}

Source: FAO, 2011

Before the wine revolution, Chilean consumers used to drink mediocre jug wines, and were not remotely pushing the industry towards rising quality standards. The drop in domestic consumption after 1982, together with the lift of market protection measures, brought the wine industry to the edge of a crisis. The stimuli for change actually came from the rising demand for New World wines of the United States, the UK and Canada. This represented a concrete export opportunity, but in turn required strong investment in technology and the adoption of a quality-conscious production model (Benavente, 2006 and 1010). As long as the Chilean wine industry remained inward-looking, the import restrictions and the over-regulation of wine production promoted a conservative attitude towards change (Crowley, 2001).

All this changed when the degree of domestic (versus export) orientation of the Chilean wine industry started to decline, until it eventually became the lowest in the world. The over-dependency on the export market is now raising increasing concerns, to the point that promotional programmes are being organized to sensitize domestic consumers through wine shows and glamorous tasting events in hotels, shopping malls and art centers, with a publicly funded budget of approximately 1 million US\$ per year (van Tienhoven, 2008). As it can be seen from the table below, the Chilean wine industry is the most export-oriented in the world. This means that, in order to succeed, it had to align its growth strategy with the increasingly sophisticated requirements of the international market (see Table 4.12). To the contrary, the Argentine wine industry is 
amongst the most inward-oriented, and domestic consumption has traditionally favoured low quality table wines. Here, the influence of changing international consumers' attitudes and tastes remained marginal for a longer period compared to other more export-oriented producers from the New World, such as Chile and Australia. At the same time, Argentina did not experience the rising income and purchasing power of a growing share of the population which characterized other Old World producers such as Italy, France or Spain in the post-war period, when it started triggering the transition from the consumption of large quantities of wine to the consumption of lower quantities but higher quality wines (Veseth, 2010).

Table 4.12 Domestic market (versus export) orientation of main wine producing countries, 2009

\begin{tabular}{lllll}
\hline & $\begin{array}{l}\text { Non-oriented } \\
\text { towards the } \\
\text { domestic } \\
\text { market }\end{array}$ & $\begin{array}{l}\text { Weakly oriented } \\
\text { towards the } \\
\text { domestic } \\
\text { market }\end{array}$ & $\begin{array}{l}\text { Oriented } \\
\text { towards the } \\
\text { domestic } \\
\text { market }\end{array}$ & $\begin{array}{l}\text { Strongly } \\
\text { oriented } \\
\text { towards the } \\
\text { domestic } \\
\text { market }\end{array}$ \\
\hline $\begin{array}{l}\text { \% of production } \\
\text { consumed } \\
\text { domestically }\end{array}$ & O-40\% & $40-60 \%$ & $60-80 \%$ & $80-100 \%$ \\
$\begin{array}{l}\text { Main wine } \\
\text { producing } \\
\text { countries }\end{array}$ & Chile (39\%) & Australia (57\%) & $\begin{array}{l}\text { Italy (69\%) } \\
\text { France (72\%) } \\
\text { Spain (68\%) }\end{array}$ & $\begin{array}{l}\text { Argentina (89\%) } \\
\text { Cana (85\%) }\end{array}$ \\
& & & $\begin{array}{l}\text { Germany (72\%) } \\
\text { South Africa (71\%) } \\
\text { New Zealand } \\
(64 \%)\end{array}$ & \\
\hline
\end{tabular}

Source: OIV

Paradoxically, it would seem that in the case of Argentina the possibility to rely on traditionally strong and relatively stable local demand has hindered rather than stimulated the process of technological upgrading and industrial modernization. This, on the other hand, has provided Argentine wine producers with the opportunity of taking more risks, and with the considerable advantage, compared to their Chilean neighbours, of always being able to count on the possibility of selling their lower quality or exceeding production in the domestic market. The situation started to change only recently. Nowadays, the segment of higher quality, bottled wines is gaining popularity, especially with younger urban consumers, who are devoting increasing attention also to the segment of premium wines. Wine is also becoming a source of national pride for Argentine people, who are learning to relate wine to their national identity. One should not forget, however, that this phenomenon is confined to the capital and to a very few larger cities. On average, Argentina is actually experiencing a rather stable income inequality level, contrary to most other Latin American countries, which have seen their inequality levels rise during the neo-liberal reforms of the 1980-2000 period, but drastically decline over the last decade (World Bank, 2011; Cornia, 2011). ${ }^{8}$ It is likely

\footnotetext{
98 According to the World Bank (2011), 10 out of the 15 countries where income inequality is most pronounced are in Latin America or in the Caribbean. In Argentina, the Gini coefficient - which measures inequality from a statistical perspective (with zero expressing complete equality) - increased from 45 to 50 over the decade of the
} 
that slow real income growth will slow down the "democratization" of luxury goods such as premium and super-premium wines, which characterized most Old World producers, and make them accessible only to a negligible segment of the Argentine population.

This poses interesting questions regarding the role of local demand conditions in international competitiveness, and more specifically the necessity of demanding home country buyers in pressuring companies into meeting high-quality standards. Indeed, the comparative analysis of the Chilean and Argentine wine industries seems to contradict the validity of the demand-pull model of technical change, which emphasizes the importance of domestic demand in supporting successful innovation (Malerba, 2001). In both the Chilean and Argentine cases, it was actually the more sophisticated taste of international consumers, and their preference for higher and consistent quality, that forced local producers to abandon their "rustic" wine style and move towards premium quality, international standards. This happened in Chile since the late 1980 s and in Argentina since the late 1990s. It may argued, therefore, that when assessing the role of domestic demand in pulling innovation, it is imperative to differentiate whether the domestic market can be associated with a low or a high income level and growth. It would seem that only the latter may encourage increased diversification and higher quality of production.

\subsection{Conclusions}

In this chapter, the reasons for the belated entry of the Chilean and Argentine wine industries into the global market have been explored, as well as the patterns of the technological upgrading process lying behind it. Solid evidence has been provided to show that increased quality is what allowed Chilean and Argentine wines to get closer to international consumer tastes. It should be noted that this was far from predictable. As a consequence of the deep crisis that occurred in the 1970s in Chile and in the 1980s in Argentina, the quality of their wines had fallen substantially behind the requirements brought about by the evolution of international demand, and exports were concentrated in markets where quality was not important (i.e., other Latin American countries). All this radically changed in the 1980s in Chile and in the 1990s in Argentina, when, as the following chapter will illustrate more in detail, a huge process of technological upgrading and innovation, with renewed plantations and vast incorporation of new technologies, led to substantial quality improvements, both in terms of product characteristics per se and of market positioning.

In particular, this chapter has revealed that large improvements characterized both the Chilean and Argentine wines, even though to a different extent, as shown in their increased quality, enhanced international ranking and rising export unit value over

1990s, and decreased again to 45 in 2005. In 2009, the ratio of the share of national income going to the richest 20 percent of the population was 52 percent, while the poorest 20 percent got not more than 3 percent. The situation is quite different in Chile, where the Gini coefficient increased from 54 to 57 in the 1990s, but decreased to 22.6 in 2005. In 2009, the ratio of the share of national income going to the richest 20 percent of the population was 31 percent, while the poorest 20 percent got 9 percent. 
time. In the case of Chile, the strongest points detected were the considerable uprooting and replacement of low-quality grapes with high-quality grapes and the introduction of zoning practices and denomination of origin regulations. In the case of Argentina, the strongest points detected were the identification of Malbec as a typical variety and the shift of Argentine wine exports towards more demanding market destinations especially the US. In none of our selected indicators - related to both wine characteristics per se and its positioning in the international market - were found truly negative results. From an in-depth analysis, therefore, it appears that the wine export boom in Chile and Argentina has been characterized by three emerging features, signalling a potential discontinuity with other natural resource-related export booms that have occurred in the past:

- Chile and Argentina have managed to penetrate a non-traditional export market largely dominated by well-established and highly competitive producers in advanced countries;

- Wine exports have become highly diversified, their quality has increased remarkably and prices have become more elastic; and

- Local producers have been able to capture increasing rents by climbing the valueadded ladder of more sophisticated processing stages.

The key issue to be addressed in the next chapter refers to the magnitude and variety of the main sources of innovation (exogenous versus endogenous) in the Chilean and Argentine wine industries, and to the long term sustainability of the Chilean and Argentine wine export boom. From a development perspective, the ultimate question is whether the availability of natural resources can become a spur to development and a platform for creating deeper competencies and increased knowledge and innovation capacity. Should this be found to be possible, interesting prospects might open up for developing countries with a tradition of pure extraction and exploitation of natural resources, or of locally processed production locked in the cheap end of the market. 



\section{CHAPTER 5}

:

Innovation and Learning

Dynamics in the Chilean and

Argentine Wine Industries 
CHAPTER 5 


\subsection{Introduction}

This chapter focuses on the magnitude, variety, and sources of innovation introduced by the Chilean and Argentine wine industries during the past two decades. It analyzes whether the continued quality upgrading and prolonged export growth of Chilean and Argentine wines, described in detail in the previous chapter, have been achieved by building the innovation capacity of local actors and creating domestic linkages with local grape producers, winemakers and input providers, or by relying exclusively upon FDI and knowledge flows generated abroad. In line with the evolutionary tradition, this chapter explores the hypothesis that, much as in the case of high-tech sectors, the ability of developing countries to enter knowledge-intensive natural resource-based sectors, such as wine, depends on their ability to access capital, technology and knowledge from abroad, that is, on what have been defined in the methodology chapter as "external" sources of innovation. It also depends on the ability to absorb and adapt imported technology and know-how to the local environment, that is, on the creation of local tacit knowledge and endogenous R\&D capabilities.

It should be recalled here that innovation is a costly, risky and path-dependent process (von Hippel, 1998; Fagerberg, 1994; Freeman and Soete, 1997). The evolutionary literature suggests therefore that for all but the largest countries in the world, foreign sources of technology are usually predominant (Fagerberg et al., 2009) and often indispensable to the innovation process (Cohen and Levinthal, 1989). As a consequence, developing countries have often been perceived solely as users of capital equipment, licenses and technical knowledge imported from abroad, in particular from advanced economies, and not as knowledge and technology producers in their own capacity (Pietrobelli, 1996; Mytelka, 2004; Agosin and Bravo-Ortega, 2009). This chapter challenges this view, emphasizing how different the situation is in the case of the Chilean and Argentine wine industries. It recognizes the role played by foreign technology and know-how in spurring the initial "resurrection" of these industries after a long period of decline. It also highlights, though, how equally important was the gradual emergence of endogenous innovation capabilities and R\&D to ensure sustained export growth.

The present chapter is structured as follows: Section 2 measures the innovativeness of the leading 25 Chilean and of the leading 25 Argentine exporters of bottled wines. Section 3 looks at the variety of innovations introduced, focusing - in line with the Schumpeterian tradition - not only on new methods of production, but also on the development of new products and new ways of organizing business. Section 4 looks at the triggering role of FDI in stimulating the phenomenal technological upgrading process of the Chilean and Argentine wine industries over the past two decades. Section 5 focuses on the importance of external sources of innovation in sustaining such a process, namely, on the importance of capital-embodied and codified knowledge flows channelled through imports of foreign machinery and quality certification mechanisms. Section 6 looks at the creation of local tacit knowledge and incremental innovation in the Chilean and Argentine wine industries, and at the emergence of a wide pool of 
highly qualified local oenologists, agronomists and viticulturalists. Section 7 analyses the role of sectoral R\&D programmes and of local universities and research centers in the creation of endogenous technological capabilities. Section 8 concludes with some considerations on the longer-term sustainability of the export boom of Chilean and Argentine wines and points to the need to look (in Chapter 6) at the systemic, geographically bound and interactive nature of innovation.

\subsection{Innovativeness of the leading Chilean and Argentine wineries}

In the modern wine industry, a remarkable number of scientific and technological changes have made possible a shift from the production of ordinary table wines to the production of fine, premium wines - that is, from a basic, undifferentiated commodity to an increasingly sophisticated and differentiated luxury good - induced by the changing demands of international consumers. This has become known in the specialized literature as the "wine revolution" (Adams, 1973; Unwin, 1991; Crowley, 2001). The term refers to a combination of technological advances and new equipment in the winery, establishing the predominance of the production of quality over quantity in wines. In the winery, these include temperature-controlled stainless steel tanks, bladder presses, the use of and frequent turnover of oak barrels for aging, and sophisticated bottling lines. Analogously, in the vineyards, these include new trellising methods, drip irrigation, clone selection, mechanical harvesting and frost protection.

As observed in Chapter 3, California was the first wine producer to undergo such a "wine revolution" in the 1960s, promptly followed by Australia. Soon after, all Old World producers were forced to innovate in order to bring the quality and taste of their wines up to what was becoming the international standard. In order to succeed under these circumstances, both the Chilean and the Argentine wine industries had to learn to compete, based on far more than their natural comparative advantages and their competitive cost structure, gradually meeting new international standards and new consumer preferences in the time span of a few decades. Evidence from the present survey, focusing on the top 25 Chilean and the top 25 Argentine exporters of bottled wines, shows that they did learn to compete by gaining greater technological complexity and a better control of wine-making habits and practices, as well as by gradually incorporating modern vine growing and marketing techniques.

In the case of Chile, the list of the top 25 exporters of bottled wines (see Table 5.1) comprises the group of the 10 most famous old Chilean wineries established after Chilean independence in 1850: Carmen (1850), Cousiño Macul (1856), San Pedro (1865), Errazuriz (1870), Tarapacà (1874), Santa Carolina (1877), Valdivieso - earlier named Santa Elena - (1879), Santa Rita (1880), Concha y Toro (1883) and Undurraga (1885). There is also a group of new companies, founded after the official liberalization of the Chilean wine market in 1974, with the arrival of foreign investors. These are Bisquertt (1975), Felipe Edwards (1976), Casa Silva (1977), Miguel Torres (1979), Canepa (1980) and Santa Emiliana (1986). Moreover, there are a group of new wineries established after the return to democracy in 1988, when the Chilean wine industry started to resurge after a period of dramatic stagnation and decline. These are Los 
Vascos (1988), Montes (1988), Cono Sur (1993), Ventisquero (1998), Casa Lapostolle (1994) and Almaviva (1997). This is not surprising, considering that more than 50 percent of the 360 officially registered Chilean wineries are less than 15 years old, and that in Chile the decades after liberalization and after the end of dictatorship were characterized by high rates of new entrants, with wealthy local entrepreneurs and foreign firms suddenly showing interest in the wine industry.

Table 5.1 List of the top 25 Chilean exporters of bottled wines, 2010

\begin{tabular}{|c|c|c|c|c|c|c|}
\hline & Winery & Type of investment & Year & $\begin{array}{l}\text { \% of wine } \\
\text { exported }\end{array}$ & Top brand & $\begin{array}{c}\text { Max } \\
\text { rating by } \\
\text { Wine } \\
\text { Spectator }\end{array}$ \\
\hline 1 & Concha y Toro & $\begin{array}{l}\text { National investment } \\
\text { (Guilisasti-Larrain } \\
\text { group since 1960) }\end{array}$ & 1883 & $53 \%$ & $\begin{array}{l}\text { Don Melchor } \\
\text { (Cabernet } \\
\text { Sauvignon) }\end{array}$ & $\begin{array}{l}96 \text { points } \\
(2007)\end{array}$ \\
\hline 2 & San Pedro & $\begin{array}{l}\text { National investment } \\
\text { (CCU since 1991) }\end{array}$ & 1865 & $75 \%$ & $\begin{array}{l}\text { 1865 Limited } \\
\text { Edition } \\
\text { (Syrah) }\end{array}$ & $\begin{array}{l}90 \text { points } \\
(2007)\end{array}$ \\
\hline 3 & Santa Rita & $\begin{array}{l}\text { National investment } \\
\text { (Ricardo Claro Group } \\
\text { since 1980) }\end{array}$ & 1880 & $60 \%$ & $\begin{array}{l}\text { Triple C } \\
\text { (blend) }\end{array}$ & $\begin{array}{l}92 \text { points } \\
(2002)\end{array}$ \\
\hline 4 & Cono Sur & $\begin{array}{l}\text { National investment } \\
\text { (Concha y Toro) }\end{array}$ & 1993 & $97 \%$ & $\begin{array}{l}\text { Ocio } \\
\text { (Pinot Noir) }\end{array}$ & $\begin{array}{l}90 \text { points } \\
\text { (2006) }\end{array}$ \\
\hline 5 & Errazuriz & Old family business & 1870 & $90 \%$ & $\begin{array}{l}\text { Don } \\
\text { Maximiano } \\
\text { (blend ) }\end{array}$ & $\begin{array}{l}91 \text { points } \\
(2005)\end{array}$ \\
\hline 6 & Undurraga & Old family business & 1885 & $60 \%$ & $\begin{array}{l}\text { Altazor } \\
\text { (blend) }\end{array}$ & $\begin{array}{l}92 \text { points } \\
\text { (2006) }\end{array}$ \\
\hline 7 & Montes & $\begin{array}{l}\text { National investment (A. } \\
\text { Montes, A. Vidadurre, } \\
\text { D. Murray, P. Grand) }\end{array}$ & 1988 & $95 \%$ & $\begin{array}{l}\text { Montes Alpha } \\
\text { M (blend) }\end{array}$ & $\begin{array}{l}95 \text { points } \\
(2005)\end{array}$ \\
\hline 8 & Santa Carolina & $\begin{array}{l}\text { National investment } \\
\text { (Larrain family since } \\
\text { 1974) }\end{array}$ & 1877 & $75 \%$ & $\begin{array}{l}\text { VSC Maipo } \\
\text { Valley } \\
\text { (Cabernet } \\
\text { Sauvignon) }\end{array}$ & $\begin{array}{l}89 \text { points } \\
(2005)\end{array}$ \\
\hline 9 & Santa Helena & $\begin{array}{l}\text { National investment } \\
\text { (Junta de Exportación } \\
\text { Agricola and CCU since } \\
\text { 1994) }\end{array}$ & 1942 & $95 \%$ & $\begin{array}{l}\text { Aureus } \\
\text { (Cabernet } \\
\text { Sauvignon } \\
\text { Gran Reserva) }\end{array}$ & $\begin{array}{l}88 \text { points } \\
(2007)\end{array}$ \\
\hline 10 & Tarapacà & $\begin{array}{l}\text { National investment } \\
\text { (Carlos Cardoen from } \\
\text { Compania Chilena de } \\
\text { Fosforos since 1992) }\end{array}$ & 1874 & $80 \%$ & $\begin{array}{l}\text { Tarapacà Gran } \\
\text { Reserva } \\
\text { (Cabernet } \\
\text { Sauvignon) }\end{array}$ & $\begin{array}{l}88 \text { points } \\
(2008)\end{array}$ \\
\hline 11 & Carmen & $\begin{array}{l}\text { National investment } \\
\text { (Ricardo Claro Group } \\
\text { since 1985) }\end{array}$ & 1850 & $94 \%$ & $\begin{array}{l}\text { Carmen Gold } \\
\text { Reserve } \\
\text { (Cabernet } \\
\text { Sauvignon) }\end{array}$ & $\begin{array}{l}92 \text { points } \\
(2002)\end{array}$ \\
\hline 12 & $\begin{array}{l}\text { Santa } \\
\text { Emiliana }\end{array}$ & $\begin{array}{l}\text { National investment } \\
\text { (Concha y Toro) }\end{array}$ & 1986 & $84 \%$ & $\begin{array}{l}\text { Ge Colchagua } \\
\text { Valley (Syrah } \\
\text { blend) }\end{array}$ & $\begin{array}{l}93 \text { points } \\
\text { (2005) }\end{array}$ \\
\hline 13 & La Rosa & Old family business & 1824 & $85 \%$ & $\begin{array}{l}\text { Don Reca } \\
\text { Cuvée (blend) }\end{array}$ & $\begin{array}{l}87 \text { points } \\
\text { (2009) }\end{array}$ \\
\hline 14 & Ventisquero & $\begin{array}{l}\text { National investment } \\
\text { (G.Vial Group, poultry, } \\
\text { salmon and fruit) }\end{array}$ & 1998 & $60 \%$ & $\begin{array}{l}\text { Grey Cabernet } \\
\text { Sauvignon } \\
\text { Maipo Valley }\end{array}$ & $\begin{array}{l}88 \text { points } \\
(2005)\end{array}$ \\
\hline 15 & Los Vascos & $\begin{array}{l}\text { Joint-venture Baron de } \\
\text { Rothschild- (France) } \\
\text { with Santa Rita }\end{array}$ & 1988 & $99 \%$ & $\begin{array}{l}\text { Le Dix, } \\
\text { Colchagua } \\
\text { (blend) }\end{array}$ & $\begin{array}{l}89 \text { points } \\
(2003)\end{array}$ \\
\hline 16 & Valdivieso & Old family business & 1879 & $95 \%$ & $\begin{array}{l}\text { Caballo Loco } \\
\text { (blend) }\end{array}$ & $\begin{array}{l}91 \text { points } \\
(2008)\end{array}$ \\
\hline
\end{tabular}




\begin{tabular}{|c|c|c|c|c|c|c|}
\hline & Winery & Type of investment & Year & $\begin{array}{l}\text { \% of wine } \\
\text { exported }\end{array}$ & Top brand & $\begin{array}{l}\text { Max } \\
\text { rating by } \\
\text { Wine } \\
\text { Spectator }\end{array}$ \\
\hline 17 & $\begin{array}{l}\text { Casa } \\
\text { Lapostolle }\end{array}$ & $\begin{array}{l}\text { Joint-venture Marnier- } \\
\text { Lapostolle (France) and } \\
\text { Chilean Rabat family }\end{array}$ & 1994 & $95 \%$ & $\begin{array}{l}\text { Clos Apalta } \\
\text { (blend) }\end{array}$ & $\begin{array}{l}96 \text { points } \\
\text { (2005) }\end{array}$ \\
\hline 18 & Miguel Torres & $\begin{array}{l}\text { Foreign investment } \\
\text { (Spanish) }\end{array}$ & 1979 & $75 \%$ & $\begin{array}{l}\text { Conde de } \\
\text { Superunda } \\
\text { (blend) }\end{array}$ & $\begin{array}{l}92 \text { points } \\
\text { (2002) }\end{array}$ \\
\hline 19 & Canepa & Family business & 1980 & $50 \%$ & $\begin{array}{l}\text { Magnificum } \\
\text { (Cabernet } \\
\text { Sauvignon) }\end{array}$ & $\begin{array}{l}92 \text { points } \\
\text { (2005) }\end{array}$ \\
\hline 20 & $\begin{array}{l}\text { Felipe } \\
\text { Edwards }\end{array}$ & Family business & 1976 & $97 \%$ & $\begin{array}{l}\text { Doña } \\
\text { Bernarda } \\
\text { (Cabernet } \\
\text { Sauvignon) }\end{array}$ & $\begin{array}{l}89 \text { points } \\
(2004)\end{array}$ \\
\hline 21 & Bisquertt & Family business & 1975 & $50 \%$ & $\begin{array}{l}\text { La Joya } \\
\text { (Reserve } \\
\text { Syrah) }\end{array}$ & $\begin{array}{l}90 \text { points } \\
\text { (2008) }\end{array}$ \\
\hline 22 & Cousiño Macul & Old family business & 1856 & $97 \%$ & $\begin{array}{l}\text { Lota } \\
\text { (blend) }\end{array}$ & $\begin{array}{l}92 \text { points } \\
(2006)\end{array}$ \\
\hline 23 & Santa Ema & Old family business & 1931 & $70 \%$ & $\begin{array}{l}\text { Rivalta } \\
\text { (blend ) }\end{array}$ & $\begin{array}{l}91 \text { points } \\
\text { (2003) }\end{array}$ \\
\hline 24 & Casa Silva & Family business & 1977 & $85 \%$ & $\begin{array}{l}\text { Altura } \\
\text { (blend) }\end{array}$ & $\begin{array}{l}89 \text { points } \\
\text { (2001) }\end{array}$ \\
\hline 25 & Almaviva & $\begin{array}{l}\text { Joint-venture between } \\
\text { Baron Phillippe de } \\
\text { Rothschild (France) and } \\
\text { Concha y Toro }\end{array}$ & 1997 & $85 \%$ & $\begin{array}{l}\text { Almaviva } \\
\text { (blend) }\end{array}$ & $\begin{array}{l}95 \text { points } \\
(2005)\end{array}$ \\
\hline
\end{tabular}

Source: Author's survey

In the case of Argentina, the list of the top 25 exporters of bottled wines (see Table 5.2) includes 8 traditional wineries, founded at the end of the nineteenth to beginning of the twentieth century, 6 of which are still family owned companies.99 Five of these are of Italian origin and were created after the engineers Alberto Zuccardi, Valentin Bianchi, Angelo Pulenta, Pasquale Toso and Nicola Catena emigrated to Argentina in 1946, 1928, 1923, 1890 and 1902, respectively. Another 3 are of Spanish origin (mostly Catalan), and were created after Don Juan de Dios Correas, Don Leoncio Arizu and Don Miguel Escorihuela Gascon emigrated to Argentina in 1824, 1901 and 1884, respectively. Unlike in Chile, where only 4 of the top wineries are foreign invested (out of which 3 are joint-ventures), in Argentina the large majority of the 25 leading wineries (17) are owned by foreign investors (mainly of French, Chilean and Spanish origin) and only 1 is an Italo-Argentine joint-venture. All of these were created - or bought and then completely renovated and equipped with state-of-the-art technology - after 1991, with the exception of the Terrazas winery, founded by Chandon in 1950. As it will be explained more in detail in the following section, the scarce presence of joint-ventures in the Argentine wine industry, compared to that of Chile, is a phenomenon that deserves some attention, and is presumably due to a strong sense of uncertainty associated with the Argentine political, economic and regulatory framework.

\footnotetext{
99 Immediately after 1991, a wide group of local winery owners sold their wineries to foreigners, fearing to be put completely out of the game as a consequence of the liberalization process. The phenomenon was so profound that in the 1990 s only six of Argentina's traditional family wineries had remained in the hands of the founding families.
} 
Table 5.2 List of the top 25 Argentine exporters of bottled wines, 2010

\begin{tabular}{|c|c|c|c|c|c|c|}
\hline & Winery & Type of investment & Year & $\begin{array}{l}\text { \% of wine } \\
\text { exported }\end{array}$ & Top brand & $\begin{array}{c}\text { Max } \\
\text { rating by } \\
\text { Wine } \\
\text { Spectator }\end{array}$ \\
\hline 1 & Zuccardi & Old family business & 1946 & $65 \%$ & Q Malbec & $\begin{array}{l}92 \text { points } \\
(2007)\end{array}$ \\
\hline 2 & Tivento & $\begin{array}{l}\text { Foreign investment (Chilean } \\
\text { Concha y Toro) }\end{array}$ & 1996 & $65 \%$ & $\begin{array}{l}\text { Malbec Eolo } \\
\text { Golden Reserve }\end{array}$ & $\begin{array}{l}93 \text { points } \\
\text { (2005) }\end{array}$ \\
\hline 3 & Catena Zapata & Old family business & 1902 & $55 \%$ & $\begin{array}{l}\text { Catena Zapata } \\
\text { Malbec }\end{array}$ & $\begin{array}{l}95 \text { points } \\
(2006)\end{array}$ \\
\hline 4 & Trapiche & $\begin{array}{l}\text { Foreign investment } \\
\text { (US investment d since 1998) }\end{array}$ & 1920 & $60 \%$ & $\begin{array}{l}\text { Trapiche Malbec } \\
\text { Single Vineyard }\end{array}$ & $\begin{array}{l}92 \text { points } \\
\text { (2006) }\end{array}$ \\
\hline 5 & Norton & $\begin{array}{l}\text { Foreign investment (Austrian } \\
\text { Swarowsky Group since 1989) }\end{array}$ & 1895 & $65 \%$ & $\begin{array}{l}\text { Norton Privada } \\
\text { (blend)) }\end{array}$ & $\begin{array}{l}92 \text { points } \\
(2006)\end{array}$ \\
\hline 6 & Finca Flinchman & $\begin{array}{l}\text { Foreign investment } \\
\text { (Portuguese SOGRAPE group } \\
\text { since 1998) }\end{array}$ & 1883 & $40 \%$ & $\begin{array}{l}\text { Cabernet } \\
\text { Sauvignon }\end{array}$ & $\begin{array}{l}94 \text { points } \\
(2009)\end{array}$ \\
\hline 7 & Navarro Correas & $\begin{array}{l}\text { Foreign investment (DIAGEO } \\
\text { since 1996) }\end{array}$ & 1824 & $35 \%$ & Alegoria Malbec & $\begin{array}{l}\text { 9o points } \\
(2005)\end{array}$ \\
\hline 8 & Pascual Toso & Old family business & 1890 & $10 \%$ & $\begin{array}{l}\text { Toso Magdalena } \\
\text { (blend) }\end{array}$ & $\begin{array}{l}92 \text { points } \\
\text { (2005) }\end{array}$ \\
\hline 9 & Terrrazas & $\begin{array}{l}\text { Foreign investment (French, } \\
\text { Moët et Chandon) since } 1950\end{array}$ & 1999 & $85 \%$ & $\begin{array}{l}\text { Terrazas Malbec } \\
\text { Mendoza }\end{array}$ & $\begin{array}{l}91 \text { points } \\
(2003)\end{array}$ \\
\hline 10 & Luigi Bosca & Old family business & 1901 & $45 \%$ & Malbec Reserva & $\begin{array}{l}91 \text { points } \\
(2005)\end{array}$ \\
\hline 11 & Escorihuela Gascon & $\begin{array}{l}\text { Foreign investment } \\
\text { (US investment fund since } \\
\text { 1992) }\end{array}$ & 1884 & $55 \%$ & $\begin{array}{l}\text { Malbec Don } \\
\text { Miguel Gascon }\end{array}$ & $\begin{array}{l}89 \text { points } \\
(2003)\end{array}$ \\
\hline 12 & La Celia & $\begin{array}{l}\text { Foreign investment } \\
\text { (Chilean San Pedro since } \\
\text { 2000) }\end{array}$ & 1890 & $80 \%$ & $\begin{array}{l}\text { La Celia Malbec } \\
\text { Reserve }\end{array}$ & $\begin{array}{l}90 \text { points } \\
(2005)\end{array}$ \\
\hline 13 & Dominio del Plata & $\begin{array}{l}\text { National investment (Susana } \\
\text { Balbo) }\end{array}$ & 1999 & $80 \%$ & Nosotros Malbec & $\begin{array}{l}94 \text { points } \\
(2008)\end{array}$ \\
\hline 14 & Séptima & $\begin{array}{l}\text { Foreign investment (Spanish- } \\
\text { Catalonian Codorniu since } \\
\text { 1999) }\end{array}$ & 1999 & $60 \%$ & Séptima Malbec & $\begin{array}{l}87 \text { points } \\
(2007)\end{array}$ \\
\hline 15 & O.Fournier & $\begin{array}{l}\text { Foreign investment (Spanish } \\
\text { family Ortega Gil-Fournier) }\end{array}$ & 1999 & $90 \%$ & Alfa Crux (blend) & $\begin{array}{l}92 \text { points } \\
(2002)\end{array}$ \\
\hline 16 & Lurton & $\begin{array}{l}\text { Foreign investment (French } \\
\text { Lurton family) }\end{array}$ & 1996 & $98 \%$ & $\begin{array}{l}\text { Belondrade y } \\
\text { Lurton Rueda }\end{array}$ & $\begin{array}{l}90 \text { points } \\
\text { (2001) }\end{array}$ \\
\hline 17 & Salentein & Foreign investment (Dutch) & 1998 & $85 \%$ & Uco Valley Malbec & $\begin{array}{l}89 \text { points } \\
(2004)\end{array}$ \\
\hline 18 & Dona Paula & $\begin{array}{l}\text { Foreign investment (Chilean } \\
\text { Claro group) }\end{array}$ & 1997 & $85 \%$ & Estate Malbec & $\begin{array}{l}92 \text { points } \\
\text { (2006) }\end{array}$ \\
\hline 19 & Nieto Senetiner & $\begin{array}{l}\text { Foreign investment (Brazil) } \\
\text { since } 1998\end{array}$ & 1888 & $60 \%$ & Cadus Malbec & $\begin{array}{l}90 \text { points } \\
\text { (2002) }\end{array}$ \\
\hline 20 & Chandon & $\begin{array}{l}\text { Foreign investment (French, } \\
\text { Moët \& Chandon, and LVMH } \\
\text { group since 1998) }\end{array}$ & 1959 & $35 \%$ & $\begin{array}{l}\text { Alta Vista Alto } \\
\text { (Malbec) }\end{array}$ & $\begin{array}{l}94 \text { points } \\
(2005)\end{array}$ \\
\hline 21 & Alta Vista & $\begin{array}{l}\text { Foreign investment } \\
\text { (French, D'Aulan family) }\end{array}$ & 1997 & $80 \%$ & Atemporal Blend & $\begin{array}{l}90 \text { points } \\
(2007)\end{array}$ \\
\hline 22 & Alto Las Hormigas & Foreign investment (Italian) & 1996 & $90 \%$ & Malbec reserva & $\begin{array}{l}92 \text { points } \\
(2005)\end{array}$ \\
\hline 23 & Valentin Bianchi & Old family business & 1928 & $45 \%$ & Elsa Malbec & $\begin{array}{l}88 \text { points } \\
(2004)\end{array}$ \\
\hline 24 & Augusto Pulenta & Old family business & 1923 & $25 \%$ & $\begin{array}{l}\text { Malbec Calchaqui } \\
\text { Valley }\end{array}$ & $\begin{array}{l}92 \text { points } \\
(2007)\end{array}$ \\
\hline 25 & Achaval Ferrer & Joint-venture (Italy-Argentina) & 1998 & $95 \%$ & $\begin{array}{l}\text { Malbec Finca } \\
\text { Altamira }\end{array}$ & $\begin{array}{l}96 \text { points } \\
(2006)\end{array}$ \\
\hline
\end{tabular}

Source: Author's survey 
The present survey reveals that, during the last two decades, a large amount of effort was put into place by both the Chilean and Argentine leading exporting wineries in order not only to integrate the most advanced winemaking knowledge and technologies in their current practices, but also to continuously innovate their products and improve their positioning in the international market (see Table 5.3). This finding is of utmost importance, as, according to the literature (Pavitt, 1984; Malerba, 2004), in natural resource-based sectors, innovation would mainly consist in process innovation, as very few innovative efforts would be required by the product characteristics per se, due to the specific sectoral patterns of acquisition of innovative knowledge. This thesis shows that this is not always the case. Even if to a different extent, in both the Chilean and Argentine wine industries an incredible amount of product, process and organizational innovations have been introduced during the last two decades. This confirms the view that Pavitt's (1984) original taxonomy of the sectoral patterns for the acquisition of innovative knowledge should be revisited, in order to reflect the rising knowledge intensity of natural resource-based industries and the importance of product differentiation and marketing strategies in sustaining their export growth.

Table 5.3 Degree of innovativeness of the top 25 Chilean and Argentine exporters of bottled wines, 2010

\begin{tabular}{|c|c|c|c|}
\hline Type & Main innovations & $\begin{array}{c}\text { Top } 25 \\
\text { Chilean } \\
\text { wineries }\end{array}$ & $\begin{array}{c}\text { Top } 25 \\
\text { Argentine } \\
\text { wineries }\end{array}$ \\
\hline \multirow{5}{*}{$\begin{array}{l}\text { Product / } \\
\text { Viticulture }\end{array}$} & $\begin{array}{l}\text { Identification of best terroirs and of best clones for } \\
\text { each variety }\end{array}$ & $23 / 25$ & $14 / 25$ \\
\hline & $\begin{array}{l}\text { Introduction of new varieties (in addition to top four } \\
\text { most widely diffused) }\end{array}$ & $16 / 25$ & $24 / 25$ \\
\hline & $\begin{array}{l}\text { Introduction of drip or furrow irrigation systems ( } v s \text {. } \\
\text { flooding irrigation) }\end{array}$ & $24 / 25$ & $14 / 25$ \\
\hline & Limitation of the yields for top quality brands & $22 / 25$ & $14 / 25$ \\
\hline & $\begin{array}{l}\text { Introduction of organic and/or biodynamic farming } \\
\text { cultivation techniques }\end{array}$ & $19 / 25$ & $8 / 25$ \\
\hline \multirow{5}{*}{$\begin{array}{l}\text { Process / } \\
\text { Viniculture }\end{array}$} & $\begin{array}{l}\text { Replacement of old big casks for aging with smaller } \\
\text { oak barriques imported from USA and/or France }\end{array}$ & $25 / 25$ & $25 / 25$ \\
\hline & Use of stainless steel tanks for vinification & $25 / 25$ & $25 / 25$ \\
\hline & $\begin{array}{l}\text { Installation of refrigeration devices for both } \\
\text { fermentation and maturation }\end{array}$ & $25 / 25$ & $25 / 25$ \\
\hline & $\begin{array}{l}\text { Replacement of old vertical presses with pneumatic } \\
\text { presses }\end{array}$ & $25 / 25$ & $24 / 25$ \\
\hline & Use of gravity flow mechanisms & $5 / 25$ & $3 / 25$ \\
\hline \multirow{5}{*}{$\begin{array}{l}\text { Organization } \\
\text { \& marketing }\end{array}$} & Creation of new "terroir" brands & $20 / 25$ & $12 / 25$ \\
\hline & Participation at international wine competitions & $25 / 25$ & $25 / 25$ \\
\hline & $\begin{array}{l}\text { Use of social networks (Facebook, Youtube and/or } \\
\text { Twitter) for marketing purposes }\end{array}$ & $9 / 25$ & $4 / 25$ \\
\hline & $\begin{array}{l}\text { Organization of winery tours, food and wine tastings, } \\
\text { cultural events }\end{array}$ & $24 / 25$ & $24 / 25$ \\
\hline & $\begin{array}{l}\text { Adoption of a sophisticated architectural design of } \\
\text { the winery as a marketing tool }\end{array}$ & $7 / 25$ & $8 / 25$ \\
\hline
\end{tabular}


The table above shows that the leading Chilean and Argentine exporting wineries managed to integrate an equally pervasive series of process innovations, mainly belonging to the vinification process. In particular, 25 out of 25 firms in both countries have adopted all the most modern winemaking technologies, except for gravity flows, which remain everywhere in the world a quite sophisticated, expensive technique adopted by a minority of winemakers. By contrast, in the area of product innovation, mainly belonging to the viticulture practice, there is a relatively larger discrepancy, in that the Chilean wineries seem to have been inclined much more than the Argentine ones to introduce modern viticulture techniques related to irrigation, yield management and clone selection - except for the search for new varieties, where Argentine firms clearly appear more advanced. This difference is not matched by much of a difference in the area of organizational innovation, where the situation appears relatively balanced. The reasons for such discrepancies are explained in the following section.

\section{$5 \cdot 3$ Types and varieties of innovation}

The findings of this survey show that, in the case of Chile, a huge technological restructuring process at the cellar level has been matched by the introduction of a massive amount of new viticulture habits and marketing practices. In particular, on the viticulture side, the survey shows that in the top 25 Chilean exporters of bottled wines, the old technique of irrigation by simply flooding and letting the water drain down, thanks to purposely dug channels, has been fully replaced by the use of drip irrigation systems, which allow better control of the amount of water that each vine receives. Key techniques in maximizing quality and producing grapes for top brands, such as the reduction of excessive yields and the introduction of trellising systems, have been introduced in 22 out of 25 wineries. New terroirs are also being sought, in contrast to the traditional areas in the hot Central Valley. In such new areas, the climatic conditions are often more difficult, especially when located in the extreme North or extreme South of Chile, but all companies interviewed are convinced that this goes along with a strong potential for quality.

On average, Chilean exporting wineries are used to handling three main grape varieties, namely, Cabernet Sauvignon, Merlot and Chardonnay. Most of them, however, are paying growing attention towards diversification in order to reach new, demanding consumers of developed countries. To this purpose, vine varieties are also matched more carefully to the sites on which they are grown. Just to cite a few examples, Santa Rita has pioneered Viognier and Riesling in Chile, and owns the oldest Pinot Noir vines in the country, for which it has recently built a new "premium" winery. Santa Helena has focused its search for non-traditional varieties on Mourvedre, Viognier and Malbec, while Casa Lapostolle has focused on Tempranillo, Monastrell and Gewürztraminer. Cono Sur pioneered plantations in Aconcagua Costa, a new viticultural area where grapes had never been grown before, to start new plantations of Sauvignon Blanc and Pinot Noir.

In Chile, the top exporting wineries are also paying particular attention to the production of organic wines. As already noted in the previous chapter, Chile benefits 
from unique phyto-sanitary barriers, since the Andes, the Pacific Ocean, the Northern Desert and Antarctica are natural obstacles, matched by the rigorous preventive efforts of Chile's Agricultural and Ranching service (SAG) in the border areas. Therefore, there are very few diseases and pests that seriously affect Chilean vines, making it possible and relatively frequent to manage vineyards free of agrochemical products and pesticides. These conditions have made Chilean wineries increasingly appropriate for integrated, organic or biodynamic vineyard management. According to SAG, currently 4.2 million litres of organic wine are produced in Chile, from approximately 2,000 hectares of planted vineyards. Three wineries, namely Santa Emiliana, Lapostolle and Matetic, also produce biodynamic wines. In early 2010, they invited French consultant Nicolas Joly, who is considered the world leading expert on biodynamic wines, to hold seminars and teach them about the most recent biodynamic techniques. Overall, 19 out of the 25 leading wineries are adopting organic or biodynamic farming techniques, as well as other types of eco-friendly practices (see Table 5.4).

Table 5.4 Eco-friendly practices adopted by the top 25 Chilean exporters of bottled wines, 2010

\begin{tabular}{|c|c|c|}
\hline & Winery & Activity \\
\hline 1 & Concha y Toro & $\begin{array}{l}\text { Organic Wine R\&D project; participation in Conicyt/Fondef project "Water } \\
\text { management technologies for sustainable intensive agriculture" }\end{array}$ \\
\hline 2 & San Pedro & $\begin{array}{l}\text { Integrated vineyard management; garbage recycling campaign; lightweight } \\
\text { bottling for export brands; measuring of carbon footprints }\end{array}$ \\
\hline 3 & Santa Rita & Application of principles of sustainable agriculture \\
\hline 4 & Cono Sur & $\begin{array}{l}\text { Integrated vineyard management; organic fertilization (from winemaking } \\
\text { residues); Carbon Neutral delivery status; creation of a Sustainable } \\
\text { Development Area }\end{array}$ \\
\hline 5 & Errazuriz & High percentage of grapes grown organically \\
\hline 6 & Undurraga & Small organic production at pilot stage \\
\hline 7 & Montes & $\begin{array}{l}\text { Organic fertilization (compost); use of horses to work on slopes; computer } \\
\text { controlled irrigation }\end{array}$ \\
\hline 8 & Santa Carolina & In progress \\
\hline 9 & Santa Helena & $\begin{array}{l}\text { Application of principles of sustainable agriculture; lightweight bottling for } \\
\text { export brands }\end{array}$ \\
\hline 10 & Tarapaca & Organically grown grapes for the Natura plus brand \\
\hline 11 & Carmen & $\begin{array}{l}\text { Organically grown grapes for the Nativa brand; pioneered use of green } \\
\text { packaging (lightweight bottling for export brands) }\end{array}$ \\
\hline 12 & Emiliana & $\begin{array}{l}100 \% \text { organic and biodynamic (managing of solid waste; efficient energy } \\
\text { consumption; environmentally friendly packaging; sustainable vineyard } \\
\text { management) }\end{array}$ \\
\hline 13 & La Rosa & Production of certified organic wines by Institute for Market-ecology $(\mathrm{CH})$ \\
\hline 14 & Ventisquero & $\begin{array}{l}\text { Cooperation with Climate-care to compensate } \mathrm{CO} 2 \text { emissions generated by } \\
\text { transport of wines; Chilean APL (agreement for clean production) }\end{array}$ \\
\hline 15 & Los Vascos & - \\
\hline 16 & Valdivieso & - \\
\hline 17 & Casa Lapostolle & - \\
\hline 18 & Miguel Torres & In progress \\
\hline 19 & Canepa & 25 hectares farmed organically; lighter bottling to reduce Carbon Footprint \\
\hline 20 & Luis Felipe Edwards & First release of organic wines in 2005 , certified by the German company BCS \\
\hline 21 & Bisquertt & Use of organic fertilization (compost) \\
\hline 22 & Cousiño Macul & $\begin{array}{l}\text { Application of principles of sustainable agriculture and of "minimal } \\
\text { intervention"; all viticultural activities conducted in an environmentally } \\
\text { responsible manner }\end{array}$ \\
\hline 23 & Santa Ema & Efficient environmental management system \\
\hline 24 & Casa Silva & - \\
\hline 25 & Almaviva & - \\
\hline
\end{tabular}

Source: Author's survey 
On the viniculture side, among the most important technological changes introduced into the Chilean industry are the use of stainless steel vats in place of large wooden casks, the installation of refrigeration devices both for fermentation and maturation, the use of pneumatic presses rather than old vertical ones, and the use of small oak barrels in place of the old large vats made of native beech, called "rauli", where previously all Chilean red wines were kept. These innovations are common to the totality of the top 25 exporting wineries, which possess, on average, 4,000-5,000 American and French (225 litre) oak barrels each, with the exception of San Pedro and Concha y Toro that possess more than 7,000 each. In five cases, namely Montes, Carmen, Ventisquero and Almaviva, modern facilities were also designed to incorporate gravity flow mechanisms, which are key to avoiding the traumatic effects of hydraulic pumps on must and fermented wines. ${ }^{100}$ More generally, the US Foreign Agricultural Service has estimated that in the Chilean wine industry, over 46 percent of wine storage containers at wineries are stainless steel tanks, while 39 percent of the wineries use oak barrels made from French or American wood, for an average of 3-5 years, which shows a high technological development standard for the whole industry (USDA, GAIN Report, 2010).

On the marketing side, the leading Chilean wineries seem to possess the capacities for developing their market knowledge, brand names and economies of scale. Practically all of them have opened doors to visitors, added tasting rooms and gift shops, and transformed wine into a social and cultural occasion. Only 7 of them, though, rely on sophisticated modern stylistic and architectural aspects to encourage wine tourism. Montes, for example, owns a feng-shui inspired facility; Casa Lapostolle, a luxury 6floor winery buried into the granite of the Apalta hillside, with gravity flows applied throughout the natural slope of the hill; Almaviva owns a native wooden facility designed by the famous Chilean architect Martin Hurtado-Covarrubias, which also includes a Mapuche crafts and silver museum. Several other wineries, however, such as Concha y Toro, Cousiño Macul, Santa Rita and Undurraga, have preserved and beautifully restored century old buildings, dating back to the 1870 , which are also historical monuments and effective tourist attractions. The most striking finding is that all 25 wineries possess a website, but only 9 of them sell on-line or use social networks, such as Facebook and Twitter, for marketing purposes. ${ }^{101}$

In the case of Argentina, the "wine revolution" is clearly reflected in the number of producers working mainly in their own estates using grapes from their own vineyards. This enables total control and monitoring of the grapes, and is at the origin of the rise in the number of good quality Argentine wines described in the previous sections. According to Robinson (2005), in Argentina the strongest brake on progress in the past has been the gap and the diverging interests between grape-growers and wine

\footnotetext{
100 Following the gravitational concept, the grape reception area is located on higher levels, and de-stemmers are placed over maceration and fermentation tanks. The difference in levels is also used to transport wine from fermentation tanks to aging barrels.

${ }^{101}$ This is corroborated by the research findings of Kunc (2007), who carried out a survey on the managerial practices of Chilean wineries. The respondents perceived a strong need to develop their innovative capabilities in the area of market development, brand management and consumer behavior, especially with respect to the use of the Internet, on-line sales and social network-related tools.
} 
producers. The practice of yield reduction and irrigation control for improving quality has been largely unknown in Argentina until very recently, and wines were rather made with extraordinary high yields and with grapes that were pumped of melted Andean snow by irrigation channels constructed in the nineteenth century.

The present survey reveals that, on the viticulture side, by the mid-1990s, the majority (14) of the 25 leading Argentine exporters of bottled wines had planted heavily in order to be more self-sufficient in terms of fruit supply, and could finally give more emphasis to lower yields, better irrigation, more attention to the vines, and careful assessment of vineyard sites. ${ }^{102}$ Vines have also begun to be planted in cooler areas than the hot Mendoza area (Lujan de Cuyo at $1100 \mathrm{~m}$, or Tupungato at $1200 \mathrm{~m}$ ) to prolong the ripening process, and to be trained carefully on wires to obtain the maximum quality of the resulting fruit. Trivento, for example, established in 2005 a "Terroir Wines" project for high-end wines, whereby vineyards have been divided into three micro-regions and vinified separately. Catena Zapata produces Malbec blends with specially selected lots from different high altitude vineyards. Terrazas has undertaken a special experimental programme to identify the ideal altitude for each variety. Altos las Hormigas has launched a "Terroir Project" to study geomorphology and soil profile, with the support of the consultant Pedro Parra, the only specialist of South American terroirs.

Almost all the 25 Argentine wineries surveyed have been busy with the search and introduction of new varieties, in addition to the top four most widely diffused, namely Malbec, Cabernet Sauvignon, Syrah, and Torrontés. Alto las Hormigas is the only exception, as it is a Malbec-only winery. The other 24 have been testing an amazing series of unusual and less known varieties, symbolizing the curiosity, openness and fantasy of Argentine winemaking culture. Just to cite a few examples, Zuccardi has created a micro-vinification room with small stainless tanks, in order to regularly test new varieties and new wines. It has trial plantings of 35 varieties, among which Grenache, Mourvèdre, Tannat, Aglianico and Zinfandel. Norton owns 90-year-old Malbec vines that are meticulously cared for. In addition, Zuccardi is experimenting with such new varieties as Barbera, Sangiovese, Aspiran Bouchet, Tannat, Raboso, Semillion and Grunner. Finca Flichman planted the first Viognier in Argentina, and is now experimenting with new varieties, such as Aspiran Bouchet, Raboso and Barbera. Escorihuela Gascon is starting to vinify (but not yet to commercialize) Verdicchio and Barbera grapes, while Dominio del Plata has been experimenting with grafted Syrah vines, Tannat, Petit Verdot, Chenin Blanc and Angelotta. Doña Paula is experimenting on plots with Pinot Noir, Tannat, Angelotta, Marsanne, Aglianico, Touliba, Casavecchia, Riesling, Petit Verdot and Grenache.

In Argentina, organic grape production seems to be far less advanced than in Chile (see Table 5.5). Zuccardi is a leading exponent of organic viticulture in Argentina, with 35 percent of its vineyards grown organically and certified under European, Canadian and Japanese standards. The remaining 65 percent are grown through sustainable

\footnotetext{
102 This reflects a world-wide tendency to "turn back to the basics", to quote famous American winemaker Robert Mondavi, who argued that after an exaggerated focus on machinery and technology in the 1980s and 1990s, winemakers in the twentyfirst century should pay more attention to soils, planting techniques and irrigation.
} 
production systems. Overall, between 2005 and 2008 its exports of organic wines increased by 203 percent, and were directed mainly to European Union countries. Two other wineries, Trivento and Catena Zapata, are experimenting with biodynamic vine cultivation. Overall, sustainable cultivation techniques and other eco-friendly practices have been adopted by 8 of the 25 leading Argentine exporters of bottled wines. Given the rising demand for organic wines, as illustrated in Chapter 3, especially in countries with higher standards of living, and the increasing interest of Argentine wineries in adopting eco-friendly practices, the National Institute for Vitiviniculture has recently decided to regulate organic wine production and create a national register of authorized certifying companies. This is the first step towards what, based on the Chilean experience, seems poised to be a sustained process of expansion.

Table 5.5 Eco-friendly practices adopted by the top 25 Argentine exporters of bottled wines, 2010

\begin{tabular}{|c|c|c|}
\hline & Winery & Activity \\
\hline 1 & Zuccardi & $\begin{array}{l}35 \text { percent of organically grown grapes; adoption of sustainable cultivation } \\
\text { techniques and comprehensive waste recycling policy; use of alternative energy } \\
\text { sources }\end{array}$ \\
\hline 2 & Trivento & Experimentation of biodynamic vine cultivation \\
\hline 3 & Catena Zapata & - \\
\hline 4 & Trapiche & Experimentation of biodynamic vine cultivation \\
\hline 5 & Norton & $\begin{array}{l}\text { First winery in Argentina to introduce eco-friendly bottling; ISO } 14001 \text { certification } \\
\text { in progress; recycling of solid waste; collection of old batteries; organic vine } \\
\text { planting }\end{array}$ \\
\hline 6 & Finca Flinchman & - \\
\hline 7 & Navarro Correas & - \\
\hline 8 & Pascual Toso & - \\
\hline 9 & Terrrazas & - \\
\hline 10 & Luigi Bosca & - \\
\hline 11 & Escorihuela Gascon & - \\
\hline 12 & La Celia & $\begin{array}{l}\text { First winery in Argentina to obtain the Integrated Management System } \\
\text { certification; reduction of electricity and water consumption; measurement and } \\
\text { reduction of waste materials through quantitative indicators }\end{array}$ \\
\hline 13 & Dominio del Plata & - \\
\hline 14 & Séptima & - \\
\hline 15 & Fournier & - \\
\hline 16 & Lurton & - \\
\hline 17 & Salentein & $\begin{array}{l}\text { Sustainable viticultural and agricultural techniques; no pesticides; organic wastes } \\
\text { returned to the land as fertilizers; water conservation; plan to reduce energy } \\
\text { consumption and research on renewable energy sources; preservation of } 49 \\
\text { hectares as native desert habitat }\end{array}$ \\
\hline 18 & Doña Paula & $\begin{array}{l}\text { Introduction of sustainable agricultural practices, e.g., keep natural endemic plants } \\
\text { and weeds in the soil, serving as natural cover crops, and use of organic mulching as } \\
\text { fertilizers }\end{array}$ \\
\hline 19 & Nieto Senetiner & - \\
\hline 20 & Chandon & - \\
\hline 21 & Alta Vista & - \\
\hline 22 & Alto Las Hormigas & - \\
\hline 23 & Valentin Bianchi & - \\
\hline 24 & Augusto Pulenta & - \\
\hline 25 & Achaval Ferrer & 100 hectares organically certified by IMC \\
\hline
\end{tabular}

Source: Author's survey

On the viniculture side, as in Chile, all the Argentine leading wine exporters own stateof-the-art wineries, equipped with the most advanced machineries and technologies, 
the closest possible to international standards. Until the 1980s, for example, Argentine wineries used to ferment wines in old "fudres", which were difficult to keep clean and sometimes released undesirable flavours and unpleasant smells onto wines. Today, stainless steel tanks are widely diffused, as well as refrigeration devices, to control fermentation and pneumatic presses. Some wineries continue to use cement vats, but these are all covered with an epoxy layer that makes them easy to clean, completely safe and good keepers of temperature. While innovative winemaking techniques from California and Australia were put in place at the cellar level, isolated ageing rooms were also built, equipped with French and American oak barrels to let top quality wines mature, which is essential to producing good quality wines. As in Chile, gravitational flows, which are effective for avoiding brusque wine movements, are being used only by a limited minority of wineries, namely 3 out of the 25 leading exporters.

On the marketing side, new management and marketing styles have also been widely adopted, based on state-of-the-art product development and quality control, on some emphasis on regional identity and branding, and on the launching of communications campaigns. Practically all 25 leading Argentine wineries participate in international wine competitions, and organize wine tastings or cultural events to promote oenotourism. Most have their own websites (in English and Spanish), but few (9) use on-line selling techniques or social networks for marketing purposes. An exception is Luigi Bosca, which offers the possibility of "virtual tasting" and of chatting on line with the chief oenologist. A few avant-garde wineries (7) are also relying on sophisticated architectural design in their quest for distinctiveness. Five of them - namely Navarro Correas, Norton, Fournier, Salentein and Séptima - are designed by renowned Argentine architects Bormida and Yanzón. In particular, Séptima, with its construction inspired by an ancestral dry-stone wall system used by the native population, and Salentein, with its cross-shaped building inspired by ancient classical temples, have become points of reference among the most recent generation of Argentine wineries.

Overall, therefore, this survey reveals that the technological upgrading process of the Chilean and Argentine wine industries over the past two decades has been deep and impressive, if not surprising, considering that it took place in two developing countries. This confirms the hypothesis that the intense quality upgrading process and related export growth of Chilean and Argentine wines, described in the previous chapter, were made possible by the increased capability of local wineries to innovate, both radically and incrementally, as will be illustrated in more detail in the following section. ${ }^{103}$ In order to understand to what extent this process was embedded in the local environment and was conducive to development, it will be necessary first to analyze what sources of innovation drove it and how sustainable they are.

\footnotetext{
103 As observed in Chapter 3, the basic principles of modern winemaking are centuries old. However, since the 1970 s both viticulture and viniculture have been characterized by continuous incremental improvements and a set of important radical innovations. In viticulture, the latter are mainly related to vine clone selection, thanks to genetic engineering techniques, which have gradually replaced the old cross-breeding techniques. In viniculture, the introduction of a revolutionary automated equipment for controlling temperature has allowed not only the processing of wines in hot areas where it was unthinkable before, but also the determination of precise temperature variations in terms of time and degree, thereby raising the quality of the wines produced to levels that were impossible to attain before.
} 


\subsection{The triggering role of FDI}

The technological modernization process of the Chilean and Argentine wine industries was triggered by the protracted access of both countries to external sources of innovation, namely to massive international flows of knowledge, capital and technology, which took place in the late 1980 os in Chile and in the mid-1990s in Argentina. This allowed the Chilean and Argentine wine industries to undertake a deep transformation process - from isolated and protected industries, which had gradually "run out of ideas and sunk into mediocrity" (Veseth, 2010), into newly successful wine producers and exporters, that is, into major players in the current era of global wine. In 1988, Chile returned to democracy and started to take advantage of the neoliberal market reforms introduced by Pinochet, which had opened up its protected and isolated market. Argentina had returned to democracy earlier on, in 1983, but political and economic instability persisted until 1991, when a drastic trade liberalization and privatization process was introduced by the newly elected president Carlos Menem. Thereafter, a massive acquisition of foreign knowledge and technology took place, thanks to various transmission mechanisms of which FDI and the transfer of foreign technology embedded in imported machinery and equipment were amongst the most important.

In the case of the Chilean and Argentine wine industries, it is undeniable that the massive flows of FDI initially brought along financial resources, the knowledge of international good practices, human resources and the technological inputs needed to drag both countries closer to international quality standards and to international consumers' tastes in a surprisingly condensed time. In the Chilean wine industry, it is unanimously acknowledged that the triggering element of the technological revolution was a foreign investor, Miguel Torres, a Spanish winemaker from a traditional wine family in the Catalonia region. He moved to Chile in 1979, when the Chilean wine industry was undergoing a deep crisis and was actually very close to disappearing. A Chilean university fellow from Talca who had studied oenology with Torres in Dijon, Alejandro Parot, had convinced him that Chile was the ideal place for modern winemaking.

Notwithstanding the military dictatorship of General Augusto Pinochet and the consequent political isolation of Chile, Torres bought his 100-hectare vineyard in the Curicó Valley and brought with him the revolutionary production tools and techniques described in the previous chapter (i.e., stainless steel tanks instead of the traditional concrete vats, strict temperature control fermentation, small oak barrels instead of the big wooden casks), which were commonly used in Europe in those years but practically unknown in Chile. At first, his wines met stark resistance. His fresh and fruity wines were denigrated as "wine for girls", since they had lost the traditional taste of prematurely old tannins linked to uncontrolled oxidation characterizing most Chilean wines. Despite the initial scepticism, however, Torres did produce a powerful demonstration effect, based on the success he visibly achieved in the export markets. In recognition of the innovation and technological revolution introduced into Chile, and of the pioneering role he played in attracting a large number of foreign investors, Miguel 
Torres was awarded the "Bernardo O'Higgins" Grand Official distinction by the Chilean Government in 1997.

A few years after the return to democracy and the election of Patricio Alwyn in 1990, Torres's example was followed by several other foreign investors (see Figure 5.1), who intensified and sped up the learning-by-imitating process he had originated, drastically upgrading the quality of Chilean wine exports (Benavente, 2006). Encouraged by the high rates of export growth, but especially by the enactment of favourable investment promotion policies (the liberalization Decree on Foreign Investment), a notable number of foreign investors, such as Rothschild-Mouton Lafite, Grand Marnier and Robert Mondavi, made a massive amount of capital flows converge into the Chilean wine industry starting in the early 1990s. As shown above, out of the top 25 Chilean exporting wineries, 11 are owned by national investment groups, such as Claro, Larrain or CCU; 10 by national investors represented by traditional wine families - out of which 6 date back to the late nineteenth century, such as Errazuriz, Undurraga or Cousiño Macul; 4 are national financial investors; 3 are joint-ventures; and only 1 is fully owned by a foreign investor, the Spaniard Miguel Torres.

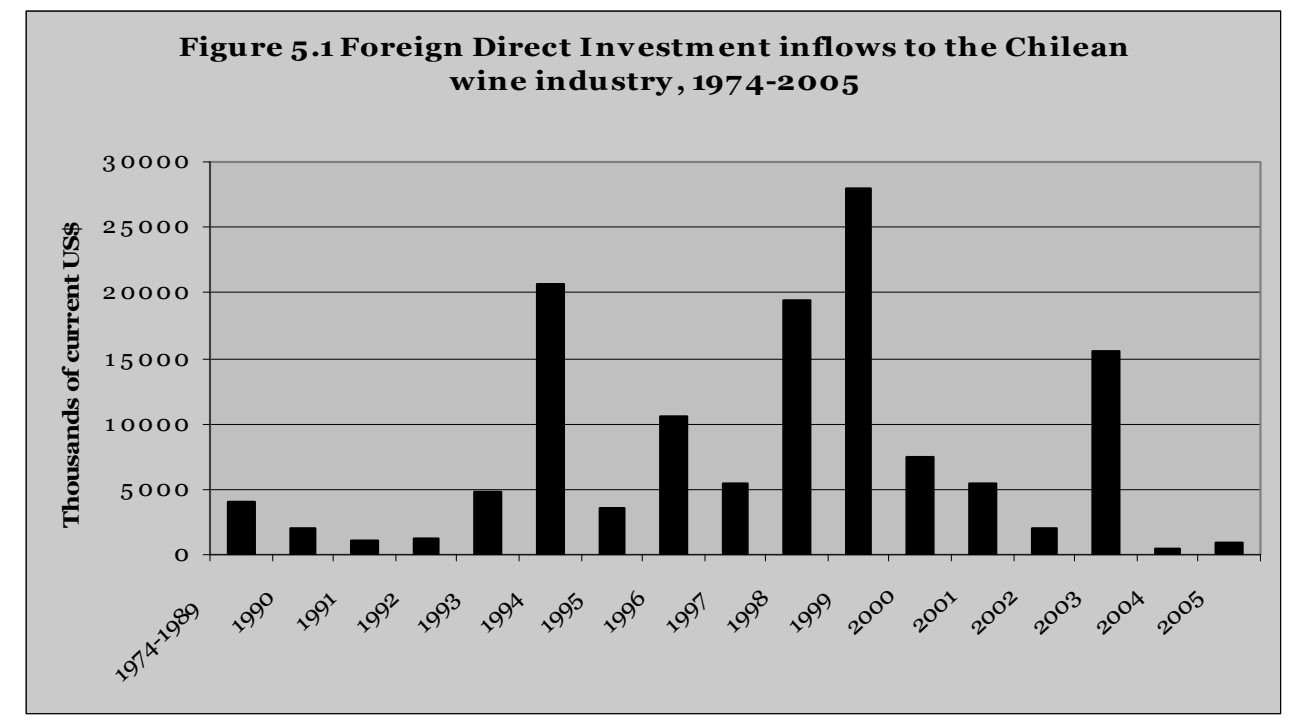

Source: Foreign Investment Committee, 2009

It can be argued, therefore, that both national and international investors have played a key role in leading the growth of Chilean wine exports. However, the latter also brought with them, in addition to the capital needed for massive improvement in technology, the knowledge of international markets and the most updated technical advice on international consumer tastes, mostly through foreign chief oenologists and "flying winemakers", as will be illustrated in more detail in the following sections. In fifteen years (1990-2005), Chile received 118.1 million US $\$$ foreign investment, including both green-field investment and joint-ventures (Foreign Investment Committee, 2009). These were mainly American, but also French and Canadian, and more recently also Spanish and Italian. From a development perspective, it is interesting to highlight that 
between 1990 and 2005 more than 52 million US\$ were invested in joint-ventures between Chilean and foreign wineries (see Table 5.6), with a peak between 1990 and 1998, when investment in joint ventures, especially French, reached 38 million US\$ (Visser and de Langen, 2006). During 1974-1989, investment through joint-ventures had amounted to 4 million US\$ only, representing just the beginning of a trend showing an increasing interest of foreign investors in Chile as a wine export platform but also in Chilean domestic wine companies as partners for strategic cooperation.

Table 5.6 Joint-ventures between foreign and Chilean wineries, 1988-2005

\begin{tabular}{|c|c|c|c|c|}
\hline Name & National company & Foreign company & $\begin{array}{c}\text { Country of } \\
\text { origin }\end{array}$ & Year \\
\hline Veramonte & Augustin Huneeus & Franciscan State Vineyards & USA & 1991 \\
\hline Caliterra & Vina Errazuriz & Mondavi Corporation & USA & 1996 \\
\hline Los Vascos & Vina Santa Rita & Château Rotschild-Lafite & France & 1988 \\
\hline Chateau los Boldos & Vina Amalia & G.E. Massenez & France & 1990 \\
\hline Casa Lapostolle & Familia Rabat & Marnier Lapostolle & France & 1994 \\
\hline De Larose & Granella Family & Chateau Larose Trintaudon & France & 1994 \\
\hline Selentia & Mayol Buchon & Bodegas y Bebidas & Spain & 1999 \\
\hline Almaviva & Concha y Toro & Baron Philippe de Rotschild- & France & 1997 \\
\hline William Fevre & Victor Pino & Soc. Vignoble William Fevre & France & 1991 \\
\hline Aquitania & Felipe de Solminhac & Bruno Prats, Paul Pontallier & France & 1990 \\
\hline Dallas Conté & Santa Carolina & Mildara Blass & Australia & 2000 \\
\hline Villard Estate & Santa Emiliana & Thierry Villard & France & 1989 \\
\hline Corpora-Boisset & Gracia y Porta & Boisset & France & 2002 \\
\hline William Cole & Gomez Soffia Family & William S.Cole & USA & 2001 \\
\hline Guelbenzu Jardin & Viñas Peralillo & Guelbenzu & Spain & 2002 \\
\hline Terravid & Viña Portal del Alto & Mata Romera & Spain & 2002 \\
\hline Santa Eliana & Jaime Izquierdo & Viñedos de Jalon & Spain & 2002 \\
\hline Conde de Aconcagua & Viñas Mercedes-Estampa & Gonzales Byass-Engel & Spain & 2002 \\
\hline Pirque/ Antinori & Haras de Pirque & Marchese Antinori & Italy & 2003 \\
\hline Altair & San Pedro & Château Dasseau & France & 2004 \\
\hline Erasmo & Caliboro & Marone-Cinzano family & Italy & 2005 \\
\hline Mapocho & Vina Canepa & BRL Hardy & USA & 2005 \\
\hline
\end{tabular}

Source: Author's elaboration from different sources (CEPAL, 2011; SAG, 2002; Chilevid, 2006; Central Bank Foreign Investments Committee: 2001)

Just to cite a few emblematic examples, Chateau Rothschild-Lafite created the Los Vascos winery in 1988, together with the Chilean family Eyzaguirre-Echenique from Vina Santa Rita; the French Marnier Lapostolle group arrived in Chile in 1988, and in 1994 created the joint-venture with the Chilean Rabat family called Casa Lapostolle, which now produces the icon wine Clos Apalta; Mondavi set up the Caliterra winery in 1996, together with the Chilean Vina Errazuriz; in 1997, the French Domain Barons Philippe de Rothschild created a joint-venture with the Chilean Guilisasti family, owner of Concha y Toro, which led to the production of Almaviva, one of the few Chilean icon wines and the only one to be sold en primeur; ${ }^{104}$ the joint-venture between Chateau Dassault and the Chilean winery San Pedro led to the creation of Altair in 2005.

\footnotetext{
104 Like in the futures market, wines sold en primeur are paid a certain year and delivered on release one or more years later. The en primeur market is especially and almost exclusively developed for Bordeaux wines, as it represents a profitable form of investment for those wines that are expected to have a higher price when they are released, compared to their en primeur prices. From the producers' perspective, this is also a very attractive sales strategy, as they don't have to wait until the wine is released to sell their production.
} 
The high value of the Chilean wines produced by joint-ventures and the analysis of the price trends over time have led some authors to argue that in the Chilean wine industry, the partnership between foreign and local companies is definitely a driver of high quality, value added and commercial value (Vergara, 2001; Mac Cawley and Contreras, 2006; Bustos, Torres and Willington, 2007). In particular, according to Bustos, Torres and Willington (2007), during the period 1998-2004 the average price per unit of exported wines was remarkably higher for Chilean joint-ventures than for foreign affiliates without a domestic partner, namely 4.9 US\$ per bottle versus 2.1 US\$ per bottle, against an overall average of 1.6 US $\$$ per bottle. Additionally, joint-ventures controlled between 23 and 30 percent of the market of super premium wines, against 917 percent of foreign affiliates.

From interviews, it emerged that in the Chilean wine industry joint-ventures were often considered a unique combination of local and international knowledge, and a precious learning opportunity for both local and international partners. In particular, most local partners saw in the joint-venture a vehicle for accelerating technological change and accessing international markets, while international partners chose the joint-venture form of investment to reduce the time and efforts needed to acquire the necessary knowledge of local soils, climates and vine-growing patterns. From a development perspective, such reciprocity points to the existence of a win-win situation, whereby the positive impact of FDI is maximized thanks to the creation of linkages and strategic partnerships with domestic producers and suppliers, originating technological spillover effects and learning opportunities. The choice of joint-ventures as the predominant mode of foreign investment, however, is very specific to the wine industry in Chile and cannot be considered the rule in the global wine industry, as the case of Argentina demonstrates. In Chile, during 1988-2004 more than 50 percent of the investments in the wine industry were done through joint-ventures. From interviews, it emerged that the reasons foreign investors clearly privileged joint-ventures above all other possible forms of investment in Chile are related to a mix of both industry-related factors and institutional advantages. These are the capability of Chilean firms to make a significant commitment; the perception of mutual benefit derived from continued cooperation; the generation of tangible synergies obtained by combining human and intangible resources, which would be undermined or diminished by more centralized control; and the political and economic stability, together with a solid regulatory framework and low corruption levels, characterizing the new image of Chile after the dark decades of the military dictatorship.

None of these positive factors were recurrently mentioned during field interviews with foreign investors in Argentina. Here, the presence of joint-ventures is quite exceptional, presumably due to the strong sense of uncertainty associated with the Argentine political, economic and regulatory framework. It is estimated that, during 1992-2004, only 14 percent of the investments in the wine industry were joint-ventures. The first ones actually started to operate quite recently, in 1998-2000. The best known example is that of Bodega Caro, a joint venture between Domaines Baron de Rotschild (Lafite) and the Catena family, established in 1998. In 2000, Italian winemakers Roberto Cipresso and Tiziano Sivieiro became associated to create the Achaval-Ferrer winery, producer of one of the most upscale Argentine Malbecs, which, as seen in the previous 
chapter, is sold on the market at more than 100 US\$. The limited number of jointventures represents a key element differentiating the Argentine from the Chilean wine industry, which otherwise show strong similarities in several other aspects. Together with the initial delay in the starting-up of the "wine revolution", this fact also contributes to explaining the lower speed of the planting conversion and the slower penetration of international markets which characterize the Argentine wine industry compared to the Chilean, as shown in Chapter 4.

In the Argentine wine industry, a deep restructuring and technology modernization process started only in 1992, well after the end of the military dictatorship of Alfonso Videla (1976-1981), as a consequence of the market liberalization process initiated in 1991, which reduced fears of hyperinflation, thanks to monetary reforms pegging the peso to the dollar. As in the case of Chile, a pioneering role in the "wine revolution" was played by a foreign investor, Chandon, who had moved to Argentina already in 1959, attracted by the good natural conditions and the size of the internal market. Since the early 1950s, the President of Moët \& Chandon, Count Robert Jean de Vogue, was convinced that in Latin America he would find the ideal conditions to produce sparkling wines in line with the Moët \& Chandon style. In 1957 he entrusted his technical advisor and chief oenologist, Renaud Poirier, to explore different countries and different areas in the continent, and to rent small plots of vineyards in the areas with the highest potential. In Argentina, Poirier considered several provinces, including Rio Negro, Salta and Mendoza, until, after the first pilot harvest, he decided that the first foreign affiliate of Moët \& Chandon outside France would be set up in Agrelo, in the South of Mendoza. Since then, Chandon has constantly expanded its production and consolidated its position as a leading producer and exporter of sparkling wines, including a visitor centre, certified under the ISO 9001 norm, receiving more than 20,000 tourists per year. More than three decades later, following the pioneering example of Chandon but only after the country had partially regained political and economic stability and defeated hyper-inflation, foreign investors discovered Argentina as a potential destination for foreign investment in the wine industry (Chudnovky et al., 1994).

From 1992 to 2008, an estimated 550 million US\$ was invested in the Argentine wine industry. Most FDI originated from the US, but also from France, Spain, the UK and, later on, Chile (see Table 5.7). Foreign investors introduced modern management techniques, planted new varieties and developed new production areas, bringing Argentine wines closer to international taste than they had ever been (Onofri, 2000). Interestingly, during those years a wide group of local winery owners sold their wineries to foreigners, fearing to be excluded as a consequence of the liberalization process. The phenomenon was so profound that in the 1990s only six of Argentina's large family wineries remained in the hands of the founding families. As observed earlier, of the top 25 Argentine exporting wineries, 17 are owned by foreign investors; one is an ItaloArgentine joint-venture; six are old family businesses, established at the beginning of the twentieth century; one is a more recent national investment (Susana Balbo). It should be noted, though, that the availability of fresh capital offered a second chance to several local winemakers and their descendants, who, after having sold their company to foreign investors, went back to winemaking with renewed culture and habits, setting up small but fully export-oriented "boutique" wineries. 
Table 5.7 Main foreign investment in the Argentine wine industry, 1992-2008

\begin{tabular}{|c|c|c|c|c|}
\hline$\overline{\text { Winery }}$ & Foreign Investor & Origin & $\begin{array}{l}\text { Total amount } \\
\text { (million US\$) }\end{array}$ & Year \\
\hline Santiago Graffigna & Allied Domecq & UK & 43 & 2004 \\
\hline Santa Ana & Donaldson, Luftkin y Jenrette & USA & 40 & 1999 \\
\hline Penaflor & Donaldson, Luftkin y Jenrette & USA & 40 & 1999 \\
\hline Trapiche & DLJ Merchant Banking & USA & 40 & 1998 \\
\hline Kendall Jackson & Kendall Jackson & USA & 30 & 1996 \\
\hline Finca La Celia & San Pedro & Chile & 30 & 1997 \\
\hline Covisan & $\mathrm{SCH}$ & Spain & 25 & 1995 \\
\hline Santa Ana & Santa Carolina & Chile & 25 & 1996 \\
\hline Maison Calve & Allied Domecq & UK & 22 & 1992 \\
\hline Bodegas Norte & Marqués Grignon & Spain & 22 & 1995 \\
\hline Trivento & Concha y Toro & Chile & $17 \cdot 5$ & $1996 / 2008$ \\
\hline Bodegas Norton & Gernot Swarovsky & Austria & 16 & 1992 \\
\hline Resero & Marubeni & Japan & 16 & 2000 \\
\hline Terrazas & Moët Chandon & France & 16 & 1999 \\
\hline Navarro Correas & CINBA & UK & 15 & 1996 \\
\hline Santa Maria & Bernard Taillan & France & 15 & 1998 \\
\hline Lopez & Exxel Group & USA & 15 & 2003 \\
\hline Viñas Argentinas & Marubeni Corp. & Japan & 14 & 2000 \\
\hline Salentein & Salentein & Holland & 14 & 1999 \\
\hline Bodegas Flichman & Sogrape Vinhos & Portugal & 15 & 1997 \\
\hline Doña Paula & Santa Rita & Chile & 10 & 1998 \\
\hline Bodegas Premier & Concha y Toro & Chile & 8 & 1996 \\
\hline O.Fournier & Fournier Family & Spain & 8 & 1999 \\
\hline Bodegas Balbi & The Hiram Walker & US & 7 & 1992 \\
\hline Bodegas Etchart & Pernod Ricard & France & 7 & 1992 \\
\hline Navarro Correas & Diageo & UK & 6 & 1997 \\
\hline Montalembert & Montalembert & France & 6 & 1995 \\
\hline Domain Vistalba & Domain Vistalba & France & 5 & 1992 \\
\hline Finca El Origen & Santa Carolina & Chile & 5 & $1998 / 2001$ \\
\hline Henri Piper & Extreme & France & 5 & 1998 \\
\hline Chateau Los Boldos & Sogrape & Portugal & 5 & 2008 \\
\hline Séptima & Codorniu & Spain & 2.5 & 1999 \\
\hline Martins Domingo & ARCO Bodegas Unidas & Spain & 2 & 1997 \\
\hline Universo Austral & Viñedos Corpora & Chile & 2 & 2008 \\
\hline Kaiken & Viña Montes & Chile & 0.4 & 2003 \\
\hline Tarapacà & Tamari & Chile & 0.25 & 2003 \\
\hline Total & & & 551.65 & \\
\hline
\end{tabular}

Source: Author's elaboration from different sources (CEPAL, 2001; SAG, 2002; Chilevid, 2003; Central Bank Foreign Investments Committee, 2009; SAGPyA, 2009; FLACSO, 2008)

It may be surprising to realize that Chilean foreign investments in the Argentine wine industry are second only to US investments. Chilean producers started to invest in Argentina in the mid-1990s, especially in Mendoza, just across the Andes, taking advantage of the geographical and cultural proximity with Santiago de Chile (van Tienhoven, 2008). ${ }^{105}$ The presence of Chilean investors is certainly a good sign for the Argentine wine industry, since Chilean wineries have invested there in order to diversify their wine export basket and to exploit the Argentine quality factors (see Table 5.8). The

\footnotetext{
105 For more than two centuries (1561-1776), both Santiago and Mendoza belonged to the Kingdom of Chile (Provincia de Cuyo de Reino de Chile). During that period, winemakers from both cities and surrounding areas formed the most important viticultural pole of Latin America, characterized by a regular transport system across the Andes, continuous exchanges of information, and simultaneous incorporation of new ideas and technological innovations into their wine production. This was sold jointly and often exported to other Latin American countries - mostly to Peru (Lacoste, 2008).
} 
wider range of varieties available in Argentina, especially Malbec, and the relatively easier access of Argentine wines to the higher priced wine segment were the key pull factors. Contrary to what is often claimed, Chilean investors give priority to Argentine wine characteristics, and have helped to position Argentine wines in international markets through their own established distribution and commercialization networks, especially in Asia and the United States. In this respect, it emerged from interviews that Chilean capital and know-how were key to teaching their Argentine neighbours how to penetrate international markets. Emblematically, Trivento has become the second largest Argentine wine exporter, while Finca la Celia was the first in Argentina to introduce quality management and certification. During an interview held in Buenos Aires, the director of the wine consulting firm Caucasia estimated that in 2010 more than 12 percent of Argentine exported bottled wine originated from Chilean investment, and that this figure could more than double to at least 25 percent during the next five years.

Table 5.8 Chilean FDI in the Argentine wine industry, 1992-20o8

\begin{tabular}{lllccc}
\hline National company & City & $\begin{array}{c}\text { Name of the } \\
\text { company }\end{array}$ & $\begin{array}{c}\text { Amount of } \\
\text { investment } \\
\text { (million US\$) }\end{array}$ & Extension & Year \\
\hline Concha y Toro & Mendoza & Trivento & 17.5 & 300 ha & $1996 / 2008$ \\
Santa Rita & Mendoza & Doña Paula & 10 & 730 ha & 1998 \\
San Pedro & Mendoza & Finca La Celia & 30 & 600 ha & 1997 \\
Santa Carolina & Mendoza & Santa Ana & 25 & 1,800 ha & 1996 \\
Tarapacà & Mendoza & Tamari & 0,25 & 120 ha & 2003 \\
Viña Montes & Mendoza & Kaiken & 0.40 & 80 ha & 2003 \\
Santa Carolina & Mendoza & El Origen & 5 & 300 ha & $1998 / 2001$ \\
Concha y Toro & Mendoza & Bodegas Premier & 1 & 250 ha & 1996 \\
Viñedos Corpora & Mendoza & Universo Austral & 2 & 150 ha & 2008 \\
\hline
\end{tabular}

Source: Author's elaboration from different sources (CEPAL, 2001; SAG, 2002; Chilevid, 2006; Central Bank Foreign Investments Committee: 2001)

\subsection{The role of capital-embodied and codified knowledge flows}

With the arrival of a large amount of foreign investment and fresh capital flows, the removal of the trade barriers that had sheltered the Chilean and Argentine wine industries from global influences, and the rising international demand for New World wines, the right incentives and conditions were present for domestic wineries to drastically improve the quality of their product, in order to meet the increasingly sophisticated demand of international consumers. In both countries, radical structural changes occurred in all aspects of wine-making, from production technologies to product development, bottling, distribution and commercialization techniques. As shown above, all 25 leading Chilean and Argentine exporting wineries adopted most modern winemaking technologies, including the use of stainless steel vats in place of large wood casks; the installation of refrigeration devices, both for fermentation and maturation; the use of pneumatic presses rather than old vertical ones; and the use of small oak barrels in place of the old large vats made of native beech. It, therefore, comes as no surprise that, according to Comtrade data, in the last three decades Chile and 
Argentina have been gigantic importers of machinery and equipment for winemaking from European leading producers (see Table 5.9).

Table 5.9 Imports of presses, crushers, and other machinery for winemaking in Chile and Argentina, 1988-2008

\begin{tabular}{lcc}
\hline & Chile & Argentina \\
\hline 1986 & $\$ 287,908$ & n.a \\
1987 & $\$ 546,938$ & n.a \\
$\mathbf{1 9 8 8}$ & $\mathbf{\$ 3 , 4 0 8 , 1 2 3}$ & n.a \\
1989 & $\$ 4,022,475$ & $\$ 248,565$ \\
1990 & $\$ 5,080,370$ & $\$ 784,822$ \\
1991 & $\$ 1,736,348$ & $\$ 496,302$ \\
$\mathbf{1 9 9 2}$ & $\$ 5,230,740$ & $\mathbf{2 , 0 9 0 , 3 8 0}$ \\
1993 & $\$ 4,250,406$ & $\$ 3,512,829$ \\
1994 & $\$ 3,408,294$ & $\$ 4,376,705$ \\
1995 & $\$ 3,182,857$ & $\$ 1,956,683$ \\
1996 & $\$ 4,559,024$ & $\$ 2,660,663$ \\
1997 & $\$ 8,438,233$ & $\$ 4,428,383$ \\
1998 & $\$ 5,767,716$ & $\$ 5,634,570$ \\
1999 & $\$ 5,722,333$ & $\$ 6,743,544$ \\
2000 & $\$ 6,164,867$ & $\$ 3,106,598$ \\
2001 & $\$ 2,166,226$ & $\$ 2,953,625$ \\
2002 & $\$ 2,406,589$ & $\$ 1,036,517$ \\
2003 & $\$ 6,163,404$ & $\$ 3,481,963$ \\
2004 & $\$ 4,383,744$ & $\$ 3,092,773$ \\
2005 & $\$ 4,232,099$ & $\$ 5,485,351$ \\
2006 & $\$ 3,540,261$ & $\$ 4,084,391$ \\
2007 & $\$ 3,704,517$ & $\$ 5,035,765$ \\
2008 & $\$ 5,723,738$ & $\$ 5,089,815$ \\
Total & $\$ 93,292,364$ & $\$ 66,300,244$ \\
\hline
\end{tabular}

Source: Comtrade, SITC Rev.2, 72191

In the case of Chile, a huge investment in machinery and modern cellar equipment (including presses, crushers and other machinery) at the enterprise level started to take place in 1988, the very same year dictatorship ended, and market reforms started to unleash their positive effects. This led to a deep technological conversion process and the overall upgrading of the local wine industry, with several wineries being transformed into state-of-the-art wineries, equipped with the most advanced machineries and technologies. From 1988 to 2008, Chile undertook an investment in foreign winemaking machinery of more than 93 million US\$, and for five consecutive years the country represented the largest importer of European winemaking equipment, to the point that it can be said without exaggeration that today the Chilean wine industry is one of the best equipped in the word. In the case of Argentina, the acquisition of foreign machinery for winemaking (as in Chile, imported from Europe, mainly France, Italy, Germany and Switzerland) took off a few years later, in 1992, after the liberalization decree entered in vigour. From 1992 to 2008, the total imports of Argentina in foreign machinery reached almost 67 million US $\$$ - a figure that, despite being remarkable in itself, ranks well below that of its Chilean neighbours in absolute terms, and even more so if one relates it to the higher amount of vine cultivated land over the same years. 
The regressions below, based on Comtrade data, show that there could be a direct correlation between the increase in the stock of capital equipment for winemaking, imported from abroad, and the growth of Chilean and Argentine wine exports (see Figures 5.2 and 5.3). However, they also point to the presence of a very different pace at which technological change spread out among domestic wineries and increased their export capacity.

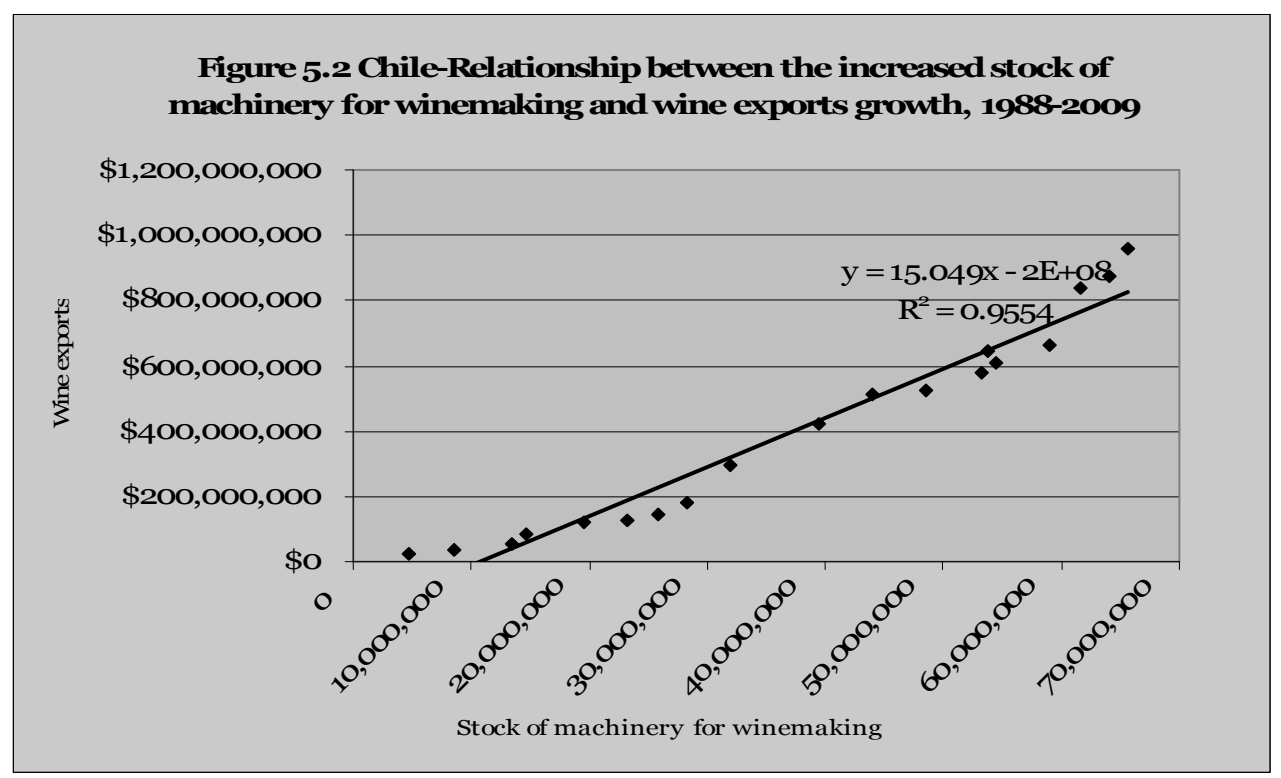

Source: Author's elaboration based on Comtrade data

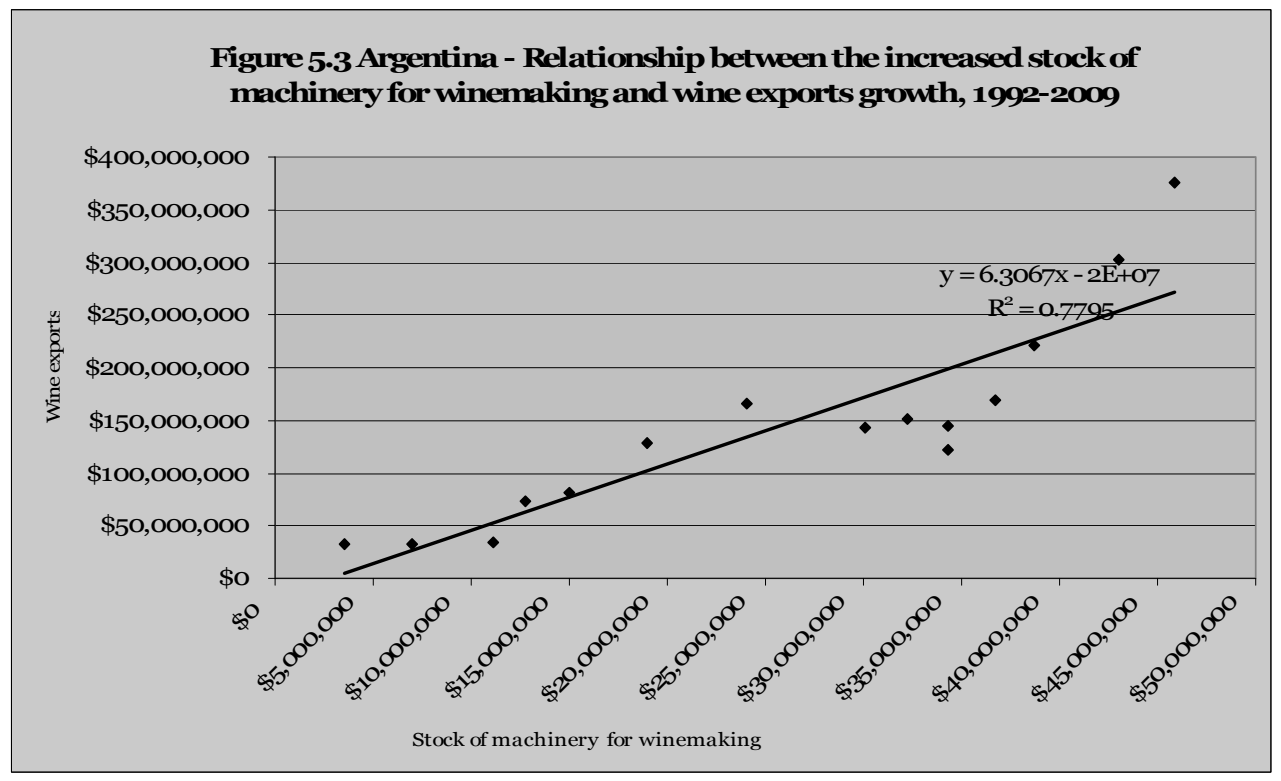

Source: Author's elaboration, based on Comtrade data 
Data on elasticity variations show that in Chile, from 1988-2009, a 1 percent increase in the amount of imported technology increased wine exports by 15 percent. In Argentina, from 1992-2009, a 1 percent increase in the amount of imported technology increased wine exports by 6.3 percent only. This can be explained by the fact that, beyond the most advanced segment of the leading exporting firms - which, as illustrated above, performed quite similarly in terms of innovative behaviours - the Argentine "sleeping giant" is awakening but at relatively slow pace compared to the more agile and fully export-oriented Chilean competitor. In other words, as The Economist put it a few years ago, "Argentina is catching up with Chile, but not as fast as it might” (The Economist, 2007b).

The slower speed of technological diffusion and export growth can be ascribed to both the stark economic fluctuations that have characterized the Argentine economy until quite recently (versus the Chilean economic and political stability), and to the mere fact that the industry structure and the size of the Chilean and Argentine wine industries are very different. Argentina presents not only double the area cultivated with wine grapes than Chile $(217,000$ hectares versus 114,000), but also almost half of the hectares per grower (8.3 versus 14), almost three times the total number of officially registered wineries (934 versus 360), and more than double the number of exporting wineries (257 versus 120). Only the degree of export concentration is very similar, with respectively 65 and 75 percent of exports originated by the group of the leading 25 exporting wineries. In both countries these wineries have been able to reach high international standards and a better consistency of the quality levels of their wines, thereby meeting international consumers' preferences and gaining increasing export shares in the international market.

The table below shows that, thanks to the incorporation of imported machinery and equipment, as well as sustained flows of knowledge and techniques brought by foreign investors, the majority of the leading Chilean and Argentine exporting wineries (14 out of 25 in both cases) have been certified not only under ISO and HACCP norms, but also under social and environmental standards (see Table 5.10). The most widespread quality certifications are ISO 9001 (quality management systems), ISO 14001 (environmental management systems), HACCP (Hazard Analysis Critical Control Points) and the British Retail Consortium, which is regarded as a global benchmark for best practices in the food industry. In addition, Argentine wineries are paying increasing attention to ISO 22000 (food safety management system), the most recent ISO standard aimed at ensuring that there are no weak links in the food supply chain. In both Chile and Argentina quality certification is playing an increasingly important role in improving the winemaking processes, and especially in stratifying different production segments (e.g., premium brands from lower quality brands) and setting up corresponding prices. This confirms the increasing importance of quality and safety standards, namely of non-price competition factors, in the consolidation of the entry strategy of "latecomers" in the global wine industry (Humphrey, 2003). It also shows that, in some cases, global quality standards may represent a useful external factor in triggering innovation, pushing local suppliers to ensure increased quality, integrity and reliability of their production, without necessarily undermining the capacity of developing countries to compete in the international market. 
Table 5.10 Quality certification of the top Chilean and Argentine exporters of bottled wines, 2010

\begin{tabular}{|c|c|c|c|c|}
\hline & \multicolumn{2}{|r|}{ Chile } & \multicolumn{2}{|r|}{ Argentina } \\
\hline & Winery & Quality certification & Winery & Quality certification \\
\hline 1 & $\begin{array}{l}\text { Concha y } \\
\text { Toro }\end{array}$ & $\begin{array}{ll}- & \text { British Retailer } \\
\text { Consortium }\left(5^{\text {th }} \text { edition) }\right. \\
\text { - } \quad \text { Organic Agricultural } \\
\text { Production (EU } \\
\text { certification) }\end{array}$ & Zuccardi & $\begin{array}{ll}- & \text { ISO } 9001 \\
- & \text { ISO } 14001 \\
- & \text { ISO } 22000\end{array}$ \\
\hline 2 & San Pedro & $\begin{array}{ll}- & \text { HACCP } \\
- & \text { British Retailer } \\
- & \text { Consortium ( } 5^{\text {th }} \text { edition) } \\
- & \text { ISO 9001 } \\
- & \text { ISO 14001 } \\
- & \text { OHSAS 18001 (audited by } \\
& \text { Bureau Veritas Quality } \\
& \text { International) }\end{array}$ & Trivento & $\begin{array}{ll}- & \text { ISO } 9001 \\
- & \text { ISO } 14001 \\
- & \text { ISO } 22000\end{array}$ \\
\hline 3 & Cono Sur & $\begin{array}{ll}- & \text { ISO } 9001 \\
- & \text { ISO } 14001 \\
- & \text { in process of obtaining ISO } \\
14064\end{array}$ & $\begin{array}{l}\text { Catena } \\
\text { Zapata }\end{array}$ & ISO 9001 \\
\hline 4 & Errazuriz & $\begin{array}{l}\text { - } \quad \text { British Retailer Consortium } \\
\left(5^{\text {th }} \text { edition }\right)\end{array}$ & Trapiche & $\begin{array}{ll}- & \text { British Retail Consortium } \\
- & \text { HACCP } \\
- & \text { GPM (Good Practice of } \\
& \text { Manufacture) }\end{array}$ \\
\hline 5 & Undurraga & $\begin{array}{ll}- & \text { ISO 9001 } \\
- & \text { HACCP (based on Codex } \\
- & \text { Alimentarium criteria) } \\
- & \text { British Retailer } \\
& \text { Consortium }\left(5^{\text {th }} \text { edition) }\right. \\
- & \text { in process of obtaining ISO } \\
& 14001\end{array}$ & Norton & $\begin{array}{ll}- & \text { ISO } 9001 \\
- & \text { ISO } 22000 \\
- & \text { ISO } 14001 \\
- & \text { HACCP } \\
- & \text { Water Quality Certification by } \\
& \text { the General Department of } \\
& \text { Irrigation }\end{array}$ \\
\hline 6 & Tarapaca & $\begin{array}{ll}- & \text { ISO 14001 } \\
- & \text { Organica (certified by IMO } \\
- & \text { Switzerland) } \\
\text { British Retailer } \\
& \text { Consortium (5 } 5^{\text {th }} \text { edition) }\end{array}$ & Terrrazas & ISO 9001 \\
\hline 7 & Emiliana & $\begin{array}{ll}- & \text { ISO 14001 } \\
\text { - } & \text { Carbon Neutral Certified } \\
\text { by the German company } \\
\text { TUV SUD } \\
\text { - } \quad \text { Social Responsibility } \\
\text { Certification by the Swiss } \\
\text { company IMO } \\
\text { Biodynamic certification } \\
\text { by German company } \\
\text { Demeter }\end{array}$ & Luigi Bosca & HACCP \\
\hline 8 & La Rosa & $\begin{array}{ll}- & \text { ISO 9001 } \\
- & \text { ISO 14001 } \\
- & \text { British Retailer } \\
- & \text { Consortium (5 } 5^{\text {th }} \text { edition) } \\
- & \begin{array}{l}\text { Organic Agricultural } \\
\text { Production (EU } \\
\text { certification) }\end{array}\end{array}$ & La Celia & $\begin{array}{ll}- & \text { ISO } 9001 \\
- & \text { ISO } 14001 \\
- & \text { OHSAS } 18001 \\
- & \text { ISO } 22000 \text { certified by Bureau } \\
& \text { Veritas International }\end{array}$ \\
\hline 9 & Ventisquero & $\begin{array}{ll}- & \text { ISO } 9001 \\
- & \text { ISO 14001 } \\
- & \text { HACCP } \\
- & \text { SGS Certificate for Food } \\
& \text { Safety (audited by Bureau } \\
& \text { Veritas Quality } \\
& \text { International) }\end{array}$ & $\begin{array}{l}\text { Dominio del } \\
\text { Plata }\end{array}$ & $\begin{array}{l}\text { - } \quad \text { ISO22000 certified by Bureau } \\
\text { Veritas Certification }\end{array}$ \\
\hline 10 & Miguel Torres & $\begin{array}{ll}\text { - } & \text { ISO 9001 (certified by } \\
\text { Bureau Veritas) } & \text { Organic production } \\
\text { - } \quad \text { (certified by IMO } \\
\text { Switzerland) } \\
\text { - } \quad \text { Social Responsibility }\end{array}$ & Salentein & ISO 14001 \\
\hline
\end{tabular}




\begin{tabular}{|c|c|c|c|c|c|c|}
\hline & & & $\begin{array}{l}\text { Certification by the Swiss } \\
\text { company IMO }\end{array}$ & & & \\
\hline 11 & $\begin{array}{l}\text { Luis Felipe } \\
\text { Edwards }\end{array}$ & - & ISO 14001 & $\begin{array}{l}\text { Nieto } \\
\text { Senetiner }\end{array}$ & - & $\begin{array}{l}\text { first Argentine winery certified } \\
\text { in with ISO } 9001\end{array}$ \\
\hline 12 & $\begin{array}{l}\text { Cousiño } \\
\text { Macul }\end{array}$ & - & ISO 14001 & Chandon & $\begin{array}{l}- \\
- \\
-\end{array}$ & $\begin{array}{l}\text { ISO } 9001 \\
\text { ISO } 22000 \\
\text { HACCP }\end{array}$ \\
\hline 13 & Santa Ema & - & $\begin{array}{l}\text { ISO } 9001 \\
\text { ISO } 14001\end{array}$ & Alta Vista & $\begin{array}{l}- \\
-\end{array}$ & $\begin{array}{l}\text { HACCP } \\
\text { ISO } 9001\end{array}$ \\
\hline 14 & Casa Silva & - & ISO 9001 & $\begin{array}{l}\text { Augusto } \\
\text { Pulenta }\end{array}$ & - & HACCP in progress \\
\hline
\end{tabular}

Source: Author's survey

\subsection{The importance of tacit knowledge flows}

This section examines the role of tacit knowledge flows as a way of learning and decodifying imported knowledge, and looks at the emergence of domestic abilities of learning, innovating and adapting foreign technologies and know-how to local conditions. It argues that, in Chile and Argentina, the "embeddedness" of the production of high-quality wines for exports and the creation of endogenous tacit knowledge and wine-related $\mathrm{R} \& \mathrm{D}$ were key to sustaining export growth for more than two decades and to obtaining deeper benefits from it. At the very initial stages, in order to "decode" the knowledge embodied in capital and intermediate goods, both Chilean and Argentine wineries relied on international oenologists, who were regularly consulting for foreign-owned wineries on a semi-permanent basis. Given the complex knowledge base of the wine industry, and the increasing codification of knowledge in scientific publications, manuals, software and digital equipment, a "knowledge conversion process" was needed in order to make it accessible to local actors and to bring the Chilean and Argentine wine industries closer to international quality standards.

Still today, international oenologists are key in transferring frontier techniques on grape growing and winemaking, and in bringing to Chile and Argentina a dynamic, periodical flow of new information. However, these are mostly "flying winemakers", namely consultants who regularly go to Chile and Argentina only for the harvest, on a counter-seasonal basis. Local oenologists, in fact, are now producing a considerable amount local tacit knowledge as a basis for the diffusion of innovation and for the use of foreign knowledge in the local context. The present survey of the leading Chilean and Argentine wine exporters reveal that in both countries, wineries have started to look for national rather than international short-term consultants in order to secure the quality of the harvest and source specific technical knowledge. It also reveals that in order to recruit permanent staff, they are increasingly looking to highly qualified national rather than international chief oenologists, and to a large pool of highly skilled agronomists with advanced university degrees.

In particular, in the case of Chile the transmission belt of intangible knowledge flows were initially a group of foreign consultants who established themselves in Chile for long periods to work as chief oenologists (see Table 5.11). Some of them, such as the Spanish chief oenologist of Torres, have played a key role in showing how Chilean wine 
could meet the requirements of international demand and are still in place today. Others were hired by supermarkets and distribution chains (especially from the UK) to help adapt Chilean wines to international characteristics. The development of internationally recognized icon wines is still triggered by international oenologists, but of a different kind. Rather than permanent oenologists or consultants hired by buyers to tailor wines to their home market, these are rather flying winemakers - many French, as the famous Michel Rolland, but also Australians, Germans and Americans - who are hired by Chilean wineries and travel to Chile only once a year, during the harvesting season.

Table 5.11 Flying winemakers hired by the top 25 Chilean exporters of bottled wines

\begin{tabular}{|c|c|c|c|}
\hline & Winery & Type of investment & $\begin{array}{l}\text { International consultants } \\
\text { ("Flying winemakers") }\end{array}$ \\
\hline \multirow{2}{*}{$\begin{array}{l}1 \\
2\end{array}$} & Concha y Toro & National investment & Jacques Boissenot (FR) and Goetz von Gersdorff (DE) \\
\hline & San Pedro & National investment & Paul Hobbes (US) for reserve line \\
\hline \multirow{2}{*}{$\begin{array}{l}3 \\
4\end{array}$} & Santa Rita & National investment & Christian Le Sommer (FR) \\
\hline & Cono Sur & National investment & Martin Prieur (FR) \\
\hline \multirow{2}{*}{$\begin{array}{l}5 \\
6\end{array}$} & Errazuriz & Old family business & Edward Flaherty, US \\
\hline & Undurraga & Old family business & - \\
\hline \multirow{2}{*}{$\begin{array}{l}7 \\
8\end{array}$} & Montes & National investment & - \\
\hline & Santa Carolina & National investment & Christian Wylie and Sven Bruchfeld (AUS) \\
\hline & Santa Helena & National investment & Pascal Chatonnet (FR) \\
\hline & Tarapacà & National investment & - \\
\hline & Carmen & National investment & Christian Le Sommer (FR) \\
\hline & Santa Emiliana & National investment & - \\
\hline & La Rosa & Old family business & - \\
\hline & Ventisquero & National investment & John Duvall (AUS) for Syrah \\
\hline & Los Vascos & Joint-venture & Christian Le Sommer (FR) \\
\hline & Valdivieso & Old family business & - \\
\hline \multirow{2}{*}{$\begin{array}{l}17 \\
18\end{array}$} & Casa Lapostolle & Joint-venture & Michel Rolland (FR) \\
\hline & Miguel Torres & Foreign investment (SP) & - \\
\hline \multirow{2}{*}{$\begin{array}{l}19 \\
20\end{array}$} & Canepa & Family business & Ian Mackenzie and David Morrison (AUS) \\
\hline & Felipe Edwards & Family business & Mike Farmilo and Brian Light (AUS) \\
\hline 21 & Bisquertt & Family business & - \\
\hline 22 & Cousiño Macul & Old family business & Matias Rivera (US) \\
\hline \multirow{2}{*}{$\begin{array}{l}23 \\
24\end{array}$} & Santa Ema & Old family business & Goetz Von Gersdorff (DE) \\
\hline & Casa Silva & Family business & - \\
\hline 25 & Almaviva & Joint-venture & - \\
\hline
\end{tabular}

Source: Author's survey

From the point of view of human resources, therefore, both Chilean and international oenologists and agronomists have actively contributed to the technological revolutions that have shaped the wine industry in Chile more quickly and more extensively than in 
any other developing country, New World producer. The first technological revolution, strictly related to winemaking processes and the import of foreign machinery, took place in the 1980 s and early 1990 s and was triggered by foreign investors, such as Miguel Torres, foreign oenologists (mainly French) and a small group of "old" Chilean oenologists, such as Prof. Alejandro Hernandez, ${ }^{106}$ who then became renowned university professors in Chilean universities. The second technological revolution started in the mid-1990s, and was driven by seasonal foreign consultants (from both the Northern and the Southern hemisphere), as well as by a much broader group of young Chilean oenologists and agronomists. It mainly consisted in the diffusion of tacit knowledge in viticulture, made necessary by modern cultivation techniques, such as limiting yields and excessive irrigation, and in the identification of the distinctive character of Chilean wines, including that of its typical variety, Carmenère. This new generation of young, highly qualified oenologists, including several women with extensive experience abroad and well reputed university degrees (in Chile they have to graduate first as agricultural engineers, so they are usually doubly qualified), has rapidly taken over technical and commercial tasks, as well as full decision-making responsibilities in both foreign and nationally owned wineries.

Currently, 18 out of the 25 top Chilean exporting wineries employ Chilean rather than foreign oenologists as chief winemakers, with top academic credentials and a broad working experience abroad, and at least one, but usually more, highly skilled agronomists with a university degree. For example, in the case of Concha y Toro, the Chilean oenologist Marcelo Papa joined the company in 1998 and was very quickly promoted to Chief Winemaker of the Puente Alto cellar. In 2002, he became Chief Winemaker of the Maycas del Limarí winery, in line with a sustained tradition of mobility and rotation of oenologists among top Chilean wineries. Max Weinlaub - who holds an oenology degree from the Universidad Mayor in Chile and has working experience in Oregon and California (Crema Winery in Santa Rosa and Franciscan Estates in Oakville) - joined Concha y Toro in 2000, where he worked for seven years as Marcelo Papa's right hand, making the highly successful global brand Casillero del Diablo. He is now chief winemaker of Viña Maipo and Viña Canepa. Ignacio Recabarren, a pioneer of the Chilean wine industry, has worked in California (Tyland Vineyard, Mendocino County), France (Chateau Mocallaux, Chateau Margaux, Chateau Lafite) and New Zealand (Morton Estate, Matua and Cloudy Bay). He is currently responsible for three of Concha y Toro's top wines, namely Carmin de Peumo, Amelia and Terrunyo. Amelia was the first Casablanca Chardonnay to receive a Wine Spectator 90-point rating, while the Carmin de Peumo Carmenère is the highest rated Carmenère in the country (see Table 5.12).

\footnotetext{
106 The Chilean winemaker and oenologist Prof. Alejandro Hernàndez was the first non-European to hold the position of Director General of the International Organization of Vine and Wine (OIV), a Paris-based organization created in 1924 for the purpose of connecting all actors who were active in the international winemaking scenario and of sharing scientific best practices and technical learning. Since 2001, both Chile and Argentina have become respected members of OIV, and are particularly active in organizing regional activities in Latin America. Twelve annual congresses on Viticulture and Oenology have been organized in Latin America, under the auspices of OIV. At the conferences, OIV provides participants (mostly scientists, oenologists and professionals) with information on the scientific work carried out by OIV experts during the annual meetings, as well as with documentation related to the most relevant discoveries and innovations worldwide in the areas of viticulture and viniculture.
} 
Table 5.12 Chief winemakers, oenologists, agronomists and national consultants hired by the top 25 Chilean exporters of bottled wines

\begin{tabular}{|c|c|c|c|c|c|}
\hline & Winery & $\begin{array}{c}\text { Chief } \\
\text { winemaker/s }\end{array}$ & Nationality & $\begin{array}{c}\text { National } \\
\text { oenologists } \\
\text { and } \\
\text { agronomists } \\
\text { with university } \\
\text { degree }\end{array}$ & $\begin{array}{c}\text { National } \\
\text { consultants }\end{array}$ \\
\hline 1 & Concha y Toro & $\begin{array}{l}\text { Carlos Halaby } \\
\text { Ridady and } \\
\text { Enrique Tirado }\end{array}$ & Chilean & 25 & $\begin{array}{l}\text { Ignacio Recabarren } \\
\text { for Carmin de Peumo } \\
\text { and Marcelo Papa for } \\
\text { Puente Alto }\end{array}$ \\
\hline 2 & San Pedro & Marco Puyo & Chilean & 3 & - \\
\hline 3 & Santa Rita & $\begin{array}{l}\text { Andrès Ilabaca } \\
\text { and Cecilia Torres }\end{array}$ & Chilean & 2 & - \\
\hline 4 & Cono Sur & Adolfo Hurtado & Chilean & 4 & - \\
\hline 5 & Errazuriz & Francisco Santiago & Chilean & 2 & - \\
\hline 6 & Undurraga & $\begin{array}{l}\text { Hernando } \\
\text { Amenabar }\end{array}$ & Chilean & 2 & $\begin{array}{l}\text { Alvaro Espinoza for } \\
\text { organic wines }\end{array}$ \\
\hline 7 & Montes & Aurelio Montes & Chilean & 1 & - \\
\hline 8 & Santa Carolina & Consuelo Marin & Chilean & 4 & - \\
\hline 9 & Santa Helena & Matias Rivera & Chilean & 2 & - \\
\hline 10 & Tarapaca & Edward Flaherty & Foreign (US) & 2 & - \\
\hline 11 & Carmen & Stefano Gandolini & Chilean & 2 & - \\
\hline 12 & Emiliana & $\begin{array}{l}\text { Alvaro Espinoza } \\
\text { and César Navia }\end{array}$ & Chilean & 5 & - \\
\hline 13 & La Rosa & José Cancino & Chilean & 2 & - \\
\hline 14 & Ventisquero & Felipe Tosso & Chilean & 1 & - \\
\hline 15 & Los Vascos & Claudio Naranjo & Chilean & 1 & - \\
\hline 16 & Valdivieso & Brett Jackson & Foreign (NZ) & 2 & - \\
\hline 17 & Casa Lapostolle & Jaques Begarie & Foreign (FR) & 1 & - \\
\hline 18 & Miguel Torres & Félix Sabat & Foreign (SP) & 2 & - \\
\hline 19 & Canepa & Max Winelaub & Chilean & 3 & - \\
\hline 20 & L.F. Edwards & Nicolas Bizzarri & Foreign (AUS) & 3 & - \\
\hline 21 & Bisquertt & Joana Pereira & Chilean & 2 & $\begin{array}{l}\text { Felipe de Solminihac } \\
\text { (technology advisor) } \\
\text { and Pedro Parra } \\
\text { (terroir specialist) }\end{array}$ \\
\hline 22 & Cousiño Macul & Pascal Marty & Foreign (FR) & 2 & - \\
\hline 23 & Santa Ema & Andrès Sanhueza & Chilean & 2 & $\begin{array}{l}\text { Irene Paiva for export } \\
\text { blendings }\end{array}$ \\
\hline 24 & Casa Silva & Mario Geisse & Chilean & 2 & - \\
\hline 25 & Almaviva & $\begin{array}{l}\text { Enrique Tirado, } \\
\text { Patrick Leon and } \\
\text { Michel Friou }\end{array}$ & $\begin{array}{l}\text { Chillean and } \\
\text { Foreign (FR) }\end{array}$ & 2 & - \\
\hline
\end{tabular}

Source: Author's survey 
The present survey also reveals the emergence of a local group of well recognized national consultants, that travels abroad regularly to provide specialized expertise or to participate in harvests on a counter-seasonal basis - mainly in France, Australia and the United States. For example, Adolfo Hurtado, the Chilean chief winemaker of Cono Sur since 1997, is the most passionate proponent of organic viticulture in Chile, and has been a long-time leading consultant in Chile and abroad on environmentally friendly production techniques. Another Chilean oenologist, Alvaro Espinoza, chief winemaker of Emiliana, is unanimously considered the father and one of the most competent national and international specialists of biodynamic wines. Felipe de Solminihac holds a degree in Oenology from the Catholic University of Chile and a specialization degree from the University of Bordeaux. He is the founder of the Aquitania winery and has working experience in France, Spain, New Zealand, Australia, China and South Africa. Furthermore, he is the President of the Chilean Association of Oeno-agronomists, the Director of the Chilean Wine Corporation, and one of the most respected national consultants and academics in the field of vine sciences.

In Chile, three universities offer a specialization in Oenology: the Catholic University of Chile, the University of Chile, both located in Santiago, and the University of Talca. All Chilean oenologists are also agronomists, a peculiarity of the Chilean education system which guarantees a particularly solid preparation of local oenologists. The profession of agricultural engineer has incorporated the specialization in Oenology since 1950. The National Association of Engineers-Oenologists was created in 1953. In the 1990s, 321 oenologists graduated in Chile, compared to 177 in the 1970 , and 50 in the 1980 s. Therefore, it can be estimated that more than 600 highly qualified professionals are currently operating in Chile. All Chilean Faculties of Oenology are part of international networks and alliances that allow recently graduated agricultural engineers to undertake post-graduate studies abroad, particularly in France (Montpellier and Bordeaux).

Based on the above, it may be less surprising to realize that at the origin of superpremium Chilean brands (>95 points Wine Spectator) there are joint-ventures or national investment, rather than foreign investment alone, which are very often led by Chilean oenologists. It is also easier to understand why, based on the presence and availability of such highly skilled professionals, all 25 Chilean wineries interviewed commented that they regularly introduce incremental innovations based on in-house R\&D efforts, aimed at continuously improving and adapting current habits and practices. Many also added that it would not have been possible to introduce such large amounts of foreign technologies as they did in the last twenty years without the presence of highly qualified local professionals who were aware of the existence of frontier technologies and could quickly learn their functioning modalities when these were finally imported. In this sense, the "technology capture" tours organized and financed by the Chilean government to stimulate "learning by looking" and "learning by interacting" processes have been key to empowering Chilean oenologists, and to stimulating their own innovation capabilities in the area - not only of winemaking, but also of marketing and vine growing (see Table 5.13). 
Table 5.13 Main incremental innovations introduced by the top 25 Chilean exporters of bottled wines during the last five years, based on in-house $R \& D$

\begin{tabular}{|c|c|c|c|}
\hline & Winery & Main innovation & Area \\
\hline 1 & Concha y Toro & $\begin{array}{l}\text { Entered New York stock Exchange in 1994; efficiency in the supply } \\
\text { chain (use of code bars for barrels) }\end{array}$ & $\begin{array}{l}\text { Organization } \\
\text { \& Marketing }\end{array}$ \\
\hline 2 & San Pedro & $\begin{array}{l}\text { Creation of a very sophisticated and well equipped laboratory; } \\
\text { Agricultural Management System }\end{array}$ & Viniculture \\
\hline 3 & Santa Rita & Improved clone materials and small-lot vinification & Viticulture \\
\hline 4 & Cono Sur & Search and selection of best terroir for Pinot Noir & Viticulture \\
\hline 5 & Errazuriz & $\begin{array}{l}\text { Promotion of Berlin wine tasting in 2004; creation of Seña brand } \\
\text { (joint-venture with Robert Mondavi Winery) }\end{array}$ & $\begin{array}{l}\text { Organization } \\
\text { \& Marketing }\end{array}$ \\
\hline 6 & Undurraga & $\begin{array}{l}\text { Use of Handling Programme for Precision Viticulture in collaboration } \\
\text { with INIA (National Institute for Agricultural Research) }\end{array}$ & Viticulture \\
\hline 7 & Montes & Use of native yeasts & Viticulture \\
\hline 8 & Santa Carolina & Creative packaging targeting the US market & $\begin{array}{l}\text { Organization } \\
\text { \& Marketing }\end{array}$ \\
\hline 9 & Santa Helena & $\begin{array}{l}\text { Incorporation of Precision Viticulture for new plantations; use of } \\
\text { massal and clonal selections }\end{array}$ & Viticulture \\
\hline 10 & Tarapaca & Creation of new "terroir" brands & $\begin{array}{l}\text { Organization } \\
\text { \& Marketing }\end{array}$ \\
\hline 11 & Carmen & Use of Pera press (cold maceration before pressing) & Viniculture \\
\hline 12 & Emiliana & Cultivation of biodynamic grapes & Viticulture \\
\hline 13 & La Rosa & Selection and planting of new grape varieties & Viticulture \\
\hline 14 & Ventisquero & $\begin{array}{l}\text { Precision farming techniques; preservation of native flora and soil } \\
\text { conservation }\end{array}$ & Viticulture \\
\hline 15 & Los Vascos & Separate vats for each plot in small premium cuvees & Viniculture \\
\hline 16 & Valdivieso & $\begin{array}{l}\text { French oeno-concept unit for dynamic cold stabilization, only one in } \\
\text { South America }\end{array}$ & Viniculture \\
\hline 17 & Casa Lapostolle & $\begin{array}{l}\text { Use of small French wooden vats for fermentation, corresponding to } \\
\text { small terroir plots }\end{array}$ & Viniculture \\
\hline 18 & Miguel Torres & Exhaustive studies of soil & Viticulture \\
\hline 19 & Canepa & Implementation of sustainability strategy in the vineyards & Viticulture \\
\hline 20 & $\begin{array}{l}\text { Luis Felipe } \\
\text { Edwards }\end{array}$ & $\begin{array}{l}\text { Experimentation of low-yield bush vineyards for Carmenère, } \\
\text { Grenache and Mouvedre }\end{array}$ & Viticulture \\
\hline 21 & Bisquertt & $\begin{array}{l}\text { Use of Handling Programme for Precision Viticulture; study of soil } \\
\text { granulometrics in subsoil profiles; creation of vinifera garden; } \\
\text { determination of terroir maps for differentiated harvesting }\end{array}$ & Viticulture \\
\hline 22 & Cousiño Macul & $\begin{array}{l}\text { Massal selections carried out at own nurseries over a period of } 10 \\
\text { years }\end{array}$ & Viticulture \\
\hline 23 & Santa Ema & Search for parcels to produce finest Carmenères (Peumo) & Viticulture \\
\hline 24 & Casa Silva & $\begin{array}{l}\text { Special marketing intelligence efforts to sell wines to serve in First } \\
\text { and Business Class of international airlines }\end{array}$ & $\begin{array}{l}\text { Organization } \\
\text { \& Marketing }\end{array}$ \\
\hline 25 & Almaviva & Revolutionary, underground drip irrigation system & Viticulture \\
\hline
\end{tabular}

Source: Author's survey 
As in the case of Chile, Argentina foreign winemakers have played a very important role in the systematic "decodification" of the knowledge transferred from abroad through the massive imports of capital and intermediate goods. They have also shown that high-quality wines could be produced in the country and be recognized by international consumers as such. In the past, only Chandon, the foreign investor who played a pioneering role, brought to Chile its own French oenologists and kept them in place for several decades. In most other cases, foreign consultants were called upon only at the beginning of the technological conversion process in order to assess the technological level of the winery equipment and related procedures, and to obtain advice on the changes to be introduced. Afterwards, they maintained an on-going relationship with the wineries but only on an counter-seasonal or occasional, problemsolving basis. Presently, as in the Chilean case, the majority of the leading Argentine exporters of bottled wines (16 out of 25) rely on "flying winemakers" (see Table 5.14).

Table 5.14 Flying winemakers hired by the top 25 Argentine exporters of bottled wines

\begin{tabular}{|c|c|c|c|}
\hline & Winery & Type of investment & $\begin{array}{l}\text { International consultants } \\
\text { ("Flying winemakers") }\end{array}$ \\
\hline \multirow{2}{*}{1} & Zuccardi & Old family business & Enrique Tirado (CL) \\
\hline & Tivento & Foreign investment & Alberto Antonini (IT) \\
\hline \multirow{2}{*}{$\begin{array}{l}3 \\
4\end{array}$} & Catena Zapata & Old family business & Paul Hobbes (US) \\
\hline & Trapiche & Foreign investment & Michel Rolland (FR) \\
\hline \multirow{2}{*}{$\begin{array}{l}5 \\
6\end{array}$} & Norton & Foreign investment & - \\
\hline & Finca Flichman & Foreign investment & Michel Rolland (FR) \\
\hline \multirow{2}{*}{$\begin{array}{l}7 \\
8\end{array}$} & Navarro Correas & Foreign investment & Jeffrey Strambot (US) \\
\hline & Pascual Toso & Old family business & Paul Hobbes (US) \\
\hline & Terrrazas & Foreign investment & Nicolas Aubert (FR) \\
\hline & Luigi Bosca & Old family business & - \\
\hline 11 & Escorihuela Gascon & Foreign investment & - \\
\hline 12 & La Celia & Foreign investment & Paul Hobbes (US) \\
\hline 13 & Dominio del Plata & National investment & - \\
\hline 14 & Septima & Foreign investment & - \\
\hline \multirow{2}{*}{$\begin{array}{l}15 \\
16\end{array}$} & Fournier & Foreign investment & - \\
\hline & Lurton & Foreign investment & Olivier Ruhard (FR) \\
\hline \multirow{2}{*}{$\begin{array}{l}17 \\
18\end{array}$} & Salentein & Foreign investment & Michel Rolland (FR) \\
\hline & Doña Paula & Foreign investment & Andrés Ilabaca (CL) \\
\hline \multirow{2}{*}{$\begin{array}{l}19 \\
20\end{array}$} & Nieto Senetiner & Foreign investment & Alberto Antonini (IT) \\
\hline & Chandon & Foreign investment & - \\
\hline 21 & Alta Vista & Foreign investment & - \\
\hline 22 & Alto Las Hormigas & Foreign investment & Alberto Antonini (IT) \\
\hline 23 & Valentin Bianchi & Old family business & Robert Pepi (US) \\
\hline 24 & Augusto Pulenta & Old family business & - \\
\hline 25 & Achaval Ferrer & Joint-venture & Roberto Cipresso (IT) \\
\hline
\end{tabular}

Source: Author's survey 
Nowadays flying winemakers are mostly called upon to broaden the knowledge of international consumption styles, fashions and trends, and to meet the requirements of new markets. It is striking to note that three of the most renowned foreign consultants, namely the French winemaker Michel Rolland, the Italian winemaker Alberto Antonini and the US winemaker Paul Hobbes, have been advising several Argentine wineries at the time, thereby laying the ground for a certain "repetitiveness" of styles that has often been criticized by the specialized literature (Nossiter, 2009), and which is not so pronounced in Chile, where the choice of foreign consultants is more diversified.

Another major factor differentiating Argentina and Chile is the presence in Argentina of a large number of "old family businesses", namely, as illustrated in the previous chapter, of traditional wineries founded at end of the nineteenth century by Italian and Spanish immigrants, who were passionate winemakers and who transmitted their passion for winemaking to their direct descendants. In several cases, despite the decision to sell part of the company to foreign shareholders, the family remained in charge of the winery and personally brought to completion its renovation and modernization process. Nicolas Catena, Alberto Zuccardi, Leoncio Arizu and Valentin Bianchi are all winemakers of the same generation, who led the diffusion and adaptation of radical innovations in Argentine wine production routines. Despite the large presence of flying winemakers, equivalent to that of Chile, this may explain the more pronounced character and "distinctive" personality of Argentine compared to Chilean wines, and the fact that they have been much less accused than their neighbours across the Andes of having adopted a uniform, homogenized international style, without paying enough attention to local uniqueness factors.

It is important to note that, in contrast to Chile, the real driver of the wine revolution in Argentina was a national winemaker - Nicolas Catena, owner of the Catena Zapata winery. When Catena took over the family winery from his father in 1982, he immediately sold the table wine part of the business and kept only the higher quality, bottled wine part, meeting with the scepticism of all his peers. Catena was the first to believe in the potential of Mendoza's poorest soils near the Andes, which immigrants had initially discarded due to their scarce fertility. As he suspected, those soils were actually ideal for high-quality viniculture, and also ideal for the cultivation of Malbec, which was thought would never ripen at high altitudes. As already seen in the previous chapter, Catena was also the first to believe in the potential of Malbec. As there was no tradition of clonal selection in Argentina, in order to improve local plants, he imported new clones from Cahors in France, with disappointing results. So, he decided to develop his own clonal selection of Argentine Malbecs. He planted 145 clones and selected the best 5 , then planted those 5 at different altitudes and in different terroirs. In 2003, he identified the best terroir for Argentine Malbecs. Recently, with his daughter Laura, he invented the revolutionary concept of "single varietal, microclimate blending", which seeks to combine the different advantages of various microclimates in Mendoza, by vinifying plots of the same grape variety, situated at different altitudes separately and blending them just prior to bottling based on their specific characteristics.

The case of Catena is not unique. For example, José Alberto Zuccardi, son of an Italian engineer from Avellino, took over the largest family-owned winery in Argentina from 
his father in 1976. Always at the forefront of winemaking innovations, he was the first to bring back to Argentina the rights for the most modern forms of irrigation introduced in California. Zuccardi always believed that good wine was made in the vineyard, even when this thinking was still very new to Argentina. Since he had always considered irrigation strategic for the quality management of the vineyards, he invested heavily to equip his vineyards with the most updated irrigation technologies, and his irrigation system was a fundamental contribution to agricultural modernization of viticulture in Mendoza. Zuccardi, though, continued to produce only for the domestic market until 1991, namely until having built an ultra-modern winery in 1998, which allowed him to reach the quality standards of export markets. In 1999, he produced the first ultrapremium wine in Argentina (Zuccardi Q Malbec), as well as the first premium wine made of a non-traditional grape variety (Zuccardi Q Tempranillo). The "old" generation of winemakers belonging to the best known family, however, is not the only important local actor generating endogenous innovation in the Argentine wine industry. As it happened in Chile, a younger generation of national oenologists and consultants, with solid academic backgrounds and extensive working experience abroad, seems to have taken over, or at least to play an increasingly important role.

The table below shows that, as in the Chilean case, only a small minority (3 out of 25) of the leading 25 Argentine exporters of bottled wines have opted for a foreign oenologist as their chief winemaker - two of them are Italian and one French (see Table 5.15). From interviews, it emerged that this is specifically due to the passion and personal involvement of Italian winemaking investors in Argentina, on the one hand, and to the still close relationship of foreign affiliates with their headquarters in France on the other. To the contrary, the vast majority (22 out of 25) of wineries currently relies on Argentine rather than foreign chief winemakers, as well as on a substantial pool of local agronomists, viticulturalists and consultants in their thirties.107 For example, Paula Borgo, the chief oenologist of Séptima, graduated from the Cuyo National University in Mendoza, holds a master's degree in Viticulture and has worked in the US (Kendall Jackson) and Spain (Solis). Gustavo Marin is the chief winemaker of Escorihuela Gascon; after his degree in Oenology at Don Bosco University in Mendoza, he took a master's degree in quality control in Portugal and a postgraduate degree in Winemaking Planning and Quality Management in France. Alejandro Vigil, the chief winemaker of Catena Zapata, graduated from the Agricultural Engineering Faculty of Cuyo National University in Mendoza. He holds a master's degree in Irrigation Management and Microclimate Definition, and headed the Soil Analysis Department of the National Institute of Technology (INTA) for several years. In 1995, Raul de la Mota, graduated from the Oenology school of the National University of Cuyo, was awarded the distinction "Best Oenologist in Argentina in the Twentieth Century" by the World Wine Press Association in Bordeaux, subsequently becoming one of the most renowned national consultants, together with Angel Mendoza, current director of the postgraduate courses at Maza University in Mendoza.

107 In 2012 Claudia Inès Quini, the President of the Argentine National Institute of Vitiviniculture, based in Mendoza (INV), was appointed President of the International Organization of Vine and Wine (OIV). Ms. Quini is a chemical engineer and is the first woman to be appointed as head of the prestigious intergovernmental organization based in Paris. At the $25^{\text {th }}$ OIV World Congress, held in Smirne, Turkey, on 18-22 June 2012, it was announced that Argentina will be the host of the OIV Congress in 2014. 
Table 5.15 Chief winemakers, oenologists, agronomists and national consultants employed by the top 25 Argentine exporters of bottled wines

\begin{tabular}{|c|c|c|c|c|c|}
\hline & Winery & $\begin{array}{c}\text { Chief } \\
\text { winemaker/s }\end{array}$ & Nationality & $\begin{array}{c}\text { National } \\
\text { oenologists } \\
\text { and } \\
\text { agronomists } \\
\text { with } \\
\text { university } \\
\text { degree }\end{array}$ & $\begin{array}{c}\text { National } \\
\text { consultants }\end{array}$ \\
\hline 1 & Zuccardi & Sebastian Zuccardi & Argentine & 3 & \\
\hline 2 & Tivento & Federico Galdeano & Argentine & 2 & \\
\hline 3 & Catena Zapata & Alejandro Vigil & Argentine & 2 & José Galante \\
\hline 4 & Trapiche & Daniel Pi & Argentine & 4 & Angel Mendoza \\
\hline 5 & Norton & Jorge Riccitelli & Argentine & 3 & \\
\hline 6 & Finca Flichman & Juan Carlos Vila & Argentine & 1 & \\
\hline 7 & Navarro Correas & Gerardo Danitz & Argentine & 2 & \\
\hline 8 & Pascual Toso & Rolando Luppino & Argentine & 1 & \\
\hline 9 & Terrrazas & Pablo Rodriguez & Argentine & 3 & Roberto de la Mota \\
\hline 10 & Luigi Bosca & José Irrera & Argentine & 3 & \\
\hline 11 & Escorihuela Gascon & Gustavo Marin & Argentine & 3 & \\
\hline 12 & La Celia & Cristian Garcia & Argentine & 4 & \\
\hline 13 & Dominio del Plata & Gustavo Bertagna & Argentine & 2 & \\
\hline 14 & Septima & Paula Borgo & Argentine & 3 & Raul de la Mota \\
\hline 15 & O.Fournier & José Mario Spisso & Argentine & 2 & \\
\hline 16 & Lurton & Dario Burgos & Argentine & 2 & \\
\hline 17 & Salentein & Laureano Gomez & Argentine & 3 & \\
\hline 18 & Dona Paula & David Bonomi & Argentine & 4 & \\
\hline 19 & Nieto Senetiner & Roberto Gonzales & Argentine & 4 & \\
\hline 20 & Chandon & Hervé Birnie-Scott & Foreign (FR) & 6 & \\
\hline 21 & Alta Vista & Rubén Sfragada & Argentine & 4 & \\
\hline 22 & Alto Las Hormigas & Attilio Pagli & Foreign (IT) & 3 & Pedro Parra \\
\hline 23 & Valentin Bianchi & Enzo Bianchi & Argentine & 3 & \\
\hline 24 & Augusto Pulenta & Hugo Angel Torres & Argentine & 3 & \\
\hline 25 & Achaval Ferrer & Tiziano Siverio & Foreign (IT) & 1 & \\
\hline
\end{tabular}

Source: Author's survey

In Argentina, becoming a licensed oenologist now requires five-years of tertiary specialized education, in addition to a high school degree. However, it was not like this in the past. Until 1999, when the Federal Law on Education was reformed, accredited oenologists were not only those graduated from the Mendoza-based University Juan Agustín Maza, which represented the only university-level training institution in oenology of the country, but also those who had a secondary education degree from the technical school Don Bosco, situated in the province of San Juan. According to the data 
collected by Walters (1997), until 1979 in Argentina there were only 81 oenologists (both with a secondary and a tertiary education degree). From 1980 to 1989 , the number increased to 159 , but fell again to 34 from 1990 to 1997 , due to the heavy crisis of the sector. According to more recent data, collected during field interviews, in 2009 there were 65 oenologists in Argentina with a university degree, out of which 41 from the Faculty Agustín Maza, as well as 427 technical specialists with a secondary education degree in oenology from the Don Bosco School. In 2000, the Don Bosco School merged with the Catholic University of Cuyo, which consequently inaugurated a new Faculty of Oenology and Fruit-culture, and is now only awarding a tertiary degree.

An interest in the discipline of oenology and an increasing demand for oenologists with tertiary education is proven by the number of universities now offering courses and degrees in the subject. In 2004, the National University of Technology, based in Mendoza, inaugurated a master's degree in wine technologies; in 2007, the University Agustín Maza inaugurated a master's degree in Management and Strategic Planning in Wine Business; in 2010, both the Universities of Catamarca and Salta created a new Faculty of Oenology, bringing to four the number of universities now providing the opportunity to undertake oenology studies in Argentina. Contrary to Chile, a degree in Agronomy is not a prerequisite, even though the increasing demand for agronomic competencies has led the National University of Cuyo to inaugurate in 2009 a master's degree in Agronomic Sciences and Vitiviniculture, and to launch a new research programme on applied agronomic research, with the direct involvement of firms.

It is not very surprising, therefore, as neither it was in the Chilean case, that all 25 leading Argentine exporters of bottled wines argued that a large amount of innovation of all types (product, process and organizational) was introduced during the last five years, thanks to local tacit knowledge and internal human resources, based on continuous trial-and-errors, observation and adaptation of imported technologies and know-how (see Table 5.16). The findings of this section, therefore, are in line with the hypothesis that the ability of developing countries to enter knowledge-intensive natural resource-based sectors, such as wine, depends not only on their ability to access capital, technology and knowledge from abroad, but also on their ability to absorb and adapt them to the local environment, thanks to the creation of local tacit knowledge by highly skilled human resources of national origin. The following section will verify whether the creation of local tacit knowledge by highly qualified local oenologists, agronomists and viticulturalists was also paralleled by the creation of endogenous R\&D capabilities of local universities and research centres. According to Giuliani (2005), strengthening domestic capabilities through advanced education and $\mathrm{R} \& \mathrm{D}$ activities in the wine industry remains key to planting the seeds of continuous innovation, knowledge diffusion and technology upgrading. 
Table 5.16 Main incremental innovations introduced by the top 25 Argentine exporters of bottled wines during the last five years, based on in-house R\&D

\begin{tabular}{|c|c|c|}
\hline Winery & Main innovation & Area \\
\hline 1 Zuccardi & $\begin{array}{l}\text { Experimentation of irrigation methods, as well as frost and hail } \\
\text { avoidance techniques and a new trellising system for top brands }\end{array}$ & Viticulture \\
\hline 2 Tivento & $\begin{array}{l}\text { Experimentation of new varieties for the production of sparkling } \\
\text { wines }\end{array}$ & Viticulture \\
\hline 3 Catena Zapata & Introduction of the concept of single varietal, microclimate blending & Viniculture \\
\hline 4 Trapiche & Experimentation of Precision Viticulture techniques & Viticulture \\
\hline 5 Norton & $\begin{array}{l}\text { Experimentation of anti-hail nets and of frost and hail avoidance } \\
\text { techniques }\end{array}$ & Viticulture \\
\hline 6 Finca Flichman & Experimentation of anti-hail nets & Viticulture \\
\hline 7 Navarro Correas & $\begin{array}{l}\text { Bottle labels painted by great Latin American artists to reach visibility } \\
\text { in stores }\end{array}$ & $\begin{array}{l}\text { Organization } \\
\& \text { Marketing }\end{array}$ \\
\hline 8 Pascual Toso & Testing of Champenoise $v s$ Charmat methods for sparkling wines & Viniculture \\
\hline 9 Terrrazas & $\begin{array}{l}\text { Matching each varietal to its ideal altitude; pioneer of high-elevation } \\
\text { viticulture }\end{array}$ & Viticulture \\
\hline 10 Luigi Bosca & $\begin{array}{l}\text { Leads the creation and implementation of controlled denomination of } \\
\text { origin system }\end{array}$ & $\begin{array}{l}\text { Organization } \\
\text { \& Marketing }\end{array}$ \\
\hline $\begin{array}{l}11 \text { Escorihuela } \\
\text { Gascon }\end{array}$ & New selling system, individualized to each customer & $\begin{array}{l}\text { Organization } \\
\text { \& Marketing }\end{array}$ \\
\hline 12 La Celia & $\begin{array}{l}\text { Pioneer in implementing an environmental and an occupational } \\
\text { health and safety management system }\end{array}$ & $\begin{array}{l}\text { Organization } \\
\text { \& Marketing }\end{array}$ \\
\hline 13 Dominio del Plata & $\begin{array}{l}\text { Winery traceability (fermentation, devatting, decanting, ageing, } \\
\text { bottling) }\end{array}$ & Viniculture \\
\hline 14 Septima & $\begin{array}{l}\text { Different pruning techniques and segmented fertilization in order to } \\
\text { homogenize plots' vigor }\end{array}$ & Viniculture \\
\hline 15 O. Fournier & $\begin{array}{l}\text { Use of dry ice for cold maceration of high-quality wines, new } \\
\text { laboratory for microvinification }\end{array}$ & Viniculture \\
\hline 16 Lurton & Use of native or selected yeasts, depending on the variety & Viniculture \\
\hline 17 Salentein & $\begin{array}{l}\text { Reducing distance of wine movements between different winemaking } \\
\text { steps }\end{array}$ & Viniculture \\
\hline 18 Doña Paula & $\begin{array}{l}\text { Pioneer in the use of cold soaks for better fruit extraction prior to } \\
\text { fermentation }\end{array}$ & Viniculture \\
\hline 19 Nieto Senetiner & first Argentine winery to create a selling space in Sao Paulo, Brazil & $\begin{array}{l}\text { Organization } \\
\text { \& Marketing }\end{array}$ \\
\hline 20 Chandon & $\begin{array}{l}\text { Creation of Chandon internal "university" to train staff and encourage } \\
\text { multidisciplinarity }\end{array}$ & $\begin{array}{l}\text { Organization } \\
\text { \& Marketing }\end{array}$ \\
\hline 21 Alta Vista & $\begin{array}{l}\text { Search for high altitude top quality vineyards; identification of } \\
\text { different microclimates }\end{array}$ & Viniculture \\
\hline 22 Alto Las Hormigas & Separate vinification and terroir microzoning techniques & Viniculture \\
\hline 23 Valentin Bianchi & $\begin{array}{l}\text { Extensive focus on vineyard management; } 6 \text { different trellising } \\
\text { systems }\end{array}$ & Viticulture \\
\hline 24 Augusto Pulenta & Search and experimentation of indigenous yeasts & Viniculture \\
\hline 25 Achaval Ferrer & Creation of "single vineyard” Malbecs & $\begin{array}{l}\text { Organization } \\
\text { \& Marketing }\end{array}$ \\
\hline
\end{tabular}

Source: Author's survey 


\subsection{The performance of sectoral domestic R\&D programmes and institutions}

In Chile and Argentina, the overall amount of resources allocated to $\mathrm{R} \& \mathrm{D}$ is rather negligible, compared to other developing countries. ${ }^{108}$ Additionally, both countries seem to suffer from weak university/industry linkages and a lack of responsiveness of research institutions and universities to industry needs (see Figure 5.4). If one looks specifically at R\&D expenditures in the wine sector, Chile and Argentina appear to lag behind other wine producing countries with respect to the level of public and private spending allocated to research institutions for wine-related R\&D (Kunc and Tiffin, 2008). For example, in 2000 the US spent 6 million US $\$$ in R\&D in wine, and Australia spent 9 million US $\$$, half of which was co-funded by the public sector. It has been estimated that in the same year Chile spent a total of 400,000 US\$, while Argentina spent 270,000 US\$ (Mouguillanksy, Salas and Cares, 2006; Thorn, 2005).

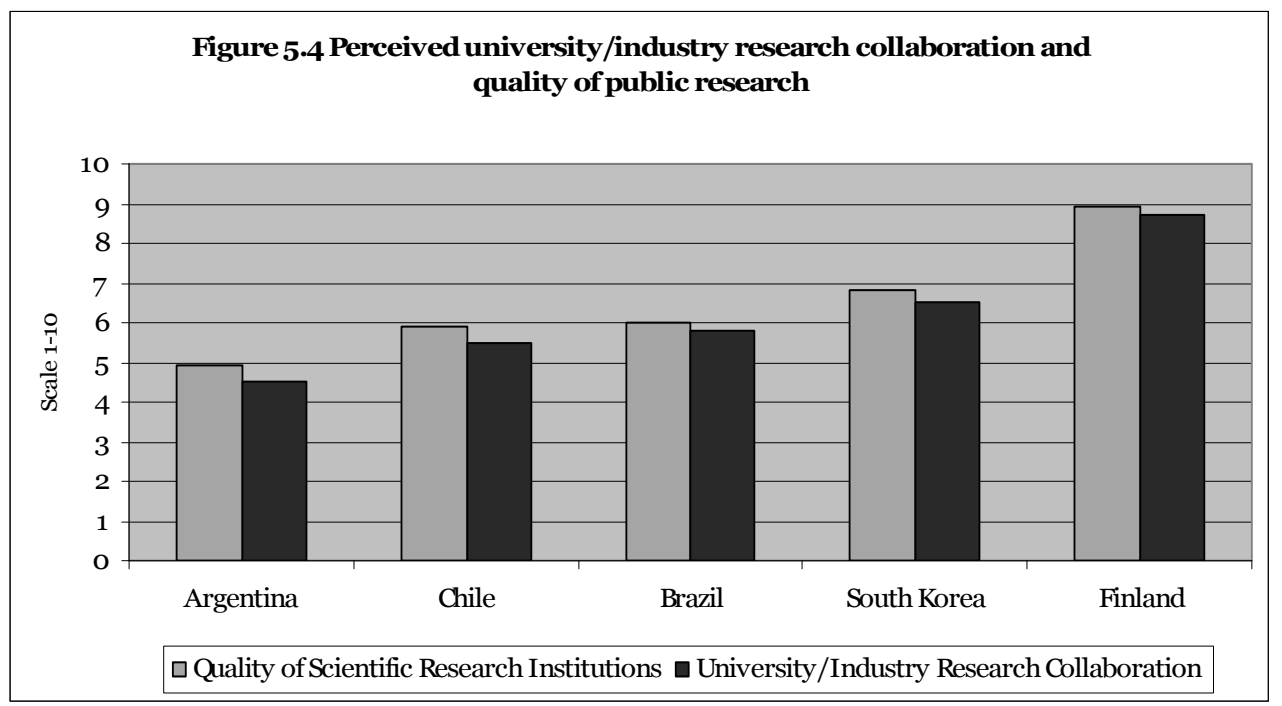

Source: World Economic Forum, 2002

Paradoxically, however, the research infrastructure devoted to R\&D in the Chilean and Argentine wine industries appears to be quite comprehensive and articulated, and the types of projects undertaken significant. Despite the limited amount of resources destined to $\mathrm{R} \& \mathrm{D}$ expenditures, the clear gaps in terms of university and industry collaboration, and research outputs that are sometimes below expectations given their ranking as global exporters, Chile and Argentina are intensifying their scientific efforts on wine in order to face the increasing competition of other wine producers from both the Old and New Worlds.

${ }^{108}$ In Chile, total R\&D expenditures went from 0.3 percent of GDP in 1965 to 0.7 percent in 2007, while in Argentina they went from 0.2 percent in 1965 to 0.4 percent in 2007. This is a modest achievement if one considers that in 2007 Brazil spent 0.9 percent of its GDP on R\&D, not to consider countries like South Korea, which exceeded 3 percent (Source: OECD at www.oecd.org/sti/rds). 
In their bibliometric analysis of wine publications and citations over a time span of one decade (1991-2001), for example, Glanzel and Veuglers (2006) show that among New World producers, Argentina and Chile rank quite low (respectively $22^{\text {nd }}$ and $26^{\text {th }}$ out of 28) in the list of countries that have undertaken sustained scientific activity on winerelated issues, as measured by the number of publications on the subject, as well as by the number of citations to these publications (see Table 5.17).

Table 5.17 Wine publication (P) output and citation (C) rates of the 28 most active countries, as well as specialization in wine research with their mean observed citation rate (MOCR) and relative citation rate (RCR), $1991-2001$

\begin{tabular}{|c|c|c|c|c|c|c|}
\hline Rank & Country & Papers & $\begin{array}{l}\text { P-share } \\
\text { (\%) }\end{array}$ & Citations & $\begin{array}{c}\text { C-share } \\
\text { (\%) }\end{array}$ & $\begin{array}{c}\text { Specialization in } \\
\text { wine research (\%)* }\end{array}$ \\
\hline 1 & United States & 1174 & 20.50 & 131796 & 27.20 & 0.04 \\
\hline 2 & France & 978 & 17.07 & 35044 & 17.63 & 0.20 \\
\hline 3 & Spain & 834 & 14.56 & 34259 & 12.45 & 0.42 \\
\hline 4 & Italy & 600 & 10.47 & 27706 & 9.84 & 0.20 \\
\hline 5 & Australia & 439 & 7.66 & 24538 & 7.16 & 0.22 \\
\hline 6 & Germany & 341 & 5.95 & 18498 & 5.74 & 0.05 \\
\hline 7 & Japan & 238 & 4.16 & 12833 & 3.89 & 0.03 \\
\hline 8 & United Kingdom & 200 & 3.49 & 9599 & 6.41 & 0.03 \\
\hline 9 & Canada & 187 & 3.26 & 10547 & 3.95 & 0.05 \\
\hline 10 & Portugal & 168 & 2.93 & 8992 & 2.30 & 0.74 \\
\hline 11 & Switzerland & 130 & 2.27 & 8049 & 1.54 & 0.10 \\
\hline 12 & Greece & 118 & 2.06 & 9020 & 1.87 & 0.28 \\
\hline 13 & Israel & 96 & 1.68 & 6987 & 2.83 & 0.10 \\
\hline 14 & Hungary & 88 & 1.54 & 6197 & 0.72 & 0.28 \\
\hline 15 & South Africa & 73 & 1.27 & 4958 & 1.42 & 0.10 \\
\hline 16 & Brazil & 71 & 1.24 & 2173 & 0.94 & 0.23 \\
\hline 17 & New Zealand & 68 & 1.19 & 4303 & 1.24 & 0.18 \\
\hline 18 & Netherlands & 56 & 0.98 & 4456 & 2.43 & 0.03 \\
\hline 19 & Austria & 55 & 0.96 & 1542 & 1.14 & 0.08 \\
\hline 20 & Denmark & 44 & 0.77 & 2852 & 2.23 & 0.06 \\
\hline 21 & India & 41 & 0.72 & 3162 & 0.23 & 0.02 \\
\hline 22 & Argentina & 35 & 0.61 & 2937 & 0.46 & 0.10 \\
\hline 23 & China PR & 35 & 0.61 & 3018 & 0.53 & 0.02 \\
\hline 24 & Russia & 34 & 0.59 & 2419 & 0.14 & 0.01 \\
\hline 25 & Slovakia & 33 & 0.58 & 2014 & 0.34 & 0.21 \\
\hline 26 & Chile & 31 & 0.54 & 1675 & 0.43 & 0.18 \\
\hline 27 & Finland & 31 & 0.54 & 2106 & 0.65 & 0.05 \\
\hline \multirow[t]{2}{*}{28} & Slovenia & 30 & 0.52 & 1912 & 0.23 & 0.18 \\
\hline & World total & 5728 & 100.0 & 19546 & 100.o & $\mathbf{0 . 0 7}$ (average) \\
\hline
\end{tabular}

Source: Glanzel and Veugelers, 2006

* The revealed specialization in wine research is calculated by relating the share of the given country in the publications on wine to the overall world share of the given country in world total publications.

According to the authors, this finding would not support the hypothesis that the shift in the globalization patterns of the wine industry is correlated to the geographical trends in the scientific wine community. ${ }^{109}$ However, the interpretation of such important

109 This view is corroborated by The Economist (1999), which observed that Australia may well have only a tiny share of the world's wine input, but produces 20 percent of the world's scientific papers in viticulture and oenology. Anderson (2011) also highlights how investments in wine R\&D have represented the most significant feature of the Australian wine industry since the 1970s, and have grown in importance following the creation of the Australian Wine Export Council and the Wine R\&D Corporation in the early 1990s. Nevertheless, Australia 
research findings should be more nuanced. The data collected by Glanzel and Veugelers show in fact that Chile and Argentina belong to a small group of countries (together with, for example, Portugal, Switzerland, Greece, Israel, Hungary and South Africa) where the absolute number of wine publications is relatively small, but the specialization in wine research is higher than the average (and $>1$ ), if related to the national publication output. Additionally, looking at the trends more dynamically, by examining the number of publications within two sub-periods, namely 1991-1995 and 1997-2001, it emerges that Chile belongs to the group of countries where the number of wine publications has increased most significantly, together with Italy, Spain and Portugal - a group of Old World producers that seem to have perceived the need to intensify their scientific efforts in order to face the increased competition of New World producers in their traditional export markets.

During field interviews, it became clear how advanced the research laboratories are in both countries working on key wine issues, such as the relationship between wine and health, the improvement of genetic characteristics of new grape varieties, the identification of chemical and sensorial characteristics of red and white wines, or the improvement of integrated production viticultural techniques, and also how impressive the premises, human resources, and research outputs of newly created university centres look that have the potential to become centres of excellence in the academic wine world.

In the case of Chile, several institutions related to technological development in the wine industry can be mapped. Among the main public ones are CONICYT (the National Commission for Research on Science and Technology); INIA (the National Institute for Agronomic Research); INDAP (National Institute for the Agriculture and Livestock Development); CNI (the National Commission for Irrigation). Among the main private or public/private ones are Fundaciòn Chile (the National Agency for Technology Transfer) and CCV (the Chilean Wine Corporation), mainly created to manage publicly funded technology development projects. The academic sphere includes the CTVV (the Centre for Vine and Wine of the University of Talca) and CEVIUC (the Centre for Viticulture of the Catholic University of Chile). In the past decades, many of these institutions have been actively involved in vine and wine research-related activities, financed mainly by two national science and technology development funds managed by CONICYT, namely FONDECYT and FONDEF (see Table 5.18). ${ }^{110}$ From interviews, it emerged that all the 25 leading Chilean exporting wineries were generally well aware of the activities carried out by both CTVV and CEVIUC, the wine research centres created, respectively, under the University of Talca and the Catholic University of Chile. The

\footnotetext{
has recently experienced a drastic slowdown of its wine exports. This can be attributed to an insufficient diversification of the supply, as well as to the lack of attention to regional diversities (Veseth, 2011).

110 CONICYT, the National Commission for Scientific and Technological Research, was created in 1971 to stimulate science and technology in Chile and orient it towards the economic and social development of the country. Its two main funds, FONDECYT and FONDEF, were created in 1982 to finance scientific and technological research projects at a high level of excellence. In the wine industry, several research projects have been financed since the 1990s, when emerging Chilean universities and research institutions started succeeding in preparing the complex applications required to run in the annual competition for research projects, normally of 1-3 years of duration.
} 
majority (17 out of 25 ) revealed that they had received some form of assistance from such centres or had participated in events, such as technical workshops or conferences, which were frequently organized and widely advertised. Fewer (11 out of 25), however, confirmed that they were actively participating in a research project, or had done so in the past. Moreover, none were actively involved in, or even aware of, any concrete activities carried out by other research organizations, such as INIA, INDAP or CNI.

Table 5.18 Funds allocated by FONDECYT and FONDEF to research projects in the Chilean wine industry, 1980-2000

\begin{tabular}{lllc}
\hline \multicolumn{1}{c}{ Fund } & \multicolumn{1}{c}{ Institution } & Period & Total amount US\$ \\
\hline FONDECYT & University of Chile & $1980-1990$ & 870,000 \\
& Catholic University of Chile & $1980-1990$ & 140,000 \\
& INIA & $1980-1990$ & 230,000 \\
FONDEF & University of Chile & $1990-2000$ & 270,000 \\
& Catholic University of Chile (CEVIUC) & $1990-2000$ & 480,000 \\
& University of Talca (CTTV) & $1990-2000$ & 350,000 \\
\hline
\end{tabular}

Source: CEPAL

In addition to the research institutions and universities mentioned above, the most proactive government agency in the development and funding of technology and innovation in the wine industry is the Chilean Economic Development Agency (CORFO). CORFO has played a key role in the re-birth of the Chilean wine industry, a role which is widely acknowledged by the vast majority (23 out of 25) of the leading exporting wineries interviewed. Among others, CORFO has promoted the study of the Chilean vitivinicultural potential, the modernization of the existing small winemaking cooperatives, the creation of sectoral wine associations, as well as financial and technical assistance to wineries needing technological upgrading. ${ }^{111}$ Among CORFO's policy instruments deserving special attention in terms of impact on the wine industry, there are: PROFO (Proyectos de Fomento); FAT (Fondo de Asistencia Técnica); FONTEC (Fondo Nacional de Desarrollo Tecnológico y Productivo); FDI (Fondo de Desarrollo e Innovación); PDP (Programa de Desarrollo de Proveedores); PAG (Programas de Gestión). These have been applied in the wine sector in a very selective, punctuated way, always jointly funded by public-private actors, and whenever there was a need for strategic and demonstrative interventions with a public good component and a "free rider" type of constraint. By implementing such a variety of instruments since

\footnotetext{
${ }^{111}$ CORFO, the Chilean Economic Development Agency, was created in 1939 to help rebuild the country after the terrible earthquake of Chillan. In the 1990s, CORFO radically changed its approach and operational tools to foster development. It stopped functioning mainly as a provider of loan extensions and started integrating its portfolio with a series of instruments and non-financial services, focusing on productive and territorial development, innovation and technology, regional and national competitiveness. As will be seen in more detail in the following chapter, CORFO supported the export and innovation capacity of the Chilean wine industry earlier and more intensively than other public institutions, such as ProChile (the Chilean Export Promotion Agency). For example, CORFO was key in the creation of the first association of wine exporters that started to make Chilean wine known to the world in the mid-1990s, as well as in the diffusion of a wide set of tools aimed at increasing quality and environmental sustainability among wine exporters, thereby increasing their access to global markets.
} 
the early 1990s, CORFO has demonstrated long-term vision and valuable strategic capabilities (see Table 5.19).

Table 5.19 Funding allocated by CORFO to promote technological innovation in the Chilean wine industry, 1993-2003

\begin{tabular}{|c|c|c|c|c|c|c|}
\hline Programme & Line & Period & $\begin{array}{c}\text { Number } \\
\text { of } \\
\text { projects }\end{array}$ & Objective & $\begin{array}{c}\text { Total } \\
\text { amount } \\
\text { US } \$\end{array}$ & $\begin{array}{l}\text { From } \\
\text { private } \\
\text { sector }\end{array}$ \\
\hline \multirow[t]{2}{*}{ FONTEC } & $\begin{array}{l}\text { Technological } \\
\text { Innovation }\end{array}$ & $\begin{array}{l}1993^{-} \\
1999\end{array}$ & 9 & $\begin{array}{l}\text { Technological } \\
\text { modernization and } \\
\text { innovation projects }\end{array}$ & $1,210,000$ & 740,000 \\
\hline & $\begin{array}{l}\text { Technological } \\
\text { Missions }\end{array}$ & $\begin{array}{l}1995^{-} \\
2000\end{array}$ & 10 & $\begin{array}{l}\text { Study tours to } \\
\text { France, Italy, Spain } \\
\text { and California }\end{array}$ & 815,000 & 480,000 \\
\hline \multirow[t]{4}{*}{ FDI } & $\begin{array}{l}\text { Strategic } \\
\text { targets }\end{array}$ & $\begin{array}{l}1998- \\
2003\end{array}$ & 4 & $\begin{array}{l}\text { Environmental } \\
\text { quality certification } \\
\text { (INTEC) }\end{array}$ & 560,000 & 270,000 \\
\hline & & & & $\begin{array}{l}\text { Identification of } \\
\text { terroirs in the VII } \\
\text { Region (CIREN) }\end{array}$ & 720,000 & 90,000 \\
\hline & & & & $\begin{array}{l}\text { Diffusion of } \\
\text { integrated } \\
\text { production } \\
\text { techniques in the } \mathrm{V} \\
\text { Region (INIA) }\end{array}$ & 580,000 & 240,000 \\
\hline & & & & $\begin{array}{l}\text { Improvement of } \\
\text { genetic } \\
\text { characteristics of } \\
\text { Chilean vineyards } \\
\text { (CEVIUC) }\end{array}$ & 800,000 & 350,000 \\
\hline
\end{tabular}

Source: CEPAL, 2006

Despite the notable engagement of local universities and research institutions described above, the relatively substantial amount of research funds allocated by CONICYT through both FONDECYT and FONDEF and the proactive role of CORFO, in the past several years criticisms have been levelled concerning the fact that until now Chilean institutions have devoted insufficient priority to research in the wine industry (Mouguillansky, Salas and Cares, 2006), or that research carried out in universities has often been far too basic, of an academic rather than a commercial nature (Hernandez, Bodeau and Vallejos, 2005). Additionally, CORFO's main instruments aimed at technological innovation in the wine industry, namely FONTEC and the Development and Innovation Fund (FDI), have been sometimes criticized for having benefitted the larger exporting wineries - such as Concha y Toro, Santa Rita, Carmen, Santa Emiliana and Cousiño Macul - at the expense of smaller wineries (CEPAL, 2006).

Lately, however, this situation has been changing drastically, with more coordination and more funds devoted to wine research, and more efforts devoted to the objective of promoting commercial innovation in the wine industry. For example, during the last decade two new technological and R\&D consortia have been created, both with government support: Vinnova in 2004 and CCDV (Centro Cooperativo para el Desarrollo Vitivinicola) in 2006. Both consortia represent a very important step 
towards institutional renewal, and respond to the urgent need for increased collaboration between the industry associations, the main research institutions and the universities (Cusmano, Morrison and Rabellotti, 2009). Their aim is to promote investment in innovation and research in order to enhance the quality and competitiveness of Chilean wines (see Table 5.20).

Table 5.20 Wine-related research projects implemented by the Vinnova Consortium, 2010-2015

\begin{tabular}{|c|c|c|}
\hline Project & Objective & Timeframe \\
\hline 1. Sustainability programme & $\begin{array}{l}\text { Establish a National Sustainability Code to } \\
\text { guide Chilean wineries towards increasingly } \\
\text { sustainable practices }\end{array}$ & $2010-2011$ \\
\hline 2. Social responsibility & $\begin{array}{l}\text { Develop a guide to SR using the Global } \\
\text { Reporting Initiative methodology and provide } \\
\text { training to the wineries }\end{array}$ & 2010-2011 \\
\hline 3. Meteorological stations & $\begin{array}{l}\text { Create the first network of meteorological } \\
\text { stations in all Chile's winegrowing valleys and } \\
\text { produce on-line information }\end{array}$ & $2010-2011$ \\
\hline 4. Energy efficiency & $\begin{array}{l}\text { Develop a guide for wineries to use as an energy } \\
\text { efficiency roadmap and an indicator to measure } \\
\text { Carbon Footprint }\end{array}$ & 2010-2013 \\
\hline 5. Consumer preference & $\begin{array}{l}\text { Develop a scientific methodology to match the } \\
\text { chemical and sensorial characteristics of wine } \\
\text { with consumer preferences }\end{array}$ & 2010-2013 \\
\hline 6. Germ plasma & $\begin{array}{l}\text { Make up the foundation block for the } \\
\text { development of certified and disease-free of } \\
\text { Chilean vine clones }\end{array}$ & 2010-2015 \\
\hline 7. Virus and phytoplasma & $\begin{array}{l}\text { Evaluate the incidence of viral pathogens and } \\
\text { phytoplasma in grapevines, associated to a } \\
\text { decrease in productivity }\end{array}$ & 2010-2013 \\
\hline 8. Sauvignon Blanc aroma & $\begin{array}{l}\text { Determine the impact of variables such as } \\
\text { irrigation, light and climate on the aromatic } \\
\text { quality of white wine grapes }\end{array}$ & 2010-2013 \\
\hline 9. Quality of red wines & $\begin{array}{l}\text { Seek economically reasonable solutions to the } \\
\text { problem of cold stability in red wines }\end{array}$ & 2010-2014 \\
\hline 10. Commercial yeasts & $\begin{array}{l}\text { Study the characteristics and requirements of } \\
\text { commercial yeasts and their impact on the } \\
\text { sensorial attributes of wines }\end{array}$ & $2010-2013$ \\
\hline 11. Flavonoles & $\begin{array}{l}\text { Provide information to stimulate the production } \\
\text { of wines with higher levels of antioxidant } \\
\text { flavonoles }\end{array}$ & 2010-2013 \\
\hline 12. Dynamics of plaguicides & $\begin{array}{l}\text { Compile and produce scientific data for the } \\
\text { zonification of plaguicide use in the different } \\
\text { wine producing valleys }\end{array}$ & 2010-2012 \\
\hline 13. Fungi and micotoxines & $\begin{array}{l}\text { Identify the presence of fungi and toxins species } \\
\text { in vineyards that have a negative effect on wine } \\
\text { and/or on human health }\end{array}$ & 2010-2013 \\
\hline 14. Liquid Industrial Residues & $\begin{array}{l}\text { Generate knowledge and technology allowing } \\
\text { cost-effective solutions for the management of } \\
\text { Liquid Industrial Residues }\end{array}$ & 2010-2012 \\
\hline 15. Technology transfer & $\begin{array}{l}\text { Build an efficient link between wineries and } \\
\text { universities, along with a permanent } \\
\text { communication channel }\end{array}$ & 2010-2015 \\
\hline
\end{tabular}

Source: Author's survey 
Vinnova is co-owned by the association Viñas de Chile (55 percent), the Catholic University of Chile (39 percent) and the University of Concepción (6 percent). It is a pioneer R\&D programme, matching public and private funds, and is supported by CORFO for 60 percent of its total budget (about 5 million US\$). It is currently working on 15 research projects, focused mainly on wine quality, productivity and environmental sustainability issues. Before the creation of Vinnova, Viñas de Chile (representing 45 wineries and 90 percent of exports) had cooperated with the Catholic University of Chile on a three-year project (2003-2006), for 1.5 million US\$, aimed at solving technical problems in vine cultivation, based on the engineering, agronomic and agro-biological competencies available at the university (Benavente, 2004). CCDV is a large consortium formed by ChileVid, the University of Talca, the University of Chile, the Technical University Santa Maria, CCV (Corporación Chilena del Vino) and the firm Toneleria Nacional. For its operations, CCDV receives financial support from the Chilean government to the tune of about 3 million US\$. Since 2010, it has been carrying out eleven different innovation projects, focusing on key strategic areas for the consolidation and further upgrading of the quality of Chilean wines, and in particular of the Carmenère variety (see Table 5.21). CCDV is undertaking special efforts to involve dynamic wineries of smaller size. It is expected that the results will generate enough resources to sustain the activities of the consortium in the long term.

Table 5.21 Wine-related research projects coordinated by the CCDV Consortium, 2006-2011

\begin{tabular}{|c|c|c|}
\hline Project & Objective & Research centre \\
\hline $\begin{array}{l}\text { 1. Market analysis and } \\
\text { benchmarking }\end{array}$ & $\begin{array}{l}\text { Develop a tool for each winery to make a comparative } \\
\text { analysis of its consumption of inputs and its costs }\end{array}$ & University of Talca \\
\hline $\begin{array}{l}\text { 2. Development of } \\
\text { biosensors }\end{array}$ & $\begin{array}{l}\text { Improve productivity and precision in the vinification of } \\
\text { quality wines through the use of biosensors }\end{array}$ & $\begin{array}{l}\text { Technical University } \\
\text { Santa Maria }\end{array}$ \\
\hline $\begin{array}{l}\text { 3. Varietal composition } \\
\text { and origin }\end{array}$ & $\begin{array}{l}\text { Detect origin and control quality and composition of } \\
\text { wines through intelligent instrumentation }\end{array}$ & University of Chile \\
\hline $\begin{array}{l}\text { 4. Characterization of } \\
\text { Carmenère }\end{array}$ & $\begin{array}{l}\text { Improve organoleptic characteristics of Chilean } \\
\text { Carmenère from the Maipo Valley }\end{array}$ & University of Chile \\
\hline $\begin{array}{l}\text { 5. Quality assessment } \\
\text { of new clones }\end{array}$ & $\begin{array}{l}\text { Broaden the genetic basis of varietals and vine clones } \\
\text { cultivated in Chile through the diffusion of new clones } \\
\text { developed at the University of Talca }\end{array}$ & University of Talca \\
\hline $\begin{array}{l}\text { 6. Characterization of } \\
\text { terroirs }\end{array}$ & $\begin{array}{l}\text { Identify the best terroirs for each of the most common } \\
\text { international varieties grown in the Colchagua Valley }\end{array}$ & University of Talca \\
\hline $\begin{array}{l}\text { 7. Study of Carmenère } \\
\text { physiology }\end{array}$ & $\begin{array}{l}\text { Understand the impact of light, water and climate on } \\
\text { the ripening of Carmenère grapes }\end{array}$ & University of Chile \\
\hline $\begin{array}{l}\text { 8. Resistance to stress } \\
\text { of Carmenère }\end{array}$ & $\begin{array}{l}\text { Understand why stressful climatic conditions affect the } \\
\text { Carmenère variety more than, e.g., the Cabernet } \\
\text { Sauvignon variety and increase its tolerance }\end{array}$ & University of Talca \\
\hline $\begin{array}{l}\text { 9.Detection of } \\
\text { unwanted flavours }\end{array}$ & $\begin{array}{l}\text { Detect the presence of unwanted bacteria in premium } \\
\text { wines and study their evolution in bottles or barriques }\end{array}$ & University of Chile \\
\hline $\begin{array}{l}\text { 10. Detection of } \\
\text { pesticides residuals }\end{array}$ & $\begin{array}{l}\text { Certify the safety standards of Chilean export wines and } \\
\text { the absence of dangerous chemical residuals }\end{array}$ & University of Talca \\
\hline $\begin{array}{l}\text { 11. Detection of } \\
\text { spontaneous yeasts }\end{array}$ & $\begin{array}{l}\text { Understand the development pattern and reduce the } \\
\text { presence of Brettanomyces in Chilean wines }\end{array}$ & University of Chile \\
\hline
\end{tabular}

Source: Author's survey 
Like Chile, Argentina can traditionally count on a relatively low level of resources allocated to R\&D, but on a solid institutional framework and highly qualified human resources devoted to science and technology in wine. FONTAR (Fondo Tecnológico Argentino) is the public fund that finances innovation projects through different instruments, such as subsidies, loans or direct fiscal credits. The projects are approved upon participation to public calls and periodic tenders, and have to be matched by private sector funds. FONTAR is administered by the National Agency for the Promotion of Science and Technology (ANPCyT), set up in 1996 within the Ministry of Education, with the exclusive role of financing research. In particular, it operates a line of non-repayable contributions designed to help firms upgrade their innovative capacity, including resources for developing business plans, building in-house R\&D capacity, preparing technology blueprints and modernizing products and processes (Dahlman et al., 2003). Additionally, since 1997 the Argentine government has operated a program of tax credits for $\mathrm{R} \& \mathrm{D}$ activities that allows Argentine firms to deduct a maximum of 50 percent of their $R \& D$ expenditure. In the wine industry, through FONTAR, between 1998 and 2008 about 17 projects were approved under the tax credit line, 24 under subsidies and less than 15 projects under the credit line, for a total contribution of FONTAR of approximately 2 million US $\$$ (see Table 5.22).

Table 5.22 Funding allocated by FONTAR to promote technological innovation in the Argentine wine industry, 1998-2008

\begin{tabular}{|c|c|c|c|c|c|c|}
\hline Project & Year & $\begin{array}{l}\text { Type of } \\
\text { support }\end{array}$ & Winery & Location & $\begin{array}{c}\text { Total amount } \\
\text { of the project } \\
\text { (Ar. pesos) }\end{array}$ & $\begin{array}{c}\text { FONTAR } \\
\text { particip. } \\
\text { (Ar. pesos) }\end{array}$ \\
\hline $\begin{array}{l}\text { Upgrading of vine } \\
\text { cultivation }\end{array}$ & 1998 & Fiscal credit & Santa Elena & Mendoza & 434,000 & 164,000 \\
\hline $\begin{array}{l}\text { Introduction of drip } \\
\text { irrigation }\end{array}$ & 1999 & Fiscal credit & La Inversora & Neuquén & 631,000 & 249,000 \\
\hline $\begin{array}{l}\text { Purchase of stabilization } \\
\text { equipment }\end{array}$ & 2000 & Fiscal credit & Anfuso & Mendoza & 80,000 & 34,000 \\
\hline $\begin{array}{l}\text { Introduction of new vine. } \\
\text { techniques }\end{array}$ & 2000 & Fiscal credit & La Agricola & Mendoza & 662,000 & 218,000 \\
\hline $\begin{array}{l}\text { Improvement of existing } \\
\text { techniques }\end{array}$ & 2001 & Fiscal credit & Quattrocchi & Mendoza & 205,000 & 100,000 \\
\hline $\begin{array}{l}\text { Assessment of new French } \\
\text { vine clones }\end{array}$ & 2001 & Subsidy & Mercier & Mendoza & 226,000 & 113,000 \\
\hline $\begin{array}{l}\text { Introduction of new vine } \\
\text { techniques }\end{array}$ & 2002 & Fiscal credit & Assi & Mendoza & 605,000 & 302,000 \\
\hline $\begin{array}{l}\text { Development of } \\
\text { autochthonous yeasts }\end{array}$ & 2002 & Fiscal credit & La Agricola & Mendoza & 475,000 & 237,000 \\
\hline $\begin{array}{l}\text { Testing of new sparkling } \\
\text { wines }\end{array}$ & 2002 & Fiscal credit & La Agricola & Mendoza & 408,000 & 204,000 \\
\hline $\begin{array}{l}\text { Development of clones on } \\
\text { rootstocks }\end{array}$ & 2003 & Subsidy & Mercier & Mendoza & 65,000 & 33,000 \\
\hline $\begin{array}{l}\text { Development of organic } \\
\text { wines }\end{array}$ & 2003 & Subsidy & Fantelli & Mendoza & 351,000 & 189,000 \\
\hline $\begin{array}{l}\text { Development of compost } \\
\text { from vines }\end{array}$ & 2003 & Subsidy & La Agricola & Mendoza & 135,000 & 55,000 \\
\hline Purchase of anti-hail nets & 2003 & Subsidy & Vintage & Mendoza & 118,000 & 66,000 \\
\hline $\begin{array}{l}\text { Purchase of filtration } \\
\text { equipment }\end{array}$ & 2003 & Subsidy & Domanico & San Juan & 252,000 & 111,000 \\
\hline $\begin{array}{l}\text { Introduction of new } \\
\text { irrigation systems }\end{array}$ & 2003 & Subsidy & Viticola Cuyo & San Juan & 116,000 & 47,000 \\
\hline
\end{tabular}




\begin{tabular}{|c|c|c|c|c|c|c|}
\hline Project & Year & $\begin{array}{l}\text { Type of } \\
\text { support }\end{array}$ & Winery & Location & $\begin{array}{c}\text { Total amount } \\
\text { of the project } \\
\text { (Ar. pesos) }\end{array}$ & $\begin{array}{c}\text { FONTAR } \\
\text { particip. } \\
\text { (Ar. pesos) }\end{array}$ \\
\hline $\begin{array}{l}\text { Experimentation of water } \\
\text { stress }\end{array}$ & 2003 & Subsidy & Fanalco & San Juan & 38,000 & 19,000 \\
\hline $\begin{array}{l}\text { Development of new } \\
\text { varietal wines }\end{array}$ & 2003 & Subsidy & De Aguilar & San Juan & 93,000 & 45,000 \\
\hline $\begin{array}{l}\text { Testing of organic wines } \\
\text { techniques }\end{array}$ & 2003 & Subsidy & Graffigna & San Juan & 35,000 & 17,000 \\
\hline $\begin{array}{l}\text { Purchase of advanced } \\
\text { machinery }\end{array}$ & 2003 & Fiscal credit & Santa Elena & Mendoza & 236,000 & 99,000 \\
\hline $\begin{array}{l}\text { Transition from table to } \\
\text { fine wines }\end{array}$ & 2003 & Credit & S.J.Frontera & San Juan & 112,000 & 59,000 \\
\hline $\begin{array}{l}\text { Technological } \\
\text { modernization }\end{array}$ & 2004 & Fiscal credit & Arizu & Mendoza & $1,175,000$ & 261,000 \\
\hline $\begin{array}{l}\text { Technological } \\
\text { modernization }\end{array}$ & 2004 & Fiscal credit & Trivento & Mendoza & $1,336,000$ & 296,000 \\
\hline $\begin{array}{l}\text { Technological } \\
\text { modernization }\end{array}$ & 2004 & Credit & Bianchi & Mendoza & $4,124,000$ & $2,826,000$ \\
\hline $\begin{array}{l}\text { Development of new } \\
\text { varieties }\end{array}$ & 2004 & Subsidy & Mercier & Mendoza & 129,000 & 62,000 \\
\hline $\begin{array}{l}\text { Development of } \\
\text { autochthonous yeasts }\end{array}$ & 2004 & Credit & Pulenta & San Juan & 741,000 & 466,000 \\
\hline $\begin{array}{l}\text { New winery with } \\
\text { gravitational flows }\end{array}$ & 2004 & Credit & Emprender & La Rioja & $3,500,000$ & 1,999,000 \\
\hline $\begin{array}{l}\text { Technological } \\
\text { modernization }\end{array}$ & 2004 & Credit & Bodegas & San Juan & 846,000 & 437,000 \\
\hline $\begin{array}{l}\text { Testing of new aging } \\
\text { techniques }\end{array}$ & 2004 & Fiscal credit & La Agricola & Mendoza & 682,000 & 238,000 \\
\hline $\begin{array}{l}\text { Development of new } \\
\text { clones }\end{array}$ & 2005 & Subsidy & Mercier & Mendoza & 129,000 & 62,000 \\
\hline $\begin{array}{l}\text { Introduction of hot } \\
\text { maceration }\end{array}$ & 2005 & Subsidy & La Agricola & Mendoza & 213,000 & 100,00 \\
\hline $\begin{array}{l}\text { Development of new } \\
\text { enzymes }\end{array}$ & 2005 & Subsidy & Key Zymes & B.Aires & 72,000 & 34,000 \\
\hline $\begin{array}{l}\text { Development of new aging } \\
\text { techniques }\end{array}$ & 2005 & Credit & C. Andinos & San Juan & 337,000 & 243,000 \\
\hline $\begin{array}{l}\text { Development of high- } \\
\text { altitude wines }\end{array}$ & 2005 & Credit & M.Olivares & San Juan & 296,000 & 222,000 \\
\hline $\begin{array}{l}\text { Introduction of new } \\
\text { varietal wines }\end{array}$ & 2005 & Subsidy & Galeano & Entre Rios & 280,000 & 127,000 \\
\hline $\begin{array}{l}\text { Introduction of sensory } \\
\text { analysis }\end{array}$ & 2006 & Subsidy & La Agricola & Mendoza & 776,000 & 228,000 \\
\hline $\begin{array}{l}\text { Vinification of new } \\
\text { premium wines }\end{array}$ & 2006 & Subsidy & S.J.Frontera & San Juan & 937,000 & 339,000 \\
\hline $\begin{array}{l}\text { Improvement of Malbec } \\
\text { varietal wines }\end{array}$ & 2006 & Subsidy & Biondolillo & Mendoza & 268,000 & 113,000 \\
\hline $\begin{array}{l}\text { Introduction } \\
\text { microvinification }\end{array}$ & 2006 & Fiscal credit & Esmeralda & Mendoza & $1,991,000$ & 697,000 \\
\hline $\begin{array}{l}\text { Development of premium } \\
\text { varietals }\end{array}$ & 2006 & Fiscal credit & Norton & Mendoza & 990,000 & 297,000 \\
\hline $\begin{array}{l}\text { Introduction of new vine } \\
\text { techniques }\end{array}$ & 2006 & Fiscal credit & Del Desierto & La Pampa & $1,479,000$ & 357,000 \\
\hline $\begin{array}{l}\text { Introduction of clean } \\
\text { technologies }\end{array}$ & 2007 & Subsidy & Viña Cobos & Mendoza & 393,000 & 192,000 \\
\hline $\begin{array}{l}\text { Improvement of } \\
\text { productivity }\end{array}$ & 2007 & Subsidy & C.Lavallino & Mendoza & 211,000 & 103,000 \\
\hline $\begin{array}{l}\text { Introduction of clean } \\
\text { technologies }\end{array}$ & 2007 & Subsidy & M.Austral & Mendoza & 63,000 & 31,000 \\
\hline $\begin{array}{l}\text { Technological } \\
\text { modernization }\end{array}$ & 2007 & Fiscal credit & Benedetti & Mendoza & 470,000 & 117,000 \\
\hline
\end{tabular}




\begin{tabular}{|c|c|c|c|c|c|c|}
\hline Project & Year & $\begin{array}{l}\text { Type of } \\
\text { support }\end{array}$ & Winery & Location & $\begin{array}{c}\text { Total amount } \\
\text { of the project } \\
\text { (Ar. pesos) }\end{array}$ & $\begin{array}{c}\text { FONTAR } \\
\text { particip. } \\
\text { (Ar. pesos) }\end{array}$ \\
\hline $\begin{array}{l}\text { Introduction of export } \\
\text { new varieties }\end{array}$ & 2007 & Fiscal credit & La Agricola & Mendoza & $1,021,000$ & 337,000 \\
\hline $\begin{array}{l}\text { Testing of new sparkling } \\
\text { wines }\end{array}$ & 2007 & Fiscal credit & La Rural & Mendoza & 420,000 & 189,000 \\
\hline $\begin{array}{l}\text { Testing of new varieties in } \\
\text { new terroirs }\end{array}$ & 2007 & Credit & A.Garcia & Neuquén & 167,000 & 62,000 \\
\hline $\begin{array}{l}\text { Development of bottling } \\
\text { machinery }\end{array}$ & 2008 & Subsidy & Metalurgica & Mendoza & 613,000 & 287,000 \\
\hline $\begin{array}{l}\text { Construction of new } \\
\text { winery }\end{array}$ & 2008 & Credit & Santa Sylvia & San Juan & $5,348,000$ & $3,081,000$ \\
\hline $\begin{array}{l}\text { Purchase of quality } \\
\text { certification equipment }\end{array}$ & 2008 & Credit & INTA & Mendoza & $4,511,598$ & $3,609,278$ \\
\hline $\begin{array}{l}\text { Introduction of high tech } \\
\text { laboratory }\end{array}$ & 2008 & Credit & CRYCIT & Mendoza & $1,271,818$ & 924,000 \\
\hline $\begin{array}{l}\text { Modernization of } \\
\text { equipment }\end{array}$ & 2008 & Credit & Cuyo Univ. & Mendoza & 312,000 & 250,000 \\
\hline $\begin{array}{l}\text { Modernization of } \\
\text { equipment }\end{array}$ & 2008 & Credit & INTA & Mendoza & 703,000 & 543,000 \\
\hline $\begin{array}{l}\text { Introduction of } \\
\text { denomination of origin }\end{array}$ & 2008 & Credit & La Riojana & La Rioja & $2,278,000$ & $1,461,000$ \\
\hline $\begin{array}{l}\text { Creation of new wine } \\
\text { research centre }\end{array}$ & 2008 & Credit & S.Martin U. & B.Aires & $1,904,000$ & 746,000 \\
\hline
\end{tabular}

Source: FONTAR, 2010

During the interviews, it emerged that all 25 leading Argentine exporting wineries were aware of the role of FONTAR as a potential source of funding to carry out technological upgrading activities, to introduce new equipment and/or modern winemaking techniques and to carry out applied research in the field of viticulture. Most of them (15 out of 25) had applied in the past in one form or another to one of FONTAR's project lines, and felt that the loan or fiscal credit lines were the most appropriate lines for their needs, while the subsidy line allowed access to more limited amounts of funds, which were more appropriate for smaller wineries. They also unanimously (25 out of 25) agreed that the reference for anything related to innovation in the wine industry was INTA, the National Institute for Agricultural Technology, whose technicians had carried out and were still carrying out work on oenology and viticulture that was known and directly relevant to all of them.

Research in Argentina is currently conducted in thirty-seven public universities and research centres, three of whom are active in wine-related research. For the wine industry, the most relevant is INTA, founded in late 1956 with the aim of improving productivity in the Argentine agro-food industry. INTA has been leading Argentina's agricultural research efforts since its founding and has been responsible for many of the successes that transformed the "pampas" into the nation's agricultural economic powerhouse (Walters, 1997). INTA's regional experimental station located in Lujan de Cuyo (Mendoza) has played a crucial role in fighting the backwardness of the wine industry in the late 1980 s and greatly contributed to the diffusion of the radical innovations needed to start producing fine varietal wines for the export market. During the 1980s, the agency's technicians were involved in two main projects aimed at the quality upgrading of the primary production and the technological conversion of the existing vineyards (see Table 5.23). 
Table 5.23 INTA projects for the technological upgrading of the wine industry in Argentina, Multi-year plan, 2009

\begin{tabular}{lc}
\hline \multicolumn{1}{c}{ Objective } & $\begin{array}{c}\text { Amount } \\
\text { (US\$) }\end{array}$ \\
\hline Study and control of vine diseases & 70,000 \\
Clonal selection for the improvement of Malbec varieties through new imported clones & 66,500 \\
Technological upgrading and mechanization of irrigation techniques in Mendoza & 100,000 \\
Study of the viticulture and viniculture value chains in Argentina & 15,000 \\
Improvement of research laboratory equipment for chemical and macro-biological analysis & 160,000 \\
Technology transfer to grape producers in Mendoza for quality upgrading & 55,000 \\
Equipment for the Centre of Oenological studies in Mendoza & 75,000 \\
\hline
\end{tabular}

Source: INTA, 2009

The first project was aimed at mapping the region's 120 varietals and at shedding light on the characteristics of the planted vines, in order to clarify widespread confusions and mistakes in the use of grape names (for example, the fine Italian grape Barbera d'Asti was confused routinely with Bonarda, of intermediate oenological quality, while Chardonnay and Chenin were both called Pinot Blanc, which never existed in Mendoza). The second project was aimed at mapping which kind of grape variety was better adapted to which microclimate. INTA's oenologists also began a systemic comparison across the country, sometimes confirming what people knew but also announcing veritable surprises, published in a well known report in 1987 (e.g., Chenin and Tocai Friulano, which usually prefer cool temperatures, did quite well in Eastern Mendoza, while red grapes which prefer hot climates did quite well in Mendoza's highest altitudes).

In order to achieve a higher impact on the technological transformation of smaller and poorer producers, in the early 1990s INTA was involved in projects aimed at transferring technologies to small farmers, through an extension programme called Rural Change (Cambio Rural). The program was specifically designed to help groups of small farmers to improve their production technology by exchanging their experiences in technological upgrading and occasionally sharing the costs of a consultant (Walters, 1997). In the late 1990s, INTA's research efforts in Cuyo focused on issues related to the study and control of vine diseases, to clonal selection and irrigation techniques, and to the study of vineyard handling systems aimed at optimizing the quality produced by independent vine growers. Over the years, INTA has played a crucial role in advancing the knowledge and categorization of Argentine wines, including, more recently, the identification of new export varieties and new wine regions, thereby allowing Argentine winemakers to keep diversifying their offer and meeting the demand of international consumers for increasingly high-quality wines.

From the data presented in this section, therefore, it emerges that the spectacular rise of the Chilean and Argentine wine industries can be ascribed to a deep technological modernization process stimulated by external sources of innovation, such as foreign knowledge and machinery, but sustained over time by the emergence of a national pool 
of highly skilled professionals, as well as of a local research community capable of adapting foreign technologies to local needs.

\section{Conclusions}

The high quality of contemporary wine is the long term result of modern oenology, originating from Pasteur's and Riberau-Gayon's discoveries less than one century ago, as well as from the technological revolution led by California and Australia in the 1970s (Paul, 2002). Most industry innovations introduced in Argentina and Chile in the 1980 s and 1990 s were, therefore, transferred from abroad, through imported, off-the-shelf technologies and the continuous flow of foreign winemakers. In this chapter it has been demonstrated, however, that the substantial adaptation of new technologies to local conditions, factors and needs was also crucial. Such adaptation was increasingly carried out with the sporadic assistance of foreign consultants and flying winemakers, and by highly skilled local oenologists, agronomists and viticulturalists. These were also key to the creation of local tacit knowledge and to the actualization of incremental changes based on learning-by-doing and internal trial-and-error efforts. Therefore, it has been demonstrated that Chile and Argentina are gradually becoming producers of winerelated knowledge in their own right, and that they are increasingly recognized as authoritative and well-respected members of the international wine community, thanks to their active participation in international wine fairs and competitions, to the solid reputation of some of their most knowledgeable winemakers, and to the active role they play in such organizations as the OIV.

Quite importantly, it has also been highlighted that not all the innovations introduced by Chilean and Argentine wineries have implied a reliance on suppliers of machinery for production, as many of the innovations were product or organizational innovations that were not necessarily linked to the machinery and equipment used in the winemaking process. This confirms the hypothesis that the development of technological capabilities involves more than the straightforward acquisition of machinery and product designs, or the simple access to foreign knowledge, which is increasingly facilitated by liberalization policies and by the presence of foreign direct investment. The development of technological capabilities also (and mostly) depends on domestic technological efforts, namely on incremental innovations, and on the improvement and adaptation of imported technologies by local actors. In the case of the Chilean and Argentine wine industries, external sources of innovation, such as imported machinery, international movements of capital and international knowledge flows, initially helped trigger the entire process of technological change. However, continued growth would not have occurred without the subsequent development of domestic abilities to exploit such external knowledge and technology flows through the creation of a pool of highly skilled human resources, and of universities and research centres with the potential to become centres of excellence in the future.

Neither the Chilean nor the Argentine wine industries, though, should sleep on their laurels. The fact that both seem to have completed the earlier phase of the wine technological revolution does not mean that they are well prepared to meet future 
challenges and to sustain their export growth in the long term. In the second phase, every single step towards the technological frontier is much more complex and difficult, and is characterized by a higher level of knowledge intensity from a systemic perspective. For example, it would seem that, on the demand side, the future behaviour of international consumers is going to be increasingly influenced by two factors - the potential health benefits of wine and its environmental sustainability (Anderson et al., 2001; Bisson et al., 2002). These can be strategically exploited only if the technical and scientific understanding of the latest developments in a wide-ranging spectrum of science and technology disciplines is present and well diffused among all main industry stakeholders. Reflecting on the future of the wine industry, Bisson et al. (2002) argue:

As we gain knowledge of the basic biology of human perception and flavour preferences, wine will become even more targeted to the genetic differences of the consumers. Consumer olfactory profiling will be common and used to guide production decisions as well as marketing of wines. Studies currently in progress will continue to document the healthful properties of wine. In addition, the industry will need to play a highly visible role in the promotion of sound and sustainable environmental stewardship, as this will be a strong motivating factor in the purchase of wines. The stakes of success in meeting consumer expectations are high, as the value-added aspects of enhanced tourism are undeniable and economically beneficial for entire regions (Bisson et al., p.21).

Additionally, and most importantly, as stated in Chapter 3, consumers from all over the world are becoming increasingly knowledgeable about and attentive to varieties and terroirs, and expect varietals from a specific region to taste very differently from the same varietals grown in other regions. This is radically changing the production and marketing strategies of winemakers worldwide, to the point that even the owners of the French Domaine de la Romanée Conti - the most renowned producer of Burgundy wines in the world - are now looking for appropriate terroirs in California to plant some hectares of Pinot Noir, which represents the base of Burgundy wines (Wine Spectator, July 2011). For a long time these winemakers have refrained from producing Pinot Noir abroad not to compete with their own Burgundy wines. However, as their foreign investment behaviour indicates, they decided to start do it to appeal to consumers who are looking for wine varieties with unique qualities which can be ascribed to specific sites, cultures and regions.

Therefore, it would seem that on the supply side, the key driver of competitiveness and profitability in the wine market will be largely determined by the diversification of choices, in terms of regions of origin, grape varieties, altitudes and microclimates (Veseth, 2011). Even countries like Australia, which built its success on the strength of its one-dimensional varietals (mostly Shiraz or Chardonnay) and on a national brand providing little information on regions, and never about terroirs, has now launched a marketing plan called "Landmark Australia", meant to shed light on the diversity of its terroirs and on the rediscovery of the importance of smaller wineries. In the future, the capability of local actors to extract a unique, original taste from different grape varieties and to reflect faithfully the characteristics of the local terroir is going to be crucial. In order to meet these expectations, wine producers need to recognize the technical 
characteristics and the composition specificities of the different soils up to the slightest detail. They also need to master the vinification process in all its phases and learn to minimize as much as possible any manipulation or any modification of the growing environment, so that the taste of the terroir may prevail without much interference of technology (Bisson et al., 2002).

The Chilean and Argentine wine industries are clear examples of how international routines, standardized technology and foreign winemakers are generally weak in extracting regional character and uniqueness factors from their wines (Robinson, 2001). In order to discover the "uniqueness character" of their varieties, local oenologists are increasingly trying to abandon their "scholastic" approach and become more self-confident and original. In this sense, it is emblematic that the discovery of Torrontés as a typical Argentine export variety of high-quality white wine can be ascribed to Susana Balbo, an Argentine winemaker graduated "cum laude" in Mendoza in 1981, and that the discovery of the Casablanca Valley, where nobody had ever thought vines could grow before, as the new wine area for top quality Chilean white wines, can be ascribed to Aurelio Montes, a Chilean winemaker graduated "cum laude" in Santiago in 1975.

At a more systemic level, however, this can hardly be achieved by individual producers, talented winemakers and fragmented efforts. Rather, as was argued in Chapter 2, it requires the development of systematic relations among the public and private sectors, dynamic inter-firm and inter-institutional linkages, and a strong interaction among the production system and the knowledge system at the local and regional level. In particular, it requires the creation of networking dynamics that are rooted in a specific territory and nurtured by proximity effects, which are indispensable for strengthening competitive advantages at the local level. The next chapter will assess the extent to which in the Chilean and Argentine wine industries these dynamics are already taking place or are likely to emerge in the near future. 



\section{CHAPTER 6}

Wine Clusters, Regional Innovation Systems and Export Growth in Chile and Argentina

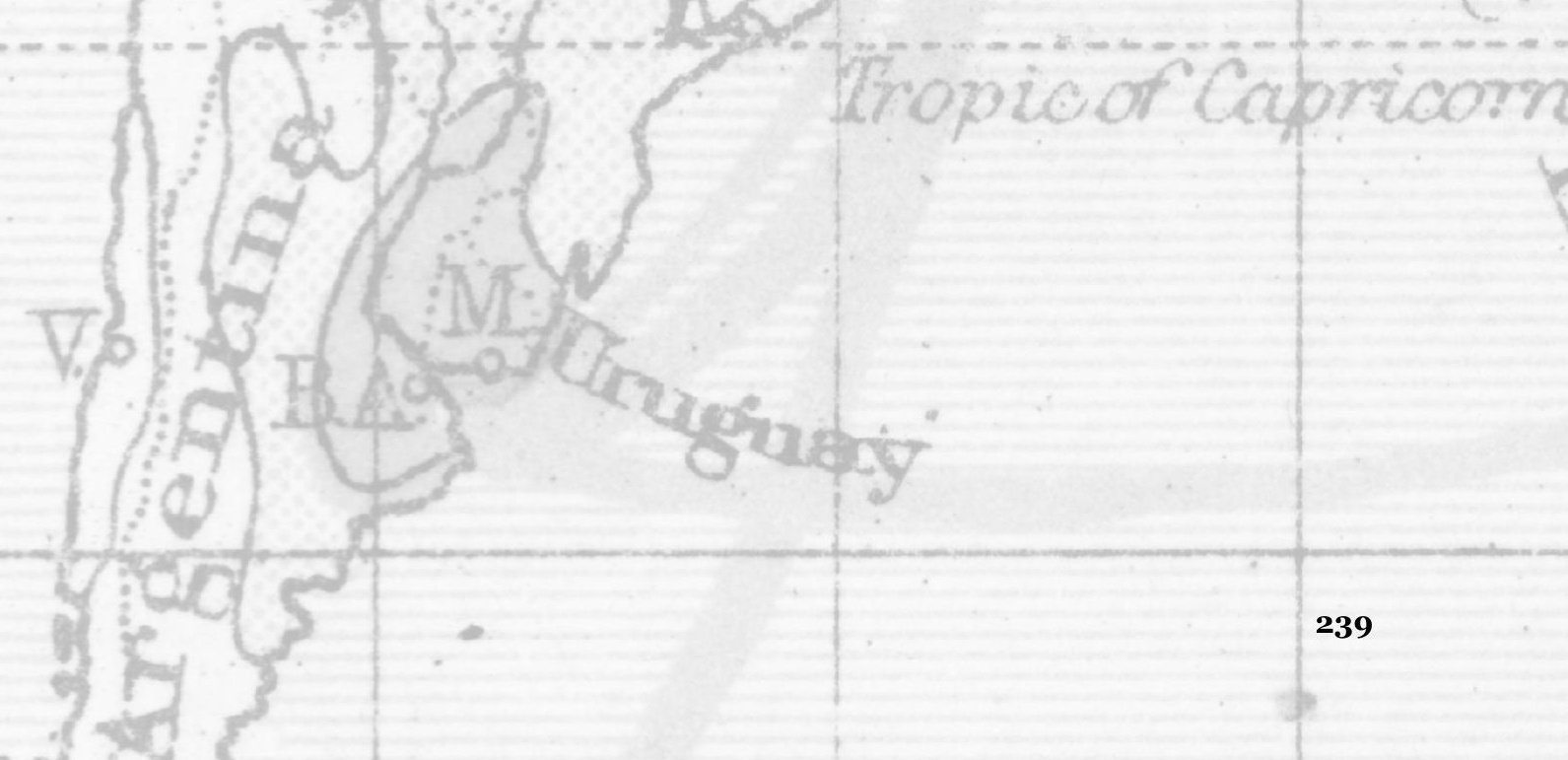


CHAPTER 6 


\subsection{Introduction}

This chapter addresses the issue of the long-term sustainability of export growth in a natural resource-based industry such as wine. In particular, it looks at the territorial and spatial dimensions of the wine revolution in Chile and Argentina. It analyzes whether, and the extent to which, the Chilean and Argentine wine industries have experienced the emergence of territorially bound specificities, "uniqueness" factors and local innovation capabilities that would make their wines original, different from each other and irreplaceable in the eyes of international consumers, thus the growth of Chilean and Argentine wine exports sustainable in the long term.

As noted in Chapter 2, most natural resources, including wine, tend to be spatially clustered due to biology and environment. Wine clusters, for example, are characterized by a delimited spatial agglomeration of the vineyards, as determined by the natural formation of valleys, areas or slopes where the territory is suitable to vine cultivation. In wine clusters, geographical proximity may play a fundamental role in promoting continuous incremental innovation and technological upgrading, thanks to the creation of inter-firm linkages between vine-growers, winemakers and specialized suppliers, as well as of localized spillover effects linked to the presence of foreign investors. This process, however, is not automatic, nor is it necessarily self-contained. Not all wine clusters, therefore, are equally innovative and equally successful in sustaining export growth in the long term.

This chapter focuses on the relationship between different types of cluster-based production, the knowledge intensity of natural resource-based sectors and sustained competitiveness. This leads to a better understanding of the unevenness of the export performance of wine clusters in both Chile and Argentina, by adopting an in-country and a cross-country comparative perspective. In particular, in Chapter 2 the distinction has been made between informal and organized clusters, according to a categorization that is based on a set of variables emphasizing the potential for learning and innovation within clusters in developing countries. It was also argued that the innovative performance of clusters is also dependent on the extent to which clusters can tap into broader opportunities offered by regional innovation systems, such as substantial investments in $\mathrm{R} \& \mathrm{D}$, incentive structures and institutional capacity.

These concepts are instrumental to exploring the third and final hypothesis, namely, that sustained export growth is linked firstly, to the transformation of natural resourcebased clusters from informal into organized, and, secondly, to the interaction of organized clusters with broader regional innovation systems. This chapter is thus structured as follows: Section 2 shows that in both Chile and Argentina wine exports are characterized by an extremely pronounced regional and spatial concentration. Section 3 looks at the learning and networking dynamics of two different typologies of wine clusters in Chile, namely Colchagua and Curio (respectively, an organized and an informal wine cluster). Section 4 illustrates the emergence of a "centralized" innovation system in the Chilean Metropolitan Region, dominating the platform of wine-related 
technology, business and services. Section 5 looks at the same different typologies (i.e. organized and informal) of wine clusters in Argentina, namely Mendoza and San Juan (respectively, an organized and an informal wine cluster). Section 6 describes the integration of Mendoza into a "learning region", capable of strengthening the learning dynamics of organized wine clusters and of generating inter-cluster knowledge flows. Section 7 looks at the Chilean and Argentine "models" from a comparative perspective. Section 8 concludes, emphasizing the key role of inter-institutional linkages and interfirm networks at local and regional levels in strengthening local competitive advantages and innovation capabilities.

\subsection{Spatial concentration, regional specialization and export growth}

In both Chile and Argentina, wine production is distributed along a number of wine clusters. As noted in Chapter 2, however, clusters are not formal administrative units of analysis. Their boundaries may or may not correspond to those of regions, municipalities, or provinces, and this contributes to the difficulty in clearly defining what clusters are from a geographical perspective and in comparing their export performance. According to Michael Porter's definition, clusters are " $a$ set of economic actors concentrated along a sectoral value chain or an agglomeration of specialized firms and related suppliers within a geographically delimited space” (Porter, 1998). This definition, however, captures the cluster phenomenon only partially. Giacomo Becattini, the Italian scholar who pioneered the study of clusters in the early 1970s, argued that clusters are "socio-territorial entities which are characterized by the active presence of both a community and a population of firms in one naturally and historically bounded area, whereby, unlike in other environments, community and firms tend to merge" (Becattini, 1990). In order to identify the presence of clusters, therefore, and to set their boundaries, it is important to make use not only of quantitative or statistical methods that may detect the existence of sectoral agglomerations of specialized firms, but also of qualitative or socio-economic criteria to detect the existence of the kind of local environment, or Marshallian "atmosphere", capable of enhancing economic growth, thanks to a mix of competence, skills, entrepreneurial ability, innovativeness, trust and sense of community.

In Chile, for example, the area where vines are cultivated is commonly divided into wine producing valleys, which the specialized literature considers as "clusters" (Giuliani, 2003, 2007 and 2010; Visser, 2004; Visser and de Langen, 2006; Gwynne, 2008). Contrary to Argentina, and to most other wine producing countries, these valleys are characterized by more distinct social and cultural identities, and a deeper sense of belonging than the administrative regions in which they are located. ${ }^{112}$ From North to South, these are Aconcagua and Casablanca (Valparaiso, V region); Maipo

\footnotetext{
${ }_{112}$ As mentioned in Chapter 4, according to the administrative system created by Pinochet in 1980, Chile is divided into 13 administrative regions (Regions I-XII from North to South, plus the Metropolitan Region of Santiago, including the capital city and its surroundings). Grape growing for wine production currently takes place in one third of the territory, and in 7 of the 13 Chilean regions.
} 
(Metropolitan Region); Colchagua and Cachapoal (Libertador O’Higgins, VI region); Curicó and Maule (Maule, VII region); and Itata and Bio Bio (Bio Bio, VIII region). Ideal conditions for growing red varieties can be found in the Maipo Valley, near Santiago, and for 300 kilometres south, while the more recent Casablanca Valley, between Santiago and Valparaiso, offers excellent conditions for white varieties. In addition, interviews confirmed that the Chilean wine clusters are characterized by very different socio-economic, cultural and historical conditions, as well as by different levels of trust and common rules, different lead actors and different habits in both cultivation and vinification techniques.

In Argentina, the two most important areas in terms of vine cultivation, the provinces of Mendoza and San Juan, are located along the Andean foothills - where the climate is cooler and there is an abundance of melt water. ${ }^{113}$ Mendoza is sub-divided into five main oases, situated at different altitudes: the Northern Oasis (600-700 m), the Central Oasis (650-1,000 m), the Eastern Oasis (650-750 m), the Southern Oasis (800 m) and the Uco Valley (900-1,200 m). San Juan is also subdivided into three main valleys situated at different altitudes, namely Tulum Valley (650 m), Pedernal Valley (1,350 m) and Ullum Valley $(1,800 \mathrm{~m})$. All these areas, despite being characterized by totally different terroirs, soils and climatic conditions, are located at relatively short distances from each other (no more than $20 \mathrm{~km}$ ). From interviews, it emerged that, in all of them, winemakers share a strong sense of identification with their respective provinces, as well as a sense of belonging to the same socio-economic and cultural environment, regardless of the oasis or valley in which they are located. This view is corroborated by the specialized literature on the subject (Salvatierra, 2006; McDermott et al., 2007; Migone and Howlett, 2010), which considers Mendoza and San Juan - and not their individual valleys or oases - as wine clusters.

Not all Chilean and Argentine wine clusters are equally successful in terms of export performance. In both countries, in fact, wine exports are extremely concentrated from a spatial perspective. Some wine clusters, and some of the regions that they are located in, are more innovative and more successful than others in terms of export growth. In Chile, for example, the Maule (VII) region is the single largest wine producing region, accounting for 48.8 percent of total production. However, the Libertador O'Higgins (VI) region - with nearly the same area of planted vineyards, but only half the amount of wine production - accounts for the highest value of exports. Within the O'Higgins (VI) region, one can find the valleys, or clusters, with the highest number of exporting wineries (see Table 6.1). A look at the list of the top 25 Chilean exporters of bottled wines selected for the present survey shows that the largest number (11) are located in the Metropolitan Region, in the Maipo cluster, as this is the region originating the largest amount of the country's wine exports in absolute terms. Maipo, however, is an atypical cluster, as this is where most exporting wineries keep their headquarters, and in some cases their bottling lines, even though whilst cultivating (or buying) and

\footnotetext{
${ }^{113}$ Argentina is a federal state and is administratively organized into 24 provinces and the autonomous city of Buenos Aires, the federal capital district. Wine grapes are grown in 13 of these 24 provinces, and in 8 of them viticulture represents an economically meaningful activity.
} 
vinifying all their grapes elsewhere. ${ }^{114}$ In this sense, it is revealing that Maipo hosts less than 10 percent of the country's vineyards, but exports the vast majority of Chilean wines, which are transported in bulk by train or truck from other areas of the country. Concha y Toro, for example, which is the ninth largest winemaker in the world in terms of production volume, owns fourteen properties, five wineries and leases more when there is an extra need. The properties cover more than 5,00o hectares and are scattered throughout the entire country (half of them having been bought after 1993). This shows how little prominence Chile has been giving, until quite recently, to the territorial dimension of its wine production, and to the intensity of the interactions between grape-growers and winemakers.

Table 6.1 Chilean planted surface with vineyards, wine production and wine exports according to administrative regions, 2008

\begin{tabular}{llrrrr}
\hline Regions & $\begin{array}{c}\text { Planted } \\
\text { vineyards } \\
\text { (hectares) }\end{array}$ & $\begin{array}{c}\text { Wine } \\
\text { production } \\
\text { (hectolitres) }\end{array}$ & $\begin{array}{c}\text { Wine } \\
\text { exports } \\
\text { (US\$) }\end{array}$ & $\begin{array}{c}\text { Number of exporting } \\
\text { wineries }\end{array}$ \\
\hline III & Atacama & 11.3 & 389 & 63,086 & 2 (Elqui Valley) \\
IV & Coquimbo & 2,060 & 470,968 & $5,471,317$ & 7 (Limari Valley) \\
V & Valparaiso & 7,953 & 158,156 & $89,026,491$ & $\begin{array}{c}5 \text { (Aconcagua Valley) } \\
13 \text { (Casablanca Valley) }\end{array}$ \\
R.M & Metropolitana & 11,695 & $1,097,019$ & $696,983,867$ & $\begin{array}{c}7 \text { (San Antonio Valley) } \\
43 \text { (Maipo Valley) }\end{array}$ \\
VI & Lib. O'Higgins & 34,397 & $2,687,436$ & $202,712,450$ & $\begin{array}{l}45 \text { (Colchagua Valley) } \\
21 \text { (Cachapoal Valley) }\end{array}$ \\
VII & Maule & 45,317 & $4,431,384$ & $176,225,333$ & $\begin{array}{c}21 \text { (Curicó Valley) } \\
31 \text { (Maule Valley) }\end{array}$ \\
VIII & Bio Bio & 3,263 & 307,031 & $1,540,698$ & $\begin{array}{c}7 \text { (Bio Bio Valley) } \\
\text { 2 (Itata Valley) }\end{array}$ \\
\hline
\end{tabular}

Source: SAG, 2009; Wines of Chile

Out of the group of the remaining 14 leading exporting wineries, 10 are situated in the O'Higgins (VI) region (8 in the Colchagua and 2 in the Cachapoal cluster), 3 in the Maule (VII) region (all in the Curicó cluster), and 1 in the Valparaiso (V) region (in the Aconcagua cluster). In order to test the third hypothesis, two Chilean wine clusters where grape growers, wineries and specialized services are located in close proximity, have been selected. These make up, on the one hand, the cluster of Colchagua (located in the O'Higgins, VI region), which has recently become the driver of the country's wine export boom, and is led by a group of dynamic (and in most cases relatively young) wineries founded by both national and international investors just prior to and immediately after the return of Chile to democracy. And, on the other hand, the cluster of Curicó (located in the Maule, VII region), which is comparable in size but performing

\footnotetext{
114 Crowley (2001) explains that the practice of cultivating and fermenting grapes throughout the country, and of locating bottling plants near Santiago, has a longstanding origin, dating to well before the wine revolution: "Since the beginning of the last century, the wineries in the South were numerous. The wine that was not consumed locally, in demijohns or casks, headed for metropolitan Santiago in bulk, to be distributed by the large metropolitan wineries as their product. All wineries that bottled, wineries that put labels on their wines, were centered in the Maipo Valley" (Crowley, 2003, p.7).
} 
far less prominently in terms of export growth, and, with a few exceptions, is mostly populated by old family wineries that date back to the end of the nineteenth century (see Table 6.2).

Table 6.2 Geographic concentration of the top 25 Chilean exporters of bottled wines

\begin{tabular}{|c|c|c|c|c|c|c|c|c|}
\hline & \multirow[t]{2}{*}{ Winery } & \multirow{2}{*}{$\begin{array}{c}\text { Geographic } \\
\text { location } \\
\text { Valley/ } \\
\text { Cluster }\end{array}$} & \multicolumn{4}{|c|}{ Province/Region } & \multirow[t]{2}{*}{ Year } & \multirow{2}{*}{$\begin{array}{c}\text { Type of } \\
\text { investment }\end{array}$} \\
\hline & & & $\begin{array}{c}\mathrm{V} \\
\text { Region }\end{array}$ & $\begin{array}{l}\text { Metr. } \\
\text { Region }\end{array}$ & $\begin{array}{c}\text { VI } \\
\text { Region }\end{array}$ & $\begin{array}{c}\text { VII } \\
\text { Region }\end{array}$ & & \\
\hline 1 & Concha y Toro & Maipo Valley & & $\mathrm{X}$ & & & 1883 & $\begin{array}{l}\text { National } \\
\text { investment }\end{array}$ \\
\hline 2 & San Pedro & Curicó Valley & & & & $\mathrm{X}$ & 1865 & $\begin{array}{l}\text { National } \\
\text { investment }\end{array}$ \\
\hline 3 & Santa Rita & Maipo Valley & & $\mathrm{X}$ & & & 1880 & $\begin{array}{l}\text { National } \\
\text { investment }\end{array}$ \\
\hline 4 & Cono Sur & $\begin{array}{l}\text { Colchagua } \\
\text { Valley }\end{array}$ & & & $\mathrm{X}$ & & 1993 & $\begin{array}{l}\text { National } \\
\text { investment }\end{array}$ \\
\hline 5 & & Aconcagua & & & & & & Old family \\
\hline 6 & Errazuriz & Valley & $\mathrm{X}$ & & & & 1870 & $\begin{array}{l}\text { business } \\
\text { Old family }\end{array}$ \\
\hline & Undurraga & Maipo Valley & & $\mathrm{X}$ & & & 1885 & business \\
\hline 7 & Montes & $\begin{array}{l}\text { Colchagua } \\
\text { Valley }\end{array}$ & & & $\mathrm{X}$ & & 1988 & $\begin{array}{l}\text { National } \\
\text { investment }\end{array}$ \\
\hline 8 & S. Carolina & $\begin{array}{l}\text { Maipo Valley } \\
\text { Colchagua }\end{array}$ & & $\mathrm{X}$ & & & 1877 & $\begin{array}{l}\text { National } \\
\text { investment } \\
\text { National }\end{array}$ \\
\hline & S. Helena & Valley & & & $\mathrm{X}$ & & 1942 & investment \\
\hline 10 & Tarapaca & Maipo Valley & & $\mathrm{X}$ & & & 1874 & $\begin{array}{l}\text { National } \\
\text { investment }\end{array}$ \\
\hline 11 & Carmen & Maipo Valley & & $\mathrm{X}$ & & & 1850 & $\begin{array}{l}\text { National } \\
\text { investment }\end{array}$ \\
\hline 12 & S. Emiliana & Maipo Valley & & $\mathrm{X}$ & & & 1986 & $\begin{array}{l}\text { National } \\
\text { investment }\end{array}$ \\
\hline 13 & La Rosa & $\begin{array}{l}\text { Cachapoal } \\
\text { Valley }\end{array}$ & & & $\mathrm{X}$ & & 1824 & $\begin{array}{l}\text { Old family } \\
\text { business }\end{array}$ \\
\hline 14 & Ventisquero & $\begin{array}{l}\text { Cachapoal } \\
\text { Valley } \\
\text { Colchagua }\end{array}$ & & & $\mathrm{X}$ & & 1998 & $\begin{array}{l}\text { National } \\
\text { investment }\end{array}$ \\
\hline 16 & Los Vascos & Valley & & & $\mathrm{X}$ & & 1988 & Joint-venture \\
\hline 17 & Valdivieso & $\begin{array}{l}\text { Curicó Valley } \\
\text { Colchagua }\end{array}$ & & & & $\mathrm{X}$ & 1879 & $\begin{array}{l}\text { business } \\
\text { businy }\end{array}$ \\
\hline 18 & Lapostolle & Valley & & & $\mathrm{X}$ & & 1994 & $\begin{array}{l}\text { Joint-venture } \\
\text { Foreign }\end{array}$ \\
\hline 19 & M. Torres & Curicó Valley & & & & $\mathrm{X}$ & 1979 & $\begin{array}{l}\text { investment } \\
\text { Family }\end{array}$ \\
\hline 20 & Canepa & $\begin{array}{l}\text { Maipo Valley } \\
\text { Colchagua }\end{array}$ & & $\mathrm{X}$ & & & 1980 & $\begin{array}{l}\text { Business } \\
\text { Family }\end{array}$ \\
\hline 21 & LF Edwards & $\begin{array}{l}\text { Valley } \\
\text { Colchagua }\end{array}$ & & & $\mathrm{X}$ & & 1976 & $\begin{array}{l}\text { Business } \\
\text { Family }\end{array}$ \\
\hline 22 & Bisquertt & Valley & & & $\mathrm{X}$ & & 1975 & $\begin{array}{l}\text { business } \\
\text { Old family }\end{array}$ \\
\hline 23 & CousiñoMacul & Maipo Valley & & $\mathrm{X}$ & & & 1856 & $\begin{array}{l}\text { business } \\
\text { Old family }\end{array}$ \\
\hline 24 & Santa Ema & $\begin{array}{l}\text { Maipo Valley } \\
\text { Colchagua }\end{array}$ & & $\mathrm{X}$ & & & 1931 & $\begin{array}{l}\text { business } \\
\text { Family }\end{array}$ \\
\hline & Casa Silva & Valley & & & $\mathrm{X}$ & & 1977 & business \\
\hline 25 & Almaviva & Maipo Valley & & $\mathrm{X}$ & & & 1997 & Joint-venture \\
\hline
\end{tabular}

Source: Author's survey 
In Argentina, the two most important provinces in terms of vine cultivation are Mendoza and San Juan. These concentrate 92 percent of planted vineyards (see Table 6.3). This research, therefore, focuses on the clusters of Mendoza and San Juan from a comparative perspective. Mendoza alone, with its 160,000 hectares of vineyards and sixteen major wine producing departments, represents the heartland of the production of fine export wines in Argentina. In 2008, 68 percent of the country's planted vineyards area were concentrated in Mendoza, nearly half of which were planted in noble varieties. Also, 80 percent of Argentine exports of premium wines and 72 percent of all Argentine wineries were concentrated there. New viticultural provinces, however, are gradually emerging in the Northwest of the country (Salta, Catamarca, La Rioja) and in the South (Rio Negro and Neuquén). ${ }^{115}$ Of these, Rio Negro and Neuquén, located in Patagonia between the 36th and the 40th parallels south, host the most southern vineyards in the world. In both Patagonian provinces vine-growing and winemaking activities are very recent and relatively limited in scale - but they are rising at a spectacular pace, to the point that in 2011 a Patagonian wine, produced by Bodega Noemía, was ranked among the top 100 wines of the year (Wine Spectator, Dec. 2011).

Table 6.3 Argentine planted surface with vineyards, wine production and wine exports according to administrative provinces, 2008

\begin{tabular}{lcccc}
\hline Provinces & $\begin{array}{c}\text { Planted surface } \\
\text { with vineyards } \\
\text { (hectares) }\end{array}$ & $\begin{array}{c}\text { Wine production } \\
\text { (hectolitres) }\end{array}$ & $\begin{array}{c}\text { Wine exports } \\
\text { (USD) }\end{array}$ & $\begin{array}{c}\text { Number of } \\
\text { exporting } \\
\text { wineries }\end{array}$ \\
\hline Mendoza & 160,704 & $8,620,869$ & $360,845,216$ & 351 \\
San Juan & 49,492 & $1,666,837$ & $13,818,723$ & 28 \\
La Rioja & 8,518 & 94,356 & $9,482,412$ & 16 \\
Rio Negro & 2,636 & 82,856 & $1,229,596$ & 9 \\
Catamarca & 2,583 & 58,474 & 190,718 & 5 \\
Salta & 2,296 & 193,791 & $10,602,004$ & 4 \\
Neuquén & 1,631 & 84,643 & $5,243,678$ & 5 \\
\hline
\end{tabular}

Source: INV, 2009

Given the persistent spatial concentration of wine exports in the province of Mendoza, the distribution of the leading 25 Argentine exporting wineries included in the present survey is quite unbalanced, compared to the Chilean case: 24 of them are situated in the cluster of Mendoza, and only 1 in the cluster of San Juan (see Table 6.4). As observed in the previous chapter, in Argentina the vast majority of the top exporting wineries was established after 1991 or was bought by foreign investors, and completely renovated and equipped with state-of-the-art technology in this period. Seventeen of the 24 leading exporting wineries located in Mendoza are actually foreign investments, while only one is a joint venture. The remaining 7 are national investments, in most

\footnotetext{
115 As observed in Chapter 4, Frey Juan Cidrón, who introduced grapes into Argentina in 1557, travelled from the recently founded city of La Serena, in Chile, and stopped in the Mendoza province after having crossed the Andes. Vines were planted there for both sacramental purposes and daily consumption. The novelty - vine cultivation - immediately reached several other northwestern Argentine provinces, namely San Juan, Cordoba, Tucuman, La Rioja and Salta. Until recently, however, vine cultivation for winemaking has represented a real source of income and economic growth only for Mendoza and San Juan.
} 
cases, traditional family-owned companies still led by the founders or their family descendants.

Table 6.4 Geographic concentration of the top 25 Argentine exporters of bottled wines

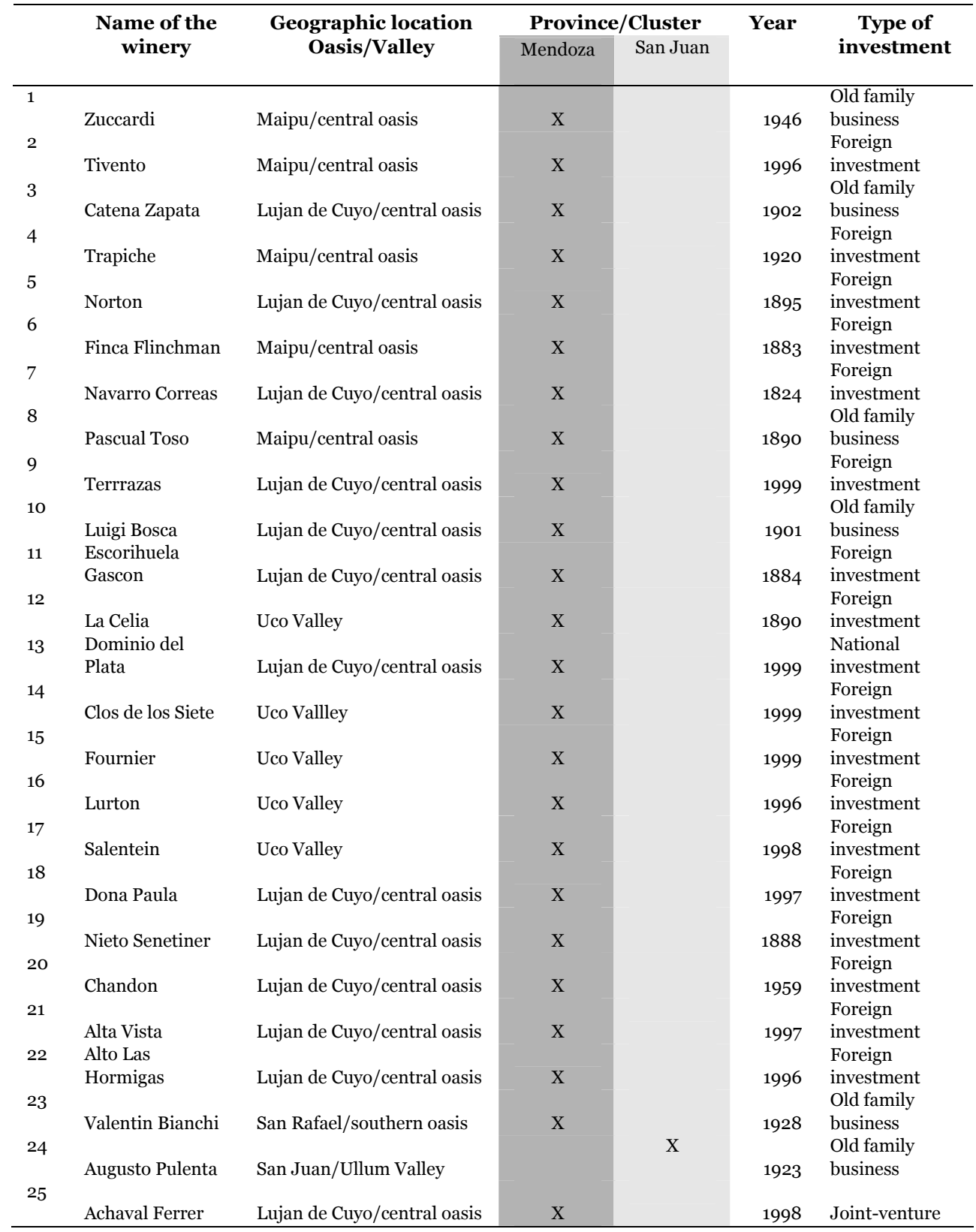

Source: Author's survey 
The following sections will show how wine clusters may follow different pathways to become innovative and to sustain export growth in the long term. Firstly, the degree of "organization" will be examined, that is, the cooperation and networking dynamics that have emerged among firms located in the cluster and local institutions through deliberate joint actions, as well as the creation of collective efficiencies, such as greater access to inputs from upstream suppliers, reduced transaction costs and more rapid technological problem-solving. This will allow an examination of the propositions raised earlier in this thesis which dealt with the typology of informal versus organized clusters, and which led to the belief that this categorization might help to illuminate the differential export performance across these geographical areas.

Secondly, the following sections will assess the extent to which the consolidation of competitiveness factors at the cluster level has benefitted from the presence of constructed advantages at the regional level. This will allow verification as to whether firms located in organized clusters exhibit a higher capacity to tap into sophisticated knowledge and innovation inputs generated within broader regional innovation systems (RSI). It has been hypothesized that RSI are key in helping organized clusters to undertake technology adaptations, to design new products and processes and to bring them quickly to market, but also to eventually change their technological trajectories through radical innovations when the pressure of international competition demands it.

\subsection{The Chilean case: Differentiating organized wine clusters (Colchagua) from informal wine clusters (Curicó)}

Before the wine revolution, all the leading wineries in Chile were headquartered in Santiago and had planted the majority of their vineyards in the Maipo Valley, bordering the Metropolitan Region where Santiago is situated. The Maipo cluster remains the best known Chilean wine area, thanks to its proximity to Santiago and to the presence of the most emblematic Chilean wineries, such as Concha y Toro, Santa Rita and Undurraga. ${ }^{116}$ Over time, however, other regions have emerged and become increasingly prominent. Under the influence of increased export opportunities, of spectacular rates of urban growth and of skyrocketing prices of land, as well as of the massive arrival of foreign investors in the 1990s, new vineyards have been planted in the so-called "Central Valley", ranging from the Maipo Valley in the north to the Maule Valley in the south.

The Colchagua cluster, situated $180 \mathrm{~km}$ south-west of Santiago in the Rapel Valley, is currently considered the "aristocracy" of Chilean terroir, especially with respect to red wines and Carmenère (Wine Spectator, June 2010). The cluster of Curicó, on the contrary, has become known not only for its latent potential, especially for white wines, but also for its technological backwardness. This is surprising as the Colchagua and Curicó clusters border on each other, are equidistant from Santiago and, at their origin,

\footnotetext{
${ }_{116}$ As observed in Chapter 5, these are more than a century old wineries, founded during the second half of the nineteenth century by entrepreneurs who had accumulated huge fortunes in the mining industry and who wanted to broaden the base of their investments.
} 
share the same productive specialization in the agro-industry. Interestingly enough, from an administrative perspective they are located in different regions: Colchagua in the O'Higgings (VI) region, and Curicó in the Maule (VII) region. Curicó, as noted in the previous chapter, is also the location chosen in 1979 by Miguel Torres, the Spanish winemaker who revolutionized the way in which wine was produced in Chile, and hosts one of the four main Chilean wine giants, San Pedro, which, with its $8 \mathrm{~km}$ of vineyards, is one of the most impressive wineries in South America in terms of size, equipment and winemaking tradition.

From an historical perspective, the O'Higgings (VI) region, where the Colchagua cluster is located, specialized in agriculture long before the resurgence of the Chilean wine industry in the mid-1980s. Until the 1990s, the region has traditionally represented the tranquil heartland of Chile's fruit orchards, with the main export crops being apples, pears, table grapes, plums and kiwis. The change since then has been profound. Within two decades, local business owners turned their attention towards the (more lucrative) production and processing of grape varieties for winemaking, thus tripling the total vineyard area from just over 8,000 hectares in 1997 to 23,000 hectares in 2007, and transforming the O'Higgins (VI) region into the second largest wine producing area of the country, accounting for 32.7 percent of total wine production. Analogously, the Maule (VII) region, where the cluster of Curicó is located, has traditionally specialized in agriculture and fruit, and has focused on wine production only recently. It currently accounts for 43.2 percent of the country's total vineyard area and 48.8 percent of national wine production. However, the Maule region has become known for its export of high volumes rather than high quality of wines. With respect to wine exports, data released by ProChile (see Table 6.5) show that the performance of the O'Higgins (VI) region has been impressive, considering the spectacular growth of bottled (versus bulk) wines $(+150$ percent in five years). Conversely, during the same period the Maule (VII) region saw its exports of bulk wines rise at twice the rate of its exports of bottled wines (+71 percent versus +37 percent).

Table 6.5 Distribution of Chilean wine exports per region, 2004-2009 (US\$)

\begin{tabular}{|c|c|c|c|c|c|c|c|c|c|}
\hline & \multicolumn{2}{|c|}{ BOTTLED } & \multirow[t]{2}{*}{ Var. } & \multicolumn{2}{|c|}{ BULK } & \multirow[t]{2}{*}{ Var. } & \multicolumn{2}{|c|}{ TOTAL } & \multirow[t]{2}{*}{ Var. } \\
\hline & 2004 & 2009 & & 2004 & 2009 & & 2004 & 2009 & \\
\hline III Atacama & 53134 & 52996 & $-0.5 \%$ & 32618 & 18960 & $-41 \%$ & 85752 & 71956 & $-16 \%$ \\
\hline IV Coquimbo & 3036406 & 5872015 & $93 \%$ & 1534354 & 5557063 & $262 \%$ & 4570760 & 11429078 & $150 \%$ \\
\hline V Valparaiso & 72899674 & 96308306 & $32 \%$ & 2642028 & 6463935 & $144 \%$ & 75451702 & 102772241 & $36 \%$ \\
\hline $\begin{array}{l}\text { Region } \\
\text { Metropolitana }\end{array}$ & 390787984 & 688861974 & $76 \%$ & 32407215 & 66481305 & $105 \%$ & 423195199 & 755343279 & $78 \%$ \\
\hline VI O'Higgins & 79034747 & 196986221 & $150 \%$ & 22964500 & 39329750 & $71 \%$ & 101999247 & 236315971 & $131 \%$ \\
\hline VII Maule & 117521343 & 161112033 & $37 \%$ & 55799419 & 95888323 & $71 \%$ & 173320762 & 257000356 & $48 \%$ \\
\hline VIII Bio Bio & 577719 & 701190 & $21 \%$ & 3732918 & 42380 & $-98 \%$ & 4310637 & 743570 & $-82 \%$ \\
\hline
\end{tabular}


Within the O'Higging (VI) region, the Colchagua cluster agglomerates a relatively small number (around 40) of new, high-quality, export oriented wineries, including names such as Casa Lapostolle, Montes, Viu Manent, MontGras and Los Vascos, which are constantly improving their reputation, thanks to rising international scores and critics, allowing them to sell at increasingly high prices. Surprisingly, Colchagua has had a comparatively small influx of foreign capital. In 2003, 87 percent of investment in the cluster was fully national (Giuliani, 2004). Even more importantly, the existing foreign firms and joint-ventures appear to be fully integrated into the local eco-system (Giuliani, 2010). In 2005, Colchagua was awarded Wine Enthusiast's "Wine Region of the Year", while in 2006 the specialized magazine Decanter declared the Cabernet Sauvignon from Colchagua "the best value Cabernet Sauvignon on the planet" (Decanter, May 2006). In 2007, the top 100 wines list released by Wine Spectator included two wines from Chile for the first time in the longstanding history of the Chilean wine industry. Both were from the Colchagua Valley. How could this happen? Which factors can explain the relatively quick transformation of the Colchagua wine cluster?

Firstly, Colchagua has 7,774 hectares of land planted in vines, with 80 percent belonging to wineries; 11 percent to independent grape growers; and 9 percent to grape growers under the supervision of wineries who buy their grapes from growers under contract farming agreements (Olavarria et al., 2008). Working mainly on an estate basis and using grapes from their own vineyards enables wineries total control and monitoring of the grapes, and is at the origin of the rise in the number of good quality wines in both Chile and (to a lesser extent) Argentina. Contract farming agreements are also part of that process, as grape growers are paid based on the area cultivated, rather than on the quantity delivered, and can therefore concentrate on the production of quality grapes. From interviews, it emerges that some larger companies, such as Casa Lapostolle, Montes or Luis Felipe Edwards, have been constantly increasing their vertical integration, or establishing highly regulated contract farming agreements. Smaller wineries, which cannot usually afford either vertical integration or contract farming arrangements, have also found alternative ways of upgrading the quality of the grapes they buy from independent grape growers. In 2004-2008, for example, a series of learning groups were created by $8-10$ firms in order to share the cost of consultants, and to solve common problems related to the need to rely on better quality grapes and to upgrade local independent vine growers.

Secondly, a wine route was created in Colchagua in 1996, as a consequence of the strong commitment of Aurelio Montes, the Chilean winemaker who pioneered the exploration of the valley and invested in the potential of Colchagua when the cluster was still at its informal stage. This is particularly important, since the ability to form and maintain effective socio-economic relations can be considered crucial for stimulating technological upgrading and innovation at the cluster level. The route, with its accurately restored wine-tourism steam engine train, is considered one of the nicest and best organized in South America, thanks to its exceptionally visible road sign system. From the observation of the website and of the promotional material, it appears clear that the route has played a key role in attracting the attention of foreign visitors to local wine-tasting opportunities, offered in both English and Spanish. From interviews with 
Montes, it emerges that the route has also been instrumental in creating a common set of goals and networking opportunities for local wineries. For example, after the creation of the route, a substantial amount of social networking has taken place among local winery owners, who have been meeting on a regular basis to identify new innovative solutions, to improve and expand the scope of activities, and to engage in joint problemsolving efforts. Additionally, an informal committee was created in 2008 in order to discuss the challenges and potential market opportunities of high-altitude viticulture, which represents a new potential source of diversification and expansion for the Colchagua wine cluster.

Thirdly, the majority of wineries in the Colchagua cluster have established linkages with the most important research institutions, business associations and other organizations. Interviews with the main wineries reveal that the majority of firms have received technical assistance from both CEVIUC (of the Catholic University of Chile) and CTVV (of the University of Talca), which has been highly valued by all of them. ${ }^{117}$ They have also largely benefitted from the assistance provided by the two main wine associations, Chilevid and Viñas de Chile, from the information provided by SAG (Servicio Agricola y Ganadero), and from the projects coordinated by CORFO. Since 2005, the presence of a training institute specialized in wine production has also triggered the organization of regular monthly meetings of local oenologists and agronomists, where each one's wines are tasted and winemaking techniques are compared. This is very important, as a substantial amount of formal and informal knowledge exchange may happen among firms, but also and especially among specialized individuals and skilled labour through social interaction. In the Colchagua cluster, for example, local oenologists have been regularly meeting to identify new innovative solutions and to engage in joint problem-solving efforts, with the assistance of local supporting institutions. This has contributed to the creation of local tacit knowledge and to the diffusion of incremental innovations, which have been further enhanced by a relatively high rate of professional "mobility" of local oenologists among the firms located in the cluster.

Fourthly, the expansion of the Colchagua cluster has been triggered by the investments of Carlos Cardoen, a wealthy businessman and public figure born in Santa Cruz, the capital of the district. In 1996 Cardoen built a luxury hotel and a gastronomic restaurant with adjoining museum, which have attracted visitors throughout the year and have promoted luxury tourism. Thanks to Cardoen's leadership, local wineries have started to group and market together their region, vigorously affirming their identity. Colchagua's wineries have also created a local business association and are known for their efforts at branding their valley, even above and beyond the national "Wines of Chile" brand name. Based on a public-private partnership, new initiatives are currently underway, such as the creation of an astronomical observatory and of a new

\footnotetext{
117 For example, the University of Talca has developed a tool for identifying vine varieties using molecular markers. Using green material taken from the plants, segments of DNA can be extracted, amplified and compared with a standard reference profile for each variety with a certainty level of 99.9 percent. The University of Talca has also created an irrigation programming system using TDR (Time Domain Reflectometry) equipment, in conjunction with a differentiated soil mapping technique. This method allows winegrowers to program their irrigation systems based on the soil's physical and chemical characteristics that affect moisture retention, thus optimizing the use of water.
} 
Technological Wine Institute. In Colchagua, there is widespread expectation that this will be of crucial importance to providing new knowledge from an endogenous source, to adapting research to local conditions, and to providing appropriate services and technologies for the clusters' stakeholders.

Based on the above, the field research reveals that Colchagua has transformed itself into an organized cluster, as several deliberate forms of inter-firm and public-private interaction were put in place, which are the origin of the competitive performance and high levels of innovativeness of the cluster. These stem from consciously pursued joint actions, of the four types identified by Nadvi and Schmitz (1997): a. joint action within vertical linkages, including backward ties and networks with suppliers and subcontractors, and forward ties with traders and buyers; b. joint action within horizontal linkages, between two or more local producers; c. joint action within institutional linkages among a large number of local producers and cluster-wide institutions (including business associations, universities and business development services); and d. joint action made possible by public-private partnerships.

Interviews with local winemakers, however, disclose that the Colchagua cluster did also largely benefit from more formal R\&D activities carried out outside the cluster, namely by research institutions such as the CTVV of the University of Talca and the CEVIUC from the Catholic University of Chile, as well as from the technical support provided by national institutions, such as SAG, from the assistance projects coordinated by CORFO, and from the market information provided by national associations, such as Chilevid and Viñas de Chile. In particular, considering the geographic conditions of Colchagua, characterized by a fiercely warm climate and deep fertile soils, the development of knowledge linkages among cluster members and the stimulus for knowledge acquisition has been driven by the need felt by leading wine exporters for quality improvement, namely to achieve ripeness and complexity of red wines without an excessive alcohol content, over-dry tannins and of over-ripening flavours, as required by international consumer taste.

In this respect, local wineries have relied on the presence of very skilled local technicians who deeply understand the biology of the plants from their previous experience in the fruit industry and introduce the needed incremental improvements at the viticultural level. These range from the local experimentation with canopy management techniques to achieve adequate but not excessive shading, to the reevaluation of traditional irrigation techniques, to the testing of different yield requirements and harvest dates. However, on the winemaking side, local oenologists have also felt the need to introduce more radical innovations, which were necessary to align the taste of the wines made in Colchagua with the requirements of the international export markets. They have thus relied on more formal R\&D activities and technical support provided by university-industry links with research institutions such as CTVV of the University of Talca or CEVIUC from the Catholic University of Santiago, located outside the cluster - within broader regional innovation systems belonging either to the nearby Central Region or to the Maule (VII) region. For example, the most relevant laboratory experiments that were carried out at the university level were aimed 
at refining methods of extraction, at using softer pressings and lower fermentation temperatures, and at testing wild yeast fermentation to lower final alcohol contents.

This suggests that the openness of clusters, namely their capacity to connect to extracluster sources of knowledge and innovation, and to draw on constructed advantages at the regional level, is sometimes key to avoiding being locked in obsolete technological trajectories. Sometimes, as in the case of Colchagua, external knowledge and inputs can be sourced in regions that are located nearby, or at the national level. In contrast, the situation of the Curicó cluster is very different from that of Colchagua, in that Curicó seems to have neither managed to complete its transition from an informal to an organized cluster, nor connected to the extra-cluster sources of knowledge and innovation needed to overcome its technological path dependency.

Curicó represents one fifth of Chile's vineyard area and produces nearly one quarter of the country's wine. Despite its acknowledged natural potential, Curicó has lagged behind other more dynamic wine clusters, such as Colchagua, and is known for its large volumes but limited scope for higher quality wines (Ross, 2006). The city of Curicó itself is quite unattractive, and has no particular sign of distinction or tourist attraction other than the annual wine festival. The process of building a common brand and identity at the valley-cluster level is still at the very embryonic stage, and is mainly triggered by and confined to commercialization and marketing activities, such as the Curicó Wine Route, created in 2003. Interviews reveal that the fragmentation, isolation and individualism of the local entrepreneurs is noticeable, as well as a lack of networking dynamics among local professionals. It is also debatable whether the emergence of active rather than purely passive forms of externalities is really taking place. Overall, therefore, the Curicó cluster seems to lack a drive for quality and continuous innovation of the sort that has allowed Colchagua to identify quality terroirs, local identity, and varietal character (see Table 6.6).

Table 6.6 Production of Chilean bottled premium wines with Denomination of Origin per Valley (in litres), 2010

\begin{tabular}{|c|c|c|c|c|c|c|}
\hline & $\begin{array}{c}\text { Cachapoal } \\
\text { Valley }\end{array}$ & $\begin{array}{c}\text { Casablanca } \\
\text { Valley } \\
\end{array}$ & $\begin{array}{c}\text { Colchagua } \\
\text { Valley }\end{array}$ & $\begin{array}{l}\text { Curicó } \\
\text { Valley }\end{array}$ & $\begin{array}{c}\text { Loncomilla } \\
\text { Valley }\end{array}$ & $\begin{array}{c}\text { Lontué } \\
\text { Valley }\end{array}$ \\
\hline Chardonnay & $3,185,957$ & $8,332,024$ & $9,810,757$ & $4,271,833$ & 490,028 & $2,389,044$ \\
\hline C. Sauvignon & $10,843,875$ & 16,075 & $41,953,693$ & $17,749,437$ & $2,496,448$ & $4,445,496$ \\
\hline Carmenère & $2,964,707$ & 6,958 & $12,631,357$ & $3,861,816$ & 551,023 & $840,45^{2}$ \\
\hline Merlot & $5,750,631$ & $1,392,213$ & $14,364,773$ & $6,215,065$ & 600,877 & $2,188,603$ \\
\hline S. Blanc & $1,931,875$ & $8,181,133$ & $5,164,999$ & $14,639,644$ & $2,158,760$ & $7,433,172$ \\
\hline Total & $5,334,230$ & $22,510,051$ & $98,190,044$ & $52,106,680$ & $7,256,523$ & $18,744,733$ \\
\hline
\end{tabular}

Source: SAG, 2011

In the Maule (VII) region, where Curicó is located, an exception is represented by Talca, the capital, where there is a university with a wine school, the second Faculty of Agronomy in the country, and a small active technological institute (CTVV) which, 
however, cannot rival the Catholic University and the University of Chile located in Santiago. From interviews, it was apparent that CTVV represents a nationally acknowledged attraction pole for wineries located both within and outside the region (e.g., for the wineries in Colchagua), and generates a considerable amount of knowledge flow. It was striking, however, to observe how the wineries located in Curicó were less connected to the University of Talca, and less aware of the research projects and initiatives carried out there than those located in Colchagua, despite being located nearer and belonging to the same region. These findings are corroborated by the informative study by Tiffin and Kunc (2008), who found that the University of Talca has played virtually no role in the evolution of the wine region where it is located, namely the Maule (VII) region, and in particular has not strengthened networking dynamics within the local clusters.

The presence in the Curicó cluster of wineries, such as Miguel Torres or San Pedro, is only apparently a paradox considering that both belong to the category of "external stars" (Allen, 1997; Giuliani, 2005). External stars are firms that have established strong linkages with external sources of knowledge but have established limited links with the intra-cluster knowledge system. In this sense, Giuliani (2005) is correct in saying that knowledge is not diffused evenly "in the air" but flows within firms characterized by advanced absorptive capacities, and that while those firms contribute actively to the acquisition, creation and diffusion of knowledge, others may remain cognitively isolated if their knowledge base remains too weak.

The field research has highlighted, therefore, that, even in the case of close geographical proximity, there is a limit to the extent to which knowledge may spill over among firms, since these are not equally capable of successfully absorbing frontier knowledge. Local firms have fewer chances of learning from foreign investors, leading exporters, or local "external stars", if the cluster is not sufficiently organized to enhance the development of their technological capabilities, and if no "constructed advantages" are created around them through synergies with broader innovation systems. Most importantly, the main factors driving export competitiveness can be identified only partially by looking at the behaviour of individual firms, as the innovation process is systemic in nature and is deeply embedded in the territory where firms are located.

\subsection{The emergence of a "centralized" IS in the Chilean Metropolitan Region}

Not surprisingly, the majority of Chile's premium wines are produced in the three central regions that are the closest to the capital, Santiago de Chile, where most leading exporters of premium wines have their headquarters and offices - even if their vineyards are often located in other regions. According to Visser and de Langen (2006), if indeed the presence of clusters is important to the competitiveness of the Chilean wine industry, even more important is the role of the Metropolitan Region, as marketing, administrative, strategic decision making and representative functions are all concentrated in Santiago. Like many other Latin American countries, Chile has 
always been capital-centred, and this characteristic is still predominant (Crowley, 2001).

The wine industry shows some "centralist" tendencies as well, and this makes of Santiago the hub not only for government but also for industry, technology and business. Banks and financial services are concentrated in the capital, as well as transport and shipping companies and services, essential for exporting effectively and reliably. Repair services, specialized technicians and representatives of foreign equipment producers are also located in Santiago, and several times during interviews, the argument was made that the farther from the capital, the more difficult to find machine parts, staff, or reliable services. Some wineries even complained that they were forced to stock two pieces of every part, in order to avoid disrupting operations.

From a business perspective, Santiago hosts not only the headquarters of all the leading wine producers and exporters, but also the totality of key specialized suppliers of the industry. Tonelería Nacional, for example, sells barrels made from French and American oak not only to Chilean wineries, but also internationally, to the point that it now ranks among the world's leading barrel producers. After six years of research, it also created a specialized company called Odysé, which provides individualized services to winemakers for creating the prototype barrel that would bring out certain specific wood flavours and aromas, depending on their needs. A similar development has also characterized the cork industry. Four Portuguese cork firms have installed their facilities around Santiago, including the ACI holding company, the world's second leading cork producer, which arrived in the country in 1998. Also in the area of bottle production, several suppliers have entered the Chilean market, introducing innovative concepts such as "light bottling" in order to compete with already established, more traditional suppliers. Finally, in Santiago the number of specialized graphic artists and design agencies is proliferating, thanks to the increasing demand for creative and artistic wine bottle labels.

Equally importantly, Santiago hosts almost entirely the institutional framework that forms part of the Chilean innovation system, encompassing laws, standards, norms, routines and established practices that shape local agents' cognition and behaviour, and influence their interaction (Malerba, 2004). In the wine industry, the main institutional actors are represented by the main national wine associations (Viñas de Chile and Chilevid); two of the three specialized universities (University of Chile and the Catholic University of Chile); the main R\&D institutes (CONICYT, the Chilean government agency for scientific research, and INIA, already mentioned the previous chapter); and the main public agencies involved in the promotion of the wine industry, such as SAG, ProChile and CORFO.

The structural dichotomy of the Chilean wine industry - where a large gap exists between the top large and medium-sized exporters, and the younger and smaller wineries - is clearly reflected in its associative articulation. There are two major associations, which mainly operate in Santiago: Viñas de Chile, which is the oldest (founded in 1949) and pulls together the 45 largest traditional companies, and Chilevid (the association of small producers of fine export wines), which was created in January 
1993 and now groups 42 viñas emergentes or boutiques. In Chile, the explosion of exports has brought about sharp changes in the industrial structure of the wine industry. A group of around 70 emerging small-scale exporting high-quality wineries, so-called viñas boutiques, or viñas emergentes, has introduced new dynamism, product diversification and real competition into a sector which previously was oligopolistically consolidated. At present, the domestic market is still dominated by the traditional core group of Chilean winemaking companies (Concha y Toro, San Pedro, Santa Rita, Undurraga), but the export market shows a tremendous rate of newcomer entrants.

In the past, the two associations have often manifested divergent interests, to the point that on several occasions deep disagreements led to the paralysis of all coordinated activities. During the last decade, however, under the pressure of international competition, the two wine producers' associations have started working closely together, especially in their activities abroad, and in 2006 created a new joint entity, called Vinos de Chile. The first important outcome of their joint efforts consisted in launching the Wines of Chile export promotion board in 2007, together with the creation of a common logo for all Chilean wines. This was an incredible step forward, as until then there was neither such "Product of Chile" identity nor symbolic image. Additionally, the Wines of Chile office in London was re-opened, after it had been closed in 2000, for lack of institutional support and due to its expensive operational costs. Wines of Chile is the only Chilean initiative that resembles a national promotion organization, similar to the Australian Wine Bureau and to Wines of South Africa. According to Tienhoven (2008), the lack of such an organization, possibly due to the initial predominance of FDI in the industry, is what has hampered the consolidation of an image of Chile in international consumers' minds. At present, there are Wines of Chile offices in Santiago, London and the US, with an annual budget of about 6 million US $\$$, with the government contributing 15 percent of the total amount devoted to export promotion through ProChile.

ProChile is the Chilean export promotion agency, founded in 1974 to support and coordinate export activities by small firms from all productive sectors. ProChile's support of the development of the wine industry has proved very important. ProChile has traditionally financed half of the costs of activities in promoting Chilean wines abroad (including fairs, travel costs, marketing materials). Moreover, it has often supported the joint participation of smaller wineries in international fairs (such as Expogourmand, Vinexpo, Vinitaly and Vinsud), as well as activities such as Chilevid's website, promotional materials on Chilean wines in different languages, the logistics of the annual "Wine Show and Tasting", and campaigns promoting the natural attractions of Chile and the quality of its products. Together with SAG, ProChile was also part of a technical lobbying commission that pushed heavily for the adoption of a denomination of origin regulation in 1994 .

SAG is the branch of the Ministry of Agriculture devoted to agricultural and phytosanitary controls, and has played a fundamental role in the development of the Chilean wine industry. It enforces national laws pertaining to winemaking and vinegrowing, and compiles statistics on crops, production and exports, allowing growers and producers to make informed decisions. All wines produced in Chile for both 
domestic consumption and export are sampled by SAG for quality control. SAG also releases export certificates specifying the wine's type, variety and origin.

From an institutional perspective, therefore, it emerges that the public sector is more present than commonly perceived. Strategically, the Chilean government has not played an active role in promoting wine exports or the development of the wine industry, but has rather played the role of legislator and good regulator. ${ }^{118}$ It has also actively pursued the signature of bilateral trade agreements (Chile has the highest number of bilateral free trade agreements in the world, currently over 40), which have contributed to the success of Chilean wine exports. For example, Chilean wines will have free access to Mercosur in 2011, China in 2015, the United States in 2016, and Japan in 2020. Additionally, scratching the surface, it becomes clear how, since the beginning of the 1990s, substantial public efforts to develop the wine industry have been channelled through CORFO, the second-tier public operational body for SME development, which, as observed in the previous chapter, is well known among development economists for the variety and impact of its policy instruments. Several of CORFO's projects were instrumental in stimulating the "wine revolution" in Chile, and in bringing Chilean wines closer to international taste and quality standards (Benavente, 2006).

To start with, it was through a CORFO project for technological innovation, called FONTEC, that, since 1991, the largest wine companies (i.e., Concha y Toro, Santa Rita, Carmen, Cusiño Macul, Santa Emiliana) could completely renew their industrial equipment and incorporate new, modern technologies into their productive processes by investing massive amounts of capital. It was also thanks to an FDI project that since 1995 the same large companies started to tackle strategic technological innovation issues with a relevant social and economic impact (such as ISO 14000 certification, identification and definition of different Chilean terroirs, integrated and organic cultivation techniques, and the development of phylloxera and oidium resistant rootstocks). Furthermore, in the 1990s, smaller companies were supported in developing their management and technical capabilities through specialized consultancy services and through supplier development projects, called PDPs, aimed at incentivizing grape-growers to increase the quality of grapes produced (and thus wine price and competitiveness).

It may also be recalled that it was through a CORFO project, in 1993-1997, that the second association of smaller exporting producers (Chilevid) was created and the notion of viñas emergentes or boutiques emerged for the first time, thereby reverting a long-standing institutional sclerosis and breaking the monopoly of the largest consolidated traditional producers. Later on, CORFO also supported the creation of the Chilean Wine Corporation (CCV), the organization aimed at promoting collaborative group actions to maximize competitiveness through grant projects. More recently, it is again thanks to CORFO that several embryonic "wine routes" have started to emerge in different valleys, generating enormous benefits in terms of tourism attraction and

118 In 2008, Chile ranked 22nd in Transparency International's Corruption Perception index, and is considered by far the least corrupt country in Latin America (Tienhoven, 2008). Consequently, in 2005-2009, the Economist Intelligence Unit ranked Chile as the number one country to do business in Latin America. 
image promotion, and setting bases for building trust processes and for consolidating common cluster identities. Finally, it is thanks to a new investment promotion programme, called TODOCHILE, that in the last decade Chile has managed to continue to attract foreign investors, mainly in the form of joint-ventures and acquisitions (see Table 6.7).

Table 6.7 CORFO's TODOCHILE programme

\begin{tabular}{|c|c|c|}
\hline Objective & Line & Description \\
\hline Promote investment & Feasibility studies & $\begin{array}{l}\text { Up to } 2 \% \text { of the investment value and up to } 50 \% \text { of } \\
\text { the cost, with a ceiling of } 30,0000 \text { US } \$\end{array}$ \\
\hline \multirow{6}{*}{$\begin{array}{l}\text { Attract high-tech } \\
\text { investment }\end{array}$} & Feasibility studies & Up to $60 \%$ of the cost, with a ceiling of 60,000 US $\$$ \\
\hline & Project launch & Up to 30,000 US $\$$ per company \\
\hline & Employee training & $\begin{array}{l}\text { Up to } 50 \% \text { of employees' gross annual wage, with a } \\
\text { ceiling of } 25,000 \text { US } \$\end{array}$ \\
\hline & Fixed assets & $\begin{array}{l}\text { Up to } 40 \% \text { of total investment, with a ceiling of } \\
2,000,000 \text { US } \$ \text { per company }\end{array}$ \\
\hline & Long-term leases & $\begin{array}{l}\text { Up to } 40 \% \text { of the lease amount during the first five } \\
\text { years, with a ceiling of } 1,000,000 \text { US } \$ \text { per company }\end{array}$ \\
\hline & $\begin{array}{l}\text { Advanced training } \\
\text { programme }\end{array}$ & $\begin{array}{l}\text { Up to } 50 \% \text { of the programme's cost on a one-time } \\
\text { basis, with a ceiling of } 100,000 \text { US } \$\end{array}$ \\
\hline
\end{tabular}

Source: CORFO, InvestChile, 2008

Overall, therefore, a quite strong, though centralized system of wine-related actors, associations, government organizations, research centres and support institutions seems to have emerged during the last few years (see Table 6.8). Indeed, during field research in the Colchagua cluster, the direct or indirect presence of activities carried out by most supporting institutions mentioned in the table below were often detected, including those operating at the national level, such as the wine associations, the industry supporting institutions, the international promotion organizations and the specialized press.

The question remains, however, to what extent such a system will be capable of supporting the development of new and existing wine clusters that are situated in the regions more distant from Santiago, such as the Maule (VII) and Bio Bio (VIII) regions, and capable of giving a "personality" to each wine region in the country, thanks to the deep knowledge of the characteristics of its soil and climate, and of the different terroirs characterizing each valley. As will be seen in the following section, in fact, to meet the demand for diversified Chilean wine exports, new areas have been explored for wine production in order to produce different, sometimes "extreme" wines, with unique qualities and flavours. Most of these areas are located in regions in the North or the South, with remote access to the main supporting institutions located in Santiago. 
Table 6.8 Supporting institutional framework of the Chilean wine industry

\begin{tabular}{|c|c|c|}
\hline Category & Name & Operational level \\
\hline Wine associations & $\begin{array}{ll}- & \text { ChileVid } \\
- & \text { Viñas de Chile } \\
- & \text { Corporación Chilena del Vino }\end{array}$ & National \\
\hline $\begin{array}{l}\text { Industry- } \\
\text { supporting } \\
\text { institutions }\end{array}$ & $\begin{array}{ll}- & \text { Servicio Agrícola Ganadero (SAG) } \\
- & \text { Corporación de Fomento de la Producción (CORFO) } \\
- & \text { Servicio Nacional de Agricultura (SNA) } \\
- & \text { Oficinas de Estudios para la Política Agraria } \\
& \text { (ODEPA) } \\
- & \text { Servicio para la Innovación Agraria (FIA) } \\
- & \text { Instituto Nacional de Investigación Agropecuaria } \\
& \text { (INIA) }\end{array}$ & National \\
\hline $\begin{array}{l}\text { International } \\
\text { promotion } \\
\text { organizations }\end{array}$ & $\begin{array}{ll}\text { - } & \text { Wines of Chile } \\
\text { - } & \text { Dirección de Promoción de Exportaciones (Prochile) }\end{array}$ & National \\
\hline Specialized press & $\begin{array}{ll}- & \text { Chile Vinos } \\
\text { - } & \text { Vendimia } \\
\text { - } & \text { La Cav } \\
\text { - } & \text { Planeta Vino } \\
\text { - } & \text { Andes Wines } \\
\text { - } & \text { Todovinos } \\
\text { - } & \text { Platos y Copas } \\
\text { - } & \text { Revista Vitivinicultura } \\
\text { - } & \text { La Vinoteca }\end{array}$ & National \\
\hline Universities & $\begin{array}{ll}- & \text { University of Chile } \\
- & \text { Catholic University of Chile } \\
\text { - } & \text { University of Talca }\end{array}$ & Regional \\
\hline $\begin{array}{l}\text { R\&D } \\
\text { organizations }\end{array}$ & $\begin{array}{ll}\text { - } & \text { Vinnova } \\
\text { - } & \text { Centro Cooperativo para el Desarrollo Vitivinícola } \\
\text { (CCDV) } \\
\text { - } \quad \text { Centro Vitivinícola de la Universidad de Chile } \\
\text { (CEVIUC) } \\
\text { - Centro de la Vid y del Vino de la Universidad de } \\
\text { Talca }\end{array}$ & Regional \\
\hline Wine routes & $\begin{array}{ll}\text { - } & \text { Valle de Casablanca (www.casablancavalley.cl) } \\
\text { - } & \text { Valle del Maule (www.valledelmaule.cl) } \\
\text { - } & \text { Valle del Cachapoal (www.cachapoalwineroute.cl) } \\
\text { - } & \text { Valle de Curicó } \\
\text { - } & \text { Valle de Colchagua }\end{array}$ & Cluster \\
\hline
\end{tabular}

Source: Author's survey

\subsection{The Argentine case: Differentiating organized wine clusters (Mendoza) from informal wine clusters (San Juan)}

Argentine wine production is concentrated in two main clusters, namely those of Mendoza and San Juan. From an historical point of view, three factors account for their 
emergence, well before the outbreak of the Argentine wine revolution in the early 1990s. First of all, the arrival in the second half of the eighteenth century of an evergrowing community of Spanish, Italian and Portuguese immigrants, largely composed of agricultural workers who were used to both consuming and making wine in their everyday life. The history of the best known Argentine wine companies - such as Arizu, Bianchi, Flichman, Pulenta, Bianchi, Graffigna, or Peñaflor - reveals the foreign origin of their founding families, the tight link between the expansion of the industry and the different waves of immigration that arrived in Argentina at different stages since the late eighteenth century. For every potential producer who arrived in the agricultural regions of Argentina, a host of potential consumers also arrived in the big cities (Fielden, 2001).

This constitutes the origin of the huge internal demand which distinguishes Argentina from all other New World producers. ${ }^{119}$ Secondly, the construction of a railway connecting Mendoza and San Juan to Buenos Aires in 1884 not only reduced the time of transportation from more than a month to two or three days, but also ensured the delivery of better quality and higher quantities of wines. This constituted a true revolution compared to the small barrels slung onto either side of a mule, the means of transportation used until then. Finally, a great influence was exerted by Domingo Sarmiento, the first president of Argentina originating from the interior provinces rather than from the capital. He established the first wine schools in San Juan and Mendoza, and invited a series of foreign wine experts to visit Argentina, including the Frenchman Pouget who introduced the first noble French varieties (including the yet unknown Malbec); the Italian Schieroni, who established an experimental wine nursery with more than 200 varieties; and the German Röveder, who founded one of the first wine schools in San Juan and Mendoza.

Like the Chilean clusters studied in the previous section, therefore, at their origin the clusters of Mendoza and San Juan share practically identical historical conditions. Until the crisis of the 1980s, they were both perceived as almost completely undifferentiated in terms of the wines they made, with a production based on an enormous extension of Criolla grapes, on management techniques oriented towards high productivity, without any attention to the oenological quality of the wines produced, and on gigantic groups or cooperatives serving the massive domestic market of bulk table wines. When a split started to arise, however, with export wines being of increasingly higher quality and the mainstay of the local market preferring tetra-bricks or similar low quality wines, Mendoza and San Juan took two different paths, showing very different levels of learning and technological capabilities, and consequently a differential export performance. In 2009, Mendoza accounted for 80 percent of total Argentine wine exports and for 85 percent of bottled wine exports. San Juan accounted for 16 percent of total Argentine wine exports but 24 percent of bulk wine exports (see Table 6.9).

\footnotetext{
119 The first group of Portuguese prisoners captured during a war between Spain and Portugal arrived in San Juan in 1777. Shortly after a group composed of 122 Italian, 96 French, 30 Spanish, 18 German and 11 Swiss immigrants followed, and included a number of agronomists and vine growers. According to an industrial census, in 1895 there were 13,000 hectares planted with vineyards and 43 registered wine enterprises, occupying 3,500 employees, 85 percent of which were owned by immigrants.
} 
Table 6.9 Distribution of Argentine wine exports per province, 2009

\begin{tabular}{lrrrrrr}
\hline Province & $\begin{array}{c}\text { Exports of } \\
\text { bulk wine } \\
\text { (hectolitres) }\end{array}$ & $\begin{array}{c}\text { \% } \\
\text { of total } \\
\text { bulk }\end{array}$ & $\begin{array}{c}\text { Exports of } \\
\text { bottled wine } \\
\text { (hectolitres) }\end{array}$ & $\begin{array}{c}\text { \% } \\
\text { of total } \\
\text { bottled }\end{array}$ & $\begin{array}{c}\text { Total } \\
\text { exports per } \\
\text { province }\end{array}$ & $\begin{array}{c}\text { \% } \\
\text { of total } \\
\text { exports }\end{array}$ \\
\hline Mendoza & $1,523,007$ & $75 \%$ & $1,784,338$ & $85 \%$ & $3,307,345$ & $80 \%$ \\
San Juan & 482,341 & $24 \%$ & 195,164 & $9 \%$ & 677,506 & $16 \%$ \\
Others & 27,794 & $1 \%$ & 127,903 & $6 \%$ & 155,696 & $4 \%$ \\
Total & $2,033,142$ & 100 & $2,107,405$ & 100 & $4,140,547$ & 100 \\
\hline
\end{tabular}

Source: INV, 2010

In order to understand the factors that have determined the different development pathways of the clusters of Mendoza and San Juan, it is important to look at the configuration of actors in the system, their traditional habits and practices, their competencies, the nature and intensity of interactions, and the degree of change in the cluster over time. In this regard, interviews reveal that in San Juan there are numerous micro and small firms whose technology level is low relative to the industry frontier, whose owners have weak management capabilities, and where the nature of coordination and networking among firms tends to be low, with a limited growth perspective and slow improvements in product quality, product diversification or the development of exports.

On the contrary, the cluster of Mendoza is characterized by a process of collective activity, mainly oriented, as will be seen in the following section, towards the provision of infrastructure and services, and the development of organizational structures designed to analyze and provide the channels in facing common problems. In terms of technological capacity, the majority of wineries in Mendoza have upgraded, which corresponds not only to a sustained export growth in general but also to a drastic increase in the production of higher quality, premium bottled wines (see Table 6.10).

Table 6.10 Evolution of premium wine production per Argentine province, 1980-2005

\begin{tabular}{ccccccccc}
\hline Year & \multicolumn{2}{c}{ Mendoza } & \multicolumn{2}{c}{ San Juan } & \multicolumn{2}{c}{ Others } & \multicolumn{2}{c}{ Total } \\
\hline & $\begin{array}{l}\text { Volume in } \\
\text { hectolitres }\end{array}$ & $\begin{array}{c}\% \\
\text { total }\end{array}$ & $\begin{array}{c}\text { Volume in } \\
\text { hectolitres }\end{array}$ & $\begin{array}{c}\% \\
\text { total }\end{array}$ & $\begin{array}{c}\text { Volume in } \\
\text { hectolitres }\end{array}$ & $\begin{array}{c}\% \\
\text { total }\end{array}$ & $\begin{array}{c}\text { Volume in } \\
\text { hectolitres }\end{array}$ & $\%$ total \\
1980 & $1,349,000$ & 80.2 & 236,000 & 14.0 & 98,000 & 5.8 & $1,682,000$ & 100 \\
1985 & $1,995,000$ & 80.8 & 339,000 & 13.7 & 136,000 & 5.5 & $2,470,000$ & 100 \\
1990 & $2,182,000$ & 82.0 & 289,000 & 10.9 & 189,000 & 7.1 & $2,660,000$ & 100 \\
1995 & $2,260,000$ & 82.1 & 219,000 & 9.1 & 240,000 & 8.7 & $2,752,000$ & 100 \\
2000 & $2,943,000$ & 83.8 & 237,000 & 8.8 & 269,000 & 7.3 & $3,670,000$ & 100 \\
2005 & $3,866,000$ & 86.3 & 257,000 & 5.7 & 355,000 & 7.9 & $4,478,000$ & 100 \\
\hline
\end{tabular}

Source: INV, 2010

Additionally, it should be considered that from its inception to the end of the twentieth century, in Argentina most wineries did not have direct control over the production of the grapes used for their wines. Rather, they typically purchased grapes from known 
growers who tended to have very small vineyards and little working capital. As observed in the previous chapters, the continued separation of most wineries from the vineyards that produce their grapes is at the origin of one of the most serious and pervasive bottlenecks hindering the process of quality upgrading of the Argentine wine industry. Here, the relationship between grape producers and winemakers has always been essentially adversarial, and the incentives to reward quality with price differentials for better grapes have always been largely irrelevant.

In Mendoza this problem has found a gradual solution in a twofold process: on the one hand, a sustained process of vertical integration took place in many boutique wineries, such as Bianchi, Catena or Zuccardi, in order to allow a valuable, tacit knowledgegenerating setting to be put into place. On the other hand, most wineries also established longer-term relationships with a group of selected vine growers, signing long-term contracts based on the area cultivated and not the quantity produced, and organizing periodical training and information-sharing sessions. Personal interviews with local wineries reveal, for example, that Chandon operates almost exclusively on a contract farming basis, but takes direct charge of grape quality improvement by organizing training workshops and by constantly helping local vine-growers through assistance via a number of specialized agronomists. With some vine-growers, Chandon has maintained a more than forty-year long uninterrupted relationship, based on trust and an understanding of each other's needs.

Equally important, the presence of several horizontal linkages among local producers, which were deeply rooted in local habits and practices, were detected in Mendoza. As early as 1884, for example, the government of Mendoza promulgated the first irrigation law (called Ley de Aguas), in order to establish a community-based sustainable irrigation system. In the semi-desert region of Mendoza, where irrigation represented a critical asset for the implementation of agro-industrial production, this sowed the seeds of a longstanding institution-building process, which reinforced the "clusterization" process and laid the ground for the consolidation of mutual trust and cooperation among vine growers, as the flooding irrigation system can only work if farmers and vine growers respect the watering time and amount they have been allocated.

Mendoza is also the headquarters of two active business associations: Bodegas de Argentina and the Argentine Viticultural Union (UVA). Bodegas de Argentina, founded in 1995, is the union of two formerly separate wine-making associations and represents most of the producers of quality and premium wines. UVA, founded in 1984, despite being open to all parties of the sector represents the majority of bulk and table wine producers. Interestingly, UVA's charter clearly states that its objectives are "to encourage the growth of medium and small local business, seek a more equitable distribution of wealth and to achieve the recomposition of the organizational structure of the national viticultural industry to allow the provinces to act on behalf of the local economy". ${ }^{120}$ Finally, another important form of horizontal interaction that emerged from personal interviews was that after the take off of Argentine wine exports, the oenologists of Mendoza's boutique wineries started to practice small and informal wine

120 Source: www.uva-ra.com.ar 
tasting among themselves, to visit each other's wineries, and to provide reciprocal comments on the results of their work. Growing out of these exchanges, a structured annual wine label competition was launched.

The field research reveals the presence of joint actions within institutional linkages among a large number of local producers and cluster-wide institutions. In 1989, for example, three organizations based in Mendoza - the association of oenologists (Centro de Licenciados en Enologia y Frutihorticultura), the business association of the largest table wine producers and retailers (Centro de Bodegueros), and the Faculty of Oenology Don Bosco - organized in Mendoza the first sectoral event to improve wine quality, called EVICO (Walters, 2000). During EVICO, a panel of recognized wine experts undertook for the first time a series of blind tastings to provide constructive feedback on how to improve the quality of local wines. The panel included representatives from INTA (the federal government's research and extension agency) and INV (the industry regulatory agency, as well as independent experts, oenologists and professors from Don Bosco University. EVICO became such a valuable source of learning and innovation that a few years later a similar event, CODEVIN, was organized in order to evaluate wines produced with intermediate and low oenological quality grapes, in order to benefit also smaller farmers and to prove that some of the least popular varieties can produce surprisingly good wines if processed correctly.

During field visits, it also emerged that several local producers and cluster-wide institutions are increasingly cooperating to organize small fairs and wine-tasting events targeting the local population, as there is a growing awareness that the future development and quality of upgrading of Argentine wines will have to rely not only on sophisticated international consumers' tastes, but also on the taste of more educated and knowledgeable local consumers. Lastly, the Mendoza cluster is widely praised at the national level for having adopted a strategy based on the promotion of publicprivate partnerships, and rules of inclusion and participatory governance, which have helped to solve collective problems and addressing complex challenges.

The dynamism and vision of Mendoza's government is symbolized by the creation in 1996 of a public-private foundation called ProMendoza, explicitly devoted to export promotion activities. In 1994, it also promulgated a provincial law to create a Vitivinicultural Fund to support the wine industry. The Fund was originally meant to cushion the impact of deregulation policies. It then served the objective of encouraging planting conversion, export growth and domestic consumption. The Fund is still operational and is financed through a .01 peso per litter levy on the wine vinified, but waived for those who produce a variable percentage of must, as stipulated by the state every year (never less than 20 percent and often 30 percent), or compensated through exports (which are always taxed with a 5 percent retention). In addition to its informative work and publications, the Fund has participated in preparing the Vitivinicultural Strategic Plan 2020, funded several research projects, held information campaigns and tasting events, and created a symbolic "airport vineyard" with 3 hectares of Malbec. Since 1993, it has also contributed to the organization of Vinandino, the industry's most important event and the first international wine competition in the 
Southern Hemisphere, which takes place every two years in Mendoza. ${ }^{121}$ Finally, another example of ProMendoza's proactive role is the launch of international marketing campaigns to promote Argentine wines abroad, organized in cooperation with Wines of Argentina (the association of the largest export wineries) in order to build up Argentina's image as a leading, highly attractive wine producer (as the sensual images of tango published on a monthly basis by Wine Spectator to advertise Argentine wines clearly show).

Overall, therefore, in view of the distinction made in the methodology chapter between informal clusters and organized clusters, following a categorization which is based on a set of variables that emphasize the potential for continuous dynamic change, Mendoza can be considered a highly organized cluster. After an initial period of practically undifferentiated development, San Juan and Mendoza have gradually diverged in their trajectories and have followed completely opposite specialization patterns. In Mendoza, the creation of an extensive knowledge exchange across the cluster, as well as of collective efficiencies facilitated by a rich network of supporting institutions, has been the main driver of quality upgrading and export growth. In contrast, San Juan has lacked the institutional strength, and the organizational dynamics, needed to sustain the accumulation of knowledge by individual firms and to adapt new knowledge and technology to local conditions, thanks to tacit knowledge flows. It has remained therefore confined to the production of table wines.

Overall, a twofold trap seems to have locked San Juan at the lower end of the wine quality segment, and has kept it isolated from the increasing international demand for premium wines. First of all, San Juan did not undertake the transformation from an informal to an organized cluster, as observed above. Secondly, it did not establish strong enough links with extra-cluster sources of knowledge and innovation because the main wine-supporting institutions (mainly located in Mendoza) were perceived as too remote, as interviews with key cluster stakeholders reveal. Mendoza, in fact, as will be seen in the following section, could gradually transform itself into a "learning region", capable of generating continuous innovation and of rejuvenating the technical paradigm of the local wine industry in order to meet international consumers' tastes and to comply with the standards imposed by export markets.

\subsection{The emergence of Mendoza as a "learning region"}

Chapter 5 highlighted that, for the leading Chilean and Argentine wine exporters to produce high-quality, premium wines for export, which extract a unique, original taste from different grape varieties and reflect faithfully the characteristics of the local terroir, the use of foreign knowledge and technology was necessary but not sufficient. The findings of this research show that, in both Chile and Argentina, the top exporting wineries have undertaken continuous incremental efforts to learn how to recognize the

121 Vinandino is co-organized by the the National Vitivinicultural Institute (INV) and ProMendoza. It is sponsored by the International Office of Wine and Vine (OIV), the International Union of Oenologists, and the World Federation of Large International Wine and Spirits Competitions (Austral Spectator, 2004). 
technical characteristics and the composition specificities of the different soils up to the slightest detail, and how to extract the maximum aroma and complexity from the locally produced grapes through modern vinification techniques. However, they have also relied on local universities and research centres to introduce more sophisticated, radical innovations, aimed, for example, at matching the chemical and sensorial characteristics of wine with consumer preferences through new digital equipment, or at improving the resistance of local vines to high or low temperatures through clonal selection techniques.

Contrary to San Juan, Mendoza has excelled at laying the groundwork for producers throughout the wine clusters to introduce innovations of both an incremental and radical nature, thanks to the creation of networking dynamics rooted in the local territory and nurtured by proximity effects, which are indispensable for strengthening competitive advantages at the local level. In particular, the case of Mendoza shows that the region is the level at which innovation activities are increasingly coordinated, and has become the foundation, as Maskell and Malmberg (1999) put it, "for maintaining the competitiveness not only of individual firms in the region, but of the whole industrial system characterizing the region". This is even more apparent considering that regional innovation systems are hardly dependent on a mono-industrial base, and that there may exist a certain "fungibility" among the competencies and skills characterizing different clusters located in the same region (Cooke, 2005).

In Mendoza, for example, four groups of clustered industrial activities can be identified: fresh, dried and processed fruits; wine and olive oil production; tourism-related activities (ecological trekking and skiing resorts); and textile and furniture manufacturing. A strong machine tool ${ }^{122}$ and service sector (especially graphic design) serves all the clusters horizontally, and thus represents a sort of crossroad for any intervention aimed at increasing the competitiveness of the regional economy. According to Salvatierra (2006), the clustered industrial activities mentioned above, excluding oil extraction and tourism, account for $85 \%$ of the regional income (1.1 billion US $\$$ out of 1.3 billion US $\$$ in 2005, as reported by the latest industrial census) with a little bit less than half of this generated by the wine sector, thereby proving the importance of a sustained clusterization process of the regional economy.

In what follows two specific examples of policies aimed at promoting learning and innovation will be examined. They illustrate the important role that localized capabilities and intangible assets have played in Mendoza. These refer to the region's unique institutional endowments or constructed advantages, which have not only acted to support and reinforce local advantages at the cluster level, but have also stimulated the creation of synergies between actors and institutions throughout the whole regional innovation system.

\footnotetext{
${ }^{122}$ If it is true that during the liberalization decade the machine tool industry tended to disappear, it is also true that in the post-devaluation period, it is showing clear signs of revival. In Mendoza, for example, there are around 40 companies producing winemaking equipment and 125 specialized providers of inputs, such as bottles, tetrabricks, labels, packaging materials and chemical yeasts. Additionally, a few foreign producers of capital goods (e.g., Della Toffola or Vello) had to establish their own affiliates in the region if they wanted to continue to supply the local wine industry, due to the loss of purchasing power of the local currency.
} 
The first example of policies conducive to local innovation and technological capacity building system-wide is related to INTA - the federal agricultural research and extension agency founded in the late 1950s. Even if INTA is a federal institution, the experimental station of Lujan de Cuyo, located in the Mendoza province, has played a prominent role in the development of the wine cluster and has recently been involved in the preparation of a bottom-up National Strategic Plan for 2020 (PEVI) on behalf of the entire sector at the national level. INTA's technicians from Mendoza have been acting as facilitators and mediators of a long and articulated process which has resulted in the definition of a shared vision and mission statements (among others, to increase exports to 2 billion US\$ per year and to account for 10 percent of total world exports). INTA's involvement has been crucial in creating consensus around strategies and projects which encompass the entire range of producers which are present in the industry, from a group of around 50 export-oriented "boutique" wineries to a group of 8,000 small, non-vertically integrated producers of must and concentrated grape juice. This is an ambitious and valuable attempt to set the basis for the implementation of an inclusive policy which tries to respond in a concerted manner to the upgrading needs of all actors, at different levels and according to their needs.

The second example of policies aimed at promoting learning and innovation in local firms is related to the activities of INV, the National Vitiviniculture Institute created in 1959 by the Ley de Vinos (nr.14.878), based on the pre-existing National Directorate of Wine and Alcoholic Beverages. With fifteen delegations in key areas and ten laboratories in different wine producing provinces, it had to move its headquarters from Buenos Aires to Mendoza to become more effective. Therefore, even if it is, again, a federal institution, the regional dimension of its activities has become very prominent, at least equal to its national scope. As a matter of fact, after the deregulation of winemaking activities in 1989, which established the complete liberalization of plantation, replantation or modification of vineyards, as well as the selling of wines, INV became the official organization in charge of guaranteeing the healthiness of wine products, from the vineyard to consumption. This has allowed a sector, which was traditionally inclined towards adulteration, to develop very high parameters of quality and to become the most controlled among all developing country, New World producers. INV is also actively involved in making progress on the still embryonic and little-developed denomination of origin system, thereby trying to put an end to a certain anarchy in the indication of the vintage, which is still considered irrelevant by many winemakers due to the little changes of climatic conditions and thus quality variations from one crop to another.

Besides INV, the Cuyo National University, also located in the Mendoza province, represents another main local knowledge source and has played a key role in the evolution of wine quality in the region, as well as in the consolidation of cluster networking dynamics and innovative capacities. Not only has it provided highly valued laboratory services, which over time have become increasingly diversified and selffinanced, but it has also become "embedded" in the local wine industry, with academics 
and practitioners often exchanging their positions in and out of the university. ${ }^{123}$ If one includes in this rich set of relationships between the main knowledge stakeholders in Mendoza two additional public-private teaching institutions, namely the Technological Institute of Mendoza (ITU) and the Industrial and Technological Development Institute (IDITS), created respectively in 2005 and 2006 to satisfy the local demand in the area of management, engineering and manufacturing, it becomes clear how uniquely "endowed" the supporting institutional framework of Mendoza's "learning region" is (see Table 6.11). The main question remains, however, to what extent other emerging Argentine wine provinces will manage to replicate the same rich institutional framework, relationships of trust and interactive dynamics of Mendoza.

Table 6.11 Supporting institutional framework of the Argentine wine industry

\begin{tabular}{|c|c|c|}
\hline Category & Name & Operational level \\
\hline Wine associations & $\begin{array}{ll}\text { - } & \text { Centro de Bodegueros de Mendoza } \\
\text { - } & \text { Bodegas de Argentina } \\
\text { - } & \text { Asociación de Cooperativas Vitivinicolas } \\
& \text { Argentina } \\
\text { - } & \text { Union Vitivinicola Argentina } \\
\text { - } & \text { Asociación Vinateros de Mendoza } \\
\text { - } & \text { Centros de Vinateros y Bodegueros del Este }\end{array}$ & National / Regional \\
\hline $\begin{array}{l}\text { Industry- } \\
\text { supporting } \\
\text { institutions }\end{array}$ & $\begin{array}{ll}\text { - } & \text { Instituto Nacional para la Vitivinicultura } \\
\text { (INV) } & \\
\text { - } & \text { Fondo Vitivinicola Mendoza } \\
- & \text { Corporación Vitivinicola Argentina } \\
& \text { (COVIAR) } \\
\text { - } & \text { Bolsa de Comercio de Mendoza }\end{array}$ & National / Regional \\
\hline $\begin{array}{l}\text { International } \\
\text { promotion } \\
\text { organizations }\end{array}$ & $\begin{array}{ll}- & \text { ProMendoza } \\
\text { - } & \text { Wines of Argentina }\end{array}$ & National / Regional \\
\hline Specialized press & $\begin{array}{ll}- & \text { El Conocedor } \\
- & \text { Winesur } \\
- & \text { Caminos del Vino } \\
- & \text { Sommelier } \\
\text { - } & \text { Vinos \& Sabores }\end{array}$ & National \\
\hline Universities & $\begin{array}{ll}- & \text { Universidad Juan Augustin Maza } \\
\text { - } & \text { Universidad Nacional de Cuyo }\end{array}$ & Regional \\
\hline $\begin{array}{l}\text { R\&D } \\
\text { organizations }\end{array}$ & $\begin{array}{ll}\text { - } & \text { Instituto para el Desarrollo Rural } \\
\text { - } & \text { Instituto Nacional de Tecnologia } \\
\text { Agropecuaria (INTA) } \\
\text { - } \quad \text { Instituto Technologico Universitario (ITU) } \\
\text { - } & \text { Instituto de Desarrollo Industrial, } \\
& \text { Technologicos y de Servicios (IDITS) }\end{array}$ & Regional \\
\hline Wine routes & $\begin{array}{ll}\text { - } & \text { Ruta del Vino - Mendoza } \\
\text { - } & \text { Ruta del Vino - Catamarca } \\
\text { - } & \text { Ruta del Vino - La Rioja } \\
\text { - } & \text { Ruta del Vino - San Juan }\end{array}$ & Cluster \\
\hline
\end{tabular}

Source: Author's survey

123 In their study, Tiffin and Kunc (2008) found, for example, that 4 full time professors of the Cuyo University had left to take over cluster jobs between 2005 and 2008, while all cluster professionals were teaching wine courses at the University. 


\subsection{Assessing the viability of the Chilean and Argentine "models"}

From the analysis of the Chilean and Argentine wine industries in this and earlier chapters, two very different development "models" have emerged. In Chile, the steep export growth of quality wines was made possible by both the access to huge external inflows of knowledge and technology from abroad, and by the creation of endogenous R\&D capabilities. This took place under the auspices of a predominant central government, as opposed to regional governments, and under the influence of a topdown policy approach that made it difficult for regions to develop local organizations and support structures, and for clusters too far from the Santiago Metropolitan Region to develop deeper innovation capabilities through linkages with external sources of knowledge and innovation.

In contrast, in Argentina a relatively delayed but equally steep export growth of quality wines was made possible not only by a larger flow of foreign capital, technology and know-how, but also by the development of local learning capabilities and local distinctive factors, under the auspices of decentralized governments and a bottom-up policy approach that was instrumental in the creation of regionally constructed advantages and innovation capabilities, as well as cluster-based linkages and networking dynamics. As observed earlier, though, questions of different nature remain about the long-term sustainability of both the Chilean and the Argentine model.

In particular, looking at the future of the Chilean wine industry and at the sustainability of its export boom, the main question to be addressed is to what extent will Chile be capable of supporting the development of new and existing wine clusters that are situated in the regions more distant from Santiago, such as the Maule (VII) and Bio Bio (VIII) regions, and the issue of creating a "personality" to each wine area or region in the country. To meet the demand for diversified Chilean wine exports, in fact, new areas have been explored for wine production in order to produce different, sometimes "extreme" wines, with unique qualities and flavours. On the one hand, vineyards have been planted where it seemed almost impossible, namely along the Southern Coast Range area, where the influence of the sea breeze produces salty flavours and cooler growing conditions (as the case of the Casablanca Valley clearly shows). Pilot plantings have also been done at high altitudes, up to 2,000 meters, where it is possible to produce wines with high fruit concentration, thanks to the presence of poor soils and great temperature ranges.

Until now, however, Limarí Valley, located close to the Pacific Ocean in the Valparaiso (IV) region, is the only cluster that has started to take off, thanks also to its relative proximity to the capital city (see Table 6.12). In other areas where vineyards are beginning to appear, located in the Southern regions of Los Rios and Los Lagos, for example, interviews reveal that investments have been limited by bottlenecks such as a lack of infrastructure, the long distance from markets and transportation difficulties. In this respect, Cusmano, Morrison and Rabellotti (2009) are correct when they argue that highly centralized innovation systems may be inappropriate in tackling the emerging pattern of diversified demand, especially where international consumers regard wine variety and specificity as positive, priority attributes. In contrast, the traditional 
endowments of regions in terms of wine culture, labour market, localized linkages and dense institutional infrastructure represent a key asset.

Table 6.12 Origin of Chilean wine exports per region, 2004-2009

\begin{tabular}{lccc}
\hline \multicolumn{1}{c}{ Regions } & \multicolumn{2}{c}{ Value } & $\begin{array}{c}\text { Variation } \\
\mathbf{2 0 0 9 / 2 0 0 4}\end{array}$ \\
\hline III Atacama & $\mathbf{2 0 0 4}$ & $\mathbf{2 0 0 9}$ & \\
IV Coquimbo & 85752 & 71956 & $-16 \%$ \\
V Valparaiso & 4570760 & 11429078 & $150 \%$ \\
R. Metropolitana & 75451702 & 102772241 & $36 \%$ \\
VI Lib. O'Higgins & 423195199 & 755343279 & $78 \%$ \\
VII Maule & 101999247 & 236315971 & $131 \%$ \\
VIII Bio Bio & 173320762 & 257000356 & $48 \%$ \\
Total & 4310637 & 743570 & $-82 \%$ \\
\hline
\end{tabular}

Source: ProChile, 2010

The survey of the leading 25 exporters of bottled wines reveals that, indeed, in Chile a production of terroir wines, with adequate reference on the label to the area of origin of production and vinification of the grapes, is gradually emerging (see Table 6.13). However, in none of the labels analyzed were found any reference to the region of origin. The vast majority of the labels studied, though, did mention the name of the valley or cluster of origin. A few of them referenced the specific vineyard site (especially in the case of the most reputed ones, such as Apalta, in the Colchagua Valley), and most of them referenced the specific mark of the Chilean denomination of origin. Therefore, that the regional dimension of vine-growing and winemaking is practically inexistent.

This can probably be ascribed to the overall weakness and late introduction of the administrative regions in Chile. However, the experience of other wine producers from both the New and the Old World shows that average international consumers more easily become familiar with the name of the country and the region of origin of new wines, while it takes a much longer time to popularize the name of specific valleys or vineyard sites internationally. Additionally, as soon as the name of certain wine areas start to become familiar to international consumers, these consumers respond positively to local oeno-tourism offers only if they can benefit from a diversified set of cultural, historical, natural and gastronomic attractions, which are usually found at the regional level. Finally, the field research has clearly shown how important it is for local clusters to tap into the broader opportunities offered by regional innovation systems, such as substantial investments in R\&D, incentive structures and institutional capacity, in order to face the challenge of international competition flexibly. In Chile, therefore, the need for strengthening local identity and competitiveness seems to be paramount. This should entail the transformation of local clusters from informal into organized clusters, but also and especially the deeper integration of organized clusters into regional dynamics. 
Table 6.13 Samples of emerging "terroir" wine production in Chile

\begin{tabular}{|c|c|c|c|c|c|}
\hline & \multirow{2}{*}{$\begin{array}{l}\text { Name of the } \\
\text { winery }\end{array}$} & \multicolumn{4}{|c|}{ Existence of a specific production line of "Terroir" wines } \\
\hline & & $\begin{array}{l}\text { Name of } \\
\text { region of } \\
\text { origin of } \\
\text { the grapes } \\
\text { mentioned } \\
\text { on label }\end{array}$ & $\begin{array}{l}\text { Name of valley of } \\
\text { origin of the grapes } \\
\text { mentioned on label }\end{array}$ & $\begin{array}{c}\text { Name of specific } \\
\text { vineyards area } \\
\text { mentioned on } \\
\text { label }\end{array}$ & DOC \\
\hline 1 & Concha y Toro & - & Cachapoal Valley & Peumo & yes \\
\hline 2 & San Pedro & - & Maule Valley & - & yes \\
\hline 3 & Santa Rita & - & Maipo Valley & - & yes \\
\hline 4 & Cono Sur & - & Cachapoal Valley & Peumo & yes \\
\hline 5 & Errazuriz & - & Aconcagua Valley & - & yes \\
\hline 6 & Undurraga & - & Maipo Valley & Talagante & yes \\
\hline 7 & Montes & - & Colchagua Valley & Apalta & - \\
\hline 8 & Santa Carolina & - & Maipo Valley & - & yes \\
\hline 9 & Santa Helena & - & Colchagua Valley & - & yes \\
\hline 10 & Tarapaca & - & Maipo Valley & Isla de Maipo & yes \\
\hline 11 & Carmen & - & Colchagua & Apalta & - \\
\hline 12 & S. Emiliana & - & Colchagua Valley & - & yes \\
\hline 13 & La Rosa & - & Cachapoal Valley & - & yes \\
\hline 14 & Ventisquero & - & Colchagua Valley & - & yes \\
\hline 15 & Los Vascos & - & Colchagua Valley & - & - \\
\hline 16 & Valdivieso & - & Colchagua Valley & Apalta & yes \\
\hline 17 & C. Lapostolle & - & Colchagua Valley & Apalta & - \\
\hline 18 & Miguel Torres & - & Curicó Valley & - & - \\
\hline 19 & Canepa & - & Maipo Valley & Puente Alto & yes \\
\hline 20 & L. F. Edwards & - & Colchagua Valley & - & yes \\
\hline 21 & Bisquertt & - & Colchagua Valley & Marchihue & yes \\
\hline 22 & Cousiño Macul & - & Maipo Valley & Buin & yes \\
\hline 23 & Santa Ema & - & Maipo Valley & Isla de Maipo & yes \\
\hline 24 & Casa Silva & - & Colchagua Valley & - & yes \\
\hline 25 & Almaviva & - & - & Puente Alto & - \\
\hline
\end{tabular}

Source: Author's elaboration

In the case of the Argentine wine industry, the main question to be addressed regarding the sustainability of its export boom is to what extent other emerging Argentine wine provinces will manage to replicate the same rich institutional framework, relationships of trust and interactive dynamics of Mendoza. Beyond Mendoza, in fact, several other provinces have seen their wine exports grow considerably during the last few years (see Table 6.14). Such provinces include Salta and Rio Negro, but also Catamarca, Neuquén and La Rioja. The northern Salta province is where the Torrontés white variety, the Argentine white wine specialty, is best produced and where the Colomé winery is producing its internationally prized Torrontés (Wine Spectator, July 2011). The province of La Rioja is specializing in higher altitude wines. New vineyards have been planted very rapidly in Chilecito (900 $\mathrm{m}$ ), especially a typical variety called Torrontés Riojano and Syrah. The Patagonian 
wines are located in the Rio Negro and Neuquén provinces, where there is only a small presence of winemakers, but also where varieties such as Pinot Noir have found exceptionally favourable conditions for cultivation. ${ }^{124}$ Wines from Patagonia are now sold at the forefront of Buenos Aires airport Duty Free Shops, and their popularity is growing exponentially, thanks to the attractiveness of its territorial regional branding.

Table 6.14 Origin of Argentine wine exports by province, 2002-2007

\begin{tabular}{lccc}
\hline & \multicolumn{2}{c}{$\begin{array}{c}\text { Value } \\
\text { US\$, FOB }\end{array}$} & $\begin{array}{c}\text { Variation } \\
\mathbf{2 0 0} / \mathbf{2 0 0 2}\end{array}$ \\
\hline Provinces & $\mathbf{2 0 0 2}$ & $\mathbf{2 0 0 7}$ & $295 \%$ \\
Mendoza & $91,262,410$ & $360,845,216$ & $565 \%$ \\
San Juan & $2,077,417$ & $13,818,723$ & $135 \%$ \\
La Rioja & $4,041,737$ & $9,482,412$ & $432 \%$ \\
Rio Negro & 231,037 & $1,229,596$ & $\mathbf{6 , 8 7 1 \%}$ \\
Catamarca & 2,736 & 190,718 & $801 \%$ \\
Salta & $1,177,270$ & $10,602,004$ & New \\
Neuquén & 0,00 & $5,243,678$ & \\
\hline
\end{tabular}

Source: INV, 2008

As Michel Rolland (2009) puts it: "If we consider that not too long ago, Argentine winemakers would buy grapes from anywhere and blend them without ever getting to know their virtues and flaws, we realize how considerable has been the improvement on this subject". In San Juan itself, habits are slowly changing, and the appearance on the market of a Syrah reserve wine labelled "from San Juan" testifies to the search for a wine with its own territorial identity. As observed throughout this chapter, however, building strong regional identities and innovation capabilities is a challenge that only well-organized wine clusters can face, and only if synergies with broader regional innovation systems are put in place (see Table 6.15).

In this respect, the recent approval of development projects financed by international organizations such as CAF (Corporación Andina de Fomento) and IDB (Inter-American Development Bank), against 50 percent of resources provided by Wines of Argentina, is a clear positive sign. Thanks to these initiatives, wine routes and professional promotional materials to publicize oeno-tourism are proliferating all over the country and in all main wine-producing regions. Additionally, new decentralized wine institutions are being created in several provinces, such as the Chamber of Patagonia Wine Producers (Cámara de Bodegas Exportadoras de la Patagonia Argentina), the Wine Chamber of Commerce of Cordoba (Bolsa de Comercio de Cordoba) and the INV offices in Salta and Neuquén.

\footnotetext{
124 In Patagonia, thanks to a 2.5 million US\$ loan from the Argentine government, the entrepreneur Julio Viola purchased 3,200 hectares of land in 1999. He planted several vineyards and gradually sold them to interested investors, who had an easy entry, thanks to his pioneering efforts. Viola, however, kept for himself only one winery, called Bodega Fin del Mundo, whose Malbec reserve wine was ranked by Wine Spectator among the 100 best wines of 2011 (Wine Spectator, December 2011).
} 
Table 6.15 Samples of emerging “terroir" wine production in Argentina

\begin{tabular}{|c|c|c|c|c|c|}
\hline & \multirow{2}{*}{$\begin{array}{c}\text { Name of the } \\
\text { winery }\end{array}$} & \multicolumn{4}{|c|}{ Existence of a specific production line of Terroir wines } \\
\hline & & $\begin{array}{c}\text { Name of } \\
\text { province of } \\
\text { origin of the } \\
\text { grapes } \\
\text { mentioned on } \\
\text { label }\end{array}$ & $\begin{array}{c}\text { Name of valley of } \\
\text { origin of the } \\
\text { grapes } \\
\text { mentioned on } \\
\text { label }\end{array}$ & $\begin{array}{c}\text { Name of vineyards } \\
\text { area mentioned on } \\
\text { label }\end{array}$ & DOC \\
\hline 1 & Zuccardi & Mendoza & - & La Consulta/Agrelo & - \\
\hline 2 & Tivento & Mendoza & - & La Consulta & - \\
\hline 3 & Catena Zapata & Mendoza & - & La Consulta & - \\
\hline 4 & Trapiche & Mendoza & - & La Consulta/S.Carlos & - \\
\hline 5 & Norton & Mendoza & Lujan de Cuyo & Perdriel & yes \\
\hline 6 & F.Flinchman & Mendoza & - & Barrancas/Tupungato & - \\
\hline 7 & N.Correas & Mendoza & Valle de Uco & Agrelo/Perdriel & - \\
\hline 8 & Pascual Toso & Mendoza & Maipu & Barrancas & - \\
\hline 9 & Terrrazas & Mendoza & Lujan de Cuyo & Vistalba/Perdriel & - \\
\hline 10 & Luigi Bosca & Mendoza & Lujan de Cuyo & Vistalba & yes \\
\hline 11 & E.Gascon & Mendoza & - & Agrelo/Altamira & - \\
\hline 12 & La Celia & Mendoza & Valle de Uco & Eugenio Bustos & - \\
\hline 13 & D. del Plata & Mendoza & - & Agrelo & - \\
\hline 14 & C.de los Siete & Mendoza & & Agrelo/Tupungato & - \\
\hline 15 & Fournier & Mendoza & Valle de Uco & La Consulta & yes \\
\hline 16 & Lurton & Mendoza & - & Barrancas & - \\
\hline 17 & Salentein & Mendoza & Valle de Uco & Tunuyàn & - \\
\hline 18 & Dona Paula & Mendoza & Lujan de Cuyo & Alto Ugarteche & - \\
\hline 19 & N.Senetiner & Mendoza & Lujan de Cuyo & Vistalba & yes \\
\hline 20 & Chandon & - & - & - & - \\
\hline 21 & Alta Vista & Mendoza & Lujan de Cuyo & Alto Agrelo & - \\
\hline 22 & Las Hormigas & Mendoza & Valle de Uco & Vista Flores & - \\
\hline 23 & V.Bianchi & Mendoza & San Rafael & Rama Caida & yes \\
\hline 24 & A.Pulenta & San Juan & - & 9 de Julio & - \\
\hline 25 & Achaval Ferrer & Mendoza & Valle de Uco & Perdriel/La Consulta & - \\
\hline
\end{tabular}

Source: Author's elaboration

\subsection{Conclusions}

This chapter has examined the hypothesis that sustained export growth is linked to the transformation of natural resource-based clusters from informal into organized clusters, as well as to the interaction of organized clusters with broader regional innovation systems. Two complementary sets of factors explaining the evolution, or lack, of selected clusters have been analyzed. These are related, on the one hand, to the internal dynamics of clusters and their capacity to transform themselves into organized entities, and on the other hand, to their capacity of catching sight and taking advantage 
of the opportunities offered by emerging regional innovation systems. The analysis of both the Chilean and Argentine cases - and in particular of the clusters of Colchagua and Curicó in Chile, and of Mendoza and San Juan in Argentina - has provided support to the first part of the hypothesis. The second part of the hypothesis was also confirmed, but in a more nuanced manner. The field research has shown, in fact, that, in order to learn, innovate and continuously upgrade, organized clusters do need to tap into regionally constructed advantages, which are a complementary factor adding greater flexibility for the cluster to meet future challenges. However, these may be located in the same region, as in the case of Mendoza, or in nearby regions, as in the case of Colchagua.

More specifically, the Chilean case has demonstrated that organized clusters such as Colchagua are characterized by several forms of inter-firm and public-private sector interactions, which are at the origin of the competitive performance and high level of innovativeness of the cluster. In Colchagua, wineries have tended to exchange knowledge quite extensively across the cluster, and the accumulation of knowledge by individual firms and with supporting institutions were the main drivers of a deep technology upgrading process, which was reflected in the rising exports of higher quality bottled wine, rather than bulk wine. To the contrary, in the informal clusters of Curicó, the decade of "easy" exports of bulk wines did not stimulate the mix of cooperation-competition and the networking dynamics that have characterized the clusters of Colchagua. As the benefits from spatial proximity for innovation and learning do not happen automatically, Curicó thus needs to broaden its horizons. On the one hand, the knowledge base of local firms should be strengthened, in order to enhance their innovative performance. On the other hand, local social networks, communication and inter-institutional linkages should be fostered, in order to promote incremental innovation and collective efficiency. Furthermore, following the example of Colchagua, a local development path in an open system should be fostered, based on more interaction with the cosmopolitan cultural environment of Santiago and with regional institutions and business networks.

The Argentine case once again highlights the important role of deliberate forms of inter-firm and public-private interaction for the development of an organized cluster even more so in Mendoza, where the technology upgrading process was mainly led by a group of foreign owned wineries. Here, in fact, this process did not remain confined to a group of foreign actors, and a pervasive trickle-down effect of imitation and diffusion of innovation took place amongst local wineries. Thanks to the assistance of an articulated network of local supporting institutions at the cluster level and to the presence of a dense thread of constructed advantages at the regional level, local wineries could undertake technology adaptations, design new products and processes, and bring them quickly to market, giving rise to widespread technological upgrading dynamics. To the contrary, the informal cluster of San Juan lacks the institutional strength needed to sustain the accumulation of knowledge by individual firms and to adapt new knowledge and technology to local conditions, as well as to access tacit knowledge flows and external sources of knowledge and innovation. From a development perspective, this is probably the main lesson to be learned from the Mendoza case, since it has created inclusive system-building dynamics crucial to avoiding a twofold risk: that of a fierce 
Darwinian selection, letting only export-oriented and élite wineries survive, and that of foreign investors crowding out local companies and discouraging any kind of technological spillovers.

Overall, therefore, this chapter shows that export success in a natural resource-based processing industry such as wine can take place, as a result of the creation of clusterbased linkages and networking dynamics that are indispensable for strengthening local competitive advantages and innovative capabilities. This phenomenon, however, is not automatic. In some cases it may stagnate or may emerge gradually in the development process, in order to answer to specific needs for collective action and interactive learning. It also shows that the integration of organized clusters into regional innovation systems may be instrumental in laying the groundwork for long-term growth, as well as embedding foreign investors in the local environment, and using them "strategically" to strengthen more complex innovation and technological capabilities.

In particular, the region seems to be the "intermediate" or "meso" level at which innovation activities are increasingly coordinated, as regional innovation systems represent the ideal bridge between global knowledge networks and local competitive advantages, bringing together international knowledge and frontier technologies with uniqueness factors and distinctive features that only locally-based production systems can originate. This is particularly important in developing countries, where, over time, actors may have developed a set of habits and practices with regard to these underlying processes that are not conducive to innovation. 
CONCLUSIONS 


\section{Main findings of the thesis}

Since the early 1990 s, a remarkable export boom in processed agricultural commodities from developing countries has developed. This surprising phenomenon deserves attention, as the development literature has traditionally focused on manufacturing, narrowly defined, as a pathway to development, and has often tended to view natural resources more as an impediment than an opportunity to industrialization. This thesis has identified the conditions under which successful export growth might open up real windows of opportunity for developing countries to reduce their technological gap with leading producers in natural resource-based processing sectors and to promote local capabilities in a way that is conducive to development. In order to do this, an analysis of two case studies on the Chilean and Argentine wine industries has been drawn upon. The main findings of the thesis are illustrated below.

First of all, it has been shown that natural resource-based processing sectors have become increasingly knowledge intensive. No industry should be considered mature, or perpetually low-tech, as almost all industries can be affected and transformed by new technologies. For example, contrary to those who think that natural resources are "low tech" industries, wine has become a knowledge-intensive and highly diversified industry. The art of winemaking is a mature and very old activity, but nowadays it relies on a sophisticated and interdisciplinary knowledge platform, based on the interaction of four major scientific fields: agronomy and scientific instrumentation; chemistry and biology; mechanical engineering and physics; and neurobiology, psychology and sensory analysis.

During the last three decades, a deep technological revolution has been at the origin of a radical shift from quantity- to quality-oriented wine production. On the demand side, this shift was facilitated by drastic changes in consumers' lifestyles and rising levels of GDP per capita. Currently, for most international consumers, wine is no longer an ordinary everyday beverage or a caloric supplement, but a high-quality, sophisticated, highly priced (occasional) luxury good. On the supply side, this has also been made possible by large amounts of codified and capital-embodied knowledge, as well as tacit knowledge supporting complex decision making, and continuous technological adaptation and improvement. Overall, therefore, wine has undergone a deep "decommodification" process, whereby major technological changes has led to product quality and diversification, originated rising entry barriers and conferred increasing value per unit to those producers who have chosen innovation-based strategies.

For developing countries, entering a natural resource-based processing industry that has undergone complex technological transformations, such as wine, has become increasingly difficult. In the 1970s the wine industry went through a deep technological revolution in all its phases, which was led by two new entrants from the developed world, namely Australia and the United States. These "New World" producers challenged the century-old hegemony and consolidated habits of "Old World" producers such as Italy, France and Spain, and gained increasing shares in the international 
market. They also reshaped the patterns of competition and the technological trajectory of the wine industry world-wide, creating rising barriers of entry and making entry conditions for developing countries particularly challenging.

Surprisingly, international trade data show that during the last quarter of the twentieth century, a number of developing countries managed to become key actors in the international wine industry. This thesis has examined two of these, namely Chile and Argentina, who have managed to join the group of the ten leading wine exporters. Even more surprisingly, the export boom of Chilean and Argentine wines was characterized by continuous quality improvements, by enhanced positioning in international markets and by rising export unit values over time. Therefore, contrary to all pessimistic views, predicting an inexorable and swift bust after each export boom, there seems to be a substantial discontinuity with other natural resource export booms that Chile and Argentina have experienced in the past.

This thesis has shown that these positive, unexpected results were the consequence of an intensive technology upgrading and innovation process, whose initial drivers can be identified in a group of foreign investors who revolutionized the traditional way of producing wines in Chile and Argentina, and brought them closer to international taste and quality standards. This is not surprising, as innovation is a costly, risky and pathdependent process, and for most countries in the world foreign sources of knowledge and technology are often predominant and indispensable to the innovation process. However, it has also been demonstrated that this process was reinforced by the emergence of internal sources of innovation, which became instrumental in consolidating the wine revolution and in "embedding" it in the local context.

By doing this, the view that looks at developing countries mainly as users of capital equipment, licenses and technical knowledge imported from abroad or as dependent on the presence of FDI has been challenged. The role played by foreign technology and know-how in spurring the initial "resurrection" of the Chilean and Argentine wine industries after a long period of decline has been recognized, but it has also been proven that the gradual emergence of endogenous innovation capabilities and wine-related R\&D to ensure sustained export growth was equally important. Furthermore, it has been shown that in Chile and Argentina the "embeddedness" of the production of highquality wines for export in the local environment and the creation of local tacit knowledge have been key to sustaining export growth for more than two decades and to obtaining deeper benefits from it.

In particular, the continued quality upgrading and prolonged export growth of Chilean and Argentine wines have been achieved by building the innovation capacity of local actors, including highly skilled oenologists, agronomists and winemakers, and by creating domestic linkages with local grape producers and input providers along the value chain. Despite the limited amount of resources destined to R\&D expenditures and the clear gaps in terms of university and industry collaboration, Chile and Argentina have also intensified their scientific efforts on wine in order to face the increasing competition of other wine producers from both the Old and New Worlds. Furthermore, the field survey shows that the leading exporting wineries in both countries have 
contributed to the adaptation and improvement of imported technologies by carrying out an extensive amount of in-house $\mathrm{R} \& \mathrm{D}$, second to none in the world of international wine production.

Based on the findings of the field research, it also emerges that the sustainability of export growth of Chilean and Argentine wines over the years has been supported at the local level by the creation of linkages and networking dynamics, which were indispensable for strengthening local competitive advantages and innovative capabilities. In particular, sustained export performance has been associated with the presence of some wine clusters that managed to transform themselves from informal into organized entities. This has allowed both the Chilean and Argentine wine industries to start experiencing the emergence of territorially bound specificities, "uniqueness" factors and local innovative capabilities that would make Chilean and Argentine wines original, different from each other and irreplaceable in the eyes of international consumers, thus ensuring the sustainability of Chilean and Argentine wine export growth in the long term.

This thesis has also shown how sustainability has also been dependent on the extent to which Chilean and Argentine organized wine clusters have managed to tap into substantial investments in $\mathrm{R} \& \mathrm{D}$, incentive structures and institutional capacity carried out at the regional level. In both Chile and Argentina, the presence of well-functioning regional systems of innovation have been essential in helping organized clusters to benefit from localized knowledge spillovers at the inter-firm and inter-cluster levels, that is, from continuous endogenous innovation (both of a radical and of an incremental nature) able to counterbalance technological path dependency and lock-in phenomena.

In sum, from an analytical perspective, a series of key findings should be highlighted.

Natural resource-based processing sectors may be considered new windows of opportunity for developing countries. However, the increasing knowledge intensity of these sectors makes it increasingly difficult for developing countries to find an entry point based exclusively on their low labour costs, or to pursue an incremental-only catching up process. The new entry dynamics have to go beyond the deepening of production capabilities and entail a conscious process of learning and innovation if developing countries wish to move from the pure extraction or production of raw materials or low value-added products to more sophisticated downstream and upstream activities, as happened in the manufacturing industry narrowly defined, in South East Asia.

The challenge for developing countries lies not only in the identification of strategic entry points, but also, and especially, in the long-term sustainability of industry growth. This is particularly true for those countries that have reached middle-income status, such as Chile and Argentina, and are facing the need for continued innovation to cope with the changes in the global patterns of international competition. In this sense, natural-resource-based industrialization could represent a way of overcoming the "middle income trap" that is hampering the growth of several Latin American countries. 
It could also represent a way of responding to the challenge of having to compete with low-wage, low-skills economies in Asia by adopting an equally successful export led strategy, drawing on the existing comparative advantages of the continent rather than trying to create brand new ones.

In natural resource-based processing sectors, export sustainability depends on the extent to which endogenous scientific, technological and innovative capabilities are developed to add increasing value to local products and to provide local solutions to emerging challenges related to issues such as branding, denomination of origin, product diversification, as well as bio-security, environmental friendliness, and control of fungi/diseases. From an evolutionary perspective, therefore, development is not exclusively about "individual product success stories" or about creating brand-new "high-tech" industries. Rather, it is also about pursuing the internal transformation of industries which already exist, through a dynamic analytical framework that allows the identification of potential windows of opportunity for creating, distributing and maintaining advanced knowledge. In this sense, a key role in the innovation process is played by inter-firm networking dynamics and inter-institutional linkages, as well as by a variety of university-industry interactions bringing different strands of knowledge together.

In order for this to happen, a redefinition of development in more systemic and innovation-oriented terms is needed. In particular, in natural resource-based sectors, knowledge intensity emerges from a systemic perspective, rather than from the observation of the behaviour of individual firms. In this sense, Pavitt's (1984) original taxonomy of the sectoral patterns for the acquisition of innovative knowledge in natural resource-based sectors should be revisited, in order to reflect not only the importance of product and organizational innovation (in addition to process innovation) in sustaining their export growth, but also the fact that the main sources of technical knowledge are located both inside and outside the firm.

Looking at the technological trajectory of natural resource-based processing industries, three main steps may be identified, which are not so different from the steps of the export-led manufacturing strategies followed by the Asian tigers. The first step is related to both process and product innovation, and to the import of foreign machinery and technology from abroad. The second step consists of the diffusion of foreign tacit and codified knowledge for quality upgrading, made necessary by the need to master modern production techniques and to adapt them to local conditions. The third step consists in the creation of product, process and organizational innovation through local tacit knowledge and endogenous R\&D findings, aimed at the diversification, branding and characterization of local products.

In this context, local demand conditions may play an important role, as demanding home country buyers may put pressure on companies to meet high-quality standards. However, the possibility of relying on traditionally strong and relatively stable local demand may also hinder rather than stimulate the process of technological and quality upgrading, particularly if the majority of local consumers cannot afford to align itself with the quality requirements of the international market. When assessing the role of 
domestic demand in pulling innovation, therefore, it is imperative to determine whether the domestic market should be associated with a low- or a high-income level and growth. It would seem that only the latter may encourage increased diversification and a higher quality of production.

In the absence of local suppliers that can produce according to international quality standards, large firms tend to "verticalize" in order to acquire direct control of production in all its phases. This is particularly true in natural resource-based sectors, which have been traditionally considered "enclaves" dominated by TNCs. In such sectors, therefore, clusters may be particularly useful for creating forward and backward linkages, and technological spillover effects on local firms. They may also play a key role in making sure that a process of collective knowledge and information exchange takes place, so that the direction and pace of technological change is based on local interests and needs. However, this process is not automatic, and has to be deliberately pursued.

The integration of clusters that have become organized into well functioning regional innovations systems may also be instrumental in embedding foreign investors in the local environment and in using them "strategically" to strengthen more complex innovation and technological capabilities. In particular, regional systems of innovation can play a crucial role in connecting local clusters with global networks, and bringing together international knowledge and frontier technologies with uniqueness factors and local distinctive features. This is particularly important in developing countries, where over time actors may have developed a set of habits and practices with regard to these underlying processes that are not conducive to innovation.

\section{Policy implications}

From a policy perspective, several important implications can be drawn from the present analysis. This aspect of the thesis is of major importance as, in the allocation of scarce resources, policy makers in developing countries face difficult choices between investing in the transformation and upgrading of industries which already exist, or creating entirely new ones. Furthermore, as Hausmann and Rodrik (2003) put it, identifying what a country is good at producing is not only an important determinant of structural change, but is also "one that is unlikely to be adequately provided under laissez-faire”. Policy makers, therefore, should be more aware of the heterogeneity, specificity and complexity of the interaction among technological change and economic growth. They should be also aware of the implications of different forms of productive organization and the associated technological knowledge base.

By applying the innovation system and cluster approaches to the context of developing countries, it was ascertained that, with specific adaptations, these approaches may be regarded as effective policy tools for promoting sustainable economic growth. It has also been emphasized how, through policy interventions, the globalization process may become functional and not detrimental to local system building and system promotion. When economies open up to international competition, as happened in the cases of 
Chile and Argentina in the 1990s, they usually undergo heavy restructuring processes and start to rely almost exclusively on exogenous sources of innovation. In developing countries, this often undermines the possibilities of competing internationally, based on local tacit knowledge and endogenous innovation, at a time when dangerous power games of exclusion and inclusion are generated by the creation of global business networks. From this study, it emerges that two aspects of the innovation system and cluster approaches may be particularly effective in preventing this from happening.

Firstly, clusters can be used as an ideal platform for diffusing technological innovation by encouraging knowledge creation and sharing at the local level. From a policy perspective, innovation is an interactive and inter-organizational learning process embedded in social relations, but sometimes non-local connections are indispensable to tapping into new knowledge created in other parts of the country and sometimes of the world, thereby avoiding the risk of lock-in phenomena. Policy makers can acknowledge and rebalance the heterogeneity characterizing the learning capabilities of the pool of firms located within the same cluster, as firms with lower absorptive capacity tend to isolate themselves and to not participate in advanced knowledge networks, unless their knowledge base is deliberately upgraded.

Secondly, clusters - adequately organized and embedded in well functioning regional innovation systems - can be used as key units of analysis in reconceptualizing foreign investment as part of a broader development process, whereby foreign investors become potential partners in stimulating local economic growth and the innovation process behind it. In particular, certain policies may be key in this process: stimulating the internal interactive process of clusters, originating cross-fertilization dynamics among different clusters, enhancing their capabilities to tap into the constructed advantages of regional innovation systems, and maximizing the potential contribution of foreign investment in terms of knowledge flows and technological spillovers.

Rather than distant or antagonist approaches, therefore, the cluster and the innovation system approaches can be considered potentially complementary in forging a better and more coherent policy framework for promoting competitiveness and economic performance, and for designing policies focused not only on the needs of export markets, but also on the needs of both domestic and export markets. This is particularly important in developing countries, where globalization has often generated irreversible inclusion-exclusion power games and has often proven inimical to endogenous innovation and long-term system building, as happened in Latin America during the "lost decade" of the 1990s.

More specifically, looking at the future of the Chilean and Argentine wine industries and at the sustainability of their wine export boom, different policy recommendations emerge from the comparison of the Chilean and Argentine "models". In Chile, the main policy issue is related to the need of complementing the existing highly centralized innovation system with stronger decentralized regional innovation systems, in order to create new opportunities to diversify. This thesis has argued, in fact, that strong regional innovation systems are more appropriate in tackling the emerging pattern of diversified demand and in putting emphasis on product variety and specificity, 
according to international consumption patterns. Natural resource-based clusters throughout the country should also attract a stronger attention from policy makers, and receive adequate support to develop local branding, linkages and networking dynamics, thereby attracting new investors even in remote areas.

In Argentina, the main policy issue to be addressed is how to make sure that other emerging Argentine wine provinces, beyond Mendoza, manage to develop a rich institutional framework, relationships of trust and interactive dynamics and how to stimulate cross-fertilization among different clusters. Argentina's "inclusive" development approach based on small producers and horizontally integrated value chains, still predominant in exporting industries such as wine, olive oil and dairy products - in contrast to exporting industries such as soybean, meat and cereals dominated by exporting giants - should be further endorsed by key public and private sector stakeholders, in line with the National Vitivinicultural Strategic Plan (Visión 2020). Moreover, the Argentine wine industry could gain some advantages from a larger presence of joint-ventures rather than companies fully owned by foreign investors, as the former often tend to be more conducive to local capacity building. Encouraging the creation of joint-ventures, however, requires consistent investment promotion efforts and strengthening the country image in terms of macroeconomic stability and legal transparency.

Overall, despite their irrefutable success, neither the Chilean nor the Argentine wine industries should sleep on their laurels. The fact that both seem to have completed the earlier phase of the wine technological revolution does not mean that they are well prepared to meet future challenges and to sustain their export growth in the long term. In the second phase, every single step towards the technological frontier is much more complex and difficult, and is characterized by a higher level of knowledge intensity from a systemic perspective. This transition can be successfully achieved only if the technical and scientific understanding of the latest developments in a wide-ranging spectrum of science and technology disciplines is present and equally diffused among all main industry stakeholders and geographic areas.

\section{Suggestions for further research}

This thesis has looked at one type of natural resource-based industry, namely that of agro-industrial, processed products. In order to further contribute to the understanding of the relationship between natural resource-based exports and development, these findings and policy recommendations should be applied to other types of natural resources. Mineral commodities, such as mining and oil products, for example, are also a key priority for developing countries. Following the recent surge in mineral commodity exports driven by the rising demand of China and India, there is an increasingly controversial debate on the need for developing countries to increase transparency regarding the use of revenues obtained from natural resources, the measures taken to minimize corruption and the promotion of good governance.

However, this study has clearly shown that this should not be the only issue to be addressed from a policy perspective, and that there is need to pay more attention to the 
importance of developing local linkages and learning capabilities along the value chain. Contrary to what is often recommended, ${ }^{125}$ this thesis argues that the key issues to be prioritized for the importance of their policy implications are: What kind of public input can support the technological upgrading of natural resource-based sectors into growing knowledge-based activities? How can policy-makers pursue a development path based on the restructuring of industries traditionally considered "low-tech" or mature?

Moreover, this thesis focuses on Latin America, but in the past Africa and Asia have not been any less affected by the tendency to exploit natural resource endowments without building related learning and innovation capabilities. Is should be just considered that, in 2000-2010, thanks to the recent boom in commodity prices, six of the fastest growing countries were African. Angola, for example, grew faster than any other African country, thanks to its diamond mines and to the extraction of 1.9 million barrels of oil a day, which has transformed the country into Africa's second largest producer of oil after Nigeria. With a Gini coefficient of 0.55 , however, it is one of the most unequal and least developed places in the world.

In Asia, some countries, such as Indonesia, have experienced an unprecedented level of investment in mining, drilling and construction related activities. Here, natural resources - including oil and gas, minerals, palm oil, base metals and rubber contributed 57 percent of GDP in 2010. Despite a growth rate of more than 6 percent in 2010, however, the Indonesian economy is suffering from an over-specialization in natural resource-based exports, bringing with it not only problems related to heavy environmental damages and unsustainable resource depletion, but also a loss of jobs in tradable manufacturing industries. It would therefore be very useful to verify whether the findings and policy recommendations presented in this thesis would be confirmed if applied to such different industries and geographical areas.

Finally, from an academic perspective wine economics is a young, emerging discipline, still dominated by the use of rigorous quantitative methods. Without neglecting the importance of econometrics to investigate issues such as "the reliability and consensus of experienced wine judges", "how to predict the quality and prices of Bordeaux wines", or "the stock market reaction to court decisions related to differential treatment of Internet wine sales", wine economics could benefit from an increased use of qualitative methods and from the adoption of a more interdisciplinary approach.

\footnotetext{
125 See, for example, the recent report on the subject entitled "Natural Resources in Latin America and the Caribbean: Beyond Booms and Busts?”, World Bank (2011).
} 


\section{Bibliography}

Abramovitz, M. (1986), "Catching Up, Forging Ahead and Falling Behind”, Journal of Economic History, no. 46, pp.385-406.

Abramovitz, M. (1994), "The Origins of the Post-war Catch Up and Convergence Boom", in J. Fagerberg, N. von Tunzelman and B. Verspagen (eds.), The Dynamics of Technology, Trade and Growth, Edward Elgar, London.

Adams, L. D. (1973), The Wines of America, San Francisco Book CompanyHoughton/Mifflin, Boston.

Agosin, M. (2006), Trade and Growth: Why Asia Grows Faster than Latin America, IDB Publications 31778, Inter-American Development Bank, Washington.

Agosin, M. and Bravo-Ortega, C. (2009), "The emergence of New Successful Export Activities in Latin America: The Case of Chile", RES Working Papers 3265, InterAmerican Development Bank, Research Department, Washington.

Agosin, M., Alvarez, R. and Bravo-Ortega, C. (2012), "Determinants of Export Diversification Around the World: 1962-2000", The World Economy, Wiley Blackwell, vol. 35, no.3, pp. 295-315.

Allen, T.J. (1977), "Managing the Flow of Technology: Technology Transfer and the Dissemination of Technological Information within the R\&D Organization”, MIT Press, Cambridge, MA.

Altenburg, T. and Meyer-Stamer, J. (1999), "How to Promote Clusters: Policy Experiences from Latin America”, World Development, vol. 27, no. 9, pp. 16931713 .

Akyuz Y. and Gore, C. (1996), "The Investment-Profits Nexus in East Asian Industrialization", World Development, vol. 24, no. 3, pp 461-470.

Alvarado, J.R. (2004), Chilean Wine: The Heritage, Chalk Hill Press.

Amerine, M.A. and Roessler E.B. (1976), "Composition of Wines", in Wines-Their Sensory Evaluation, pp. 72-77, W.H. Freeman, New York.

Amin, A. and Wilkinson, F. (1999), "Learning, Proximity and Industrial Performance: An Introduction", Cambridge Journal of Economics, no. 23, pp. 121-125.

Amsden, A. (1989), Asia's Next Giant: South Korea and Late Industrialization, Oxford University Press, Oxford.

Andersen, E.S. (1994), Evolutionary Economics: Post-Schumpeterian Contributions, Pinter, London.

Andersen, E.S. (2009), Schumpeter's Evolutionary Economics: A Theoretical, Historical and Statistical Analysis of the Engine of Capitalism, Anthem Press, London. 
Anderson, K. (2004), The World's Wine Markets: Globalization at Work, Edward Elgar, Cheltenham.

Anderson, K. (2005), “Why Pursue Trade Liberalization?,” Agricultural Outlook Forum 2005, United States Department of Agriculture, Agricultural Outlook Forum.

Anderson, K. (2011), "Wine's Globalization: New Opportunities, New Challenges for Australia”, Crush 2011 Symposium - National Wine Centre, Adelaide, 28 September 2011.

Anderson, K. and Wood, D. (2006), "What Determines the Future Value of an Icon Wine? New Evidence from Australia”, Journal of Wine Economics, vol. 1, no. 2, pp. 141-161.

Andersson, T., Serger, S.S., Sörvik, J., and Hansson, E.W. (2004), The Cluster Policies Whitebook., IKED: Sweden www.iked.org

Archibugi, D. (2007), "Introduction to The Special Issue on Knowledge and Innovation in The Globalising World Wine Industry”, International Journal of Technology and Globalisation, vol. 3, no. 2-3, pp. 125-126.

Archibugi, D., Denni, M. and Filippetti, A. (2009), "The Technological Capabilities of Nations: A Review of the Synthetic Indicators", Technological Forecasting and Social Change, vol. 76, no. 7, pp. 917-31.

Arkell, J. (1999), New World Wines, Ward Lock Publishing, London.

Asheim, B.T. (1995), "Regional Innovation Systems - A Socially and Territorially Embedded Technology Policy?”, Nordisk Samhällsgeografisk Tidskrift, 20, pp. 1734 .

Asheim, B. T. (2000), "Industrial Districts", in Clark, G., Feldman, M., and Gertler, M. (eds.), The Oxford Handbook of Economic Geography, pp. 413-431, Oxford University Press, Oxford.

Asheim, B. T. (2005), “Clusters, Regional Innovation Systems and Learning Regions: A Synthesizing Overview”, in Benner, M. (ed.), Innovationer, Dynamikk och förnyelse i ekonomi och samhällsliv, Dahmen institutet, Studentlitteratur, Lund, pp.33-6o.

Asheim, B. T. and Gertler, M. (2005), "The Geography of Innovation: Regional Innovation Systems", in Fagerberg, J., Mowery, D., and Nelson, R. (eds.), The Oxford Handbook of Innovation, Oxford University Press, Oxford, pp. 291-317.

Austral Spectator, (2004), South American Vineyards, Wineries \& Wines Guide, Editors of Austral Spectator Chelsea Green Publishing, March 1, London.

Auty, R.M. (1998), "Resource abundance and economic development: improving the performance of resource-rich countries", World Institute for Development Economics Research RFA Paper no. 44, Helsinki.

Auty, R. (2001), Resource Abundance and Economic Development, UNU, Helsinki, World Institute for Development Economics Research.

Auty, R. and Mikesell (1998), Sustainable Development in Mineral Economies, Oxford University Press, Oxford.

Aylward, D. (2004), "Innovation-Export Linkages within Different Cluster Models: A Case Study of the Australian Wine Industry", Prometheus, vol.22, no. 4, pp.423437.

Aylward, D. and Zanko, M. (2006), "Emerging Interorganizational Structures in the Australian Wine Industry: Implications for SMEs", Faculty of Commerce Papers, Adelaide, mimeo. 
Bagnasco, A. (1977), Tre Italie: la problematica territoriale dello sviluppo italiano, Il Mulino, Bologna.

Bairoch, P. (1993), Economics and World History: Myths and Paradoxes, Haverster Wheatsheaf, Luton, Great Britain.

Bairoch, P. and Kozul-Wright, P. (1996), "Globalization Myths: Some Historical reflections on Integration, Industrialization and Growth in the World Economy", UNCTAD Discussion Paper, no.113, New York and Geneva.

Balassa, B. (1982), "Disequilibrium Analysis in Developing Economies: An Overview", World Development, vol. 10, no. 12, pp. 1027-1038.

Bas, T.G., Amoros, E. and Kunc, M. (2008), "Innovation, Entrepreneurship and Clusters in Latin America Natural Resource - Implication and Future Challenges", Journal of Technology, Management and Innovation, vol. 3, no. 3, pp.52-65.

Batista, J.C. (2001), "Estrategia de desarrollo de clusters basados en recursos naturales: el caso de la bauxita en el norte de Brasil”, CEPAL, Santiago.

Beazley, M. (2000), Essential Wine Tasting: The Complete Practical Winetasting Course, Octopus Books.

Becattini, G. (1979), Scienza Economica e Trasformazioni Sociali, La Nuova Italia, Firenze.

Becattini, G. (1990), “The Marshallian Industrial District As a Socio-Economic Notion”, in F. Pyke, G. Becattini and W. Sengerberger (eds.), Industrial Districts and Interfirm Cooperation in Italy, IILS, Geneva.

Becattini, G. and Rullani, E. (1993), "Sistema locale e mercato globale", Economia e Politica Industriale, no. 80, pp.25-48.

Bélis-Bergouignan M.-C., Corade N., Pesme J.-O. (2010), "Strategic Operations and Concentration in the Bordeaux-Aquitaine Region", International Journal of Wine Business Research, no. 22, pp. 308-324.

Bell, M. and K. Pavitt (1993), "Technological Accumulation and Industrial Growth: Contrasts Between Developed and Developing Countries", Industrial and Corporate Change, vol. 2, no. 2, pp. 157-210.

Bell, M., and K. Pavitt (1995). “The Development of Technological Capabilities,” Trade, Technology and International Competitiveness. Washington, DC, the World Bank, pp. 69-101.

Bell, M. and Albu. M. (1999), "Knowledge Systems and Technological Dynamism in Industrial Clusters in Developing Countries”, World Development, vol.27, no.9, pp.1715-1734.

Bell, M., and Giuliani, E. (2007), "Catching Up in the Global Wine Industry: Innovation Systems, Cluster Knowledge Networks and Firm-Level Capabilities in Italy and Chile", International Journal of Technology and Globalisation, no. 3, pp.197-223.

Benavente, J.M. (2004), "Technological Change in Chile's Grape and Wine Producing Industry”, Departamento Economía, Universidad de Chile.

Benavente, J.M. (2006), "The Role of Research and Innovation in Promoting Productivity in Chile," Economics of Innovation and New Technology, vol. 15, no. 4-5, pp. 301-31.

Benavente, J.M. (2010), "Innovación, crecimiento y distribución de las rentas", en C. Hardy (ed) Ideas para Chile, aportes de la Centroizquierda, LOM Ediciones, Santiago. 
Bercovich, N. (2000), "Evolución y situación actual del complejo forestal en Argentina”, documento de trabajo. Proyecto CEPAL/IDRC "Reestructuración industrial, innovación y competitividad internacional en América Latina (Fase II)”, Santiago.

Bercovich, N. and Katz, J. (1997), "Reestructuración industrial y apertura económica: La industria de celulosa y papel de Argentina, Brasil y Chile en los años 90", Alianza Editorial, Buenos Aires.

Bernat, G. (2012), “Patron Exoportador, Emplo e Ingresos en América Latina: el Caso de las Manufacturas Industriales en Argentina”, Working Paper no. 144, LATN.

Bhagwati, J. (1958), "Immiserizing Growth: a Geometrical Note", Review of Economic Studies, no.3, pp. 201-5.

Bianchi, R. (1994), "Le model industriel italien : reflexion theorique et historique à la lumière des années '80”, Université Paris 13, Paris.

Bisang, R., Anllo, G. and Salvatierra, G. (2010), "Cambios estructurales en las actividades agropecuárias. De lo primario a las cadenas globales de valor”, CEPAL, Buenos Aires, Argentina.

Bisson, L., Waterhouse, A., Ebeler, S., Walker, M., and Lapsley, J. (2002), “The Present and Future of the International Wine Industry", Nature, vol. 418, pp. 696-699.

Boschma, R.A. (2004), "The Competitiveness of Regions from an Evolutionary Perspective", Regional Studies, vol. 38, pp. 1001-1014.

Boschma, R. and Iammarino, S. (2007), "Related Variety and Regional Growth In Italy“, SPRU Electronic Working Paper Series 162, Science and Technology Policy Research, Brighton.

Bresnahan, T. (1991), "Industrial Dynamics and the Evolution of Firms and Nations' Competitive capabilities in the World Computer Industry", in R. Nelson and D. Mowery (eds.) The Sources of Industrial Leadership, MIT Press, Boston.

Bresnahan, T., Gambardella, A., Saxenian, A. (2001), "Old Economy Inputs for New Economy Outputs: Cluster Formation in the New Silicon Valleys”, Industrial and Corporate Change, vol.10, no. 4, pp.835-86o.

Brook, S. (2000), A Century of Wine: the Story of a Wine Revolution, Mitchell Beazley, US.

Brook, S. (2006), Bordeaux: Medoc and Graves, Mitchell Beazley, US.

Brugnoli, (2005), Fostering International Investment in Micro, Small and Medium Size Enterprises in Latina America, ISLA, IDB, Washington.

Brusco, S. (1982), “The Emilian Model: Productive Decentralization and Social Intergration", Cambridge Journal of Economics, vol. 6, pp. 167-184.

Buitelaar, R. (2000), "Maquila, Economic Reform and Corporate Strategies", World Development, vol. 28, no. 9, pp. 1627-1642.

Bulmer-Thomas, V. (1994), The Economic History of Latin America since Independence, Cambridge Latin American Studies 77, Cambridge University Press, New York.

Bustos, J. S., Torres, J.P. and Willington, M. (2007), "Propiedad Extranjera y Especialización Productiva en la Industria del Vino en Chile,” ILADES-Georgetown University Working Papers no. 184, Ilades-Georgetown University, Universidad Alberto Hurtado/School of Economics and Business.

Camagni, R. (1991), "Introduction: From The Local 'Milieu' To Innovation Through Cooperation Networks", in Camagni, R. (Ed.) Innovation Networks, Belhaven Press, London, pp. 1-9. 
Campbell, C. (2004), The Botanist and the Vintner: How Wine Was Saved for the World, Algonquin Books, Chapel Hill.

Cardoso, F.H. and Faletto, E. (1979), Dependency and Development in Latin America, University of California Press, Berkley and Los Angeles.

Carlsson, B, and R. Stankiewicz (1991), "On the Nature, Function and Composition of Technological Systems”, Journal of Evolutionary Economics, no. 1, pp. 93-118.

Casaburi, G. (1999), Dynamic Agroindustrial Clusters: The Political Economy of Competitive Sectors in Argentina and Chile, New York, St. Martin's Press.

Chang, H. and Cheema, A. (2002), "Conditions for Successful Technology Policy in Developing Countries - Learning Rents, State Structures, and Institutions", Economics of Innovation and New Technology, vol. 11, no. 4-5, pp. 369-398.

Chenery, H. and Syrquin, M. (1975), Patterns of Development, 1950-1970, with assistance of Hazel Elkington, World Bank, Oxford University Press, Oxford.

Christopherson, S. (2002), "Why Do National Labor Marker Practices Continue to Diverge in the Global Economy? - The "Missing Link" of Investment Rule", Economic Geography, vol. 78, pp. 1-20.

Chudnovsky, D., Lopez, A. and Porta, F. (1994), "La nueva inversion extranjera directa en Argentina: Privatizaciónes, mercado interno e integración regional”, Centro de Investigaciones para la Transformación, Buenos Aires, Argentina.

Cimoli, M. (2000), Developing Innovation Systems: Mexico in a Global Context, (ed.) Continuum, London and New York.

Cimoli M. and Dosi G. (1995), "Technological Paradigms, Patterns of Learning and Development: An Introductory Roadmap", Journal of Evolutionary Economics, vol. 5, pp. 243-268.

Cimoli M. and della Giusta M. (2000), “The Nature Of Technological Change and Its Main Implication On National and Local Systems Of Innovation”, in Batten, D., Bertuglia, C.S., Martellato D., and Occelli, S. (eds.) Learning, Innovation and Urban Development, Kluwer, Boston.

Cimoli M. and Katz J. (2003), "Structural Reforms, Technological Gaps and Economic Development: a Latin American Perspective", Industrial and Corporate Change, vol. 12, no. 2, pp.387-411.

Cimoli, M, Ferraz, J. and Primi, A (2005), Science and Technology Policies in Open Economies: The Case of Latin America and the Caribbean, CEPAL, Santiago.

Cimoli, M., Primi, A. and Pugno, M. (2005), "An Enclave-Led Model of Growth: The Structural Problem of Informality Persistence in Latin America," Department of Economics Working Papers 0504, Department of Economics, University of Trento, Italy.

Cipresso, R., Negri, G. and Milioni, S. (2006), Il Romanzo del vino, Piemme, Roma.

Clarke, O., May, J. and Arkell, J. (2006), Oz and James's Big Wine Adventure, BBC Books, First Edition edition.

Coenen, L., Asheim, B., Moodysson, J., Vang, J. (2005), "Regional Innovation System Policy: a Knowledge-based Approach”, CIRCLE Electronic Working Paper Series WP 2005/13, Centre for Innovation, Research and Competence in the Learning Economy, Lund University and Blekinge Institute of Technology.

Cohen, W.M. and Levinthal, D.A. (1989), "Innovation and learning: The two faces of R\&D”, The Economic Journal, vol. 99, pp. 569-596. 
Collier, P. (2007), "Growth Strategies for Africa”, paper prepared for the Spence Commission on Economic Growth Centre for the Study of African Economies, Department of Economics, Oxford University

Collier, P. (2010) The Political Economy of Natural Resources, Social Research, vol. 77, no. 4, pp.1105-1132.

Collier, Paul and B. Goderis (2007), "Commodity Prices, Growth, and the Natural Resource Curse: econciling a Conundrum" Center for the Study of African Economies. Working Paper Series.

Cooke, P. (1992), "Regional Innovation Systems: Competitive Regulation in the New Europe", GeoForum, vol. 23, pp. 365-382.

Cooke, P. (1998), "Introduction: Origin of the Concepts", in Braczyk H. J, Cooke P. and Heidenreich M. (ed.) Regional Innovation Systems: The Role of Governances in a Globalized World, UCL Press, London.

Cooke, P. (2001), "Regional Innovation Systems, Clusters, and the Knowledge Economy”, Industrial and Corporate Change, vol. 10, no. 4, pp. 945-974.

Cooke, P. (2003), "The Evolution Of Biotechnology In Three Continents: Schumpeterian Or Penrosian?”, European Planning Studies, no. 11, pp. 789-804.

Cooke, P. (2004), "Integrating Global Knowledge Flows for Generative Growth in Scotland: Life Sciences as a Knowledge Economy Exemplar”, in Potter, J. (Ed.), Global Knowledge Flows and Economic Development, OECD, Paris, pp. 73-96.

Cooke, P. (2005), "Regionally Asymmetric Knowledge Capabilities and Open Innovation: Exploring Globalisation 2 - A New Model of Industry Organization”, Research Policy, no. 32, pp. 1128-1149.

Cooke, P., and Leydesdorff, L. (2006), "Regional Development in the Knowledge-Based Economy: the Construction of Advantages", Journal of Technology Transfer, vol. 31, no. 1 , pp. 5-15.

Corden, W. M., Neary, J.P. (1982), “Booming Sector and De-Industrialization in a Small Open Economy”, The Economic Journal, vol. 92, pp. 825-848.

Cornia, G.A (2011), "Economic Integration, Inequality and Growth: Latin America vs. the European Economies in Transition”, DESA Working Paper no. 101, New York.

Cowan, R. and Foray, D. (1997), "The Economics of Codification and the Diffusion of Knowledge”, Industrial and Corporate Change, vol. 6, no. 3, pp. 595-622.

Crevoisier, O. (1994), "Dynamique industrielle et dynamique régionale: l'articulation par les milieux innovateurs", Revue d'Economie Industrielle, 70, pp. 33-48.

Crevoisier, O. (2004), "The Innovative Milieus Approach: Toward A Territorialized Understanding Of The Economy?”, Economic Geography, vol. 80, pp. 367-379.

Crowley, W.K. (2001), "Chile's Wine Industry: Historical Character and Changing Geography”, Journal of Latin American Geography, pp. 87-101.

Cusmano, L., Morrison, A., and Rabellotti, R. (2009), "Catching-up Trajectories in the Wine Sector: A Comparative Study of Chile, Italy and South Africa”, American Association of Wine Economists, California.

Dahlman, C., Scherer, P., Utz, A.A, Zeng, D.Z, Chatzinikolaou, A. and Kuznetsov, Y. (2003), "Beyond the Crisis: From the Old to the New Economy in Argentina", Unpublished research paper, The World Bank Institute, Washington D.C.

Dana L.P., Winstone K.E. (2008), Wine cluster formation in New Zealand: operation, evolution and impact", International Journal of Food Science \& Technology, no. 43, pp.2177-219o. 
Datamonitor (2008), “Global Wine Industry Overview”, Datamonitor Industry Market Research, December 15, 2008.

David, P. and Wright G. (1997), “The Origins of American Resource Abundance", Industrial and Corporate Change, vol. 6, no 2, pp.6-19.

Decanter (2006), “50 Best Value Red Wines”, January 2006, New York.

Del Pozo, J. (1998), Historia del Vino Chileno, Editorial Universitaria, Santiago de Chile.

Ditter, J-G. (2005), "Reforming the French Wine Industry: Could Clusters Work?", Cahiers du CEREN, vol. 13, pp.39-54.

Dosi, G. (1982), "Technological paradigms and technological trajectories", Research Policy, vol. 11, no. 3. pp. 147-162.

Dosi, G. (1984), Technical Change and Industrial Transformation, Macmillan, London, New York.

Dosi, G. and Malerba, F. (1996), Organization and Strategies in the Evolution of the Enterprise, Mcmillan, London, New York.

Duijker, H. (1999), “The Wines of Chile”, Spectrum, Utrecht.

Dunning, J.H. (1981), International Production and the Multinational Enterprise, George Allen and Unwin, London.

Dyster, B. (1979), "Argentine and Australian Development Compared", Past and Present, no. 84, pp. 91-110.

Easterly, W. (2006), “The Big Push Déjà Vu: a Review of Jeffrey Sachs's The End of Poverty: Economic Possibilities for Our Time”, Journal of Economic Literature, vol. XLIV, pp.96-105.

ECLAC (2011), Estudio Económico de América Latina y el Caribe 2010-2011, División de Desarrollo Económico, Documento Informativo, ECLAC, Santiago de Chile.

Edquist, C. and Johnson, B. (1997), "Institutions and Organizations in Systems of Innovation”, in Edquist, C. (ed.) Systems of Innovation: Technologies, Institutions and Organizations, Pinter Publishers/Cassell Academic.

Ellison, G. and Glaeser, E. (1999), "The Geographic Concentration of Industry: Does Natural Advantage Explain Agglomeration?”, American Economic Review, American Economic Association, vol. 89 (2), pp. 311-316.

Ellman, M. (1981), "Natural Gas, Restructuring and Reindustrialisation: The Dutch Experience of Industrial Policy.” In Oil or Industry? Energy Industrialisation and Economic Policy: Issues in Canada, Mexico, Norway, and the United Kingdom, ed. Terry Barker andVladimir Brailovsky, London Academic Press.

Enright, M. J. (2000), "The Globalization of Competition and the Localization of Competitive Advantage: Policies Towards Regional Clustering”, in Hood, N. and Young, S. (eds.), The Globalization of Multinational Enterprise Activity and Economic Development, Macmillan, London, pp. 303-31.

Ernst, D., Ganiatsos, T. and Mytelka, L. (eds.) (1998), Technological Capabilities and Export Success in Asia, Routledge, London.

Estreicher, S. (2006), Wine: From Neolithic Times to the $21^{\text {st }}$ Century, Algora Publishing.

Fagerberg, J. (1994), “Technology and International Differences in Growth Rates", Journal of Economic Literature, XXXII (3), pp. 1147-1175.

Fagerberg, J. (1999), "Technology, Policy, Growth - Theory, Evidence and Interpretation", Nordic Journal of Political Economy, vol. 25, pp. 5-14. 
Fagerberg, J. (2004), "What do we know about innovation? Lessons from the TEARI project“, Working Papers on Innovation Studies, Centre for Technology, Innovation and Culture, University of Oslo.

Fagerberg, J. and Godinho, M.M. (2004), "Innovation and Catching-up", in J. Fagerberg, D.C. Mowery and R.R. Nelson (eds.), The Oxford Handbook of Innovation, Oxford University Press, Oxford.

Fagerberg, J. and Srholec, M. (2007), "National Innovation Systems, Capabilities and Economic Development," Working Papers on Innovation Studies, Centre for Technology, Innovation and Culture, University of Oslo.

Fagerberg, J., Srholec, M. and Verspagen, B. (2009), "Innovation and Economic Development”, TIK Working Paper on Innovation Studies, Centre for Technology, Innovation and Culture, Oslo.

Farinelli, F. (2003), "Technological Catch-up and Learning Dynamics in the Chilean Wine Industry", Conference on Innovation and Competitiveness in the New World of Wine, 12 November 2003, Niagara, Canada.

Farinelli, F. (2007), "The Awakening of the Sleeping Giant: Export Growth and Technological Catch-up of the Argentine Wine Industry", International Journal of Technology and Globalisation, vol. 32, no. 3, pp. 179-96.

FAO (2009), Agribusiness Handbook: Grapes and Wines, Rome.

FAO (2010), Agro-based Clusters in Developing Countries: Staying Competitive in a Globalized Economy, United Nations publications, New York.

Farrell, T. M. A. (1979), "A Tale of Two Issues: Nationalization, the Transfer of Technology and the Petroleum Multinationals in Trinidad-Tobago", Social and Economic Studies, vol. 28, no. 1, pp.234-81.

Feldman, M. P. and Francis, J. L. (2004), "Homegrown Solutions: Fostering Cluster Formation”, Economic Development Quarterly, vol. 18, no. 2, pp. 127-137.

Ffrench-Davis, R. (1983), "The Monetarist Experiment in Chile: A Critical Survey" World Development, Elsevier, vol. 11, no.11, pp. 905-926.

Ffrench-Davis, R. (2000), Reforming the Reforms in Latin America, Macmillan Press Ltd., London.

Fielden, C. (2001), The Wines of Argentina, Chile and Latin America: From Chile and Argentina to Mexico, Classic Wine Library, Faber.

Frank, A.G. (1966), The Development of Underdevelopment, Volume 18, MRP.

Freeman, C. (1987), Technology Policy and Economic Performance: Lessons from Japan, Pinter Publishers, London.

Freeman, C. (1988), “Japan: A new national innovation system?”, in G. Dosi, C. Freeman, R. R. Nelson, G. Silverberg and L. Soete (eds.) Technology and Economy Theory, Pinter, London.

Freeman, C. (2008), Systems of Innovation: Selected Essays in Evolutionary Economics, Edward Elgar Publishing Ltd.

Freeman, C. and Perez, C. (1988), "Structural Crises of Adjustment, Business Cycles and Investment Behaviour”, in G. Dosi et al. (eds.), Technical Change and Economic Theory, Pinter Publishers, London.

Freeman, C. and Soete, L. (1997), The economics of industrial innovation, Routledge.

Fu, X., Pietrobelli, C. and Soete, L, (2011), 'The Role of Foreign Technology and Indigenous Innovation in the Emerging Economies: Technological Change and Catching-up”, World Development, vol. 39, no. 7, pp.1204-1213. 
Furtado, C. (1962), Development and Underdevelopment, University of California Press, Los Angeles.

Furtado, C. (1976), Economic Development in Latin America, $2^{\text {nd }}$ Edition, Cambridge University Press.

Galet, P. (2000), General Viticulture, Oenoplurimedia.

Garofoli, G. (1991), "Local Networks, Innovation and Policy in Italian Industrial Districts”, in Bergman E., Maier G., and Tödtling F. (eds.) Regions Reconsidered: Economic Networks, Innovation, and Local Development in Industrialised Countries, Manell, New York.

Gelb, A. (1988), Oil Windfalls: Blessing or Curse?, Oxford University Press, New York. Gereffi, G. (1994), 'The Organisation of Buyer-Driven Global Commodity Chains: How Us Retailers Shape Overseas Production Networks', in G. Gereffi and M. Korzeniewicz (1994), Commodity Chains and Global Capitalism, Frederick A. Praeger, pp. 95-122.

Gereffi, G. (1999), "International Trade and Industrial Upgrading in the Apparel Commodity Chain”, Journal of International Economics, vol. 48, no. 1, pp.37-70.

Gerschenkron, A. (1962), Economic Backwardness in Historical Perspective, A Book of Essays, Frederick A. Praeger, New York.

Gertler, M. (2003), "Tacit Knowledge and the Economic Geography of Context, or the Undefinable Tacitness of Being (There)", Journal of Economic Geography, vol. 3, pp.75-99.

Gibbs, M., Tapia, M. and Warzynski, F. (2009), "Globalization, Superstars and the Importance of Reputation: Theory \& Evidence from the Wine Industry", Chicago Booth School of Business Research Paper no. 9-13.

Giuliani, E. (2003), "How Clusters Learn: Evidence From a Chilean Wine Cluster", University of Pisa and SPRU, Brighton, University of Sussex.

Giuliani, E (2004), "Laggard Clusters as Slow Learners, Emerging Clusters as Locus of Knowledge Cohesion (and Exclusion): A Comparative Study in the Wine Industry“, LEM Papers Series 2004/o9, Laboratory of Economics and Management (LEM), Sant'Anna School of Advanced Studies, Pisa, Italy.

Giuliani, E. (2005), "The Structure of Cluster Knowledge Networks Uneven, not Pervasive and Collective", DRUID Working Papers 05-11, DRUID, Copenhagen Business School, Department of Industrial Economics and Strategy/Aalborg University, Department of Business Studies.

Giuliani, E. (2006), “The Uneven and Selective Nature of Cluster Knowledge Networks: Evidence from the Wine Industry," CIRCLE Electronic Working Papers 2006/11, Lund University, CIRCLE - Center for Innovation, Research and Competences in the Learning Economy.

Giuliani, E. (2007), "The Selective Nature of Knowledge Networks in Clusters: Evidence from the Wine Industry", Journal of Economic Geography, 7, pp. 139-168.

Giuliani, E. (2010), "The Role of Technological Gatekeepers in The Growth of Industrial Clusters: Evidence from Chile”, Papers in Evolutionary Economic Geography (PEEG) 1013, Utrecht University, Section of Economic Geography.

Giuliani, E., Morrison, A., Rabellotti, R., Pietrobelli, C. (2010), "Who Are the Researchers That Are Collaborating with Industry? An Analysis of the Wine Sectors in Chile, South Africa and Italy”, Research Policy, vol. 39, no. 6, pp. 748-761.

Giuliani, E., Pietrobelli, C. and Rabellotti, R. (2005), "Upgrading in Global Value Chains: Lessons from Latin American Clusters“, World Development, vol. 33, no. 4, pp. 549-573. 
Glänzel, W. and Veugelers, R. (2006), "Science for Wine: A Bibliometric Assessment of Wine and Grape Research for Wine-Producing and Consuming Countries," Open Access publications from Katholieke Universiteit Leuven, Katholieke Universiteit Leuven.

Goedhuys, M., Janz, N. and Mohnen, P. (1998), "Knowledge-Based Productivity in "Low-Tech" Industries: Evidence from Firms in Developing Countries", UNUMERIT Working Paper no.7, Maastricht.

Goldfarb, A. (2007), "A Visit to Prager Port Works: Has the Ship Finally Come in for California Port-Style Wines?”, Appellation America.

Goldstein, A. (2005), 'Emerging Multinationals' in the Global Economy: Data Trends, Policy Issues, and Research Questions, Paris, OECD Development Centre, mimeo.

Gwynne, R. (2008), "Firm Creation, Firm Evolution and Clusters in Chile's Dynamic Wine Sector: Evidence from the Colchagua and Casablanca Regions", AAWE Working Paper no. 20, American Association of Wine Economists.

Hadj, A., Lecocq, H. and Visser, M. (2007), "The Impact of Gurus: Parker Grades and En Primeur Wine Prices", American Association of Wine Economists, AAWE Working Paper no.1.

Hall, A. (2007), "Challenges to Strengthening Agricultural Innovation Systems: Where Do We Go from Here?”, UNU-MERIT Working Paper no.38.

Halliday, J. (2007), Australian Wine Companion 2007 Edition, HarperCollins, Australia.

Harrison, L. (1985), Underdevelopment is a State of Mind, Madison Books, Madison.

Hausmann, R. and Rodrik, D. (2003), "Economic development as self-discovery", Journal of Development Economics, Elsevier, vol. 72, no. 2, pp.603-633.

Hausmann, R., Hwang J. and Rodrik, D. 2007. "What you export matters," Journal of Economic Growth, Springer, vol. 12, no. 1, pp. 1-25, March.

Hausmann R. and Klinger B. (2007), "The Structure of the Product Space and the Evolution of Comparative Advantage.” CID Working Paper no. 146. Center for International Development at Harvard University, April 2007.

Hemingway, E. (1934), "Letter to F. Scott Fitzgerald (28 May 1934)", Ernest Hemingway, Selected Letters 1917-1961, ed. Carlos Baker (1981).

Hernández, L. M. (2000), "Breve Diagnóstico del Sector de Productos Orgánicos Chilenos", ProChile, 28 December 2000.

Hernández, A., Bordeau, E., Vallejo, C. (2005), "Estudio Para el Desarrollo el Apoyo a La Innovación en la Industria Vitivinícola”, PTI Vitivinícola Puerta Sur de Santiago.

Herrera, A. (1973), "Social Determinants of Science Policy in Latin America”, Journal of Development Studies, vol. 9, no. 1, pp.19-37.

Hirschman, A. O. (1958), The Strategy of Economic Development, New Haven.

Hirschman, A. O. (1981), "The Rise and Decline of Development Economics", in Hirschman, A.O., Essays in Trespassing .Economics to Politics and Beyond, Cambridge, Cambridge University Press, pp.1-24.

Hobday, M. (1994), "Export Led Technology and Development in the Four Dragons: The Case of Electronics”, Development and Change, no.25, vol.2, pp. 333-361.

Hobday, M. (1995), Innovation in East Asia: The Challenge to Japan, E. Elgar, London. Hobday, M. (2012), "Learning from Asia's Success. Beyond Simplistic 'Lesson-making”, in A. Szirmai, W. Naudé and L. Alcorta, Pathways to Industrialization in the $21^{\text {st }}$ 
Century. New Challenges and Emerging Paradigms, Oxford, Oxford University Press (forthcoming).

Hobsbawm, E. (1968), Labouring Men: Studies in the History of Labour, Weidenfeld and Nicolson, 1968, University of Virginia.

Hobsbawm, E. (1994), Age of Extremes: the Short Twentieth Century, 1914-1991, Michael Joseph, London.

Howells, J. (1999), 'Regional Systems of Innovation?', in Archibugi, D., Howells, J. and Michie, J. (eds.), Innovation Policy in a Global Economy, Cambridge, Cambridge University Press.

Humphrey, J., and Schmitz, H. (2002), "How Does Insertion in Global Value Chains Affect Upgrading Industrial Clusters?”, Regional Studies, vol. 36, no. 9, pp. 10171027.

Iizuka, M. and Katz, J. (2011), "Natural Resources: Tragedy of the Commons and the Case of Chilean Salmon Farming", International Journal of Institutions and Economies, vol. 3, no. 2, pp.259-286.

IMF (2005), World Economic Outlook, Washington.

INV, Principales Variables de la Vitivinicultura Argentina Anos 1979-2002, Buenos Aires.

ITC (2009), "Guide to Geographical Indications: Linking Products and Their Origins", Geneva.

Jackson, R. (2008), Wine Science: Principles and Applications ( ${ }^{\text {rd }}$ ed.), Elsevier, Oxford.

Jacobs, J. (1969), The Economy of Cities, Random House, New York.

Jaffee S. and Gordon P. (2003), "Exporting High-Value Food Commodities: Success Stories from Developing Countries", World Bank Discussion Paper no. 198, Washington D.C.

Jenster, P., Smith, D., Jenster, L., and Mitry, D. (2008), The Business of Wine: a Global Perspective, Copenhagen Business School Press, Copenhagen.

Johnson, H. (1998), Hugh Johnson's Modern Encyclopedia of Wine, Simon and Schuster.

Johnson, H. (2007), Hugh Johnson's Pocket Wine, Octopus Publishing Group.

Kaldor, N. (1957), “A model of economic growth", The Economic Journal, vol. 67, no. 268, pp. 591-624.

Kaldor, N. (1967), Strategic Factors in Economic Development, W.F. Humphrey Press, Cornell University.

Kaplan, D. (2007), "Industrial Policy in South Africa: Targets, Constraints and Challenges", paper prepared for Sanjaya Lall memorial Conference, UNCTAD, 8-9 March.

Kaplinsky, R. and Fitter, R. (2004), "Technology and Globalization: Who Gains When Commodities Are De-Commodified?”, International Journal of Technology and Globalization, vol. 1, no. 1, pp.1-28.

Kaplinsky, R. (2005), "How Can Agricultural Commodity Producers Appropriate a Greater Share of Value Chain Incomes”, in M. Sarris and D. Hallam, Agricultural Commodity Markets and Trade: New Approaches to Analyzing Market Structure and Instability, Cheltenham, Edward Elgar.

Kaplinsky, R. (2006), "Revisiting the Revisited Terms of Trade: Will China Make a Difference?” in World Development, vol. 4, no. 6, pp.981-995. 
Kaplinsky, R. (2007), "Capability Building in South Africa: What Difference Do the Asian Drivers Make?”, paper prepared for Sanjaya Lall memorial Conference, UNCTAD, 8-9 March.

Katz, J. (2000), "Pasado y Presente Del Comportamiento Tecnológico de America Latina”, CEPAL, Santiago de Chile.

Katz, J. (2006), "Market-Oriented Reforms, Globalisation and the Recent Transformation of the Production and Social Structure of Developing Countries", International Journal of Technology Management, vol. 36, no. 1-3, pp.21-24.

Kim, L. (1997), Imitation to Innovation - The Dynamics of Korea's Technological Learning, Harvard Business School Press, Boston.

Kindleberger, C. (1956), Terms of Trade: a European Case Study, Wiley, New York.

Kline, S. and Rosenberg, N. (1986), “An Overview of Innovation”, in Landau, R. (ed.) The Positive Sum Strategy: Harnessing Technology for Economic Growth, National Academy Press, Washington.

Kosacoff, B. (2009), "Desarrollo económico desde una perspectiva productiva", Movimiento ProductivoArgentino, IV Ciclo de Formación de Dirigentes para una Argentina Productiva, Buenos Aires.

Kosacoff, B. and Ramos, A. (2009) "Microeconomic Evolution in High Uncertainty Contexts: The Manufacturing Sector in Argentina” in Cimoli, M., Dosi, G. and Stiglitz, J. (eds) Industrial Policy and Development: The Political Economy of Capabilities Accumulation, IPD Book Series.

Krugman, P. (1991), Geography and Trade, MIT Press, London.

Kunc, M. (2007), "A Survey of Managerial Practices in the Small to Medium Chilean Wineries", Journal of Wine Research, vol. 18, no. 2, pp. 113-119.

Kunc, M. and Tiffin, S. (2008), "University Involvement in Wine Region Development: A Comparative Case Study between Universidad de Talca (Chile) and Universidad de Cuyo (Argentina)", 4th International Conference of the Academy of Wine Business Research, Siena.

Kuramoto, J. (2001), "Las agglomeraciones mineras en Peru”, in Buitelaar, R. (ed) Aglomeraciones Mineras y Desarrollo Local en América Latina, CEPAL, IDRC y AlfaOmega, Bogotá.

Kuznets, S. (1955), "Economic Growth and Income Inequality", American Economic Review, vol.45, no.1, pp. 1-28.

Kuznets, S. (1966), Modern Economic Growth: Rate, Structure and Spread, Yale University Press, New Haven.

Lacoste P. (2008), La mujer y el vino : emociones, vida privada, emancipación económica (entre el reino de Chile y el virreinato del Rio de La Plata, 1561-1810), Caviar Bleu, Mendoza, Argentina.

Lall, S. (1992), “Technology Capabilities and Industrialization”, World Development, vol. 20, no. 2, pp. 165-186.

Lall, S. (1994), “The East Asian Miracle: Does the Bell Toll for Industrial Strategy?”, World Development, vol. 22, no. 4, pp. 645-654.

Lall, S. (1996), Learning from the Asian Tigers, Macmillan, London.

Lall, S. (2000), “The Technological Structure and Performance of Developing Country Manufactured Exports, 1985-1998”, Oxford Development Studies.

Lall, S. (2001), Competitiveness, Technology and Skills, Edward Elgar, Cheltenham. 
Lall, S. (2003), Foreign Direct Investment, Technology Development and Competitiveness in East Asia, (editor with Urata, S.), Edward Elgar, Cheltenham.

Lall, S. and Pietrobelli, C. (2003), "Africa's Technology Gap: Case Studies on Kenya, Ghana, Tanzania and Uganda”, UNCTAD, New York and Geneva.

Lall, S. and Urata, S. (2003), "Competitiveness, FDI and Technological Activity in East Asia”, Business \& Economics, Edward Elgar Publishing.

Lam R. and Wantchekon L. (2003), Political Dutch Disease, New York University Working Paper, web document, available at URL: www.nyu.edu/gsas/dept/politics/faculty/wantcheko/research/lr-04-10.pdf

Larreina, M. and Aguado, R. (2008), "Beyond the Cluster: How Wine Drives Regional Economy to Success: Oenopolis, the Case of Rioja”, International Journal of Wine Business Research, vol. 20, no. 2, pp. 153-170.

Lence, S. (2010), "The Agriculturak Sector in Argentina: Major Trends and Recent Developments", The Midewest Agribusiness Trade research and Information Center, Iowa State University, Ames, Iowa.

Leontief, W. (1953), "Domestic Production and Foreign Trade: The American Capital Position Re-Examined". Proceedings of the American Philosophical Society, reproduced in Input-Output, Oxford University Press (1966) , pp.349-369.

Lewin, B. (2009), “What Price Bordeaux?”, Wine Appreciation Guild, London.

Lewis, W. A. (1954), "Economic Development with Unlimited Supplies of Labour", Manchester School of Economic and Social Studies, vol. 22, pp.139-191.

Linder, S.B. (1961), An Essay on Trade and Transformation, Almqvist \& Wicksell, Stockholm.

Lindsay, P. and Norman, D. (1977), Human Information Processing: An Introduction to Psychology ( $2^{\text {nd }}$ edition), Academic Press, New York.

List, F. (1841), The National System of Political Economy, Longman, Greens and Co, London.

Liu, M. (2002), "Determinants of Taiwan's Trade Liberalization: The Case of a Newly Industrialized Country", World Development, vol. 30, no. 6, pp.975-989.

Lundvall, B. Å. (1988), "Innovation as an Interactive Process - from User-Producer to National Systems of Innovation”, in Dosi, G. etal. (eds.) Technology and Economic Theory, London, Pinter.

Lundvall, B. Å. (1992), National Systems of Innovation: Towards a Theory of Innovation and Interactive Learning, (ed.) Pinter Publishers, London.

Lundvall, B.-Å. (1998), "Why Study National Systems and National Styles of Innovation?”, in Technology Analysis \& Strategic Management, vol. 10, no. 4, 1998, pp. 407-422.

Lundvall, B.-Å. and Borras, S. (1997), “The Globalising Learning Economy: Implications for Innovation Policy”, Brussels, DG XII, Commission of the European Union.

Lundvall, B. Å., Johnson, B., Andersen, E., and Dalum, B. (2002) "National Systems of Production, Innovation and Competence Building”, Research Policy, vol. 31, no. 2, pp. 213-231.

Lundvall, B. Å. and S. Borras (2005), "Science, Technology, Innovation and Knowledge Policy", in Fagerberg, J., D.Mowery and R.R. Nelson (eds.), The Oxford Handbook of Innovation, Oxford University Press, Norfolk. 
Lyberaki, A. and Pesmazoglou, V. (1994), "Mirages and Miracles of European Small and Medium Enterprise (SME) Development”, Research Papers, no. 5, Hellenic University Association for European Studies.

Mac Cawley, A. and Contreras, H. (2006), "Implementacion de un Modelo de Costos Abc en una Empresa Vitivinicola”, Economia Agraria, Agrarian Economist Association (AEA), vol. 10, Chile.

Maddison, A. (1990), The World Economy in the twentieth century, OECD, Development Centre Studies, Paris.

Maddison, A. (2001), The World Economy: a Millennial Perspective, OECD Development Centre Studies, Paris.

Maddison, A. (2007), Chinese Economic Performance in the Long Run, OECD, Development Centre Studies, Paris.

Maizels, A. (1963), Industrial Growth and World Trade, Cambridge University Press, Cambridge.

Malerba, F. (2001), "Sectoral Systems of Innovation and Production: Concepts, Analytical Framework and Empirical Evidence", paper presented at the ECIS Conference on "The Future of Innovation Studies", Eindhoven University of Technology, the Netherlands, 20-23 September 2001.

Malerba, F. (2002), "Sectoral Systems of Innovation and Production”, Research Policy, no. 31, pp. 247-264.

Malerba, F. (2004), "Sectoral Systems of Innovation: How and Why Innovation Differs Across Sectors", in Handbook of Innovation, J. Fagerber, D. Mowery and R. Nelson (ed). Cambridge University Press, Cambridge.

Malerba, F. and Orsenigo, L. (1996), "Schumpeterian Patterns of Innovation", Cambridge Journal of Economics, vol.19, no.1, pp. 51-87.

Malerba, F. and Bresnahan, T.F. (1999), "Industrial Dynamics and the Evolution of Firms and Nations' Competitive Capacities in the World Computer Industry", in Mowery D.C. and Nelson R.R (eds), Source of Industrial Leadership: Studies of Seven Industries, Cambridge University Press, Cambride, pp. 79-132.

Malmberg, A. (2003), "Beyond the Cluster: Local Milieus and Global Connections" in: Peck, J. \& Yeung, H. (eds), Remaking the Global Economy, Sage, London.

Malmberg, A. and Maskell, P. (1997), "Towards an Explanation of Industry Agglomeration and Regional Specialization”, European Planning Studies, vol. 5, no. 1 , pp. 25-41.

Malmberg, A. and Power, D. (2005), “(How) Do (Firm in) Clusters Create Knowledge?”, Industry and Innovation, vol. 12, pp. 409-431.

Marins, L. (2008), “The Challenge of Measuring Innovation in Emerging Economies Firms: A Proposal of a New Set of Indicators on Innovation”, UNU-MERIT Working Paper no. 44, Maastricht.

Marshall, A. (1920), Principles of Economics (Revised Edition), Macmillan; reprinted by Prometheus Books, London.

Marsili, O. (2001), The Anatomy and Evolution of Industries: Technological Change and the Industrial Dynamics, Edward Elgar, Cheltenham and Northampton.

Martin, R. and Sunley, P. (2003), "Deconstructing Clusters: Chaotic Concept Or Policy Panacea?”, Journal of Economic Geography, no.3, pp.5-35. 
Marx, K. (1967), "Capital: Critique of Political Economy. The Commodity", in Dragstedt, A. Value: Studies By Karl Marx, New Park Publications, London, 1976, pp. 7-40.

Maskell, P. and Malmberg, A. (1999), "Localised Learning and Industrial Competiveness", Cambridge Journal of Economics, vol. 23, no. 2, pp. 167-185.

Matsuyama, K. (1992), "Agricultural Productivity, Comparative Advantage, and Economic Growth”, Journal of Economic Theory, 58, no. 2, pp. 317-334.

Matthews, P. (2000), Real Wine:The Rediscovery of Natural Winemaking, Mitchell Beazley.

McCormick, D. (1999) "African Enterprise Clusters and Industrialization: Theory and Reality”, World Development, vol. 27, no. 9, 1531-52, pp.

McCoy, E. (2006), The Emperor of Wine: The Rise of Robert M. Parker, Jr., and the Reign of American Taste, Harper Perennial.

McDermott, G.A. (2005), "The Politics of Institutional Renovation and Economic Upgrading: Lessons from the Argentine Wine Industry”, The Wharton School, University of Pennsylvania.

McDermott, G.A, Corredoira, R.A, Kruse, G. (2007), "Public-Private Networks as Sources of Knowledge and Upgrading Capabilities: A Parametric Stroll through Argentine Vineyards", Academy of Management Proceedings: 1-6. Academy of Management.

McGovern, P. (2003), Ancient Wine: The Search for the Origins of Viniculture, Princeton University Press, Princeton.

Meller, P. (1994), “Chilean Export Growth, 1970-90: An Assessment”, in. Helleiner, G. K (ed.), Manufacturing for Export in the Developing World - Problems and Possibilities, Routledge, London.

Metcalfe, J. S. (1998), Evolutionary Economics and Creative Destruction, Routledge, London.

Meyer-Stamer, J., Maggi C., Seibel S. (2001), "Improving Upon Nature: Creating Competitive Advantage in Ceramic Tile Clusters in Italy, Spain and Brazil”, Institute for Peace and Development, Duisburg.

Migone, A. and Howlett, M. (2010), "Comparative Networks and Clusters in the Wine Industry", American Association of Wine Economists, AAWE working paper no 62.

Mikesell, R. (1997), "Explaining the Resource Curse, with Special Reference to MineralExporting Countries”, Research Policy, vol.23, no.4, pp. 191-199.

Millan Constain, F. (2002), "El conglomerado del azucar del Valle de Cauca: Cien años de construcción social”, Serie Desarrollo Productivo, CEPAL, Santiago.

Moguillansky, G. (1999), La inversion en Chile, el fin de un ciclo en expansion?, CEPAL, Santiago.

Moguillansky, G. (2005), "La importancia de la tecnologia de la información y la comunicación para las industrias de recursos naturales", Santiago: CEPAL, ECLAC.

Moguillansky, G., Salas, G.J and Cares, G. (2006), "La innovación en la industria del vino", document prepared for the project "Determinantes e impacto de la innovación en industrias exportadoras de Chile”, CEPAL, UAI, CORFO.

Montero, C. (2004), "Formación y desarrollo de un cluster globalizado: el caso de la industria del salmón en Chile”, CEPAL, Santiago de Chile. 
Morel-Astorga, P. (2001), “The Chilean Wine Industry - Its Technological Transformation and New Export Orientation”, Iberoamericana, Nordic Journal of Latin American and Caribbean Studies, Vol. XXXI: 2, pp. 85-101.

Morrison, A. and Rabellotti, R. (2006), "The Role of Research in Wine: the Emergence of a Regional Research Area in an Italian Wine Production System," ERSA conference papers, European Regional Science Association.

Muhr, D. and Rebelo, J. (2011), "Innovation in Wine SMEs: the Portuguese Douro Boys”, AAWE Working Paper no.84.

Murphy, K., Schleifer, A., Vishny, R.W. (1989), "Industrialization and the Big Push", Journal of Political Economy, vol. 97 no. 5, pp. 1003-1026.

Myint, H. (1980), The Economics of the Developing Countries, Hutchinson University library, London.

Mytelka, L.K. (1978), "Licensing and Technology Dependence in the Andean Group", World Development, vol. 6, no. 4, pp. 447-459.

Mytelka, L.K. (1979), Regional Development in a Global Economy: The Multinational Corporation, Technology and Andean Integration, Yale University Press, New Haven.

Mytelka, L.K. (1989), “The Unfulfilled Promise of African Industrialization”, African Studies Review, vol.32, no.3, pp.77-137.

Mytelka, L.K. (ed.), (1999), Competition, Innovation and Competitiveness in Developing Countries, OECD Development Centre, Paris.

Mytelka, L.K. (2000), "Local Systems of Innovation in a Globalized World Economy", Industry and Innovation, vol.7, no.1, pp. 15-32.

Mytelka, L.K. (2004), "Catching-Up in New Wave Technologies", Oxford Development Studies, vol. 32, no. 3, pp. 289-405.

Mytelka, L. K. (ed.) (2007), Innovation and Economic Development, Edward Elgar, UK.

Mytelka, L., Farinelli, F. and Taye, T. (1999), "Spatial Clusters and Export Growth", International Trade Centre Executive Forum, Annecy.

Mytelka, L.K. and Farinelli, F. (2000), "Local Clusters, Innovation Systems and Sustained Competitiveness“, Discussion Papers 5, United Nations University, Institute for New Technologies, Maastricht.

Mytelka, L.K. and Barclay, L.A. (2004), "Using Foreign Investment Strategically for Innovation”, European Journal of Development, vol. 6, no. 3, pp. 527-555.

Mytelka, L.K. and Bortagaray, I. (2006), "Strengthening the Agricultural Innovation System in Colombia: an Analysis of the Cassava and Flower Sectors", Project on Enhancing Agricultural Innovation: How to go Beyond the Strengthening of rsearch Systems?, World Bank, Washington D.C.

Mytelka, L.K. and Goertzen, H. (2004), "Learning, Innovation and Cluster Growth: A Study of Two Inherited Organizations in the Niagara Peninsula Wine Cluster" in Clusters in a Cold Climate: Innovation Dynamics in a Diverse Economy, edited by D. A. Wolfe and M. Lucas. Montreal and Kingston: McGill-Queen's University Press.

Narula, R. and Lall, S. (2004), "FDI and Its Role in Economic Development: Do We Need a New Agenda?," Research Memoranda 019, MERIT, Maastricht Economic Research Institute on Innovation and Technology, Maastricht. 
Natarajan, K.A. (1992), Bioprocessing for Enhanced Gold Recovery, Mineral Processing and Extractive Metallurgy Review: An International Journal, vol. 8, no. 1-4, pp. 43-153.

Neary, J. and Wijnbergen, S. (1986), Natural Resources and the Macroeconomy, MIT Press, Cambridge, Massachusetts.

Nelson, R. (1994) "The Co-evolution of Technology, Industrial Structure, and Supporting Institutions", Industrial and Corporate Change, vol. 3, no. 1, pp. 47-63.

Nelson, R. and Winter, S. (1982), An Evolutionary Theory of Economic Change, Harvard University Press, Cambridge.

Nelson, R. and Rosenberg, N. (1993), "Technical Innovations and National Systems", in R.R. Nelson (ed.) National Innovation Systems: a Comparative Analysis, Oxford University Press, Oxford.

Nonaka, I. and Takeuchi, H. (1994), The Knowledge-Creating Company, Oxford University Press, New York.

Nossiter, J. (2009), Liquid Memory: Why Wine Matters, MacMillan, New York.

Nurkse, R. (1953), Problems of Capital Formation in Underdeveloped Countries, Columbia University Press, New York.

Ocampo, J. A. (2002), "Rethinking the Development Agenda", Cambridge Journal of Economics, vol. 26, no. 3, pp. 393-407.

Oczkowski, E. (2001), "Hedonic Wine Price Functions and Measurement Error”, The Economic Record, vol. 77, no. 239, pp. 374-82.

OECD (2006), The Rise of China and India, Development Centre Study, Paris.

OIV (2010), "Annual Statistics Report on the World Vitiviniculture Situation in 2010", 34th World Congress of Vine and Wine, Porto, Portugal.

OIV (2011), "Global Economic Vitiviniculture Data for 2011", OIV Conference 8 November 2011, Paris.

Olavarria, J.A, Moreno, Y.M, Garcia, M. and Monsalvez, C. (2008), "Caracterización y performance tecnológico en dos clusters vitivinícolas: Valles de Colchagua y Maule”, Programa Bicentenario de Ciencia y Tecnología, Santiago.

Onofri, E. (2000), "La economía nacional y su influencia en los cambios de la vitivinicultura", Viñasy Vinos, March 2000, Buenos Aires.

Outreville, J.F. and Hanni, M. (2011), "Multinational Firms in the World Wine Industry”, Université de Montreal, Quebec, mimeo.

Oyelaran-Oyeyinka, B. and McCormick, D. (eds.) (2007), Industrial Clusters and Innovation Systems in Africa: Institutions, Markets and Policy, United Nations University Press, Tokyo.

Parker, R. (2002), Wine Buyer's Guide, 6th edition, published 2002.

Parker, R. (2005), The World's Greatest Wine Estates: A Modern Perspective, Simon and Schuster, New York.

Parker, R. (2008), “Robert Parker's Rating System”, eRobertParker.com, The Wine Advocate, http://www.erobertparker.com/info/legend.asp, retrieved August 22, 2010.

Parker, R. (2009), Parker's Wine Bargains: The World's Best Wine Values Under \$25, Simon and Schuster.

Pasteur, L. (1875), Etudes sur le Vin, ses maladies, causes qui les provoquent, F. Savy, Paris. 
Paul, H. (1996), Science, Vine, and Wine in Modern France, Cambridge University Press, Cambridge.

Pavitt, K. (1984), "Sectoral Patterns of Technical Change: Towards a Taxonomy and a Theory", Research Policy, vol. 13, pp. 3443-373.

Pavitt, K. and Bell, M. (1993), "Technological Accumulation and Industrial Growth: Contrast Between Developed and Developing Countries", Industrial and Corporate Change, vol.2, no.2, pp. 157-211.

Pavitt, K. (2002), "Comparative Economics of Research Development \& Innovation in East \& West”, Harwood Fundamentals of Pure and Applied Economics, Routledge, Taylor \& Francis Group, London, U.K.

Pellechia, T. (2006), Wine: The 8,ooo-Year-Old Story of the Wine Trade, Thunder's Mouth Press, New York.

Penn, C. (2001), “Uruguay is Ready”, Wine Business Monthly, The Industry's Leading Print Publication for Wineries and Growers, 25 July 2001.

Perez, C. (1988), "New Technologies and Development, in Freeman, C. and Lundvall, B.A. (eds), Small Countries Facing the Technological Revolution, Pinter Publisher, London, pp.85-87.

Perez, C. (1989), “Technical change, competitive restructuring and institutional reform in developing countries" SPR Publications, Discussion Paper no. 4, The World Bank, Washington D.C.

Perez, C. (2002), Technological Revolutions and Financial Capital: The Dynamics of Bubbles and Golden Ages, Elgar, Cheltenham.

Perez, C. (2003), "Technological Change and Opportunities for Development as a Moving Target”, in Toye, J. (ed.) Trade and Development: Directions for the $21^{\text {st }}$ Century, Elgar, Cheltenham.

Perez, C. (2010), “Technological Dynamism and Social Inclusion in Latin America: A Resource-Based Production Development Strategy”, CEPAL Review 100, Santiago.

Perez, C. and Soete, L. (1988), "Catching Up in Technology: Entry Barriers and Windows of Opportunity", Technical Change and Economic Theory, pp. 458-79.

Perez, C., Marin, A. and Navas-Aleman, L. (2009), "The Possible Dynamic Role of Natural Resource-Based Networks in Latin American Development Strategies", prepared for the CEPAL-SEGIB Project - July 2009.

Perez-Aleman, P. (2005), "Cluster Formation, Institutions and Learning: The Emergence of Clusters and Development in Chile", Industrial and Corporate Change, vol. 14, no. 4, 2005, pp. 651-677.

Peynaud, E. (1984), Knowing and Making Wine, Wiley and Sons Ltd. Phillips, R. (2000), A Short History of Wine, Ecco, London.

Pietrobelli, C. (1994), "Technological Capabilities at the National Level: An International Comparison of Manufacturing Export Performances”, Development Policy Review, vol. 12, no. 2, pp.115-148.

Pietrobelli, C. (1996), "Emerging Forms of Technological Cooperation: The Case for Technology Partnerships - Inner Logic, Examples and Enabling Environment”, Science and Technology Issues, UNCTAD, United Nations, Geneva.

Pietrobelli, C. and Rabellotti, R. (2003), "Upgrading in Clusters and Value Chains in Latin America - the Role of Policies", Sustainable Development Department, InterAmerican Development Bank, Washington D.C. 
Piore, M. and Sabel, C. (1984), The Second Industrial Divide: Possibilities for Prosperity, Basic Books, New York.

Polanyi, M. (1956), The Tacit Dimension, Anchor Books, Doubleday \& Company, inc, Garden City, New York.

Porter, M. (1990), The Competitive Advantage of Nations, MacMillan, London.

Porter, M. (1998), Clusters and The New Economics of Competition, Harvard Business Review.

Posner, M., (1961), "International Trade \& Technical Change”, Oxford Economic Papers, vol.13, no. 3, pp. 323-42.

Powell T.C. (2005), "Total quality management as competitive advantage: A review and empirical study", Strategic Management Journal, vol. 16, pp. 1537-1552.

Power, D. and Lundmark, M. (2004), "Working through Knowledge Pools: Labour Market Dynamics, the Transference of Knowledge and Ideas, and Industrial Clusters", Urban Studies, vol. 41, pp. 1025-1044.

Prebisch, R. (1950), "The Economic Development of Latin America and its Principal Problems", Economic Bulletin for Latin America, no. 7, United Nations, New York.

Prebisch, R. (1978), Socioeconomic Structure and Crisis of Peripheral Capitalism, United Nations Commission for Latin America.

Pszczólkowski, P. (1991), "Vitivinicultura: Crisis y Perspectivas", Panorama Económico de la Agricultura (January-February), vol. 12, no. 74, pp.27-31.

Purdy, F. (2001), The Gringo's Guide to Chilean Wine, Impresos Offset Bellavista Ltda, Fourth-Y2K edition.

Pyke, F. and Sengerberger, W. (1992), Industrial Districts and Local Economic Regeneration, Institute for Labour Studies, Geneva.

Rabobank (2007), "Changing Competitiveness in the Wine Industry: The Rise and Fall of Wine Countries”, by Arend Heijbroek, January 2007, Amsterdam.

Rabobank (2009), "Rabobank Wine Quarterly Report”, Amsterdam.

Rebelo, J., Caldas, J. and Matulich, S. (2010), "Performance of Traditional Cooperatives: the Portuguese Douro Wine Cooperatives”, Economya Agraria e Recursos Naturales, vol. 10, no. 2, pp. 143-158.

Robinson, J. (1999) (ed.), The Oxford Companion to Wine (Second ed.), Oxford University Press, Oxford, England.

Robinson, J. (2001), Jancis Robinson's Concise Wine Companion, Oxford University Press, Oxford.

Robinson, J. (2005), The World Atlas of Wine, Mitchell Beasley Publishing.

Robinson, J. (2010), “Grape Wars: Chile v. Argentina”, Financial Times, 24 Sept 2010.

Rodriguez, F. and Sachs, J. (1999) "Why Do Resource-Abundant Economies Grow More Slowly?”, Journal of Economic Growth, 4, pp.277-303.

Rodrik, D. (1999), The New Global Economy and Developing Countries: Making Openness Work, John Hopkins University Press, Washington D.C.

Rodrik, D. (2004), "Industrial Policy for the Twenty-First Century", CEPR Discussion Papers 4767, C.E.P.R. Discussion Papers.

Rodrik, D. (2006), “Goodbye Washington Consensus, Hello Washington Confusion? A Review of the World Bank's Economic Growth in 1990s: Learning from a Decade of Reforms", Journal of Economic Literature, no. 44, pp. 973-987.

Roemer, M. (1979), "Resource-Based Industrialization in Developing Countries: A Survey”, Journal of Development Economics, vol. 6, no. 2, pp. 163-202. 
Roemer, M. (1996), Could Asian Policies Propel African Growth?, Harvard Institute for International Development, mimeo.

Rohel, J. (2010), Book Review of “The Taste of Place: A Cultural Journey Into Terroir",

by Trubek A., Journal of Wine Economics, vol. 5, no. 1, pp. 188-216.

Rolland, M. (2005), Winemaker's Collection Michel Rolland Cuvee 1, Mirrol.

Rolland, M. and Chrabolowsky, E. (2003), Wines of Argentina, Mirroll.

Romer, P. (1993), “Idea Gaps and Object Gaps in Economic Development”, Journal of Monetary Economics, vol. 32, no. 3, pp. 543-573.

Rosenberg, N. (1976), Perspectives on Technology, Cambridge University Press, London.

Rosenstein-Rodan, P. (1943), "Notes on the Theory of the "Big Push", in Ellis, H.S., Wallich, H.C. (eds.), Economic Development for Latin America, St. Martin's press, New York.

Ross, M. (2001) “Does Oil Hinder Democracy?”, World Politics, 53, pp. 325-361.

Ross, J. (2006), Where Angels Thread: The Story of Vina Montes, Santiago, Montes SA.

Rosser, A. (2006), "Escaping the Resource Curse”, New Political Economy, vol. 11, no. 4, pp.557-570.

Rostow, E. (1960), The Stages of Economic Growth, Cambridge University Press.

Sachs, J. (1999), "Resource Endowments and the Real Exchange Rate: A Comparison of Latin America and East Asia", in Changes in Exchange Rates in Rapidly Developing Countries, University of Chicago Press, Chicago, pp.133-153.

Sachs, J. (2005), The End of Poverty: Economic Possibilities for Our Time, Penguin Press, New York.

Sachs, J. and Rodriguez R. (1999), "Why do Resource-Abundant Economies Grow More Slowly?”, Journal of Economic Growth, vol.4, pp.277-303.

Sachs, J. and Warner A. (1997), "Natural Resources and Economic Growth,” revised version, Center for International Development and Harvard Institute for International Development, Discussion Paper, Harvard University, Cambridge MA.

Sachs, J. and Warner A. (1999), “The Big Push, Natural Resource Booms and Growth", in Journal of Development Economics, vol.59, pp. 43-76.

Sachs, J. and Warner A. (2001), "Natural Resources and Economic Development: the Curse of Natural Resources", European Economic Review, vol. 45, no. 4-6, pp. 827838.

Sagasti, F. (1973), "Underdevelopment, Sicence and Technology: The Point of View of Underdeveloped Countries", Science Studies, vol. 3, no. 1, pp. 47-59.

Salvatierra, G. (2006), "Lecciones de las transformaciones y emergencia de una vitivinicultura competitiva en Argentina: Factores influyentes en el proceso de cambio de los clusters Sajuanino y Mendocino", mimeo, Buenos Aires, Argentina.

Sapford, D. (1985), The Prebisch-Singer terms of trade hypothesis: Some new evidence, Economics Letters, vol. 18, no. 2-3, pp. 229-232.

Sarkar, P. (1986), “The Singer-Prebish Hypothesis: A Statistical Evaluation”, Cambridge Journal of Economics, pp. 355-371.

Sarkar, P. and Singer, H. (1991), "Manufacturing Exports of Developing Countries and their Terms of Trade since 1965”, World Development, vol. 19, no. 4, pp. 333-340.

Saxenian, A.L. (1994), Regional Advantage: Culture and Competition in Silicon Valley and Route 128, Harvard University Press, Cambridge. 
Saxenian, A.L. (1996), "Inside-Out: Regional Networks and Industrial Adaptation in Silicon Valley and Route 128", Cityscape: A Journal of Policy Development and Research, vol. 2, no. 2, May 1996, pp.41-60.

Schaffaeddin, M. (1998), "How Did Developed Countries Industrialize? The History Of Trade And Industrial Policy: The Cases Of Great Britain And The Usa“, UNCTAD Discussion Papers 139, Geneva.

Schmitz, H. (1982), "Growth Constraints on Small-scale Manufacturing in Developing Countries: A Critical Review”, World Development, vol. 10, no. 6, pp. 429-450.

Schmitz, H. (1995), "Collective Efficiency: Growth Path for Samll-Scale Industry", Journal of Development Studies, vol. 34, no. 4, pp. 529-566.

Schmitz, H., Nadvi, K. and Humphrey, J. (1997), "Collective Efficiency: A Way Forward for Small Firms”, IDS Policy Briefing 10, IDS, Brighton.

Schmitz, H. and Nadvi, K. (1999). "Clustering and Industrialisation: Introduction”, World Development, vol. 27, no. 9, pp.1503-1514.

Schumpeter, J.A. (1934), The Theory of Economic Development, Harvard University Press, Cambridge.

Schumpeter, J.A. (1939), Business Cycles: A Theoretical, Historical and Statistical Analysis of the Capitalist Process, New York, Toronto, London, McGraw-Hill Book Company.

Sharples, L. and Knowles, T. (2002), "The History and Development of Chilean Wines", International Journal of Wine Marketing, vol. 14, no. 2, pp.7-16.

Sforzi, F. (2005), "Dal distretto industriale allo sviluppo locale", Dipartimento di Economia, Università degli Studi di Parma. Testo della lezione inaugurale tenuta ad Artimino 2005, Incontri pratesi sullo sviluppo locale: Dal distretto industriale allo sviluppo locale, organizzati dall'IRIS, 12 settembre 2005

Singer, H. (1950), "The Distribution of Gains between Investing and Borrowing countries", American Economic Review, vol. 15, pp. 473-485.

Smith, A. (1776), An Inquiry into the Nature and Causes of the Wealth of Nations, Clarendon Press, Oxford.

Smith, K. (1999), "Industrial structure, technology intensity and growth: issues for policy", paper prepared for the DRUID conference on National Innovation systems, Industrial Dynamics and Innovation Policy, Rebild, Denmark, June 9-12.

Smith, K. (2001), "Industrial Structure, Technology Intensity and Growth", UNUINTECH Discussion Paper, Maastricht.

Smith, K. (2005), Measuring Innovation, in Fagerberg J. (ed.) The Oxford Handbook of Innovation, Oxford, Oxford University Press.

Smith, K. (2007), “The Strategic Role of Knowledge and Innovation Systems Thinking”, International Journal of Business and Systems Research, vol. 1, no. 2, pp. 200-215.

Smith, K., and Marsh, I. (2007), "Wine and Economic Development: Technological and Corporate Change in the Australian Wine Industry", International Journal of Technology and Globalisation, vol. 3, pp. 224-245.

Soete, L. (2006), "A Knowledge Economy Paradigm and its Consequences“, UNUMERIT Working Paper Series 001, United Nations University, Maastricht Economic and Social Research and Training Centre on Innovation and Technology, Maastricht.

Soete, L. (2007), "From Industrial to Innovation Policy", Journal of Industy, Competition and Trade, vol. 7, pp. 273-284. 
Spraos, J. (1980), “The Statistical Debate on the Net barter Terms of Trade Between Primary Commodities and Manufactures”, The Economic Journal, vol. 90, pp. 107128.

Stein, S. (2004), "Grape Wars: The Conflict between Quantity and Quality in the History of Argentine Wine”, Paper presented at the International Wine Conference held at the University of Avignon, France.

Stein, S. (2008), “Our Saviors May Not Speak Spanish: Changing Markets and Strategies in Argentina's Wine Revolution, 1990-2008”, American Association of Wine Economists, AAWE Working Paper no. 21., August 2008.

Stein, S. and Zucca, G. (2005), "The Boutique Winery Phenomenon in Argentina and California: Global Parallels and Regional Distinctions”, presented at 2005 International Wine Marketing Symposium, Sonoma State University, June 2005, published in conference proceedings.

Stevens, P. (2003), "Resource Impact: Curse or Blessing? A Literature Survey", Journal of Energy Literature, vol. 9, no. 1, pp.3-42.

Stiglitz, J. (2002), Globalization and its Discontents, W.W. Norton \& Company, New York.

Stiglitz, J. (2006), Making Globalization Work, W.W. Norton, New York.

Storchmann, K. (2011), "Wine Economics: Emergence, Developments, Topics", American Association of Wine Economists Working Paper no. 85.

Szirmai, A. (2005), The Dynamics of Socio-Economic Development, Cambridge University Press, Cambridge.

Szirmai, A. (2011), “Angus Maddison and Development Economics," UNU-MERIT Working Paper Series 035, UNU-MERIT, Maastricht.

Taber, G. (2005), Judgement of Paris: California vs. France and the Historic 1976 Paris Tasting that Revolutionized Wine, Simon and Schuster.

Taber, G. (2007), To Cork or Not To Cork: Tradition, Romance, Science, and the Battle for the Wine Bottle, Scribner, New York.

Te Velde, D.W. (2006), "Foreign Direct Investment and Development: An historical perspective”, Background paper for 'World Economic and Social Survey for 2006' Overseas Development Institute (paper Commissioned by UNCTAD).

Te Velde, D.W. and Nair, S. (2006), "Foreign Direct Investment, Services Trade Negotiations and Development: The Case of Tourism in the Caribbean," Development Policy Review, Overseas Development Institute, vol. 24, no. 4, pp. 437-454.

The Economist (1999), “A Survey f Wine: the Globe in a Glass”, Dec. $16^{\text {th }} 1999$.

The Economist (2007), "Thinking out of the box; Chocolate. Cocoa-growers move upstream”, Apr $7^{\text {th }} 2007$.

The Economist (2007b), "Vino's twin peaks. Argentina is catching up with Chile-but not as fast as it might”, Mar $15^{\text {th }} 2007$.

The Economist (2010), "It's only natural. Commodities alone are not enough to sustain flourishing economies", Sep 9th 2010.

The Financial Times (2010), “Jancis Robinson’s Column on Wine”, 25-26 September 2010.

The Wall Street Journal (2011), "Perhaps a Red, 4,100 B.C. In Armenia, Scientists Find Oldest Known Winery; A Big Vat for Treading Grapes”, 11 January 2011. 
Thoburn, J. (1977), Primary Commodity Exports and Economic Development: Theory, Evidence, and a Study of Malaysia, Wiley, New York.

Thorn, K. (2005), "Science, Technology and Innovation in Argentina: A Profile of Issues and Practices", Working Paper September 2005, World Bank.

Timmer, C.P. (1988), "The Agricultural Transformation”, in Chenery, H.B. and Srinivasan, T.N, Handbook of Development Economics, Amsterdam, North Holland.

Tomsik, P. and Prokes, M. (2011), "New strategic alliances of wine producers in the Czech Republic", Agricultural Economics - Czech, vol. 57, no. 12, pp. 573-579.

Torres-Zorrilla, J. (2000), "Una estrategia de desarrollo basada en recursos naturales: Análisis del cluster del complejo de Cobre en Peru”, CEPAL, Santiago.

Toulan, O. and Guillen, M. (1997), "Beneath the Surface: The Impact of Radical Economic Reforms on the Outward Orientation of Argentine and Mendozan Firms, 1989-1995”, Journal of Latin American Studies, vol. 29, pp. 395-418.

Tregenna, F. (2011), "Manufacturing Productivity, Deindustrialization, and Reindustrialization," Working Papers UNU-WIDER Research Paper, World Institute for Development Economic Research, Helsinki.

Trubek, A. (2008), The Taste of Place: A Culture Journey into Terroir, Berkeley, University of California Press.

UNCTAD (1998), "Promoting and Sustaining SMEs Clusters and Networks for Development", Paper prepared for an Expert Meeting on Clustering and Networking for SME Development, Geneva, 2-4 September, TD/B/COM.3/EM.5/2.

UNCTAD (2003), Trade and Development Report, New York and Geneva.

UNCTAD (2005), "A Case Study on the Salmon Industry in Chile", series on the Transfer of Technology for the Successful Integration into the Global Economy, New York and Geneva.

UNCTAD (2006), Trade and Development Report, New York and Geneva.

UNCTAD (2007), Trade and Development Report, New York and Geneva.

UNCTAD (2007b), World Investment Report, New York and Geneva.

UNCTAD (2008), "The Changing Face of Commodities in The Twenty-First Century", Note prepared by the UNCTAD Secretariat, Accra Ghana, 20-25 April 2008.

UNCTAD (2009), Trade and Development Report, New York and Geneva.

UNCTAD (2010), Trade and Development Report, New York and Geneva.

UNCTAD (2011), Trade and Development Report, New York and Geneva.

Unwin, T. (1991), Wine and the Vine: An Historical Geography of Viticulture and the Wine Trade, Routledge, London.

USDA (2010), "Chile: Wine Annual Report”, Global Agricultural Information Network, Washington.

Van Tienhoven, A. (2008), "The Global Wine Industry; How Small Chilean Wineries Should Compete", Centre for Latin American Research and Documentation, Amsterdam.

Vargas, M.A. (2001), "Local Systems of Innovation in Developing Countries: A Study of Technological Learning in Local Productive Arrangements in Brazil", Institute of Economics, Federal University of Rio de Janeiro - GEI-IE/ UFRJ, Brazil and Institute of Development Studies - IDS, UK. Paper prepared for the DRUID's Winter Conference on Industrial Dynamics. 
Vargas, M. A., Cassiolato, J. E. and Britto, J. N. P., (2005), “Arranjos Cooperativos e Inovação na Indústria Brasileira”, in De Negri, J. A., \& Salerno, M. S. (Orgs.) Inovações, padrões tecnológicos e desempenho das firmas industriais brasileiras, IPEA, Brasília.

Varricchio, P. and Queiroz, S. (2010), "Innovation and Knowledge Production in Traditional Sectors: The Brazilian Bioethanol Case", paper presented at the DRUIDDIME Academy Winter 2010 PhD Conference on Comwell Rebild Bakker, Aalborg, Denmark, January 21 - 23, 2010.

Vergara, S. (2001), "El mercado vitivinicola mundial y el flujo de inversión extranjera en Chile”, ECLAC, Serie Desarrollo Productivo, no. 102, Santiago de Chile.

Vernon, R. (1966), "International Investment and International Trade in the Product Cycle”, Quarterly Journal of Economics, vol. 80, pp. 190-207.

Veseth, M. (2010), Globaloney 2.o: The Crash of 2008 and the Future of Globalization, Rowman \& Littlefield.

Veseth, M. (2011), Wine Wars: The Curse of the Blue Nun, The Miracle of Two Buck Chuck, and the Revenge of the Terroirists, Rowman \& Littlefield Publishers.

Visser, E-J. (2004), "A Chilean Wine Cluster? The Quality and Importance of Local Governance in a Fast Growing and Internationalizing Industry”, CEPAL, Santiago de Chile.

Visser, E-J. and de Langen, P. (2006), "The Importance and Quality of Governance in the Chilean Wine Industry", GeoJournal, no.65, pp.177-197.

Von Hippel, E. (1998), "Economics of Product Development by Users: The Impact of 'Sticky' Local Information”, Management Science, vol. 44, no. 5, pp.629-644.

Von Tunzelmann, N. and Acha, V. (2005), "Innovation in 'Low-tech' Industries", in Fagerberg, Mowery and Nelson, The Oxford Handbook of Innovation, Oxford, Oxford University Press, pp.407-432.

Wade, R. (1990), Governing the Market: Economic Theory and the Role of Government in East Asian Industrialization, Princeton University Press, Princeton.

Walker M. and Jourdan P. (2003), Resource-based sustainable development: an alternative approach to industrialisation in South Africa, Minerals and Energy Raw Materials Report, vol. 18, no. 3, pp.25-43.

Walters, A. (1999), "Rebuilding Technologically Competitive Industries: Lessons from Chile's and Argentina's Wine Industry Restructuring”, Urban Studies and Planning, Massachusetts Institutue of Technology, Unpublished Ph.D. Thesis.

Watkins, M. (1963), “A Staple Theory of Economic Growth", Canadian Journal of Economics and Political Science, vol. 29 no.2, pp.141-158.

Westphal, L. (2002), “Technological Strategies for Economic Development in a Fastvol. 11, no. 4-5, pp. 275-320.

Wine Spectator (30 June 2009), "Harvest 2009: Malbec Survives a Dry Year in Mendoza. Heat Spike Hurts White Wines of Argentina".

Wine Spectator (15 December 2009), "Malbec Madness. Argentina's Star Red is Running Up the Score".

Wine Spectator (20 March 2010), “2009 Bordeaux Barrel Tasting, Is this Another Classic Vintage?".

Wine Spectator (31 March 2011), "Beyond Malbec. Malbec is an Argentine Phenomenon, but a Host of Other Grapes are Making Gains and Adding Diversity”. 
Wine Spectator (11 July 2011), "14 Enticing Wines from Argentina. New Reviews Showcase Argentina's Diversity-and Most Are Under \$20”.

Wine Spectator (15 November 2011), "Why Appellations Matter".

Wine Spectator (15 December 2011), "Argentina Tests the Extremes. A Hot 2009 Vintage Delivers Power".

Wine Spectator (31 March 2012), "Chile's New Players. Syrah and Pinot Noir Take the Lead with Cool-Climate Versions".

Wine Spectator (30 April 2012), "Egyptional Crossroads: a Revival in Winemaking Faces the Maelstorm of Revolution".

Wolfe, D.A., Davis, C., and Lucas, M. (2005), "Global Networks and Local Linkages: An Introduction" in Wolfe, D.A. and Lucas, M. eds.. Global Networks and Local Linkages: The Paradox of Cluster Development in an Open Economy, Montreal and Kingston, McGill-Queen's University Press, pp.1-23.

Wood, E. and Kaplan, D. (2005), "Innovation and Performance Improvement in the South African Wine Industry", International Journal of Technology and Globalisation, vo. 1 , no. 3/4, pp. 381-399

Wood, E. and Kaplan, D. (2008), "The Wine Cluster in South Africa”, in Knowledge, Technology, and Cluster-Based Growth in Africa, Zhihua Zeng, D. (ed), Washington, DC: World Bank Publications.

World Bank (1993), The East Asian Miracle. Economic Growth and Public Policy, Oxford University Press, New York.

World Bank (1995), World Development Report, Oxford University Press, New York.

World Bank (1999), World Development Report, Oxford University Press, New York.

World Bank (2010), "World Development Indicators", http://data.worldbank.org/datacatalog/world-development-indicators/wdi-2010.

World Bank (2011), The World Development Report 2011: Conflict, Security, and Development, Oxford University Press, New York.

World Bank (2011b), "Natural Resources in Latin America and the Caribbean: Beyond Booms and Busts?", World Bank, Washington.

Wright, G. (2001), "Resource-Based Growth Then and Now", Stanford University/ World Bank, Washington, DC.

Yeats, A. (1991), "Do Natural Resource-Based Industrialization Strategies Convey Important (Unrecognized) Price Benefits for Commodity Exporting Countries?”, World Bank Working Paper no. 580.

Young, A. (1994), "Accumulation, Exports and Growth in the High Performing Asian Economies: A Comment”, Carnegie-Rochester Conference Series on Public Policy no. 40.

Young, A. (1994b), "Lessons from the NICs: A Contrarian View”, European Economic Review, no. 38, pp.964-73.

Zanni, L. (2004), Leading Firms and Clusters: Understanding the Evolution of the Tuscan Wine Business through an International Comparative Analysis (ed.), FrancoAngeli, Milano.

Ziesemer, T. (2010), "From Trends in Commodities and Manufactures to Country Terms of Trade”, UNU-MERIT Working Papers Series no. 022, Maastricht. 



\section{Annex I}

Open-ended questionnaire used to carry out the survey of the leading 25 Chilean and the leading 25 Argentine exporters of bottled wines:

Interview Date:

Name of the winery:

Name of Interviewed:

Position in the company:

Location:

Tel \& E-mail Address:

This section aims to gather some background information on the company and the structure of ownership:

Q1: Date of establishment

Q2: Type of ownership

Q3: Major shareholders

Q4: Total number of employees

Q5: Turnover of the company (optional)

$\square<\$ 1$ million

$\square$ \$1 million - \$5 million

$\square$ \$6 million - \$10 million

$\square$ \$11 - \$40 million

$\square \$ 41$ - \$70 million

$\square \$ 71$ - \$100 million

$\square>\$ 100$ million

Q5: Brief history of the company (open)

This section aims to gather some information on products:

Q6: What are your most important lines of wines? 
Q7: How many new wines have your introduced in the past five years?

Q8: What is your top brand? How does Wine Spectator (one the most influential and reputed international wine magazines) rate it?

Q9: Has there been any evolution of the national and international rankings of your wines, as measured by Wine Spectator and/or any national wine guide?

Q10: Did your wines recently experience rising export unit values trends? If so, does this reflect a higher quality of the wines being produced or not necessarily?

This section aims to gather some information on markets:

Q11: Where is the market mainly located? (e.g., locally, regionally, nationally, internationally)?

Q12: Who are your most important clients?

Q13: What is the \% of the wine exported?

Q14: Did you company experience any major changes in the composition of destination markets? If so, are the new markets oriented towards wines of different (higher or lower) quality levels?

Q15: What is the degree of competition in the different lines of wines your company is involved in?

Q16: Who are the main competitors? Where are they located? (e.g., locally, regionally, nationally, internationally)

This section aims to gather some information on marketing strategies:

Q17: Is your company currently attempting to increase its market shares? How is this being done? (e.g., company growth, quality, location, R\&D, certification, benchmarking, IT)

Q18: Has your company introduced zoning practices of main winemaking areas and has it obtained any designation of origin certification?

Q19: Has your company adopted any eco-friendly practices? If so, which ones? Since when? How is the market reacting?

Q20: Has your company obtained any quality certification? If so, which one? How is the market reacting? 
This section aims to gather some information on skilled human resources:

Q21: Who is the chief winemaker? What is his/her nationality?

Q22: How many other agronomists and oenologists (with university degree) are working for the company?

Q23: Has the company ever hired (recently and in the past) any international consultant? If so, when? From what country? How frequently does the consultant work for the company? What does he/she bring that cannot be found locally?

Q24: Has the company hired (recently and in the past) any national consultant? For what reason?

This section aims to gather some information on innovation:

Q25: In order to assess your degree of innovativeness, could you specify whether your company has been engaged in the following activities in the past five years:

\begin{tabular}{|c|c|c|c|}
\hline Type & Main innovations & Yes & No \\
\hline \multirow[t]{5}{*}{$\begin{array}{l}\text { Product / } \\
\text { Viticulture }\end{array}$} & $\begin{array}{l}\text { Identification of best terroirs and of best clones for } \\
\text { each variety }\end{array}$ & & \\
\hline & $\begin{array}{l}\text { Introduction of new varieties (in addition to top four } \\
\text { most widely diffused) }\end{array}$ & & \\
\hline & $\begin{array}{l}\text { Introduction of drip or furrow irrigation systems ( } v s \\
\text { flooding irrigation) }\end{array}$ & & \\
\hline & Limitation of the yields for top quality brands & & \\
\hline & $\begin{array}{l}\text { Introduction of organic and/or biodynamic farming } \\
\text { cultivation techniques }\end{array}$ & & \\
\hline \multirow[t]{5}{*}{$\begin{array}{l}\text { Process / } \\
\text { Viniculture }\end{array}$} & $\begin{array}{l}\text { Replacement of old big casks for aging with smaller oak } \\
\text { barriques imported from USA and/or France }\end{array}$ & & \\
\hline & Use of stainless steel tanks for vinification & & \\
\hline & $\begin{array}{l}\text { Installation of refrigeration devices for both } \\
\text { fermentation and maturation }\end{array}$ & & \\
\hline & $\begin{array}{l}\text { Replacement of old vertical presses with pneumatic } \\
\text { presses }\end{array}$ & & \\
\hline & Use of gravity flows mechanisms & & \\
\hline \multirow{3}{*}{$\begin{array}{l}\text { Organization } \\
\text { \& Marketing }\end{array}$} & Creation of new "terroir" brands & & \\
\hline & Participation at international wine competitions & & \\
\hline & $\begin{array}{l}\text { Use of social networks (Facebook, Youtube and/or } \\
\text { Twitter) for marketing purposes }\end{array}$ & & \\
\hline
\end{tabular}




\begin{tabular}{|l|l|l|l|}
\hline Type & Main innovations & Yes & No \\
\hline & $\begin{array}{l}\text { Organization of winery tours, food and wine tastings, } \\
\text { cultural events }\end{array}$ & & \\
\cline { 2 - 4 } & $\begin{array}{l}\text { Adoption of a sophisticated architectural design of the } \\
\text { winery as a marketing tool }\end{array}$ & & \\
\hline
\end{tabular}

Q26: Did your company receive any credit to engage in these activities? If so, from what bank or institution?

Q27: Has the company participated in any research project (recently and in the past)?

Q28: If so, funded by whom? Which were the partners involved (both public and private sector)? What were the objectives? To what extent were they achieved?

Q29: What have been the most relevant support institutions to facilitate the adoption of innovations in your company? Are they locally, regionally, nationally or internationally based?

Q30: Based on in-house R\&D, did your company introduce any incremental innovation during the last five years?

Q31: Is the company part or planning to be part of any external R\&D collaboration? On what topic?

This section aims to gather some information on cluster dynamics and on the relevance of geographic location for the winery:

Q32: Does your company belong to a "cluster"?

Q33: If so, which one? What are its geographic boundaries?

Q34: If not, is there scope for the development of a cluster in your area? (perspectives, the actions required, expected results)

Q35: Does your company belong to an industry association?

Q36: If so, is it cluster, regionally or nationally-based? What is its role?

Q37: Who are the most important partners of your company? (e.g., upstreamdownstream suppliers, horizontal networks)

Q38: What is the nature of the relationship in terms of trust, knowledge (costs, prices, strategies) and transparency with main suppliers? And with competitors? 
Q39: What are the key strengths and weaknesses of your company within the cluster and what is their origin? (e.g., size, quality contacts, trust, competencies, quality, costs or price of the product/service)

Q40: Which are the key assets - or lack of them - that make your company's position in the cluster strong or weak?

Q41: What are the biggest threats to your company's position in the cluster? (e.g., costs, quality, technology)

Q42: Is your company happy with its current position in the cluster?

This section looks at expectations and suggestions related to government intervention:

Q43: Should public policy assist the wine industry in your country? Why?

Q44: Has your company received any support from any government agencies?

Q45: If so, in which field was the support? (e.g., finance, $\mathrm{R} \& \mathrm{D}$, training, production, export, identification of markets, outlets)

Q46: Would your company need government support to increase its performance?

Q47: If so, in what ways would you suggest government should assist you?

Q48: What are the main challenges ahead for your business?

Q49: Is there any specific support that your competitors are benefitting from that you would like to see introduced in your country?

Q50: Is it there any shared long-term strategy of the wine industry as a whole (including public and private actors) in your country? What do you think about it? 



\section{Summary}

Since the early 1990s, there has been a remarkable export boom of natural resourcebased products from developing countries. Some of the most prominent cases are related to the export of processed agricultural commodities such as cut flowers from Colombia, Ethiopia and Kenya; wine from Argentina, Chile and South Africa; farmed salmon from Chile; Nile perch from Uganda; and frozen shrimps from Thailand, Viet Nam, Ecuador and Peru. This thesis investigates the recent export boom of natural resource-based processed products from developing countries and reflects on whether the conditions under which they are taking place are any different from those that led to the failure of a development model based on raw material exports in the past. The surge in exports of processed agricultural commodities by some developing countries is particularly surprising, considering the monopolistic role played by advanced countries in these industries, namely the presence of well-established, highly competitive producers that have dominated for decades the global market of most processed and semi-processed primary products (e.g., Italy and France in the wine industry; the Netherlands and Israel in the cut flower industry; Norway, Canada and Japan in the fishing industry).

This thesis, therefore, addresses the issue of the sustainability of the current export boom of processed natural resources from developing countries. It investigates whether, contrary to common belief, this sectoral specialization may represent a viable strategy for long-term economic development. This is a particularly timely issue for those developing countries, especially in Latin America and Asia, which are caught in the "middle income trap" and can no longer compete on the basis of low wages and standardized manufacturing products. However, understanding whether an alternative use of natural resources is possible and desirable is even more important for those developing economies, mostly concentrated in Africa, that have been pushed back to dependence on raw material exports by structural adjustment programmes aimed at boosting foreign exchange earnings through the production of cash crops or other commodities for exports.

Currently, we are at the early stage of an historical transition from a consolidated natural resource "pessimism" to an embryonic natural resource "optimism". In the 1960 s, 1970s and 1980s, a number of development theories emerged that emphasized the negative impact of primary exports on development. The most prominent among these are the "resource curse", the "declining terms of trade" and the "commodity trap" theories, examined in depth in the theoretical foundations of the thesis. These theories 
are at the origin of a widespread and deeply rooted negative view of the development potential of natural resource-based sectors. Such pessimism reached its peak in the early 1990s, when the Information Technology (IT) sector came to be considered the major driver of competitiveness and growth. In that period several schools of thought emerged, arguing that economic growth was strictly dependent on the creation of "hightech", knowledge-intensive sectors, involving major new technologies. Only in the late 1990 did scholars acknowledge that, to the contrary, advanced economies had grown on a widely distributed sectoral basis and that many of the significant industries that were traditionally considered "low-tech" or traditional were contributing to overall economic growth.

Evolutionary economists contributed to this debate by making clear that supposedly "low-tech" or traditional industries could be seen as highly innovative, if their growing $\mathrm{R} \& \mathrm{D}$ content as well as the use of scientific-based inputs in the production process were taken into account. They also observed that the knowledge intensity of production, which had permeated the manufacturing sector in the 1970s, had gradually extended to all sectors of the economy, creating a wide platform for innovation and technological accumulation in both developed and developing countries.Only in the last few years, however, have scholars begun to acknowledge that processed primary products increasingly apply knowledge along the entire value chain, require a continuous process of innovation, and are less "staples" than specialized and diversified branded products.

This has led some theorists to envisage that a process of "de-commodification" of primary resources is taking place - whereby a variety of primary resources would be gradually transformed into high quality, diversified, processed goods - with rising barriers of entry, increasing value added content and higher export price per unit. Quite surprisingly, this holds even for the most traditional and paradigmatic primary commodities, such as coffee, tea and cocoa. Their production has increasingly integrated new concepts, such as that of "vintage plantation", "geographical indication" and "denomination of origin", giving rise to a range of extremely diversified, fashionable and thus premium-priced luxury goods, such as the Indian Darjeeling tea, the Jamaican Blue Mountain coffee, or the Arriba Nacional Ecuadorian cacao.

This thesis argues, therefore, that the old pessimism about the development potential of natural resources has become obsolete and that a new way of looking at natural resource-based processing industries is needed. To build up such a new and different approach, it looks in detail at the relationship between different forms of organization in production, continuous innovation and sustained export growth. It also analyzes the reasons explaining the competitive performance of natural resource-based processing industries at the local, regional and national levels. In particular, the thesis analyzes how, under the current globalizing trends, which began in the last quarter of the twentieth century, developing countries can transform raw primary commodities into high quality, diversified, processed goods, with increasing value-added content and export price per unit, thus becoming a platform for development.

In this context, the thesis addresses the issue of the long-term sustainability of export growth in natural resource-based processing industries by looking at their territorial 
and spatial dimension. Most natural resources, in fact, tend to be spatially clustered due to biological and environmental reasons. The thesis illustrates how, within clusters, geographical proximity may play a fundamental role in promoting continuous incremental innovation and technological upgrading, thanks to the creation of interfirm linkages and localized spillover effects linked to the presence of foreign investors. However, the thesis also highlights that not all clusters are equally innovative and equally successful in sustaining export growth in the long term. Consequently, it undertakes an in-depth analysis of whether, and the extent to which, natural resourcebased clusters may experience the emergence of territorially bound specificities, "uniqueness" factors and local innovation capabilities that would make their products original, different from each other and irreplaceable in the eyes of international consumers, thus the export growth of natural resource-based products sustainable in the long term.

This process is illustrated by comparing the Chilean and Argentine wine industries. Since the 1970s, wine has represented a particularly rapidly growing natural resourcebased process industry. Currently, Chile and Argentina represent the leaders within the group of new entrants from the developing world. Wine, moreover, is an example of a processed primary product characterized by complex technological changes and a sustained increase in knowledge intensity. Paradoxically, some developing country producers, including Chile, Argentina and South Africa (but later on also Morocco, Lebanon, Brazil and Uruguay) have been successful in entering the industry, in sustaining their competitive positions, and in increasing their market shares. So, it is fruitful to study such entrants, and especially to compare two cases where the performance of the wine industry has evolved differently, despite similar conditions at the outset. In particular, this raises one of the central themes of the thesis: from the analysis of the Chilean and Argentine wine industries, we can be argue that a new, viable model of export-oriented industrialization through primary processing is gradually emerging in Latin America - that is, a model which can be considered an alternative to the East Asian export-oriented industrialization model based on narrowly defined manufacturing. 



\section{Nederlandse samenvatting}

Sinds het begin van de jaren ' 90 , is er een opmerkelijke opleving van de export van verwerkte natuurlijke hulpbronnen uit ontwikkelingslanden. Een aantal van de meest prominente gevallen hebben betrekking op de export van verwerkte landbouwproducten, zoals snijbloemen uit Colombia, Ethiopië en Kenia; wijn uit Argentinië, Chili en Zuid-Africa; gekweekte zalm uit Chili; nijlbaars uit Oeganda en diepgevroren garnalen uit Thailand, Viet Nam, Ecuador en Peru. Dit proefschrift onderzoekt de recente export hausse van verwerking van op natuurlijke hulpbronnen gebaseerde producten uit ontwikkelingslanden. Het onderzoekt in hoeverre deze exportgroei verschilt van het primaire export model dat in het verleden tot zoveel teleurstellingen heeft geleid. De sterke stijging van de uitvoer van verwerkte landbouwproducten in een aantal ontwikkelingslanden is bijzonder verrassend gezien het monopolie van hoogontwikkelde landen in deze sectoren, en met name de rol van gevestigde producenten die decennialang de wereldmarkt van de meeste verwerkte en semiverwerkte primaire producten hebben beheerst (b.v. Italië en Frankrijk in de wijnindustrie, Nederland en Israël in de snijbloementeelt ; Noorwegen, Canada en Japan in de visindustrie).

Dit proefschrift richt zich daarom op de houdbaarheid van de huidige opleving van de export van verwerkte natuurlijke hulpbronnen uit ontwikkelingslanden. Het onderzoekt of een dergelijke specialisatie, in tegenstelling tot de gevestigde opvatting, een levensvatbare strategie is voor duurzame economische ontwikkeling. Dit is met name van belang voor landen in Latijns Amerika en Azië die geconfronteerd worden met de z.g. "middle-income trap" en niet langer kunnen concurreren op basis van lage lonen en de productie van gestandaardiseerde industriële producten. Een beter inzicht in een alternatieve omgang met natuurlijke hulpbronnen is in het bijzonder van belang voor die ontwikkelingslanden, vooral in Africa, die onder druk van structurele aanpassingsprogramma's gericht op het stimuleren van exportinkomsten, meer en meer afhankelijk zijn van de export van handelsgewasssen en andere primaire producten.

Momenteel bevinden we ons in een vroeg stadium van een historische overgang van een gevestigd "pessimisme" met betrekking tot natuurlijke hulpbronnen naar een embryonaal "optimisme". In de jaren ' 60 , '70 en '80 kwam een aantal ontwikkelingstheorien op die de negatieve invloeden van primaire exporten op de economische ontwikkeling benadrukten. De meest prominente theorieën zijn die van de "resource curse", de "dalende ruilvoet" en de "commodity trap", die uitgebreid behandeld worden in dit proefschrift. Deze theorieën staan aan de oorsprong van een 
wijdverbreidde en diepgewortelde negatieve kijk op het ontwikkelingspotentieel van primaire sectoren in de economie.

Dergelijk pessimisme bereikte zijn hoogtepunt in de vroege jaren ' 90 , toen de Informatie Technologie (IT) beschouwd werd als de belangrijkste factor voor versterking van het concurrentievermogen en de economische groei. In die periode kwamen verschillende theoretische stromingen op die benadrukten dat economische groei strikt afhankelijk was van het creëren van "high-tech", kennisintensieve sectoren, gericht op het gebruik van belangrijke nieuwe technologieën. Pas in de late jaren '90 erkenden onderzoekers dat de groei van de hoogontwikkelde economieën gebaseerd is op groei in een breed spectrum van sectoren. Ook sectoren die van oudsher beschouwd werden als traditioneel en "low-tech" hebben een bijdrage geleverd aan de totale economische groei.

Evolutionaire economen hebben aan dit debat bijgedragen door duidelijk te maken dat ook de zogenaamde "low-tech" of traditionele industrieën kunnen worden gezien als innovatief, indien er voldoende rekening wordt gehouden met de groei in R\&D uitgaven alsmede de toepassing van de uitkomsten daarvan in het productieproces. Verder werd opgemerkt dat de kennisintensiteit, die in de jaren ' 70 in de productieprocessen in de nijverheid was doorgedrongen, zich geleidelijk aan had uitgebreid tot alle sectoren van de economie. Daarmee was een breed platvorm voor innovatie en technologische vooruitgang in zowel ontwikkelde als ontwikkelingslanden geschapen. Pas recentelijk zijn onderzoekers gaan erkennen dat bij de verwerking van natuurlijke hulpbronnen in toenemende mate kennis wordt toegepast over de gehele waardeketen en dat dit een voortdurend proces van innovatie vereist. Steeds minder worden zulke verwerkte producten gezien als gestandaardiseerde "staples", steeds meer als hoogwaardige gespecialiseerde en gediversifieerde "merkartikelen”.

Sommige theoretici interpreteren dit als een proces van "de-commodificatie" van natuurlijke hulpbronnen - waarbij een verscheidenheid van natuurlijke hulpbronnen geleidelijk verwerkt worden tot gevarieerde kwaliteitsgoederen - met stijgende toetredingsbarrières, met hogere toegevoegde waarde en een hogere exportprijs per eenheid product. Dit geldt zelfs voor de meest traditionele natuurlijke goederen, zoals koffie, thee en cacao. In de productie daarvan zijn in toenemende mate nieuwe concepten geïntegreerd, zoals "vintage plantation", "geografic indication" en "denomination of origin". Dit heeft aanleiding gegeven tot een reeks van zeer gediversifieerde, trendgevoelige en dus premium geprijsde luxe goederen, zoals de Indiase Darjeeling thee, de Jamaicaanse Blue Mountain koffie, of de Arriba Nacional Ecuadoriaanse cacao.

Dit proefschrift stelt daarom het pessimisme over het ontwikkelingspotentieel van de op natuurlijke goederen gebaseerde sectoren aan de kaak en pleit voor een nieuwe kijk op deze sectoren. Om een dergelijke nieuwe visie te ontwikkelen bestudeert het proefschrift in detail de relatie tussen de verschillende organisatievormen van de productie, de continue innovatie en de duurzame groei van de export. Het analyseert ook de factoren die de concurrentiekracht van de op verwerking van natuurlijke hulpbronnen gerichtte sectoren kunnen verklaren, zowel op lokaal, regionaal als op 
nationaal niveau. In het bijzonder, analyseert dit proefschrift hoe ontwikkelingslanden in de huidge geglobaliseerde wereldeconomie ruwe grondstoffen kunnen verwerken tot kwaliteitgoederen met een hogere toegevoegde waarde en hogere exportprijzen, en zodoende een platform kunnen scheppen voor economische ontwikkeling.

In dit verband behandelt dit proefschrift ook de lange termijn duurzaamheid van de exportgroei van producten gebaseerd op natuurlijke hulpbronnen door te kijken naar hun territoriale en ruimtelijke dimensie. De meeste natuurlijke hulpbronnen zijn in feite vaak ruimtelijk geconcentreerd vanwege biologische en natuurlijke oorzaken. Dit proefschrift laat zien hoe, binnen clusters van bedrijven, geografische ligging een fundamentele rol kan spelen in het bevorderen van continue incrementele innovatie en technologische modernisering. Deze innovaties vloeien voort uit relaties tussen bedrijven onderling en uit lokale spillover effecten als gevolg van de aanwezigheid van buitenlandse investeerders. Echter, het benadrukt ook dat niet alle clusters even innovatief en succesvol zijn in het bevorderen van de exportgroei op de lange termijn. Daarom onderzoekt het proefschrift of, en in welke mate de op natuurlijke hulpbronnen gebaseerde clusters gekenmerkt worden door geographisch specifieke kenmerken, "uniqueness" factoren en lokale innovatiemogelijkheden die hun producten origineel, onderscheidend en onvervangbaar maken in de ogen van internationale consumenten, zodat zij een duurzame exportgroei van deze producten kunnen realiseren.

Dit proces wordt onderzocht aan de hand van een vergelijking tussen de Chileense en Argentijnse wijnindustrie. Sinds de jaren '70 vertegenwoordigt wijn een zeer snel groeiende, op primaire producten gebaseerde industrie. Op dit moment zijn Chili en Argentinië de leiders binnen de groep van nieuwkomers onder de ontwikkelingslanden. Bovendien is wijn een voorbeeld van een verwerkt primair product gekenmerkt door complexe technologische veranderingen en een aanhoudende toename van de kennisintensiteit. Paradoxaal genoeg zijn sommige producenten uit ontwikkelingslanden zoals Chili, Argentinië en Zuid-Afrika (later ook Marokko, Libanon, Brazilië en Uruguay) erin geslaagd om tot deze industrie toe te treden, hun concurrentiepositie te handhaven en hun marktaandeel zelfs te vergroten. Het is dus vruchtbaar om deze toetreders te bestuderen en vooral om twee landen te vergelijken waar de wijnindustrie een sterk verschillende ontwikkeling heeft doorgemaakt, ondanks een vergelijkbare uitgangsvoorwaarden.

Uit de analyse van de lotgevallen van de Chileense en Argentijnse wijnindustrie kan worden geconcludeerd dat er in Latijns Amerika geleidelijk een nieuw, levensvatbaar model van exportgerichte industrialisatie op basis van de verwerking van primaire producten tot ontwikkeling komt. Dit ontwikkelingsmodel kan worden beschouwd als een alternatief voor het Oost-Aziatische exportgerichte industrialisatiemodel, gebaseerd op een beperkte definitie van de nijverheidssector. 



\section{About the Author}

Fulvia Farinelli was born in Rome, Italy, in 1966. She holds a Master degree in International Economic Relations at the Rome-based LUISS University. She joined the UNU-MERIT PhD programme on "Economic and Policy Studies on Innovation and Technical Change" in Maastricht in 2001. Since 1998, she works in Geneva at the United Nations Conference on Trade and Development (UNCTAD), in the Division on Investment and Enterprise. Before joining UNCTAD, she was a researcher in Rome at the Directorate for Studies of the Italian National Agency on New Technology, Energy and the Environment (ENEA) and at the Italian Institute for Economic Planning (ISPE). In this context, she undertook several sectoral studies on innovation and technology in traditional sectors. She was also involved in large EU-financed projects for industrial upgrading in the Mercosur region. Thanks to her participation in those projects, she gained a deep knowledge of several Latin American countries, and in particular of Argentina, Chile, Uruguay, Brazil and Paraguay. After joining UNCTAD, she became responsible for UNCTAD's entrepreneurship development programme Empretec - in Latin America. Subsequently, she was in charge of technical assistance projects for the creation of business linkages between transnational corporations and local suppliers in Argentina, Uganda, Mozambique and Viet Nam, in the automobile, electronics, agro-processing and handicraft industries. From an analytical perspective, her work at UNCTAD focuses on issues related to trade, investment and enterprise development. In particular, she specializes on technological innovation, entrepreneurship, clusters, foreign investment and global value chains related issues. She has wide experience in delivering training courses on these topics to government officials and development practitioners. 


\section{Annex II}

\section{Map of Chilean and Argentine Wine Areas}

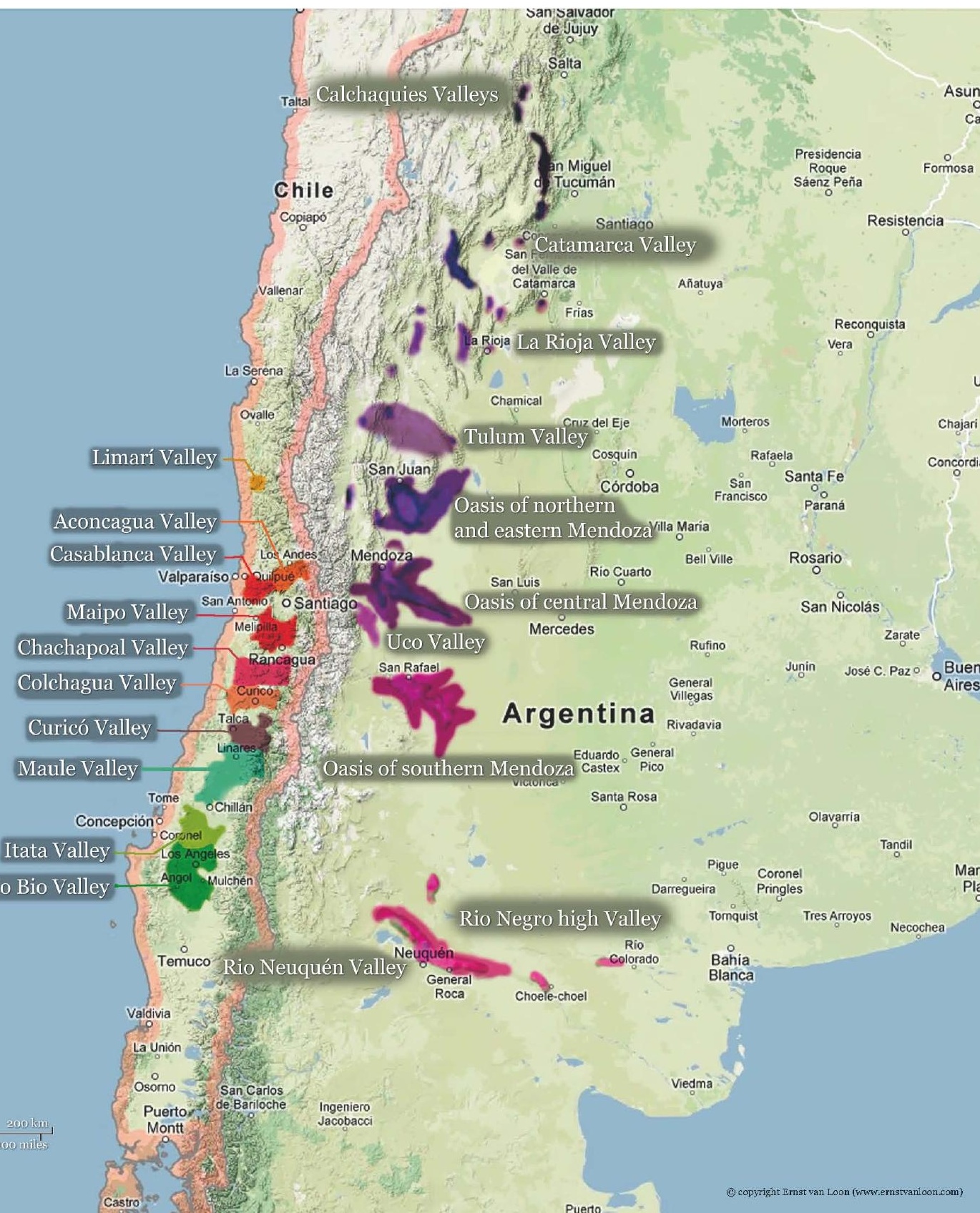

